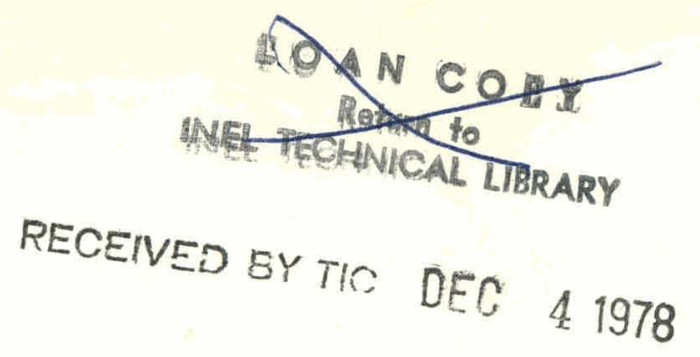

\title{
MATPRO - VERSION 10 \\ A HANDBOOK OF MATERIALS PROPERTIES FOR USE IN THE ANALYSIS OF LIGHT WATER REACTOR FUEL ROD BEHAVIOR
}

February 1978

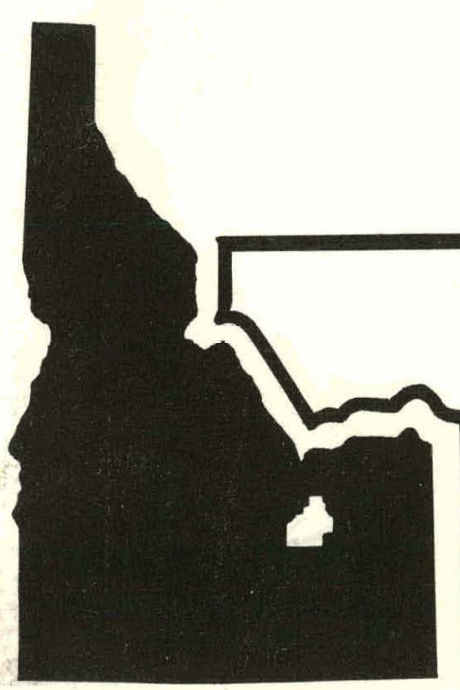

\section{EG\&G Idaho, Inc.}

\section{DEPARTMENT OF ENERGY}




\section{DISCLAIMER}

This report was prepared as an account of work sponsored by an agency of the United States Government. Neither the United States Government nor any agency Thereof, nor any of their employees, makes any warranty, express or implied, or assumes any legal liability or responsibility for the accuracy, completeness, or usefulness of any information, apparatus, product, or process disclosed, or represents that its use would not infringe privately owned rights. Reference herein to any specific commercial product, process, or service by trade name, trademark, manufacturer, or otherwise does not necessarily constitute or imply its endorsement, recommendation, or favoring by the United States Government or any agency thereof. The views and opinions of authors expressed herein do not necessarily state or reflect those of the United States Government or any agency thereof. 


\section{DISCLAIMER}

Portions of this document may be illegible in electronic image products. Images are produced from the best available original document. 
Printed in the United States of America Available from

National Technical Information Service

U.S. Department of Commerce

5285 Port Royal Road

Springfield, Virginia 22161

Price: Printed Copy $\$ 14.00$; Microfiche $\$ 3.00$

"The NRC will make available data tapes and operational computer codes on research programs dealing with postulated loss-of-coolant accidents in light water reactors. Persons requesting this information must reimburse the NRC contractors for their expenses in preparing copies of the data tapes and the operational computer codes. Requests should be submitted to the Research Applications Branch, Office of Nuclear Regulatory Research, Nuclear Regulatory Commission, Washington, D.C. 20555."

\section{NOTICE}

This report was prepared as an account of work sponsored by the United States Government. Neither the the United States nor the Department of Energy, nor the Nuclear Regulatory Commission, nor any of their employees, nor any of their contractors, subcontractors, or their employees, makes any warranty, express or implied, or assumes any legal liability or responsibility for the accuracy, completeness or usefulness of any information, apparatus, product or process disclosed, or represents that its use would not infringe privately owned rights. 
i

TREE-NUREG-1180

MATPRO-VERSION 10

A HANDBOOK OF MATERIALS PROPERTIES

FOR USE IN THE ANALYSIS OF LIGHT WATER REACTOR FUEL ROD BEHAVIOR

Approved:

$\frac{\text { Mlichoet P Bohr }}{\text { M. P. Bon, Manager }}$

Fuel Analysis Research and Development Branch

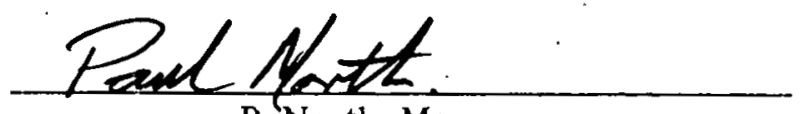

P. North, Manager

Code Development and Analysis Program

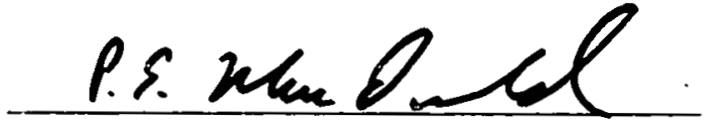

P. E. MacDonald, Manager Thermal Fuels Behavior Division

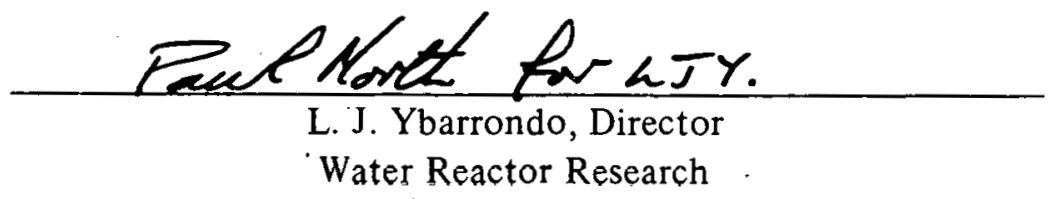

This report was prepared as an account of work sponsored by the United States Government. Neither the
United States no: the United States Department of United States nos the United States Department of
Energy, nor any of Uteri timployecs, nor any of their contractors, subcontractors, or their employees, makes any warranty, express or implied, or assumes any legal
liability or responsibility for the accuracy, completeness liability or responsibility for the accuracy, completeness
or usefulness of any information. apparatus, product or process disclosed. of represents that its use would not infringe privately owned rights.

DISTRIBUTION OF THUS DOCUMENT ISS UNLIMITED 
MATPRO-VERSION 10

A HANDBOOK OF MATERIALS PROPERTIES

FOR USE IN THE ANALYSIS OF LIGHT WATER REACTOR FUEL ROD BEHAVIOR

\author{
Compiled and Edited by \\ Gregory A. Reymann \\ Materials Properties Models Prepared by \\ Fuel Rod Materials Properties Section, \\ Under Direction of \\ Donald L. Hagrman
}

Technical Editorial Assistance Provided by

Steven B. Letson

EG\&G IDAHO, INC.

- February 1978

PREPARED FOR THE

U.S. NUCLEAR REGULATORY COMMISSION

AND THE

DEPARTMENT OF ENERGY

IDAHO OPERATIONS OFFICE

UNDER CONTRACT NO. EY-76-C-07-1570 


\section{ACKNOWLEDGMENTS}

The authors would like to gratefully acknowledge the assistance in maintaining the MATPRO library provided by B. W. Burnham. In addition the work of the following persons in preparing individual models is recognized:

Fuel Specific Heat Capacity (FCP)

Fuel Thermal Conductivity (FTHCON)

Fuel Emissivity (FEMISS)

Fuel Thermal Expansion (FTHEXP)

Fuel Elastic Modúlus (FELMOD)

Fuel.POISSON's Ratio (FPOIR)

Fuel Creep Rate (FCREEP)

Fuel Fracture Strength (FFRACS)

Fuel Swelling (FSWELL) and the Integration of Swelling and Densification (CONECT)

. Fuel Restructuring (FRES'I'R)

Fuel Densification (FUDENS)

Fission Gas Release (FG^SRL)

Cesium and lodine Release (CESIOD)

Cladding Specific Heat (CPP) and the Effect of Hydride Solution on Cladding Specific Heat (CHSCPे)

Cladding Thermal Conductivcity (CTHCON)

Cladding Surface Emissivity (ZOEMIS)

Zirconium Dioxide Thermal Conductivity (ZOTCON) ...

Cladding Axial Thermal Expansion (CATHEX)
C. S. Olsen

C. S. Olsen and

G. A. Reymann

D. L. Hagrman

C. S. Olsen

C. S. Olsen

C. S. Olsen

C. S. Olsen

C. S. Olsen

R. E. Mason

R. E. Mason

G. A. Reýmann

D. L. Hagrman

D. L. Hagrman

R. L. Miller

D. L. Hagrman

R. L. Miller

G. A. Reymann 


\begin{tabular}{|c|c|}
\hline Cladding Diametral Thermal Expansion (CDTHEX) & G. A. Reymann \\
\hline Cladding Elastic Modulus (CELMOD) & R. L. Miller \\
\hline Cladding Stress Versus Strain (CSTRES and CSIGMA) & D. L. Hagrman \\
\hline Cladding Strain Versus Stress (CSTRAN) & D. L. Hagrman \\
\hline $\begin{array}{l}\text { Cladding Mechanical Limits (CMLIMT), Cladding } \\
\text { Strain at Rupture (CSRUPT), and Cladding Local } \\
\text { Strains at Rupture (CLOCRP) }\end{array}$ & D. L. Hagrman \\
\hline Cladding Creep Rate (CCRPR) & G. A. Reymann \\
\hline Cladding POISSON's Ratio (CPOIR) & R. L. Miller $\cdots: \therefore$ \\
\hline Cladding Cyclic Fatigue (CFATIG) & D. L. Hagrman \\
\hline Cladding Meyer Hardness (CMHARD) & D. L. Hagrman : . \\
\hline Cladding Axial Growth (CAGROW) & D. L. Hagrman \\
\hline Cladding Oxidation (CORROS and CHITOX) & $\begin{array}{l}\text { D. L. Hagrman and } \\
\text { G. A. Reymann }\end{array}$ \\
\hline Cladding Hydrogen Uptake (CHUPTK) & D. L. Hagrman \\
\hline Gas Thermal Conductivity (GTHCON) & P. E. MacDonald \\
\hline Gas Viscosity (GVISCO) & G. A. Reymann \\
\hline Physical Properties (PHYPRO) & $\begin{array}{l}\text { C. S. Olsen and } \\
\text { R. L. Miller }\end{array}$ \\
\hline
\end{tabular}




\section{ABSTRACT}

This handbook describes the materials properties correlations and computer subcodes (MATPRO-Version 10) developed for use with various LWR fuel rod behavior analytical programs at the Idaho National Engineering Laboratory. Formulations of fuel rod material properties, which are generally semiempirical in nature, are presented for uranium dioxide and mixed uranium-plutonium dioxide fuel, zircaloy cladding, and fill gas mixtures. 


\section{CONTENTS}

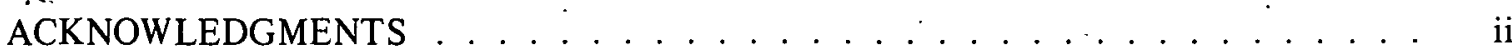

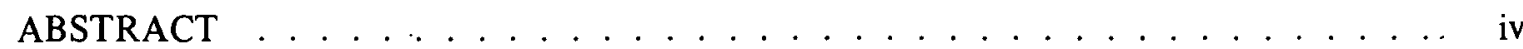

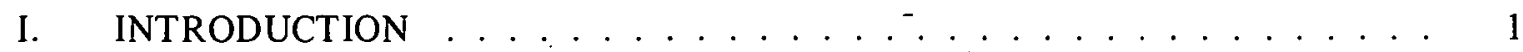

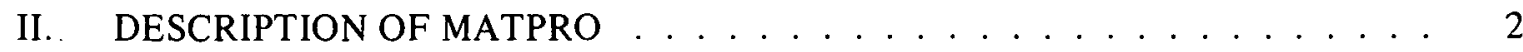

III. FUTURE VERSIONS OF MATPRO . . . . . . . . . . . . . . . . 5

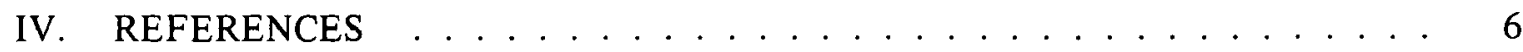

APPENDIX A - FUEL MATERIAL PROPERTIES . . . . . . . . . . . . 7

1. FUEL SPECIFIC HEAT CAPACITY $(\mathrm{FCP}) \ldots \ldots \ldots$

$1.1 \mathrm{UO}_{2}$ Specific Heat Capacity . . . . . . . . . . . . . . . . 9

$1.2(\mathrm{U}, \mathrm{Pu})_{2} \mathrm{O}_{2}$ Specific Heat Capacity . . . . . . . . . . . . . . 11

1.3 Fuel Specific Heat Capacity Subcode FCP Listing . . . . . . . . . . 13

1.4 References : . . . . . . . . . . . . . . 13

2. FUEL THERMAL CONDUCTIVITY (FTHCON) . . . . . . . . 15

2.1 Summary ....................... 15

2.2 Survey of Available Data . . . . . . . . . . . . . . . . 17

2.3 Analytical Model . . . . . . . . . . . . . . . . . 19

2.4 Fuel Thermal Conductivity Subcode FTCHON Listing . . . . . . 26

2.5 References,.................... 26

3. FUEL EMISSIVITY (FEMISS) . . . . . . . . . . . . . . 30

3.1 Summary ..................... 30

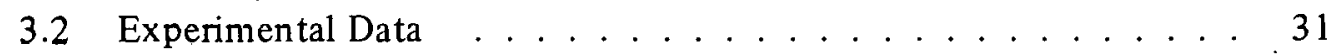

3.3 Selection of Emissivity Values . . . . . . . . . . . . 32

3.4 Fuel Emissivity Subcode FEMISS Listing … . . . . . . . . . . 34

3.5 References ... . . . . . . . . . . . . . . . . 34

4. FUEL THERMAL EXPANSION (FTHEXP) . . . . . . . . . . . 35

$4.1 \mathrm{UO}_{2}$ Thermal Expansion $\ldots \ldots \ldots . \ldots . \ldots 36$

$4.2 \cdot(\mathrm{U}, \mathrm{Pu}) \mathrm{O}_{2}$ Thermal Expansion ............. . . . 37

4.3 Fuel Thermal Expansion Subcode FTHEXP Listing . . . . . . . . . 40

4.4 References ................... 41 
5. FUEL ELASTIC MODULUS (FELMOD) . . . . . . . . . . . . . 42

$5.1 \mathrm{UO}_{2}$ Elastic Modulus .................. 42

$5.2(\mathrm{U}, \mathrm{Pu}) \mathrm{O}_{2}$ Elastic Modulus . . . . . . . . . . . . . 46

5.3 Fuel Elastic Modulus Subcode FELMOD Listing . . . . . . . . . 47

5.4 References ...................... . . 49

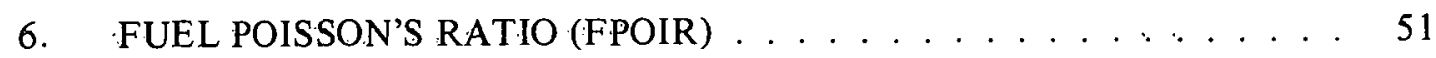

6.1 Poisson's Ratio Subcode FPOIR Listing . . . . . . . . . . . 51

6.2 References .................... 53

7. FUEL CREEP RATE (FCREEP) . . . . . . . . . . . . 53

7.1 Theoretical Models for $\mathrm{UO}_{2} \mathrm{Creep} \ldots \ldots \ldots . \ldots 33$

7.2 Review of Published Creep Data . . . . . . . . . . . . 56

7.3 Fuel Creep Model . . . . . . . . . . . . . . . . . 68

7.4 Fuel Creep Subcode FCREEP Listing . . . . . . . . . . . . . 73

7.5 References ........................... 74

8. FUEL FRACTURE STRENGTH (FFRACS) . . . . . . . . . . 76

8.1 Out-of-Pile $\mathrm{UO}_{2}$ Deformation . . . . . . . . . . 77

$8.2 \mathrm{UO}_{2}$ Fracture Stress Model . . . . . . . . . . . . 83

8.3 Fuel Fracture Strength Subcode FFRACS Listing . . . . . . . . 85

8.4 References .................. 85

9. FUEL SWELLING (FSWELL) AND THE INTEGRATION

OF SWELLING AND DENSITICATION (CONECT) . . . . . . . . . . 86

9.1 Summary . . . . . . . . . . . . . . . . . . . . 87

9.2 Survcy of Swclling Data . . . . . . . . . . . . . . . . . . . . . 90

9.3 Survey of Swelling Models . . . . . . . . . . . . . . 101

9.4 Survey of Models Combining Swelling and Densification . . . . . . 102

9.5 FSWELL Model . . . . . . . . . . . . . . . . . . 102

9.6 CONECI Model for Integrating Swelling and Densification . . .. . 104

9.7 Fuel Swelling Subcode FSWELL and Swelling and

Densitıcation Integration Subcode CONECT Listings . . . . . . . 108

9.8 References . . . . . . . . . . . . . . . . . 108

10. FUEL RESTRUCTURING (FRESTR) . . . . . . . . . . . . . . 113

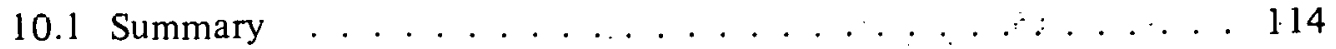

$10.2 \mathrm{UO}_{2}$ and $(\mathrm{U}, \mathrm{Pu}) \mathrm{O}_{2}$ Equiaxed Grain Growth $\ldots \ldots \ldots . . \ldots 114$

10.3 Columnar Grain Growth . . . . . . . . . . . . . . . . 119 
10.4 Fuel Restructuring Model . . . . . . . . . . . . . . . . 125

10.5 Fuel Restructuring Subcode FRESTR Listing . . . . . . . . . . 128

10.6 References . . . . . . . . . . . . . . . . 128

11. FUEL DENSIFICATION (FUDENS) . . . . . . . . . . . . . 131

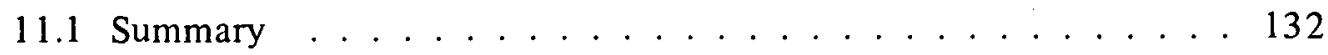

$11.2 \mathrm{UO}_{2}$ and Mixed Oxide Densification Data and Models . . . . 133

11.3 FUDENS Model Development . . . . . . . . . . . . . . . . . 144

11.4 Fuel Densification Subcode FUDENS Listing . . . . . . . . . . . . 145

11.5 References . . . . . . . . . . . . . . . 145

12. FISSION GAS RELEASE (FGASRL) . . . . . . . . . . . . . . . . 149

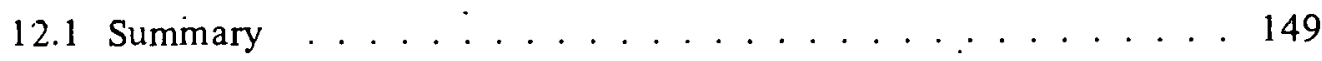

12.2 Analytical Model . . . . . . . . . . . . . . 150

12.3 Evaluation of Constants ................ 151

12.4 Evaluation of Model Uncertainty . . . . . . . . . . . . 152

12.5 Extension of the Model to Variable Power-Time Histories . . . . . 153

12.6 Additional Parameter Which Influence Gas Release . . . . . . . . . 154

12.7 Fission Gas Release Subcode FGASRL - Eisting . . . . . . . . 155

12.8 References . . . . . . . . . . . . . . . 155

13. CESIUM AND IODINE RELEASE (CESIOD) . . . . . . . . . . . 157

13.1 Summary . . . . . . . . . . . . . . . . . 157

13.2 Development of the Model . . . . . . . . . . . . 160

13.3 Model Calculations and Comparison with Experimental Data . . . . 168

13.4 Cesium and Iodine Release Subcode CESIOD Listing . . . . . . . . 172

13.5 References . . . . . . . . . . . . . . . . 172

APPENDIX B - CLADDING MATERIAL PROPERTIES . . . . . . . . . . . . 175

1. CLADDING SPECIFIC HEAT (CCP) AND THE EFFECT OF HYDRIDE SOLUTION ON CLADDING SPECIFIC HEAT (CHSCP) $\ldots \ldots$. . . . . 177

1.1 Specific Heat . . . . . . . . . . . . . . . . . 177

1.2 Effect of Hydride Solution . . . . . . . . . . . . . . . . 179

1.3 Uncertain ties in Specific Heat Predictions . . . . . . . . . . . . 183

1.4 Cladding Specific Heat Subcode CCP and Effect of Hydride Solution Subcode CHSCP Listings . . . . . . . . . . . 185

1.5 References.................... 185 
2. CLADDING THERMAL CONDUCTIVITY (CTHCON) . . . . . . . 188

2.1 Summary . . . . . . . . . . . . . . . . . 188

2.2 Survey and Analysis of Available Data . . . . . . . . . . . . . 190

2.3 Model Formulation Considering All Available Data . . . . . . . . . 190

2.4 Cladding Thermal Conductivity Subcode CTHCON Listing . . . . . 194

2.5 References . . . . . . . . . . . . . . . . 194

3. CLADDING SURFACE EMISSIVITY (ZOEMIS) . . . . . . . . 195

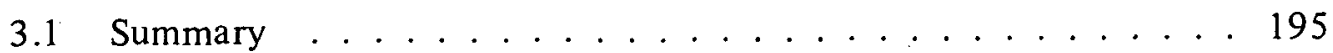

3.2 Literature Review . . . . . . . . . . . . . . . . . . 197

3.3 Development of the Model . . . . . . . . . . . . . 199

3.4 Uncertainty ... . . . . . . . . . . . . . . . . . 203

3.5 Cladding Surface Emissivity Subcode ZOEMIS Listing . . . . . . . 203

3.6 References . . . . . . . . . . . . . . . . . . 204

4. ZIRCONIUM DIOXIDE THERMAL CONDUCTIVITY (ZOTCON) ... . 206

4.1 Zirconium Dioxide Thermal Conductivity Subcode ZOTCON Listing . . . . . . . . . . . . . . . . . . . . . . . . . . . . . 208

4.2 References . . . . . . . . . . . . . . . . 209

5. CLADDING AXIAL THERMAL EXPANSION (CATHEX) . . . . . . 209

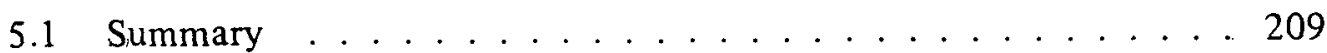

5.2 Derivation of CATHEX Model . . . . . . . . . . . . 210

5.3 Cladding Axial Thcrmal Expansion Subcodc.CATHEX

Listing . . . . . . . . . . . . . . . . . . . 213

54 Referencess .213

6. CLADDING DIAMETRAL THERMAL EXPANSION (CDTHEX) . . . . 215

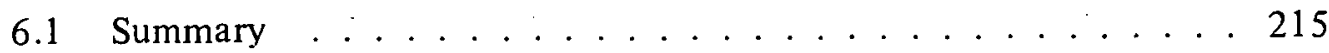

6.2 Derivation of CD'lHEX Model . . . . . . . . . 216

6.3 Cladding Diametral Thermal Expansion Subcode CDTHEX

Listing . . . . . . . . . . . . . . . . . . . 217

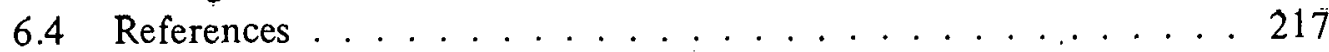

7. CLADDING ELASTIC MODULUS (CELMOD) $\ldots \ldots \ldots \ldots$

7.1 Cladding Elastic Modulus Subcode CELMOD Listing . . . . . . . 224

7.2 References . . . . . . . . . . . . . . . . 224 
8. CLADDING STRESS VERSUS STRAIN (CSTRES AND CSIGMA) . . . 225

8.1 Summary ....................... . . 225

8.2 Temperature Dependence of $\mathrm{m}, \mathrm{K}$, and $\mathrm{n} \ldots \ldots . . .229$

8.3 Effects of Irradiation, Cold Work, and Annealing . . . . . . . . . 234

8.4 Examples of CSTRES Output . . . . . . . . . . . . 238

8.5 Cladding Stress Subcode CSTRES and CSIGMA Listing . . . . . . . 238

8.6 References . . . . . . . . . . . . . . . . 238

9. CLADDING STRAIN VERSUS STRESS (CSTRAN) . . . . . . . . . . 245

9.1 Summary . . . . . . . . . . . . . . . . . . . 245

9.2 Computation of Strain Rate When It Is Not Input . . . . . . . . . 247

9.3 Examples of CSTRAN Expressions . . . . . . . . . . . . . 248

9.4 Cladding Strain Subcode CSTRAN Listing . . . . . . . . . . . . 248

10. CLADDING MECHANICAL LIMITS (CMLIMT), CLADDING STRAIN AT RUPTURE (CSRUPT), AND CLADDING LOCAL STRAINS AT RUPTURE (CLOCRP) . . . . . . . . . . . . . . . 253

10.1 Summary . . . . . . . . . . . . . . . 253

10.2 Derivation of Expressions Used for Yield Points and Ultimate Strength . . . . . . . . . . . . . . . 257

10.3 Derivation of Expressions Used for Strain at Rupture and Biaxial Instability Strains . . . . . . . . . . . . . . 258

10.4 Uncertainty of the Prediction for Strain at Rupture . . . . . . . . 261

10.5 Derivation of Expressions Used for Local Strain . . . . . . . . . . 262

10.6 Examples of CMLIMT and CSRUPT Output . . . . . . . . . 264

10.7 Cladding Mechanical Limit CMLIMT, Cladding Strain at Rupture CSRUPT, and Cladding Local Strains at Rupture CLOCRP Subcode Listings . . . . . . . . . . . . . 268

10.8 References . . . . . . . . . . . . . . . 270

11. CLADDING CREEP RATE (CCRPR) . . . . . . . . . . . . 276

11.1 Introduction . . . . . . . . . . . . . . 276

11.2 Data Survey . . . . . . . . . . . . . . . . . . 277

11.3 Model Derivation . . . . . . . . . . . . . . . . . 281

11.4 Comparison of Model Predictions with Experimental

Data . . . . . . . . . . . . . . . . . . . . . . 284

11.5 Model Limitations . . . . . . . . . . . . . . . . . 288

11.6 Uncertainties . . . . . . . . . . . . . . . . . . . . 289

11.7. Cladding Creep Rate Subcode (CCRPR) Listing . . . . . . . . . 289

11.8 References . . . . . . . . . . . . . . . . . 290 
12. CLADDING POISSON'S RATIO (CPOIR) . . . . . . . . . . . 293

12.1 Cladding Poisson's Ratio Subcode CPOIR Listing . . . . . . . . . . 294

12.2 References . . . . . . . . . . . . . . . . . . . 294

13. CLADDING CYCLIC FATIGUE (CFATIG) . . . . . . . . . . 295

13.1 Summary . . . . . . . . . . . . . . . . . . . 295

13.2 Basis for High Cycle Fatigue Material Constants . . . . . . . . . . 297

13.3 Basis for Low Cycle Fatigue Material Constants . . . . . . . . . . 299

13.4 Cladding Cyclic Fatigue Subcode CFATIG Listing . . . . . . . . 299

13.5 References . . . . . . . . . . . . . . . 301

14. CLADDING MEYER HARDNESS (CMHARD) . . . . . . . . . . . 301

14.1 Cladding Meyer Hardness Subcode CMHARD Listing . . . . . . . . 302

14.2 References . . . . . . . . . . . . . . . 303

15. CLADDING AXIAL GROWTH (CAGROW) . . . . . . . . . . . 304

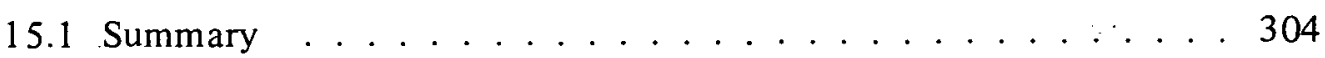

15.2 Background and Approach . . . . . . . . . . . . 305

15.3 Review of Experiment Data . . . . . . . . . . . . . 307

15.4 The Effect of Texture on Axial and Circumferential Growth . . . . . . . . . . . . . . . . . 309

15.5 Analysis of Irradiation-Induced Growth Factors Other

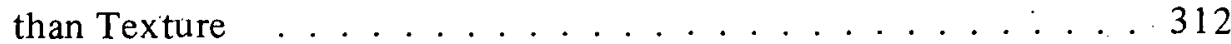

13.6 Evaluation of the Model and Its Uncertainty . . . . . . . 316

15.7 Cladding Axial Gıuwlı Bubcude CAGROW Lisling . . . . . . . . . 319

15.8 References . . . . . . . . . . . . . . . . 319

16. CLADDING OXIDATION (CORROS AND CHITOX) . . . . . . . 321

16.1 Summary . . . . . . . . . . . . . . . 321

16.2 Low Temperature Oxidation Model (CORROS) .. . . . . . . . 325

16.3 High Temperature Oxidation Model (CHITOX) . . . . . . . . . 333

16.4 Cladding Oxidation Subcodes CORROS and CHITOX

Listings . . . . . . . . . . . . . . . . . . . . . . . 349

16.5 References . . . . . . . . . . . . . . . . . . . 349

17. CLADDING HYDROGEN UPTAKE (CHUPTK) . . . . . . . . . . . . . 354

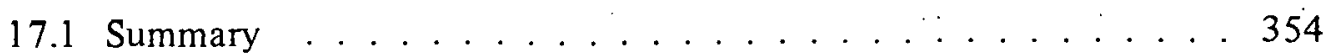

17.2 Background and Approach . . . . . . . . . . . 356

17.3 Out-of-Pile Basis for the Model . . . . . . . . . . . . . 357 
17.4 Generalization to an In-Pile Model . . . . . . . . . . . . . . 359

17.5 Cladding Hydrogen Uptake Subcode CHUPTK Listing . . . . . . . 361

17.6 References . . . . . . . . . . . . . . 361

APPENDIX C - GAS AND FUEL ROD PROPERTIES . . . . . . . . . . . . 363

1. GAS THERMAL CONDUCTIVITY (GTHCON) . . . . . . . . . . . 365

1.1 Conductivity of Gases and Gas Mixtures . . . . . . . . . . . . 365

1.2 Conductivities in the Knudsen Domain . . . . . . . . . . . 367

1.3 Gas Thermal Conductivity Subcode GTHCON Listing . . . . . . . 371

1.4 References . . . . . . . . . . . . . . . . 373

2. GAS VISCOSITY $($ GVISCO $) \ldots \ldots . \ldots . \ldots . \ldots . \ldots 77$

2.1 Gas Viscosity Subcode GVISCO Listing . . . . . . . . . . . . . . 378

2.2 References ..................... 381

3. PHYSICAL PROPERTIES (PHYPRO) . . . . . . . . . . . 381

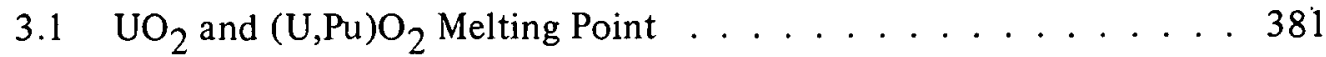

$3.2 \mathrm{UO}_{2}$ and $(\mathrm{U}, \mathrm{Pu}) \mathrm{O}_{2}$ Heat of Fusion ............ . . . 382

3.3 Zircaloy Melting Point and Transformation

Temperatures . . . . . . . . . . . . . . . . 383

3.4 Zircaloy Heat of Fusion . . . . . . . . . . . . . . . . . . . . . . . 384

3.5 Physical Properties Subcode PHYPRO Listing . . . . . . . . . . . . 387

3.6 References . . . . . . . . . . . . . . . . . . . . 384

APPENDIX D - SUPPORTING MATERIAL FOR MATPRO . . . . . . . . . 387

1. INPUT-OUTPUT ARGUMENTS OF MATRPO SUBCODES . . . . . . . 389

2. BASE AND DERIVED SI UNITS USED IN MATPRO $\ldots \ldots \ldots \ldots . . . . .411$

3. LINEAR INTERPOLATION ROUTINE (POLATE) . . . . . . . . 411

\section{FIGURES}

A-1.1. Temperature dependence of mixed oxide specific heat capacily calculated by $\mathrm{FCP}$ for $\mathrm{UO}_{2}$ and $(\mathrm{U}, \mathrm{Pu}) \mathrm{O}_{2} \ldots \ldots \ldots$

A-1.2. Comparison of calculated and experimental enthalpy values from Leibowitz et al and Gibby . . . . . . . . . . . . . . . 
A-2.1. Comparison of measured and predicted values of the thermal conductivity of $\mathrm{UO}_{2}$ for materials corrected to $95 \% \mathrm{TD}$ and standard deviation of data from theoretical curve . . . . . . . . . . 16

A-2.2. Comparison of measured and predicted values of the thermal conductivity of $(\mathrm{U}, \mathrm{Pu}) \mathrm{O}_{2}$ for materials corrected to $96 \%$ ' $\mathrm{ID}$ and standard deviation of data from the theoretical curve . . . . . . . . 17

A-2.3. Calculated curves showing comparison between $\mathrm{UO}_{2}$ and $(\mathrm{U}, \mathrm{Pu}) \mathrm{O}_{2}$ thermal conductivity ................ 18

A-2.4. The effect of varying the assumed values for the electronic contribution, $\mathrm{k}_{\mathrm{e}}$, on the calculated thermal conductivity of $95 \% \operatorname{Tn} \operatorname{In}_{2}$ with $\int k d T=96 \ldots \ldots \ldots$

A-2.5. The effect of varying the assumed value for $J_{0}{ }^{\mathrm{T}} \mathrm{m}_{\mathrm{m}} \mathrm{kd}$ on the calculated thermal conductivity of $95 \%$ TD $\mathrm{UO}_{2}$ with $\mathrm{k}_{\mathrm{e}}$

$18 \%$ held constant at $0.002 \mathrm{~W} \cdot \mathrm{cm}^{-1} \cdot \mathrm{K}^{-1}$

A-2.6. The standard deviation of the calculated $\mathrm{UO}_{2}$ thermal conductivity from the data base as a function of the assumed value of the

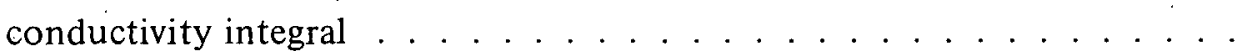

A-2.7. Temperature as a function of the conductivity integral calculated for $\mathrm{UO}_{2}$ and $(\mathrm{U}, \mathrm{Pu}) \mathrm{O}_{2} \ldots \ldots . \ldots . \ldots 27$

A-3.1. Comparison of fitting polynomials with emissivity data of Claudson . . . . 33

A-3.2. FEMISS representation of $\mathrm{UO}_{2}$ emissivity . . . . . . . . . . 34

A-4.1. Comparison of $\mathrm{UO}_{2}$ thermal expansion data with those calculated from FTHEXP subcode ... . . . . . . . . . . . . 38

A-4.2. Comparison of $\mathrm{PuO}_{2}$ thermal expansion data with those calculated from FTHEXP subcode . . . . . . . . . . . . . . . 39

A-5.1. Comparison of Young's modulus data for $\mathrm{UO}_{2}$ at ambient temperature and the fraction of porosity, from a least-squares fit to Equation $($ A-5.3) . . . . . . . . . . . . . . . .

A-5.2. Comparison of Young's modulus for $\mathrm{UO}_{2}$ normalized to $100 \%$ TD as a function of temperature, with least-square fits to Equation $(\mathrm{A}-5.4) \ldots \ldots \ldots \ldots . \ldots . \ldots . \ldots 45$ 
A-5.3. Young's modulus as à function of temperature and porosity for $(\mathrm{U}, \mathrm{Pu}) \mathrm{O}_{2}$ mixed oxides as calculated from Equation (A-5.8) . . . . 48

A-6.1. Computer generated curves showing Poisson's ratio as a function of temperature for two plutonia contents . . . . . . . . . . . . 52

A-7.1. Transition stress as a function of grain size . . . . . . . . . . . 60

A-7.2. Arrhenius plot of irradiated $\mathrm{UO}_{2}$ creep normalized to a fission rate of $10^{19}$ fissions $/ \mathrm{m}^{3} \cdot \mathrm{s} \ldots \ldots 62$

A-7.3. Comparison of irradiated and unirradiated $\mathrm{UO}_{2}$ experimental data with corresponding calculated values from FCREEP

A-7.4. Comparison of mixed oxide experimental data with corresponding values from FCREEP

A-8.1. Comparison of Equation (A-8.4) in the elastic behavior regime with out-of-pile $\mathrm{UO}_{2}$ fracture strength data normalized to $10-\mu \mathrm{m}$ grain size and $95 \%$ TD ................... 79

A-8.2. Comparison of Equation (A-8.5) in the elastic behavior regime with out-of-pile $\mathrm{UO}_{2}$ fracture strength data normalized to $10-\mu \mathrm{m}$ grain size and $95 \%$ TD

A-8.3. Least-squares regression fit of $\mathrm{UO}_{2}$ fracture strength in the elastic-plastic regime to out-of-pile data of Cannon et al .

A-8.4. Calculated curves showing the predictions of FFRACS as a function of temperature for two fuel densities . . . . . . . . . . . . . . . 84

$\Lambda$-9.1. Comparison of predicted and averaged measured swelling rates over the temperature ranges shown $\ldots \ldots \ldots \ldots$

A-9.2. Volumetric swelling rate as a function of cladding surface temperature for $\mathrm{UO}_{2}$ and $(\mathrm{U}, \mathrm{Pu}) \mathrm{O}_{2}$ clad in $\mathrm{W} / \mathrm{Re}$ as seen in Battelle experiments ..................... 93

A-9.3. Swelling of $\mathrm{UO}_{2}$ at high temperatures measured at Battelle . . . . . . . 94

A-9.4. Total swelling as a function of burnup from Babcock \& Wilcox high burnup fuel behavior program . . . . . . . . . . . . . . . . 97

A-9.5. Schematic of in-pile fuel column length change ........... 103 
A-9.6. A smoothed histogram showing the effect of irradiation on the volumc distribution of porosity in a stable (pore-former) sintered $\mathrm{UO}_{2}$ fuel ........................ 105

A-9.7. Densification data for different EPRI type fuels . . . . . . . . 106

A-9.8. Comparison of calculated (CONECT) density changes and experimental data . . . . . . . . . . . . . . 108

A-10.1. Comparison of Equation (A-10:7) with experimental data for $\mathrm{UO}_{2}$ grain growth $\ldots \ldots \ldots \ldots 118 \ldots \ldots$

A-10.2. Comparison of Ainscough et al correlation (Equation A-10.8b) with experimental data for $\mathrm{UO}_{2}$ grain growth . . . . . . . . . . . . 119

A-10.3. Lenticular void in $\mathrm{ThO}_{2}-5 \% \mathrm{UO}_{2}$ fuel showing injection of spherical bubbles into grain boundaries . . . . . . . . . . . . . 123

A-10.4. Comparison of Equation (A-10.16) with experimental data for $\mathrm{UO}_{2}$ grain growth ........................ 127

A-11.1. The effect of burnup and fission rate on the density change of EPRI fuel types 1,2 , and $4 \ldots \ldots$. . . . . . . . . . . . . $\ldots$

A-11.2. Change in fuel stack length of Halden fuel as a function of burnup . . . . . . . . . . . . . . . . 135

A-11.3. Fuel stack length changes for $92 \% \mathrm{TD} \mathrm{UO}_{2}$ processed by different techniques

A-1 1.4. FUDENS calculations using EPRI fuel fabrication parameters and resintering values correlated with experimental EPRI in-pile data

A-12.1. Calculated versus measured gas release percentages for the data points from R. M. Carroll et al $\ldots \ldots \ldots . \ldots 153$

A-13.1. Surface area per unit volume recommended by Belle . . . . . . . . . . . 164

A-13.2. Hission chains for mass numbers' $127-132$ from the thermal fission of $\mathrm{U}-235 \ldots \ldots \ldots \ldots$. . . . . . . . . . . . . . . . . . . . . . . . . . . .

A-13.3. Fission chains for mass numbers $133-138$ from the thermal fission of $\mathrm{U}-235 \ldots \ldots \ldots \ldots 6$ 
A-13.4. Model calculations for iodine and cesium releases from $97 \%$ dense fuel as a function of temperature for a burnup of $2.6 \times 10^{5} \mathrm{MWs} / \mathrm{kgU}$ at 0.1 year and a burnup rate of $3 \times 10^{6} \mathrm{MWs} / \mathrm{kgU}$ per year . . . . . . . 169

A-13.5. Iodine release from fuels of varying density with $2 \times 10^{6} \mathrm{MWs} / \mathrm{kgU}$ burnup at one year and a burnup rate of $3 \times 10^{6} \mathrm{MWs} / \mathrm{kgU}$ per year . . . . . 170

B-1.1 Specific heat of zircaloys as calculated by CCP for alloys without hydrides . . . . . . . . . . . . . . . . . . . 180

B-1.2. Available data, MATPRO expressions for specific heat, and estimated uncertainty of the MATPRO expression for temperatures from 300 to $1000 \mathrm{~K}$

B-1.3. Available data, MATPRO expressions for specific heat, and estimated uncertainty of the MATPRO expression for temperatures from 1000 to $2100 \mathrm{~K}$

B-1.4. Data base for MATPRO prediction of the effect of hydride solution on specific heat, Scott's proposed curve for specific heat of zirconium, and the MATPRO predictions for the effect of $28 \mathrm{ppm}$ and $300 \mathrm{ppm}$ of hydrogen on the specific heat curve . . . . . . . . . . . 184

B-1.5. MATPRO predictions for apparent zircaloy specific heat for several hydrogen concentrations compared with one curve measured with as-received zircaloy-2 . . . . . . . . . . . . . . . . . 186

B-2.1. Thermal conductivity data, least-squares fit, and the two standard deviation limits . . . . . . . . . . . . . . . . . . . . . 189

B-3.1. Total hemispherical emittance of zircaloy-4 versus time at temperature in steam . . . . . . . . . . . . . . . . . . . 198

B-3.2. ZOEMIS calculations compared with the data base of the model . . . . . 202

B-3.3. Expected standard errors of emissivity for temperatures below $1500 \mathrm{~K}$ and at $1573 \mathrm{~K} \ldots \ldots . . \ldots 204$

B-4.1. Thermal conductivity of zirconium dioxide as a function of tcmpcrature as calculatcd by the ZOTCON subcodc . . . . . . . . . . 206

B-4.2. Temperature dependence of the therrial conductivity of zirconium dioxide according to Lapshov and Bashkatov, showing the trend line . . . . . . . . . . . . . . . . . . . . 208 
B-5.1. Nomenclature used to describe directions in rolled plate and drawn tubing . . . . . . . . . . . . . . . . 210

B-5.2. Axial thermal expansion of.zircaloy tubing as calculated by CATHEX, including data base and estimated low-temperature uncertainty limits

B-6.1. Diametral thermal expansion of zircaloy tubing as calculated by CDTHEX, including data base and low-temperature uncertainty

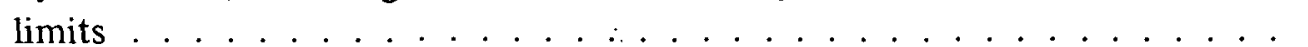

B-6.2. Comparison of the diametral thermal expansion of zircaloy tubing as calculated by CDTHEX with the axial thermal expansion of tubing as calculated by CATHEX . . . . . . . . . . . . . . 218

B-7.1: Elastic modulus of zircaloy-2 as a function of tcmpcrăture showing the data and correlation of Spasic et al

B-7.2. Zircaloy elastic modulus as a function of temperature showing. the correlation of Busby, Spasic et al; Mehan and Wiesinger, and CELMOD for the $\alpha$-phase for zircaloy

B-7.3. Elastic modulus of zircaloy as a function of temperature as. calculated by the CELMOD subcode . . . . . . . . . . . . . . . . . 223

B-8.1. Values of strain rate sensitivity constant and data base as a function of temperature and strain rate used by MATPRO mechanical properties routines ...................... . . 230

B-8.2. Increase in the strain sensitivity constant at $1173 \mathrm{~K}$ as a function of strain rate shown with the expression used for this increase in MATPRO . . . . . . . . . . . . . . . . . . . . 231

B-8.3: Data for $\mathrm{K}$, modified to represent annealed tubing with the analytical expressions used in MA'IPKO to represent $\mathrm{K}$ as a function of temperature . . . . . . . . . . . . . . . . . 233

B-8.4. Base data and the expression used to represent the.strain hardening exponent for annealed tubes

B-8.5. Data and least-squares fit to strength coefficients as a function of cold work and irradiation at ambient temperature 235

B-8.6. Data and analy tical functions for strain hardening coefficient as a function of cold work and irradiation at ambient temperature 236 
B-8.7. Predicted values of true and engineering stress as a function

of true strain at a strain rate of $10^{-3} / \mathrm{s}$ and several temperatures . . . . . 239

B-8.8. Effects of cold work or irradiation on true stress predicted by

CSTRES at a temperature of $600 \mathrm{~K}$ and a strain rate of $10^{-3} / \mathrm{s} \ldots 240$

B-8.9. True stress versus true, strain for several constant strain rates at $900 \mathrm{~K} \ldots \ldots \ldots . \ldots \ldots$

B-9.1. Values of true and engineering strain calculated by CSTRAN at several temperatures and a constant strain rate of $10^{-3} / \mathrm{s} \ldots \ldots 249$

B-9.2. Effect of different constant rates of stress and strain on the values of true strain calculated by CSTRAN at $900 \mathrm{~K}$

B-10.1. Ratios of elongation at failure for samples with varying amounts of cold work and fast neutron fluence to elongation at failure of an annealed samp

B-10.2. Measured values of instability strain from W. R. Smalley compared to the MATPRO correlation for total circumferential elongation

B-10.3. Cross section, perpendicular to the axis, of a zircaloy tube showing location of the center of curvature of the side opposite

B-10.4. Graphic correlation of the components of true local strain at rupture with temperature

B-10.5. Engineering ultimate strength predicted by CMLIMT at a strain rate of $10^{-5} / \mathrm{s}$ as a function of temperature for several levels of cold work and typical fluences $\ldots \ldots \ldots \ldots$. . . . . . . . . .

B-10.6. Measured values of ultimate strength at $630 \mathrm{~K}$ and a strain rate of $8 \times 10^{-5} / \mathrm{s}$ with Saxton cladding as a function of fast neutron fluence compared to CMLIMT predictions for engineering ultimate strength.

B-10.7. Predicted circumferential elongation at rupture, measured values, and standard error of new in-reactor data predicted as a function of tempcraturc by the CSRUPT model for annealed tubing

B-10.8. Predicted circumferential elongation at rupture of annealed cladding compared to predictions and measurements for cold-worked and irradiated cladding 
B-11.1. Typical pole figures showing texture differences between zircaloy pressure tubes and fuel rod cladding . . . . . . . . . . . . . . . 279

B-11.2. Total creep predicted by the cladding creep rate equation for. typical PWR operating conditions and for two different flux levels, as a function of time . . . . . . . . . . . . . . . . . 285

B-11.3. Comparison of the predictions of the cladding creep rate equation: with the Saxton data. . . . . . . . . . . . . . . . 286

B-11.4. Comparison of Ibrahim's pressure tube data with the cladding creep rate equation . . . . . . . . . . . . . . . . 287

B-12.1. Temperature dependence of Poisson's ratio for zircaloy as 'used in the CPOIR subcode . . . . . . . . . . . . . . . . . . . . . . 294

B-14.1. The CMHARD correlation for the Meyer hardness of zircaloy . . . . . 303,

B-1.5.1. Model predictions and measured values of zircaloy tube axial growth as a function of fast neutron fluence, irradiation temperature, cold work, and texture coefficient $\mathrm{f}_{\mathrm{z}} \ldots \ldots . \ldots . \ldots 306$

B-15.2. The growth of schematic unit cells in a grain . . . . . . . . . . 310

B-15.3. Model predictions and measured values of growth of zircaloy tubes adjusted to a common texture coefficient of $f_{z}=0.05$

B-1 5.4, Zircaloy growth, versus square root of fast neutron fluence for data adjusted to a common tube texture coefficient of $f_{L}=0.05$ with linear least-squares fits superimpose

B-15.5: Zircaloy growth versus square root of fast neutron fluence for data adjusted to a common tube texture coefficient of $f_{z}=0.05$ and to a common temperature of $300^{\circ} \mathrm{C}$, with linear least squares fits superimpused.

B-16.1. Schematic of posttransition oxide showing an intact 'rate-determining layer of varying thickness, with another oxide layer which does not affect the oxidation rate . . . . . . . . . . . . . . 327

B-16.2. Estimates of enhancements over out-of-pile oxidation rates when cladding is irradiated in typical BWR and PWR eriviromments

B-16.3. Comparison of the predicted oxide layer thickness with the base data from average values of six Shippingpont zircaloy-2 rods in a PWR cnvironment at $277^{\circ} \mathrm{C} \ldots \ldots \ldots . \ldots . \ldots . \ldots . \ldots 34$ 
B-16.4. Comparison of the predicted oxide layer thickness with the base data from Saxton zircaloy 4 rods in a PWR at $340^{\circ} \mathrm{C} \ldots \ldots 335$

B-16.5. Comparison of the predicted oxide layer thickness with the base data from zircaloy:2 rods irradiated in the Vallecitos and Dresden BWRs at $286^{\circ} \mathrm{C}$

B-16.6. Calculated temperatures versus measured $\xi$ layer thickness with temperature estimates made from the microstructure 340

B-16.7. Comparison of calculated and measured $\mathrm{ZrO}_{2}$ thicknesses for six temperatures

B-16.8. Heating rate per meter for a rod of initial diameter $1.25 \times 10^{-2} \mathrm{~m}$ as a function of temperature for various initial oxide thicknesses

B-16.9. Comparison of calculated and measured $\xi$ layer thicknesses for six temperatures . . . . . . . . . . . . . . . . . 347

C-1.1. Thermal conductivity of xenon-helium mixtures at $520^{\circ} \mathrm{C} \ldots \ldots 8$

C-1.2. Effect of measured internal gas pressure on fuel temperatures near the pellet surface .................. 371

C-2.1. Gas viscosity as a function of temperature for pure helium, for a binary mixture of helium and xenon, and for an equal molar mixture of helium, argon, krypton, and xenon . . . . . . . . . . . . 379

C-3.1. Phase diagram for stoichiometric mixed uranium-plutonium oxides

\section{TABLES}

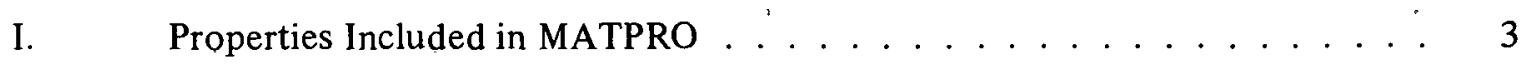

A-1.I. Listing of the FCP Subcode . . . . . . . . . . . . . . . . . . 14

A-2.1. Values of the Constants used in Fruation (A-2.1) for $\mathrm{Un}_{2}$ and for $(\mathrm{U}, \mathrm{Pu})_{2} \mathrm{O}_{2}$ Thermal Conductivity . . . . . . . . . . 16

A-2.II. The Effect of Different Assumptions on the Calculated Values of $\mathrm{K}_{3}$ and $\mathrm{K}_{4}$ in Equation $(\mathrm{A}-2.1)$ for $\mathrm{UO}_{2} \ldots \ldots \ldots$

A-2.III. Listing of the FTHCON Subcode . . . . . . . . . . . . . . 28 
A-3.I. Spectral Emissivity of $\mathrm{UO}_{2}$ as Measured by Claudson . . . . . . . 31

A-3.II. Spectral Emissivity of $\mathrm{UO}_{2}$ as Measured by Ehlert and Margrave . . . . . . . . . . . . . . . . . . 32

A-3.III. Standard Deviation of the Least-Squares Approximations to Claudson's Data . . . . . . . . . . . . . . . . . . . . . 33

A-3:IV. Listing of the FEMISS Subcode . . . . . . . . . . . . . . 35

A-4.I. Listing of the FTHEXP Subcode . . . . . . . . . . . . . . . 40

A-5.I. Listing of the FELMOD Subcode . . . . . . . . . . . . . . . . . . 49

A-6.I. Listing of the FPOIR Subcode . . . . . . . . . . . . . 52

A-7.I. Values of $m /(1-n)$ from Possible Values of $m$ and $n \ldots \ldots$ $\therefore$.

A-7.II. Test Conditions and Fuel Rod Characteristics of Low Temperature In-Reactor $\mathrm{UO}_{2}$ Creep Experiments . . . ........... . . 61

A-7:II. Properties of Sintered Pellêts Used by Evanis et al . . . . . . . . . 65

A-7.IV. Listing of the FCREEP Subcode . . . . . . . . . . . . . . 73

A-8.I. Listing of the FFRACS Subcode . . . . . . . . . . . . . . . 85

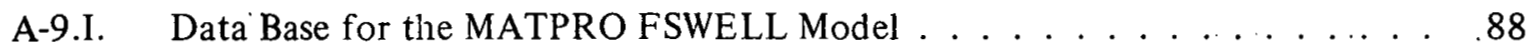

A-9.II. Calculated Values of the Relative Swelling Rate . . . . . . . . . . . 88

A-9.III. Nominal Conditions and Parameters for Battelle Swelling

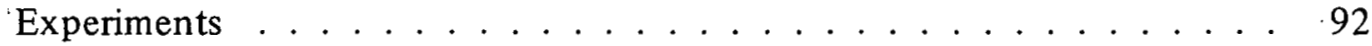

A=9.IV. Nominal Conditions and Parameters for Bettis Flat Plate Swelling

. Experiments . . . . . . . . . . . . . . . . . . 95

A-9.V. Swelling Rates of $(\mathrm{U}, \mathrm{Pu}) \mathrm{O}_{2}$ Obtained by Nelson and Zebroski . . . . . . . . . . . . . . . . . . . . . . . . . . . . . . . . . 98

A-9.VI. Fuel Temperature-Gas Release-Grain Structure Correlation . . . . . . . . . . 99

A-9.VII. Summary of Macroscopic Swelling Data . . . . . . . . . . . . . . . . 100

A-9.VIII. Summary of Solid Fission Product Swelling Values _. . . . . . . . . . 101 
A-9.IX. Temperature Dependence of the Swelling Rate . . . . . . . . . . 104

A-9.X. Listing of the FSWELL Subcode . . . . . . . . . . . . . 109

A-9.XI. Listing of the CONECT Subcode . . . . . . . . . . . . . 110

A-10.I. Summary of Pore Migration Rate Experiments . . . . . . . . . 126

A-10.II. Listing of the FRESTR Subcode . . . . . . . . . . . . . . . . . . 129

A-11.I. Listing of the FUDENS Subcode . . . . . . . . . . . . . . 147

A-12.I. Listing of the FGASRL Subcode . . . . . . . . . . . 155

A-13.I. Fission Yields of Stable and Long-Lived Isotopes of Iodine and Cesium . . . . . . . . . . . . . . . . . 167

A-13.11. Fission Yields of Short-Lived Isotopes of Iodine and Cesium $\ldots \ldots \ldots$

A-1 3.III. Comparison of Model Predictions for Escape Rate Coefficients with Values Reported in WCAP-TM-159 . . . . . . . . . . . . . 171

A-13.IV. Listing of the CESIOD Subcode . . . . . . . . . . . . 173

B-1.I. Specific Heat Capacity as a Function of Temperature - Alpha Phase . . . 178 .

B-1.II. Specific Heat Capacity as a Function of Temperature - Beta Phase . . . . 179

B-1.HI. Uncertainties in Spccific Heat of Zircaloy . . . . . . . . . . . . . 187

B-1.IV. Listing of the CCP Subcode . . . . . . . . . . . . . . . . 187

B-1.V. Listing of the CHSCP Subcode . . . . . . . . . . . . . 188

B-2.I. Zircaloy Thermal Conductivity Data Base . . . . . . . . . . . 191

B-2.II. Listing of the CTHCON Subcode . . . . . . . . . . . . . . 194

B-3.I. Emissivity of Thin Oxide Films as Reported by Murphy and Havelock . . 198

B-3.II. Emissivity Data From Burgoyne and Garlick . . . . . . . . . . . . . 200

B-3.III. Emissivity Versus Oxide Thickness From Juenke and Garlick's Data . . . . 201

B-3.IV. Standard Errors of Model Predictions . . . . . . . . . . . . . 203 
B-3.V. Listing of the ZOEMIS Subcode . . . . . . . . . . . . 205

B-4.I. Thermal Conductivity of Zirconium Dioxide from Maki . . . . . . . . 207

B-4.II. Listing of the ZOTCON Subcode . . . . . . . . . . . . 208

B-5.I. Listing of the CATHEX Subcode ................ 214

B-6.I. Listing of the CDTHEX Subcode . . . . . . . . . . 219

B-7.I. Listing of the CELMOD Subcode . . . . . . . . . . . 224

B-8.I. Listing of the CSIGMA Subcode . . . . . . . . . . . . . . 242

B-8.II. Listing of the CSTRES Subcode ................ 243

B-9.I. Listing of the CSTRAN Subcode . . . . . . . . . . . 251

B-10.I. Standard Error of Predicted Strains at Rupture . . . . . . . . . . 261

B-10.II. Components of Local True Strain for Seven Bursts . . . . . . . . . 265

B-10:III. Listing of the CMLIMT Subcode . . . . . . . . . . 271

B-10.IV. Listing of the CSRUPT Subcode . . . . . . . . . . . . 273

B-10.V. Listing of the CLOCRP Subcode . . . . . . . . . . . . 274

B-11.I. 'Saxton Rods Creepdown Data at 9750 Hours . . . . . . . . . . . . 280

B-11.II. Ibrahim Pressure Tube Creep Data at 10000 Hours $\therefore \ldots \ldots$

B-11.III. Listing of the CCRPR Subcode . . . . . . . . . . . 289

B-12.I. Listing of the CPOIR Subcodc . . . . . . . . . . . . 295

B-1 3.1. Crack Growth Kate Versus Stress Intensity ${ }^{\circ}$ Kange From Rao . . . . . . . 297

B-13.II. Values of Low Cycle Fatigue Material Parameters . . . . . . . . . . 300

B-I3.III. Listing of the CFATIG Subcode . . . . . . . . . . . 300

B-14.1. Listing of the CMHARD Subcode . . . . . . . . . . . 304

B-1 5.1. Measurements of Growth in Zircaloy Tubing . . . . . . . . . . 308 
B-1 5.II. Zircaloy Growth Data as a Function of Cold Work and Fluence . . . . . . . 318

B-1 5.III. Determination of Cold Work Coefficient . . . . . . . . . . . 318

B-15.IV. Listing of the CAGROW Subcode . . . . . . . . . . . . . . . 320

B-16.I. Summary of $\mathrm{ZrO}_{2}$ and $\xi$ Correlations and Their Standard Errors

From the Data Bases . . . . . . . . . . . . . . . . . . . 339

B-16.II. Uncertainties in CHITOX Correlations . . . . . . . . . . . . . . . . 349

B-16.III. Listing of the CORROS Subcode . . . . . . . . . . . . 350

B-16.IV. Listing of the CHITOX Subcode . . . . . . . . . . . . . . 351

B-1 7.I. Rate Equations for Hydrogen Uptake . . . . . . . . . . . . 358

B-17.II. Listing of the CIIUPTK Subcode . . . . . . . . . . . . . . . 362

C-1.I. Listing of the GTHCON Subcode . . . . . . . . . . . . . . . 372

C-2.I. Listing of the GVISCO Subcode . . . . . . . . . . . . 380

C-3.I. Listing of the PHYPRO Subcode . . . . . . . . . . . . . 385

D-1.I. Input-Output Arguments of MATPRO Subcodes . . . . . . . . . . 390

D-2.I. SI Units for Use in MATPRO . . . . . . . . . . . . 410

D-2.II. Conversion Factors ................... 411

D-3.I. Listing of POLATE Subcode . . . . . . . . . . . . . 412 
MATPRO-VERSION 10

\section{A HANDBOOK OF MATERIALS PROPERTIES}

FOR USE IN THE ANALYSIS OF LIGHT WATER REACTOR FUEL ROD BEHAVIOR

\section{INTRODUCTION}

Understanding the performance of light water reactor (LWR.). fuel under accident conditions is a major objective of the Reactor Safety Research Program being conducted by the U.S. Nuclear Regulatory Commission (NRC). An extensive program has been defined - centered upon out-of-pile and in-pile experiments and their analyses - with the goal of verifying analytical models. These models are designed to predict fuel transient performance during a wide range of accident types and conditions, and at any time during the operating life of a fuel rod.

These models are based on the materials properties correlations which define the physical condition of LWR fuel and cladding under changing thermal, nuclear, and physical load conditions. The NRC and the nuclear industry have accumulated a large amount of data on these properties. This handbook describes the materials properties correlations and computer subcodes developed for use with various LWR fuel rod behavior analytical models at the Idaho National Engineering Laboratory (INEL). 


\section{DESCRIPTION OF MATPRO}

This handbook is a computer library of 39 subcodes dealing with uranium dioxide and mixed uranium-plutonium dioxide fuel, zircaloy cladding, gas mixture, and LWR fuel rod material properties. Each property is programmed in MATPRO as a separate unit, either as a function or as a subroutine, so that individual correlations may be altered without changes being made elsewhere in the program. This modular format is consistent with the structure of other INEL light water reactor safety analysis programs.

The previously published version of this handbook, MATPRO 09[1] has been improved. Five new models have been added; nine models have been completely rewrillen to incorporate the effects of new experimental data and to more accurately describe an effect, and the remaining 25 descriptions have been somewhat rewritten without change in their basic correlations to obtain a more uniform format and to incorporate SI units whenever possible ${ }^{[2]}$. Table I lists the specific materials properties documented in MATPRO 10. New models and models from MATPRO 09 which have been completely rewritten are denoted by footnotes. Appendix A contains the uranium dioxide and mixed uranium-plutonium dioxide fuel material properties correlations and subcodes. Appendix B describes the zircaloy cladding thermal and mechanical material properties subcodes; Appendix C presents the gas LWR fuel rod material properties subcodes; and Appendix D presents various supporting material including a description of the linear interpolation routine (POLATE) used by a number of the subcodes described in Appendixes A and B; a list of the basic SI units and derived units used in MATPRO, and a list of the MATPRO arguments by subcoule.

Appendixes A, B, and C' contain separate sections tor each maternal property listed in' Table I. In each section, the results of a review and evaluation of the data in the literature are presented; the development of a mathematical model based upon theory and experiment is documented; a FORTRAN subcode and comparisons of predictions using that subcode with data are presented; and the limitations of the model are explained. References are provided for each subcode. The name of the author of each section is listed in each subcode listing.

The subcodes generally are functions rather than subroutines. Considerable effort has been expended to ensure a consistent format for these"subcodes and that input and output variables are clearly identified with their proper units given. The FORTRAN names of these variables has been standardized to aid the reader.

Many of the subcodes have been assigned a local index, designated by the acronym LOCIDX, which has a unique value for each subcode. When the MATPRO subroutine is used in conjunction with a fuel rod analysis code such as FRAP-S ${ }^{[3]}$ or FRAP-T ${ }^{[4]}$. This index is used as an identifier allowing specific material property subcodes to be replaced with alternative codes specified by the user. 
TABLE I

PROPERTIES INCLUDED IN MATPRO

Property $[\mathrm{a}]$

Subcode

Fuel Material Properties (Appendix A)

1. Specific Heat Capacity

2. Thermal Conductivity [b]

FCP

3. Emissivity

FTHCON

4. Thermal Expansion

FEMISS

5. Elastic Modulus

FTHEXP

6. Poisson's Ratio

FELMOD

7. Creep Rate

8. Fracture Strength ${ }^{[b]}$

9. Swelling ${ }^{[\mathrm{b}]}$ and Integration ${ }^{[\mathrm{C}]}$ of Swelling and Densification Effects

FPOIR

FCREEP

FFRACS

FSINELL, CONECT

10. Restructuring

11. Densification [b]

FRESTR

FUDENS

12. Fission Gas Release

FGASRL

13. Cesium and Iodine Release ${ }^{[\mathrm{C}]}$

CESIOD

Cladding Material. Properties (Appendix B)

1. Specific Heat Capacity and the Effect of Hydride Solution on Cladding Specific Heat

2. Thermal Conductivity

3. Surface Emissivity[b]

CTHCON

4. Oxide Thermal Conductivity

ZOEMIS

5. Axial Thermal Expansion

ZOTCON

6. Diametral Thermal Expansion

CATHEX

7. Elastic Modulus

CDTHEX

8. Stress versus Strain

CELMOD

9. Strain versus Stress

10. Cladding Mechanical Limits ${ }^{[b]}$

Cladding Strain at Rupture and Cladding Local Strains at Rupture[c]

CSTRES, CSIGMA

CSTRAN

CMLIMT, CSRUPT CLOCRP

11. Creep Rate ${ }^{[b]}$

CCRPR

12. Potsson's Ratio

CPOIR 
TABLE I (continued)

Cladding Material Properties (Appendix B)

Subcode

13. Cyclic Fatigue ${ }^{[\mathrm{c}]}$

CFATIG

14. Meyer Hardness

CMHARD

15. Axial Growth

16. Low ${ }^{[b]}$ and $\mathrm{High}^{[\mathrm{c}]}$ Temperature Oxidation

CAGROW

17. Hydrogen Uptake ${ }^{[b]}$

CORROS, CHITOX

CHUPTK

Gas and Fue 1: Rod Material Properties (Appendix C)

1. Gas Therimal Conductivity

GTHCON

2. Gas Viscosity

GVISCO

3. Physical Properties

PHYP.RO

[a] Models without superscript have been somewhat rewritten, but the correlations and thus subcodes are identical to those in MATPRO-09.

[b] Model was contained in MATPRO-09 but has been substantially changed. Computer program differs from that in MATPRO-09.

[c] Model is completely new and not contained in MATPRO-09. 


\section{FUTURE VERSIONS OF MATPRO}

In order to describe the behavior of LWR fuel rods, the properties of the materials used to fabricate the fuel rods must be known for the entire life of the fuel rods. Anisotropic effects and the effects of irradiation and dissolved oxygen during operation or during the course of an accident have in many cases not yet been modeled. Provisions have been made in some of the material subcodes for adding these effects.

Experimental and theoretical investigations of material properties are underway at a number of laboratories in many countries. As new information becomes available, the correlations describing those material properties will be improved in MATPRO, and revisions will be issued. 
1. P. E. MacDonald and L. B. Thompson, (eds.), MATPRO-Version 09,. A Handbook of Materials Properties For Use in the Analysis of Light Water Reactor Fuel Rod Behavior, TREE-NUREG-1005 (December 1976).

2. American Society for Testing and Materials, "Standard for Metric Practice," ASTM Designation: E 380-76.

3. J. A. Dearien et al, FRAP-S2: A Computer Code for the Steady State Analysis of Oxide Fuel Rods, Report 1, Analytical Models and input Manual, TREENUREG-1 107.(July 1977).

4. J. A. Dearien et. al, FRAP-T2: A Computer Code for the Transient Analysis of Oxide Fuel Rods, Report 1, Analytical Models and Input Manual, TREE-NUREG-1040 (August 1.977). 


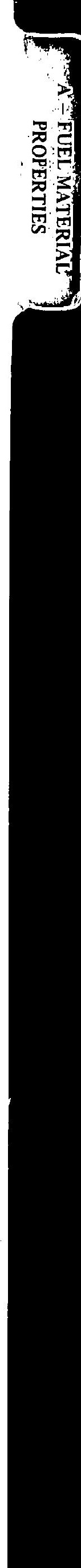


APPENDIX A

FUEL MATERIAL PROPERTIES 
THIS PAGE

WAS INTENTIONALLY

LEFT BLANK 


\section{APPENDIX A}

\section{FUEL MATERIAL PROPERTIES}

Thirteen materials properties of light water reactor fuel have been modeled for inclusion in MATPRO-Version 10. The approaches range from: (a) a least-squares fit to available data using a polynomial or other function having little or no theoretical basis to (b) a semiempirical correlation employing an analytical expression suggested by theory with constants determined by comparison with data. The intent of current and future work is to take the second approach whenever possible.

Each material property description includes a listing of a FORTRAN subcode which may be used to calculate the value of the property for various input conditions. All 13 MATPRO fuel subcodes have temperature as an argument. In addition many are functions of burnup, plutonia content, density, time, and other variables. A complete list of the input and output variables for each routine is given in Table D-1.I of Appendix D in this document.

Several of the subcodes call a physical properties subcode (PHYPRO, Appendix C, Section 3 ) to get fuel melting temperatures and heats of fusion. These and other commonly used material parameters have been placed in this separate subroutine which can be called by any of the subcodes so that as changes become necessary, updating may be done in only one place rather than individually in many separate subcodes.

Also included in Appendix $\mathrm{A}$ is a subcode to integrate the fuel swelling and densification functions. This subcode is included in the fuel swelling description.

\section{FUEL SPECIFIC HEAT CAPACITY (FCP)}

The specific heat capacity of nuclear fuel is needed for temperature calculations in time-dependent fuel behavior problems. Enthalpy data, from which the heat capacity correlations are taken, are employed in stored energy calculations. The subcode FCP presents correlations for the specific heat capacity of $\mathrm{UO}_{2}$ and of $(\mathrm{U}, \mathrm{Pu}) \mathrm{O}_{2}$ fuel. The correlations are shown in Figure A-1.1.

\section{$1.1 \quad \mathrm{UO}_{2}$ Specific Heat Capacity}

Kerrisk and Clifton $[\mathrm{A}-1.1]$ have fit unirradiated $\mathrm{UO}_{2}$ enthalpy data from five different investigators, covering the temperature range of 298 to $3100 \mathrm{~K}$, to one equation and differentiated to obtain the specific heat capacity over that temperature range. The uncertainty of their enthalpy data, for a $95 \%$ confidence level, was reported to be less than $1 \%$. The uncertainty of their heat capacity relation was reported to range from 2 to $6 \%$ 


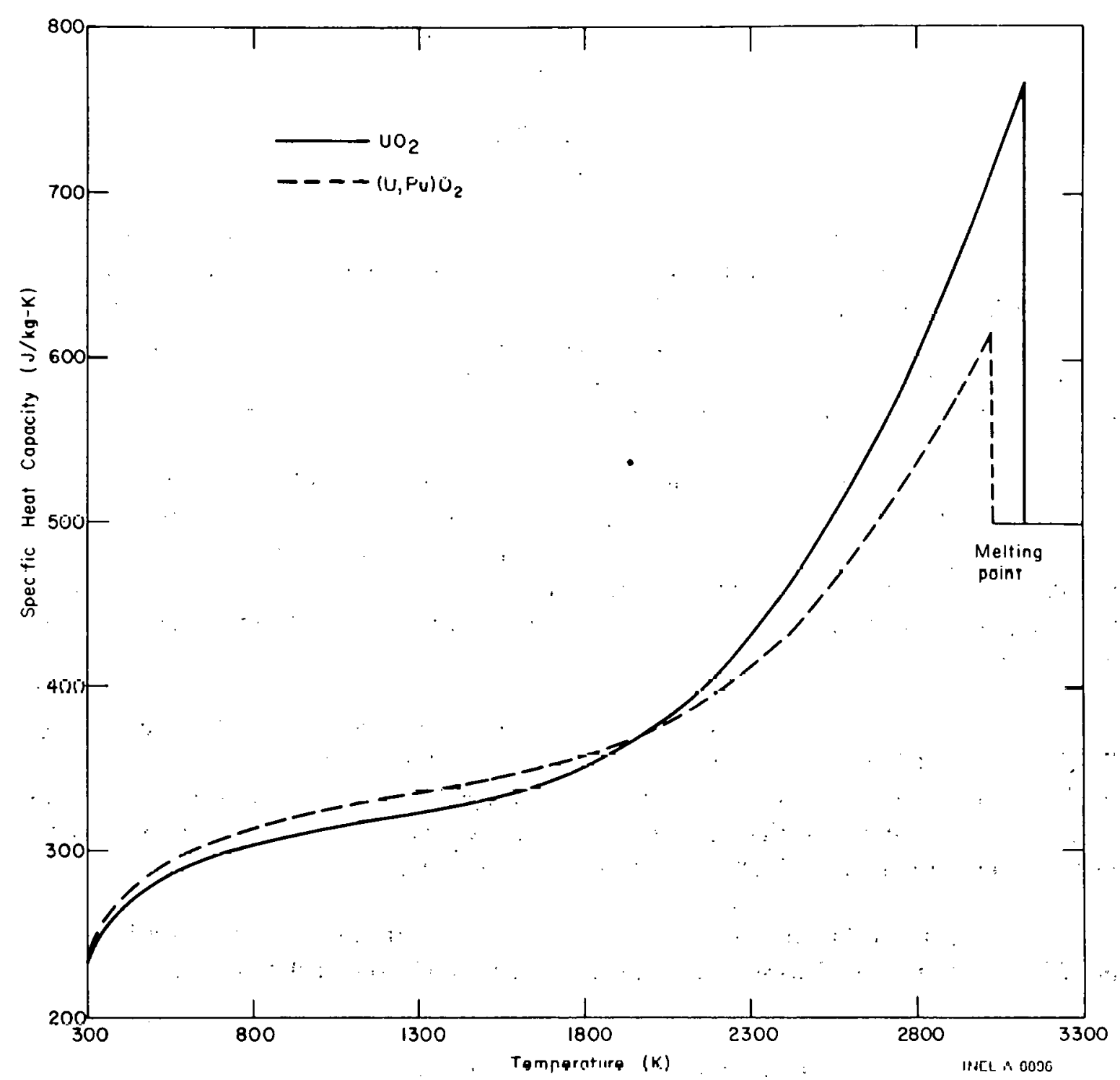

Fig. A-1.1 Temperature dependence ö mixed oxide specific heat capacity calculated by FCP for $\mathrm{UO}_{2}$ and $(\mathrm{U}, \mathrm{Pu}) \mathrm{O}_{2}$.

between 500 and $3000 \mathrm{~K}$. The Bureau of Mines Bulletin \#605 $[\mathrm{A}-1.2]$ also provides a specific heat capacity relationship for the temperature range 298 to $1500 \mathrm{~K}$. This relationship agrees very well with that of Kerrisk and Clifton, suggesting that the specific heat capacity of unirradiated $\mathrm{UO}_{2}$ is adequately characterized.

Kerrisk and Clifton's correlation is used in FCP for the specific heat capacity of the solid phase and extrapolated from $3100 \mathrm{~K}$ to the melting temperature. The specific heat capacity for the liquid phase is based on the data of Leibowitz et al $[\mathrm{A}-1.3]$ (3173 to $3523 \mathrm{~K})$. The $\mathrm{UO}_{2}$ correlations used in FCP are as follows: 
$\mathrm{UO}_{2}$ Solid Phase:

$$
C_{p}=15.496\left[\frac{K_{1} \theta^{2} \exp (\theta / T)}{T^{2}[\exp (\theta / T)-1]^{2}}+2 K_{2} T+\frac{K_{3} E_{D}}{R T^{2}} \exp \left(-E_{D} / R T\right)\right]
$$

where

$$
\begin{aligned}
& \mathrm{C}_{\mathrm{P}}=\text { specific heat capacity }(\mathrm{J} / \mathrm{kg} \cdot \mathrm{K}) \\
& \mathrm{K}_{1}=19.145(\mathrm{~J} / \mathrm{mol} \cdot \mathrm{K}) \\
& \mathrm{K}_{2}=7.8473 \times 10^{-4}\left(\mathrm{~J} / \mathrm{mol}: \mathrm{K}^{2}\right) \\
& \mathrm{K}_{3}=5.6437 \times 10^{6}(\mathrm{~J} / \mathrm{mol}) \\
& \theta=535.285(\mathrm{~K}) \\
& \mathrm{E}_{\mathrm{D}}=1.577 \times 10^{5}(\mathrm{~J} / \mathrm{mol}) \\
& \mathrm{T}=\text { temperature }(\mathrm{K}) \\
& \mathrm{R}=8.314(\mathrm{~J} / \mathrm{mol} \cdot \mathrm{K}) .
\end{aligned}
$$

$\mathrm{UO}_{2}$ Liquid Phase:

$$
C_{p}=502.95 \mathrm{~J} / \mathrm{kg} \cdot \mathrm{K} \text {. }
$$

No specific heat capacity measurements are available for irradiated fuel but Bleiberg et al $^{[A-1.4]}$ have suggested that irradiation will not directly affect $\mathrm{UO}_{2}$ specific heat capacity.

\section{$1.2(\mathrm{U}, \mathrm{Pu}) \mathrm{O}_{2}$ Specific Heat Capacity.}

R. L. Gibby et al ${ }^{[A-1.5]}$ correlated enthalpy data from Ogard and Leary $[A-1.6]$ and Leibowitz et al $[\mathrm{A}-1.7]$ for 20 wt $\% \mathrm{PuO}_{2}$ fuel and from Gibby ${ }^{[A-1.8]}$ for solid 25 wt $\%$ $\mathrm{PuO}_{2}$ mixed oxide fuel. However, they restricted their correlation to samples with oxygen-metal ratios of 1.97 and 1.98 because the enthalpy of the mixed oxide was observed to be a function of stoichiometry above $1300 \mathrm{~K}$, and oxygen-to-metal ratios of 1.97 to 1.98 are characteristic of commercial mixed oxide fuels. These data were fitted over the temperature range 298 to $3000 \mathrm{~K}$ to the theoretical equation proposed by Kerrisk and Clifton ${ }^{[A-1.1]}$ for $\mathrm{UO}_{2}$. The equation was then differentiated to obtain the specific heat capacity as a function of temperature for the solid phase.

The one-standard deviation uncertainty in specific heat capacity was reported to range from 2 to $14 \%$ for temperatures from 500 to $3000 \mathrm{~K}$, respectively. This uncertainty in 
specific heat capacity corresponds to uncertainties in enthalpy of 0.6 to $1.5 \%$. The enthalpy - relation for mixed oxides [the integral of Equation (A-1.1) with use of the mixed oxide constants] is compared in Figure A-1.2 with the enthalpy data for mixed oxides from Leibowitz et al $[\mathrm{A}-1.7]$ and Gibby $[\mathrm{A}-1.8]$.

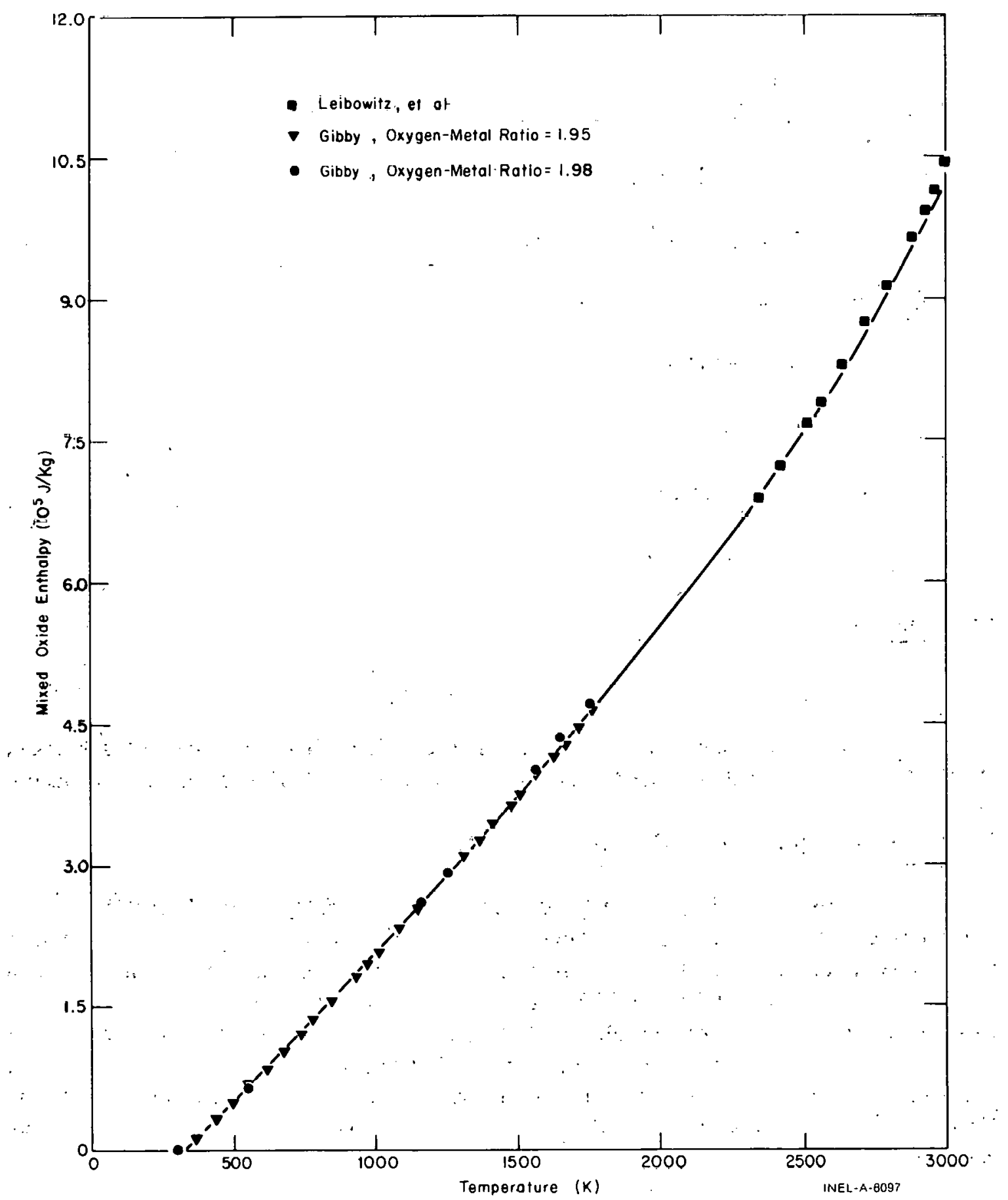

Fig. A-1 2 Comparison of calculated and experimental entholpy valucs from Lcibowitz et al and Gibby. 
Leibowitz et al $[\mathrm{A}-1.9]$ also determined a value of $155 \mathrm{~J} / \mathrm{mol} \cdot \mathrm{K}$ for the specific heat capacity of liquid mixed oxide (as compared with $136 \mathrm{~J} / \mathrm{mol} \cdot \mathrm{K}$ for $\mathrm{UO}_{2}$ ). The $12 \%$ difference between the specific heats of liquid $\mathrm{UO}_{2}$ and liquid $(\mathrm{U}, \mathrm{Pu}) \mathrm{O}_{2}$, is relatively small and suggests that until more data become available, the $\mathrm{UO}_{2}$ value can be used for the heat capacity of liquid (U,Pu)O $\mathrm{O}_{2}$ mixtures. Similar values are theoretically expected for $(\mathrm{U}, \mathrm{Pu}) \mathrm{O}_{2}$ and $\mathrm{UO}_{2}$ liquid specific heat capacities because of the similarity in structure and atomic bonding.

The (U,Pu) $\mathrm{O}_{2}$ correlations employed in FCP, depicted in Figure A-1.1, and coded in Table A-1.I are

$(\mathrm{U}, \mathrm{Pu}) \mathrm{O}_{2}$ Solid Phase:

Equation $(\Lambda \cdot 1.1)$, with

$$
\begin{aligned}
\mathrm{K}_{1} & =19.53(\mathrm{~J} / \mathrm{mol} \cdot \mathrm{K}) \\
\mathrm{K}_{2} & =9.25 \times 10^{-4}\left(\mathrm{~J} / \mathrm{mol} \cdot \mathrm{K}^{2}\right) \\
\mathrm{K}_{3} & =6.02 \times 10^{6}(\mathrm{~J} / \mathrm{mol}) \\
\theta & =539(\mathrm{~K}) \\
\mathrm{E}_{\mathrm{D}} & =1.678 \times 10^{5}(\mathrm{~J} / \mathrm{mol}) .
\end{aligned}
$$

$(\mathrm{U}, \mathrm{Pu}) \mathrm{O}_{2}$ Liquid Phase:

$$
C_{P}=502.95 \mathrm{~J} / \mathrm{kg} \cdot \mathrm{K} \text {. }
$$

1.3. Fuel Specific Heat Capacity Subcode FCP Listing

A listing of the FORTRAN subcode FCP is presented in Table A-1.I.

\subsection{References}

A-1.1. J. F. Kerrisk and D. G. Clifton, "Smoothed Values of the Enthalpy and Heat Capacity of $\mathrm{UO}_{2}$," Nuclear Technology, 16 (December 1972).

A-1.2. C. E. Wicks and F. E. Block, Thermodynamic Properties of 65 Elements - Their Oxides, Halides, Carbides, and Nitrides, Bureau of Mines Bulletin \#605 (1963).

A-1.3. L. Leibowitz, M. G. Chasanov, L. W. Mishler, D. F. Fischer, "Enthalpy of Liquid Uranium Dioxide to 3,500 K," Journal of Nuclear Materials, 39 (1971) p 115.

A-1.4. M. L. Bleiberg, R. M. Berman, B. Lustman, Effects of High Burnup on Oxide Ceramic Fuels, WAPD-T-1455 (March 1962). 
TABLE A-1. I

LISTING OF THE FCP SUBCODE

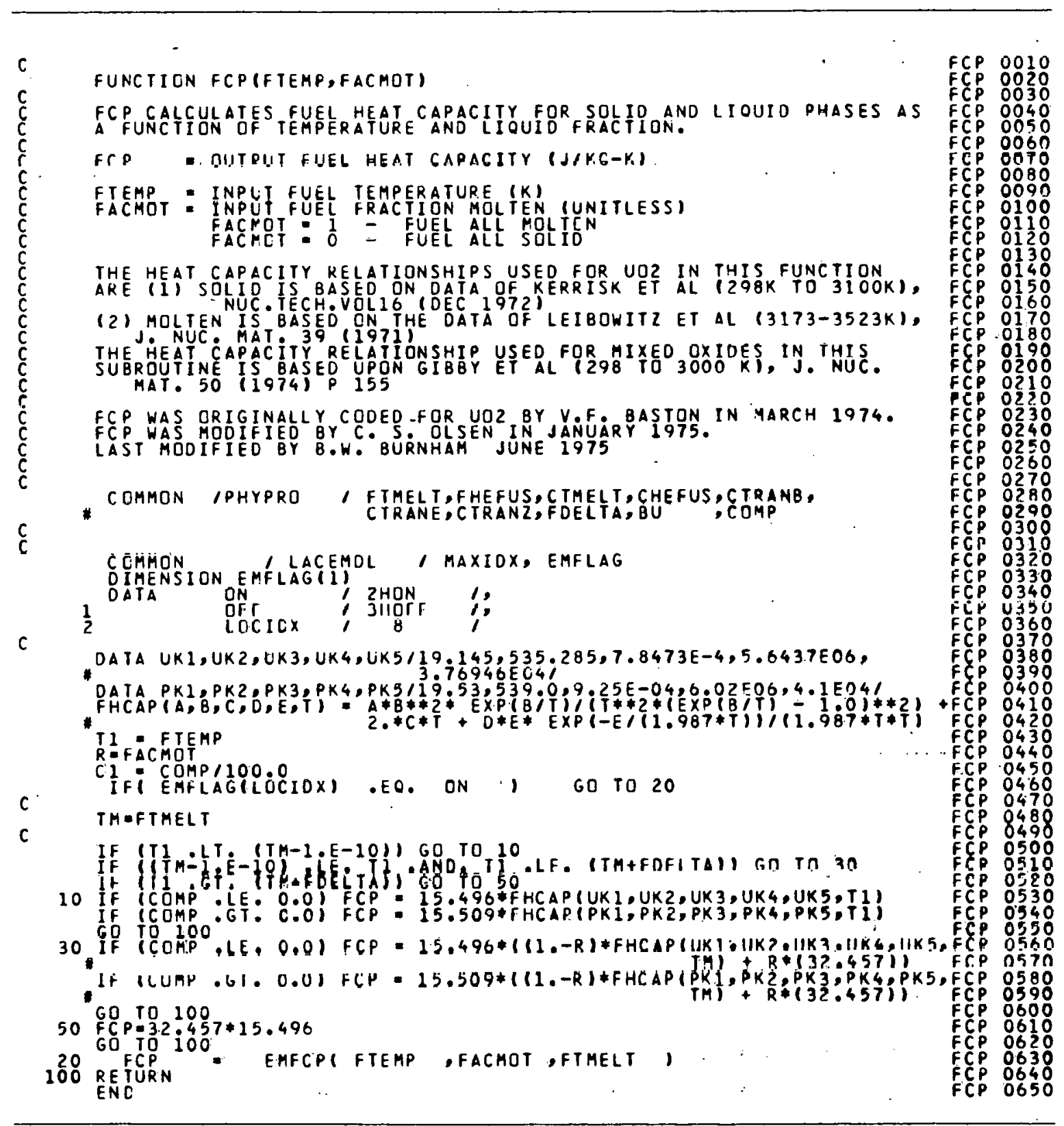

A-1.5. R. L. Gibby et al, "Analytical Expressions for Enthalpy and Heat Capacity for Uranium-Plutonium Oxide," Journal of Nuclear Materials, 50 (1974) p 155.

A-1.6. A. E. Ogard and J. A. Leary, in Thermodynamics of Nuclear Materials, IAEA, Vienna (1968) p 651. 
A-1.7. L. Leibowitz, D. F. Fischer, M. G. Chasanov, "Enthalpy of Uranium-Plutonium Oxides $\left(\mathrm{U}_{0.8} \mathrm{Pu}_{0.2}\right) 0_{1.97}$ from 2,350 to $3,000^{\circ} \mathrm{K}$," Journal of Nuclear Materials, 42 (1972) p 113.

A-1.8. R. L. Gibby, Enthalpy and Heat Capacity of $U_{0.75} P u_{0.25} O_{2-x}\left(25-1,490^{\circ} \mathrm{C}\right)$. HEDL-TME 73-19, (January 1973).

A-1.9. L. Leibowitz, D. F. Fischer, M. G. Chasanov, Enthalpy of Molten UraniumPlutonium Oxides, ANL-8042, (February 1974).

\section{FUEL THERMAL CONDUCTIVITY (FTHCON)}

In this section a correlation is presented for the thermal conductivity of $\mathrm{UO}_{2}$ and $(\mathrm{U}, \mathrm{Pu}) \mathrm{O}_{2}$ fuels based on the pooled data from ten sources in the former case and six sources in the latter. The uncertainty in these correlations is also evaluated.

\subsection{Summary}

The thermal conductivity of unirradiated $\mathrm{UO}_{2}$ and $(\mathrm{U}, \mathrm{Pu}) \mathrm{O}_{2}$ is well documented, especially in the temperature range below $1400^{\circ} \mathrm{C}$. The correlations used to fit the data are: for $0^{\circ} \mathrm{C}<\mathrm{T} \leqslant 1650^{\circ} \mathrm{C}$ :

$$
k=P\left[\frac{K_{1}}{K_{2}+T}+K_{3} \exp \left(K_{4} T\right)\right]
$$

for $1650^{\circ} \mathrm{C} \leqslant \mathrm{T}<2840^{\circ} \mathrm{C}$ :

$$
k=p\left[k_{5}+K_{3} \exp \left(k_{4} T\right)\right]
$$

where

$$
\begin{aligned}
\mathrm{k} & =\text { thermal conductivity in }\left(\mathrm{W} \cdot \mathrm{cm}^{-1} \cdot \mathrm{K}^{-1}\right) \\
\mathrm{D} & =\text { fraction of theoretical density } \\
\mathrm{P} & =\text { porosity correction factor } \\
\mathrm{T} & =\text { temperature }\left({ }^{\circ} \mathrm{C}\right) .
\end{aligned}
$$

The values of the constants $\mathrm{K}_{1}$ through $\mathrm{K}_{5}$ are given in Table A-2.I for $\mathrm{UO}_{2}$ and $(\mathrm{U}, \mathrm{Pu}) \mathrm{O}_{2}$. For mixed oxide fuel the break between the low and high temperature regions is taken at $1550^{\circ} \mathrm{C}$ rather than at $1650^{\circ} \mathrm{C}$. 
FTHCON

TABLE A-2.I

VALUES OF THE CONSTANTS USED IN EQUATION (A-2.1) FOR UO $\mathrm{UO}_{2}$ AND
FOR $(U, \mathrm{PU}) \mathrm{O}_{2}$ THERMAL CONDUCTIVITY

\begin{tabular}{lllllll}
\hline & $\frac{k_{1}}{u_{2}}$ & $\frac{k_{2}}{10.4}$ & $\frac{k_{3}}{1.64}$ & $1.216 \times 10^{-4}$ & $\frac{k_{4}}{1.867 \times 10^{-3}}$ & $\frac{k_{5}}{0.0191}$ \\
$(\mathrm{U}, \mathrm{Pu}) 0_{2}$ & 33.0 & 375 & $1.540 \times 10^{-4}$ & $1.710 \times 10^{-3}$ & 0.0171 \\
\hline
\end{tabular}

The thermal conductivity of $\mathrm{UO}_{2}$ given by Equations (A-2.1a) and (A-2.1b) is compared with the available experimental data (normalized to $95 \%$ theoretical density) in Figure A-2.1. The mixed oxide results (normalized to $96 \%$ theoretical density) calculated

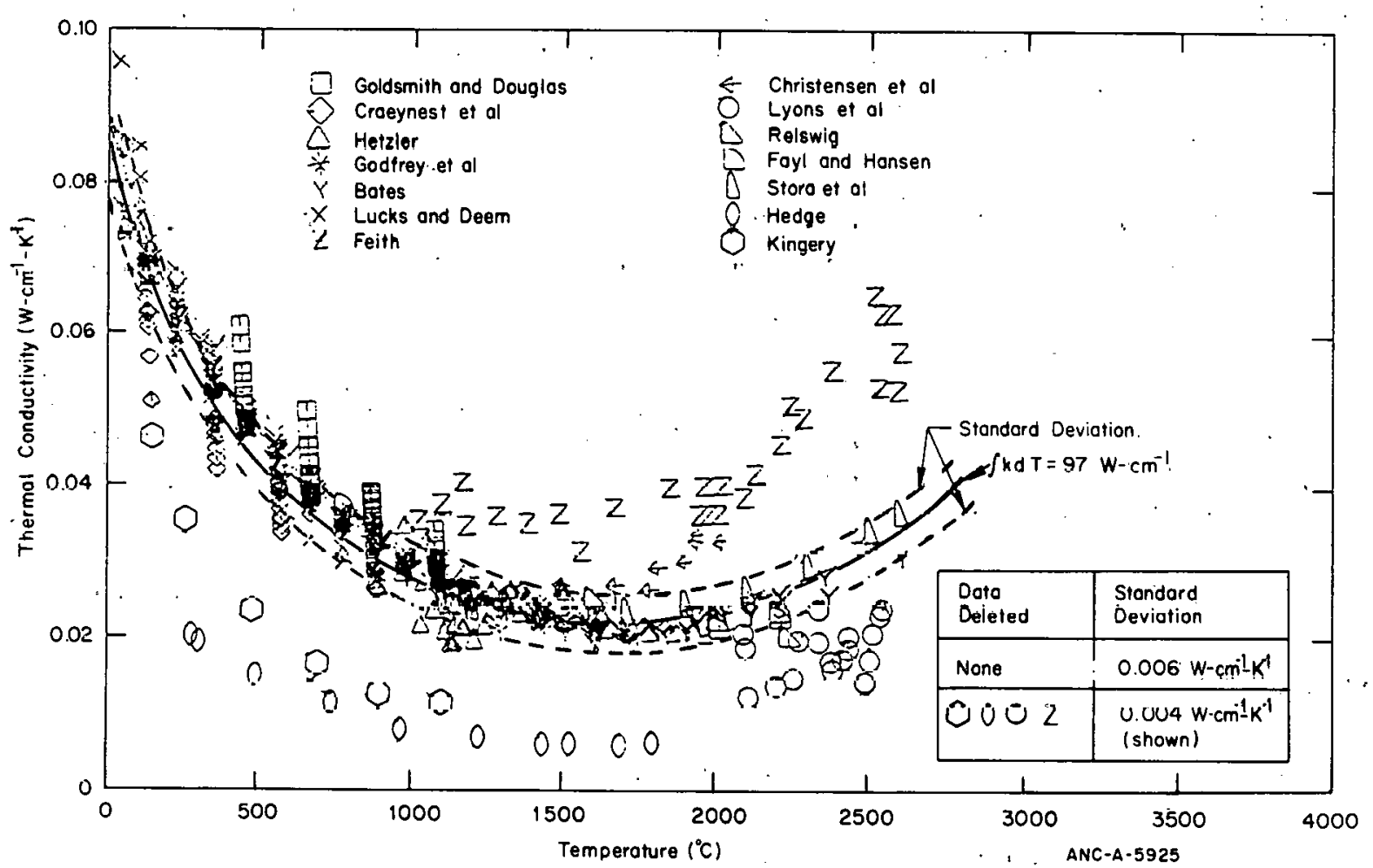

Fig. A-2.1 Comparison of measured and predicted values of the thermal conductivity of $\mathrm{UO}_{2}$ for materials corrected to 95\% TD and standard deviation of data from theoretical curve.

using the same equations but with a different porosity correction factor are shown in Figure A-2.2. Computer-generated curves, without the obscuring data points, are presented in Figure A-2.3 showing the $\mathrm{UO}_{2}$ and $(\mathrm{U}, \mathrm{Pu}) \mathrm{O}_{2}$ curves on a single graph for comparison. The one-standard deviation uncertainties are virtually independent of temperature and are of the magnitude:

$$
\sigma_{K}=3.5 \times 10^{-3} \mathrm{~W} \cdot \mathrm{cm}^{-1} \cdot \mathrm{K}^{-1} \text { for } \mathrm{UO}_{2}
$$




$$
\sigma_{K}=4 \times 10^{-3} \mathrm{~W} \cdot \mathrm{cm}^{-1} \cdot \mathrm{K}^{-1} \text { for }(\mathrm{U}, \mathrm{Pu}) \mathrm{O}_{2} \text {. }
$$

More precisely, the uncertainty for $\mathrm{UO}_{2}$ below $1650^{\circ} \mathrm{C}$ is $3.6 \times 10^{-3} \mathrm{~W} \cdot \mathrm{cm}^{-1} \cdot \mathrm{K}^{-1}$ and above $1650^{\circ} \mathrm{C}$ is $3.0 \times 10^{-3} \mathrm{~W} \cdot \mathrm{cm}^{-1} \cdot \mathrm{K}^{-1}$ if the available data points are weighted equally. The uncertainty for mixed oxides is given with only one significant figure due to a smaller data base, a variation of plutonia contents within the data basc and a lack of data for temperatures above $2000^{\circ} \mathrm{C}$.

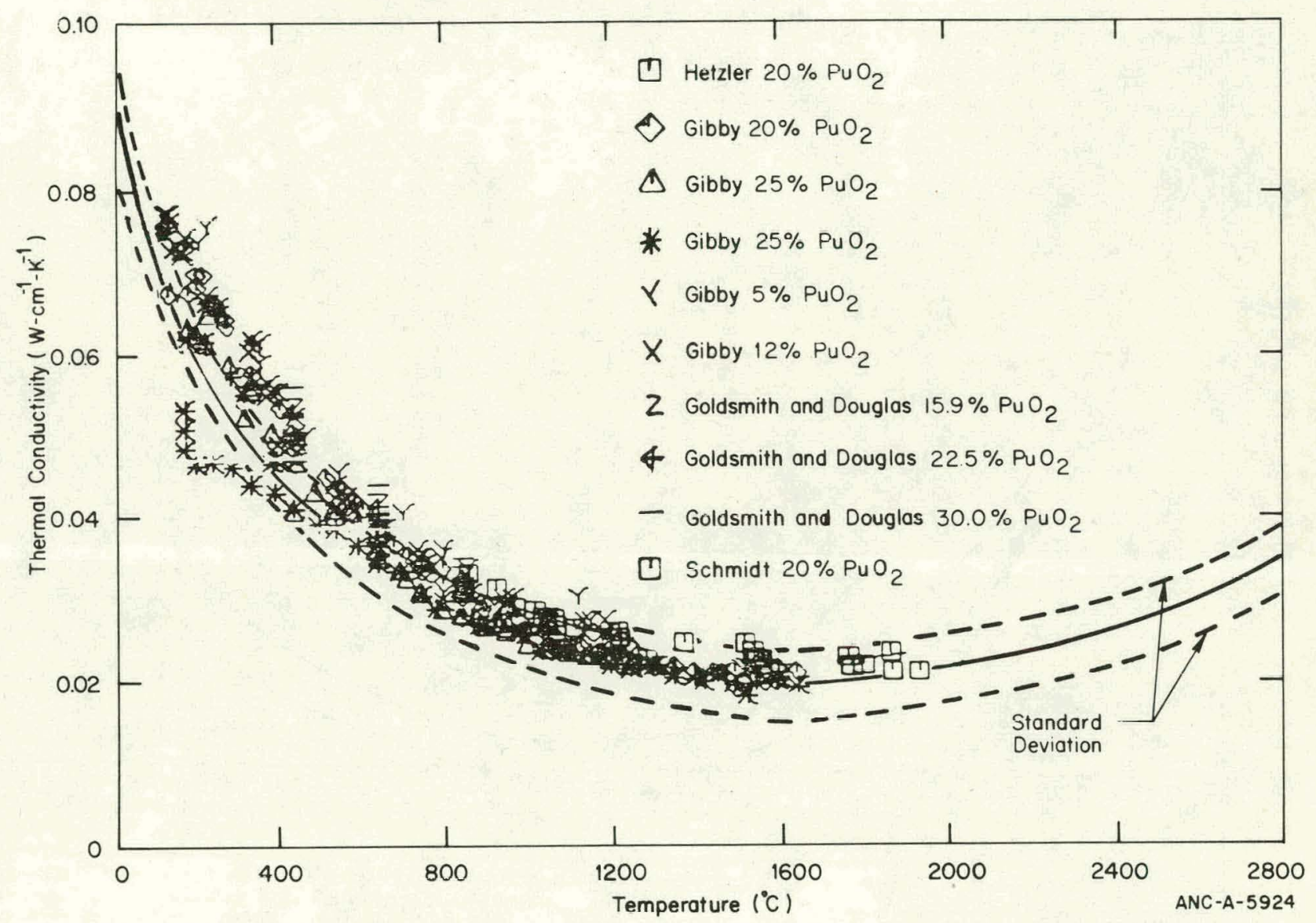

Fig. A-2.2 Comparison of measured and predicted values of the thermal conductivity of $(\mathrm{U}, \mathrm{Pu}) \mathrm{O}_{2}$ for materials corrected to $96 \% \mathrm{TD}$ and standard deviation of data from the theoretical curve.

The integral of the $\mathrm{UO}_{2}$ thermal conductivity between $0^{\circ} \mathrm{C}$ and the melting point $\left(2840^{\circ} \mathrm{C}\right)$ was analytically determined. Assuming that the electronic contribution, $\mathrm{K}_{3} \exp$ $\left(\mathrm{K}_{4} \mathrm{~T}\right)$, has the value $2 \times 10^{-3} \mathrm{~W} \cdot \mathrm{cm}^{-1} \cdot \mathrm{K}^{-1}$ at $1500^{\circ} \mathrm{C}$, a least squares value of $97 \mathrm{~W} \cdot \mathrm{cm}^{-1}$ is obtained for the integral of $\mathrm{k}$ from $0^{\circ} \mathrm{C}$ to the melting point.

\subsection{Survey of Available Data}

The available $\mathrm{UO}_{2}$ data $[\mathrm{A}-2.1-\mathrm{A}-2.13]$ are presented in Figure A-2.1. The data of $\operatorname{Hedge}^{[A-2.1]}$, Kingery[A-2.2], Feith (unpublished), Reiswig[A-2.11] and Lyons ${ }^{[A-2.10]}$ were not used in the present analysis. Hedge and Kingery used samples having densities 


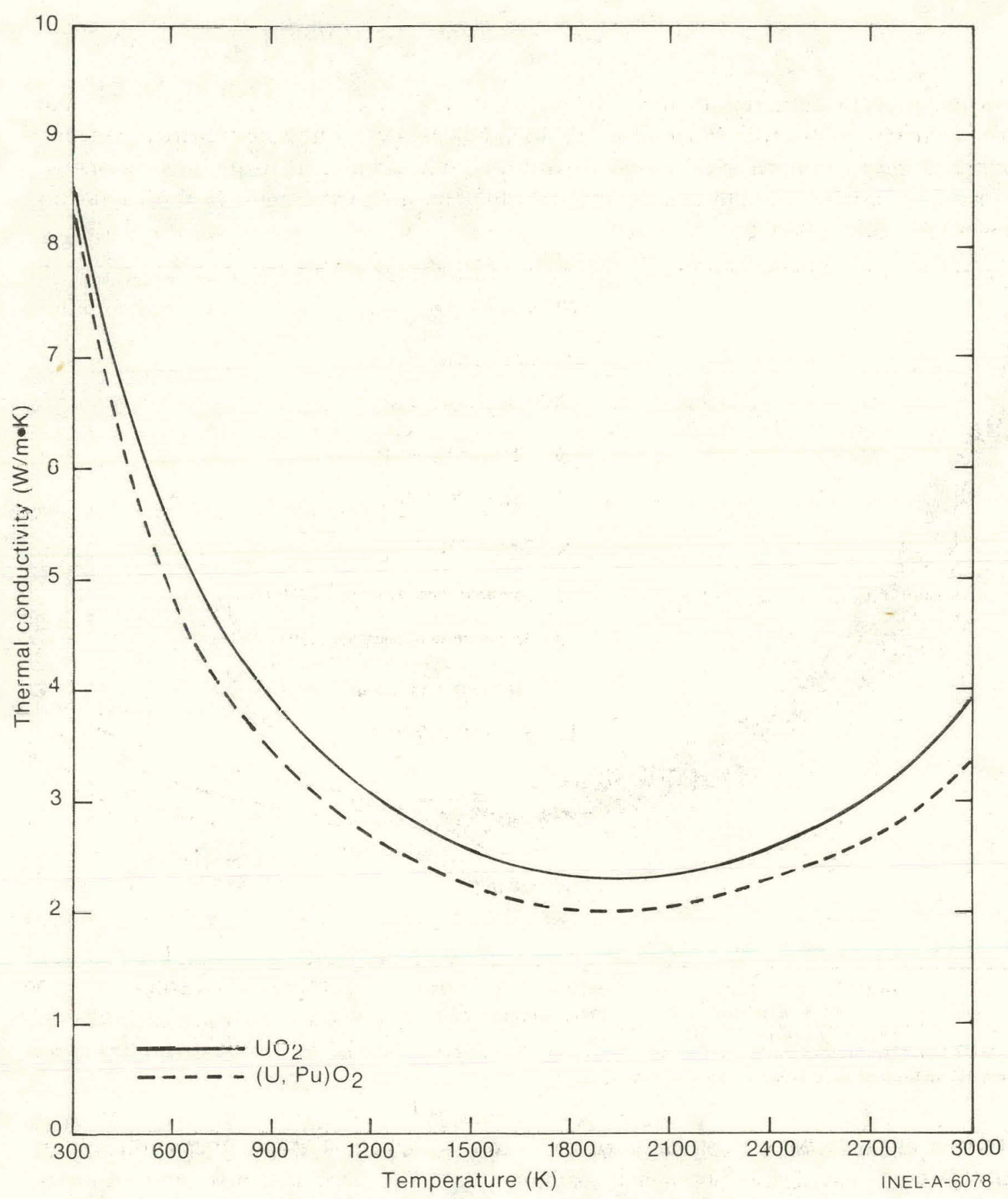

Fig. A-2.3 Calculated curves showing comparison between $\mathrm{UO}_{2}$ and (U,Pu) $\mathrm{O}_{2}$ thermal conductivity.

between 70 and 75\% TD - far below those used in commercial fuel. Feith and Reiswig employed a radial heat flow method in which the electrically heated centerline wire was not insulated from the oxide sample, so that Joule heating of the oxide could result and indicate anomalously high conductivity. The data of Lyon et al were derived from observation of postirradiation grain growth and restructuring, a less reliable method than that used by other investigators. The remaining 476 data points were fit to an equation including a temperature-dependent, modified Loeb porosity correction [A-2.4, A-2.14, A-2.15]. 
The thermal conductivity of mixed uxides as a function of temperature has been measured to determine the effect of plutonia content $[\mathrm{A}-2.16, \mathrm{~A}-2.18]$ and the effect of porosity $[A-2.4]$. However, the only high temperature data $\left(T>1650^{\circ} \mathrm{C}\right)$ available for stoichiometric mixed (U,Pu)O $\mathrm{O}_{2}$ is that of Hetzler et al ${ }^{[\mathrm{A}-2.5]}$, V. Craeynest et al ${ }^{[\mathrm{A}-2.19]}$, and Schmidt $[A-2.20]$. All these had a $20 \%$ plutonia content. Only ten points are available in this temperaturc range, with the maximum temperature from these sources being $2000^{\circ} \mathrm{C}$. Due to this scarcity of data, the high temperature fit for the mixed oxides must be considered an interirn curve pending the publication of additional data.

The causes of the data scatter seen in Figures A-2.1 and A-2.2 include pellet cracking, relocation, irradiation, and differences in oxygen to metal ratios. In fuel rods having a gap width greater than about one percent of the diameter, cracking and bulk relocation of the oxide may occur and result in apparent conductivities different from those shown in Figure A-2.1. Stoichiometry also affects the thermal conductivity. Most data indicate an enharicement $[A-2.9, A-2.21 ; A-2.22]$ for hypostoichiometric samples and a degradation $[\mathrm{A}-2.23, \mathrm{~A}-2.24]$ for hypérstoichiometric samples.

\subsection{Analytical Model}

Expressions are derived in this section for the thermal conductivity of $\mathrm{UO}_{2}$ and of mixed oxide fuels. An "inverse" function (temperature as a function of $\int \mathrm{kdT}$ ) is also derived for both types of fuel.

2.3.1 Thermal Conductivity Expressions. Expressions having the form of Equations (A-2.1 a) and (A-2.1b) are employed for both $\mathrm{UO}_{2}$ and $(\mathrm{U}, \mathrm{Pu}) \mathrm{O}_{2}$. The optimum value of the integral of $\mathrm{k}$ with respect to temperature between $0^{\circ} \mathrm{C}$ and the $\mathrm{UO}_{2}$ melting point is also determined under certain simplifying assumptions.

(1) $\mathrm{UO}_{2}$ Fuel. The constants $\mathrm{K}_{1}$ and $\mathrm{K}_{2}$ in Equation (A-2.1 a) which yicld the smallest standard deviation with respect to the data are 40.4 and 464 respectively. To obtain agreement between the high $\left(\mathrm{T}>1650^{\circ} \mathrm{C}\right)$ and low $\left(\mathrm{T}<1650^{\circ} \mathrm{C}\right)$ temperature portions of the curve, $\mathrm{K}_{5}$ must then have a value of $0.0191 \mathrm{~W} \cdot \mathrm{cm}^{-1} \cdot \mathrm{K}^{-1}$. Only $\mathrm{K}_{3}$ and $\mathrm{K}_{4}$ then remain to be evaluated. However, $\mathrm{K}_{3}$ and $\mathrm{K}_{4}$ do have some effect on the low temperature curve, especially above $500^{\circ} \mathrm{C}$. Therefore, the choice of these constants must not disturb the previously found good fit for $\mathrm{T}<1650^{\circ} \mathrm{C}$ and must also give a good fit for $1650^{\circ} \mathrm{C}<\mathrm{T}$ $<2840^{\circ} \mathrm{C} \cdot \mathrm{K}_{3}$ and $\mathrm{K}_{4}$ may be evaluated by integrating Equations (A-2.1a) and (A-2.1b) from $0^{\circ} \mathrm{C}$ to the melting point, $\mathrm{T}_{\mathrm{m}}$, by assuming a value for this integral and solving the resulting equation numerically. An outline of this procedure is

$$
\begin{aligned}
\text { INT } \equiv \int_{0^{\circ} \mathrm{C}}^{\mathrm{T}} \mathrm{kdT}= & \int_{0^{\circ} \mathrm{C}}^{1650^{\circ} \mathrm{C}} \frac{40.4}{464+\mathrm{T}} \mathrm{dT}+\int_{1650^{\circ} \mathrm{C}}^{\mathrm{T}} 0.0191 \mathrm{dT} \\
& +\int_{0^{\circ} \mathrm{C}}^{\mathrm{m}} \mathrm{K}_{3} \operatorname{exp~} \mathrm{K}_{4} \mathrm{~T}
\end{aligned}
$$


or

$$
\frac{K_{3}}{K_{4}}\left[\exp \left(K_{4} 2840\right)-1\right]=I N T-83.99
$$

Even knowing the value of INT, Equation (A-2.3b) alone is not sufficient to solve for $\mathrm{K}_{3}$ and $\mathrm{K}_{4}$. The necessary second equation is obtained from the observation that for $T<1650^{\circ} \mathrm{C}$, the data show no significant deviation from the hyperbolic part of Fruation $(\mathrm{A}-2.1 \mathrm{a}) \quad\left[\mathrm{K}_{1}\left(\mathrm{~K}_{2}+\mathrm{T}\right)^{-1}\right]$. Since these dutu are accurate to $\pm 5 \%$ at $1500^{\circ} \mathrm{C}$, the electronic contribution $\left(\mathrm{k}_{\mathrm{e}}\right)$ to the thermal conductivity is $\leqslant 0.002 \mathrm{~W} \cdot \mathrm{cm}^{-1} \cdot \mathrm{K}^{-1}$. If $\mathrm{k}_{\mathrm{e}}<0.002 \mathrm{~W} \cdot \mathrm{cm}^{-1} \cdot \mathrm{K}^{-1}$ at $1500^{\circ} \mathrm{C}$, then the fit for $\mathrm{T}<1650^{\circ} \mathrm{C}$ is disturbed, as shown in Figure $\Lambda$-2.4. This heing inadmissable, $0.002 \mathrm{~W} \cdot \mathrm{cm}^{-1} \cdot \mathrm{K}^{-1}$ is chosen for $\mathrm{k}_{\mathrm{e}}$ at $1500^{\circ} \mathrm{C}$, and another equation in $\mathrm{K}_{3}$ and $\mathrm{K}_{4}$ is obtained:

$$
0.002 \mathrm{~W} \cdot \mathrm{cm}^{-1} \cdot \mathrm{K}^{-1}=\mathrm{K}_{3} \exp \left(\mathrm{K}_{4} 1500\right) \text {. }
$$

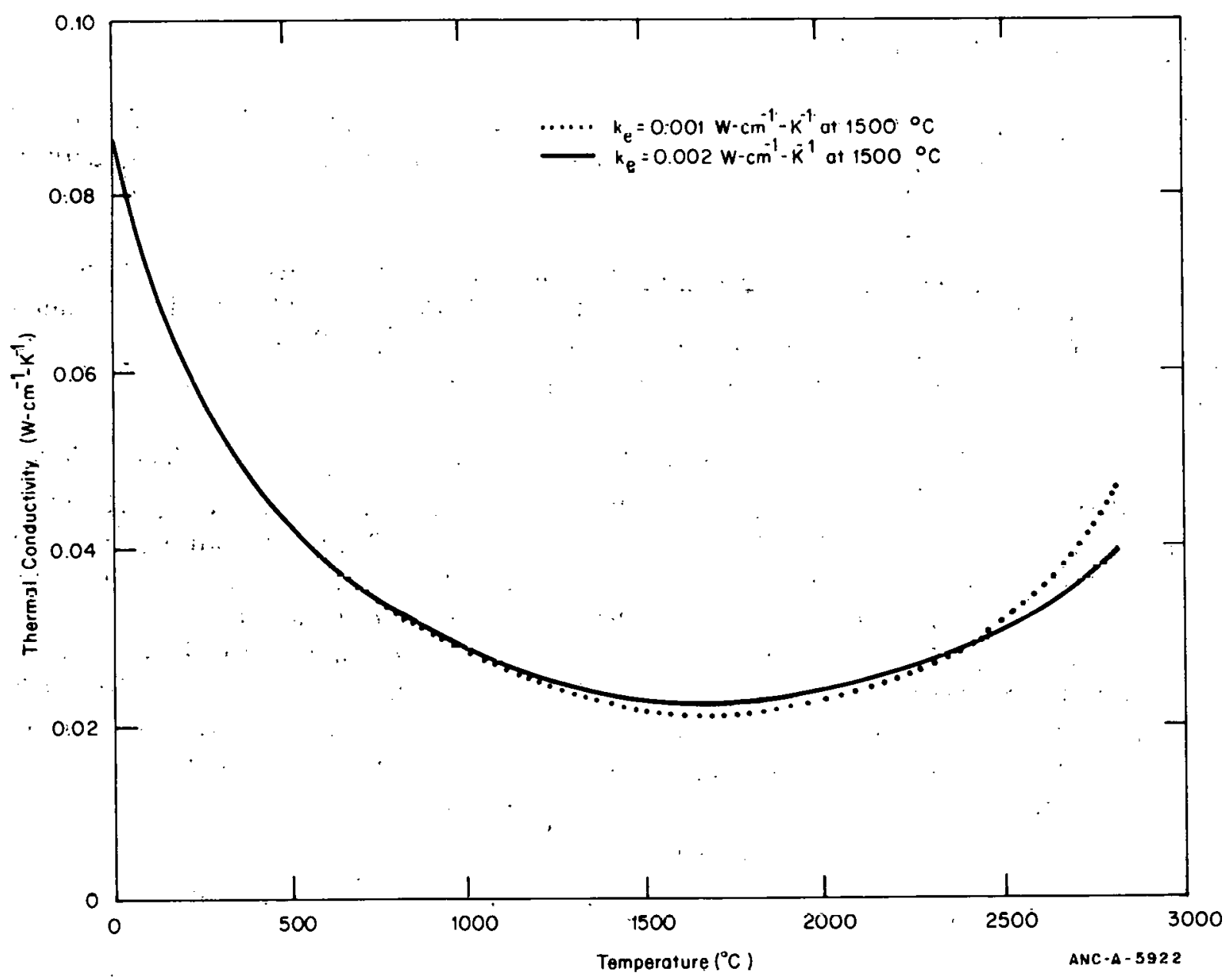

Fig. A-2.4 The effect of varying the assumed values for the electronic contribution, $k_{e}$, on the calculated thermal conductivity of $95 \% \mathrm{TD} \mathrm{UO} \mathrm{N}_{2}$ with $\int \mathrm{kdT}=96$. 
The exponential term in Equations (A-2.1) and (A-2.3) has been used in preference to other forms because it is of the same.general form as the theoretical equation for the temperature dependence of the density of conduction band electrons, and the contribution to $\mathrm{K}$ from these electrons should become important at high temperatures.

The consequences of employing Equations (A-2.1), (A-2.3), and (A-2.4) for different values of $\int \mathrm{kdT}$ are shown in Figures A-2.5 and A-2.6. Figure A-2.5 shows the sensitivity of $\mathrm{k}(\mathrm{T})$ under the above assumptions for values of the integral ranging from 93 to $98 \mathrm{~W} \cdot \mathrm{cm}^{-1}$. Figure A-2.6 indicates the standard deviation of such curves with respect to the experimental data shown in Figure A-2.1 for temperalures greater than $1650^{\circ} \mathrm{C}$. The value of INT giving the smallest standard deviation is:

$$
\int_{0^{\circ} \mathrm{C}}^{\mathrm{T}} \mathrm{kdT}=97 \mathrm{~W} \cdot \mathrm{Cim}^{-1} \text {. }
$$

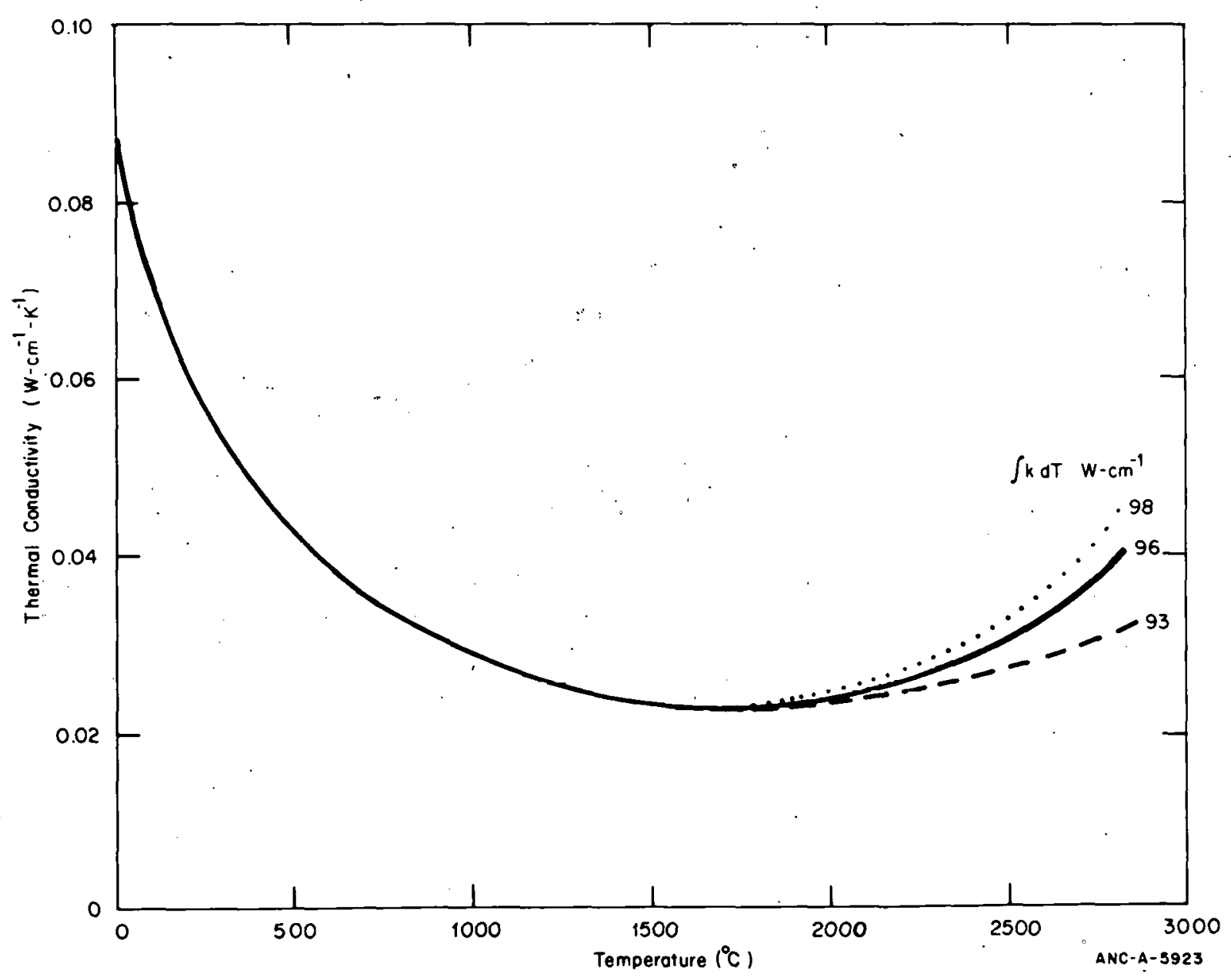
Fig. A-2.5 The effect of varying the assumed value for $\int_{0^{\circ}}^{\mathrm{T}_{\mathrm{m}}} \mathrm{kdT}$ on the calculated thermal conductivity of $95 \%$ TD UO
with $\mathrm{k}_{\mathrm{e}}$ held constant at $0.002 \mathrm{~W} \cdot \mathrm{cm}^{-1} \cdot \mathrm{K}^{-1}$. 


\section{FTHCON :}

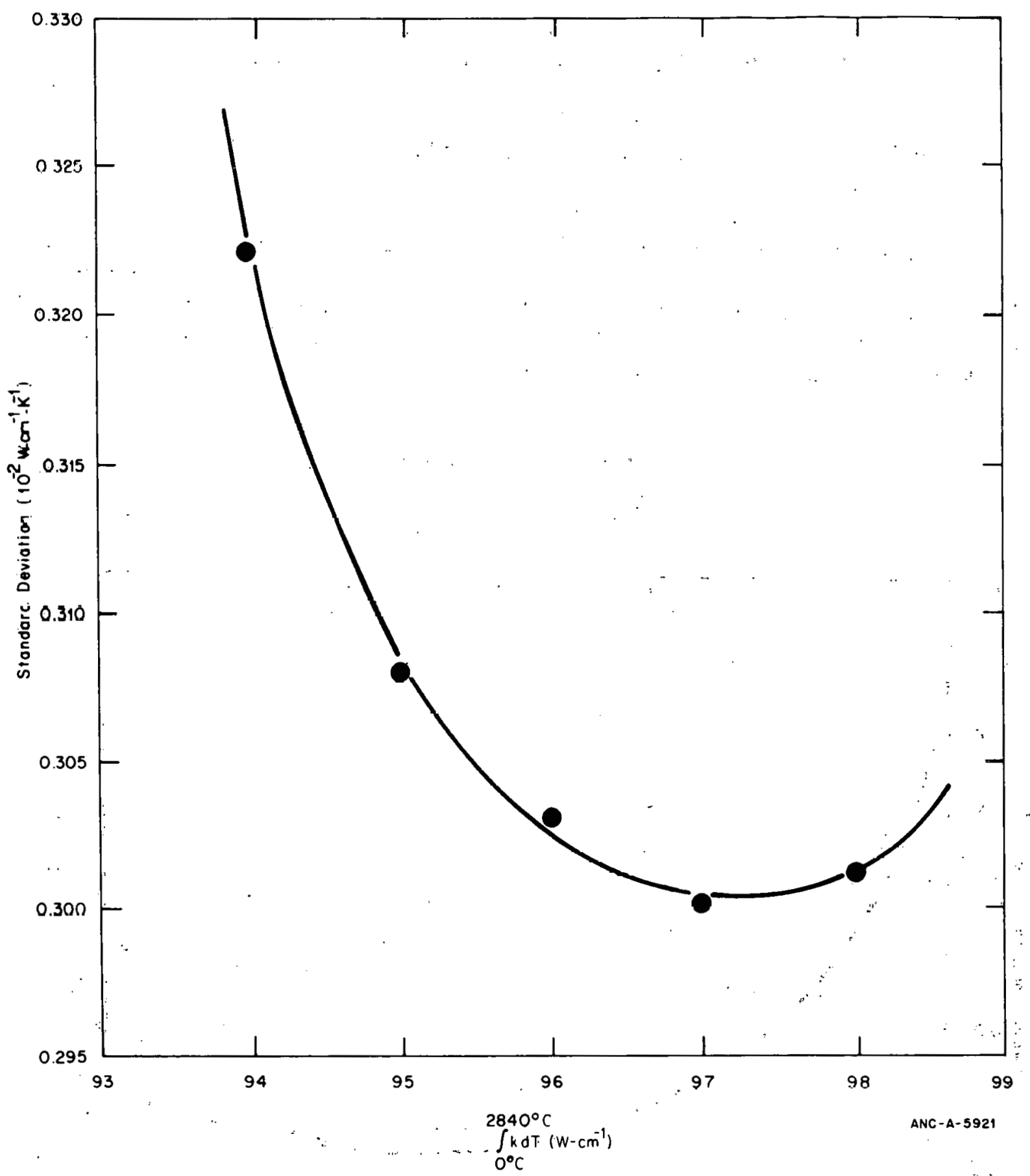

Fig. A-2.6 The standard deviation of the calculated $\mathrm{UO}_{2}$ thermal conductivity from the data base as a function of the assumed value of the conductivity integral.

The values of $\mathrm{K}_{3}$ and $\mathrm{K}_{4}$ resulting from different assumed values of the conductivity integral of the electronic contribution are shown in Table (A-2.II).

(2) $(\mathrm{U}, \mathrm{Pu}) \mathrm{O}_{2}$ Fuel. Equations of the same form as Equations (A-2.1a) and (A-2.1b) can be employed to fit the data base for mixed oxides: The hyperbolic temperature 
FTHCON

TABLE A-2. II

THE EFFECT OF DIFFERENT ASSUMPTIONS ON

THE CALCULATED VALUES OF $K_{3}$ AND $K_{4}$ IN EQUATION $(A-2.1)$ FOR $\mathrm{UO}_{2}$

\begin{tabular}{|c|c|c|c|}
\hline $\int k d T$ & $k_{3}$ & $K_{4}$ & $\begin{array}{l}\mathrm{k}_{\mathrm{e}} \text { at } 1500^{\circ} \mathrm{C} \\
\left(\mathrm{W} \cdot \mathrm{cm}^{-1} \cdot \mathrm{K}^{-1}\right)\end{array}$ \\
\hline 93 & $2.535 \times 10^{-4}$ & $1.377 \times 10^{-3}$ & 0.002 \\
\hline 94 & $2.024 \times 10^{-4}$ & $1.627 \times 10^{-3}$ & 0.002 \\
\hline 95 & $1.668 \times 10^{-4}$ & $i .656 \times 10^{-3}$ & 0.002 \\
\hline 96 & $1.412 \times 10^{-4}$ & $1.767 \times 10^{-3}$ & 0.002 \\
\hline 96 & $2.116 \times 10^{-5}$ & $2.555 \times 10^{-3}$ & 0.001 \\
\hline 97 & $1.216 \times 10^{-4}$ & $1.867 \times 10^{-3}$ & 0.002 \\
\hline 98 & $1.064 \times 10^{-4}$ & $1.956 \times 10^{-3}$ & 0.002 \\
\hline
\end{tabular}

dependence of $\mathrm{k}$ shown in Equation (A-2.6a) was reported to be valid to at least $1200^{\circ} \mathrm{C}$ by all the investigators except by Craeynest $[\mathrm{A}-2.19]$ who reported an upper limit of $1000^{\circ} \mathrm{C}$ on Equation (A-2.6a). The thermal conductivity for mixed oxides can then be represented by Equations (A-2.6a) and (A-2.6b) for 96\% TD using the Euken-Maxwell porosity correction factor:

for $0^{\circ} \mathrm{C}<\mathrm{T}<1550^{\circ} \mathrm{C}$ :

$$
\begin{aligned}
k= & \left(\frac{D}{1+B(1-D)}\right)\left(\frac{1+B \times 0.04}{0.96}\right)\left[\frac{33}{375+T}+\left(1.54 \times 10^{-4}\right.\right. \\
& \left.\left.\quad \exp \left(1.71 \times 10^{-3} \mathrm{~T}\right)\right)\right]
\end{aligned}
$$

for $1550^{\circ} \mathrm{C}<\mathrm{T}<2840^{\circ} \mathrm{C}$ :

$$
\begin{aligned}
k= & \left(\frac{D}{1+B(1-D))}\right)\left(\frac{1+B \times 0.04}{0.96}\right)\left[0.0171+\left(1.54 \times 10^{-4}\right.\right. \\
& \left.\left.\exp \left(1.71 \times 10^{-3} \mathrm{~T}\right)\right)\right]
\end{aligned}
$$




\section{FTHCON}

where

$$
\begin{aligned}
& \mathrm{T}=\text { temperature }\left({ }^{\circ} \mathrm{C}\right) \\
& \mathrm{B}=1.43 \\
& \mathrm{D}=\text { the fraction of the theoretical density. }
\end{aligned}
$$

The experimental data, normalized to $96 \% \mathrm{TD}$ and using the Eucken-Maxwell relation is compared with Equations (A-2.6a) and (A-2.6b) in Figure A-2.2. The data are from six sources $[\mathrm{A}-2.5, \mathrm{~A}-2.17, \mathrm{~A}-2.18, \mathrm{~A}-2.25, \mathrm{~A}-2.26$ and A-2.27], comprising a total of 234 points. The standard deviation of the data from the curve, estimated on the basis of the number of points which should lie beyond one standard deviation on the graph, was $0: 004 \mathrm{~W} \cdot \mathrm{cm}^{-1} \cdot \mathrm{K}^{-1}$. This is given to only one significant figure because of the widely varying plutonia contents in the data base and the scarcity of higher temperature data.

2.3.2 Inverse Functions. "Inverse functions" giving temperature $\mathrm{T}$ as a function of $\int \mathrm{kdT}$ (evaluated between $0^{\circ} \mathrm{C}$ and $\mathrm{T}$ ) are presented here due to their usefulness in some fuel rod analysis approaches.

(1) Derivation of Inverse Functions of $\mathrm{UO}_{2}$. Equations (A-2.1a) and (A-2.1b) are integrated with respect to temperature to obtain the integral of $k$ as a function of temperature:

for $0^{\circ} \mathrm{C}<\mathrm{T}<1650^{\circ} \mathrm{C}$ :

$\int_{0^{\circ} \mathrm{C}}^{T} k d T=40.4 \ln (464+T)+6.573 \times 10^{-2} \exp \left(1.867 \times 10^{-3} T\right)-248.12$

for $1650^{\circ} \mathrm{C}<\mathrm{T}<2840^{\circ} \mathrm{C}$ :

$$
\int_{1650^{\circ} \mathrm{C}}^{T} k d T=0.0191 \mathrm{~T}+6.513^{\circ} \times 10^{-2} \exp \left(1.867 \times 10^{-3} \mathrm{~T}\right)-32.93
$$

where

$\mathrm{T}^{\cdot}=$ Temperature $\left({ }^{\mathrm{O}} \mathrm{C}\right)$

The inverse of Equations (A-2.7a) and (A-2.7b), where temperature, $T$, is expressed as a function of the conductivity integral $\left(\mathrm{I} \equiv \int_{0^{\circ} \mathrm{C}}^{\mathrm{T}} \mathrm{kdT}\right)$, was obtained by first ignoring the 
electronic contribution expressed by the exponential function and determining temperaturc as an analytical solution of the integral, and then adding a second order polynomial to represent the effect of the electronic contribution. The constants were determined from a least-squares regression analysis of calculated integral conductivities from Equation (A-2.7) for given temperatures. The result is expressed as follows:

for $0^{\circ} \mathrm{C}<\mathrm{T}<1650^{\circ} \mathrm{C}$ :

$$
T=464.8 \exp (I / 40.4)-485.761+1.340 I-0.0351 I^{2}
$$

for $1650^{\circ} \mathrm{C}<\mathrm{T}<2840^{\circ} \mathrm{C}$ :

$$
T=-2669.82+91.22 I-0.355 I^{2}
$$

where

$$
\mathrm{T}=\text { Temperature }\left({ }^{\circ} \mathrm{C}\right)
$$

(2) Derivation of Inverse Functions for $(\mathrm{U}, \mathrm{Pu}) \mathrm{O}_{2}$. Proceeding in a manner similar to that used for $\mathrm{UO}_{2}$, Equations (A-2.6a) and (A-2.6b) are integrated with respect to temperature to obtain Equations (A-2.9a) and (A-2.9b):

for $0^{\circ} \mathrm{C}<\mathrm{T}<1550^{\circ} \mathrm{C}$ :

$$
\int_{0^{\circ} \mathrm{C}}^{T} \mathrm{kdT}=33.0 \cdot \ln (375+\mathrm{T})+9.006 \times 10^{-2} \exp \left(1.71 \times 10^{-3} \mathrm{~T}\right)-195.7
$$

for $1550^{\circ} \mathrm{C}<\mathrm{T}<\mathrm{T}_{\text {melting }}$

$$
\int_{1550^{\circ} \mathrm{C}}^{\mathrm{T}} \mathrm{kdT}=(0.0171) \mathrm{T}+9.006 \times 10^{-2} \exp \left(1.71 \times 10^{-3} \mathrm{~T}\right)-27.78:
$$

The inverse function of temperature as a function of the conductivity integral $\left(\mathrm{I} \equiv \int_{0^{\circ} \mathrm{C}}^{\mathrm{T}} \mathrm{kdt}\right)$ was determined for mixed oxides following the method outlined above. The results are expressed in Equations (A-2.10a) and (A-2.10b):

for $0^{\circ} \mathrm{C}<\mathrm{T}<1550^{\circ} \mathrm{C}$

$$
T=376 \exp (I / 33)-396.45+1.277 I-0.041 I^{2}
$$


FTHCON

for $1550^{\circ} \mathrm{C}<\mathrm{T}<\mathrm{T}_{\text {melting }}$

$$
T .=-2629+.98 .33 I-0.409 I^{2}
$$

where.

$\mathrm{T}=$ Temperature $\left(\mathrm{C}^{\mathrm{n}}\right)$

The temperatures calculated_frnm these ronductivity integralo for both: $\mathrm{UO}_{2}$ and (U,Fu) $\mathrm{O}_{2}$ are plotted in'Figure A-2.7.

2.4 Fuel Thermal Conductivity Subcode FTHCON Listing

A listing of the-FORTRAN subcode FTHCON is presented in Table A-2.III.

\subsection{References}

A-2.1. J. C. Hedge, Measurement of 'Thermal Conductivity of Uranium Oxide, AECU-3881, Armour Research Foundation of Illinois Institute of Tcchnology (September 20. 1956):

A-2.2: W. D. Kingery et al, "lhermal Conductivity X: Data for Several Pure Oxide Màterials Corrected to Zero Porosity," Journul of the American Ceramic Society, 37 (1.954) p 107.

A-2.3. L. A: Goldsmith and J. A. M. Douglas, Measurements of the Thermal Conductivity of Uranium Dioxide at 670-1,270 $0^{\circ}$, TRG Department 21:03 Reactor Development Laboratury Windscale (1971).

A-2.4: J. C. Van Craeynest and Jean Pierre Stora, "Effect de la Porosite sur la Variation de C'onductibilite Thermique du Biuxyde d'Uianium en Fonction de la lemperature," Journal of.Nuclear Materials, 37 (19.70) p 153.

A-2.5. F. J. Hetzler et al, The Thermal Conductivity of Uranium and Uranium-Plutonium Oxides, GEAP-4879 (August 1967).

A-2.6. T. G. Godfrey et al, Thermal Conductivity of Uranium Dioxide and Armco Iron by. an Improved Radial Heat Flow Technique, ORNL-3556 (June 1964).

A-2.7. J. Lambert Bates, High Temperature Thermal Conductivity of "Round Robin" Uranium Dioxide, BNWL-1431 (July 1970).

A-2.8. C. F. Lucks and H. W. Deem, "Thermal Conductivity and Electrical Conductivity of $\mathrm{UO}_{2}$," Progress Relating to Civilian Applications During June 1960, BMI-1448 (July 1, 1960). 


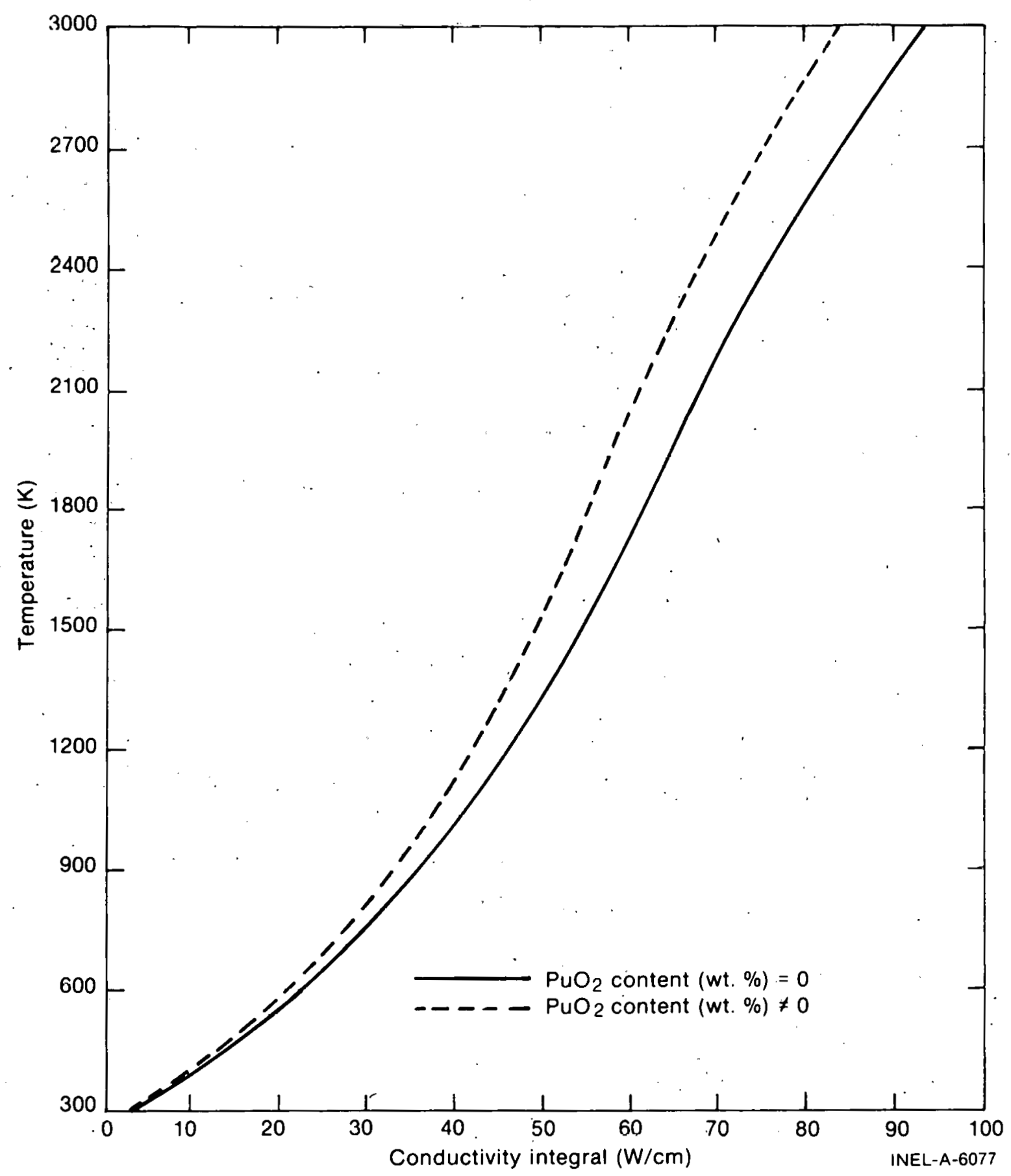

Fig. A-2.7 Temperature as a function of the conductivity integral calculated for $\mathrm{UO}_{2}$ and $(\mathrm{U}, \mathrm{Pu}) \mathrm{O}_{2}$.

A-2.9. J. A. Christensen et al, "Uranium Dioxide Thermal Conductivity," Transactions of the American Nuclear Society, 7 (1964) p 391.

A-2.10. M. F. Lyons et al; $U_{2}$ Pellet Thermal Conductivity from Irradiations with Central Melting, GEAP-4624 (July 1964). 
FTHCON

TABLE A-2. III

LISTING OF THE FTHCON SUBCODE

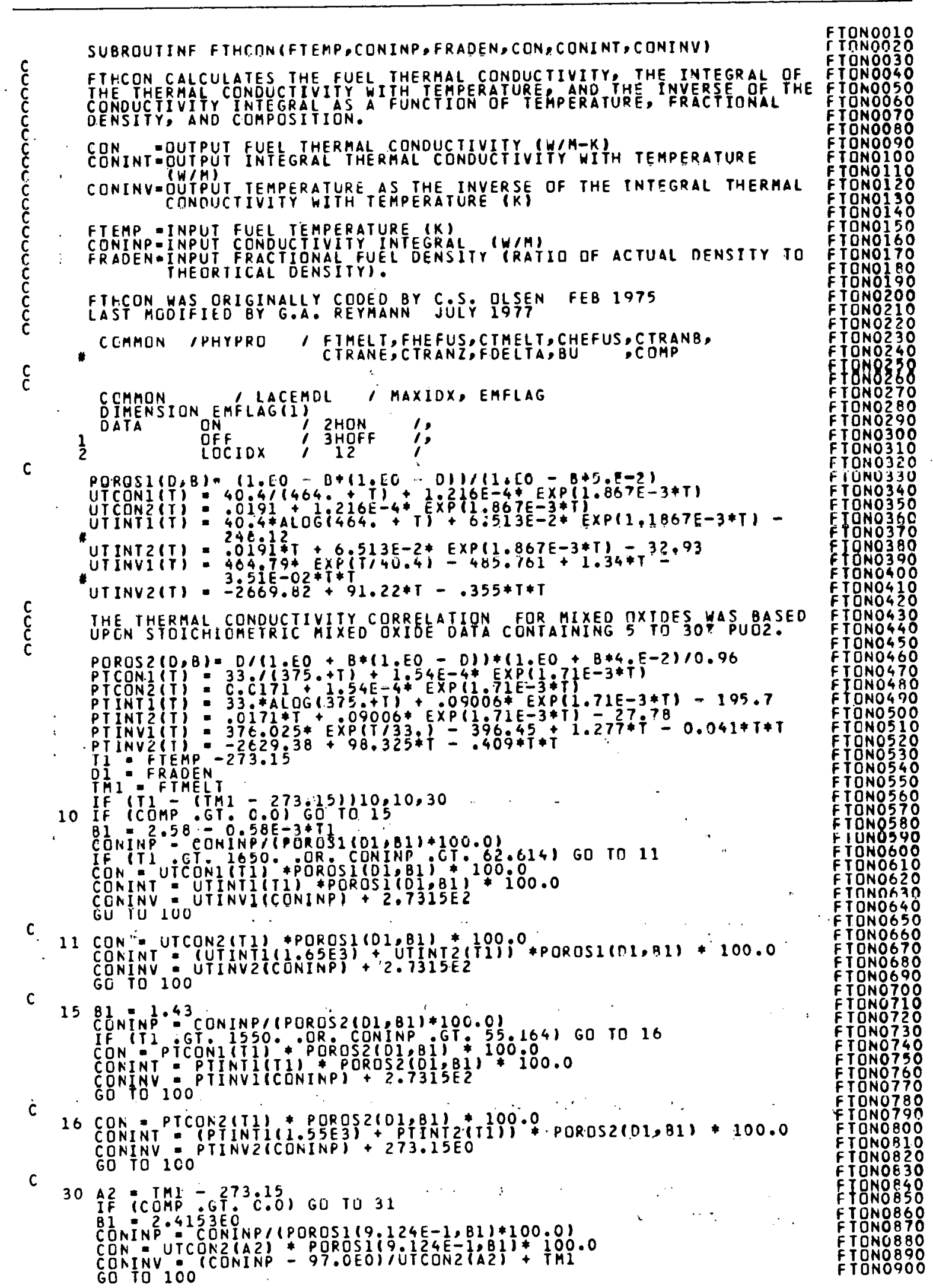


C

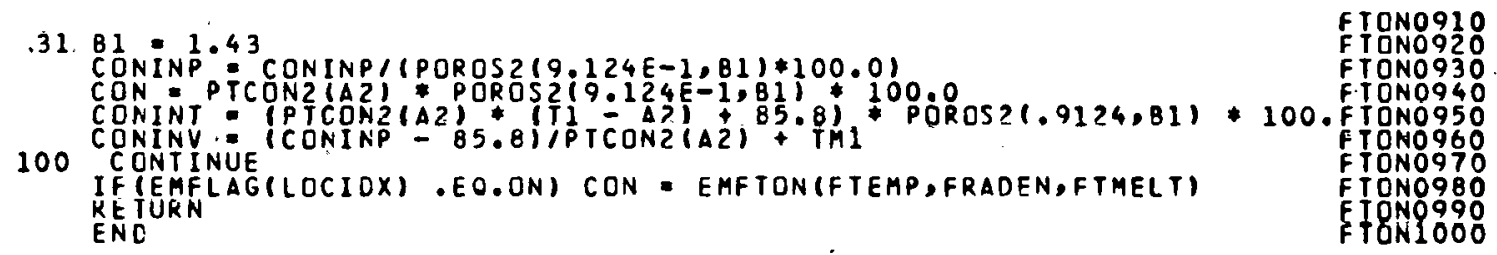

A-2.11. R. D. Reiswig, "Thermal Conductivity of $\mathrm{UO}_{2}$ to $2,100^{\circ} \mathrm{C}$," Journal of the American Ceramic Society, 44 (1961) p 48.

A-2.12. G. liayl and K. Hansen, In-Reuclur Delerimination of the Thermal Conductivity of $\mathrm{UO}_{2}$-Pellels up to $2,200^{\circ} \mathrm{C}$, RISO Department 269, Danish Atomic Energy Commission Research Establishment RISO, (July 1972).

A-2.13. J. Stora et al, Thermal Conductivity of Sintered Uranium Oxide Under In-Pile Conditions, EURAEC 1095 (CEA-R 2586) (August 1964).

A-2.14. A. L. Loeb, "Thermal Conductivity: A Theory of Thermal Conductivity of Porous Materials," Joumal of the American Ceramic Society, 37 (1954) p 96.

A-2.15. J. R. MacEwan, R. L. Stoute, and M. F. Notley, "Effect of Porosity of the Thermal Conductivity of $\mathrm{UO}_{2}$," Journal of Nuclear Materials, 24 (1967) p 109.

A-2.16. M. Serizawa et al, "Thermal Diffusivity and Thermal Conductivity of UraniumPlutonium Dioxide," Journal of Nuclear Materials, 34 (1970) p 224.

A-2.17. R. L. Gibby, "The Effect of Plutonium Content on the Thermal Conductivity of (U,Pu) $\mathrm{O}_{2}$ Solid Solutions," Journal of Nuclear Materials. 38 (1971) pp 163-177.

A-2.18. L. A. Goldsmith and J. A. M. Douglas, "The Thermal Conductivity of PlutoniumUranium Dioxide at Temperatures up to 1,273K,"Journal of Nuclear Materials, 43 (1972) p 225.

A-2.19. J. C. Van Craeynest and J. C. Weilbacher, "Etude de la Conductibility Thermique des Oxides Mixed d'Uranium et de Plutonium," Journal of Nuclear Materials, 26 (1968) pp 132-136.

A-2.20. H. E. Schmidt, "Die Waermeleitfaehigkeit von Uran und Uran-Plutonium Dioxyd bei Hohen Temperaturen," Forschung, Ingenieur-Wesen, 38 (19.72) pp 149-151.

A-2.21. T. G. Kollie et al, "A Thermal Comparator Method for Thermal Conductivity Measurements from 50 to $400^{\circ} \mathrm{C}$," International Symposium Compounds of Interest, Nuclear Metallurgy, Volume X, IMD Special Report Series 13. 
A-2.22. A. D. Feith, "Thermal Conductivity of Several Ceramic Materials to $2,500^{\circ} \mathrm{C}$," Proceedings 4th Conference Thermal Conductivity (October 1964) IV-C1-IV-C-17.

A-2.23. A. M. Ross, The Dependence of the Thermal Conductivity of Uranium Dioxide on Density, Microstructure, Stvichiornetry and Therrmal Neutron irradiation, CRFD-817, AECL-1096 (1960).

A-2.24. V. C. Howard and T. F. Gulvin, Thermal Conductivity Determinations on Uranium Dluxtac by a Radial Flow Mcthod, U.K.A.E.A. IG Report 51 (Rd/c) (1960).

A-2.25. R. L. Gibby, The Thermal Diffusivity and Thermal Conductivity of Stoichiometric $\left(U_{0.8} P u_{0.2}\right) U_{2}$, BNWL-704 (May 1968).

A-2.26. R. L: Gibby, The Effect of Oxygen Stoichiometry on the Thermal Diffusivity and Conductivity of $U_{0.75} \mathrm{Pu}_{0.25} \mathrm{O}_{2-x}$, BNWL-927. (January 1969).

A-2.27. H. E. Schmidt, "Die Waermeleitfaehigkeit von Uran and Uran-Plutonium Dioxyd bei Hohen Temperaturen," High Tcmperatures - High Pressure, 3 (1971) p 345.

\section{FUEL EMISSIVITY (FEMISS)}

This function returns a value for the spectral emissivity of uranium dioxide at a given temperature. The only argument of the function is FTEMP, the fuel temperature at which the emissivity is required.

\subsection{Summary}

This version of the FEMISS subcode is a simplification of the previously, used representation of the functional dependence of the emissivity on temperature. The fifth nrder nnlynnmial fit described in MATPROEVersion $06^{[A-3.1]}$ is replaced by a linear function in the temperature range $1000 \mathrm{~K} \leqslant \mathrm{~T} \leqslant 2050 \mathrm{~K}$. Uutside this range, the emissivity is assumed to be independent of temperature.

The emissivity is defined as follows:

$$
\begin{aligned}
T & <1000 \mathrm{~K}, \quad & e & =0.8707 \\
1000 \mathrm{~K} \leq T & \leq 2050 \mathrm{~K}, & e & =1.311-4.404 \times 10^{-4} \mathrm{~T} \\
T & >2050 \mathrm{~K}, & e & =0.4083
\end{aligned}
$$

where

$$
\cdot \mathrm{T}=\text { temperature of the fuel }(\mathrm{K}) \text {. }
$$


This representation is justified on the basis of a statistical evaluation of the measured values.

\subsection{Experimental Data}

The measured values of spectral emissivity using nonpolished $\mathrm{UO}_{2}$ specimens obtained by Claudson $[\mathrm{A}-3.2]$ as reported by Belle $[\mathrm{A}-3.3]$ are shown in Table A-3.I.

TABLE A-3. I

SPECTRAL EMISSIVITY OF $U_{2}$ AS MEASURED BY CLAUDSON $[\mathrm{A}-3.3]$

\begin{tabular}{cc}
\hline$\frac{T(K)}{1000}$ & $\begin{array}{c}\text { Emissivity } \\
\text { (Dimensionless) }\end{array}$ \\
1320 & 0.850 \\
1593 & 0.798 \\
1755 & 0.623 \\
1795 & 0.510 \\
1853 & 0.515 \\
1920 & 0.417 \\
1955 & 0.402 \\
2053 & 0.484 \\
2220 & 0.446 \\
\hline
\end{tabular}

The one standard deviation uncertainty in Claudson's data is estimated to be about $10 \%$ based on the scatter in the values.

Ehlert and Margrave reported several values for the spectral emissivity at 650 nanometers of a polished solid $\mathrm{UO}_{2}$ surface ${ }^{[\mathrm{A}-3.4]}$. These results are given in Table A-3.II. The reported uncertainty is about $5 \%$.

The following conclusions based on the data sets above are relevant:

(1) The accuracy of the data is on the order of $10 \%$ 
(2) Spectral emissivity monotonically decreases as temperature increases

(3) The spectral emissivity of $0.4 \mathrm{~m}$ the temperature range $2073<\mathrm{T}<$ obtained by Ehlert and Margrave is consistent with the Claudson data.

TABLE $A=3$. II.

SPECTRAL EMISSIVITY OF UO ${ }_{2}$ AS. MEASURED BY EHLERT AND MARGRAVE ${ }^{[A-3.4]}$

\begin{tabular}{|c|c|c|}
\hline \multirow{3}{*}{. } & Temperature (K) & Emissivity \\
\hline & $2073-2373$ & $0.40 \pm 0.02$ \\
\hline & $\begin{array}{l}\text { "within no more than } 100^{\circ} \mathrm{C} \\
\text { of the melting point" } \\
(\sim 3000 \mathrm{~K})\end{array}$ & $0.416 \pm 0.026$ \\
\hline
\end{tabular}

\subsection{Selection of Emissivity Values}

The data for Claudson is used in the temperature range from $1000 \mathrm{~K}$ to approximately $2000 \mathrm{~K}$. Above $2000 \mathrm{~K}$ the mean value of the Ehlert-Margrave data is used, namely 0.408 . Also, since no data are available below $1000 \mathrm{~K}$, where the spectral emissivity is difficult to measure, a constant value consistent with Claudson's data is chosen.

First, second, and third degree polynominals were generated by least-square fitting Claudson's data. These results are compared with the measured values in Figure A-3.1. The calculated standard deviation for each of the approximations is given in Table A-3.III.

These standard deviations indicate only how closely the fitting polynominal approximates the measured values and do not take into account the error associated with each data point. Recognizing the $10 \%$ error, the linear fit is statistically adequate. Any higher order fit attributes unrealistic accuracy to the data set.

The equation describing the data is of the form $y=a+b T$. The computed coefficients are

$$
\begin{aligned}
& a=1.31107 \\
& b=4.40374 \times 10^{-4} .
\end{aligned}
$$

This equation is used in the temperature range $1000 \mathrm{~K} \leqslant \mathrm{~T} \leqslant 2050 \mathrm{~K}$. 


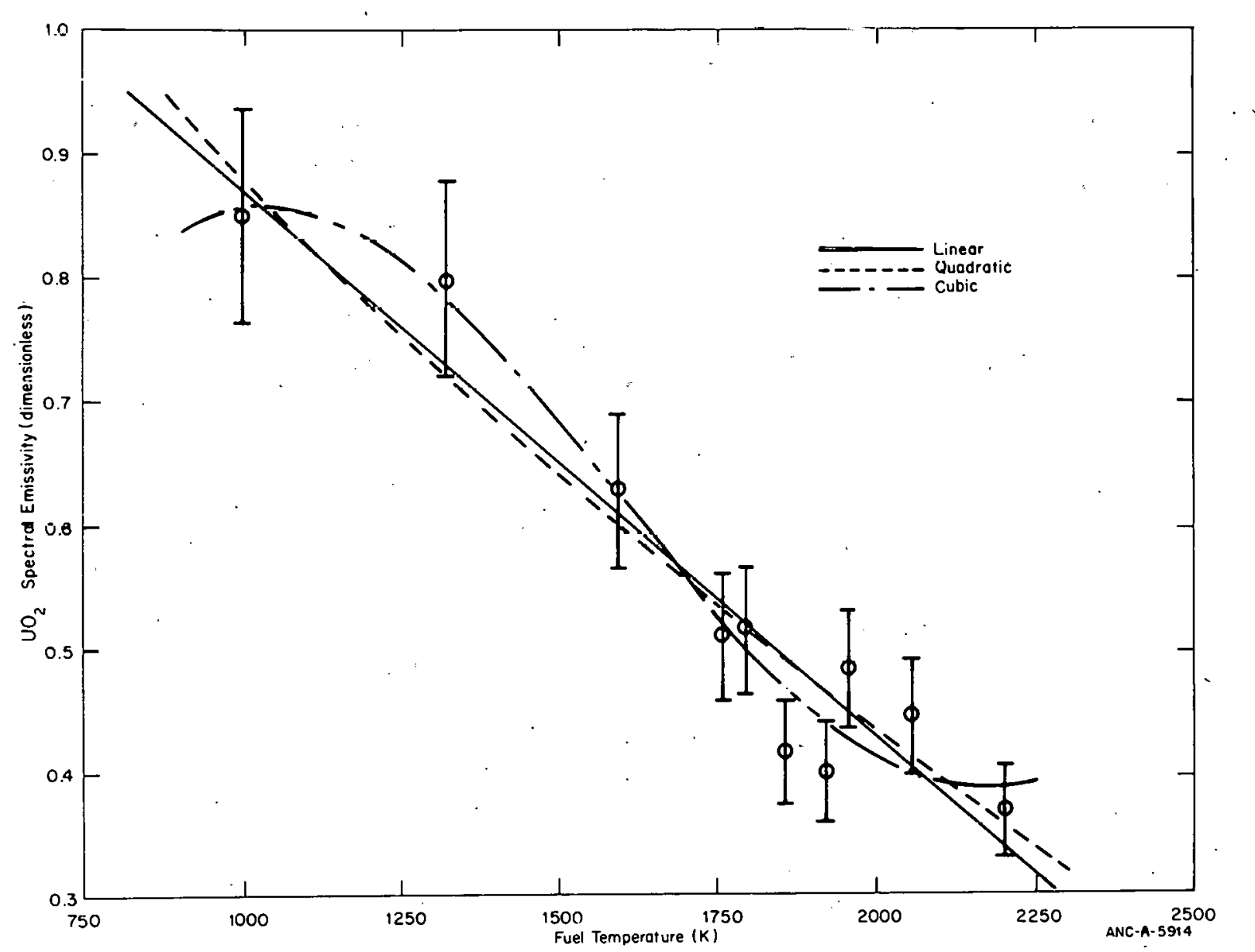

Fig. A-3.1 Comparison of fitting polynomials with emissivity data of Claudson.

\section{TABLE A-3.111}

STANDARD DEVIATION FOR THE LEAST-SQUARES APPROXIMATIONS TO CLAUDSON'S DATA

\begin{tabular}{cc} 
Degree & $\begin{array}{l}\text { Standard } \\
\text { Deviation }\end{array}$ \\
1 & 0.0505 \\
2 & 0.0529 \\
3 & 0.0432 \\
\hline
\end{tabular}


The lower temperature limit is taken as the lowest temperature at which a measured value was reported by Claudson. Below $1000 \mathrm{~K}$, the emissivity is assumed to be independent of temperature. The constant value is the calculated value at $1000 \mathrm{~K}$, namely 0.8707 .

The uppor temperature limit was chosen as $2050 \mathrm{~K}$ since evalualion of the lincar function at that temperature gives a value of 0.4083 for the emissivity, consistent with the Ehlert-Margrave high temperature data point as discussed proviously. This value, 0.4083 , is used for temperatures above $2050 \mathrm{~K}$.

The emissivity is plotted as a function of temperature in Figure A-3.2 over the range $500 \mathrm{~K}<\mathrm{T}<2300 \mathrm{~K}$. The importance of emissivity in fuel rod behavior analysis is to specify the radiant heat transfer contribution across the fuel-cladding gap. Typical calculated fuel surface temperatures, including those from transient analyses, fall in the range from 800 to $2000 \mathrm{~K}$.

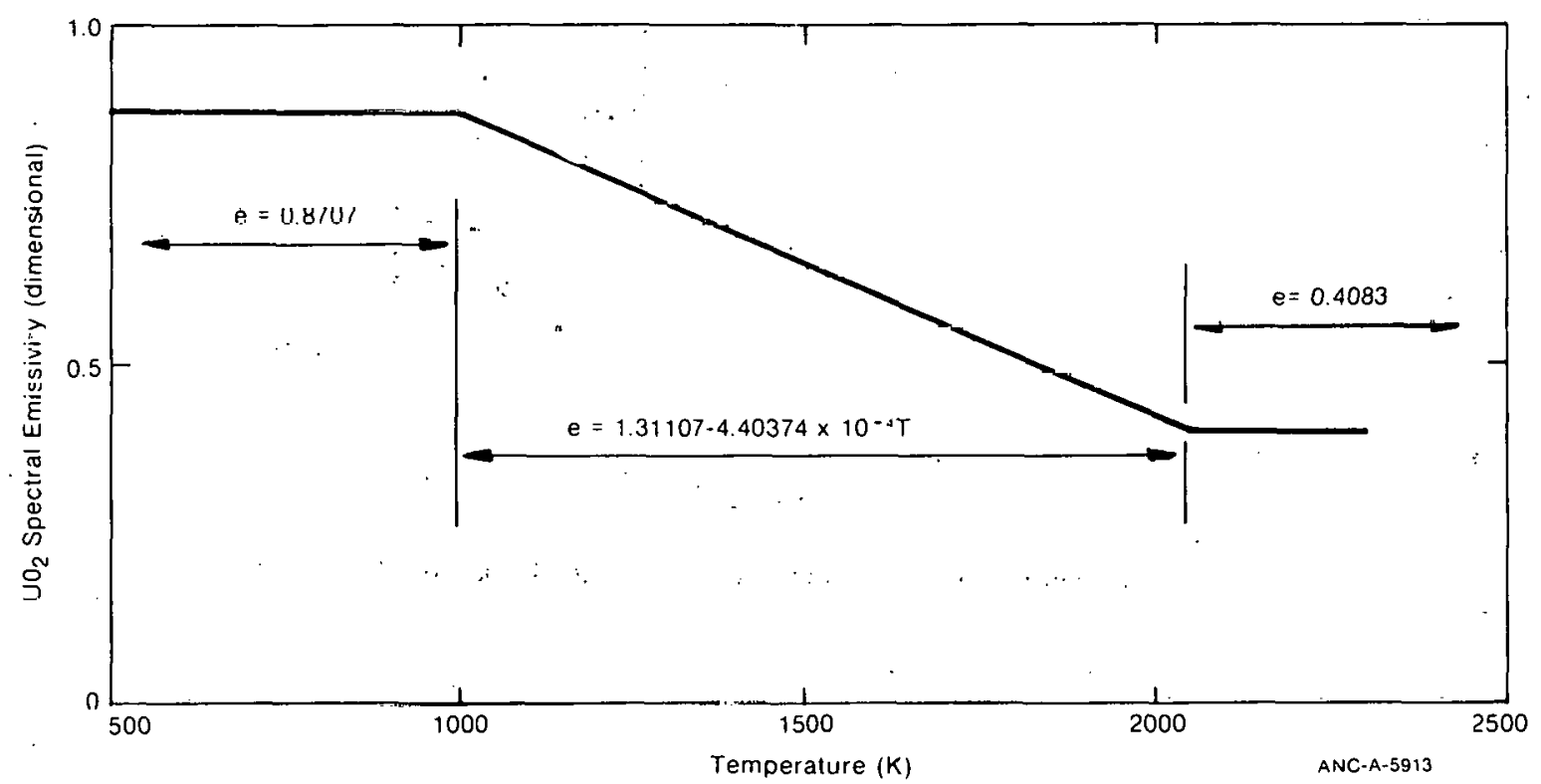

Fig. A-3.2 FEMISS representation of $\mathrm{UO}_{2}$ emissivity.

\subsection{Fuel Emissivity Subcode FEMISS Listing}

A listing of the revised FEMISS subcode is given in Table A-3.IV.

\subsection{References}

A-3.1. P. E. MacDonald and L. B. Thompson (eds.), MATPRO, A Handbook of Materials Properties for Use in the Analysis of Light Water Reactor Fuel Rod Behavior, ANCK-1 263 (February 1976).

A-3.2: T: T. Claudson, "Emissivity Data for Uranium Dioxide," HW-55414 (November 5,1958 ). 
FTHEXP

TABLE A-3.IV

LISTING OF THE FEMISS SUBCODE

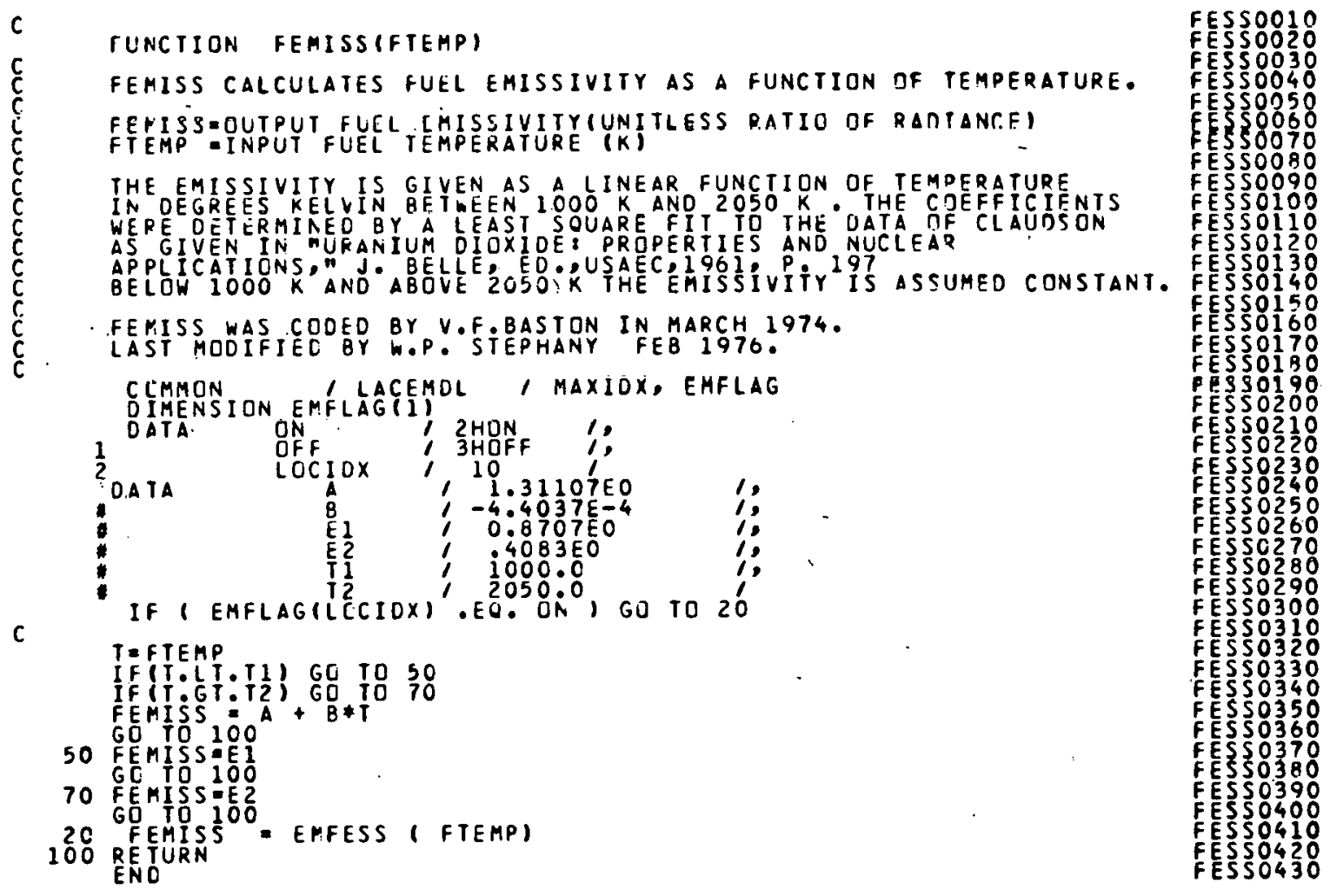

A-3.3. J. Belle (ed.), Uranium Dioxide: Properties and Nuclear Applications, TID-7546, U.S. Government Printing Office, Washington, D.C. (196i).

A-3.4. T. C. Ehlert and J. L. Margrave, "Melting Point and Spectral Emissivity of Uranium Dioxide," Joumal of the American Ceramic Society, 41 (1958) p 330.

\section{FUEL THERMAL EXPENSION (FTHEXP)}

A fuel thermal expansion model is required to predict changes in pellet geometry due to changes in temperature. Linear thermal expansion models have been developed for both $\mathrm{UO}_{2}$ and $(\mathrm{U}, \mathrm{Pu}) \mathrm{O}_{2}$ fuel. The models used in FTHEXP include three regimes: expansion in the solid phase, expansion due to the phase change at the melting point, and expansion in the liquid phase. 


\section{1 $\mathrm{UO}_{2}$ Thermal Exparision}

Linear thermal expansion data for unirradiated $\mathrm{UO}_{2}$ have been published by Burdick and Parker [A-4.1], Conway et al $[\mathrm{A}-4.2, \mathrm{~A}-4.3]$, Christensen $[\mathrm{A}-4.4]$, and Hoch and $\operatorname{Momin}^{[A-1.5]}$. Belle $[\Lambda \cdot 4.6]$ also reports data from Lambertson and Handwerk ${ }^{[A-4.7]}$, Bell and Makin $[\mathrm{A}-4.8]$, and Murray and Thackray [A-4:9]. These sets of data are generally consistent although Christensen reported slightly. lower values at temperatures below $2000^{\circ} \mathrm{C}$. The effect of irradiation on $\mathrm{UO}_{2}$ thermal expansion is usually assumed to be negligible. However, no experimental data are available to support this assumption. In-pile fuel themal expansion is uncertain because accurate descriptions of fuel cracking (resulting from thermal stresses) and healing are not available.

4.1.1 $\mathrm{UO}_{2}$ Solid Phase. The data between 1000 and $2250^{\circ} \mathrm{C}$ presented by Conway et.al $[\mathrm{A}-4.2]$ and the low temperature data of Burdick and Parker ${ }^{[A-4.1]}$, Lambertson and Handwerk $[\mathrm{A}-4.7]$, Bell and Makin [A-4.8], and Murray and Thackray ${ }^{[A-4.9]}$ for the solid phase were fitted by regression analysis to a third-order polynomial. The resulting correlation is given by Equation (A-4.1):

$$
\begin{aligned}
& \begin{array}{r}
\Delta L=-4.972 \times 10^{-4}+7.107 \times 10^{-6} \mathrm{~T}+2.581 \times 10^{-9} \mathrm{~T}^{2}+1.140 \times 10^{-13} \mathrm{~T}^{3} \\
\therefore(\mathrm{A}-4.1)
\end{array} \\
& \text { for } 0^{\circ} \mathrm{C}<\mathrm{T}<\mathrm{T}_{\mathrm{m}} \\
& \text { where } \\
& \begin{array}{l}
\frac{\Delta \mathrm{L}}{\mathrm{I}}=\text { fractional linear thermal expansion } \\
\mathrm{T}-\operatorname{tcmpcrature}\left({ }^{\circ} \mathrm{C}\right) \\
\mathrm{T}_{\mathrm{III}}=\text { melting temperature of tuel }\left({ }^{\circ} \mathrm{C}\right)
\end{array}
\end{aligned}
$$

The melting point of the fuel is a function of burnup and plutonia content and is found using the subroutine PHYPRO.

4.1.2 $\mathrm{UO}_{2}$ Phase Change at Melting Point. The data of Christensen ${ }^{[\mathrm{A}-4.4]}$ are used for the thermal expansion due to the phase change at the melting point. Uniform expansion is assumed. The resulting correlation is expressed by Equation (A-4.2) :

$$
\frac{\Delta L}{L}=\frac{\Delta L}{L}\left(T_{m}\right)+3.096 \times 10^{-2} \cdot R
$$

for $\mathrm{T}>\mathrm{T}_{\mathrm{m}}$. 
where

$$
\begin{array}{ll}
\frac{\Delta \mathrm{L}}{\mathrm{L}}\left(\mathrm{T}_{\mathrm{m}}\right)= & \begin{array}{l}
\text { the fractional linear thermal expansion given by } \\
\text { Equation }(\mathrm{A}-4.1) \text { with } \mathrm{T} \text { equal to } \mathrm{T}_{\mathrm{m}}
\end{array} \\
\mathrm{R}= & \text { fraction of molten fuel. }
\end{array}
$$

4.1.3 $\mathrm{UO}_{2}$ Liquid Phase. The coefficient of expansion presented by Christensen $\left[\mathrm{A}^{-4.4]}\right.$ is used for the liquid phase (above the temperature at which all the fuel is molten). The resulting correlation is given by Equation (A-4.3):

$$
\frac{\Delta L}{L}=\frac{\Delta L}{L}\left(T_{m}\right)+3.096 \times 10^{-2}+3.5 \times 10^{-5}\left(T-T_{m}\right)
$$

for $\mathrm{T}>\mathrm{T}_{\mathrm{m}}$.

This correlation and those for the solid and phase change regimes are shown in Figure A-4.1, superimposed upon the data for the solid phase.

\section{2 (U,Pu) $\mathrm{O}_{2}$ Thermal Expansion}

Linear thermal expansion data for solid unirradiated $\mathrm{PuO}_{2}$ have been published by Tokar et al ${ }^{[A-4.10]}$ and by Brett and Russell $[\mathrm{A}-4.11]$. The data of these investigators were fit to a third-order polynominal and programmed in FTHEXP as follows:

$$
\begin{aligned}
\frac{\Delta L}{L}= & -3.9735 \times 10^{-4}+8.4955 \times 10^{-6} T+2.1513 \times 10^{-9} T^{2} \\
& +3.7143 \times 10^{-16} T^{3}
\end{aligned}
$$

for $0<\mathrm{T}<\mathrm{T}_{\mathrm{m}}$

where

$$
\mathrm{T}=\text { temperature }\left({ }^{\mathrm{O}} \mathrm{C}\right) \text {. }
$$

The expansion of solid mixed oxides is calculated from the weighted average of the expansion of $\mathrm{UO}_{2}$ [Equation $\left.(\mathrm{A}-4.1)\right]$ and the expansion of $\mathrm{PuO}_{2}$ [Equation (A-4.4)]

The thermal expansion for the phase change and for the liquid phase of mixed oxides is assumed to be the same as that for $\mathrm{UO}_{2}$ [Equations (A-4.2) and (A-4.3)] because of the similarity in structure of $\mathrm{UO}_{2}$ and $(\mathrm{U}, \mathrm{Pu}) \mathrm{O}_{2}$ mixed oxides.

Figure A-4.2 shows the linear expansion of $\mathrm{PuO}_{2}$ as a function of temperature as based on the preceding correlations and the data of Tokar et al ${ }^{[\mathrm{A}-4.10]}$ and Brett and Russell ${ }^{[A-4.11]}$. 
FTHEXP

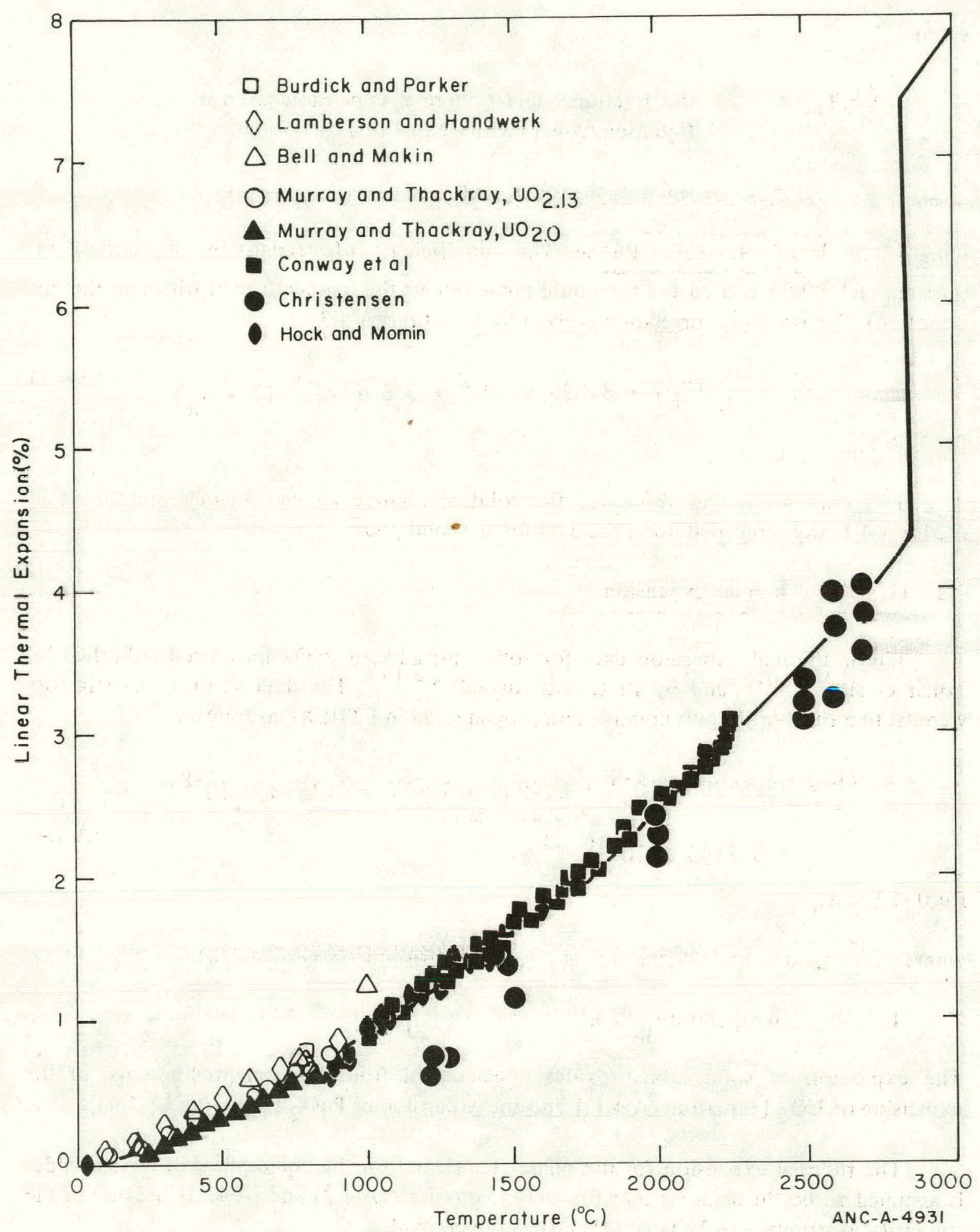

Fig. A-4.1 Comparison of $\mathrm{UO}_{2}$ thermal expansion data with those calculated from FTHEXP subcode. 


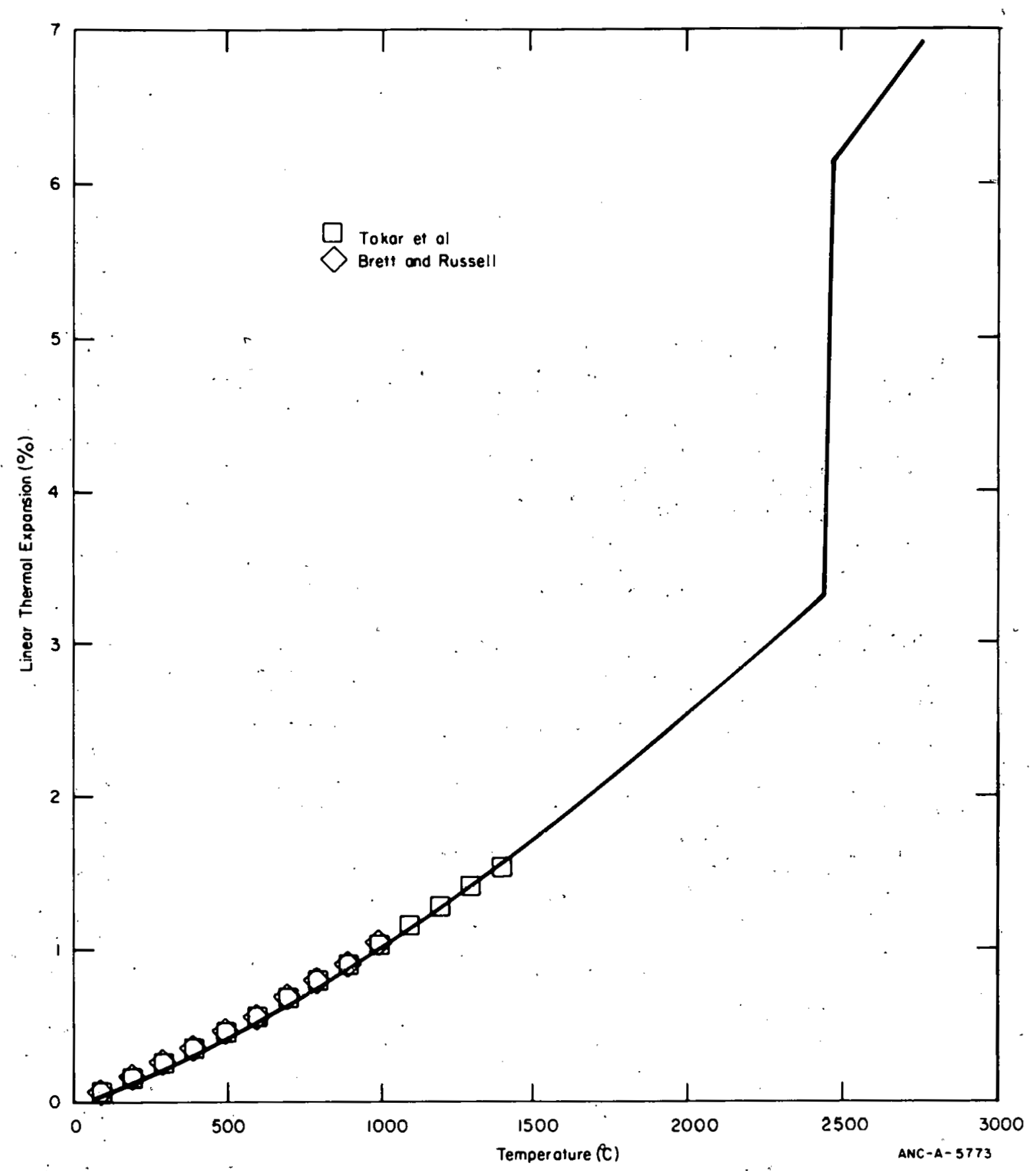

Fig. A-4.2 Comparison of $\mathrm{PuO}_{2}$ thermal expansion data with those calculated from FTHEXP subcode. 
FTHEXP

\subsection{Fuel Thermal Expansion Subcode FTHEXP Listing}

Table A-4.I presents a listing of the FORTRAN subcode FTHEXP used for calculation of fuel thermal expansion.

TABLE A-4. I

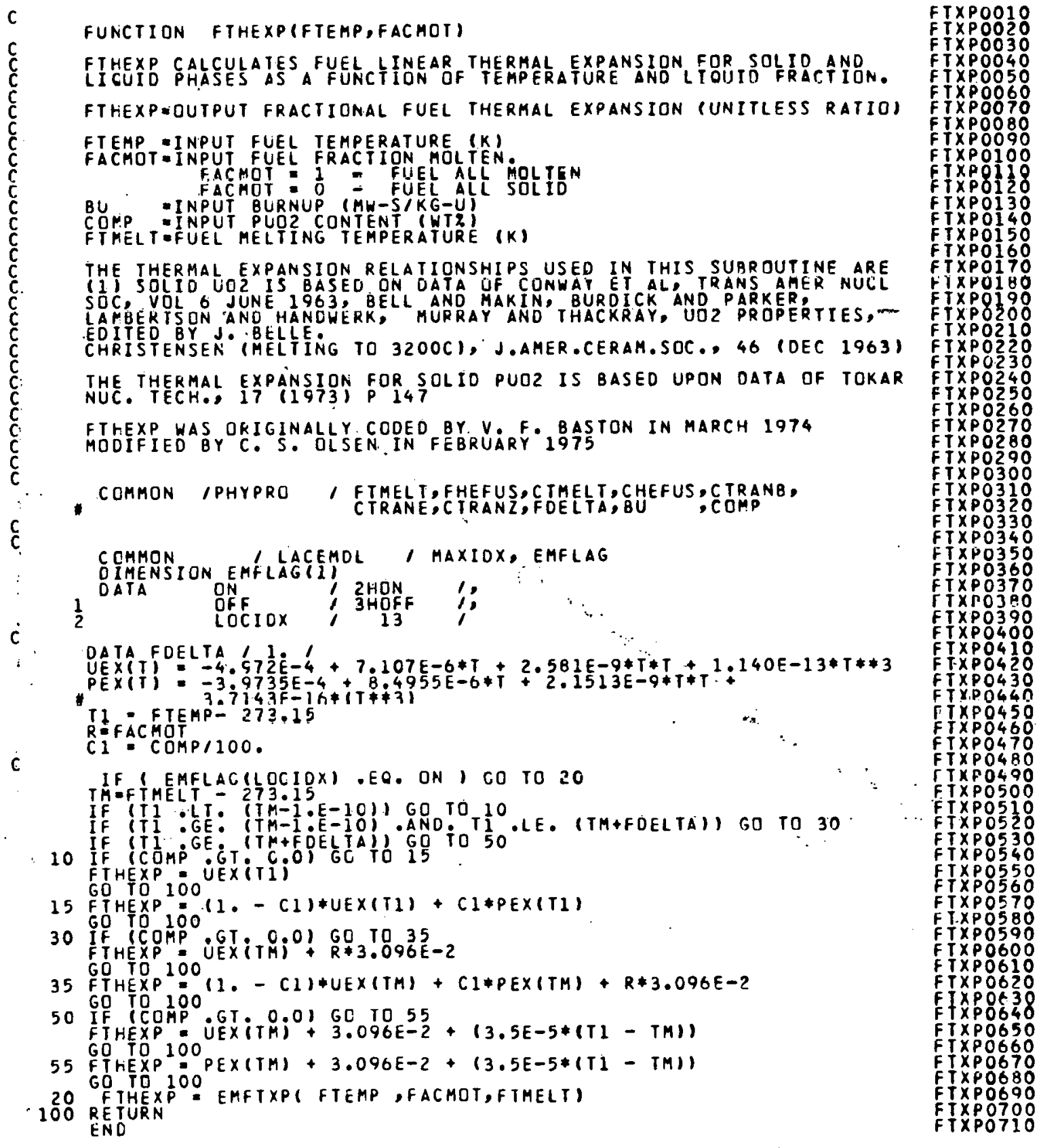


FTHEXP

\subsection{References}

A-4.1. M. D. Burdick and H. S. Parker, "Effect of Particle Size on Bulk Density and Strenglli Properties of Uranium Dioxide Specimens", Journal of the American Ceramic Society, 39, (1956) p 181.

A-4.2. J. B. Conway, R. M. Fincel, Jr., R. A. Hein, "The Thermal Expansion and Heat Capacity of $\mathrm{UO}_{2}$ to $2,200^{\circ} \mathrm{C}$," Transactions American Nuclear Soclety, $\sigma, 1$ (June 1963).

A-4.3. J. B. Conway, R. M. Fincel, Jr., R. A. Hein, The Thermal Expansion and Heat Capacity of $\mathrm{UO}_{2}$ to 2,200 $\mathrm{C}$, TM-63-6-6, General Electric Company (1963).

A-4.4. J. A. Christensen, "Thermal Expansion and Change in Volume of Uranium Dioxide on Melting," Journal of the American Ceramic Society, 46, 12 (1963) p 607.

A-4.5. M. Hoch and A. C. Momin, "High Temperature Thermal Expansion of Uranium Dioxide and Thorium Dioxide," High Temperatures - High Pressures, 1, 4 (1969) p 401 .

A-4.6. J. Belle (ed.), Uranium Dioxide: Properties and Nuclear Applications, TID-7546 USAEC (1961).

A-4.7. W. A. Lambertson and J. H. Handwerk, The Fabrication and Physical Properties of Urania Bodies, ANL-5053 (1956).

A-4.8. I. P. Bell and S. M. Makin, "Fast Reactor - Physical Properties of Materials of Construction," Review of Progress from September 1.1953. to A pril 1, 1954, RDB(C)/TN-70 (1954).

A-4.9: P. Murray and R. W. Thackray, The Therrnal Expansion of Sintered $\mathrm{UO}_{2}, \Lambda \mathrm{ERE}$ M/M 22 (undated).

A-4.10. M. Tokar, A. W. Nutt, T. K. Keenan, "Linear Thermal Expansion of Plutonium Dioxide," Nuclear Technology, 17 (February 1973) p 147.

A-4.11. N. H. Brett and L. E. Russell, "The Thermal Expansion of $\mathrm{PuO}_{2}$ and Some Other Actinide Oxides Between Room Temperature and 1,000 ${ }^{\circ} \mathrm{C}$," in Plutonium 1960; E. Grison, W. B. H. Lord, and R. D. Fowler (eds.), Proceedings of the 2nd International Conference on Plutonium Metallurgy, Grinoble, France, April 19-22 1960, p 397. 


\section{FUEL ELASTIC MODULUS (FELMOD)}

FFLMOD calculates the elastic modulus for $\mathrm{UO}_{2}$ and (U,Pu) $\mathrm{O}_{2}$ mixicd oxides as a function of porosity and temperature. The available data support the assumption of a linear dccrease in elastic modulus with both increasing temperature and porosity. The relationships in FELMOD are

$$
\begin{aligned}
& E=2.26 \times 10^{11}\left(1.1 .131 \times 10^{-1} \mathrm{~T}\right)[1-2.62(1-D)] \\
& E=2.52 \times 10^{11}\left(1-7.843 \times 10^{-4} T\right)[1-2.03(1-D)]
\end{aligned}
$$

for $0<\mathrm{T}<1300^{\circ} \mathrm{C}$ and $\mathrm{UO}_{2}$ and $\left(\mathrm{U}, \mathrm{P}_{11}\right) \mathrm{O}_{2}$ respectively,

where

$$
\begin{aligned}
\mathrm{E} & =\text { Young's modulus (pascals) } \\
\mathrm{T} & =\text { temperäture }\left({ }^{\mathrm{O}} \mathrm{C}\right) \\
\mathrm{D} & =\cdots \text { fraction of theoretical density. }
\end{aligned}
$$

The $\mathrm{UO}_{2}$ data have a standard deviation with respect to Equation (A-5.1) of $0.037 \times 10^{11}$ pascals. The mixed oxide equation is less certain and the limited data do not allow an accurate quantitative estimate of error.

\section{1. $\mathrm{UO}_{2}$ Elastic Modulus}

The elastic modulus for $\mathrm{UO}_{2}$ is a function of porosity, temperature, oxygen-metal ratio, and irradiation. Potentially it is also a function of other parameters such as grain size and impurity level. The variables considered to he the most significant, and those for which data are available, are temperalure and porosity. The following paragraphs describe the effect of these two variables on the $\mathrm{UO}_{2}$ elastic modulus and a model is developed and compared with experimental data.

5.1.1 Porosity Dependency of $\mathrm{UO}_{2}$ Elastic Modulus at Room Temperature. Young's modulus for stoichiometric $\mathrm{UO}_{2}$ has been determined at room temperature $\left(20^{\circ} \mathrm{C}\right)$ as a function of porosity by the resonant frequency $[A-5.1, A-5.7]$ and bending $[A-5.8, A-5.9]$ techniques. Since deformation measurements lack the accuracy needed to determine elastic modulus, only the more reliable resonant frequency measurements were used in a least-squares regression analysis to derive the coefficients $E_{O}$ and $\beta$ in Equation ( $\left.\dot{A}-5.3\right)$.

$$
E=E_{0}[1-\beta(1-D)]
$$


where

$$
\begin{aligned}
\mathrm{E}_{\mathrm{O}}= & \text { Young's modulus for theoretically dense } \mathrm{UO}_{2} \text { at } \\
& 20^{\circ} \mathrm{C}\left(2.256 \times 10^{11} \text { pascals }\right) \\
\beta= & \text { porosity cuefficient }=2.62 \text { (unitless) }
\end{aligned}
$$

and $\mathrm{E}$ and $\mathrm{D}$ have been defined previously.

Equation (A-5.3) calculates a value of zero elastic modulus at 0.38 volume fraction porosity ( 0.62 of theoretical density). Exponential functions that relate Young's modulus to porosity have been used empirically $[\mathrm{A}-5.10]$, but these relationships do not yield zero elastic modulus with increasing porosity. Theoretical considerations for a material composed of uniform spherical particles predict zero elastic modulus for porosities less than 0.4764 volume fraction $[A-5.11]$. Also, Gatto ${ }^{[A-5.12]}$ predicted zero elastic modulus at 0.424 volume fraction porosity using the theory of sound propagation. The value 2.62 for $\beta$ is consistent with these theoretical considerations.

The $2.256 \times 10^{11}$ pascals in Equation (A-5.3) for $\mathrm{E}_{\mathrm{o}}$ for theoretically dense $\left(10.96 \mathrm{~g} / \mathrm{cm}^{3}\right) \mathrm{UO}_{2}$ at $20^{\circ} \mathrm{C}$ is between $2.170 \times 10^{11}$ pascals (Reuss average) and $2.440 \times 10^{11}$ pascals (Voigt average) $[A-5.13]$. These average values are respectively lower and upper bounds for Young's modulus of isotropic theoretically dense $\mathrm{UO}_{2}[\mathrm{~A}-5.14]$. Thus $2.256 \times 10^{11}$ pascals appears to be a good estimate for $E_{0}$. Equation $(A-5.3)$ is compared with experimental data taken at ambient temperature in Figure A-5.1.

5.1.2 Temperature Dependency of $\mathrm{UO}_{2}$ Elastic Modulus. Elastic modulus data were obtained as a function of temperature by Padel and Novion[ A-5.3], Wachtman et al, [A-5.6] and Belle and Lustman $[\mathrm{A}-5.7]$ and were used in a least-squares regression analysis using Equation (A-5.4) to determine the temperature dependency of Young's modulus:

$$
E=E_{0}(1-\alpha T)
$$

where

$$
\begin{aligned}
& \mathrm{F}_{\mathrm{O}}=\text { Young's modulus at } 0^{\circ} \mathrm{C} \\
& \alpha=\text { temperature coefficient }=1.131 \times 10^{-4}{ }^{\circ} \mathrm{C}^{-1}
\end{aligned}
$$

and $\mathrm{E}$ and $\mathrm{T}$ have been previously defined.

Equation (A-5.3) was used to normalize the modulus data from $\mathrm{UO}_{2}$ of different densities to values for theoretically dense $\mathrm{UO}_{2}$. The low density data (91\% TD) from Padel and Novion ${ }^{[A-5.3]}$ and all of the data (93\% TD) from Belle and Lustman ${ }^{[A-5.6]}$ lie on a line that is nearly parallel to that of the remaining normalized data, but which results in a lower modulus at a given temperature (Figure A-5.2). The room temperature modulus 


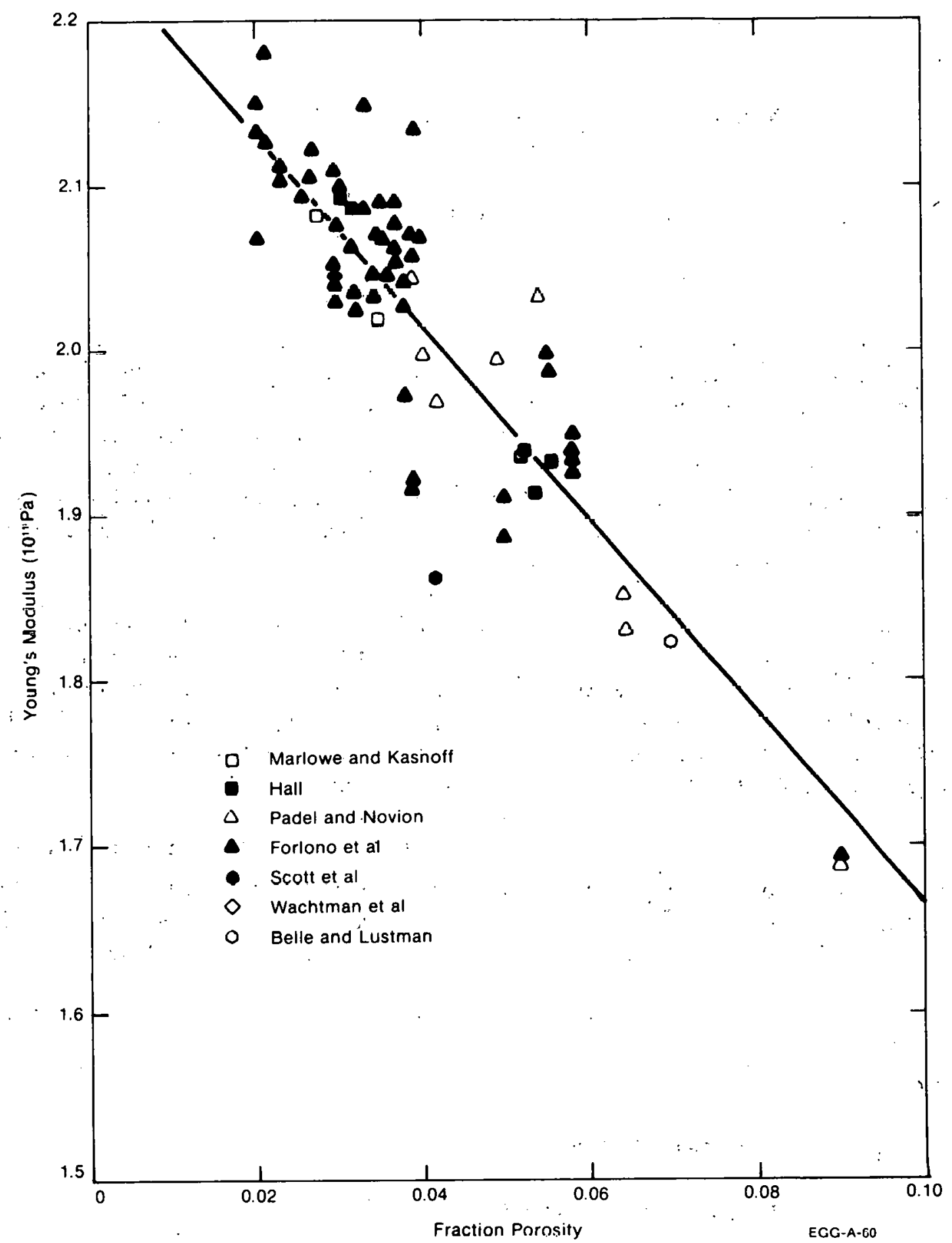

Fig. A-5.1 Comparison of Young's modulus data for $\mathrm{UO}_{2}$ at ambient temperature and the fraction of porosity, from a least-squares fit to Equation (A-5.3).

obtained from this data from the low density fuel and extrapolated to theoretically dense $\mathrm{UO}_{2}$, is $2.143 \times 10^{11}$ pascals, which is outside the range expected for isotropic, theoretically dense $\mathrm{UO}_{2}[\mathrm{~A}-5.13]$. Young's modulus, determined from the remaining data, was $2.2 \times 10^{11}$ pascals which is in the expected range. However, both sets of data resulted 


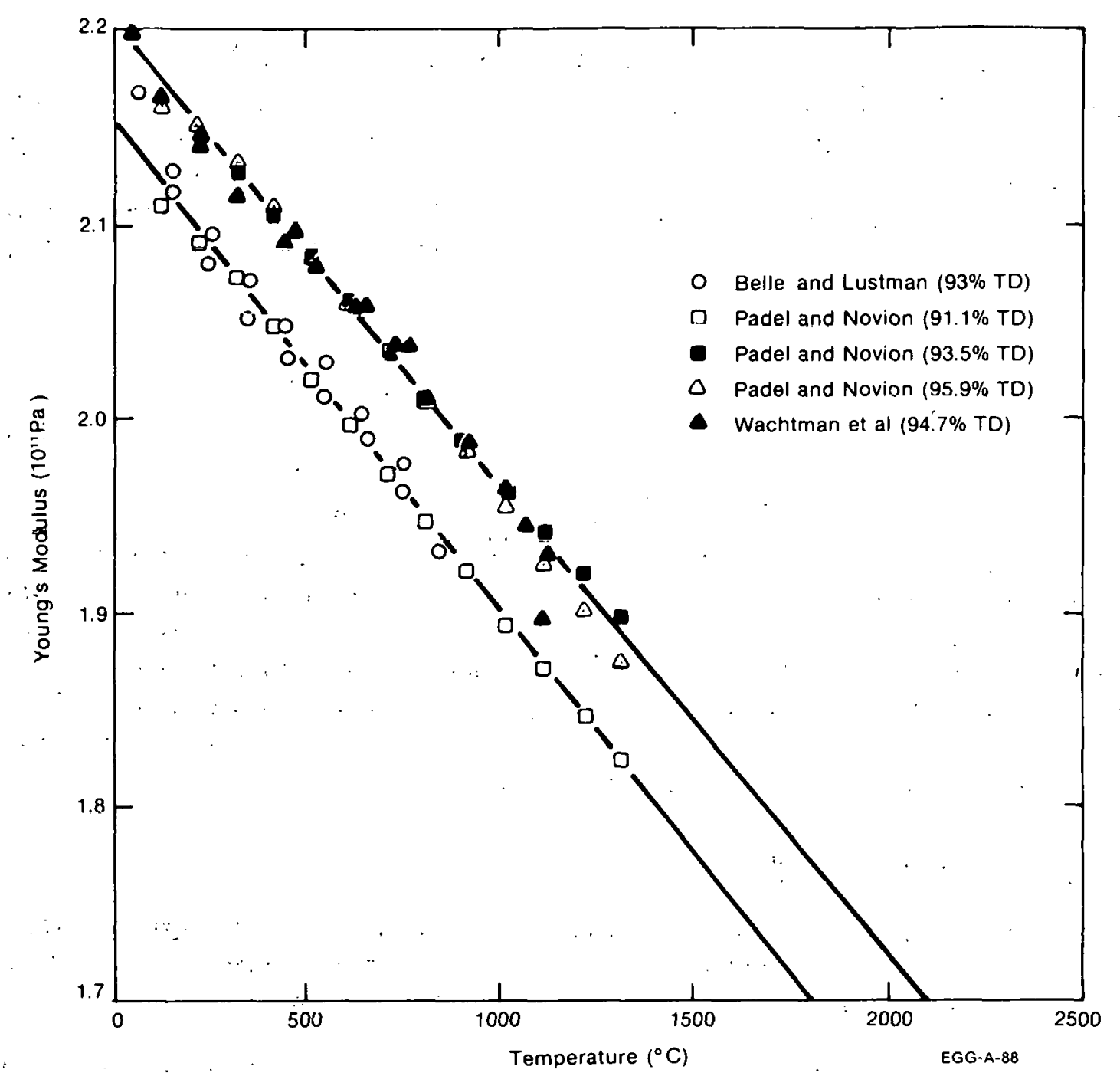

Fig. A-5.2 Comparison of Young's modulus for $\mathrm{UO}_{2}$ normalized to $100 \% \mathrm{TD}$ as a function of temperature, with least-square fits to Equation (A-5.4).

in nearly the same slope given by $\alpha$ in Equation (A-5.4), thus indicating that the temperature coefficient is independent of porosity. The average value of $1.131 \times 10^{-4}{ }^{\circ} \mathrm{C}^{-1}$ is used for the temperature coefficient $\alpha$. .

Equation (A-5.4) predicts a linear decrease in Young's modulus as the tcmpcrature increases. For temperatures between room temperature and about $1000^{\circ} \mathrm{C}$, this linear decrease has been observed experimentally on other oxide systems ${ }^{[A-5.15]}$. However, with other ceramic materials $[A-5.15, A-5.16]$, grain boundary sliding occurs at. high temperatures. When sliding occurs, the modulus decreases more rapidly with temperature than at lower temperatures. This phenomenon has been observed for $\mathrm{UO}_{2}[\mathrm{~A}-5.14]$ and also contributes to creep deformation (see Section 7). The abrupt change in elastic modulus with temperature expected at temperatures greater than $1300^{\circ} \mathrm{C}$ has not been modeled because of the lack of data as a function of temperature and porosity for this phenomenon. The extrapolation of Equation (A-5.4) to temperatures higher than $1300^{\circ} \mathrm{C}$ is therefore not recommended. 
5.1.3 $\mathrm{UO}_{2}$ Elastic Modulus as a Function of Both Porosity and Temperature. The resultant expression for Young's modulus as a function of temperature and porosity, assuming that the temperature and porosity coefficient are independent, (Equation A-5.5) was obtained by combining Equations (A-5.3) and (A-5.4). The best-estimate value for $E_{0}$ derived in Equation (A-5.3) for theoretically dense $\left(10.96 \mathrm{~g} / \mathrm{cm}^{3}\right) \mathrm{UO}_{2}$ was normalized to $0^{\circ} \mathrm{C}$ using equation (A-5.4) and used in Equation (A-5.5). Then for stoichiometric $\mathrm{UO}_{2}$, with the standard deviation shown:

$$
\begin{aligned}
E= & 2.26 \times 10^{11}\left(1-1.131 \times 10^{-4} 1\right)[1-2.62(1-D)] \\
& \pm 0.037 \times 10^{11}
\end{aligned}
$$

5.1.4 Effect of Irradiation on $\mathrm{UO}_{2}$ Elastic Modulus. Equation (A-5.5) can be used as an approximation for irradiated fuel although it has been derived solely from measurements on unirradiated fuel. The porosity term can be used to account for the changes in porosity induiced by irradiation. While other structural changes such as cracking would not be accounted for, Marlowe and Kaznoff ${ }^{[A-5.14]}$ have indicated that fission products in small concentration ( $10 \%$ or less) would have a negligible effect upon the elastic modulus. The minor effect of solute additions is due to the fact that Young's modulus is primarily determined by the interatomic bonding of the solvent.

\section{$5.2(\mathrm{U}, \mathrm{Pu}) \mathrm{O}_{2}$. Elastic Modulus}

As with $U)_{2}$, temperature and porosity are considered to be the most significant variables affecting the elastic modulus of $\mathrm{U}_{\mathrm{x}} \mathrm{Pu}_{1-\mathrm{x}} \mathrm{O}_{2}$. However, in the case of mixed oxides, the oxygen-metal ratio at room temperature has also been found to be important.

5.2.1 $\mathrm{O} / \mathrm{M}$ Ratio Dependency of Mixed Oxide Elastic Modulus. Padel and Novion $\left[\mathrm{A}-5.3\right.$ ] determined the Young's modulus for $95 \%$ theoretical density $\mathrm{U}_{0.8} \mathrm{Pu}_{0.2} \mathrm{O}_{2} \pm \mathrm{x}$ between 25 and $1300^{\circ} \mathrm{C}$. A Young's modulus of $1.808 \times 10^{11}$ pascals was measured at $25^{\circ} \mathrm{C}$ for an oxygen-metal ratio of 1.962 ; for an oxygen-metal ratio of 2.00 a Young's modulus of $2.265 \times 10^{11}$ pascals was measured. However, while Young's modulus is observed to vary substantially with the change in oxygen-metal ratio in mixed oxides, the data arc not cxtensive eliuugh lo support an empirical modeling effort. FELMOD will be restricted to the stoichiometric case.

5.2.2 Temperature Dependency of $(\mathrm{U}, \mathrm{Pu}) \mathrm{O}_{2}$ Elastic Modulus.' Young's modulus for stoichiometric $(\mathrm{U}, \mathrm{Pu}) \mathrm{O}_{2}$ was found to decrease linearly with temperature as follows: [A-5.3]

$$
E=2.265 \times 10^{11}\left(1-7.843 \times 10^{-4} \mathrm{~T}\right)
$$


where

$$
\begin{aligned}
& \mathrm{E} \cdot \text { Young's modulus (pascals) } \\
& \mathrm{T}=\text { temperature }\left({ }^{\mathrm{o}} \mathrm{C}\right) .
\end{aligned}
$$

5.2.3. Porosity Dependency of (U,Pu) $\mathrm{O}_{2}$ Elastic Modulus. Nutt et al (A-5.17) determined Young's modulus for $\mathrm{U}_{0.8} \mathrm{Pu}_{0.2}{ }^{0} 1.984$ at room temperature as a function of porosity as follows:

$$
E=2.103 \times 10^{11}[1-2.03(1-D)]
$$

where

$$
\mathrm{D}=\text { fraction of theoretical density. }
$$

5.2.4 (U,Pu) $\mathrm{O}_{2}$ Elastic Modulus as a Function of Both Porosity and Temperature. Equations (A-5.6) and (A-5.7) were combined to obtain an overall effect of temperature and porosity on Young's modulus for stoichiometric mixed oxides. A value of $2.52 \times 10^{11}$ pascals was obtained from the value $2.265 \times 10^{11}$ pascals in Equation (A-5.6) after normalizing to theoretically dense $\mathrm{UO}_{2}$ at $0^{\circ} \mathrm{C}$. The resultant expression given by Equation (A-5.8) is shown in Figure A-5.3 as a function of temperature and porosity and used in FELMOD to calculate Young's modulus for mixed oxides.

$$
E=2.52 \times 10^{11}\left(1-7.843 \times 10^{-4} \mathrm{~T}\right)[1-2.03(1-D)]
$$

where

$$
\begin{aligned}
& \mathrm{D}=\text { fraction of theoretical density } \\
& \mathrm{T}=\text { temperature }\left({ }^{\circ} \mathrm{C}\right)
\end{aligned}
$$

As in the case of $\mathrm{UO}_{2}$, the effects of irradiation upon the elastic modulus of (U,Pu) $\mathrm{O}_{2}$ are expected to be small. There are no data presently available to contradict this expectation and Equation (A-5.8) may therefore be used for irradiated as well as unirradiated $(\mathrm{U}, \mathrm{Pu}) \mathrm{O}_{2}$.

\subsection{Fuel Elastic Modulus Subcode FELMOD Listing}

A listing of the FORTRAN subcode FELMOD used for calculating Young's modulus for $\mathrm{UO}_{2}$ and $(\mathrm{U}, \mathrm{Pu}) \mathrm{O}_{2}$ mixed oxides is presented in Table A-5.I. 


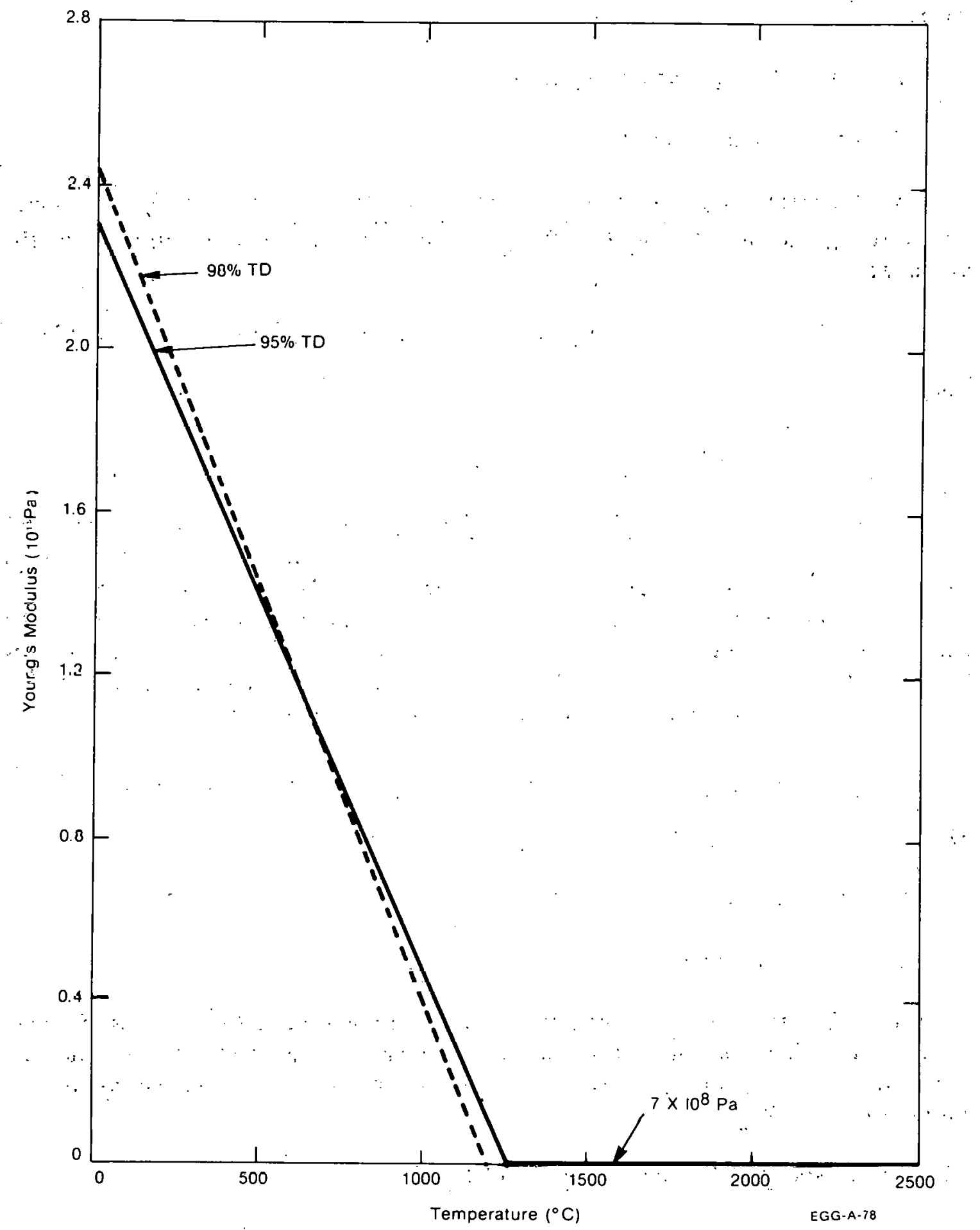

Fig. A-5.3 Young's modulus as a function of temperature and porosity for $(\mathrm{U}, \mathrm{Pu}) \mathrm{O}_{2}$ mixed oxides as calculated from Equation (A-5.8). 
TABLE A-5. I

LISTING OF THE FELMOD SUBCODE

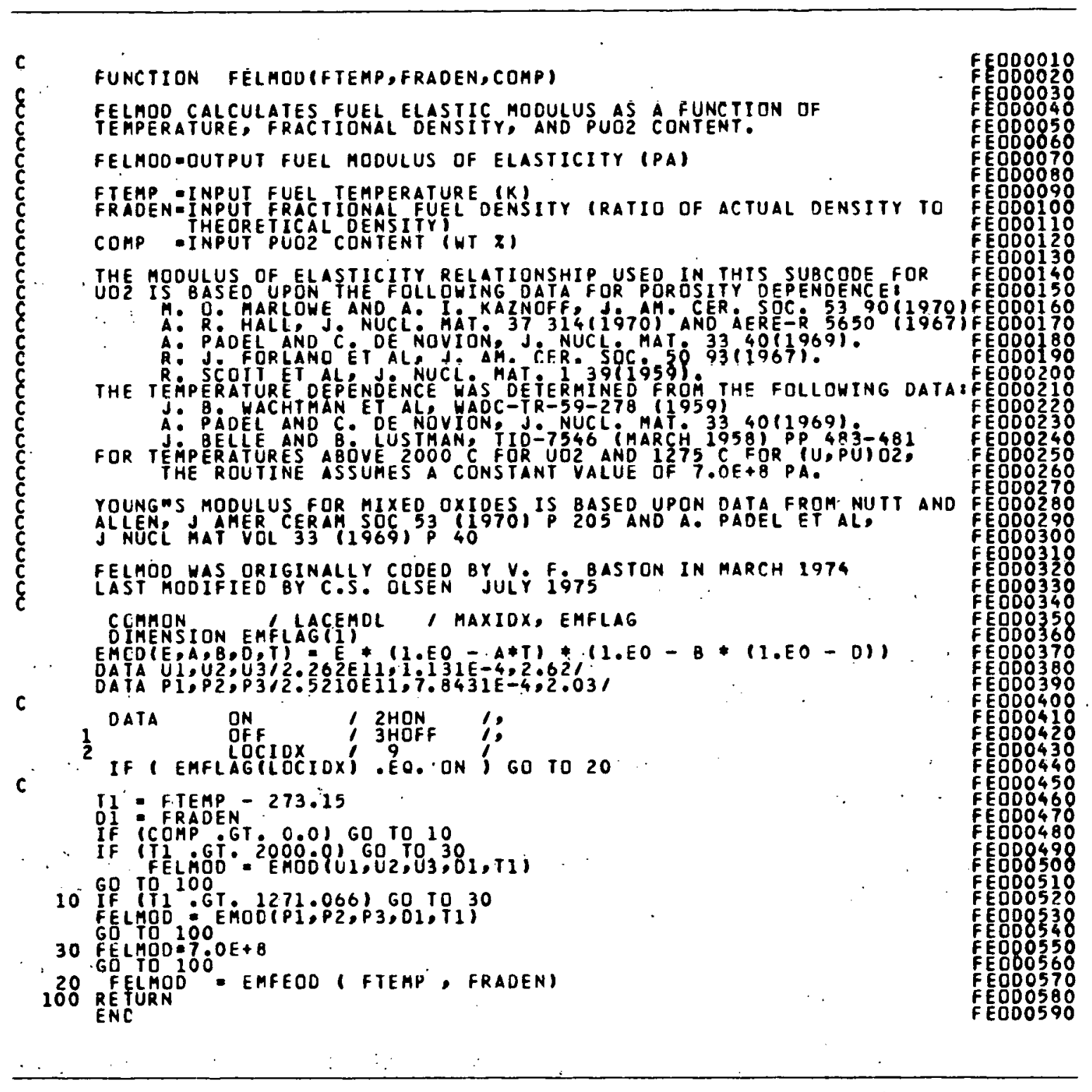

\section{$5.4 \quad$ References}

A-5.1. M. O. Marlowe and A. I. Kaznoff, "Elastic Behavior of Uranium Dioxide," Journal of the American Ceramic Society, 53 (1970) pp 90-99.

A-5.2. A. R. Hall, "Elastic Moduli and Internal Friction of Some Uranium Ceramics," Journal of Nuclear Materials, 37 (1970) pp 314-323. Also AERE-R 5650 Atomic Energy Research Establishment (1967). 
FELMOD

A-5.3. A. Padel and C. de Novion, "Constants Elastiques des Carbures, Nitures et Oxydes $\mathrm{d}^{\prime}$ Uranium et de Plutonium," Journal of Nuclear Materials, 33 (1969) pp 40-51.

A-5.4. R. J. Forlano et al, "Elastivily and Anclasticity of Uranium Oxides at Room Temperature: I Stoichiometric Oxide," Journal of the American Ceramic-Society, 50 (1967) pp 92-96.

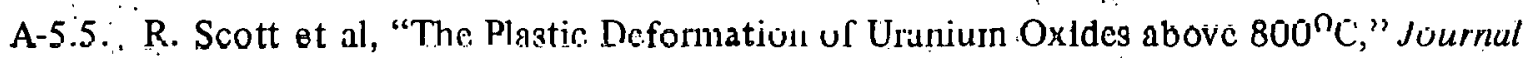
of Nuclear Materials, $l$ (1959) pp 39-48.

A-5.6. J. B. Wachtman et al, Factors Controlling Resistance to Deformation and Mechanicàl Failure in Polycrystalline. (Glass-Free) Ceramics. Period covered July 1, 1975, WADC-TR-59-278 (1959).

A-5.7. J. Belle and B. Lustman, "Prnperties of U.Janium Dioxide," in Fuel Elemtents. Conference; Paris, France, (November 18-23, 1957), TID-7546 (March 1958). pp 442-515.

A-5.8. W. A. Lambertson and J. H. Handwerk, The Fabrication and Physical Propertics of Urania Bodies, ANL-5053 (February 1956).

A-5.9. J. T. A. Ruberts and Y. Ueda, "Influence of Porosity and Deformation and Fracture of $\mathrm{UO}_{2}$," Journal of the American Ceramic Society, 55 (1972) pp 117-124.

A=5.10. N. Igata and K. Domoto, "Fracture Stress and Elastic Modulus of Uranium Dioxide Including Excess Oxygen," Journal of Nuclear Materials, 45 317-322 (1972/73).

A-5.11. M. O. Marlowe and D. R. Wilder, "Elasticity and Internal'Friction of Polycrystalline Yittrium Oxide," Journal of the American Ceramic Society, 48 (1965) pp 227-233.

A-5.12.F. Gatto, "Influence of Small Cavities on Velocity of Sound in Metale," Alluminico $19,1(1950) \mathrm{pp} 19-26$.

A-5.13. J. B. Wachtman et al "Elastic Constants of Single Crystal $\mathrm{UO}_{2}$ at $25^{\circ} \mathrm{C}$," Journal of Nuclear Materials, 16 (1965) pp 39-41.

A-5.14. R. Hill, "The Elastic Behavior of a Crystalline Aggregate," Proceeds Physical Society London, $A 65$ (1952) pp 349-354.

A-5.15. J. B. Wachtman et al, "Exponential Temperature Dependence of Young's Modulus for Several Oxides," Physical Review, 122, 6.(1961) pp 1754-1759.

A-5.16. M. O. Marlowe and D. R. Wilder, "Elasticity and Internal Friction of Polycrystalline Yittrium Oxide," Journal of the American Ceramic Society, 48 (1965) pp 227-233. 
A-5.17. A. W. Nutt, Jr., A. W. Allen, J. H. Handwerk, "Elastic and Anclastic Response of Polycrystalline $\mathrm{UO}_{2}-\mathrm{PuO}_{2}$," Journal of the American Ceramic Society, 53 (1970) p 205.

\section{FUEL POISSON'S RATIO (FPOIR)}

Poisson's ratio for both $\mathrm{UO}_{2}$ and $(\mathrm{U}, \mathrm{Pu}) \mathrm{O}_{2}$ fuels is calculated by the routine FPOIR. .

Poisson's ratio can be related to Young's modulus and the shear modulus as follows $[\mathrm{A}-6.1]$ :

$$
1=\frac{E}{2 G}-1
$$

where

$$
\begin{aligned}
& \mu=\text { Poisson's ratio (unitless) } \\
& \mathrm{E}:=\text { Young's modulus }(\mathrm{Pa}) \\
& \mathrm{G}=\text { shear modulus }(\mathrm{Pa})
\end{aligned}
$$

Wachtman et al ${ }^{[A-6.2]}$ report mean values for the Young's modulus and shear modulus of $\mathrm{UO}_{2}$ from two experiments as $\mathrm{E}=2.30 \times 10^{11} \mathrm{~Pa}$ and $\mathrm{G}=0.874 \times 10^{11} \mathrm{~Pa}$. Consequently, the value of Poisson's ratio is 0.316 and the routine FPOIR returns this value for $\mathrm{UO}_{2}$. The Wachtman et al paper only considers single crystal $\mathrm{UO}_{2}$ data at $25^{\circ} \mathrm{C}$. However, Padel and de Novion[A-6.3] have reported values of 0.314 and 0.306 for the Poisson's ratio of polycrystalline $\mathrm{UO}_{2}$. These values are in reasonable agreement with Wachtman's value of 0.316 .

Nutt and Allen $[\mathrm{A}-6.4]$ determined Poisson's ratio for $\mathrm{U}_{0.8} \cdot \mathrm{Pu}_{0.2} \mathrm{O}_{2-\mathrm{x}}$ at room temperature by determining the Young's modulus. and the shear modulus and calculating Poisson's ratio using Equation (A-6.1). Nutt and Allen's room temperature Poisson's ratio for $(\mathrm{U}, \mathrm{Pu}) \mathrm{O}_{2}$ fuel of $0.276 \pm 0.094$ was found to be independent of density and is returned by: FPOIR for mixed oxides.

Poisson's ratio for the fuel is shown in Figure A-6.1 as a function of temperature and fuel composition as can be seen from the figure, any plutonia content is assumed to reduce Poisson's ratio, which is independent of temperature.

\subsection{Fuel Poisson's Ratio Subcode FPOIR Listing}

The listing of the FORTRAN subcode FPOIR is presented in Table A-6.I. 
FPOIR:

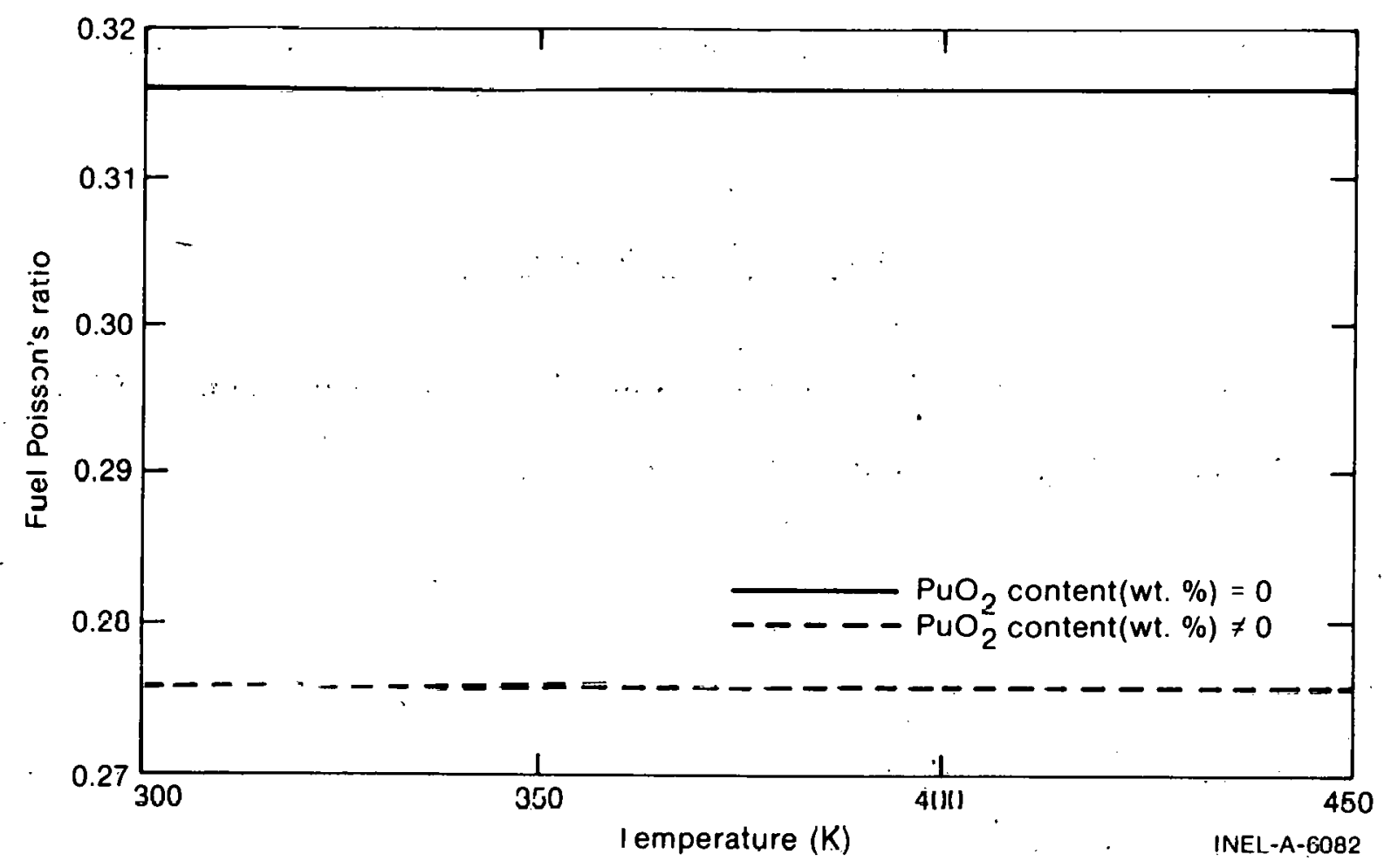

Fig. A-6.1 Computer generated curves showing Poișon's ratio as a funstinn of temperature for two plutonia content3.

\section{TABLE A-6.I}

\section{L.ISTING OF THE FPOIR SUBCOOE}

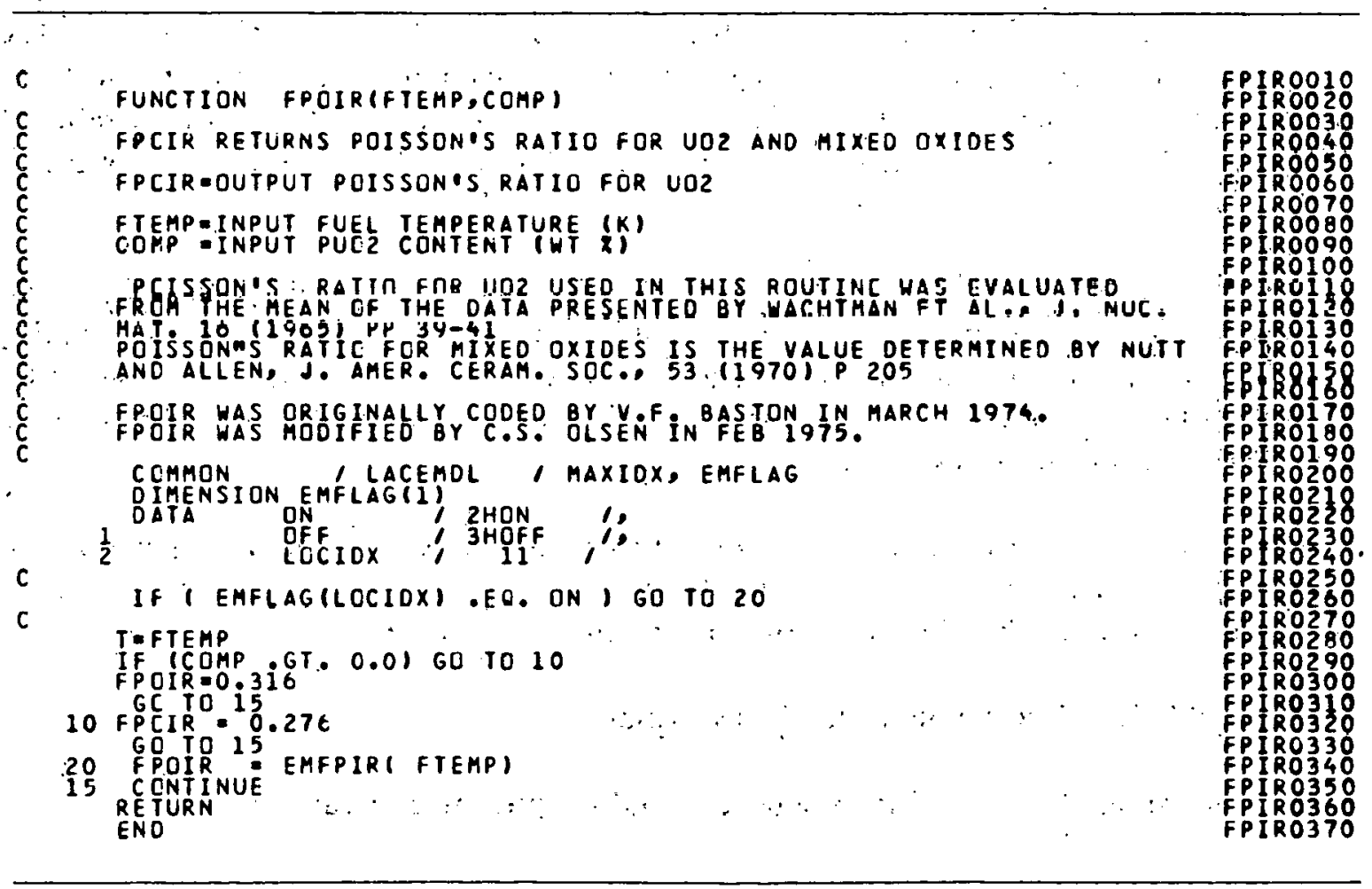




\subsection{References}

A-6.1. I. S. Sokolnikoff and R. D. Specht, Mathematical Theory of Elasticity, 2nd Edition, New York: McGraw-Hill Book Company, Inc, 1956.

A-6.2. J. B. Wachtman, Jr., M. L. Wheat, H. J. Anderson, J. I. Bates, "Elastic Constants of Single Crystal $\mathrm{UO}_{2}$ at $25^{\circ} \mathrm{C}$," Journal of Nuclear Materials, 16, 1 (1965) p 39.

A-6.3. A. Padel and C. H. de Novion, "Constantes Elastiques des Carbures, Nitrures et Oxydes d'Uranium et de Plutonium," Journal of Nuclear Materials, 33 (1969) pp 40-51.

A-6.4. A. W. Nutt and A. W. Allen. "Elastic and Anelastic Response of Polycrystalline $\mathrm{UO}_{2}-\mathrm{PuO}_{2}$," Journal of the American Ceramic Society (1970) p 205.

\section{FUEL CREEP RATE (FCREEP)}

The fuel creep model FCREEP predicts the steady state creep rate of $\mathrm{UO}_{2}$ and $(\mathrm{U}, \mathrm{Pu}) \mathrm{O}_{2}$ fuel with semiempirical relationships. Because several factors (stress, temperature, grain size, density, and fission rate during irradiation) affect the steady state creep rate, correlations which reflect these parameters are required so that fuel deformation luring operation of a fuel rod can be predicted realistically. A theoretically based model is required to provide guidance in the selection of the most appropriate relationships between variables because the data are limited and exhibit much scatter.

Theoretical creep models that have been applied to ceramic materials are discussed in Section 7.1, and experimental $\mathrm{UO}_{2}$ and mixed oxide creep data are reviewed in Section 7.2. Information regarding out-of-pile and in-pile creep behavior is included in these discussions. In Section 7.3 the FCREEP models for $\mathrm{UO}_{2}$ and mixed oxide fuels based upon data and theory are presented.

\subsection{Theoretical Models for $\mathrm{UO}_{2}$ Creep}

Theoretical creep models for the out-of-pile creep behavior of $\mathrm{UO}_{2}$ are generally based on the diffusion of vacancies at low stresses and on dislocation climb at high stresses. During irradiation the fissioning process introduces point defects that affect the creep rate. Theoretical models for out-of-pile creep behavior have received more attention than models for in-pile creep behavior.

7.1.1 Models for Out-of-Pile Creep Behavior. Two models have been proposed for out-of-pile $\mathrm{UO}_{2}$ creep phenomena: a viscous creep model based on diffusion and a power-law model based on dislocation climb. 
The theoretical model $[A-7.1, A-7.2]$ for viscous creep is based on diffusion of vacancies from grain boundaries in tension to grain boundaries in compression. This model results in a creep rate that is (a) proportional to the diffusion coefficient of the rate controlling species, (b) inversely proportional to the square of the grain size, and (c) proportional to stress. Visrnus rrecp using an Arrhenius equation to represent llte diffusion coefficient can be written as follows:

$$
\dot{\varepsilon}=\frac{A_{1} \sigma}{G^{\prime}} \exp \left(-Q_{1} / R T\right)
$$

where

$$
\begin{aligned}
& \dot{\epsilon}=\text { steady state creep rate }\left(\mathrm{s}^{-1}\right) \\
& \mathrm{A}_{1}=\text { constant } \\
& \sigma \quad=\operatorname{stress}(\mathrm{Pa}) \\
& \mathrm{G}=\operatorname{grain} \text { size }(\mu \mathrm{m}) \\
& \mathrm{R}=\operatorname{gas} \text { constant }(8.134 \mathrm{~J} / \mathrm{mol} \cdot \mathrm{K}) \\
& \mathrm{T}=\operatorname{temperature~}(\mathrm{K}) \\
& \mathrm{Q}_{1}=\operatorname{activation} \text { energy for diffusion }(\mathrm{J} / \mathrm{mol}) .
\end{aligned}
$$

Equation (A-7.1) is based on the assumption that the diffusion path is through the lattice (volume diffusion). Therefore, this model results in a creep rate that is inversely proportional to. the square of the grain size with an activation energy that corresponds to a value for volume diffusion. However, Coble ${ }^{[A-7.3]}$ has shown that if the diffusion path is along grain boundaries, then the creep rate should be inversely proportional to the cube of the grain size with an assnciated artivation energy that corresponds to a value fur grain boundary diffusion.

Equation (A-7.1) was derived solely for diffusion of vacancies in $\mathrm{UO}_{2}$. However, grain boundary sliding has also been observed to occur during viscous creep deformation of $\mathrm{UO}_{2}[\mathrm{~A}-7.4, \mathrm{~A}-7.5]$. Both grain boundary sliding and diffusional creep have the characteristics of linear stress dependence and an activation energy nearly that of self-diffusion. Therefore, distinguishing between mechanisms of grain boundary sliding and diffusion is very difficult experimentally. Regardless of which mechanism predominates, the form of Equation (A-7.1) is still applicable.

At high stresses, the movement of dislocations due to applied shear stresses within the crystal structure results in a macroscopic movement of material. And, at high temperatures, dislocation climb can occur and results in an increase in deformation rate by allowing 
dislocations to surmount barriers which normally would restrict movement. Weertman ${ }^{[A-7.6]}$ has proposed a power-law model based on dislocation climb which results in a creep rate proportional to stress raised to the 4.5 power. In this case, creep rate is not a function of grain size. This model is represented by Equation (A-7.2):

$$
\dot{\varepsilon}=A_{2} \sigma^{1.5} \exp \left(-Q_{2} / R T\right)
$$

where

$$
\begin{aligned}
& \mathrm{A}_{2}=\text { constant } \\
& \mathrm{Q}_{2}=\text { activation energy }(\mathrm{J} / \mathrm{mol})
\end{aligned}
$$

and the other terms are as defined previously.

7.1.2 Models for In-Pile Creep Behavior. A model has been proposed by Speight [A-7.7] for the irradiation enhancement of $\mathrm{UO}_{2}$ creep. This model considers the effect of local dislocations and voids on the diffusion creep rate when large numbers of atomic displacements and the production of Frenkel defect pairs occur. Under these circumstances, dislocations show a preference for absorbing the irradiation-produced interstitials. To establish equilibrium, the dislocations and voids behave as continuous thermal vacancy sinks and sources, and the resulting interchange of matter is the process that enhances the creep rate.

The principal result from this model is that the diffusion creep rate is enhanced by irradiation although it has the same temperature dependence as unirradiated fuel.

The defect concentration and the creep rate can be considered to depend upon the fission rate $[\mathrm{A}-7.8]$. Creep experiments using $\mathrm{Co}^{60}$ gamma-irradiation sources show no creep deformation at temperatures between 100 and $200^{\circ} \mathrm{C}$ and stresses from about 20 to $43.5 \mathrm{MPa}[\mathrm{A}-7.9]$. These results suggest that the energy from fission events is necessary to move radiation-produced defects at low temperatures.

7.1.3 Conclusions from the Review of Theory. The creep behavior of $\mathrm{UO}_{2}$ can be represented by the sum of the previously discussed modcls as indicated by Equation (A-7.3):

$$
\dot{\varepsilon}=\frac{A_{1} \sigma}{G^{2}} \exp \left(-Q_{1} / R T\right)+A_{2} \sigma^{4.5} \exp \left(-Q_{2} / R T\right) .
$$

The constants $A_{1}, A_{2}, Q_{1}$, and $Q_{2}$ must be evaluated for both irradiated and unirradiated fuel. 


\subsection{Review of Published Creep Data}

The general form of the creep equation has been established from the theoretical models previously discussed. The constants in this equation must be evaluated and the grain size dependency must be verified.

Various techniques have been used to determine the creep rate of ceramics. These techniques include either three- or four-point bending tests, tension or compression of helical springs, and compression testing of cylinders. Each of these techniques induces different stresses in the $\mathrm{UO}_{2}$ specimens, and consequently the creep behavior changes with the technique used. Compressive creep of $\mathrm{UO}_{2}$ cylinders is preferred because this technique simulates more closely the conditions of stress induced in light water reactor fuel by fission product swelling, fuel thermal expansion, and cladding and fuel restraint. Although the other techniques are not considered representative and may not be appropriate for determining absolute creep rates, they are useful for determining the effects of different paramcters on the creep rate.

In this section, creep measurememts from. $\mathrm{UO}_{2}$ out-of-pile tests, $\mathrm{UO}_{2}$ in-pile tests, and mixed-oxide tests are discuseed and a summury and conclusions are given.

7.2.1 Out-of-Pile $\mathrm{UO}_{2}$ Creep Data. Scott et al ${ }^{[A-7.1 .0]}$ used a three-point-bend apparatus to determine the gross differences in the plastic flow properties of $95 \%$ dense stoichiometric and nonstoichiometric $\mathrm{UO}_{2}$. Stresses up to $48 \mathrm{MPa}$ and temperatures between 800 and $1700^{\circ} \mathrm{C}$ were used. They found that hyperstoichiometric $\mathrm{UO}_{2}$ can be deformed readily at $800^{\circ} \mathrm{C}$, but stoichiometric $\mathrm{UO}_{2}$ only becomes plastic above $1600^{\circ} \mathrm{C}$. The activation energy for viscous creep, $Q_{1}$, was estimated to be greater than $4 \times 10^{5} \mathrm{~J} / \mathrm{mol}$.

Armstrong et al ${ }^{[\mathrm{A}-7.4]}$ also used a three-point-bending test to detcrmine the plastic behavior of stoichiometric $\mathrm{UO}_{2}$ for temperatures between 1250 and $1400^{\circ} \mathrm{C}$ and stresses between 5 and $110 \mathrm{MPa}$. The influence of grain size $(6$ to $40 \mu \mathrm{m})$ and density $(0.933$ to 0.980 of theoretical) was also investigated. The creep curves exhibited instantancous elastic deflection upon application of the load follower by periods of primary and steady state creep. Tertiary creep was observed when samples exhibited strains greater than $1.5 \%$.

Creep rates decreased with an increase in the density of the $\mathrm{UO}_{2}$. This effect was noted for specimens sintered at $1650^{\circ} \mathrm{C}$, but not for specimens sintered at $1750^{\circ} \mathrm{C}$. Examination of microstructural features disclosed that materials sintered at lower temperatures have irregularly shaped porosity located predominately at grain boundaries; whereas materials sintered at higher temperatures exhibit porosity located primarily within the grains. The enhancement of creep by porosity for specimens sintered at $1650^{\circ} \mathrm{C}$ was attributed to grain boundary sliding induced by the pores at the grain boundaries.

Grain separation was observed in all the samples. Grain separation occurred predominately along grain boundaries lying transverse to the direction of fiber stresses and on the tension side of the neutral axis. Grain separation would not be expected during the compressive creep which is typical in reactor fuel. 
The effect of density and grain separation in these tests indicates that creep in bonding is not representative of the predominately compressive creep behavior during steady state irradiation of $\mathrm{UO}_{2}$.

Armstrong and Irvine ${ }^{[A-7.11]}$ also studied the creep deformation of nonstoichiometric $\mathrm{UU}_{2}$ by the three-poinl-bend method. Densities of 96 and $97.2 \%$ and grain sizes of 6 and $30 \mu \mathrm{m}$ were used. Desired oxygen-uranium ratios were obtained by equilibrating a $\mathrm{UO}_{2}$ specimen with $\mathrm{U}_{3} \mathrm{O}_{8}$ powder. Creep tests were conducted for temperatures between 975 and $1.350^{\circ} \mathrm{C}$, stresses up to $48 \mathrm{MPa}$, and oxygen-uranium ratios between 2.02 and 2.16 .

For the stress range studied, the creep rate was linearly proportional to stress, and the resultant activation energy (for oxygen-uranium ratios up to 2.08 ) was $2.33 \times 10^{5} \mathrm{~J} / \mathrm{mol}$, somewhat less than that for stoichiometric $\mathrm{UO}_{2}$. This result indicates that the activation energy may be dependent on the oxygen-uranium ratio for ratios up to 2.08 .

Grain boundary sliding occurred in nonstoichiometric as well as stoichiometric samples. This result supports the previous suggestions by Armstrong et al ${ }^{[A-7.4]}$ that grain boundary sliding must accompany the diffusion mechanism.

Poteat and Yust ${ }^{[A-7.5]}$ related fuel microstructure with the compressive creep deformation of $\mathrm{UO}_{2}$. Fine grain polycrystalline specimens were prepared in the form of right-circular cylinders with $97.5 \%$ theoretical density and an average grain size of $10 \mu \mathrm{m}$. Fine residual porosity was distributed uniformly on grain boundaries. Compressive creep data were obtained for temperatures between 1430 and $1666^{\circ} \mathrm{C}$ and for stresses between 14 and $76 \mathrm{MPa}$. Their $\mathrm{UO}_{2}$ samples exhibited two regimes of creep deformation, viscous creep with an approximate linear stress dependence and a power-law stress dependence. A least-squares analysis of the Poteat and Yust data [A-7.5] shows that the stress coefficicnt, $\mathrm{n}$, varies from 1.10 to 1.76 at low stresses and from 3.0 to 4.0 at high stresses. An estimate of the activation energy at $52 \mathrm{MPa}$ is $4.13 \times 10^{5} \mathrm{~J} / \mathrm{mol}$.

In a review of creep experiments performed up to 1967, Wolfe and Kaufman [A-7.12] reported additional data obtained from compression testing of $\mathrm{UO}_{2}$ cylinders. Temperatures varied from 1600 to $2000^{\circ} \mathrm{C}$ and stresses varied from 6.9 to $34.5 \mathrm{MPa}$. Samples with grain sizes of 18 and $55 \mu \mathrm{m}$ were used with densities of 97.5 and $98.5 \% \mathrm{TD}$, respectively.

Analysis of the stress dependence of the Wolfe and Kaufman creep rate data for different temperatures and grain sizes yields a stress exponent for the material with an $18-\mu \mathrm{m}$ grain size is 1.18 at $1800^{\circ} \mathrm{C}$. The stress exponent of the $55-\mu \mathrm{m}$ material is 4.72 at $1800^{\circ} \mathrm{C}$ and 3.58 at $2000^{\circ} \mathrm{C}$. The 1.18 value corresponds to the values expected for viscous creep. The $55-\mu \mathrm{m}$ grain size material stress exponents are near the 4.5 value expected for dislocation creep. However, because of the large grain size of $55 \mu \mathrm{m}$, a different mechanism may be occurring. The activation energy for the $55-\mu \mathrm{m}$ material at $20 \mathrm{MPa}$ is $3 \times 10^{5} \mathrm{~J} / \mathrm{mol}$. Again, this value is lower than the values between $3.7 \times 10^{5}$ and $4.2 \times 10^{5} \mathrm{~J}$ determined by other investigators for small grain material. Therefore, the creep models discussed previously may not be applicable for materials with grain sizes larger than about $40 \mu \mathrm{m}$. 
Bohaboy et al ${ }^{[\mathrm{A}-7.13]}$ performed compressive creep tests on stoichiometric $\mathrm{UO}_{2}$ as a function of temperature $\left(1400\right.$ to $\left.1760^{\circ} \mathrm{C}\right)$, stress $(6.9$ to $100 \mathrm{MPa})$, grain size (4 to $\left.35 \mu \mathrm{m}\right)$, and theoretical density ( 92 to $98 \%$ theroretical). Bohaboy et al, like Armstrong, found that at low applied stresses their measured creep rates were nearly proportional to stress and inversely proportional to the square of the grain size. These results arc consistent with the viscous creep model proposed by Naborro ${ }^{[A-7.1]}$ and Herring $[$ A-7.2]. The activation energy was found to be $3.7 \times 10^{5} \mathrm{~J} / \mathrm{mol}$ and compatible with values for self-diffusion of uranium in $\mathrm{UO}_{2}$. The crcep rate increased with a decrease in theoretical density.

The creep rates at stress values greater than $55 \mathrm{MPa}$ were reported by Bohaboy et al to be proportional to the stress raised to the 4.5 power. The activation energy for the high stress mechanism was reported to be $5.5 \times 10^{5} \mathrm{~J} / \mathrm{mol}$, considerably higher than values for self-diffusion in $\mathrm{UO}_{2}$. No correlation between grain size and deformation rate was found in this regime.

Bohaboy et al fit the constants in Equation (A-7.3) to their data and obtained the following equation $[\mathrm{a}]$ :

$$
\begin{aligned}
\varepsilon= & \left(\frac{3.919 \times 10^{5}}{(0-87.7) G^{7}}\right) \sigma \exp (-377000 / R T)+\left(\frac{203.7}{(0-.90 .5)}\right) \sigma^{4.5} \\
& \exp (-552550 / R T)
\end{aligned}
$$

where

$$
\begin{aligned}
\dot{\boldsymbol{\epsilon}} & =\text { creep rate }\left(\mathrm{s}^{-1}\right) \\
\mathrm{G} & =\text { grain size }(\mu \mathrm{m}) \\
\sigma & =\operatorname{stress}(\mathrm{MPa}) \\
\mathrm{R} & =\text { gas constant }(8.314 \mathrm{~J} / \mathrm{mol} \cdot \mathrm{K}) \\
\mathrm{T} & =\text { temperature }(\mathrm{K}) .
\end{aligned}
$$

7.2.2 Transition Stress. Wolfe and Kaufman [A-7.12] suggested that the stress at which the transition from viscous creep to power-law creep occurs is only weakly dependent upon temperature, but strongly affected by grain size. Seltzer et al $[A-7.14, A-7.15]$, performed an analysis of the transition stress and prescnted circumstantial evidence for a power-law creep rate with a 4.5 stress coefficient and a viscous creep rate with an inverse dependence on the square of the grain size. $\Lambda t$ the transition, Equations (A-7.1) and (A-7.2) can be written:

[a] The constants in this equation agree with those in the reference, however, here they have been converted to SI units. 


$$
\frac{A_{1} \sigma}{G^{2}} \exp \left(-Q_{1} / R T\right)=A_{2} \sigma^{4.5} \exp \left(-\Omega_{2} / R T\right)
$$

Equation (A-7.5) can be put in more general terms by letting $\mathrm{n}$ replace the exponent on stress and $m$ replace the exponent on grain size. Solving for the stress at the transition:

$$
\sigma_{t}=\left(\frac{A_{2}}{A_{1}}\right)^{n-1} G^{\dot{m} / 1-n} \exp \left[-\left(Q_{2}-Q_{1}\right) / R T\right]
$$

If the activation energies, $Q_{2}$ and $Q_{1}$, are about the same magnitude, the temperature dependence of $\sigma_{\mathrm{t}}$ would be expected to be small and can be ignored.

Table A-7.l summarizes the values of $m /(1-n)$ from various possible values of $m$ and $n$.

TARI.E A-7,I

VALUES OF $m /(1-n)$ FROM POSSIBLE VALUES OF $m$ AND $n$

\begin{tabular}{llllll}
$m$ & $\frac{n=2}{2}$ & $\frac{n=3}{n}$ & $\frac{n=4}{n}$ & $\frac{n=4.5}{n}$ & -5 \\
3 & -2 & -1.0 & -0.667 & -0.571 & -0.50 \\
\hline
\end{tabular}

A plot of the logarithm of the transition stress versus the logarithm of the grain size results in a slope equal to $m /(1-n)$. Seltzer $[A-7.14]$ plotted the transition stress for compression testing versus grain size obtained from Poteat and Yust $[A-7.5]$, Wolfe and Kaufman $[$ A-7.12], and Bohaboy and Asamato $[A-7.16]$. As indicated in Figure A-7.1, a slope of -0.61 resulted from a least squares fit of the data. Comparison of this value with those in Table A-7.I shows that the assumption of grain size to the second power i.e. $m=2$ and a value of $n$ between 4 and 4.5 for the strain exponent in Equation (A-7.5) are consistent with this result. However, the results from bend tests (Figure A-7.1) indicate that the transition stress is not a function of grain size. These results are inconsistent with theoretical predictions and with previous experimental results.

Burton and Reynolds $[\mathrm{A}-7.17, \mathrm{~A}-7.18]$ have studied the creep behavior of $\mathrm{UO}_{2}$ as a function of grain size and stoichiometry. Compressive crecp tests were employed with either cylindrical pellets or with helical springs with square cross sections. The $\mathrm{UO}_{2}$ samples used for the stoichiometric tests had grain sizes of 7 and $17 \mu \mathrm{m}$ and were $97 \%$ of theoretical density. Control of the stoichiometry was obtained by equilibrating $\mathrm{CO}-\mathrm{CO}_{2}$ mixtures with the oxide specimens. Specimens tested to determine the effect of grain size on the $\mathrm{UO}_{2}$ creep were annealed for various times to obtain the desired grain sizes.

The stoichiometric samples showed a transition at about $69 \mathrm{MPa}$ above which the creep was controlled by dislocation motion. Below the transition, the stress dependence of the creep rate diminished as the diffusional creep made an increasing contribution. The occurrence of this threshold stress in Burton and Reynold's work seems dubious because 


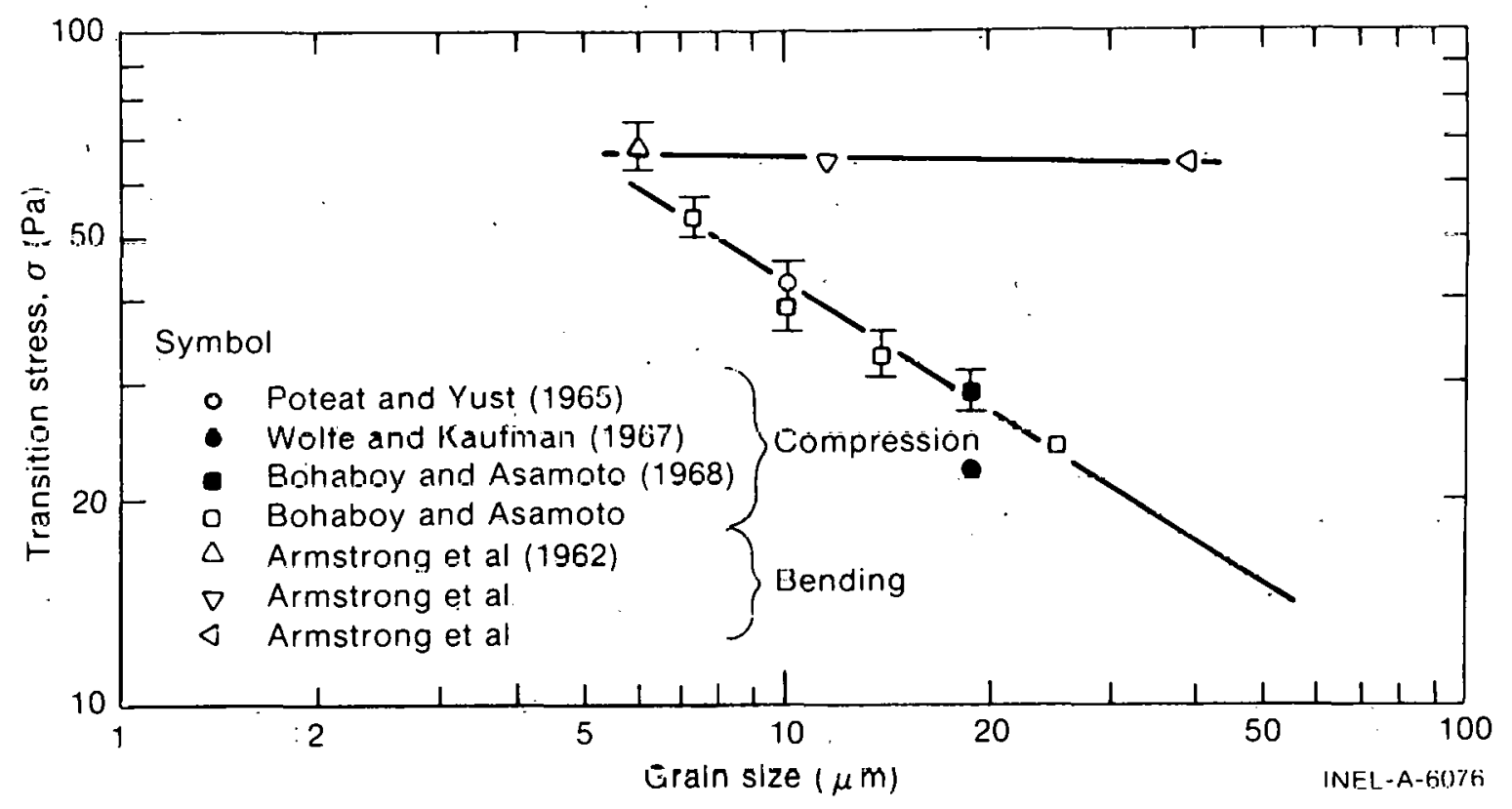

- Fig. A-7.1 Transition stress as a function of grain size. .

they did not distinguish between their different testing techniques. Qualitatively, the thrcshold stress seems to occur in the region of very low creep ratcs where the helical spring samples were probably used (with grain sizes larger than those of the cylindrical creep samples)

7.2.3 In-Pile $\mathrm{UO}_{2}$ Creep Data. Fission-induced creep test of $\mathrm{UO}_{2}$ samples at temperatures less than $900^{\circ} \mathrm{C}$ have been performed by Sykes and Sawbridge ${ }^{[A-7.19]}$, Clough[A-7.20], Brucklacher and Dienst $[A-7.21]$, and Solomon and Gebner $[A-7.22]$. In-pile creep measurcments were also performed by Perrin $[A-7.23]$ at higher temperatures between 1110 and $1215^{\circ} \mathrm{C}$. All thesc measurements have been summarized by Solomon et al $[\mathrm{A}-7.24]$. The test conditions are summarized in Table A-7.II.

Solomon et al ${ }^{[A-7.24]}$ concluded, on the basis of the data, that the in-pile creep of $\mathrm{UU}_{2}$ consists of (a) an elevated temperature regime, in which a normal thermal creep mechanism is enhanced, and (b) a low temperature regime, in which the fission process induccs significant tcmperature indeperident ireep.

The results at temperatures less than $900^{\circ} \mathrm{C}$ indicate that the creep rate is linearly proportional to fission rate and to stress. As shown in Figure A-7.2, all the data appeared to lie within a broad scatter band that is insensitive to temperature at tempcratures bclow about $1400 \mathrm{~K}$. The evidence was insufficient to determine whether that scatter is due primarily to variations of material properties (density, grain size, stoichiometry, and impurity concentration) or test conditions (temperature, stress, and fission rate). In accounting for the experimental uncertainties, Solomon concluded that material variations probably influenced the fission-induced creep.

A linear regression analysis of the data in Figure A-7.2 results in an activation energy of $3 \times 10^{5} \mathrm{~J} / \mathrm{mol}$ for Perrin's data and $-9210 \mathrm{~J} / \mathrm{mol}$ for the remaining data. The 
TABLE A-7. II

TEST CONDITIONS AND FUEL ROD CHARACTERISTICS OF LOW TEMPERATURE IN-REACTOR $\mathrm{UO}_{2}$ CREEP EXPERIMENTS

\begin{tabular}{|c|c|c|c|c|c|c|c|}
\hline Reference & Test & $\begin{array}{c}\text { Grain } \\
\text { Size }(\mu \mathrm{m}) \\
\end{array}$ & $\begin{array}{l}\text { Density } \\
(\% \text { TD })\end{array}$ & $\begin{array}{l}\text { Stoichi- } \\
\text { ometry }\end{array}$ & $\begin{array}{l}\text { Fission Rate } \\
\left.\text { (fissions } / \mathrm{m}^{3} \cdot \mathrm{s}\right)\end{array}$ & $\begin{array}{l}\text { Temperature } \\
\left({ }^{\circ} \mathrm{C}\right) \\
\end{array}$ & Stress (MPa) \\
\hline $\begin{array}{l}\text { Sykes and } \\
\text { Sawbridge }\end{array}$ & $\begin{array}{l}\text { Compression of } \\
\text { helical springs }\end{array}$ & 8 to 10 & $>97.5$ & - & 0.08 to $0.17 \times 10^{19}$ & 525 to 880 & 6 to 12.5 \\
\hline $\begin{array}{l}\text { Brucklacher and } \\
\text { Dienst }\end{array}$ & $\begin{array}{l}\text { Compression } \\
\text { disks }\end{array}$ & 30 to 40 & 95 & - & $11.8 \times 10^{19}$ & 400 to 600 & 7.8 to 17.7 \\
\hline Clough & $\begin{array}{l}\text { Three-point } \\
\text { bend }\end{array}$ & 8 to 10 & 96 to 97 & 2.0005 & 0.82 to $1.6 \times 10^{19}$ & 595 to 650 & 26.4 to 30.5 \\
\hline $\begin{array}{l}\text { Solomon and } \\
\text { Gebner }\end{array}$ & $\begin{array}{l}\text { Tension helical } \\
\text { springs }\end{array}$ & 22 & 96 & 2.000 & $0.26 \times 10^{19}$ & 110 & 34.5 \\
\hline
\end{tabular}




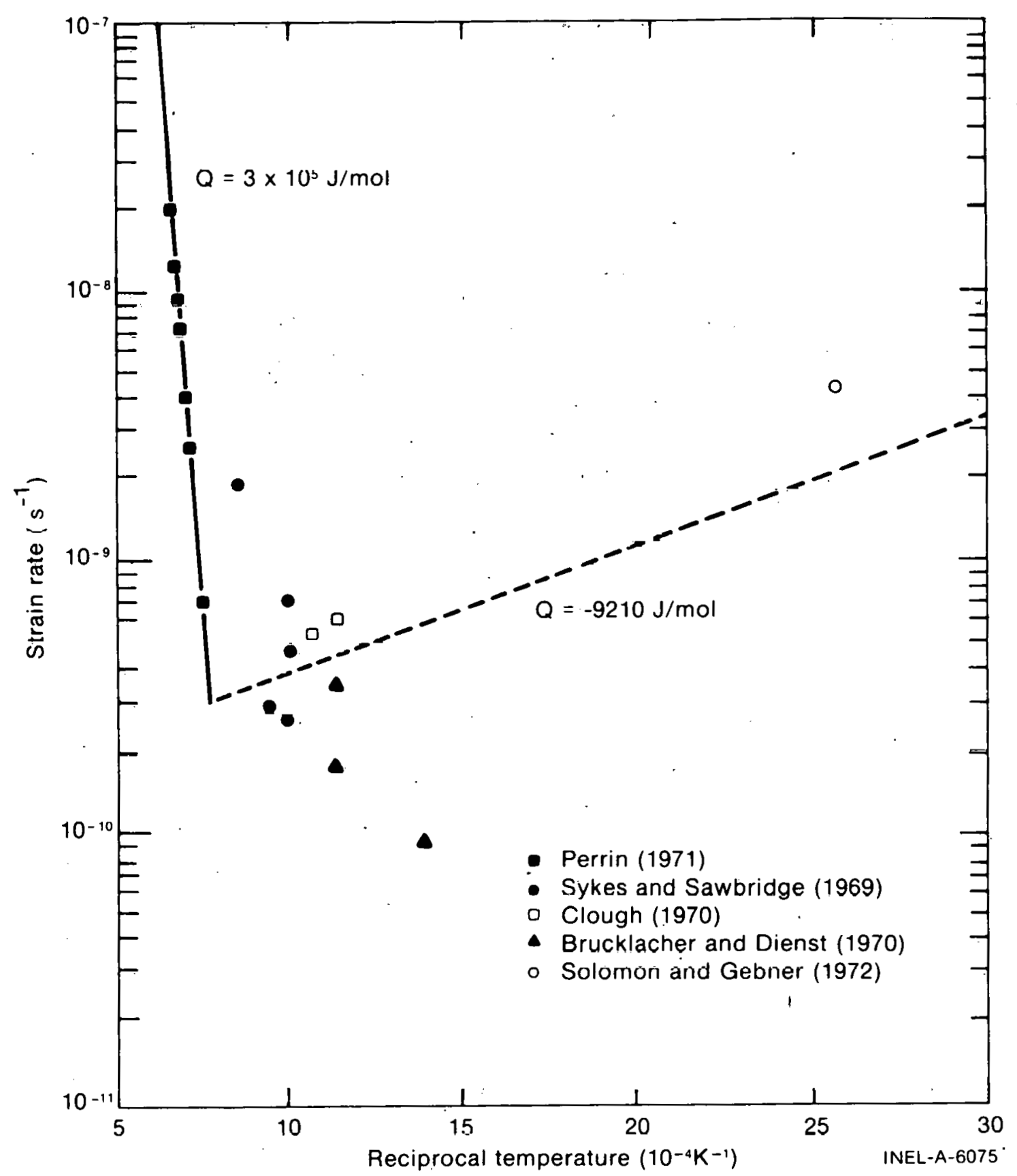

Fig. A-7.2 Arrhenius plot of irradiated $\mathrm{UO}_{2}$ creep normalized to a fission rate of $10^{19}$ fissions $/ \mathrm{m}^{3}: \mathrm{s}$.

$3 \times 10^{5} \mathrm{~J} / \mathrm{mol}$ value is near that for thermal creep in the viscous regime. The $-9210 \mathrm{~J} / \mathrm{mol}$ value indicates a relatively temperature-insensitive creep rate, but it cannot be considered very credible because it was determined from data obtained by different testing techniques and from materials with significant grain size and density variations.

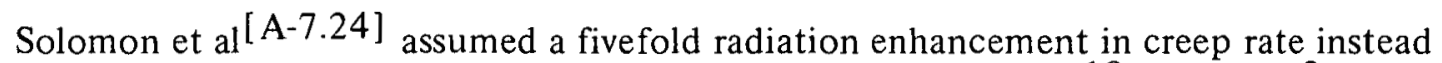
of the fourfold increase reported by Perrin at a fission rate of $1.2 \times 10^{19}$ fissions $/ \mathrm{m}^{3} \cdot \mathrm{s}$. The fivefold increase was also assumed at higher stresses for which dislocation creep occurs and for which no experimental data are available. 
Brucklacher et al ${ }^{[A-7.25]}$ measured the creep rate of stoichiometric $\mathrm{UO}_{2}$ with a density of $96 \%$ TD and a grain size of $10 \mu \mathrm{m}$. At a constant fission rate the fuel temperature was varied from 250 to $500^{\circ} \mathrm{C}$. The sample was compressively loaded with stresses from 1 to 38.6 MPa. The uranium fission rate was $1.5 \times 10^{20}$ fissions $/ \mathrm{m}^{3} \cdot \mathrm{s}$ up to $2.5 \%$ uranium burnup and $8.2 \times 10^{19}$ fissions $/ \mathrm{m}^{3} \cdot \mathrm{s}$ up to a maximum $8.5 \%$ burnup.

For burnups up to $2.5 \%$, the irradiation-induced creep rate measured by Brucklacher et al depended linearly on the stress and increased slightly with increasing temperature. (The latter result is different than that of Solomon et al [A-7.24].) An activation energy of $2.18 \times 10^{4} \mathrm{~J} / \mathrm{mol}$ was obtained from the Brucklacher et al irradiation-induccd creep data. This very low activation energy suggests a nearly temperature-independent creep rate. However, since the activation energy reported by Brucklacher et al was determined using materials with the same grain size and density, the value of $2.18 \times 10^{4} \mathrm{~J} / \mathrm{mol}$ is probably more credible than the value discussed previously and indicated in Figure A-7.2.

For burnups between 3 and 4\%, the stress exponent determined from the data of Brucklacher el al was reported to increase from 1 to 1.5 . This change was attributed to a possible change in creep mechanism.

7.2.4 Out-of-pile and In-pile Mixed Oxide Creep Data. Vollath ${ }^{[A-7.26]}$ reported compressive creep measurements on mechanically mixed oxide pellets of two compositions: $19.5 \mathrm{wt} \% \mathrm{PuO}_{2}$ and $19.4 \mathrm{wt} \% \mathrm{PuO}_{2}$; with densities of $94 \% \mathrm{TD}$ and $95.5 \% \mathrm{TD}$, respectively. Grain size was $10 \mu \mathrm{m}$ for both materials. Test temperatures were between 1100 and $1700^{\circ} \mathrm{C}$ and stresses were between 4.8 and $48 \mathrm{MPa}$. The fuel stoichiometry was 1.94 .

Slagle $[\mathrm{A}-7.27]$ measured the high temperature creep of coprecipitated $\mathrm{UO}_{2}-20 \mathrm{wt} \% \mathrm{PuO}_{2}$ pellets. One series of tests used pellets with a density of $90.5 \pm 1.0 \%$ and a grain size of $4 \mu \mathrm{m}$. Another series of tests used pellets with a density of $96 \pm 0.5 \%$ and a grain size of $17 \mu \mathrm{m}$.

The creep measurements were performed under constant load in a four-point-bend apparatus with maximum stresses and strain rates computed from elastic theory. For the $90.5 \%$ theoretical density material the stress exponent was found to be 2.38 at $1400^{\circ} \mathrm{C}$ and 2.35 at $1300^{\circ} \mathrm{C}$, with an activation energy of $5.15 \times 10^{5} \mathrm{~J} / \mathrm{mol}$. For a slightly more dense material (91\% TD), stress exponents of 1.97 at $1400^{\circ} \mathrm{C}$ and 2.21 at $1300^{\circ} \mathrm{C}$ were determined. These exponents are slightly higher than the value expecled for viscous creep. For the $96 \%$ material, the stress exponents varied from 1.14 to 1.53 . These values are in better agreement with the viscous creep model. The analysis of the temperature dependence of the creep of the $96 \%$ dense material resulted in an activation energy of $4.6 \times 10^{5} \mathrm{~J} / \mathrm{mol}$.

Difficulty was encountered by Slagle in obtaining reproducible strain rates on the same sample when the order of loading the sample was varied. The difficulty in getting reproducibility and the high values for the stress exponents place some doubts on the credibility of these experiments. 
Creep experiments on irradiated and unirradiated mixed oxide fuel have been reported by Perrin $[\mathrm{A}-7.28]$. The samples were fabricated from mechanically mixed $\mathrm{UO}_{2}$ and $22 \mathrm{wt} \% \mathrm{PuO}_{2}$ powder and sintered to yield pellets with $95 \%$ theoretical density, a 3- to 5- $\mu \mathrm{m}$ grain size, and an oxygen-metal ratio of 1.98 . The samples were tested compressively at temperatures from 910 to $1125^{\circ} \mathrm{C}$, stresses of $13.8 \mathrm{MPa}$, and fission rates from 0.7 to $1.2 \times 10^{19}$ fissions $/ \mathrm{m}^{3} \cdot \mathrm{s}$.

These experiments indicate that the irradiation-enhanced creep rate of mixed oxide fuel is linearly dependent upon fission rate. Perrin compared his in-pile mixed oxide results with in-pile and out-of-pile $\mathrm{UO}_{2}$ creep data and suggested that at low temperatures the in-pile creep rate of :mixed oxides is either athermal, or only moderately dependent on temperature, and at high. temperatures the in-pile creep rate is strongly dependent on temperature with an'activation energy of the order of the out-of-pile creep data. Perrin reported that for the same stress and temperature conditions and a fission rate of $10^{19}$ fissions $/ \mathrm{m}^{3} \cdot \mathrm{s}$, the in-pile creep rate is enhanced by a factor of about 30 over that of unirradlated mixed oxides. However; some of the data indicated an enhancement of only a factor of about nine.

Evans et al $[$ A-7.29] have performed compressive creep tests on coprecipitated mixed oxide fuel containing 10,20 , and $30 \mathrm{wt}^{\circ} \mathrm{PuO}_{2}$ and mcchanically mixed and sintered pellets containing $20 \mathrm{wt} \% \mathrm{PuO}_{2}$. The characteristics of the samples are listcd in Tablc A-7.III. The experiments were performed to determine the effects of density, stoichiometry, composition, grain size, and homogeneity on the compressive creep behavior. The data were analyzed using Equation.(A-7.3).

The -effect. of density was found to be much weaker at high stresses than at low stresses. This effect was attributed to grain boundary sliding which would be enhanced by grain boundary porosity.

The effect of stoichiometry on the steady state creep deformation was very pronounced. An eightfold decrease in creep rate occurred when the stoichiometry decreased frum 2.00 to 1:95. This decrease was simflar in both low. and high stress regions and was attributed to a decrease in metal vacancies as anion vacancies increase (when the stoichiometry decreases from 2.00 to 1.95 ):

The effect of the $\mathrm{PuO}_{2}$ concentration was to increase the creep rate as the plutonium content increased. The degree of softening appeared to be similar in both the low and high stress regions. The plutonium composition did seem to complicate the activation energy. For example, the activation. energies for pure $\mathrm{PuO}_{2}$ were notably smaller than for $\left.\mathrm{U}_{0.8}, \mathrm{Pu}_{0.2}\right) \mathrm{O}_{2}$, being $2.9 \times 10^{5} \mathrm{~J} / \mathrm{mol}$ and $4.2 \times 10^{5} \mathrm{~J} / \mathrm{mol}$ in the low and high stress regions, respectively, for pure $\mathrm{PuO}_{2}$.

A comparison of coprecipitated fuel with mechanically mixed fuel could not be made. The mechanically mixed material contained regions of widely different grain sizes. Because of the different grain sizes, the creep behavior could not be correlated. 
TABLE A-7. III

PROPERTIES OF SINTERED PELLETS USED BY EVANS ET AL ${ }^{\text {[a] }}$

\begin{tabular}{|c|c|c|c|c|}
\hline $\begin{array}{l}\text { Composition } \\
\text { (wt\% Pu) } \\
\end{array}$ & $\begin{array}{c}\text { Density } \\
\text { Range (\%TD) } \\
\end{array}$ & $\begin{array}{l}\text { Approximate } \\
\text { Grain Size }(\mu \mathrm{m}) \\
\end{array}$ & $\begin{array}{l}\text { Sintered Stoichiometry } \\
\text { Oxygen-Metal Ratio } \pm 0 .[1 \\
\end{array}$ & $\begin{array}{l}\text { Test Stoichiometry } \\
\text { Oxygen-idetal Ratio } \pm 0.01\end{array}$ \\
\hline 10 & 93.5 to 94.5 & 20 & 1.98 & 1.98 \\
\hline 20 & 94.5 to 95.5 & 20 & 1.98 & 1.95 \\
\hline 20 & 92.5 to 94.0 & 22 & 1.98 and 2.00 & 1.95 and 2.00 \\
\hline 20 & 88.0 to 91.0 & 22 & 1.98 and 2.00 & 1.95 and 2.00 \\
\hline 20 & 93.8 & 4 & 1.98 & 1.95 \\
\hline 30 & 93.0 to 94.0 & 18 & 1.97 & 1.95 \\
\hline 100 & 93.0 & 31 & 1.78 & 1.78 \\
\hline $\begin{array}{l}\text { Physically } \\
\text { Mixed }\end{array}$ & 95.0 & 12 & 2.00 & $2.00^{\circ}$ \\
\hline
\end{tabular}


Evans et al $[A-7.29]$ described the creep data for mixed oxide fuel with an oxygen-metal ratio of 1.95 to 1.96 by the following equation:

$$
\dot{\varepsilon}=A \sigma \exp (-418600 / R T)+B \sigma{ }^{4.5} \exp (-586000 / R T)
$$

where

$$
\begin{aligned}
& \dot{\epsilon}=\text { steady state creep rate }(\mathrm{m} / \mathrm{m} \cdot \mathrm{s}) \\
& A \quad=1.25 \times 10^{6} \exp [33.3(1-\mathrm{D})] \exp \left(3.56 \mathrm{C} / \mathrm{G}^{3}\right) \\
& \mathrm{B} \quad=\quad 647 \exp [10.3(1-\mathrm{D})] \exp (3.56 \mathrm{C}) \\
& \sigma \quad=\quad \text { compressive stress }(6.9 \text { to } 69 \mathrm{MPa}) \\
& \mathrm{R} \quad=\quad 8.314 \mathrm{~J} / \mathrm{mol} \cdot \mathrm{K} \\
& \mathrm{T} \quad=. . \quad \text { temperature }(1473 \text { to } 1898 \mathrm{~K}) \\
& \mathrm{D} \quad=\quad \text { fractional density }(0.86 \mathrm{to} 0.95 \mathrm{TD}) \\
& \mathrm{G} \quad-\quad \text { grain size }(4 \text { lo } 35 \mu \mathrm{m}) \\
& \mathrm{C} \quad=\quad \text { Pu/(Pu }+\mathrm{U}),(0.2 \text { to } 0.3) .
\end{aligned}
$$

Routbort et al ${ }^{[A-7.30]}$ performed compressive creep tests on mechanically mixed oxide fuel containing $25 \mathrm{wt} \% \mathrm{PuO}_{2}$ to determine the effects of grain size, stress, temperature, and oxygen-metal ratio. Two batches of matcrial were used. One batch contained $93 \%{ }^{235} \mathrm{U}$ with a grain size of $20 \mu \mathrm{m}$ and a density. of $93 \% \pm 0.5 \%$ of theoretical. The other batch contained $65 \% 235 U$ with a grain size of $10 \mu \mathrm{m}$ and density of $95 \% \pm 0.5 \%$ TD. The pellets from both batches had a nonhomogeneous grain size distribution with the average grain size in the peripheral arcas of the pellets heing smaller hy a faritnr of twn to three than the central grains. Stoichiometry was controlled by equilibrating.specimens with different mixtures of hydrogen and water vapor. Tests for oxygen-metal ratios of about 2.00 were performed by equilibrating the samples with $\mathrm{CO}-\mathrm{CO}_{2}$ mixtures.

The creep rate as a function of stress exhibited two regions: a viscous creep region at low stresses $(\epsilon \propto \sigma)$ and a power-law creep region $\left(\epsilon \propto \sigma^{n}\right)$ where $n$ was found to be 4.4. An Arrhenius plot indicated that the creep deformation in the viscous region was thermally activated with an activation energy of $(3.88 \pm 0.13) \times 10^{5} \mathrm{~J} / \mathrm{mol}$. Similarly, the Arrhenius plot for the high stress region yielded an activation energy of $(5.73 \pm 0.22) \times 10^{5} \mathrm{~J} / \mathrm{mol}$.

The creep rate was found to be inversely proportional to the square of the grain size. Thus, this effect indicated that lattice diffusion was involved rather than the grain boundary diffusion reported by Evans et al ${ }^{[A-7.29]}$. (Six data points were used in this analysis 
compared to three in Evan's analysis, so that Routbort's analysis appears to bc morc credible on the basis of sample size.) The analysis performed by Routbort ${ }^{[A-7.30]}$ based upon the transition stress and the grain size resulted in a ratio $\mathrm{m} / \mathrm{n}-1$ of 0.51 , compared with the theoretical valuc of 0.57 for the stress exponent of 4.5 and $m=2$. (A theoretical value of 0.86 results from the stress exponent of 4.5 and $m=3$.) Therefore, the creep rate as a function of the reciprocal of the square of grain size seems to he a more appropriate relationship for mixed oxides.

The effect of the oxygen-metal ratio on the creep rate was very complex. At 1650 and $1550^{\circ} \mathrm{C}$ in the low stress region, the creep rate decreased with a decrease in oxygen-metal ratio to a minimum at an oxygen-metal ratio of 1.94 to 1.96 , respectively. The creep rate then increased with further reductions in the oxygen-metal ratio. As the temperature was further reduced to $1400^{\circ} \mathrm{C}$, this trend was not followed. The creep rate increased as the oxygen-metal ratio decreased in the range 2.0 to 1.9. The oxygen-metal ratio did not affect the stress dependency, but the activation cncrgies did vary with the oxygen-metal ratio in a complicated fashion.

Routbort $^{[A-7.30]}$ proposed an equation similar in form to Equation (A-7.4) to describe the creep rate of $\mathrm{UO}_{2}-25$ wt $\% \mathrm{PuO}_{2}$ fuel pellets with an oxygen-metal ratio of 1.97 .

7.2.5 Summary of Experimental Data Review. Two different thermal creep mechanisms have been observed. A viscous creep mechanism with some grain boundary sliding operates at low stressses and the creep rate at low stresses is linearly proportional to stress. A mechanism based upon dislocation climb operates at high stresses and the creep rate at high stresses is proportional to the stress raised to about the 4.5 power. The transition stress from viscous creep to dislocation creep is a function of grain size but not temperature.

In the viscous creep regime, creep rate is inversely proportional to the square of grain size and results from lattice diffusion. The reported activation energy for this process varied between $3.7 \times 10^{5}$ and $4.2 \times 10^{5} \mathrm{~J} / \mathrm{mol}$. The only value for the activation energy for the high stress mechanism was reported by Bohaboy to be $552550 \mathrm{~J} / \mathrm{mol}$.

During irradiation, the fission process enhances the thermal creep mechanisms at high temperatures and induces creep at low temperatures where out-of-pile thermal creep normally does not occur.

In the viscous regime, the thermal creep rate is enhanced by a factor of four to five and the activation energy is nearly that of unirradiated fuel. No data are available for the creep enhancement in the dislocation controlled regime. The same creep enhancement in the viscous regime was assumed by Solomon et al ${ }^{[A-7.24]}$ in the dislocation controlled regime but no data exist to substantiate this assumption.

The fission-induced creep rate has been found to be linearly proportional to stress and fission rate. Early. experimenters reported the process to be athermal, but suggested that the 
temperature dependency could be maskcd by material variations. Later, Brucklacher $[A-7.25]$ reported a slightly temperature-dependent process with an activation energy of $2.18 \times 10^{4} \mathrm{~J} / \mathrm{mol}$. Available data are not sufficient to determine the effects of material properties such as grain size and density on the irradiation-induced creep of $\mathrm{UO}_{2}$.

The creep rate of mixed oxides exhibits behavior similar to that observed for $\mathrm{UO}_{2}$. The creep rate is controlled by viscous creep at low stresses with an activation energy between $3.7 \times 10^{5}$ and $5.23 \times 10^{5} \mathrm{~J} / \mathrm{mol}$, and is controlled by dislocation creep at high stresses with an activation cnergy between $5.7 \times 10^{5}$ and $7.3 \times 10^{5} \mathrm{~J} / \mathrm{m}$ nol, and stress exponent of 4.5. The creep rate is inversely proportional to the square of grain size in the viscous regime, and is enhanced by irradiation by a factor of about 9 to 30 in the viscous regime, but data are unavailable to quantify the effect of fission-induced creep at low temperalures or fission-enhanced creep in the dislocation controlled region at high stresses.

\subsection{Fuel Creep Model}

The FCREEP subroutine incorporates the model proposed by Bohaboy et al [A-7.13] with the modifications suggested by Solomon et al [A-7.24] for fission-enhanced and fission-induced creep. The fission-induced creep constant proposed by Solomon et al has been changed slightly to reflect the slight temperature dependence of fission-induced creep. Also, the model has been changed to remove the temperature dependence in the transition from viscous creep to dislocation controlled creep. Irradiation-enhanced creep in the dislocation controlled regime is not assumed in FCREEP due to the lack of data. The following equation is used to calculate $\mathrm{UO}_{2}$ creep:

$$
\dot{c}=\frac{\left(A_{1}+A_{2} \dot{F}\right) \sigma \exp \left(-Q_{1} / R T\right)}{\left(A_{3}+D\right) G^{2}}+\frac{A_{4} \sigma^{4.5} \exp \left(-Q_{2} / R T\right)}{\left(A_{6}+D\right)}+A_{7} \sigma \dot{F} \exp \left(-Q_{3} / R T\right) .
$$

where

$$
\begin{aligned}
& \dot{\epsilon}=\text { creep rate }\left(\mathrm{s}^{-1}\right) \\
& \mathrm{A}_{1}=3.919 \times 10^{5} \\
& \mathrm{~A}_{2}=1.305 \times 10^{-13} \\
& \mathrm{~A}_{3}=-87.7 \\
& \mathrm{~A}_{4}=203.7 \\
& \mathrm{~A}_{6}=-90.5 \\
& \mathrm{~A}_{7}=3.723 \times 10^{-29} \\
& \mathrm{Q}_{1}=376740(\mathrm{~J} / \mathrm{mol})
\end{aligned}
$$




$$
\begin{aligned}
& \mathrm{Q}_{2}=552552(\mathrm{~J} / \mathrm{mol}) \\
& \mathrm{Q}_{3}=21767(\mathrm{~J} / \mathrm{mol}) \\
& \dot{\mathrm{F}}=\text { fission rate }\left(8.4 \times 10^{17} \text { to } 1.18 \times 10^{20} \text { fissions } / \mathrm{m}^{3} \cdot \mathrm{s}\right) \\
& \sigma \quad=\quad \text { stress }(6.9 \text { to } 69 \mathrm{MPa}) \\
& \mathrm{R} \quad=\quad \text { gas constant }(8.314 \mathrm{~J} / \mathrm{mol} \cdot \mathrm{K}) \\
& \mathrm{T} \quad=\text { temperature }(713 \mathrm{to} 2073 \mathrm{~K}) \\
& \mathrm{D}=\text { density }(0.92 \text { to } 0.98 \mathrm{TD}) \\
& \mathrm{G} \quad=\text { grain size }(4 \text { to } 35 \mu \mathrm{m}) \text {, and stoichiometry }(2.00 \text { to } 2.01) .
\end{aligned}
$$

The transition stress is given by the following expression:

$$
\sigma_{\text {trans }}=165.5 G^{-0.5714}
$$

where

$$
\begin{array}{ll}
\sigma_{\text {trans }} & =\text { transition stress }(\mathrm{MPa}) \\
\mathrm{G} & =\quad \text { grain size }(\mu \mathrm{m}) .
\end{array}
$$

When the stress is less than $\sigma_{\text {trans' }}$ the actual stresses are used in the first term of Equation (A-7.8); for stresses greater than $\sigma_{\text {trans }}$, the transition stress is used in the first term.

The predictions of FCREEP are compared in Figure A-7.3 with experimental data selected from out-of-pile compressive creep experiments for unirradiated stoichiometric $\mathrm{UO}_{2}$ and from available experiments for irradiated stoichiometric $\mathrm{UO}_{2}$. This comparison includes data from Bohaboy et al ${ }^{[A-7.13]}$, Poteat and Yust ${ }^{[A-7.5]}$. Perrin ${ }^{[A-7.23]}$, and Wolfe and Kaufman $[A-7.12]$ for unirradiated $U_{2}$ and from Sykes and Sawbridge $[A-7.19]$, Clough[A-7.20], Solomon and Gebner[A-7.22], Brucklacher and Dienst[A-7.21] as reported by Solomon et al $[A-7.24]$ and Perrin $[A-7.23]$ for irradiated fuel. Data from Burton and Reynolds $[\mathrm{A}-7.17, \mathrm{~A}-7.18]$ are not included because of the uncertainty in separating their compressive pellet data from their helical spring data. Good agreement was obtained among all these data except the data from Poted and Yust $[\mathrm{A}-7.5]$ in the high stress region, data for the $55-\mu \mathrm{m}$ material used by Wolfe and Kaufman $[\mathrm{A}-7.12]$, and data from Perrin ${ }^{[A-7.23]}$ for unirradiated fuel. Although the discrepancy in the high stress data of Poteat and Yust ${ }^{[A-7.5]}$ and the data for the large grain size material used by Wolfe and Kaufman is less than an order of magnitude; the discrepancy in the unirradiated data of Perrin is about two orders of magnitude. No explanation is available for this discrepancy. 


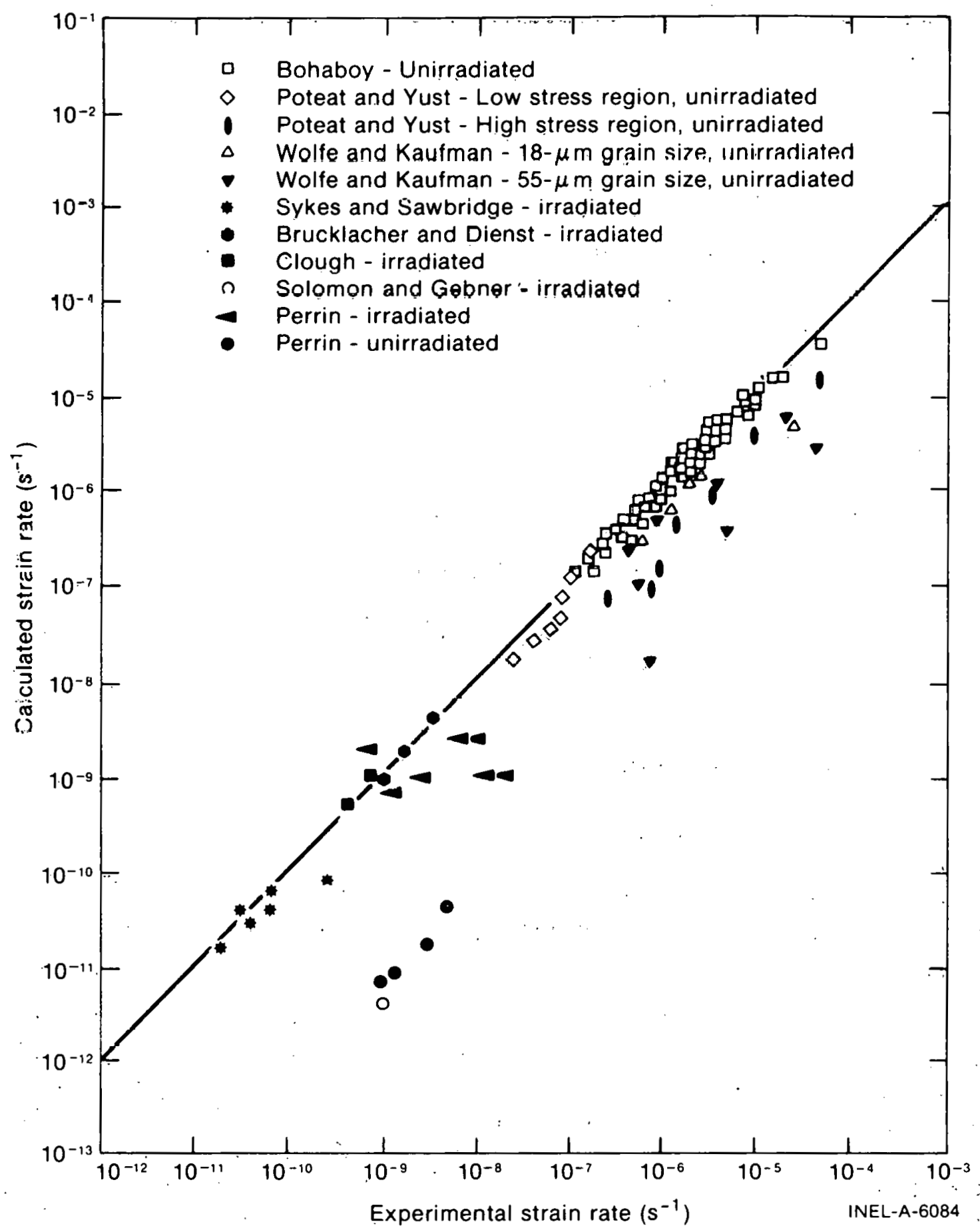

Fig. A-7.3 Comparison of irradiated and unirradiated $\mathrm{UO}_{2}$ experimental data with corresponding calculated values from FCREEP.

The solid line shown in Figure A-7.3 would result if there was perfect agreement between experimental and calculated values.

For the creep of mixed oxides, the equation suggested by Evans et al [A-7.29] is adopted with modifications similar to the $\mathrm{UO}_{2}$ model for the fission-enhanced creep. The 
constant, $B_{1}$, has been slightly changed to improve the correlation with experimental data. The steady state creep rate for mixed oxides is described by the following equation:

$$
\begin{aligned}
\dot{\varepsilon}= & \frac{\left(B_{1}+B_{2} \dot{F}\right)}{G^{2}} e^{-Q_{1} / R T_{\sigma e} B_{3}(1-D)} e^{B_{4} C} \\
& +B_{5} \sigma^{4.5} e^{-Q_{2} / R T} e^{B_{6}(1-D)} e^{B_{4} C}
\end{aligned}
$$

where

$$
\begin{aligned}
& \mathrm{B}_{1}=100720 \\
& \mathrm{~B}_{2}=7.57 \times 10^{-14} \\
& \mathrm{~B}_{3}=33.3 \\
& \mathrm{~B}_{4}=1.40 \\
& \mathrm{~B}_{5}=647 \\
& \mathrm{~B}_{6}=10.3 \\
& \mathrm{Q}_{1}=4.605 \times 10^{5}(\mathrm{~J} / \mathrm{mol}) \\
& \mathrm{Q}_{2}=5.860 \times 10^{5}(\mathrm{~J} / \mathrm{mol}) \\
& \dot{\mathrm{F}}=\text { fission rate }\left(7.0 \times 10^{18} \text { to } 1.2 \times 10^{19} \text { fissions } / \mathrm{m}^{3} \cdot \mathrm{s}\right) \\
& \sigma=\text { stress }(6.9 \text { to } 100 \mathrm{MPa}) \\
& \mathrm{R}=\text { gas constant }(8.314 \mathrm{~J} / \mathrm{mol} \cdot \mathrm{K}) \\
& \mathrm{T}=\text { temperature }(1663 \text { to } 1948 \mathrm{~K}) \\
& G= \\
& \mathrm{C}=
\end{aligned}
$$

In Figure A-7.4 the predictions of FCREEP are compared with mixed oxide creep data selected from compressive experiments with oxygen-metal ratios between 1.95 and 1.98. This comparison includes data from Evans et al [A-7.29], Routbort et al [A-7.30], and Perrin $[A-7.28]$. Good agreement is obtained for oxygen-metal ratios between 1.95 and 


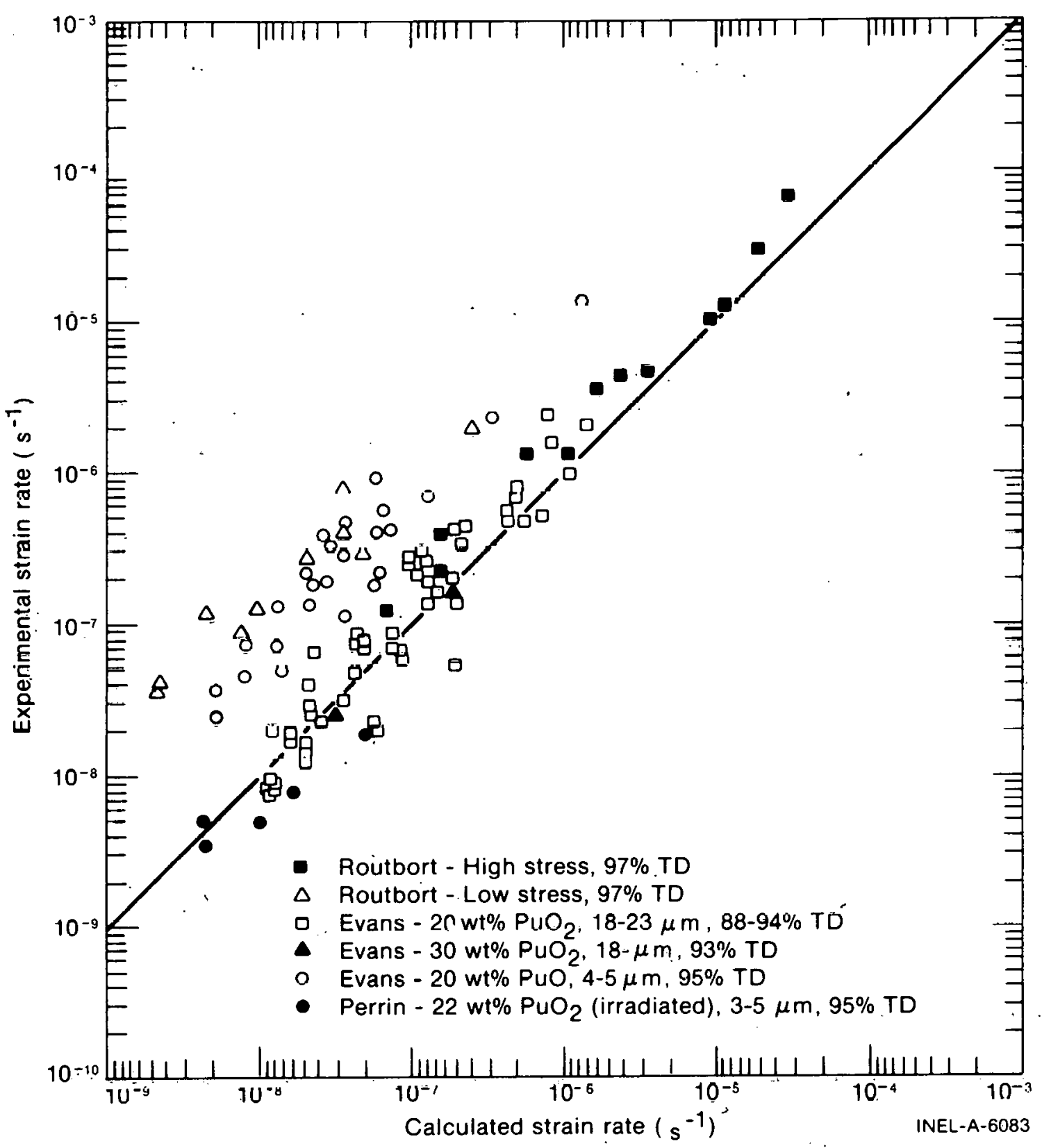

Fig. A-7.4 Comparison of mixed oxide experimental data with corresponding values from FCREEP.

1.96 and grain sizes between 18 and $23 \mu \mathrm{m}$. However, measured values for the $4-\mu \mathrm{m}$ material used by Evans et al[A-7.29] are one to two orders of magnitude higher than the corresponding values calculated by FCREEP. Also, the high stress data of Routbort [A-7.30] (in the dislocation-controlled creep regime) compare favorably with FCREEP calculations even though the oxgyen-metal ratio is slightly higher than 1.95 . The low stress data lie about an order of magnitude higher than that calculated by the FCREEP model indicating the significance of the stoichiometry on the diffusion mechanism in the viscous creep regime. Perrin's $[A-7.28]$ data were used to determine the constant for fission-enhanced creep in the viscous creep regime (assuming the same amount of creep enhancement for material with a 
1.98 oxygen-metal ratio as for material with a 1.95 oxygen-metal ratio). Reasonably good agreement is achieved for the irradiated material but the calculated values for unirradiated material are about an order of magnitude less than experimental values. The solid line represents the ideal comparison if pcrfoct agreement is achieved between experimental and calculated values.

\subsection{Fuel Creep Subcode FCREEP Listing}

A listing of the subcode FCREEP used for calculation of $\mathrm{UO}_{2}$ and mixed oxide fuel creep is presented in Table A-7.IV.

\section{TABLE A-7.IV}

\section{LISTING OF THE FCREEP SUBCODE}

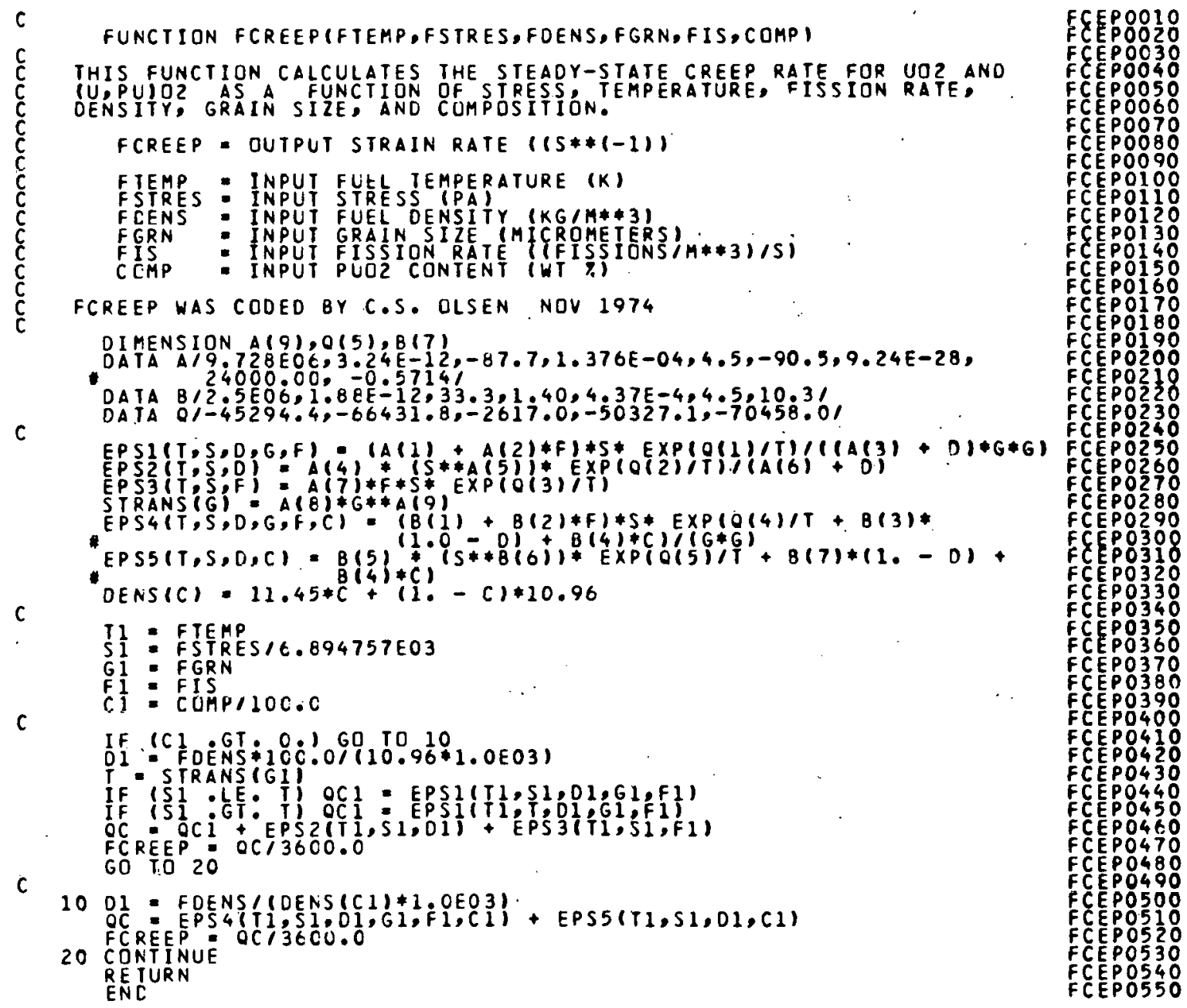


FCंREEP

\section{$7.5 \quad$ References}

A-7.1. F. R. N. Nabarro, Report of a Conference on the Strength of Solids, Physical Society, London, 1949, p 75.

A-7.2. C. Herring, "Diffusional Viscosity of a Poly-Crystalline Solid," Journal of Applied Physics, 21 (1950) p 437.

A-7.3. K. L. Coble, "A Model for Boundary Diffusion Controlled Creep in Poly-Crystalline Materials," Jouinal of Applied Physics, 34 (1963) p 1679.

A-7.4 W. M. Armstrong, W. R. Irvine, R. H. Martinson, "Creep Deformation of Stoichiometric Uranium Dioxide," Journal of Nuclear Materials, 7, 2 (1962) pr 133-141.

A-7.5. L. E. Poteat and C. S. Yust, Grain Boundary Reactions during Deformation, ORNL-P-2371 (1965).

A-7.6. J. Weertman, "Steady State Creep Based Through Dislocation Climb," Journal of Applied Ph.vsics. 28 (1957) p 362.

A-7.7. M. V. Speight, Enhancoment of Diffusion Creep Under Irraulialion, Central Electricity Generating Board, RD/B/N-2402 (August 1972).

A-7.8. D. Brucklacher and W. Dienst, "Creep Behavior of Ceramic Nuclear Fuels Under Irradiation," Journal of Nuclear Materials, 42 (19.72) pp 285-296.

A-7.9. A. A. Solomon, "Effect of $\gamma$-Radiation on the Deformation of $\mathrm{UO}_{2}$," Journal of Nucleur Maiertals, 47 (1973) pp 345-346.

A-7.10. R. Scott, A. R. Hall, J. Williams, "The Plastic Deformation of Uranium Oxides above 8000.," Joumal of Nuclear Materials, $l$ (1959) pp 39-48.

A-7.11.W. M. Armstrong and W. K. Irvine, "Creep Deformation of Nonstoichiometric Uranium Dioxide," Journal of Nuclear Materials, 9 2(1963).

A-7.12. R. A. Wolfe and S. F. Kaufman, Mechanical Properties of Oxide Fuels, WAPD-TM-587 (October 1967).

A-7.13. P. E. Bohaboy, R. R. Asamoto, A. E. Conti, Compressive Creep Characteristics of Stoichiometric Uranium Dioxide, GEAP-10054 (May 1969).

A-7.14. M. S. Seltzer, A. H. Clauer, B. A. Wilcox, "The Stress Dependence for High Temperature Creep of Polycrystalline Uranium Dioxide," Journal of Nuclear Materials, 34 (1970) pp 351-353. 
A-7.1 5. M. S. Seltzer, J. S. Perrin, A. H. Clauer, B. A. Wilcox, "A Rcvicw of Creep Behavior of Ceramic Nuclear Fuels," Reactor Technology, 14, 2 (January 1971) pp 99-135.

A-7.16. P. E. Bohaboy and R. R. Asamóto, "COmpessive Creep Characteristics of Ceramic Oxide Nuclear Fuels: Part I: Uranium Dioxide," Presented at American Ceramic Suciely Nuclear Division, Pittsburgh, Pennsylvania, October 6-8, 1968.

A-7.17. B. Burton and G. L. Reynolds, "The Diffusional Creep of Uranium Dinxide: Its Limitation by Interfacial Processes," Acta Metallurgica, 21 (August 1973) pp 1073-1078.

A-7.18. B. Burton and G. L. Reynolds, "The Influence of Deviations from Stoichiometric Composition on the Diffusional Creep of Uranium Dioxide," Acta Metallurgica, 21 (December 19'3) pp 1641-1647.

A-7.19. E. C. Sykes and P. T. Sawbridge, The Irradiation Creep of Uranium Dioxide, $\mathrm{RD} / \mathrm{B} / \mathrm{N} / 1489$ (November 1969).

A-7.20. D. J. Clough, "Irradiation-Induced Creep of Ceramic Fuels," Proceedings on Fast Reactor Fuel and Fuel Elements Meeting, Karlsruhe, September 28-30, 1970, pp 321-342.

A-7.21. D. Brucklacher and W. Dienst, 'Kontinuicrliche Messung Des Kriechens von $\mathrm{UO}_{2}$ Unter Bestrahlung," Journal of Nuclear Materials, 36 (1970) pp 244-247.

A-7.22. A. A. Solomon and R. H. Gebner, "Instrumented Capsule for Measuring Fission-Induced Creep of Oxide Fuels," Nuclear Technology, I 3 (February 1972) p 177.

A-7.23. J. S. Perrin, "Irradiation-Induced Creep of Uranium Dioxide," Journal of Nuclear Materials, 39 (1971) pp 175-182.

A-7.24. A. A. Solomon, J. L. Routbort, J. C. Voglewede, Fission-Induced Creep of $\mathrm{UO}_{2}$ and Its Significance to Fuel-Element Performance, ANL-7857 (September 1971).

A-7.25. D. Brucklacher, W. Dienst, F. Thummler, Creep Bchavior of Oxide Fuels Under Neutron Irradiation, Translated from German by J. L.Routbort, ANL-Trans-942 (May 1973).

A-7.26. D. Vollath, "Thermal Creep of Plutonium-Containing Nuclear Fuels," Reactor Meeting, Bonn, Germany (March 30, 1971) pp 558-561.

A-7.27. O. D. Slagle, High Temperature Creep of $\mathrm{UO}_{2}-20$ wt\% $\mathrm{PuO}_{2}$, HEDL-TME-71-28 (August 1971). 
A-7.28. J. S. Perrin, "Effect of Irradiation on Creep of $\mathrm{UO}_{2}-\mathrm{PuO}_{2}$," Jourral of Nuclear Materials, 42 (1972) pp 101-104.

A-7.29. S. K. Evans, P. E. Bohaboy, R. A. Laskiewicz, Compressive Creep of Urania-Plutonia Fuels, GLAF-13\%32 (Augusl 1971).

A-7.30. J. L. :Ruutbort, N. A. Javed, J. C. Voglewede, "Compressive Creep of Mixed-Oxide Fuel Pellets," Journal of Nuclear Materials, 44 (1972) pp 247-259.

\section{FUEL FRACTURE SIRENGTH (FFRACS)}

FFRACS calculates the fracture strength of brittle $\mathrm{UO}_{2}$ as a function of porosity and temperature for temperatures up to $1000 \mathrm{~K}$, the lowest temperature at which plasticity has been observed in-pile. For temperatures above $1000 \mathrm{~K}$; a constant value is used to represent the - in-pile fracture strength of plastic $\mathrm{UO}_{2}$. The $\mathrm{UO}_{2}$ fracture model is given by the following equations:

for $273<\mathrm{T} \leqslant 1000 \mathrm{~K}$ :

$$
\sigma_{F}=1.7 \times 10^{8}\left[1-2.62(1-D) .1^{1 / 2} \exp (-1590 / 8.314 \mathrm{~T}) \quad(\mathrm{A}-8 \text { 1.a) }\right.
$$

for $\mathrm{T}>1000 \mathrm{~K}$

$$
\sigma_{F}=\sigma_{f}(\text { IUOU } K)
$$

where

$$
\begin{array}{lll}
\sigma_{\mathrm{F}} & =\text { fracture strength (pascals) } \\
\mathrm{D} & =\text { fraction of theoretical density (dimensionless) } \\
\mathrm{T} & =\text { temperature }(\mathrm{K}) \\
\sigma_{\mathrm{F}}(1000 \mathrm{~K}) & =\text { fracture stress found with } \mathrm{T}=1000 \mathrm{~K}
\end{array}
$$

Equation (A-8.1a) is based upon out-of-pile $\mathrm{UO}_{2}$ fracture strength data and describes the behavior of brittle $\mathrm{UO}_{2}$. Because no in-pile measurements of fracture strength have been made, Equation (A-8.1b) is based upon theoretical considerations and fragmentary out-of-pile data and applies to plastic $\mathrm{UO}_{2}$. The transition from brittle to ductile material is accompanied by a discontinuity in fracture strength and occurs at temperatures below the usual out-of-pile brittle-ductile transition temperature due to fission-induced plasticity. Equation (A-8.1a) has a standard deviation with respect to experimental fracture strength data of $0.19 \times 10^{8}$ pascals. The uncertainty in Equation $(A-8.1 \mathrm{~b}$ ) is not estimated because of a lack of in-pile data. The following pages describe first the out-of-pile studies and then the model development. 


\subsection{Out-of-Pile $\mathrm{UO}_{2}$ Deformation}

The out-of-pile deformation of $\mathrm{UO}_{2}$ exhibits either elastic or elastic-plastic behavior. Elastic behavior is characterized by stress being linearly proportional to strain up to the fracture point $[A-8.1, A-8.5]$. Elastic-plastic behavior is characterized by the stress-strain curve which is initially elastic (to the elastic proportional limit), and which then exhibits plastic behavior $[A-8.1, A-8.5]$. Each of these phenomena will be discussed in further detail.

8.1.1 Review of Out-of-Pile $\mathrm{UO}_{2}$ Elastic Behavior Data and Theory. At temperatures below a ductile-brittle transition temperature, $T_{c}, U_{2}$ deforms elastically up to the fracture point $[\mathrm{A}-8.1, \mathrm{~A}-8.5]$. In such cases the fracture stress, $\sigma_{\mathrm{F}}$, is much less than the yield stress, $\sigma_{y}$, so that no yielding occurs prior to fracture. The fracture topography of near-theoretically dense $\mathrm{IO}_{2}$ exhibits the cleavage fracture mode of a brittle material. However, this fracture mode is affected by the amount of porosity and grain size, where, in general, the relative proportion of brittle to ductile fracture decreases with an increase in porosity and a decrease in grain size $[\mathrm{A}-8.6]$.

The crack initiator $[\mathrm{A}-8.1, \mathrm{~A}-8.2, \mathrm{~A}-8.4, \mathrm{~A}-8.6]$ has been suggested as the largest pore. The Griffith fracture theory $[A-8.7]$ can be applied to theoretically examine the parameters which affect the fracture stress. Griffith showed that the fracture stress or critical stress required to propagate an elliptical crack of length $2 \mathrm{c}$ with an "infinitely" small radius of curvature is given by Equation $(\mathrm{A}-8.2)$ :

$$
\sigma_{F}=\sqrt{\frac{2 E \gamma}{\pi c\left(1-\nu^{2}\right)}}
$$

where

$$
\begin{aligned}
\mathrm{E} & =\text { elactic modulus }(\mathrm{Pa}) \\
\gamma & =\text { surface energy }(\mathrm{J}) \\
\mathrm{c} & =\text { crack length }(\mathrm{m}) \\
\nu & =\quad \text { Poisson's ratio (unitless). }
\end{aligned}
$$

This equation applies to plane strain conditions and to an infinitely thick section of purely elastic material.

In Equation (A-8.2), the fracture stress is proportional to the square root of the elastic modulus, which in turn linearly decreases with porosity and temperature as discussed in Section A-5. Therefore, the fracture strength should decrease with increasing temperature. However, the fracture strength of $\mathrm{UO}_{2}$, has been observed to increase slightly with temperature $[\mathrm{A}-8.2, \mathrm{~A}-8.4]$. These measurements can be explained by the fact that $\gamma$ in Equation (A-8.2) probably increases with temperature ${ }^{[A-8.4]}$ at a faster rate than the rate of decrease of $E$ with temperature. 
Hasselman ${ }^{[A-8.8]}$ has shown that when a matcrial contains numerous elliptical cracks of length $2 c$ spaced a distance $2 \mathrm{~h}$ from each other, Equation ( $\mathrm{A}=8.2)$ becomes for plane strain conditions:

$$
\sigma_{F}=\sqrt{\frac{E \gamma}{2\left(1-v^{2}\right) h}} \cot \left(\frac{\pi \ddot{c}}{2 h}\right)
$$

where the terms are defined as above.

Equation (A-8.3) and Equation (A-8.2) both predict a $\mathrm{UO}_{2}$ fracture strength which is dependent on porosity because of the effect of porosity on the elastic modulus. Equation (A-8.3) also predicts a crack spacing effect upon fracture strength, which in turn depends upon both the pore size and volume of porosity. A fracture stress dependency upon the pore morpholngy (size, shape, and distribution) has also been observed by Roberts and Ueda[A-8.1].

8.1.2 Out-of-Pile Elastic Morels. The experimental data $[$ A-8.1, A-8.2, A-8.6, A-8.9, $A=8.101$, for fraoture strength in the brittle region were fit to Equation (A-8.4) using a linear least-squares.. regression analysis [after reducing Equation (A-8.4) to a linear form] to determine the.coefficients $A, m$, and $Q$ :

$$
\sigma_{F}=\Lambda[1 \quad-2.62(1-D)]^{1 / 2} G^{-m} \exp (-Q / R T)
$$

where

$$
\begin{aligned}
& \sigma_{\mathrm{F}}=\text { fracture stress }(\mathrm{Pa}) \\
& \mathrm{D}=\text { fraction of theoretical density (dimensionless) } \\
& \mathrm{C} \quad=\text { grain size }(\mu \mathrm{m}) \\
& \mathrm{T}=\text { ternuelature }(\mathrm{K}) \\
& \mathrm{R}=\text { gas sinnstant }(8.314 \mathrm{~J} / \mathrm{mol} \cdot \mathrm{K}) .
\end{aligned}
$$

The following values of $\mathrm{A}, \mathrm{m}$, and $\mathrm{Q}$ were determined:

$$
\begin{aligned}
& A=1.70 \times 10^{8} \text { pascals } \\
& \mathrm{m}=0.047 \\
& \mathrm{Q}=1590 \mathrm{~J} / \mathrm{mol} .
\end{aligned}
$$

The expression $[1-2.62(1-D)]^{1 / 2}$ arises from the proportionality between $\sigma_{F}$ and $\sqrt{E}$ in Equation (A-8.2) and (A-8.3) and the. relation between $E$ and D (see Section A-5). The 
expression bctween fracture stress and grain size was bascd upon the suggestion of Orowan $[A-8.11]$ and Petch $[A-8.12]$ and the data of Igata and Domoto $[A-8.13]$ which relate the strength of a material to $G^{-1 / 2}$. In general terms, this factor is written $G^{-m}$. The Boltzmann factor was selected to represent the temperature dependency. The effects of pore morphology have been ignored because of a lack of appropriate data. In Figure A-8.1, Equation (A-8.4) is compared with experimental data which are normalized to a $10-\mu \mathrm{m}$ grain size and to $95 \%$ TD using Equation (A-8.4).

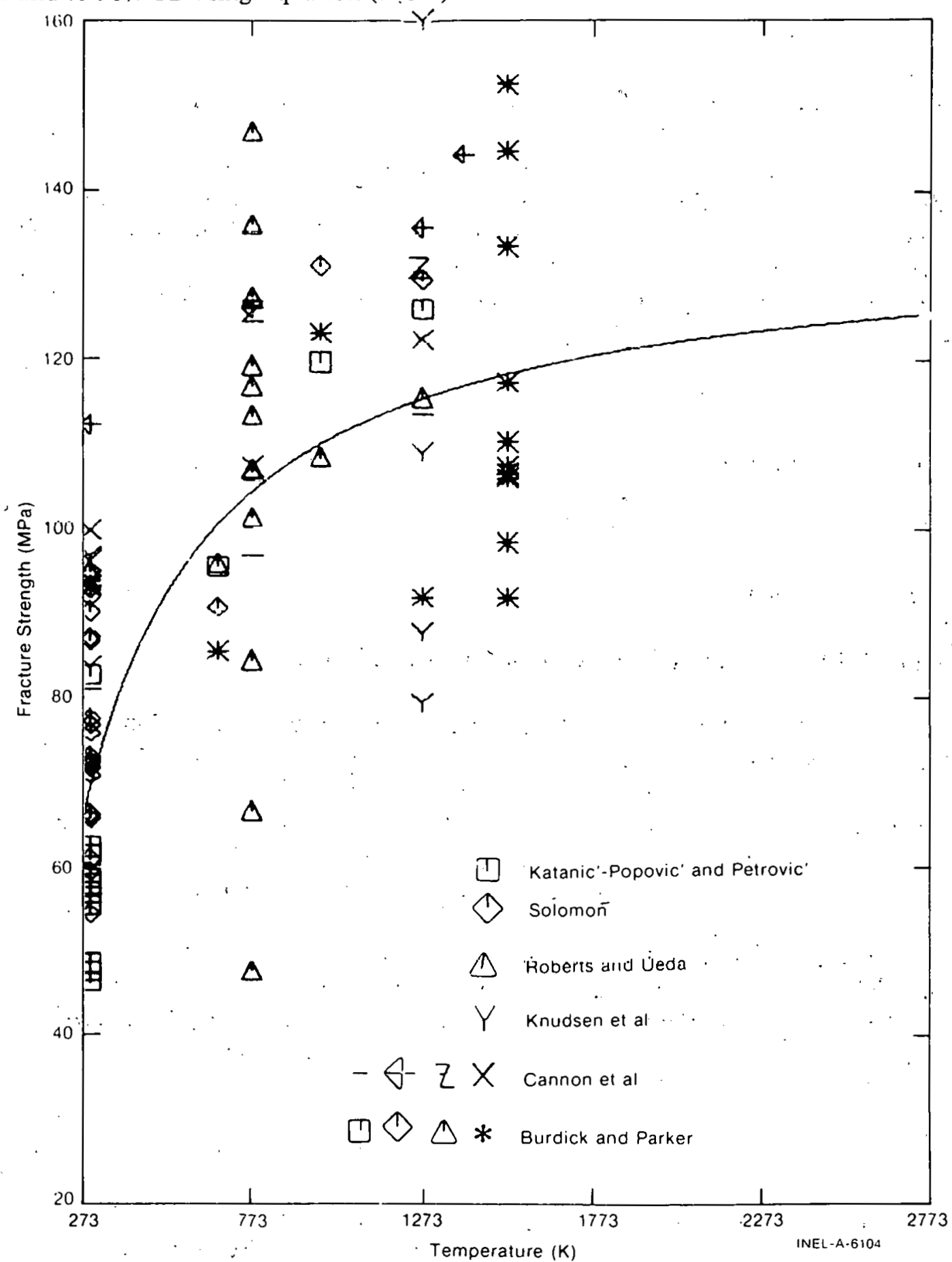

Fig. A-8.1 Comparison of Equation (A-8.4) in the elastic behavior regime with out-of-pile $\mathrm{UO}_{2}$ fracture strength data normalized to $10-\mu \mathrm{m}$ grain size and $95 \% \mathrm{TD}$. 
Knudsen ${ }^{[A-8.14]}$ proposed the following empirical equation relating fracture stress to grain size and porosity:

$$
\sigma_{F}=A G-m e^{-b}(1-D)
$$

where

$$
\mathrm{b}=\mathrm{a} \text { constant }
$$

and the other terms have becn defined above, and cunstants are given below.

Kinulsen suggested that this relation represints the strength of thoria and chromium carbide reasonably well. This expression was fit to the $I \Omega_{2}$ fracture strength data, exccpt that the Arrhenius term from Equation (A-8.4) was added to provide a temperature dependency. The resultant expression was reduced to a linear form and a linear, multiple variahle regression analysis was used to determine the coefficients $A, m, b$, and $Q$. The resultant values are:
$\mathrm{A}=1.7108 \times 10^{8} \mathrm{~Pa}$
$\mathrm{m}=0.05136$
$\mathrm{b}=2.412$
$\mathrm{Q}=1649 \mathrm{~J} / \mathrm{mol}$.

Equation (A-8.5) is compared with experimental data in Figure A-8.2.

Both Equations (A-8.4) and (A-8.5) indicate a very small effect of grain size upon the fracture stress. Values of $m$ on the order of $1 / 2$ are exprsted thenretirally $[A-8.11, A-8.12]$ but values of 0.05 were obtained, indicating a very insignificant effect of grain size on $\mathrm{UO}_{2}$ fracture strsss. Murh-scatter exists in the data with rcspect to Equativins (A-8.4) and (A-8.5) and is attributed to differences in pore morphology which are not accounted for in these equations and which were also not reported with the experimental data.

In some cases, porosity has not been the initiator of cracks in $\mathrm{UO}_{2}$. Instead, silica or alumina $[A-8.15]$ precipitated at grain boundaries has considerably reduced the fracture stress, whereas small additions of titania increased the fracture strength of $\mathrm{UO}_{2}[\mathrm{~A}-8.9]$. These additions are not normally part of the fabrication process and were not considered in the $\mathrm{UO}_{2}$ fracture stress model.

8.1.3 Out-of-Pile Transition Temperature. The transition temperature, $\mathrm{T}_{\mathrm{c}}$, is defined to be the temperature at which the stress-strain curve departs from (linear) elastic to plastic behavior. Density, grain size, and strain rate are expected to effect this transition temperaturc, but experimental data is insufficient to obtain a precise relationship. 


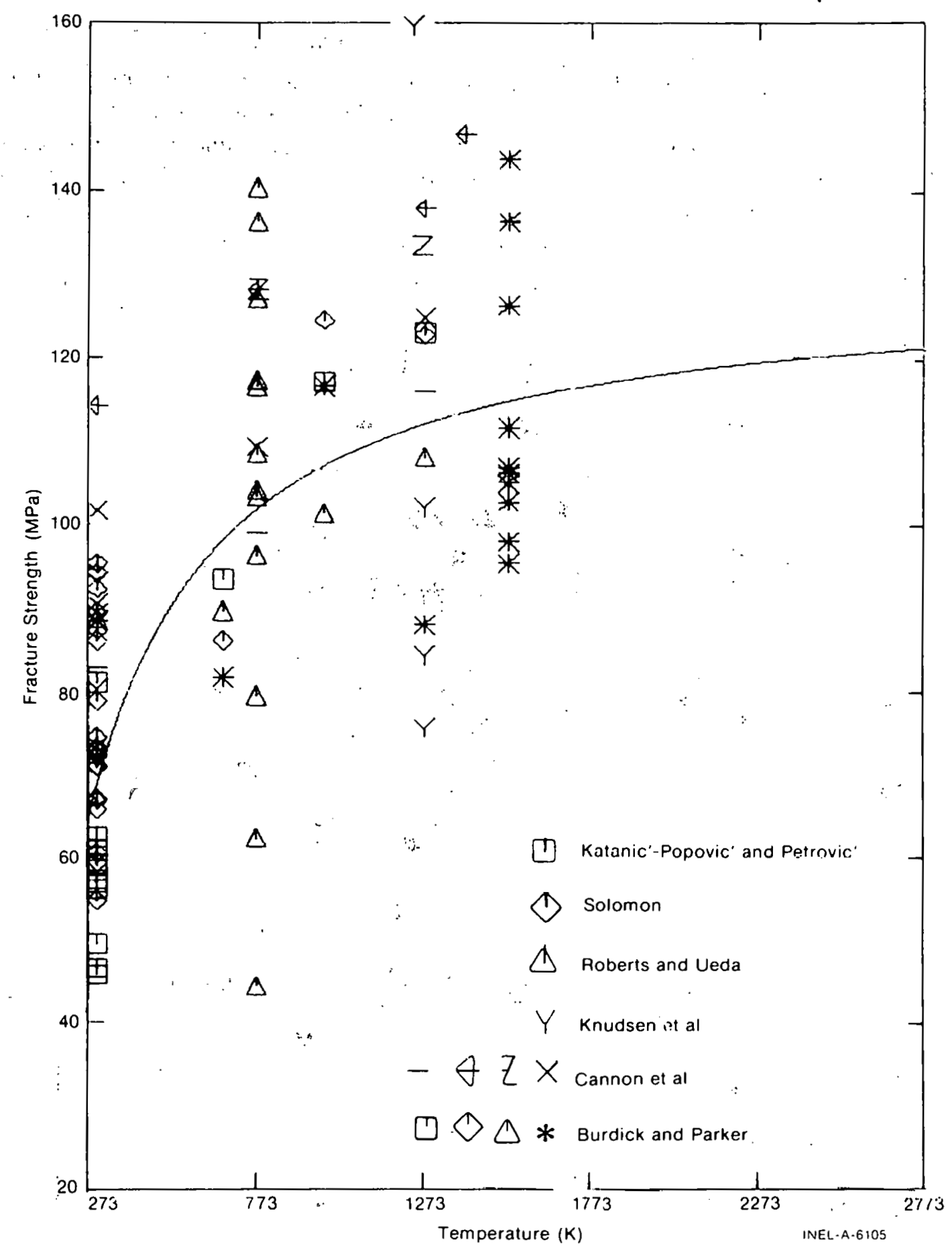

-Fig. A-8.2 Comparison of Equation (A-8.5) in the elastic behavior regime with out-of-pile $\mathrm{UO}_{2}$ fracture strength data normalized to $10-\mu \mathrm{m}$ grain size and $95 \% \mathrm{TD}$.

Cannon et al ${ }^{[\mathrm{A}-8.2]}$ reported out-of-pile transitions at 1100,1375 , and $1450^{\circ} \mathrm{C}$ for strain rates of $0.092,0.93$, and $9.2 / \mathrm{h}$, respectively, in material with an $8-\mu \mathrm{m}$ average grain size. Transitions at 1050 and $1100^{\circ} \mathrm{C}$ occurred for a strain rate of $0.092 / \mathrm{h}$ in material with $15-$ and $31-\mu \mathrm{m}$ average grain sizes, respectively. Evans and Davidge ${ }^{[A-8.4]}$ reported transition temperatures of 1200 and $1300^{\circ} \mathrm{C}$ for $8-$ and $25-\mu \mathrm{m}$ materials. A transition temperature of $1250^{\circ} \mathrm{C}$ is assumed for the FFRACS since that is the midpoint of the 1050 to $1450^{\circ} \mathrm{C}$ range of measurements. 
8.1.4 Out-of-Pile $\mathrm{UO}_{2}$ Elastic-Plastic Behavior. At temperatures above the transition temperature, the deformation of $\mathrm{UO}_{2}$ exhibits plastic behavior after some elastic deformation has occurred. The yield stress is less than the fracture stress and yielding occurs prior to fracture ${ }^{[\mathrm{A}-8.1, \mathrm{~A}-8.5]}$. The fracture mode is mostly intergranular, and a significant contribution to the deformation arises from grain boundary sliding. Figure A-8.3 shows the fracture strength of $\mathrm{UO}_{2}$ as a function of temperature. At temperatures above $\mathrm{T}_{\mathrm{c}}$ the

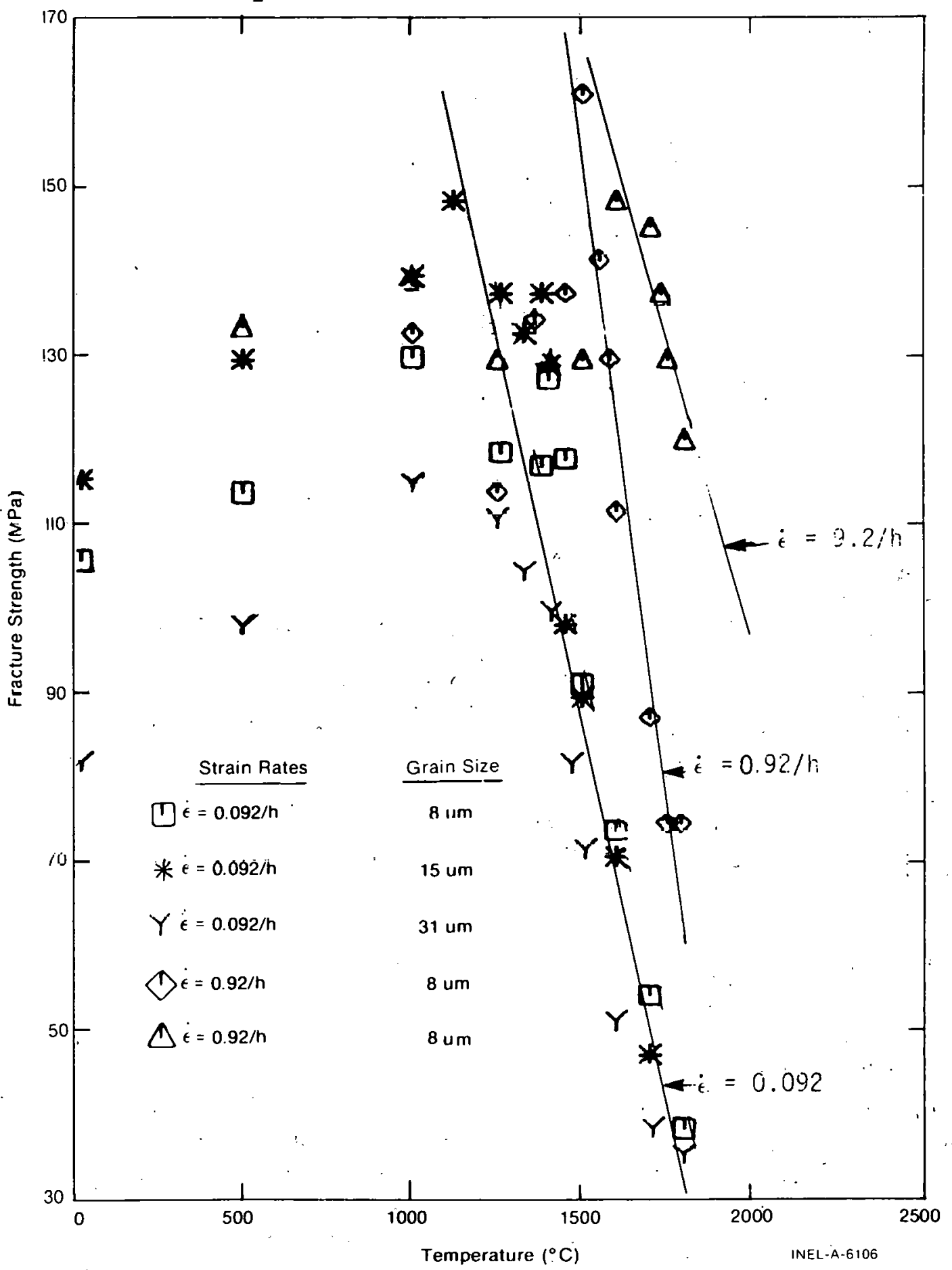

Fig. A-8.3 Least-squares regression fit of $\mathrm{UO}_{2}$ fracture strength in the elastic-plastic regime to out-of-pile data of Cannon et al. 
ultimate tensile strength dccreases with an increase in temperature. The effect of strain rate is significant but the effect of grain size is negligible for grain sizes up to about $30 \mu \mathrm{m}$. Strain rate effects and grain boundary sliding strongly suggest that creep plays a dominant role at these temperatures. When the creep rate for a given temperature is near the same order of magnitude as the strain rates, then stress relaxation reduces the fracture stress. This effect is shown in Figure A- 8.3 by the increase in fracture stress with the increase in strain rate.

\section{2 $\mathrm{UO}_{2}$ Fracture Stress Model}

Irradiation substantially reduces the ductile-brittle transition temperature. As discussed in Section 7, in-pile creep measurements show plasticity exists in $\mathrm{UO}_{2}$ at temperatures as low as $1000 \mathrm{~K} . \mathrm{UO}_{2}$ is assumed to be brittle below this temperature, and Equation (A-8.4) (without the grain size term) is selected for the low temperature fracture stress model for $\mathrm{UO}_{2}$. Equations (A-8.4) and (A-8.5), each with a standard deviation of about $1.9 \times 10^{7} \mathrm{~Pa}$, predict the experimental out-of-pile fracture stress about equally well but Equation (A-8.4) has more theoretical foundation.

Above $1000 \mathrm{~K}$, irradiation and thermal effects enhance the plasticity of $\mathrm{UO}_{2}$ so that a decrease in fracture strength with increase in temperature may not occur. A strain rate effect may also exist, but the experimental data available are not sufficient to quantify a strain rate effect. Therefore, the in-pile fracture stress for plastic $\mathrm{UO}_{2}$ at temperatures higher than $1000 \mathrm{~K}$ is taken to be that found with the low temperature correlation at $1000 \mathrm{~K}$. This ensures calculational continuity between the two correlations.

The in-pile $\mathrm{UO}_{2}$ fracture stress model is summarized by the following equations:

for $273<\mathrm{T} 1000 \mathrm{~K}$

$$
\sigma_{F}=1.7 \times 10^{8}[1-2.62(1-0)]^{1 / 2} \exp (-1590 / 8.314 \mathrm{~T})
$$

for $\mathrm{T}>1000 \mathrm{~K}$

$$
\dot{\sigma}_{F}=\sigma_{F}(1000 \mathrm{~K})
$$

where

$\begin{array}{lll}\sigma_{\mathrm{F}} & = & \text { fracture strength }(\mathrm{Pa}) \\ \mathrm{D} & = & \begin{array}{l}\text { fraction of theoretical density (dimen- } \\ \text { sionless) }\end{array} \\ \mathrm{T} & \text { temperature (K) } \\ \sigma_{\mathrm{F}}(1000 \mathrm{~K})= & \begin{array}{l}\text { fracture stress found with } \mathrm{T}=1000 \mathrm{~K} \\ \text { using Equation (A-8.6a) }\end{array}\end{array}$




\section{FFRACS}

Equation $(\mathrm{A}-8.6 \mathrm{a})$ can be used for temperatures up to about $(1323 \mathrm{~K})$ for out-of-pile use. The predictions of FFRACS for two different fuel densities as a function of temperature are shown in Figure A-8.4.

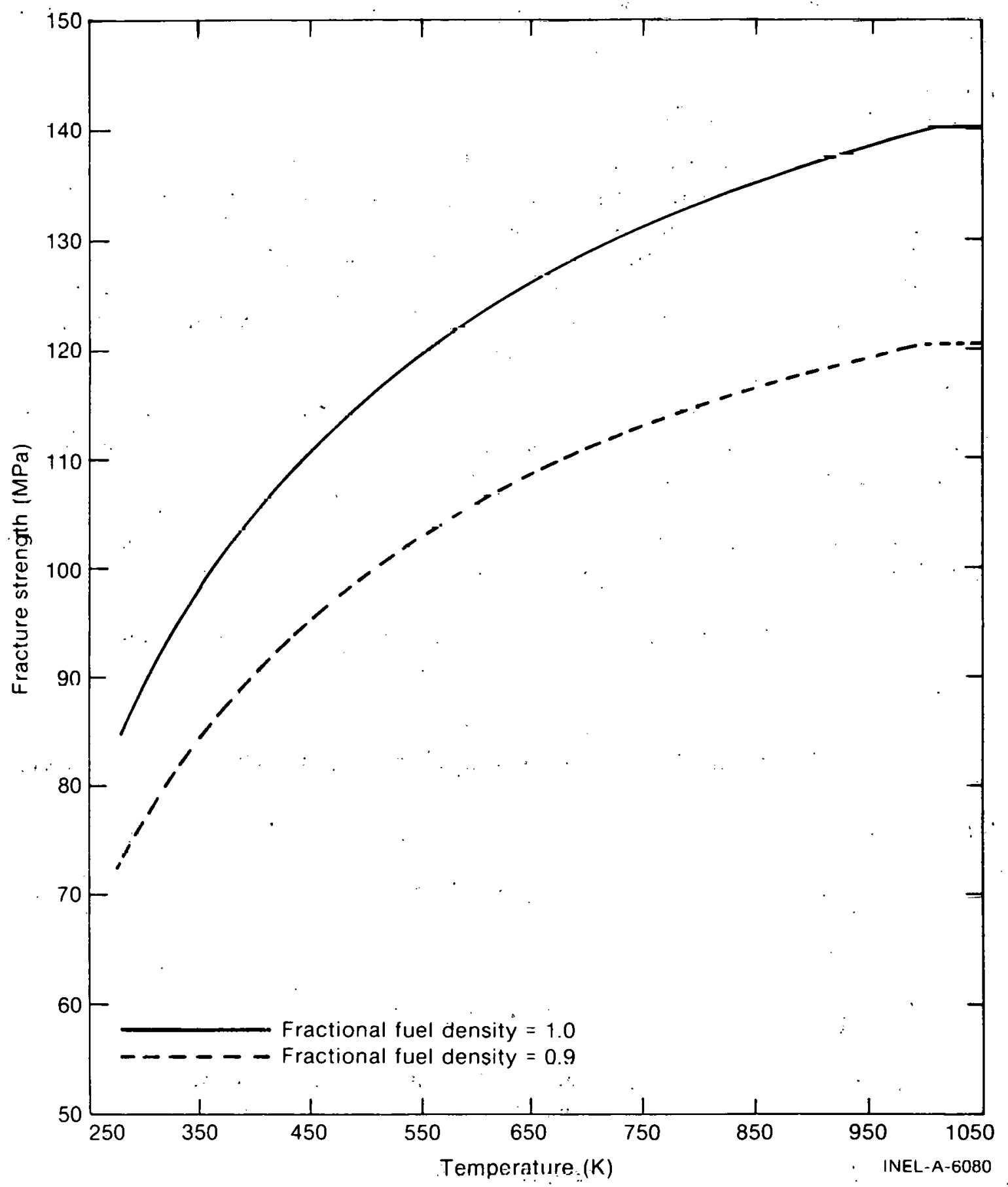

Fig. A-8.4 Calculated curves showing the predictions of FFRACS as a function of temperature for two fuel densities. 


\subsection{Fuel Fracture Strength Subcode FFRACS Listing}

The FORTRAN listing of the FFRACS subcode is presented in Table A-8.I.

TABLE A-8. I

LISTING OF THE FFRACS SUBCODE

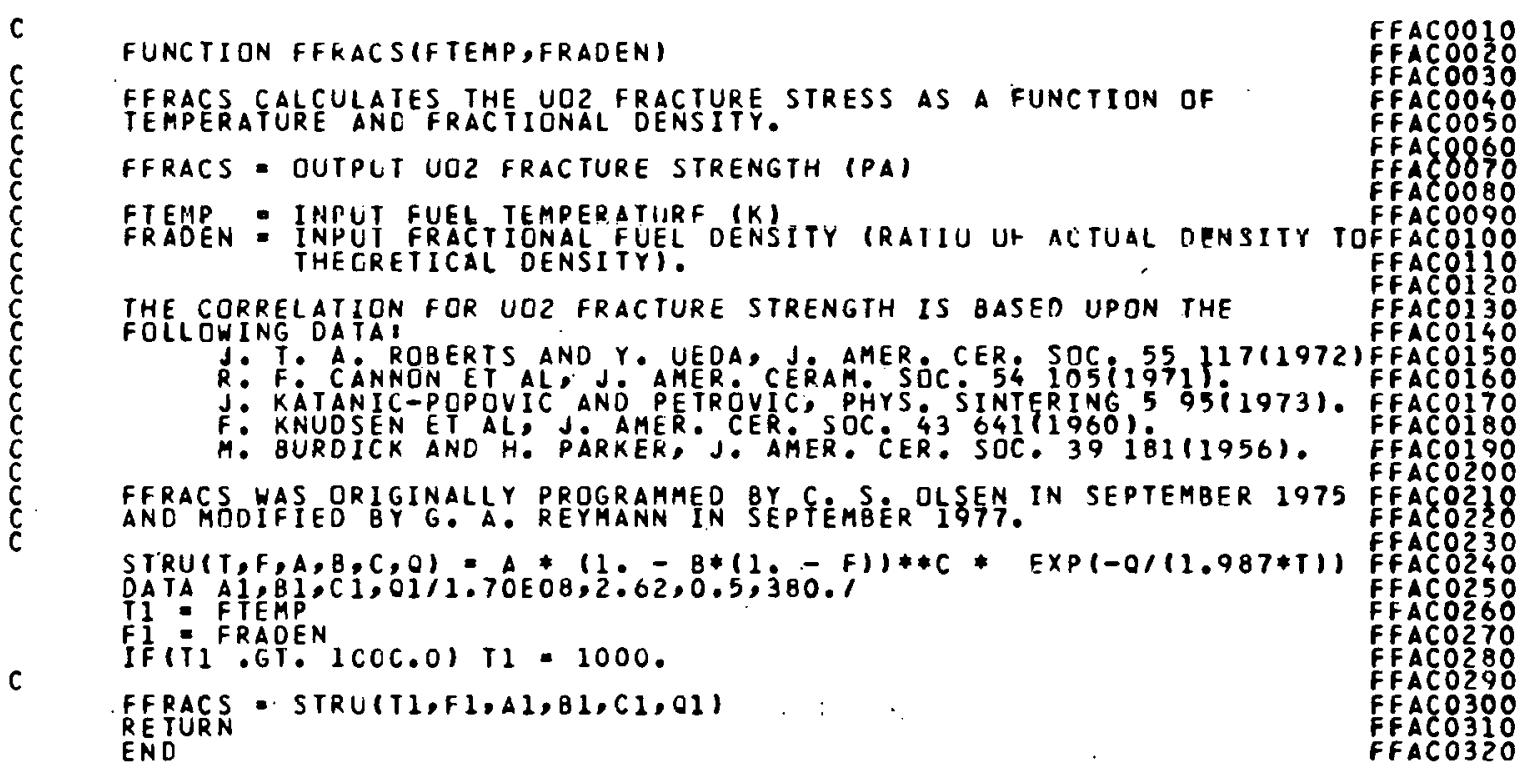

\subsection{Rererences}

A-8.1. J. T. A. Roberts and Y. Ueda, "Influence of Porosity on Deformation and Fracture of $\mathrm{UO}_{2}$, , Journal of the American Ceramic Society, 55, 3 (1972) pp 117-124.

A-8.2. R. F. Cannon, J. T. A. Roberts, R. J. Beals, "Deformation of $\mathrm{UO}_{2}$ at High Temperatures," Journal of the American Ceramic Society, 54 (1971) pp 105-112.

A-8.3. Y. Guerin, "Etude par Compression a'Hautes Temperatures de la Deformation Plastique du Bioxyde d'Uranium Polycristallin," Journal of Nuclear Materials, 56, (1975) pp 61-75.

A-8.4. A. G. Evans and R. W. Davidge, "The Strength and Fracture of Stoichiometric Polycrystalline $\mathrm{UO}_{2}$," Journal of Nuclear Materials, 33 (1969) pp 249-260.

A-8.5 C. R. Tottle, Mechanical Properties of Uranium Compounds, ANL-7070 (November 1965). 
A-8.6. J. Katanic'-Popovic' and V. Petrovic', "Strenglh Dependence on Microstructure Characteristics of Sintered UO, 2 ," Physics Sintering, 5 ; 2 (1973) pp 95-105.

A-8.7. A. Tetelman and A. McĖvily, Jr., Fracture of Structural Materials, Nëw York: John Wiley and Sons, (1967) p 53.

A-8.8. D. Hasselman, "Analysis of the Strain at Fracture of Brittle Solids" with High Densities of Microcracks," Joumal of the American Ceramic Society, 52 (1969) pip $450-459$.

A-8.9. F. H. Knudsen, H. S. Parker, and M. D. Burdick, "Flexural Strength of Specimens Prepared from Several Uranium Dioxide Powers; Its Dependence on Porosity and Grain Size and the Influence of Additions of Titania," Journal of the American Ceramic Society, 43 (1960) pp 641-647.

A-8.10. M. C. Burdick and II. S. Parker, "Effect of Particle Size on Bulk Density and Strength Properties of Uranium Dioxide. Specimens," Journal of the American Ceramic Society, 39 (1956) pp 181-187.

A-8.11. E. Orowan, "Die Erhöhtc Festigkeit Dünner Faden, die Joffe-Effekt, und Verwandte Erscheinungen vom Standpunkt der Griffithschen Bruchtheorie," Zeitschrift Fuer Physik, (3/4) pp 195-213.

A-8.12. N. J. Petch, "Cleavage Strength of Polycrystals," Journal of the Iron Steel Institute, 174 Part 1 (1953) pp 25-28.

A-8.13. N. Igata and K. Domoto, "Fracture Stress and Elastic Modulus of Uranium Dioxide Including Excess Oxygen," Journal of Nuclear Materials, 45 (1972/73) pp 317-322.

A-8.14. F. P. Knudsen, "Mependenre of Mechanical Strength of Brittle Polycystallino Specimen on Porosity and Grain Size," Journal of the American Ceramic Society, 12 (1959) pp 376-387.

A-8.15. A. A. Solomon, "Influence of Impurity Particles on the Fracture of $\mathrm{UO}_{2}$," Journal of the American Ceramic Society, 55 (1972) pp 622-627.

\section{FUEL SWELLING (FSWELL) AND THE INTEGRATION OF SWELLING}

\section{AND DENSIFICATION (CONECT)}

A model for the gaseous and solid fission product swelling of uranium dioxide and mixed uranium-plutonium dioxide fuels (with relatively low plutonium content) in light water reactor environments, is presented in this section. The model is empirical, based on 
PWR and BWR fuel swelling results, taking into account the Bettis flat plate data. The temperature dependence of the swelling rate was incorporated using mixed oxide swelling data. The data describe internal changes in the fuel dimensions so that macroscopic swelling is represented by the model.

A model to incorporate the effects of fuel densification on fuel swelling and to calculate the combined effects of densification and swelling on in-reactor fuel dimensional changes is also presented. The net contribution of these two effects to the changes in fuel dimensions during irradiation is not a simple sum of the dimensional changes contributed by each effect. The subcode CONECT combines the contributions of swelling and densification (provided by the MATPRO subcode FUDENS) and completes the description of fuel dimensional changes caused by these phenomena during irradiation.

\subsection{Summary}

Swelling, densification, and the approach to integrating their net effect on fuel geometry are modeled in three district subcodes in order to facilitate future modeling of LWR fuel swelling and densification and still combine the two models (FSWELL and FUDENS). The swelling and the integration subcodes are described in this section, while the densification subcode is presented in Section A-9.6.

9.1.1 FSWELL Model. Description. The model assumes constant (temperature independent) values for the burnup dependent swelling rate below $1673 \mathrm{~K}$ and above $2473 \mathrm{~K}$. The swelling rate is modeled as a linear function of temperature between these extremes, having a maximum at $2073 \mathrm{~K}$. The values for the relative swelling rates were taken from the mixed oxide data of Nelson and Zebroski $[$ A-9.1].

The temperature dependent swelling rate was normalized to a value of $0.7 \% \Delta \mathrm{V} / \mathrm{V}$ per $10^{26}$ fissions $/ \mathrm{m}^{3}$ at $2273 \mathrm{~K}$ based on a linear average of measured swelling data. The data. base for the model is shown in Table A-9.I.

The swelling rate value of $0.7 \% \Delta \mathrm{V} / \mathrm{V}$ per $10^{26}$ fissions $/ \mathrm{m}^{3}$ was obtained by linearly averaging the data presented in Table A-9.I. This averaged swelling rate was used to calculate the relative swelling rate, giving the values shown in Table A-9.II. The temperature dependent swelling rate is compared with measured values in Figure A-9.1.

9.1.2 CONECT Model Description. The subcode CONECT calls FSWELL and FUDENS to determine net dimensional changes and utilizes as a key parameter the porosity which may be filled by densification or swelling without causing outward swelling of the fuel. The parameter is defined by

$$
P=P_{f}-P_{s}-P_{d}
$$

with

$$
P_{f}=\frac{1}{\rho_{0}}-9.425 \times 10^{-5}
$$


TABLE A-9. I

DATA BASE FOR THE MATPRO FSWELL MODEL

\begin{tabular}{|c|c|}
\hline Source & $\begin{array}{l}\text { Measured Swelling Rate } \\
\left(\% \Delta V / V \text { per } 10^{26} \text { fissions } / \pi^{3}\right) \\
\end{array}$ \\
\hline Bettis flat plate data - [A-9.2] & $0.7 \%$ \\
\hline $\begin{array}{l}\text { Bettis flat plate data - }[\mathrm{A}-9.3] \\
\text { (reevaluated by GE) }\end{array}$ & $0.5 \%$ \\
\hline $\begin{array}{l}\text { General Electric Company } \\
\text { BWR data }[A-9.3, A-9.4]\end{array}$ & $0.4 \%$ \\
\hline $\begin{array}{l}\text { Babcock \& Wi Icox Company } \\
\text { PWR data }[A-y . b]\end{array}$ & $1.10 \%$ \\
\hline
\end{tabular}

TABLE A-9. II

CALCULATED VALUES OF THE RELATIVE SWELLING RATE

\begin{tabular}{|c|c|}
\hline Temperature $(K)$ & $\left(\% \Delta V / V\right.$ per $10^{26}$ fissions $\left./ \mathrm{m}^{3}\right)$ \\
\hline$T \leq 1673$ & 0.28 \\
\hline $1673<T \leq 2073$ & $0.28[1 .+0.00575(T-1673)]$ \\
\hline $2073<T \leq 2473$ & $0.28[3.3-0.0104(1-70073)]$ \\
\hline$T>2473$ & 0.476 \\
\hline
\end{tabular}

where

. $\mathrm{P}=$ porosity which has not been filled by densification or swelling but which is potentially fillable without outward swelling

$\mathrm{P}_{\mathrm{f}}=$ porosity àvailable for filling by densification and swelling phenomena 


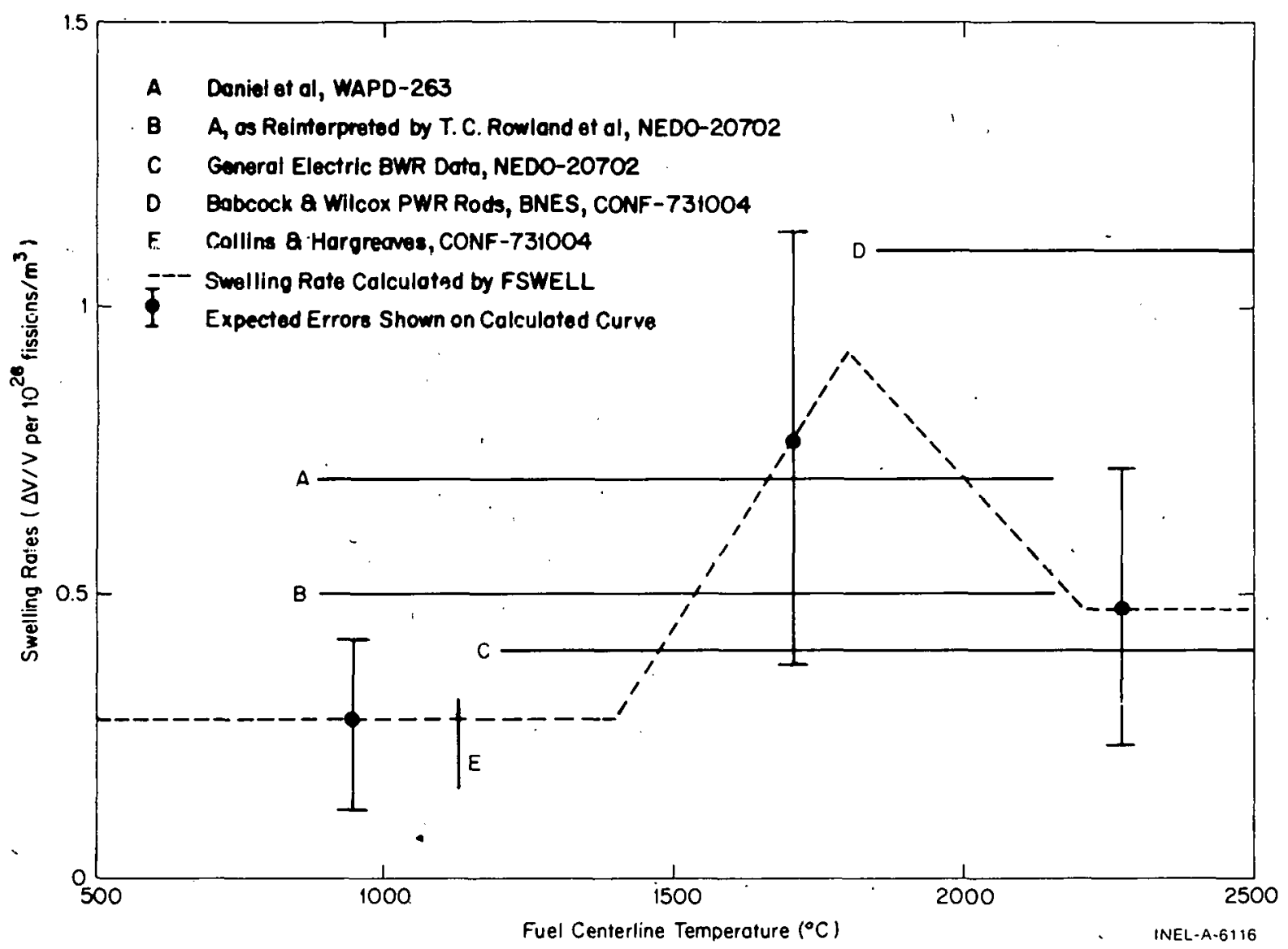

Fig. A-9.1 Comparison of predicted and averaged measured swelling rates over the temperature ranges shown.

$\mathrm{P}_{\mathrm{S}}=$ porosity filled by swelling (equal to the net change in volume calculated by FSWELL)

$\mathrm{P}_{\mathrm{d}}=$ porosity filled by densification (equal to the net change in volume calculated by FUDENS)

$\rho_{\mathrm{o}}=$ as-fabricated fuel density $\mathrm{kg} / \mathrm{m}^{3}$.

When $P$ is greater than zero (requiring an initial density less than $1.061 \times 10^{4} \mathrm{~kg} / \mathrm{m}^{3}$ by Equation (A-9.2) porosity may be filled, densification will occur, and the net volume change is calculated by the FUDENS model alone. When $\mathrm{P}$ is zero or negative, densification is no longer possible and further geometry changes are determined by the FSWELL subcode (with outward swelling generally beginning in the 3 to $10 \mathrm{GWd} / \mathrm{MtM}$ burnup range). In terms of net volume changes relative to the as-fabricated fuel volume:

for $\mathrm{P}>0$

$$
\frac{\Delta V}{V}=\left(\frac{\Delta V}{V}\right) \text { FUDENS }
$$


for $P \geqslant 0$

$$
\frac{\Delta V}{V}=\left(\frac{\Delta V}{V}\right)_{P=0}^{\text {FUDENS }}+\left[\left(\frac{\Delta V}{V}\right)^{\text {FSWELL }}-\left(\frac{\Delta V}{V}\right)_{P=0}^{\text {FSWELL }}\right]
$$

where

$$
\begin{array}{lll}
\left(\frac{\Delta V}{\mathrm{~V}}\right)^{\text {FUDENS }} & = & \begin{array}{l}
\text { percent change in fucl volume } \\
\text { calculated by FUDENS }
\end{array} \\
\left(\frac{\Delta V}{V}\right)^{\text {FSWELL }} & =\quad \begin{array}{l}
\text { percent change in fuel volume } \\
\text { calculated by FSWELL }
\end{array} \\
\left(\frac{\Delta V}{V}\right)_{P=0}^{\text {FUDENS }} & = & \begin{array}{l}
\text { percent change in fucl volume } \\
\text { calculated by FUDENS when } \\
\mathrm{P}=0
\end{array} \\
\left(\frac{\Delta V}{\mathrm{~V}}\right)_{\overline{\mathrm{P}}=0} & = & \begin{array}{l}
\text { percent change in fuel volume } \\
\text { calculated by FSWELL when } \\
\mathrm{P}=0 .
\end{array}
\end{array}
$$

In summary the assumptions made to combine the two models are:

(1) Densification - will occur until equilibrium between pore gases and pore surface tension is reached. This is modeled in FUDENS.

(2) The fuel grains initially swell into the available void space without changing the actual external fuel dimensions due to the stresses caused by fission products in the grains.

(3) Some fission gas is lost into the pores so that thermal sintering cannot be completed.

The CONECT model is described in morc detail in Scction 9.6 .

\subsection{Survey of Swelling Data}

9.2.1 Introduction. This section presents an evaluation of fuel swelling results obtained from sources available in the open (nonproprietary) literature. In addition to macroscopic swelling data, results pertaining to the solid fission product contribution to the aforementioned macroscopic swelling are given. The following sources were used:

Macroscopic Swelling Data:

Battelle, Columbus Laboratories 
Bettis - Flat Plate Resulls

Bettis - Rod Data

General Electric BWR Data

Babcock \& Wilcox PWR Data

United Nuclear Corporation

Turnbull (CEGB ${ }^{[a]}$, Berkeley, UK)

Nelson and Zebroski (GE).

Solid Fission Product Contribution:

Anselin (GE)

Wait (Harwell)

Whapham and Sheldon (AERE, UK)

Harrison and Davies (Harwell)

Olander (U. of C., Berkeley).

\subsubsection{Macroscopic Swelling Data.}

(1) Battelle Columbus Laboratories. Reference A-9.6 presents a summary of the results from the extensive fuel irradiation program at Battelle Columbus Laboratories. Swelling data were obtained for $\mathrm{UO}_{2}$ and $(\mathrm{U}, \mathrm{Pu})_{2}$ fuels clad with a tungsten-rhenium alloy as a function of temperature and burnup.

There are two distinctive characteristics of these experiments. First, the cladding surface temperatures were in the range from 1200 to $1900^{\circ} \mathrm{C}$, as compared with typical BWR and PWR cladding surface temperatures of 280 to $350^{\circ} \mathrm{C}$. Secondly, the tempcrature gradients in the fuel were small, with the fuel centerline-to-surface temperature drop estimated to be less than $300^{\circ} \mathrm{C}$. Nominal corresponding temperature differences for a commercial LWR are typically about $550^{\circ} \mathrm{C}$ at $20 \mathrm{~kW} / \mathrm{m}$ and $1300^{\circ} \mathrm{C}$ at $46 \mathrm{~kW} / \mathrm{m}$. The data showed the swelling rate to have an "Arrhenius" dependence on the cladding surface temperature for fuel temperatures above $50 \%$ of the melting point. This conclusion is discussed in Reference A-9.7. Also, the swelling was a linear function of burnup and the rate a function of the fuel temperature. The nominal experimental conditions and parameters are summarized in Table A-9.III.

[a] Central Electricity Generating Board. 


\section{TABLE A-9. III}

\section{NOMINAL CONDITIONS AND PARAMETERS FOR BATTELLE SWELLING EXPERIMENTS}

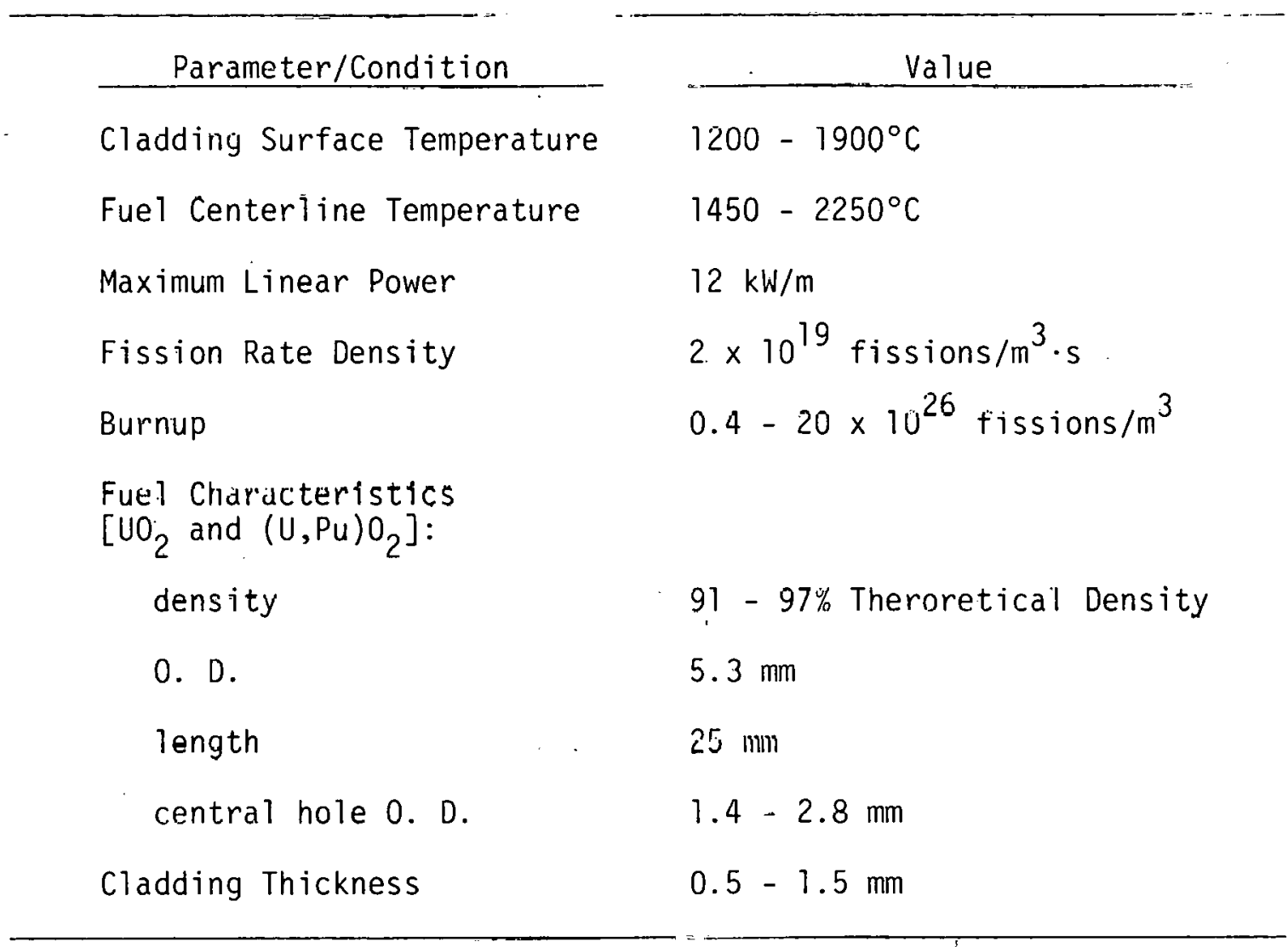

The temperature and burnup dependence of the yolumetric swelling rates are shown in Figures A-9.2 (from Reference A-9.8) and A-9.3 (from Reference A-9.9), respectively. Note that the temperatures in both figures are cladding surface temperatures which were the only tompcraturcs measured. The fuel surface and centerline temperatures were estimated to be 50 and $300^{\circ} \mathrm{C}$ higher, respectively. The volumetric swelling rates were calculated from extcrnal dimensional changes of the fuel which were determined by radiography [A-9.9]. The swelling rates varied from 3 to $15 \% \Delta \mathrm{V} / \mathrm{V}$ per $10^{26}$ fissions $/ \mathrm{m}^{3}$ for a variation in cladding surface temperature from 1325 to $1900^{\circ} \mathrm{C}$.

The swelling rates reported by Battelle are atypical of swelling rates associated with LWR fuel. The method of applying these data to relevant conditions has been discussed by Chubb ${ }^{[A-9.7]}$. In the opinion of this author, these data can only be used in the framework of an analytic model incorporating the free swelling of elemental fuel volumes. The effects of the restraint imposed by cooler adjacent volume elements and of the cladding would have to be taken into account. A complication exists inasmuch as the Battelle data represent macroscopic swelling, i.e., changes in the external dimensions of the fuel, whereas density change data would be more appropriate to such a modeling effort. The Battelle data have been used for such modeling efforts $[$ A-9.10, A-9.12]. 


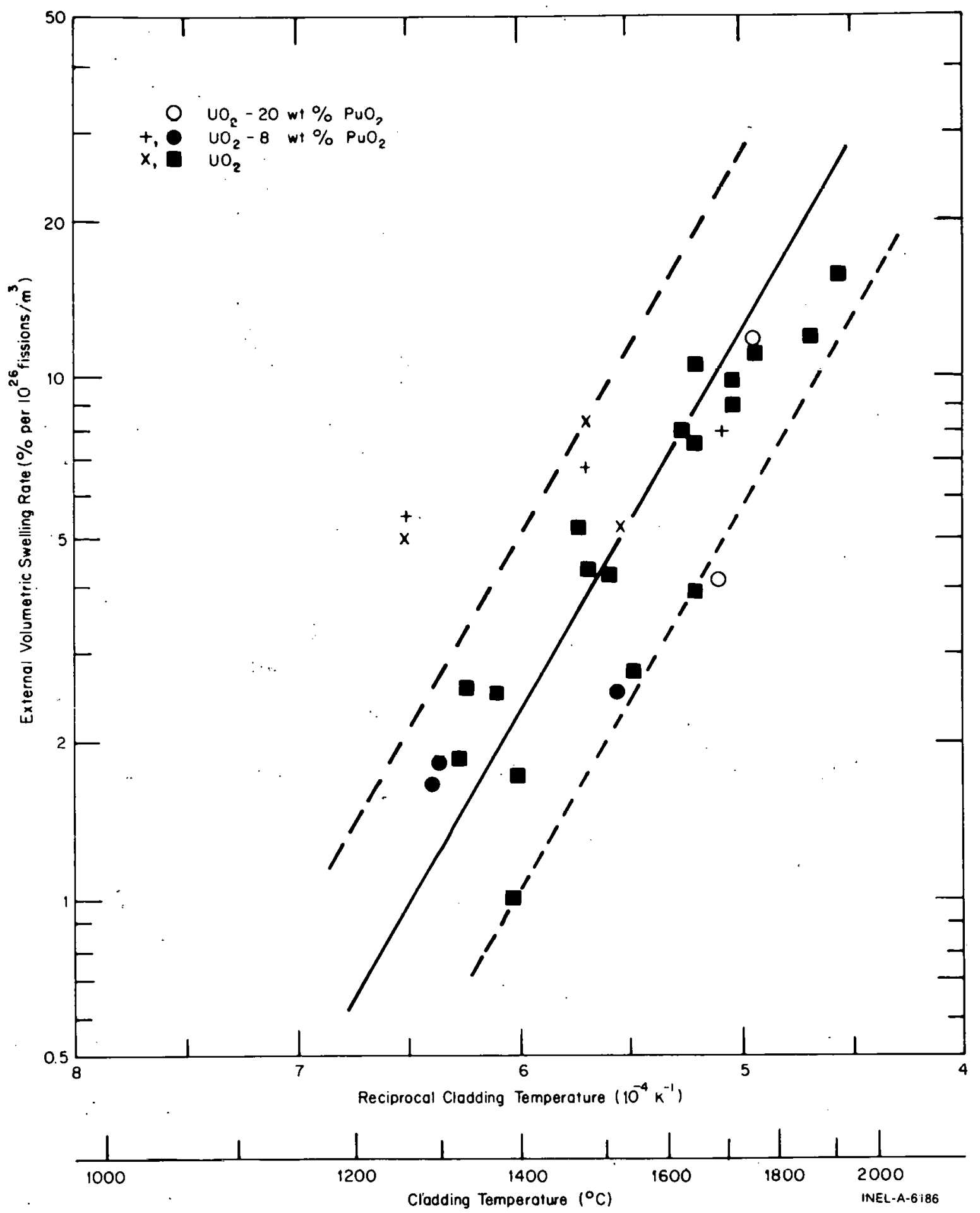

Fig. A-9.2 Volumetric swelling rate as a function of cladding surface temperature for $\mathrm{UO}_{2}$ and $(\mathrm{U}, \mathrm{Pu}) \mathrm{O}_{2}$ clad in W/Re as seen in Battelle experiments. 


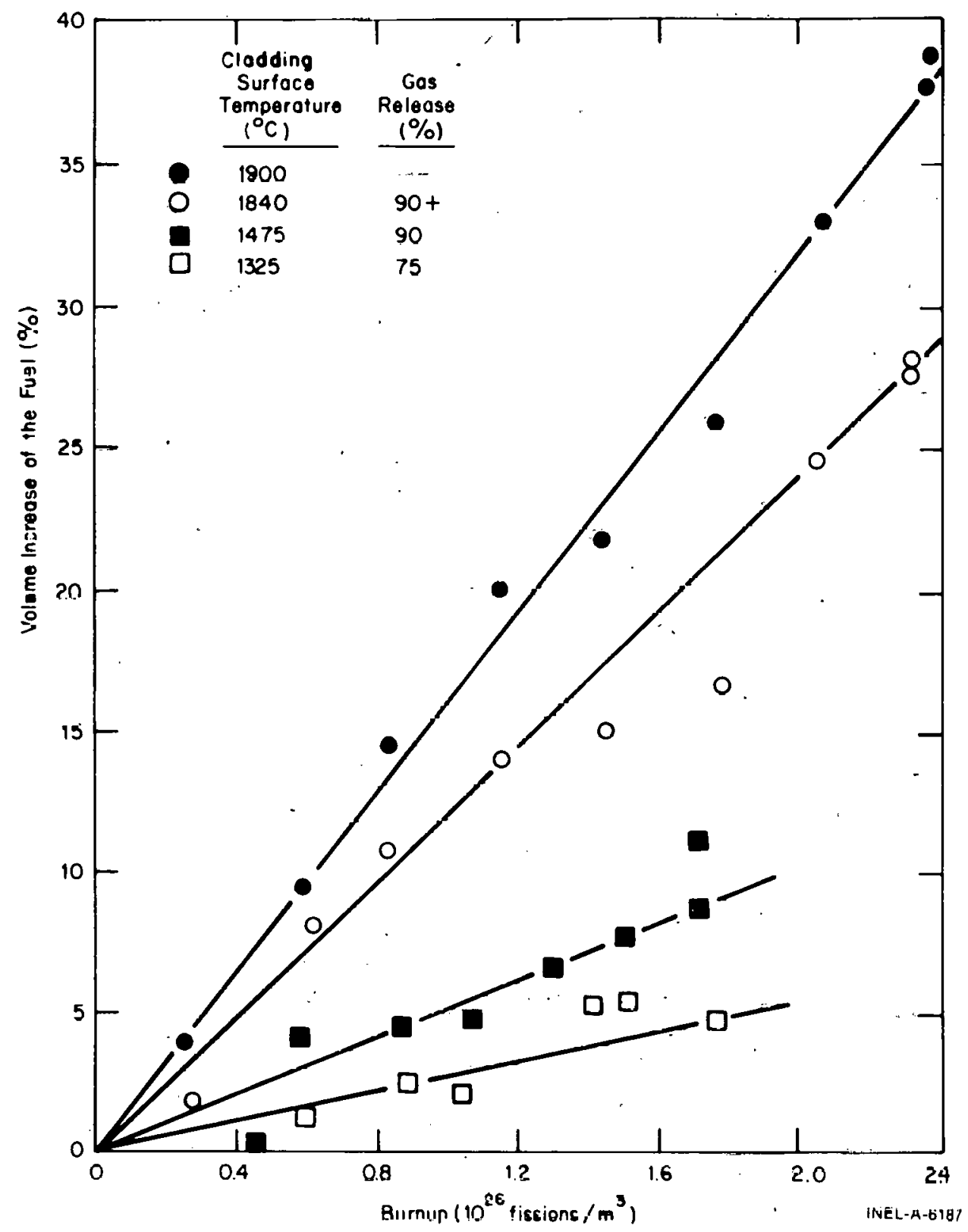

Fig. A-9.3 Swelling of UO 2 at high temperatures measured at Battelle.

An extensive program at General Electric investigating swelling of BWR fuel concluded that the very high swelling rates manifested in the Battelle data apply only to fuel with very low restraint $[A-9.3, A-9.4]$. The significance of restraint in reducing swelling has been reported by Grando et al ${ }^{[: A-9.13]}$.

(2) Bettis Flat Plate Swelling Data. The data from this Westinghouse program indicate that $\mathrm{UO}_{2}$ undergoes a volume increase at a rate of $0.16 \% \Delta \mathrm{V} / \mathrm{V}$ per $10^{26}$ fissions $/ \mathrm{m}^{3}$ up to a "threshold" burnup $[\mathrm{A}-9.2, \mathrm{~A}-9.14]$. Above this threshold burnup, the swelling rate is 0.5 to $0.7 \% \Delta \mathrm{V} / \mathrm{V}$ per $10^{26}$ fissions $/ \mathrm{m}^{3}$. Threshold burnup values ranged from $11 \times 10^{26}$ to $17 \times 10^{26}$ fissions $/ \mathrm{m}^{3}$. Based on an analysis of low density fuel, the true 
swelling rate of $\mathrm{UO}_{2}$, independent of burnup, was determined to he $0.7 \% \Delta \mathrm{V} / \mathrm{V}$ per $10^{26}$ fissions $/ \mathrm{m}^{3}$. This true rate is only observed after the internal pores are sealed. Thus, this rate is masked during the initial exposure period until the as-fabricated porosity is filled by fission products. The experimental conditions and parameters are summarized in Table A-9.IV.

\section{TABLE A-9. IV}

NOMINAL CONDITIONS AND PARAMETERS

FOR BETTIS FLAT PLATE SWELLING EXPERIMENTS

\begin{tabular}{ll}
\hline \multicolumn{1}{c}{ Parameter/Condition } & \multicolumn{1}{c}{ Value } \\
\hline Cladding Surface Temperature & $290-315^{\circ} \mathrm{C}$ \\
Fuel Centerline Temperature & $885-2150^{\circ} \mathrm{C}$ \\
Maximunil Linear Power & $16 \mathrm{~kW} / \mathrm{m}$ \\
Burnup & $1-36 \times 10^{26}$ fissions $/ \mathrm{m}^{3}$ \\
Fuel Characteristics $\left(\mathrm{UO}_{2}\right):$ & $87-98 \% \mathrm{Theoretical} \mathrm{Density}^{\text {density }}$ \\
thickness & $0.8-4 \times 10^{-3} \mathrm{~m}$ \\
width & $0.32-1.27 \times 10^{-2} \mathrm{~m}$ \\
$\quad$ length & $3.8-15.2 \times 10^{-2} \mathrm{~m}$ \\
Cladding Thickness & $3.8-6.4 \times 10^{-4} \mathrm{~m}$ \\
\hline
\end{tabular}

These data have been frequently used as the basis for semiempirical swelling models and for model verification. (See, for example, Reference A-9.15.) Although the experimental conditions are representative of LWR conditions, extrapolation from the flat plate geometry to a rod configuration is not straightforward. Also, the Bettis data have been reevaluated by workers at General Electric who concluded the swelling rate is $0.5 \% \Delta \mathrm{V} / \mathrm{V}$ per $10^{26}$ fissions $/ \mathrm{m}^{3}$ rather than the $0.7 \% \Delta \mathrm{V} / \mathrm{V}$ per $10^{26}$ fissions $/ \mathrm{m}^{3}$ value originally extracted by the Bettis workers $[A-9.3]$.

(3) Bettis Rod Data. Swelling data were obtained on two fuel rods containing $\mathrm{UO}_{2}$ in the form of dished-end pellets ${ }^{[A-9.3]}$. The swelling rate was estimated as $0.82 \% \Delta \mathrm{V} / \mathrm{V}$ per $10^{26}$ fissions $/ \mathrm{m}^{3}$. This result was interpreted as consistent with the Bettis flat plate value of $0.7 \% \Delta \mathrm{V} / \mathrm{V}$ per $10^{26}$ fissions $/ \mathrm{m}^{3}$ on the basis of higher temperatures in the rod experiments. The justification for the statement that higher temperatures were maintained in the rod experiments than in the plate experiments is not obvious. 
"The total swelling rate of $0.82 \% \Delta \mathrm{V} / \mathrm{V}$ per $10^{26}$ fissions $/ \mathrm{m}^{3}$ was analyzed into three components:

(1) $35 \%$ accommodated in pellet dishes

(2) $49 \%$ fillcd internal porosity

(3) $16 \%$ caused diametral expansion.

(4) General Electric BWR Data. Results from an extensive General Electric

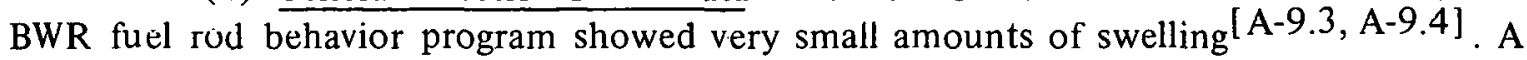
major conclusion from the program is that fuel pins with diametral clearances typical of BWR design ( 0.23 to $0.30 \mathrm{~mm}$ ) did not show any significant positive diameter changes due to the combined effects of differential thermal expansion and fission product swelling up to a burnup of $25.7 \times 10^{26}$ fissions $/ \mathrm{m}^{3}$. Since no actual cladding diameter changes were observed, the maximum swelling rate is that inferred by assuming all the internal volume of the fuel rod is filled by fission products. This assumption leads to a maximum swelling rate of $0.4 \% \Delta \mathrm{V} / \mathrm{V}$ per $10^{26}$ fissions $/ \mathrm{m}^{3}$.

Pins with smaller diametral clearances did exhibit diameter increases. However, the measured expansion of high exposure pins in this group falls within the data scatter of similar clearance, low exposure pins. It was concluded that all of these observed diameter increases can be attributed to thermal expansion early in life.

A complementary General Electric program evaluating swelling of LMFBR ${ }^{[a]}$ type fuel ruds led to a maximum swelling rate of $0.23 \% \Delta \mathrm{V} / \mathrm{V}$ per $10^{26}$ fissions $/ \mathrm{m}^{3}$.

(5) Babcock \& Wilcox PWR Data. Babcock \& Wilcox have conducted a high burnup irradiation program to determine the performance characteristics of typical PWR fuel $[\mathrm{A}-9.5]$. The fuel rods were designed to operate at 59.1 and $70.5 \mathrm{~kW} / \mathrm{m}$, the normal and peak transient heat rates, respectively, for design bases in PWR fuel rods.

Swelling rates were calculated from measured increases in fuel rod diameters and fuel column lengths. Corrections for internal porosity were not made. Also, the calculations assumed that the peak diameter increase occurred over the entire length of the fuel column, an assumuption considered valid for most rods.

The averaged swelling rate determined for pelletized $\mathrm{UO}_{2}$ fuel rods is $1.10 \% \Delta \mathrm{V} / \mathrm{V}$ per $10^{26}$ fissions $/ \mathrm{m}^{3}$. These data and the averaged swelling rate as a function of burnup are shown in Figure A-9.4.

(6) Miscellaneous Data. A United Nuclear Corporation program on the swelling and gas release of fast reactor fuels confirmed that unrestrained swelling rates are considerably higher than swelling rates of fuels restrained by cladding $[A-9.13]$. The unrestrained swelling

[a] Liquid Metal Fast Breeder Reactor. 


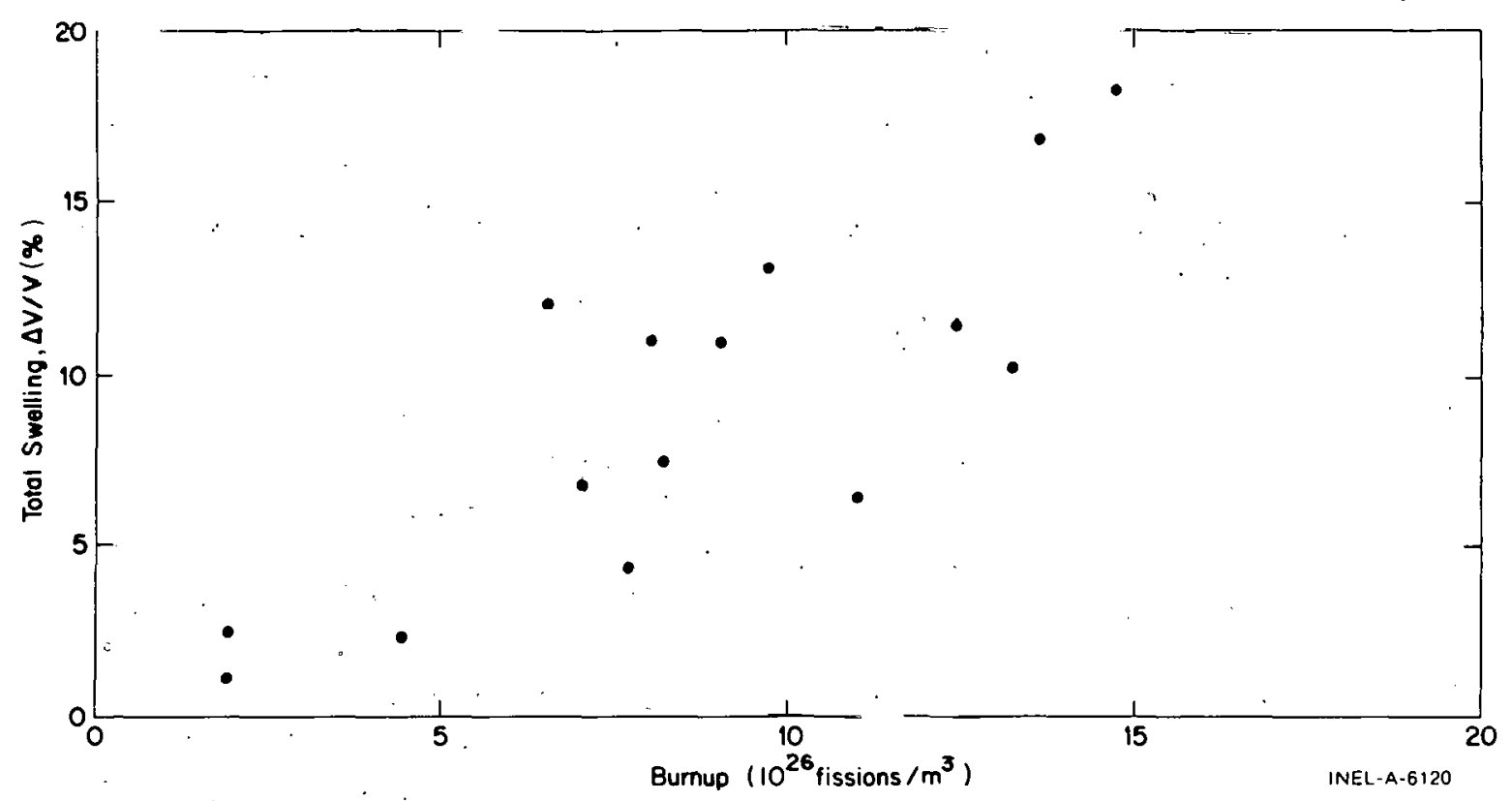

Fig. A-9.4 Total swelling as a function of burnup from Babcock \& Wilcox high burnup fuel behavior program

fuel specimens consisted of $1.524 \times 10^{-3} \mathrm{~m}$ diameter by $1.27 \times 10^{-2} \mathrm{~m}$ long free-standing pins in helium, held at the ends in tantalum carbide supports with space provided for axial expansion. The small diameter of the specimens was chosen to obtain essentially isothermal conditions. Test capsules were designed to operate at 1000,1300 , and $1600^{\circ} \mathrm{C}$ controlled to $\pm 25^{\circ} \mathrm{C}$ with a fuel $\triangle \mathrm{T}$ of less than $50^{\circ} \mathrm{C}$.

Two specimens of $\left(\mathrm{U}_{0.85} \mathrm{Pu}_{0.15}\right) \mathrm{O}_{2}$ were irradiated at fuel temperatures of 1365 and $1580^{\circ} \mathrm{C}$, respectively, to a burnup of $4.9 \times 10^{26}$ fissions $/ \mathrm{m}^{3}$. The lower temperature specimen was observed to have a swelling rate of $1.5 \% \Delta \mathrm{V} / \mathrm{V}$ per $10^{26}$ fissions $/ \mathrm{m}^{3}$. The higher temperature specimen swelled at a rate of $2.6 \% \Delta \mathrm{V} / \mathrm{V}$ per $10^{26}$ fissions $/ \mathrm{m}^{3}$. The conclusion drawn is that the mixed oxide swelling rate at $1600^{\circ} \mathrm{C}$ is 1.7 times the rate at $1300^{\circ} \mathrm{C}$.

Collins and Hargreaves ${ }^{[A-9.18]}$ have summarized swelling results obtained from several sources. They report swelling rates from 0.17 to $0.33 \% \Delta \mathrm{V} / \mathrm{V}$ per $10^{26}$ fissions $/ \mathrm{m}^{3}$ for "low temperature" fuel, i.e., fuel with a maximum temperature below $1125^{\circ} \mathrm{C}$. They conclude that a swelling rate of $0.33 \% \Delta \mathrm{V} / \mathrm{V}$ per $10^{26}$ fissions $/ \mathrm{m}^{3}$. is conservative for describing such low temperature swelling. This value corresponds to what is commonly referred to as solid fission product swelling, however, it includes the effects of gaseous fission products although bubble formation and interconnected porosity are insignificant at this low temperature. Above $1125^{\circ} \mathrm{C}$ they state that gas bubble swelling hecomes important. Fuel porosity increases at approximately $0.5 \%$ per $100^{\circ} \mathrm{C}$ fuel centerline temperature increase.

Turnbull [A-9.19] reported swelling rates of approximately $4 \% \Delta \mathrm{V} / \mathrm{V}$ per $10^{26}$ fissions $/ \mathrm{m}^{3}$ for $\mathrm{UO}_{2}$ having an average initial grain size of $40 \mu \mathrm{m}$. As in the Battelle 
Columbus experiments the temperature gradients in the fuel wcrc small, with a fuel $\Delta \mathrm{T}$ of approximately $100^{\circ} \mathrm{C}$. The fuel was maintained at $1750^{\circ} \mathrm{C}$ and the maximum burnup was low, less than $10^{26}$ fissions $/ \mathrm{m}^{3}$. The $\mathrm{UO}_{2}$ specimens themselves were small, $1 \mathrm{~cm}$ in length and $0.3 \mathrm{~cm}$ in diameter. They were encapsulated in ' $12 \angle C$ ' molybdenum ${ }^{[a]}$. The results are consistent with those obtained in the Battelle experiments and probably represent unrestrained swelling.

Nelson and Zebroski reported $[A-9.1]$ some data on the temperature dependence of swelling rates for (U, $\mathrm{Pu}) \mathrm{O}_{2}$ fuel. The irradialion capsules were designed to provide strong radial constraint so that any swelling resulted in axial elongation of the fuel. The fuel pellets wcre approximately $7.6 \mathrm{~cm}$ in length and $0.25 \mathrm{~cm}$ in diameter. The cladding was $1.031 \mathrm{~cm}$-thick 304 stainless steel. Linear heat rates of $25.40 \mathrm{~kW} / \mathrm{m}$ and cladding surface temperatures between 290 and $420^{\circ} \mathrm{C}$ were typical of commercial LWR conditions.

The results of the measurements have been summarized by Cox $[A-9.20]$. Two major conclusions were drawn: first, the fuel volume increase is linear with burnup for each temperature range up to $14 \times 10^{26}$ fissions $/ \mathrm{m}^{3}$; second, the swelling rate is sharply affected by temperature. The swelling rates of the fuel are shown in Table A-9.V. The data were obtained for burnups between $14 \times 10^{26}$ and $21 \times 10^{26}$ tissions $/ \mathrm{m}^{3}$.

TABLE A-9.V

SWELLING RATES OF $(U, P U) U_{2}$

OBTAINED BY NELSON AND ZEBROSKI

Fuel Centerline

Temperature $\left({ }^{\circ} \mathrm{C}\right)$

$14 \cap n$.

1800

2200

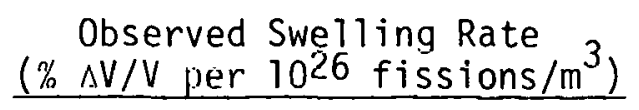

0.12
Relative Swelling

Rate

1.0

3.3

1.7

An explanation has been given for the temperature dependence observed in the swelling data shown in Table A-9.V. The low swelling rate at $1400^{\circ} \mathrm{C}$ is due to the strong radial restraint and accommodation of fission in interstitial sites, even though a higher percentage of the fission gas is retained in the fuel. The rate at $2200^{\circ} \mathrm{C}$ is lower than the rate at $1800^{\circ} \mathrm{C}$ due to high gas release. This is consistent with the commonly known temperature-gas release correlation, summarized in Table A-9.VI ${ }^{[A-9.22, ~ A-9.23] . ~ A l l ~ o f ~ t h e ~}$ above results on macroscopic swelling are summarized in Table A-9.VII.

[a] An alloy consisting of $1.25 \%$ titanium, $0.3 \%$ zirconium, $0.15 \%$ carbon, and the balance molybdenum. 
TABLE A-9.VI

FUEL TEMPERATURE-GAS RELEASE-GRAIN STRUCTURE CORRELATION

\begin{tabular}{ccc}
\hline $\begin{array}{c}\text { Fue } \begin{array}{c}\text { Temperature } \\
\left({ }^{\circ} \mathrm{C}\right)\end{array} \\
1200-1400\end{array}$ & $\begin{array}{c}\text { Fission Gas } \\
\text { Release }(\%)\end{array}$ & $\begin{array}{c}\text { Observed } \\
\text { Grain Structure }\end{array}$ \\
$1400-1700$ & $<10$ & $\begin{array}{c}\text { As-sintered } \\
\text { Equiaxed }\end{array}$ \\
$>1700$ & $70-100$ & Columnar \\
\hline
\end{tabular}

9.2.3 Solid Fission Product Swelling. The contribution to swelling due to solid fission products has been evaluated by a number of authors and is included here for completeness.

Anselin $[$ A-9.24] found the solid fission product contribution to the swelling rate, based on irradiations performed under a wide range of conditions, to be $0.35 \% \Delta \mathrm{V} / \mathrm{V}$ per $10^{26}$ fissions $/ \mathrm{m}^{3}$. However, he cautions that there is no unique number, since this contribution to swelling depends on irradiation conditions, fuel pin design, and the properties of the fuel itself. Maximum and minimum swelling rates were calculated by assuming zero and then complete use of fission produced vacancies in the fuel, giving values of $0.54 \% \Delta \mathrm{V} / \mathrm{V}$ per $10^{26}$ fissions $/ \mathrm{m}^{3}$ and $0.13 \% \Delta \mathrm{V} / \mathrm{V}$ per $10^{26}$ fissions $/ \mathrm{m}^{3}$, respectively. Note that the mcasured value, $0.35 \% \Delta \mathrm{V} / \mathrm{V}$ per $10^{26}$ fissions $/ \mathrm{m}^{3}$, is very nearly the average of these calculated extremes.

Anselin also found the solid fission product swelling rates for mixed oxide fuel to be nearly the same as for $\mathrm{UO}_{2}$. Using $(80 \% \mathrm{U}, 20 \% \mathrm{Pu}) \mathrm{O}_{2}$ and $\mathrm{UO}_{2}$, minimum swelling rates of $0.12 \% \Delta \mathrm{V} / \mathrm{V}$ per $10^{26}$ fissions $/ \mathrm{m}^{3}$ and $0.13 \% \Delta \mathrm{V} / \mathrm{V}$ per $10^{26}$ fissions $/ \mathrm{m}^{3}$ were calculated, respectively. (These calculations were made to room temperature.)

Lyons $^{[A-9.25]}$ has summarized the solid fission product swelling results of several authors, including those of Anselin. Wait $[\mathrm{A}-9.26]$ obtained a value of $0.21 \% \wedge \mathrm{V} / \mathrm{V}$ per $10^{26}$ fissions $/ \mathrm{m}^{3}$. Whapham and Sheldon $[A-9.27]$ obtained $0.20 \% \Delta \mathrm{V} / \mathrm{V}$ per $10^{26}$ fissions $/ \mathrm{m}^{3}$.

Harrison and Davies ${ }^{[A-9.28]}$ calculated solid fission product swelling values as a function of thermal neutron flux. They concluded that the swelling contribution monotonically decreased as the flux increased. Swelling contributions of $0.45 \% \Delta \mathrm{V} / \mathrm{V}$ per $10^{26}$ fissions $/ \mathrm{m}^{3}$ and $0.39 \% \Delta \mathrm{V} / \mathrm{V}$ per $10^{26}$ fissions $/ \mathrm{m}^{3}$ were calculated for thermal neutron flux values of $10^{16}$ and $10^{19}$ neutrons $/ \mathrm{m}^{2} \cdot \mathrm{s}$, respectively.

Olander $[A-9.29]$ also calculated the solid fission product swelling contribution. He obtained a value of $0.32 \% \Delta \mathrm{V} / \mathrm{V}$ per atom $\%$ burnup, which corresponds closely to Anselin's 
TABLE A-9.VII

SUMMARY OF MF.CROSCOPIC SWELLING DATA

\begin{tabular}{|c|c|c|c|}
\hline Data Source & $\begin{array}{r}\text { Observed Swelling } \\
\text { Rate }(\% \Delta V / \mathrm{per} \\
\left.1026 \text { fissions } / \mathrm{m}^{3}\right) \\
\end{array}$ & $T_{\text {fuel }}\left({ }^{\circ} \mathrm{C}\right)$ & Comments \\
\hline Battelle $e^{[A-9.6]}$ & $3-15$ & $1450-2250$ & Isothermal, free swelling \\
\hline United Nuclear $[A-9.13]$ & 1.5 & 1365 & Isothermal, free swelling \\
\hline United Nuclear ${ }^{[A-9.13]}$ & 2.6 & 1580 & $(U . P u) G_{2}$ \\
\hline Turnbu11 ${ }^{[A-9.19]}$ & 4.0 & 1750 & Isothermal \\
\hline $\operatorname{Bettis}[A-9.2, A-9.1 .6]$ & 0.7 & $1000-2000$ & Flet plate data \\
\hline Bettis $^{[A-9.16]}$ & 0.82 & $900-1700$ & Fod data \\
\hline GE BWR rods $[A-9.3, A-9.4]$ & $0.4(\max )$ & 1200 - melting & \\
\hline GE LMFBR rods ${ }^{[A-9.17]}$ & $0.23(\max )$ & 540 - melting & $(\mathrm{U}, \mathrm{Pu}) \mathrm{O}_{2}$ \\
\hline$B \& W$ PWR rods $[A-9.5]$ & 1.10 & $1850-$ melting & \\
\hline Collins \& Hargreaves ${ }^{[A-9.18]}$ & $0.17-0.33$ & 1125 & Low temperature \\
\hline \multirow[t]{3}{*}{ Nelson \& Zebroski[A-9.1] } & 0.12 & 1400 & $(\mathrm{U}, \mathrm{Pu}) \mathrm{O}_{2}$ \\
\hline & $0.2-0.3$ & 1800 & \\
\hline & 0.20 & 2200 & \\
\hline
\end{tabular}


minimum value of $0.12 \% \Delta \mathrm{V} / \mathrm{V}$ per $10^{26}$ fissions $/ \mathrm{m}^{3}$. Olander points out that this value does not account for fission product migration and is influenced by uncertainties in the physical and chemical states of the fission products, leading to an error of $\pm 50 \%$ in the calculated value. Also, the influcnce of deviations from stoichiometry is discussed. For initially hypostoichiometric $\mathrm{UO}_{2}, \frac{\Delta \mathrm{V}}{\mathrm{V}} \approx 0.074 \%$ per $10^{26}$ fissions $/ \mathrm{m}^{3}$; for initially hyperstoichiometric fuel or fuel irradiated to high burnups, $\frac{\Delta V}{V} \approx 0.22 \%$ per $10^{26}$ fissions $/ \mathrm{m}^{3}$. These results are summarized in Table A-9.VIII.

TABLE A-9.VIII

\section{SUMMARY OF SOLID FISSION PRODUCT SWELLING VALUES}

$\frac{\text { Source }}{\text { Ansel in }[A-9.24]}$

Wa it $[A-9.26]$

Whapham \& Sheldon [A-9.27]

Harrison \& Davies [A-9.28]

01 ander [A-9.29]

\section{Value (\% $\Delta V / V$ per} 1026 fissions $/ \mathrm{m}^{3}$ )

$0.13-0.54$, calculated

0.35 measured

0.20

$0.46-0.39$, flux dependent

$0.12 \pm 50 \%$

\subsection{Survey of Swelling Models}

Since the fuel swelling model described in this report is empirical, a detailed review of mechanistic or semiempirical swelling models will not be attempted. For such a review see, for example, the article by Frost $[A-9.30]$. However, a summary of recent modeling efforts will be given for completeness and future reference.

Swelling data are best described in terms of "geometrical" swelling. Geometrical swelling is defined as comprising all the effects which cause an increase, $\Delta V(b)$, of the volume $(\mathrm{V})$ of the original fuel pellet after a given burnup, $\mathrm{b}^{[\mathrm{A}-9.31]}$. The major mechanical swelling models, GRASS and BUBL, address that gaseous fission product contribution to this phenomenon $[A-9.32-A-9.35]$. To describe the observed phenomenon, such models must be coupled to a fuel behavior code which takes into account stresses in the fuel, creep, densification, and the thermal-stress-induced pellet cracking. GRASS, for example, has been joined to the SST code and calculated geometrical swelling results have been obtained $[A-9.36]$. 
The bubble growth and transport model of Greenwood and Speight ${ }^{[A-9.37]}$ has been used in the CYGRO ${ }^{[A-9.38]}$ and FIGRO ${ }^{[. A-9.15]}$ codes with reasonable success.

The model recently proposed by Sun and Okrent ${ }^{[A-9.11]}$ relies on the isothermal data from Battelle[A-9.6, A-9.9] to definc a simplified, semiempinical swelling model. Bauer's model $[A-9.10]$ as well as that of Bupara $[A-9.12]$, intended to describe the Battelle results, but had some similarities to the Sun-Okrent approach in that they are based on the empirical simplification that the strain rate in the low-stress (high temperature) regions of the fuel can he represented as an Arrhenius function.

A distinct approach has been formulated by Dollins and Ocken, who focus on the resolution phenomena $[\mathrm{A}-9.39, \mathrm{~A}-9.41]$. The model as originally proposed underpredicted the swelling $[A-9.39]$ and has been revised. However, it still remains a research tool rather than a verified predictive mechanism.

In summary, fuel swelling models range from the first principle predictive approach exemplified by GRASS to empirical data correlations as illustrated by Daniel ${ }^{[A-9.2]}$. The processes affecting swelling are extremely complex, so modelers are forced to adjust unknowns to obtain agreement. In terms of steady state swelling, an empirical corrclation giver almost as much accuracy with cünpalıalively trivial effurt.

\subsection{Survey of Models Combining Swelling and Densification}

Many investigators have assumed that fuel swelling and fuel densification dimensional changes could simply be added together in the appropriate manter lo obtain proper correlation of the model with the data. For example, Chubb et al ${ }^{[\text {A-9.42] }}$ proposed a method which is summarized graphically in Figure A-9.5. They assumed that swclling was a linear function of burriup al any given irradiation temperature, and that swelling occurs whether or not pore removal is occurring. Stehle and Assman $[A-9.43]$ also addressed the problem of combining densification and swelling models. They combined models of the two phenomena in à manner very simular to Chubb's method.

Filkins e.t al ${ }^{[A-9.44]}$ also suggested that swelling and densification are additive and lhal the swelling rate per unit exposure time is constant. Their model differs from Chubb's because it assumed no external dimensional changes of the fuel until the pores and the fuel pellet dish volumes are filled.

\subsection{FSWELL Model}

9.5.1 Preliminary Comments. The proposed FSWELL model is empirical, based on the following swelling data sets:

General Electric BWR $[$ A-9.3, A-9.4]

Bettis Flat Plate $[$ A-9.2, A-9.14]

Babcock \& Wilcox PWR ${ }^{[A-9.5]}$ 


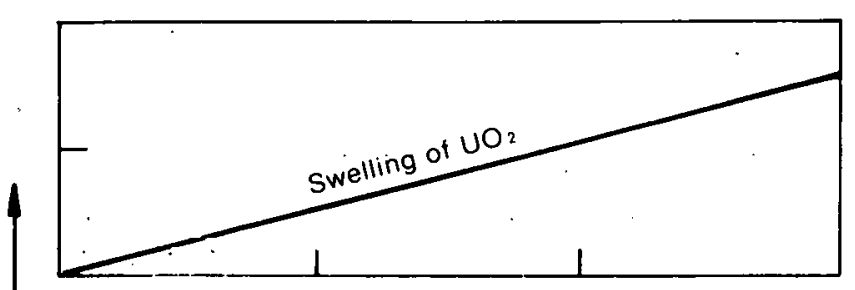

(a) Length Change Due to Fuel Swelling

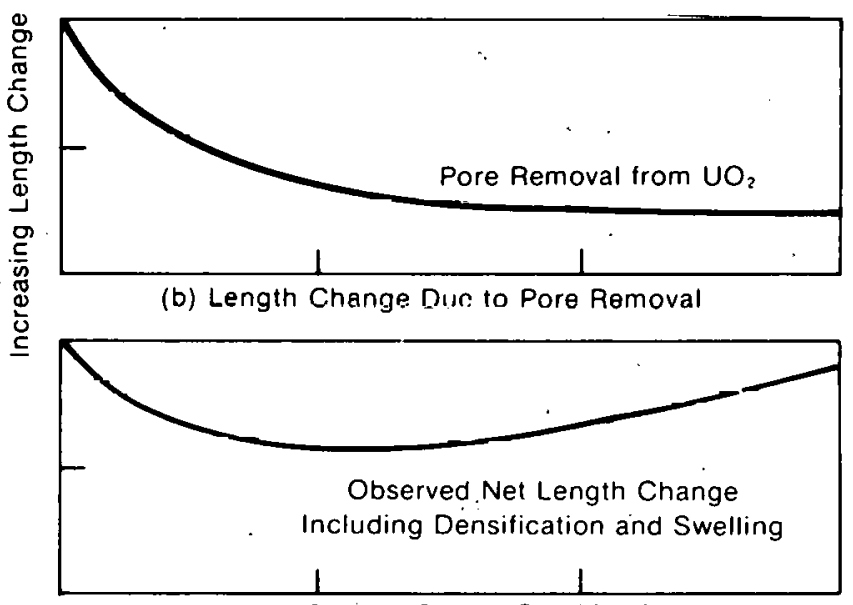

(c) Length Change Due to Combination of Swelling and Densification

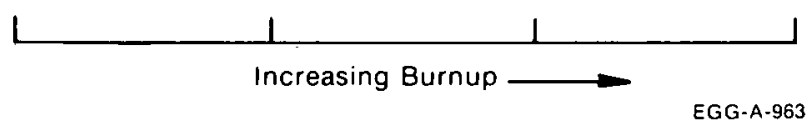

Fig. A-9.5 Schematic of in-pile fuel column length change.

The Battelle ${ }^{[A-9.6]}$, United Nuclear ${ }^{[A-9.13]}$, and Turnbull[A-9.19] data sets were rejected since they are nonrepresentative of LWR fuel conditions. The Bettis rod data $[A-9.16]$ were obtained under what appears to have been widely varied fuel temperature conditions and at fuel centerline temperatures lower than typical LWR conditions.

The low temperature swelling results summarized by Collins and Hargreaves $L-9.18$ ] are consistent with the General Electric BWR results, but documentation is limited. The General Electric LMFBR results $[A-9.17]$ were excluded from the model data base, but do corroborate the General Electric BWR results which are typical of LWR conditions.

Finally, the relative swelling rate results of Nelson and Zebroski will be used to quantify the temperature dependence.

9.5.2 Definition of the Model. The Bettis flat plate data, the General Electric BWR data, and the Babcock \& Wilcox PWR data were obtained at similar linear power levels and overlap in the fuel centerline temperature region near $2000^{\circ} \mathrm{C}$. A linear average of the swelling rate results gives a mean value of $0.7 \% \Delta \mathrm{V} / \mathrm{V}$ per $10^{26}$ fissions $/ \mathrm{m}^{3}$. This value is assumed to apply at $2000^{\circ} \mathrm{C}$. 
Using the relative swelling rate data of Nelson and Zebroski shown in Table A-9.V to account for the variation of swelling rate with temperature, and linearly interpolating between the values at the given fuel centerline temperatures, gives the relative swelling rates shown in Table A-9.IX. Also, the maximum swelling rate values obtained by normalizing the relative swelling rates to $0.7 \% \Delta \mathrm{V} / \mathrm{V}$ per $10^{26}$ fissions $/ \mathrm{mi}^{3}$ at $2000^{\circ} \mathrm{C}$ are shown in the same table.

TABLE A-9. IX

TEMPERATURE DEPENDENCE OF THE SWELLING RATE

\begin{tabular}{rcc}
$\begin{array}{c}\text { Fuel Centerline } \\
\text { Temperature }(\mathrm{K})\end{array}$ & $\begin{array}{c}\text { Relative } \\
\text { Swelling Rate }\end{array}$ & $\begin{array}{c}\text { Maximum Swelling Rates } \\
\left(\% \Delta V / V \text { per } 10^{26} \text { fissions } / \mathrm{m}^{3}\right)\end{array}$ \\
\cline { 2 - 3 }$T \leq 1673$ & 1.0 & 0.28 \\
$1673<T \leq 2073$ & $1+0.00575(T-1673)$ & 0.92 at $2073 \mathrm{~K}$ \\
$2073<T \leq 2473$ & $3.3-0.004(T-2073)$ & 0.476 at $2473 \mathrm{~K}$ \\
$T>4930$ & 1.7 & 0.476
\end{tabular}

\subsection{CONECT Model for Integrating Swelling and Densification}

The subroutine CONECT was modeled to combine effects of fuel densification (FUDENS) and swelling (FSWELL) on fuel dimensions and to allow the models for these separate effects to be improved separately as new data become available for either model: The available porosity fabricated in to the fuel is considered in adding the.contributions of densification and swelling to the dimensional changes. The model views densification as a form of thermal sintering (radiation induced) which reduces the pore sizes and volumes. Must of the very small pores (less than $1 / \mathrm{m}$ ) are eliminated and the larger porca $(1 \mu \mathrm{m}$ or grcater) attain surface tension and internal gas pressure equilibrium. The densification process is stopped by the combined. effects of increased quantitics of fission gases in the pores and by the reduction of the pore volumes.

The EEI/EPRI ${ }^{[A-9.45]}$ data show that pores of $1 \mu \mathrm{m}$ or less are relatively unstable during densification. Pores of $10 \mu \mathrm{m}$ or greater are stable and increase in size. Figure A-9.6 shows how the porosity size distribution changes during irradiation. Since the actual pore size distribution is very difficult to obtain (an electron microscope must be used), the approach in developing the code CONECT was to use bulk porosity.

As long as sufficient porosity is available, swelling is accommodated by pore space and the external fuel dimensions do not change because of swelling. The grains are assumed to creep into the available pores due to intragranular fission product pressures (from both solid 


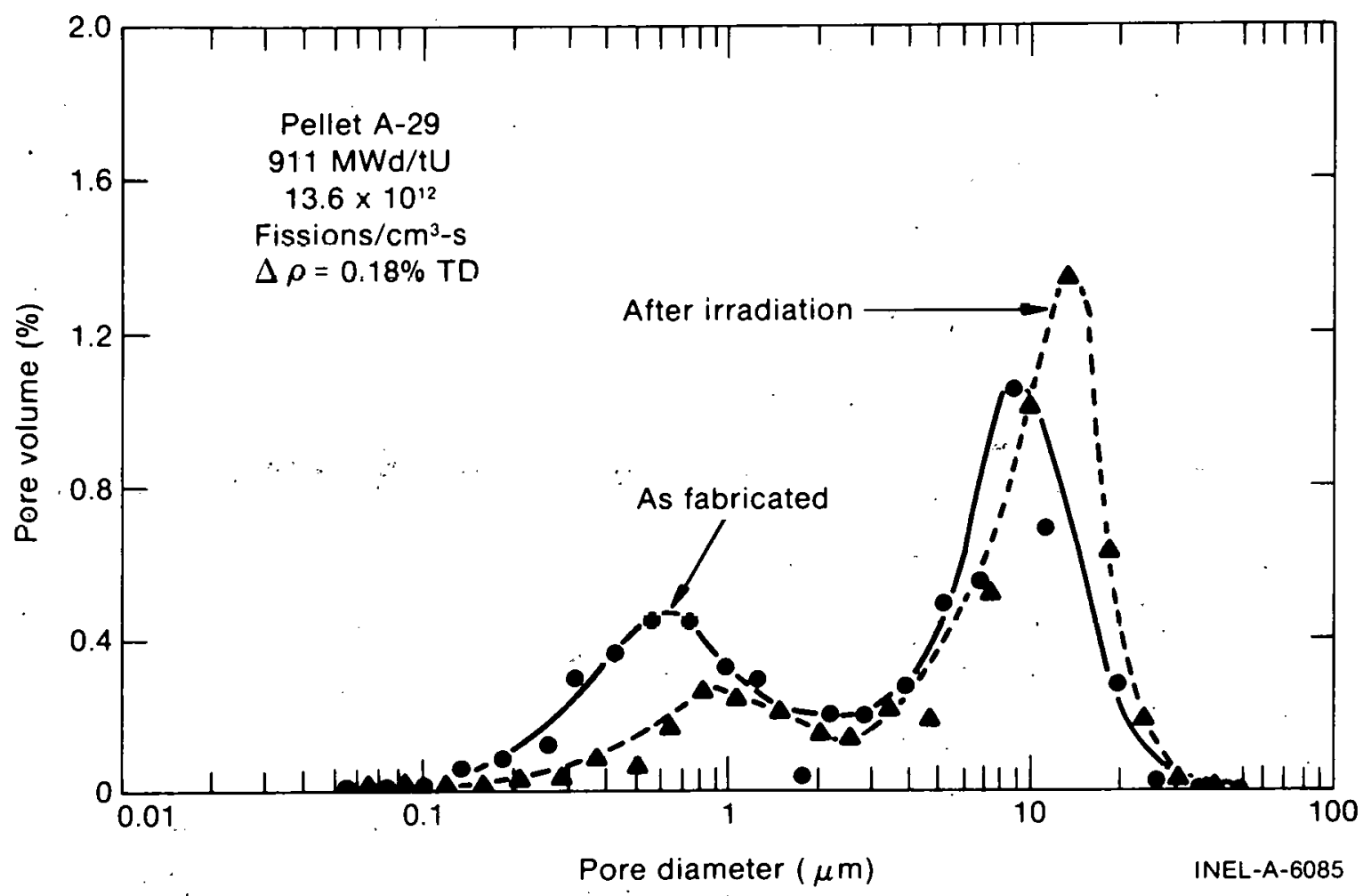

Fig. A-9.6 A smoothed histogram showing the effect of irradiation on the volume distribution of porosity in a stable (pore-former) sintered $\mathrm{UO}_{2}$ fuel.

and gas fission products). Since the grains are randomly oriented, the net effect of this swelling will be to close the intergranular pore space and leave the pellet dimensions unchanged, although each grain will creep only in definite directions. Since fission gases are filling the pores and equilibrium is reached before all the porosity is removed, the fuel density can never reach $100 \%$ of theoretical density. Based on a fit to available data, it was assumed that the maximum porosity that can be taken up by swelling and densification is

$$
P_{f}=\frac{1}{\rho_{0}}-9.425 \times 10^{-5}
$$

where

$$
\begin{aligned}
& \mathrm{P}_{\mathrm{f}}:=\begin{array}{l}
\text { porosity available to be filled by densification and fuel } \\
\text { swelling }
\end{array} \\
& \rho_{\mathrm{O}}=\text { fabricated density of the fuel }\left(\mathrm{kg} / \mathrm{m}^{3}\right)
\end{aligned}
$$

This model implies that if $\rho_{\mathrm{O}}>1.061 \times 10^{4} \mathrm{~kg} / \mathrm{m}^{3}$ (96.7\% of theoretical density) the fuel will not densify, but will immediately begin swelling. The maximum porosity that can be filled by swelling and densification was determined by a best fit to the EPRI ${ }^{[A-9.45]}$ and Banks $[$ A-9.46] data. The EPRI fuel types 1 and 2 were used for the initial calculations. The EPRI data shown in Figure A-9.7 showed rapid densification, with density remaining approximately at the maximum values between 1 and $3.5 \mathrm{GWd} / \mathrm{MtM}$. The Rolstad data $[A-9.47]$ show apparently stable densities at maximum densification values up to 


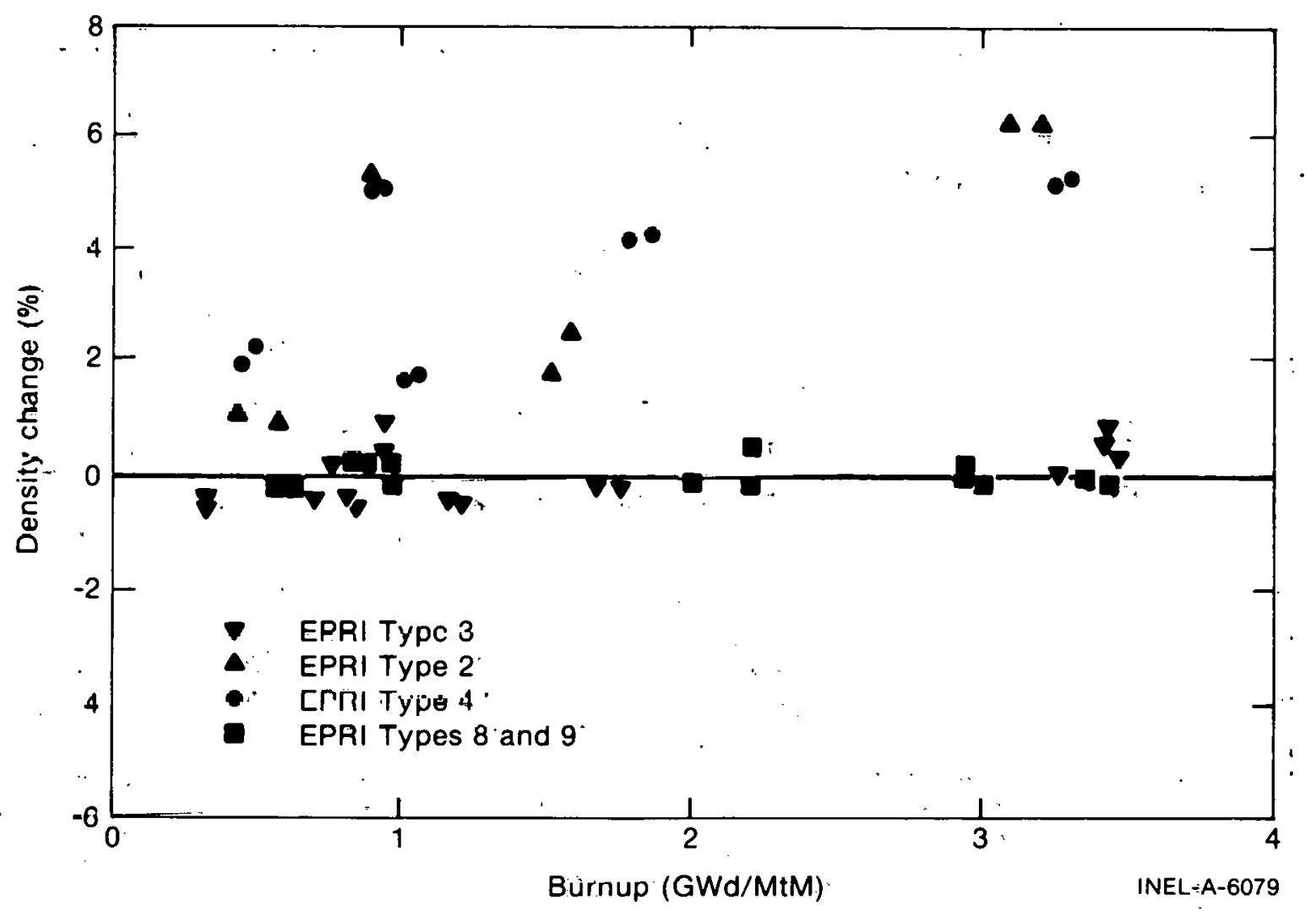

Fig. A-9,7 Densificatinn data for different ERRI ty'pe fucls.

$8 \mathrm{GWd} / \mathrm{MtM}$. The Banks ${ }^{[\mathrm{A}-9.46]}$ data also indicate that outward swelling begins by at least $10 \mathrm{GWd} / \mathrm{MtM}$. Using the EPRI fuel :type 1 data, the amount of swelling (calculated by FSWELL) and the amount of densification (calculated by. FUDENS) were calculated at $5 \mathrm{GW} d / \mathrm{MtM}$ and their sum was used to determine $\mathrm{P}_{\mathrm{f}}$ : Then the constant in Equation (A-9.2) was determined so that calculations using the resintering values of other EPRI fuel types and the Rolstad $[\mathrm{A}-9.47]$ data indicated outward swelling within the 3.0 to $10 \mathrm{GWd} / \mathrm{MtM}$ range. An exception is that for very low density stable fuels, the code calculates no outward. swelling until high burnup is reached (as great as $40 \mathrm{GWd} / \mathrm{MtM}$ ) and the available porosity is . filled.

The point at which outward swelling begins and densification ceases (if it has not done so earlier by limits set in the FUDENS code) is given by $\mathrm{P}=0$, where

$$
P=P_{f}-P_{s}-P_{d}
$$

and

$$
\begin{aligned}
& \mathrm{P}=\quad \begin{array}{l}
\text { remaining porosity which has not been filled by densifi- } \\
\text { cation and swelling }
\end{array} \\
& \mathrm{P}_{\mathrm{f},}=\begin{array}{l}
\text { porosity available to be filled by densification and fuel } \\
\text { swelling }
\end{array}
\end{aligned}
$$




$$
\begin{aligned}
& \mathrm{P}_{\mathrm{S}}=\begin{array}{l}
\text { porosity filled by fuel swelling into the pores (cqual to the } \\
\text { volume change calculated by FSWELL) }
\end{array} \\
& \mathrm{P}_{\mathrm{d}}=\begin{array}{l}
\text { porosity filled by densification (equal to the volume } \\
\text { change calculated by FUDENS) }
\end{array}
\end{aligned}
$$

When $\mathrm{P}$ calculated with Equation (A-9.4) is greater than zero densification may occur. The net volume change is negative and is calculated by the FUDENS model alone. When $\mathrm{P}$ is equal to zero or becomes less than zero (as burnup proceeds) densification is not possible and the fuel volume may increase due to swelling. The change in volume (relative to the original fuel dimensions) is given by CONECT according to:

for $\mathrm{P}<0$

$$
\frac{\Delta V}{V}=\left(\frac{\Delta V}{V}\right)^{\text {FUDENS }}
$$

for $P \geqslant 0$

$$
\frac{\Delta V}{V}=\left(\frac{\Delta V}{V}\right)_{P=0}^{\text {FUDENS }}+\left[\left(\frac{\Delta V}{V}\right)^{\text {FSWELL }}-\left(\frac{\Delta V}{V}\right)_{P=0}^{\text {FSWELL }}\right]
$$

wherc

$$
\begin{aligned}
& \frac{\Delta \mathrm{V}}{\mathrm{V}} \quad=\quad \text { percent change in fuel volume } \\
& \left(\frac{\Delta V}{V}\right)^{\text {FUDENS }}=\quad \begin{array}{l}
\text { percent change in fuel volume } \\
\text { calculated by FUDENS }
\end{array} \\
& \left(\frac{\Delta V}{V}\right)^{\text {FSWELL }}=\text { percent change in fuel volume } \\
& \text { calculated by FSWELL }
\end{aligned}
$$

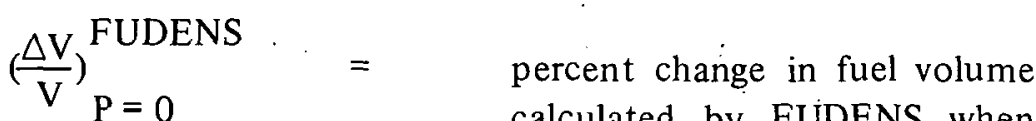

$$
\begin{aligned}
& \text { calculated by FUDENS when } \\
& \mathrm{P}=0 \\
& \left(\frac{\Delta V}{V}\right)_{P=0}^{\text {FSWELL }}=\begin{array}{l}
\text { percent change in fuel volume } \\
\text { calculated by FSWELL when } \\
\mathrm{P}=0 .
\end{array}
\end{aligned}
$$

Figure A-9.8 shows the calculated values of volume change for fuel centerline temperatures of 1800 and $1300 \mathrm{~K}$ with accompanying experimental data points in the centerline temperature range $(1000-2000 \mathrm{~K})$. 


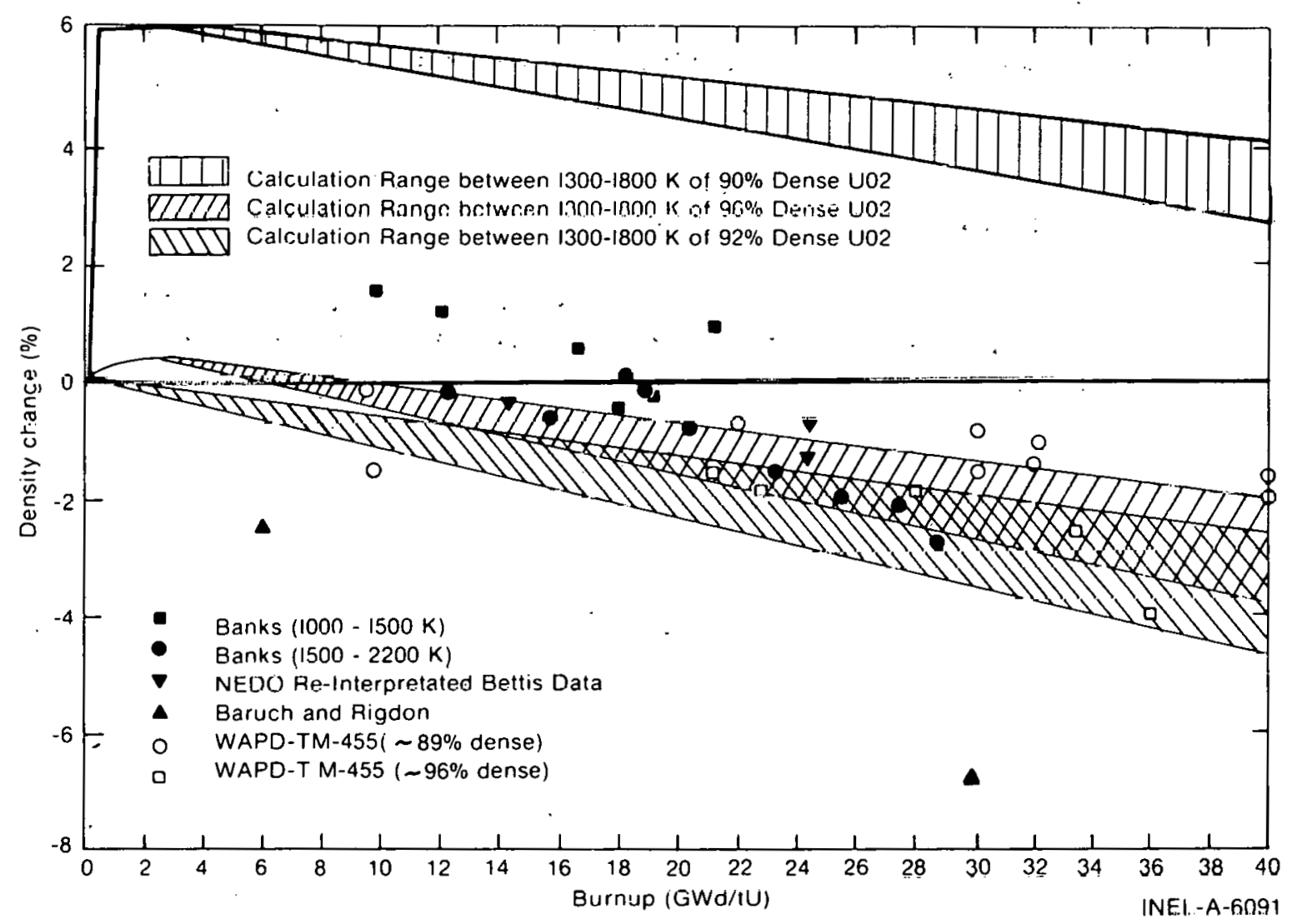

Fig. A-9.8 Comparison of calculated (CONECT) density changes and experimental data.

9.7 Fuel Swelling Subcode FSWELL and Swelling and Densification Integration Subcode CONECT Listings

A listing of the FSWELL subcode is shown as Table A-9.X. A listing of the CONECT subcode is provided in Table A-9.XI.

\subsection{Reterences}

A-9.1. R. C. Nelson and E. L. Zebroski, "Irradiation-Induced Swelling Rates of $\mathrm{PuO}_{2}-\mathrm{UO}_{2}$ with Strong Radial Restraint," Transactions of the American Nuclear Society, 9 (1966) pp 412-413.

A-9.2. R. C. Daniel, M. L. Bleiberg, H. B. Meieran, W. Yeniscavich, Effects of High Burnup on Zircaloy Clad Bulk $\mathrm{UO}_{2}$ Fuel Element Samples, WAPD-263 (September 1962).

A-9.3. T. C. Rowland, M. O. Marlowe, R. B. Elkins, Fission Product Swelling in BWR Fuels, NEDO-20702 (November 1974).

A-9.4. M. F. Lyons, T. C. Rowland, D. T. Weiss, "BWR Fuel Testing at General Electric - An Overview," Paper No. 68 in Proceedings of the BNES International Conference on Nuclear Fuel Performance, 15-19 October 1973, London. CONF-731004 (1974). 
TABLE A-9.X

LISTING OF THE FSWELL SUBCODE

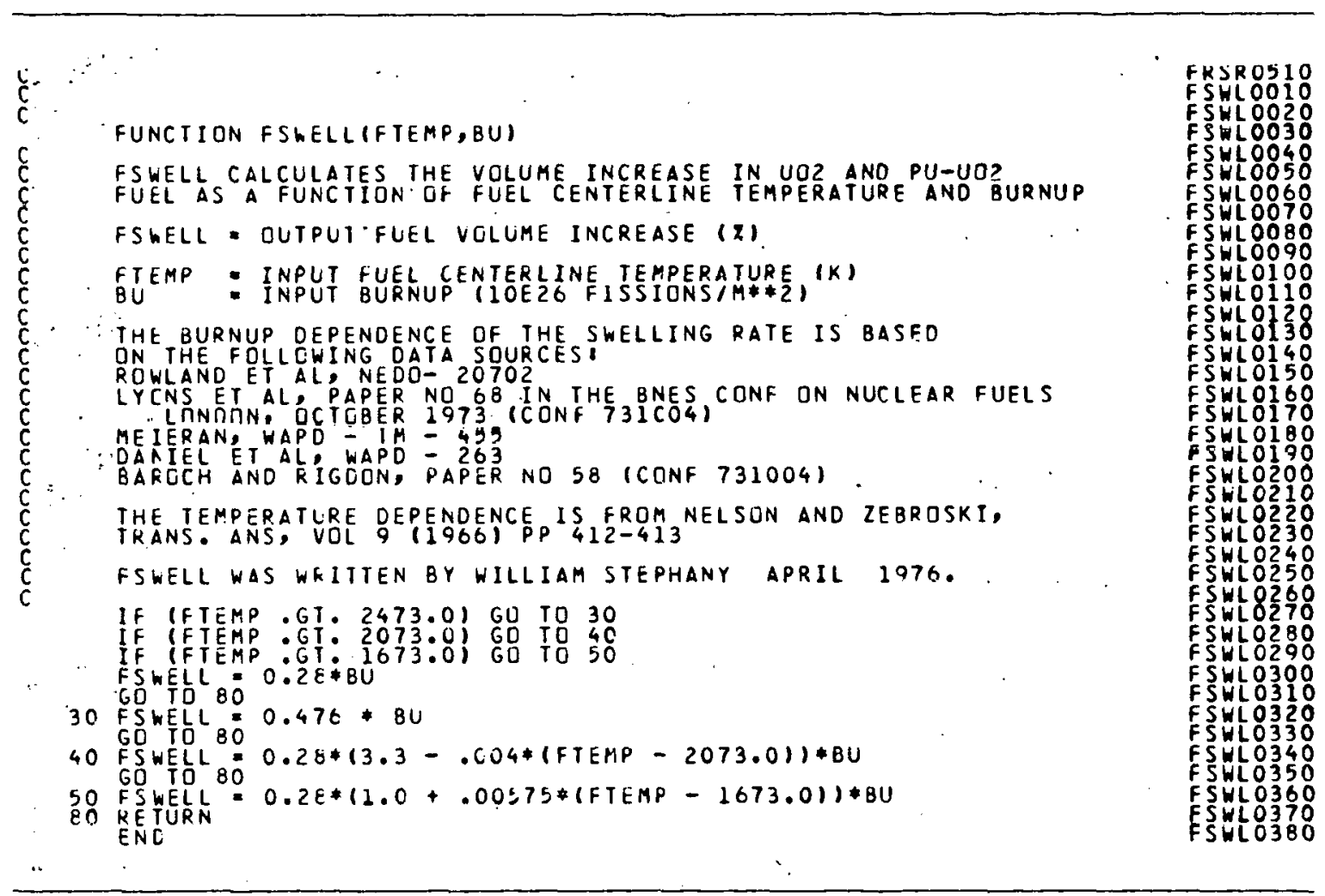

A-9.5. C. J. Baroch and M. A. Rigdon, "Irradiation Behavior of $\mathrm{UO}_{2}$ at Burnups from 10 to $80 \mathrm{GWd} /$ tonne U," Paper No. 58, Procecdings of the BNES International - Conference on Nuclear Fuel Performance, 15-19 October 1973, London, CONF-731004 (1974).

A-9.6. W. Chubb, V. W. Storhok, and D. L. Keller, "Factors Affecting the Swelling of Nuclear Fuel at High Temperatures," Nuclear Technology, 18 (June 1973) pp 231-255.

A-9.7. W. Chubb and D. L. Keller, "Implications of High Temperature Irradiation Data for Low Temperature Reactor Design," Progress on Development of Fuels and Technology for Advanced Reactors During July 1970 through June 1971, BMI-1918 (July 1971) pp B98-B112.

A-9.8. R. F. Hilbert, W. J. Zielenbach, D. E. Lozier, R. B. Clark, V. W. Storhok, "Irradiation Behavior of Oxide Fuels at High Temperatures," Progress on Development of Fuel and Technology for Advanced Reactors During July 1970 through June 1971, BMI-1918 (July 1971) pp B2-B43.

A-9.9. R. F. Hilbert, V. W. Storhok, W. Chubb, D. L. Keller, "Mechanisms of Swelling and Gas Release in Uranium Dioxide," Journal of Nuclear Materials, 38, (1971) pp 26-34. 


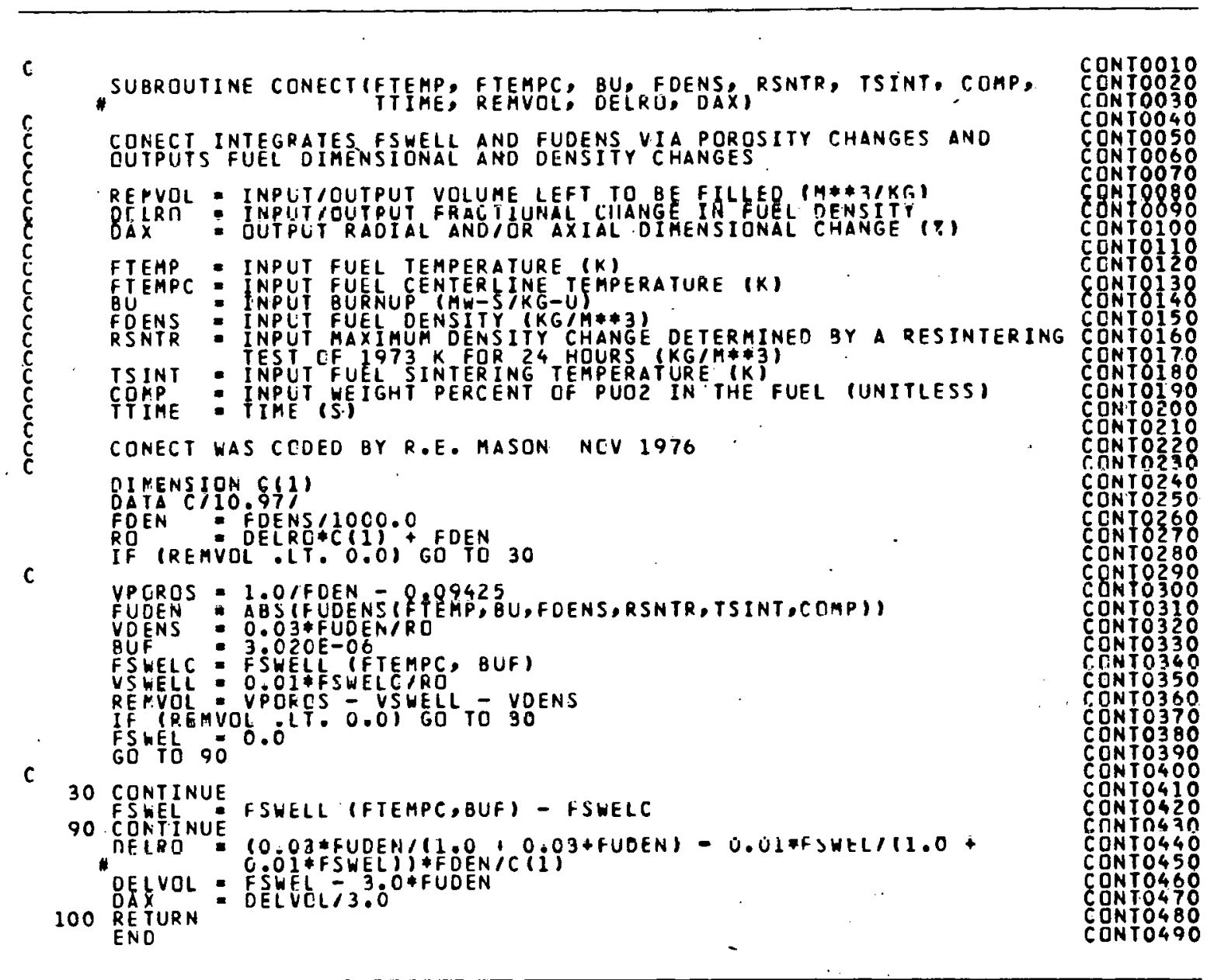

A-9.10. V. A. Bauer, "A Model for the High Tempcrature Swelling of Clad Oxide Fuel," Nuclear Technology, 13 (April 1972) pp 65-70.

A-9.11. Y. Sun and D. Okrent, A Simplified Method of Computing Clad and Fuel Strain and Stress During Irradiation, UCLA-ENG-7591 (October 1975).

A-9.12. S. S. Bupara and R. L. Jentgen, "Mechanical Model of Swelling of Nuclear Fuels," Progress on Development of Fuels and Technology for Advanced Reactors During July 1970 through June 1971; BMI-1918 (July 1971) pp B85-B98.

A-9.13. C. Grando, M. Montgomery, A. Strasser, "Unrestrained Swelling and Fission Gas Release of Fast Reactor Fuels," Proceedings of the Conference on Fast Reactor Fuel Element Technology, 13-15 April, 1971, New Orleans, (Ruth Farmakes) (ed.) pp 771-784. 
A-9.14. H. B. Meieran, History of ithe NRX Reactor $X I q$ and $X-3=n$ Tesis and the Nondestructive Post Irradiation Examination of Their Plate Type Ceramic Fuel Elements, WAPD-TM-455 (March 1966).

A-9.15. I. Goldberg, L. L. Lynn, C. D. Sphar, FIGRO - FORTRAN IV Digital Computer Program for the Analysis of Fuel Swelling and Calculation of Temperature in Bulk Oxide Cylindrical Fuel Elements, WAPD-TM-618 (December 1966).

A-9.16. R. M. Berman, H. B. Meieran, P. W. Patterson, Irradiution Behavior of Zircaloy-Clad Fuel Rods Containing Dished-End UO 2 Pellets, WAPD-TM-629 (July 1967).

A-9.17. R. N. Duncan, D. A. Cantley, K. J. Perry, R. C. Nelson, "Fuel Swelling-Fast Reactor Mixed Oxide Fuels," Proceedings of the Conference on Fast Reactor Fuel Element Technology, 13-15 April 1971, New Orleans, Ruth Farmakes (ed.).

A-9.18. D. A. Collins and R. Hargreaves, "Performance-Limiting Phenomena in Irradiated $\mathrm{UO}_{2}$," Paper No. 50, Proceedings of the BNES International Conference on Nuclear Fuel Performance, 15-19 October 1973, London (CONF - 731004).

A-9.19. J. A. Turnbull, "The Effect of Grain Size on the Swelling and Gas Release Properties of $\mathrm{UO}_{2}$ During Irradiation," Journal of Nuclear Materials, 50, (1974) pp 62-68.

A-9.20. C. M. Cox, "The Irradiation Performance of Uranium-Plutonium Oxide Fuel Pins," Nuclear Safety, 10, 5 (September - October 1969) pp 380-391.

A-9.21. W. B. Lewis, J. R. MacEwan, W. H. Stevens, R. G. Hart, "Fission-Gas Behavior in $\mathrm{UO}_{2}$ Fuel," Proceedings of the Third International Conference on the Peaceful Uses of Atomic Energy, Geneva, August 31 through September 9, 1964, Volume 11, New York: United Nations 1965, pp 405-415.

A-9.22. P. Chenebault and R. Delmas, "In-Pile Mobility of Fission Gases in $\mathrm{UO}_{2}$ Fuel Rods," Journal of the American Ceramic Society, (1970).

A-9.23. P. Chenebault and R. Delmas, "Release of Fission Gases by Uranium Dioxide in Fuel Elements," Panel on the Behavior and Chemical States of Irradiated Ceramic Fuels, International Atomic Energy Agency, Vienna, August 1972, pp 337-348.

A-9.24. F. Anselin, The Role of Fission Products in the Swelling of Irradiated $\mathrm{UO}_{2}$ and (U, Pu) $\mathrm{O}_{2}$ Fuel, GEAP-5583 (January 1969).

A-9.25. M. F. Lyons, R. F. Boyle, J. H. Davies, V. E. Hazel, T. C. Rowland, "UO 2 Properties Affecting Performance," Nuclear Engineering and Design, 21, (1972) pp 167-199.

A-9.26. B. R. T. Frost, "Studies of Irradiation Effects in Ceramic Fuel at Harwell," Ceramic Nuclear Fuels, Journal of the American Ceramic Society, Columbus, Ohio (1969). 
A-9.27. $\Lambda$. D. Whapham and B. E. Sheldon, Electron Microscope Observation of the Fission Gas Distribution in $\mathrm{UO}_{2}$, AERE-R-4970 (April 1966).

A-9.28. J. W. Harrison and L. M. Davies, "The Variation of Solid Fission Product and Gas Swelling in Uranium Compounds with Thermal Neutron Dose Rate," Journal of Nuclear Materials, 27 (1968) pp 239-240.

A-9.29. D. R. Olander, Fundamental Aspects of Nuclear Reactor Fuel Elements, Technical Lilurmalion Center Energy Kesearch and Development Administration, TID-26711-P1 (1976).

A-9.30. B. R. T. Frost,"“"Theories of Swelling and Gas Release in Ceramic Fuels," Nuclear Applications and Technology, 9, (August 1970) pp 128-140.

A-9.31. H. Blank, "On the Driving Forces for Bubble Growth and Swelling in MX-Type Fast Brecder Fuels," Journul of Nuclear Materials, 58, (1973) pp 123-139.

A-9.32. H. R. Warner and F. A. Nichols, "A Statistical Fuel Swelling and Fisșion Gas Kelease Model," Nucleur Applications and Technology, 9, (August 1970) pp 148-166.

A-9.33. F. A. Nichols and H. R Warner, "Swelling and Gac-Relcasc Models for Oxide Fuel Rods (LWBR Dèvelopment Program)," Proceedings of the Conference on Fast Reactor Fuel Element Téchnology, 13-15 April 1971, New Orleans, Ruth Farmakes (ed.) pp 267-289.

A-9.34. R. B. Poeppel, "An Advanced Gas Release and Swelling Subroutine," of the Proceedings of the Conference on Fast Reactor Fuel Element Technology, 13-15 April 1971, Now Orleuns, :Ruth Farmakes (ed.) pp 311-326.

A-9.35. J. W. Dias and R. B. Poeppel, Transient Swelling Studies with the GRASS Code, $\Lambda$ NL 7992 (March 1973).

A-9.36. J. Rest, "Behavior of Fission Gas in LWR Fuel During Steady-State Operating Conditions," Transactions Volume 23, American Nuclear Society, Toronto Meeting, 13-18 June 1976, pp 171-172.

A-9.37. G. W. Greenwood and M. V. Speight "An Analysis of the Diffusion of Fission Gas Bubbles and its Effect on the Behavior of Reactor Fuels;" Journal of Nuclear Materials, 10, (1963) pp 140-144.

A-9.38. E. Duncombe, J. E. Meyer, W. A. Coffman, Comparisons with Experiment of Calculated Dimensional Changes and Failure Analysis of Irradiated Bulk Oxide Fuel Test Rods Using the CYGRO-1 Computer Program, WAPD-TM-583 (September 1966). 
A-9.39. C. C. Dollins and H. Ocken, "A Fission Gas Swelling Model Incorporating Re-Solution Effects," Nuclear Application and Technology, 9., (August 1970) pp 141-147.

A-9.40. C. C. Dollins and H. Ocken, "Re-Solution Effects and Fission Gas Swelling in $\mathrm{UO}_{2}$," Journal of Nuclear Materials, 45, (1.972/73) pi 150-162.

A-9.41. C. C. Dollins, "Fission Gas Swelling and Long Range Migration at Low Temperature," Journal of Nuclear Materials, 49, (1973/74) pp 10-20.

A-9.42. W. Chubb, A. C. Hott, B. M. Argall, and G. R. Kilp, "The Influence of Fuel Micro-Structure on In-Pile Densification," Nuclear Technology, 26, (August 1975) pp 486-495.

A-9.43. H. Stehle and H. Assman, "The Dependence of In-Re'actor $\mathrm{UO}_{2}$ Densification on Temperature and Microstructure," Journal of Nuclear Materials, 52, (1974) pp 303-308.

A-9.44. R. B. Elkins, M. O. Marlowe, E. B. Johannson, G. A. Potts, R. Stijovic, and T. C. Rowland, "Effect of Fuel Densification and Relocation on Thermal Performance," Arrerican Nuclear Society 1974 Annual Meeting 23-27 June 1974, Philadelphia.

A-9.45. D. W. Brite, J. L. Daniel, N. C. Davis, M.D. Freshley, P. E. Hart, and R. K. Marshall, EEI/EPRI Fuel Densification Project, Research Project 131 Final Report-June 1975, pp 0-76.

A-9:46. D. A. Banks, "Some Observations of Density and Porosity Changes in $\mathrm{UO}_{2}$ Fuel Irradiatcd in Water-Cooled Reactors," Journal of Nuclear Materials, 54, (1974) pp 97-107.

A-9.47. E. Rolstad, A. Hanevik, and K. K. Knudsen, "Mcasurements of the Length Changes of $\mathrm{UO}_{2}$ Fuel Pellets During Irradiation," The Enlarged HPR Meeting on Computer Control and Fuel Research, June 4-7 1974, HPR 188 (1975).

\section{FUEL RESTRUCTURING (FRESTR)}

During the irradiation of light water reactor fuels at relatively high powers, equiaxed grain growth occurs near the outer periphery of the fuel, and columnar grains form near the center of the fuel $[\mathrm{A}-10.1]$. At the periphery the temperatures are lower than those necessary for noticeable equiaxed grain growth to occur and the as-sintered structure remains. The subroutine FRESTR calculates the equiaxed grain growth as a function of temperature, initial grain size, and time and also calculates a time-dependent threshold temperature necessary for the formation of columnar grains. 


\subsection{Summary}

The FRESTR subroutine consists of the following equations. Equiaxed grain growth is expressed by:

$$
D^{4}-D_{0}^{4}=1.717 \times 10^{10} \exp \left(-3.87 \times 10^{5} / R T\right) t
$$

where

$$
\begin{aligned}
& \mathrm{D}=\text { grain sizc }(\mu \mathrm{m}) \\
& \mathrm{D}_{\mathrm{O}}=\text { initial grain size }(\mu \mathrm{m}) \\
& \mathrm{R}=8.314 \mathrm{~J} / \mathrm{mol} \cdot \mathrm{K} \\
& \mathrm{T}=\text { temperature }(\mathrm{K}) \\
& \mathrm{t}=\text { time }(\mathrm{s}) .
\end{aligned}
$$

The columnar grain formation is characterized by a threshold tempcrature, FTCRIT. If the fuel temperature at a particular location exceeds the threshold temperature, columnar grains with a density of $98 \%$ TD are assumed to form instantaneously. FTR.RIT is defined by the following equation:

$$
1 / \text { FTCRIT }=3.435 \times 10^{-5} \log _{10} t+3.47 \times 10^{-4}
$$

where

$$
\begin{aligned}
& \mathrm{t} \cdot=\text { time }(\mathrm{s}) \\
& \text { FRCRIT }=\quad \text { threshold tempcrature }(\mathrm{K}) \text {. }
\end{aligned}
$$

Equiuxed grain growtl will be liscussed in the next section and columnar grain formation is discussed in Section A-10.3. Finally, an integrated restructuring model representing $\mathrm{UO}_{2}$ and $(\mathrm{U}, \mathrm{Pu}) \mathrm{O}_{2}$ equiaxed grain growth and columnar grain formation is presented.

\section{$10.2 \mathrm{UO}_{2}$ and $(\mathrm{U}, \mathrm{Pu}) \mathrm{O}_{2}$ Equiaxed Grain Growth}

Several models for equiaxed grain growth have been developed to predict grain growth 'as a function of time and temperature. These different models correspond to different mass transport mechanisms. The theoretical models will be discussed first, followed by a review of the experimental data and comparisons of the data with these models and with an empirical model which was developed to explain grain growth in $\alpha$-brass.

10.2.1 Theoretical Models for Equiaxed Grain Growth. The driving force for equiaxed grain growth is the decrease in surface free energy brought about by the decrease 
in the number of grains and, consequently, the total surface arca. The pressure drop (or chemical potential) within a.grain (analogous to a soap bubble) is given by $2 \gamma / \mathrm{r}$ where $\gamma$ is the surface free energy and $\mathrm{r}$ is the radius of the bubble $(1 / \mathrm{r}$ is the curvature). The grain boundaries move outward from the center of curvature; the larger grains consuming the smaller grains or the grains with fewer than six sides. If the grain growth rate is assumed to be proportional to the curvature and the curvature is defined by the grain diameter, then:

$$
\frac{d D}{d t}=\frac{k}{D}
$$

where

$$
\begin{aligned}
& \mathrm{D}=\text { grain size } \\
& \mathrm{t}=\text { time } \\
& \mathrm{k}=\mathrm{a} \text { proportionality constant which contains diffusion } \\
& \text { coefficient for the material. }
\end{aligned}
$$

Using the Arrhenius equation for the diffusion coefficient and the boundary condition that at $\mathrm{t}=0$, the initial grain size is $\mathrm{D}_{\mathrm{O}}$, Equation (A-10.3) becomes upon integration:

$$
D^{2}-D_{0}^{2}=k_{0} \exp \left(-Q / R T_{t}\right)
$$

where

$$
\begin{aligned}
& \mathrm{Q}=\text { the activation encrgy } \\
& \mathrm{T}=\text { temperature } \\
& \mathrm{R}=\text { the gas constant }
\end{aligned}
$$

other terms are defined as above.

Equation (A-10.4) has been used successfully to predict the grain growth of metals at high temperatures, but with considerable deviations at low temperatures. The presence of inclusions at the fuel pin grain boundaries may explain why Equation (A-10.4) does not make a good prediction of low temperature grain growth in metals ${ }^{[A-10.2]}$. In ceramic materials such as $\mathrm{UO}_{2}$ or $(\mathrm{U}, \mathrm{Pu}) \mathrm{O}_{2}$, a large fraction of the porosity is located at the grain boundaries. Speight and Greenwood $[$ A-10.3] performed an analysis that showed bubbles could not prevent the movement of grain boundaries, but their effect was to reduce the velocity of movement as long as they remain attached to the boundary, whereas larger bubbles move more slowly, and for a given spacing, have the greatest effect in retarding boundary movement. In this way, the effect of voids is markedly different from that of solid precipitates which remain relatively fixed in position and permit only local boundary movement or complete boundary breakaway. 


\section{FRESTR}

Kingery and Francois $[A-10.4]$ developed a model that considers the retarding effect of pores located on grain boundaries or more commonly at grain intersections. For grain boundary movement, the pores on these boundaries have to migrate at a rate inversely proportional to the pore diameter, $\mathrm{D}_{\mathrm{p}}$. When, as usually found, the grain (and pore) growth. is more rapid than other changes, the pore-grain geometry remains about the same and thus the pore size remains nearly proportional to the grain size, $\mathrm{D}$. For the ideal case, Equation (A-10.3) is modified by the retardation effects of the pore and:

where

$$
\frac{\mathrm{dD}}{\mathrm{dt}}=\frac{K}{\mathrm{D}}\left(\frac{K^{\prime}}{D_{\mathrm{p}}}\right)=\left(\frac{K}{D}\right)\left(\frac{K^{\prime \prime}}{D}\right)
$$

$$
\begin{aligned}
& \mathrm{K}^{\prime}=\begin{array}{l}
\text { a constant which contains the diffusion constant for the } \\
\text { pores }
\end{array} \\
& \mathrm{K}^{\prime \prime}=\mathrm{K}^{\prime} \text { divided by the constant of proportionality relating the } \\
& \text { pure slze to the graln slze }
\end{aligned}
$$

and upon integration

$$
D^{3}-D_{0}^{3 \cdot}=3 K K^{\prime \prime} t=k t \exp (-Q / R T)
$$

where

$\mathrm{k}=\mathrm{a}$ single empirical constant of the material.

Thus when pores restrict grain boundary movement, a cubic relationship between grain size and time results rather than the square of grain size with time relationship cxpressed in Equation (A-10.4).

Nichols $[A-10.2]$ extended the analysis of Kingery and Francois $[A-10.4]$ and showed that thcir rcsults implicitly assumed a vapor transport mechanism with the pressure in the pore remaining equal to the equilibrium pressure drop $2 \gamma / \mathrm{r}$ where $\gamma$ is the surface tension and $\mathrm{r}$ is the pore radius.

Nichols $[$ A-10.2] also showed that for a constant pore pressure (which is not a function of pore radius), equiaxed grain growth due to a vapor-transport mechanism can be expressed by:

$$
D^{4}-D_{0}^{4}=k t \exp (-Q / R T)
$$

10.2.2 Model Comparisons with Experimental Data. Lyons et al ${ }^{[A-10.5]}$ compared available grain growth data[A-10.6 to A-10.T1] with the cubic model represented by Equation (A-10.5). He obtained a reasonable fit to the data with this equation except for Padden's data $[\mathrm{A}-10.7]$ at 1500 and $1700^{\circ} \mathrm{C}$ during the initial grain growth period, and most of the Hausner data ${ }^{[A-10.9]}$. The problems with the Hausner data were attributed to $\mathrm{UO}_{2}$ 
evaporation during annealing in an open system. A rerun of Hausncr's experiments with incapsulation of the $\mathrm{UO}_{2}$ specimens resulted in a constant time dependency at all temperatures and values equal to that initially obtained at $1950^{\circ} \mathrm{C}$. However, the rerun values were still different than the third order time dependency predicted by Equation (A-10.3). This behavior, as well as Padden's data ${ }^{[A-10.7]}$ from the initial grain growth period, may represent discontinuous grain growth where the pores are not at the grain boundaries and therefore are not hindering the rate of boundary migration.

Nichols ${ }^{[A-10.2]}$ reevaluated the MacEwan data ${ }^{[A-10.6]}$ and calculated an activation energy of $5.19 \times 10^{5} \mathrm{~J} / \mathrm{mol}$ which compares favorably with the value of $5.77 \times 10^{5} \mathrm{~J} / \mathrm{mol}$ for the heat of vaporization of $\mathrm{UO}_{2}$. Using this value of $5.19 \times 10^{5} \mathrm{~J} / \mathrm{mol}$ rather than the $4.98 \times 10^{5} \mathrm{~J} / \mathrm{mol}$ value from Lyons et al and a constant $\mathrm{k}$ of $8.57 \times 10^{14}$ from Lyons et al, the cubic grain growth equation becomes:

$$
D^{3}-D_{0}^{3}=8.57 \times 10^{14} t \exp \left(-5.19 \times 10^{5} / R T\right) .
$$

Equation (A-10.7) was compared with all the experimental data [A-10.6, A-10.8, $A-10.10, A-10.12]$ except those from Hausner $[A-10.9]$, Runfors $[A-10.11]$ and Padden data[A-10.7] which were questioned by Lyon ${ }^{[A-10.5]}$. The results of this comparison are shown in Figure A-10.1. The standard deviation is $\pm 10.5 \mu \mathrm{m}$.

Ainscough et al ${ }^{[A-10.12]}$ performed measurements of equiaxial grain growth at temperatures between 1300 to $1500^{\circ} \mathrm{C}$ over fairly long periods (up to 24 weeks). They rejected the cubic relationship given by Equation (A-10.5). In its place, Ainscough et al proposed a limiting grain size, $\mathrm{D}_{\mathrm{m}}$, which is only a function of temperature. The grain growth kinetics for $\mathrm{UO}_{2}$, then become:

$$
\frac{d D}{d t}=k\left(\frac{1}{D}-\frac{1}{D_{m}}\right)
$$

and upon in tegration:

$$
D_{m}\left(D_{0}-D\right)+D_{m}^{2} \ln \frac{\left(D_{M}-D_{0}\right)}{\left(D_{m}-D\right)}=k t .
$$

Burke[A-10.13] successfully used this expression to correlate grain growth data for $\alpha$-brass specimens containing a stable array of inclusions. A comparison of Equation (A-10.8b) with the higher temperature grain growth studies reported by other workers showed the rate constants calculated with this equation to be, in general, higher than those calculated by this author by extrapolating the results of Ainscough et al. However, most of the measurements made on $\mathrm{UO}_{2}$, where the $\mathrm{O} / \mathrm{U}$ ratio was close to 2.0, gave rate constants within a factor of four of the predicted values.

A comparison of the Ainscough correlation with the experimental data used in Figure A-10.1 is shown in Figure A-10.2. The resultant standard deviation is $\pm 5.5 \mu \mathrm{m}$. 


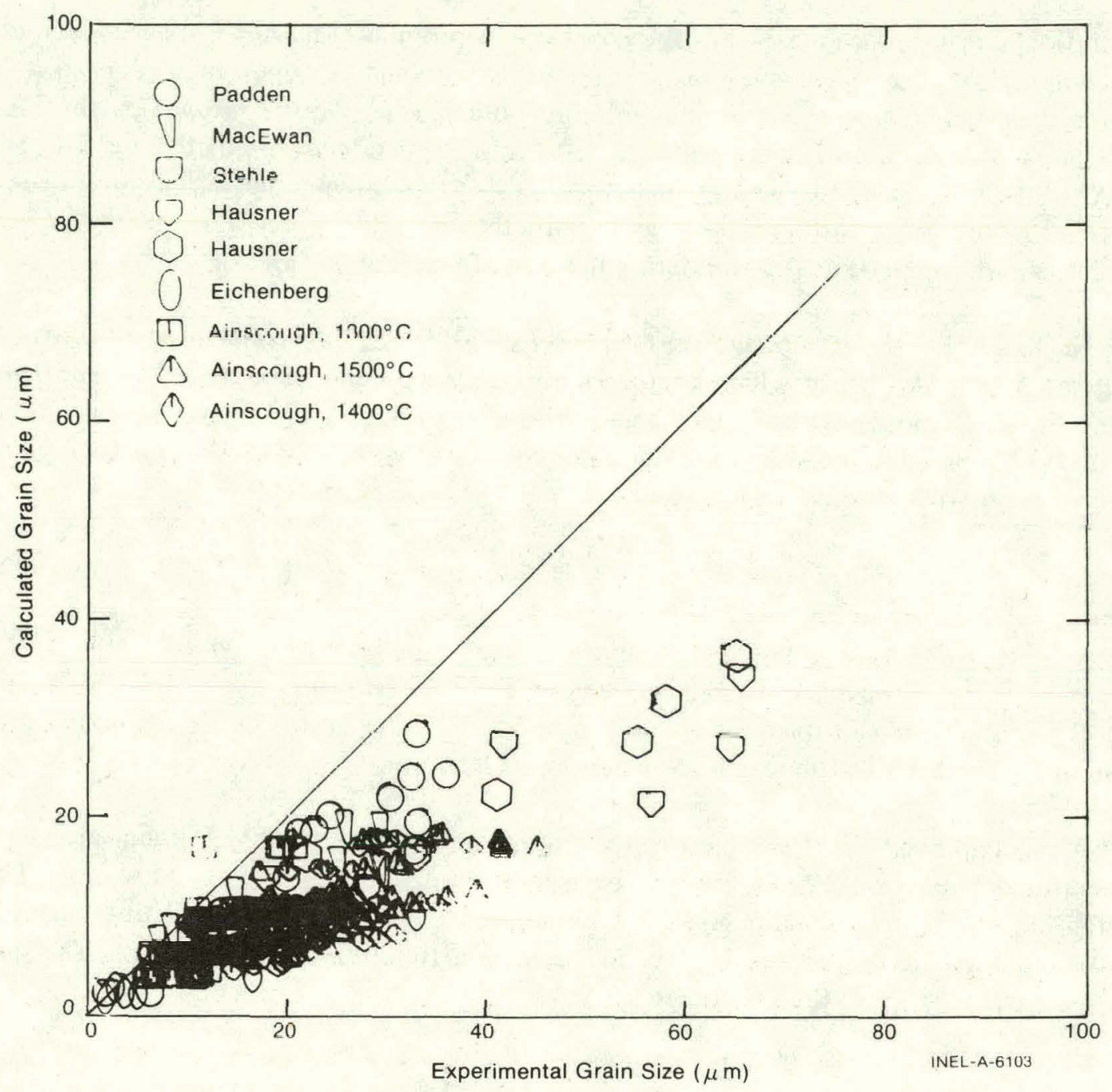

Fig. A-10 1 Comparisnn of Fquation $(A-1 \cap .7)$ with experimental data for $\mathrm{UO}_{2}$ grain growth.

The fountlı under Equation (A-10.6) devcloped by Nichols was also evaluated using the same experimental data for $\mathrm{UO}_{2}$ grain growth as shown in Figures A-10.1 and A-10.2 to determine the constants $\mathrm{k}$ and $\mathrm{Q}$. The average value of $\mathrm{Q}$ was $3.87 \times 10^{5} \mathrm{~J} / \mathrm{mol}$ and the resultant expression is:

$$
D^{4}-D_{0}^{4}=1.717 \times 10^{10} \exp \left(-3.87 \times 10^{5} / R T\right) t .
$$

A value of $3.87 \times 10^{5} \mathrm{~J} / \mathrm{mol}$ for the activation energy is less than the $5.77 \times 10^{5} \mathrm{~J} / \mathrm{mol}$ expected for the heat of vaporization. However, reevaluation of the activation energy using the cubic relation [Equation $(\mathrm{A}-10.5)$ ] resulted in an even lower value of about $3.64 \times 10^{5} \mathrm{~J} / \mathrm{mol}$. Even though the activation energies do not compare with the expected value for the heat of vaporization, Equation (A-10.9) is the best representation of the present grain growth data with a standard deviation of $\pm 4.8 \mu \mathrm{m}$. 


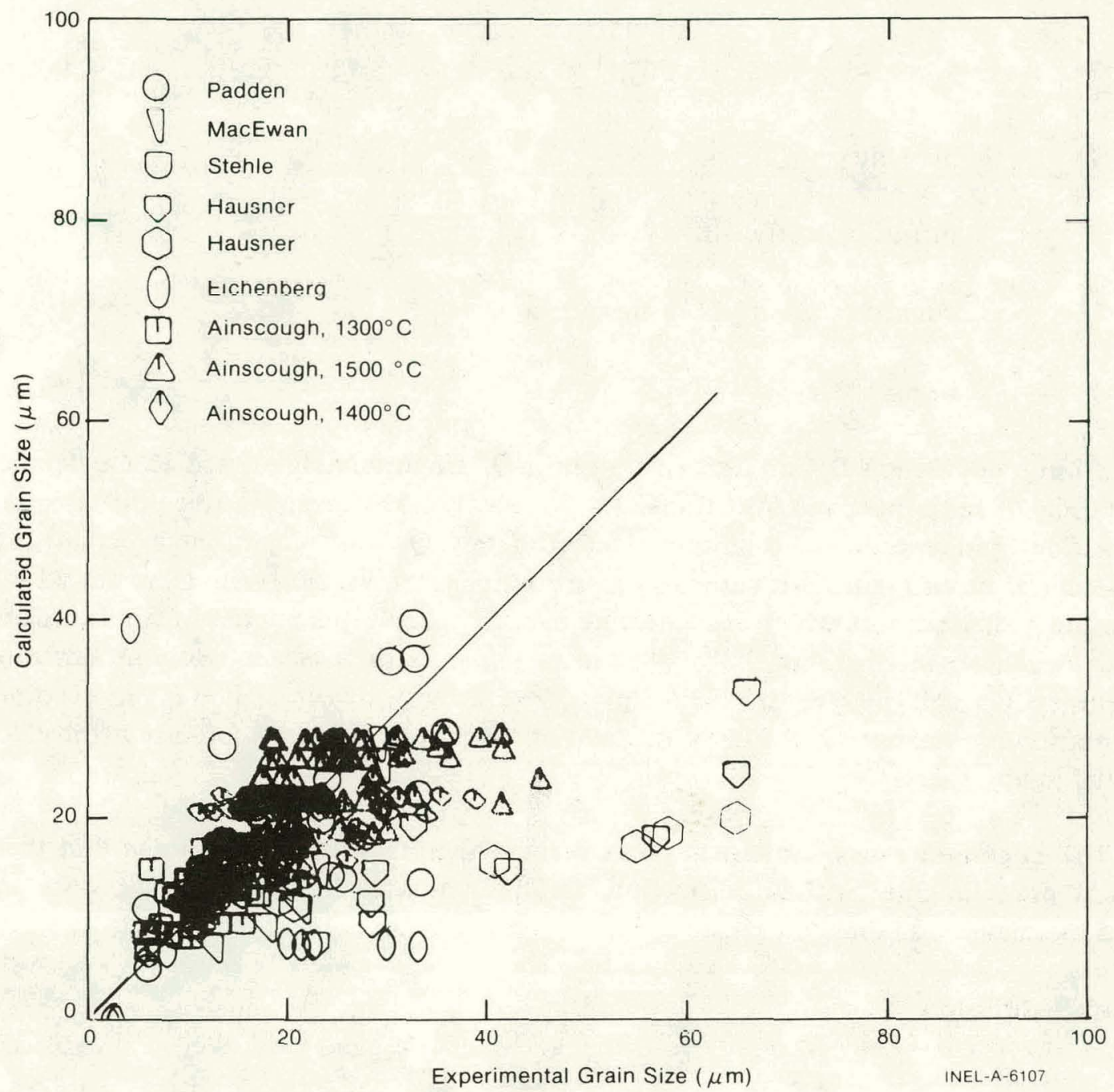

Fig. A-10.2 Comparison of Ainscough et al correlation (Equation A-10.8b) with experimental data for $\mathrm{UO}_{2}$ grain growth.

\subsection{Columnar Grain Growth}

Most sources $[\mathrm{A}-10.2, \mathrm{~A}-10.14-\mathrm{A}-10.17]$ attribute the formation of columnar grains in $\mathrm{UO}_{2}$ or $(\mathrm{U}, \mathrm{Pu}) \mathrm{O}_{2}$ mixed oxide fuels to the migration of lenticular pores up a temperature gradient. Various theoretical models $[\mathrm{A}-10.18, \mathrm{~A}-10.23]$ for the rates of pore migration have been proposed which depend upon a particular mechanism of mass transfer: surface diffusion, volume diffusion, or vaporization-condensation mechanisms with either pore pressure held constant or pore pressure in equilibrium with the surface tension. These models will be discussed first, followed by an evaluation of the experimental data on $\mathrm{UO}_{2}$ pore migration rates.

10.3.1 Theoretical Models. From irreversible thermodynamics, the diffusion of gas bubbles, or voids, up a temperature gradient implies a corresponding transfer of mass down the gradient proportional to the temperature grandient $[\mathrm{A}-10.24]$. The mass flux is given by Equation (A-10.10):

$$
J_{M}=\frac{D_{i}}{k T} C_{i}\left(-\frac{Q_{i}}{T} \nabla T\right)
$$


where

$$
\begin{aligned}
& \mathrm{J}_{\mathrm{M}}=\text { mass flux } \\
& \mathrm{D}_{\mathrm{i}}=\text { diffusion coefficient } \\
& \mathrm{C}_{\mathrm{i}}=\text { concentration of diffusing species } \\
& \mathrm{Q}_{\mathrm{i}} \quad-\quad \text { heat of transport. }
\end{aligned}
$$

The diffusion coefficient $\mathrm{D}_{\mathrm{i}}$ and heat of transport $\mathrm{Q}_{\mathrm{i}}$ are intimately related to the detailed mechanisms of both mass and heat transfer such as volume diffusion, surface diffusion, or vaporization-condensation mechanisms. Unfortunately, $\mathrm{Q}_{\mathrm{i}}$ for migration in condensed phases cannot be calculated with any degree of confidence, even as to sign. $Q_{i}$ is viewed as a process heat of transport which may include certain specific parameters if one considers specific migration mechanisms $[A-10.18]$. For example, with a vacancy volume diffusion mechanism, $Q_{i}$ will involve the enthalpy of vacancy formation. For a vaporizationcondensation mechanism, $\Omega_{\mathrm{i}}$ is simply the heat of vaporization since it does not involve any activated jump process.

The migration rate of spherical pores along a thermal gradient, assuming that these spherical pores migrate without distortion, has been treated by various authors for the various mechanisms and may be written $[\mathrm{A}-10.20, \mathrm{~A}-10.21]$ :

for surface diffusion

$$
V=\frac{2 D_{S} v \Omega_{S} Q_{S}}{r k T^{2}} \cdot \frac{d T}{d x} .
$$

For volume diffusion

$$
V=\frac{2 D Q_{v}}{f k T^{2}} \cdot \frac{d T}{d x} .
$$

For vapor transport

with $\mathrm{P}=$ constant

$$
V=A(T) P \Delta H_{V} \cdot \frac{d T}{d x} .
$$

For vapor transport with $\mathrm{P}=2 \lambda / \mathrm{r}$

$$
V=B(T) r P_{v} \Delta H_{v} \cdot \frac{d T}{d x}
$$


where

\begin{tabular}{|c|c|c|}
\hline $\mathrm{D}_{\mathrm{S}}$ & $=$ & surface diffusion coefficient \\
\hline$\nu$ & $=$ & number of diffusing species per unit area \\
\hline$\Omega$ & $=$ & atomic volume \\
\hline $\mathrm{Q}_{\mathrm{S}}$ & $=$ & heat of transport for surface diffusion \\
\hline $\mathrm{r}$ & $=$ & pore radius \\
\hline$\frac{\mathrm{dT}}{\mathrm{dx}}$ & $=$ & thermal gradient in pore \\
\hline $\mathrm{D}_{\mathrm{v}}$ & $=$ & volume diffusion coefficient \\
\hline$Q_{V}$ & $=$ & heat of transport for volume diffusion \\
\hline$f$ & $=$ & correlation factor \\
\hline$P_{V}$ & $=$ & matrix vapor pressure \\
\hline$\Delta \mathrm{H}_{\mathrm{v}}$ & $=$ & heat of vaporization \\
\hline $\mathrm{P}$ & - & vapor pressure in pore \\
\hline $\mathrm{k}$ & $=$ & Boltzmann's constant \\
\hline $\mathrm{A}(\mathrm{T})$, & 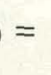 & constants. \\
\hline
\end{tabular}

Analysis by Gruber ${ }^{[A-10.21]}$ of a spherical pore moving by surface diffusion showed that a spherical pore would not be distorted during migration. Similarly, Nichols $[A-10.22$, A-10.28] analyzed the case for the vapor transport mechanism and showed that the spherical pore would essentially retain spherical geometry but would tend to elongate in the direction of the temperature gradient. No mechanism is described to explain the formation of the often observed lenticular pores situated perpendicular to the temperature gradient.

The relative importance of the various mechanisms of mass transport should depend upon the pore size and temperature. Surface diffusion should dominate at small pore sizes for all temperatures and its relative importance may sometimes increase with lower temperature. For larger pore sizes, vapor transport or volume diffusion may dominate. The critical radius between surface diffusion and vapor transport $(\mathrm{P}=2 \gamma / \mathrm{r})$ has been evaluated by Speight $[\mathrm{A}-10.25]$ to be about $1 \mu \mathrm{m}$ at $2000 \mathrm{~K}$. Bubbles with radii larger than $1 \mu \mathrm{m}$ would migrate by vapor transport with $\mathrm{P}=\frac{2 \gamma}{\mathrm{r}}$ and surface diffusion would dominate at smaller radii. 
Oldfield and Markworth[A-10.26] developed a model for the formation of columnar grains based upon pore migration by vapor transport and the formation of steps by layer nucleation or by the development of screw dislocations. This process is analogous to a zone-melting situation in which the hot surface of the bubble is "melting" (actually evaporating into a gaseous "solution") and then crystallizing upon the cool surface. Tlie atoms of vapor attach to the solid at favorable low energy sites, usually provided by a kink in a layer edge or reentrance in the lattice. Atoms reach the surface and migrate along it until they reach a suitable site. The driving force to cause attachment is a function of the concentration gradient of atoms at the surface. Thus all giuwth takes place at laycr cdgcs so that eventually one might expect them to grow out, leaving a close-packed surface in contact with the vapor. This behavior can be expressed by the Bravais law which states that a crystal is bounded by its slowest growing surfaces.

Oldfield and Markworth ${ }^{[A-10.26]}$ consider the variation of surface angle, and hence the variation in number of growth steps around the crystal surface. Their model is expressed by Equatiun $(\Lambda-10.15)$.

$$
V=B \frac{\tanh \left(\frac{\lambda L}{2}\right)}{L} \Delta T
$$

where

$$
\begin{aligned}
& \mathrm{B}=\frac{\mathrm{PQ}}{\mathrm{RT}^{2} \lambda 2 \pi \mathrm{RT}} \mathrm{b}_{\mathrm{O}} \\
& \lambda^{2}=\frac{\nu}{\mathrm{D}} \exp (\phi / \mathrm{RT}) \\
& \mathrm{V}=\text { growth velocity associated with a layer } \\
& \mathrm{P}=\text { partial pressure of vapor in the bubble } \\
& \phi \quad=\quad \text { seat of crystallization (or with vapor transport, the heat of } \\
& \mathrm{D}=\text { surface diffusion coefficient } \\
& \nu=\text { atomic vibration frequency } \\
& \mathrm{L}=\text { is related directly to the angle between the surface and the } \\
& \mathrm{b}_{\mathrm{O}}=\text { migration direction }
\end{aligned}
$$

Oldfield and Markworth ${ }^{[A-10.26]}$ used this equation to compute the shape of a migrating bubble, assuming fixed velocity, over the entire surface, matching the $\Delta T$ in Equation (A-10.15) to the corresponding total available $\Delta \mathrm{T}$, and solving for $\mathrm{L}$. Repetition of 
this calculation around the bubble surface yielded the bubble shape. When $\Delta \mathrm{T}$ was assumed to be equal at the top and bottom, the calculated bubble was flattened and had a lenticular shape as has been observed.

The equations for migration rates [Equations (A-10.11) to (A-10.14)] do not predict the proper sliape of the bubbles. Huwever, llie analyses by Oldfield and Markworth[A-10.26] predicts the general shape of the bubble when a process of crystallization is factored in to the analysis of pore migration. The fact that this model does predict observed bubble shapes suggests that the rate controlling step for columnar grain formation may be the recrystallization process rather than diffusion through the pore. Under these circumstances, measurements of migration rates of pores located at grain boundaries would not be governed by Equations (A-10.11) to (A-10.14). Instead, these equations would be applicable only to pore migration in single crystals or within grains. Equation (A-10.15) predicts the rate of formation of columnar grains.

Lenticular pores contain impurities so that the smooth surface bounding the pore becomes unstable beyond a certain growth velocity or impurity concentration and steepwalled grooves develop into which the impurities are rejected. These grooves form at the end of the lenticular void and leave a trail of spherical bubbles in the boundary between two adjacent columnar grains. This rejection of bubbles into the grain boundaries has been experimentally observed (Figure A-10.3)[A-10.18, A-10.22].

The association of crystal growth with the movement of lenticular voids also accounts for the observed orientation of the $\langle 111\rangle$ crystallographic direction in the radial direction of the fuel ${ }^{[A-10.14]}$.

\subsubsection{Experimental Pore} Migration Rates. Based on the preceding discussion of pore migration rates, the experimental data were se parated into two categories: (a) pore migration in single crystals and (b) pore migration at

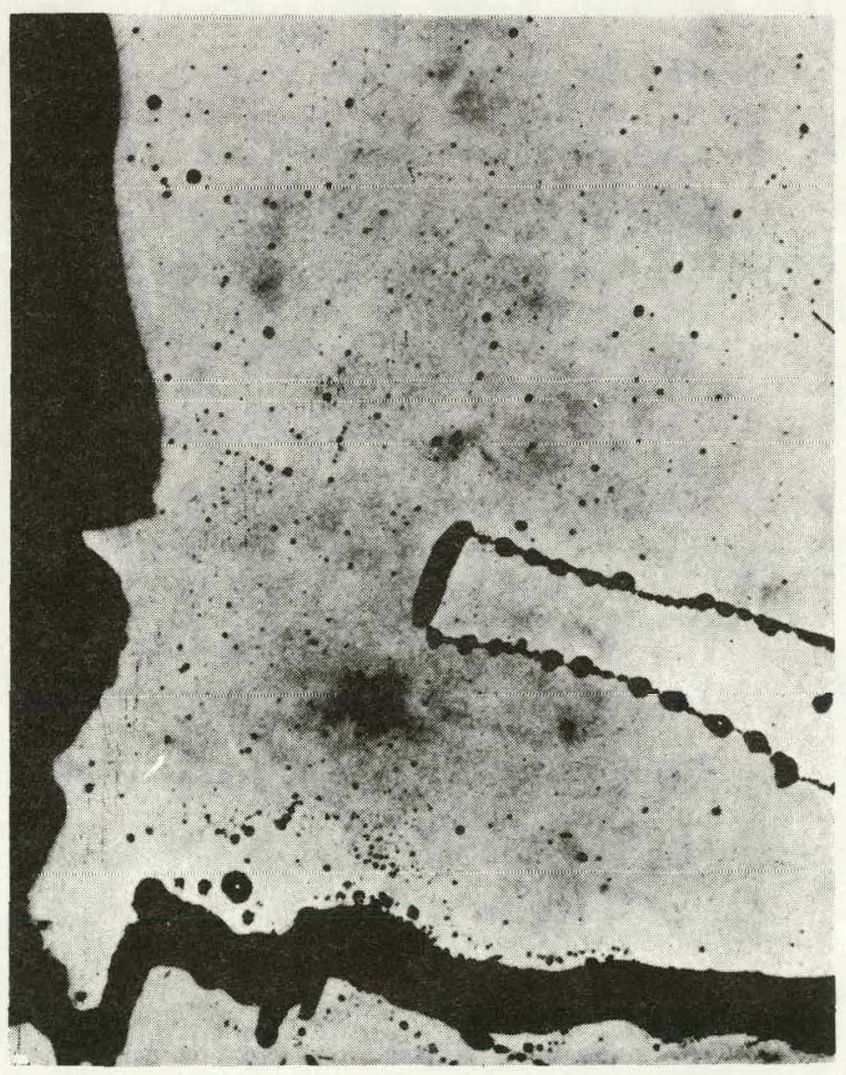

Fig. A-10-3 Lenticular void in $\mathrm{ThO}_{2}-5 \% \quad \mathrm{UO}_{2}$ fuel showing injection of spherical bubbles into grain boundaries. 
grain boundaries. The initial migration of pores at grain boundaries leads directly to the formation of columnar grains. Whereas after the formation of columnar grains, pore migration through the columnar grains results in fission gas release and fuel swelling.

Williamson and Cornell ${ }^{[\mathrm{A}-10.27]}$ measured the pore migration rates in $\mathrm{UO}_{2}$ single crystals at temperatures between 1250 and $1450^{\circ} \mathrm{C}$. These authors attributed the pore migration to surface diffusion since small bubbles were observed to move faster than larger ones. Pore sizes were less then $0.5 \mu \mathrm{m}$.

Gulden $[\mathrm{A}-10.28]$ measured the migration of fission gas bubbles in $\mathrm{UO}_{2}$ at temperatures between 1400 and $1500^{\circ} \mathrm{C}$ and for pore sizes between 2.5 and $14 \mathrm{~nm}$. From the effect of diffusion coefficient upon the bubble radius, a volume diffusion mechanism was attributed to be the rate controlling mechanism for a pore radius greater than $3.7 \mathrm{~nm}$. These results conflict with the expectation that volume diffusion occurs only in very large pores.

Oldfield and Brown ${ }^{[A-10.29]}$ measured the migration rate of bubbles located at columnar grain boundaries in $\mathrm{UO}_{2}$. The measured rates were much lower than corresponding values predicted by a vapor transport mechanism. This experimental result supports the theoretical contention that the migration rates of pores located at grain houndaries should be different than the migration rates of pores located within grains. Migration rates of columnar grains ranged between 0.01 and $1 \mu \mathrm{m} / \mathrm{s}$ for temperatures between 1900 and $2450^{\circ} \mathrm{C}$.

Michels and Poeppel ${ }^{[A-10.30]}$ measured the migration rates of fission-gas bubbles in (U,Pu) $\mathrm{O}_{2}$ mixed oxide fuel for pore sizes ranging from 2.5 to $6.5 \mu \mathrm{m}$. Much scatter existed in the pore migration rates and precluded an exact determination of the effect of pore size upon the migration rate. However, they selected the surface diffusion mechanism because it gave more reasonable predicted values than a vapor transport mechanism. Michels and Pneppel stated that a vapor transport mechanism was also possible.

Ronchi and Sari ${ }^{[A-10.31]}$ measured the out-nf-pile migration rates for pores located at columnar grain boundaries in $\mathrm{UO}_{2}$. Based upun a measured activation energy of $4.85 \times 10^{5} \mathrm{~J} / \mathrm{mol}$ (slightly below the evaporation enthalpy of $\mathrm{UO}_{2}$ ) and using a constant pore pressure, they deduced that the pores in their samples migrated by a vapor transport mechanism with a constant pore pressure. Their migration rates were higher than those of Oldfield and Brown ${ }^{[A-10.29]}$ but their values were in agreement with values predicted by a vapor transport model. They concluded that the pore pressure could not be in equilibrium with the surface tension.

Buescher and Meyer ${ }^{[\mathrm{A}-10.32]}$ measured pore migration rates in single crystal $\mathrm{UO}_{2}$ for pore radii between 0.01 and $1.0 \mu \mathrm{m}$. The migration velocities were found to be independent of pore size. The observed values were found to be substantially larger than those predicted by mechanisms of volume diffusion and vapor transport $(\mathrm{P}=2 \gamma / \mathrm{r})$ but smaller than those predicted by surface diffusion models. They proposed a model based upon nonlocalized 
surface diffusion that is affected by collisions between diffusing species and gas atoms within the bubble. In ruling out the vapor transport mechanism, they ignored the constant pore pressure model which predicts the migration rates to be independent of the pore size, as observed in their results. The absolute values for pore migration rates, of course, depend upon the assumed pore pressure. In other words, vapor transport with constant pore pressure is a possible mechanism in their experiments.

The results from experimental measurements of pore migration rates are summarized in Table A-10.I. As a whole, the conclusions reached by various authors are mixed and leave no concensus as to the mechanism of pore migration. Factors contributing to this lack of consensus include: (a) different pore sizes, (b) imprecise estimates of the temperature gradients, (c) inaccurate temperature measurements, (d) mutual interaction of grain boundaries and pores in retarding pore migration, and (e) assumption of pore pressure and size relation migration rates.

However, in considering these data some general conclusions can be drawn. The measurements of Williamson and Cornell[A-10.27] clearly indicate a surface diffusion mechanism when the pore sizes are less than about $0.5 \mu \mathrm{m}$. For pore sizes larger than about $1 \mu \mathrm{m}$, Ronchi and Sari [A-10.31] suggest a vapor transport mechanism with a constant pore pressure as the rate controlling mechanism, and the results from Michels and Peoppel ${ }^{[\mathrm{A}-10.30]}$ and Buescher and Meyer ${ }^{[\mathrm{A}-10.32]}$ do not preclude this mechanism. At very small pore sizes $(2.5-14 \mathrm{~nm})$, volume diffusion appears to be the rate controlling mechanism.

Large uncertainties still exist in the absolute values of pore migration rates of pores located both at grain boundaries and within grains. Also, one must distinguish between the initial formation of columnar grains probably by the movement of pores located at grain boundaries and the subsequent pore migration within or through essentially single crystal columnar grains.

\subsection{Fuel Restructuring Model}

A number of theoretical models have been proposed for equiaxed grain growth in $\mathrm{UO}_{2}$. Since pores located at grain boundaries apparently restrict grain boundary movement, either a third or fourth order relationship between grain size and time is theoretically expected, depending upon whether the pore pressure is in equilibrium with the surface tension or whether the pore pressure is constant. The models were compared with the available data, as discussed in Subsection A-10.2.2, and the grain growth rates predicted with the fourth order Equation (A-10.9) gave the smallest standard deviation of the models tested. This result suggests that the vapor transport mechanism operates with a constant pore pressure and is independent of the pore size. Moreover, examination of pore migration rates as a function of pore size shows the rates to be independent of size. Therefore, equiaxed grain growth in $\mathrm{UO}_{2}$ and $(\mathrm{U}, \mathrm{Pu}) \mathrm{O}_{2}$ mixed oxide fuels is represented in the FRESTR subcode by Equation (A-10.16):

$$
D^{4}-D_{0}^{4}=1.717 \times 10^{10} \exp \left(-3.87 \times 10^{5} / R T\right) t
$$


TABLE A-7D.:

SUMMARY OF PORE MIGRATIOV RATE EXPERIMENTS

\begin{tabular}{|c|c|c|c|c|c|}
\hline Investigation & Material Type & Temperature & Pore & Size & Comments on Mechanism \\
\hline Wi11iamson and Corne11 $[A-10.27]$ & $\mathrm{UO}_{2}$ single crystal & $\begin{array}{l}1250 \text { to } \\
1450^{\circ} \mathrm{C}\end{array}$ & 2.5 to & $5.0 \mathrm{~nm}$ & $\begin{array}{l}\text { Inferred surface diffusion } \\
\text { mechanism }\end{array}$ \\
\hline Gulden $[A-10.28]$ & Polycrystalline $\mathrm{UO}_{2}$ & $\begin{array}{l}1400 \text { to } \\
1500^{\circ} \mathrm{C}\end{array}$ & 2.5 to & $14.0 \mathrm{~nm}$ & $\begin{array}{l}\text { yolume diffusion for } \\
r>3.7 \mathrm{~nm} \text {, unknown for } \\
r<3.7 \mathrm{~nm}\end{array}$ \\
\hline 0ldfield and Brown $[A-10.29]$ & Polycrystalline $\mathrm{UO}_{2}$ & $\begin{array}{l}1955 \text { to } \\
2410^{\circ} \mathrm{C}\end{array}$ & 0.2 to & $0.2 \mu \mathrm{m}$ & $\begin{array}{l}\text { Ledge nucleation impeded } \\
\text { motion }\end{array}$ \\
\hline Michels and Poeppe $]^{[A-10.30]}$ & $\begin{array}{l}\text { Polycrystalline } \\
(\mathrm{U}, \mathrm{Pu}) \mathrm{O}_{2}\end{array}$ & $\begin{array}{l}1585 \text { to } \\
1850^{\circ} \mathrm{C}\end{array}$ & 1 to & $10 \mu \mathrm{m}$ & $\begin{array}{l}\text { Size dependence undetermined } \\
\text { but authors indicated surface } \\
\text { diffusion with a possibility } \\
\text { of vapcr transport }\end{array}$ \\
\hline Ronchi and Sari $[A-10.31]$ & $\begin{array}{l}\text { Polycrystalline } \\
\mathrm{UO}_{2} \text { and }(\mathrm{U}, \mathrm{Pu}) \mathrm{O}_{2}\end{array}$ & $\begin{array}{l}1600 \text { to } \\
26.00^{\circ} \mathrm{C}\end{array}$ & not & given & Vapor transport mechanism \\
\hline Buescher and Meyer $[A-10.32]$ & $\mathrm{UO}_{2}$ single crystal & $\begin{array}{l}1940 \text { to } \\
202 C^{\circ} \mathrm{C}\end{array}$ & 0.01 to & $1.0 \mu \mathrm{m}$ & $\begin{array}{l}\text { Rates independent of pore } \\
\text { size; cuthors proposed an } \\
\text { impeded surface diffusion } \\
\text { mechanism but results could } \\
\text { fit vapor transport with } \\
\text { constant pore pressure }\end{array}$ \\
\hline
\end{tabular}


where the terms have been defined above. A comparison of this equation with experimental data (Figure A-10.4) shows a standard deviation of $\pm 4.8 \mu \mathrm{m}$.

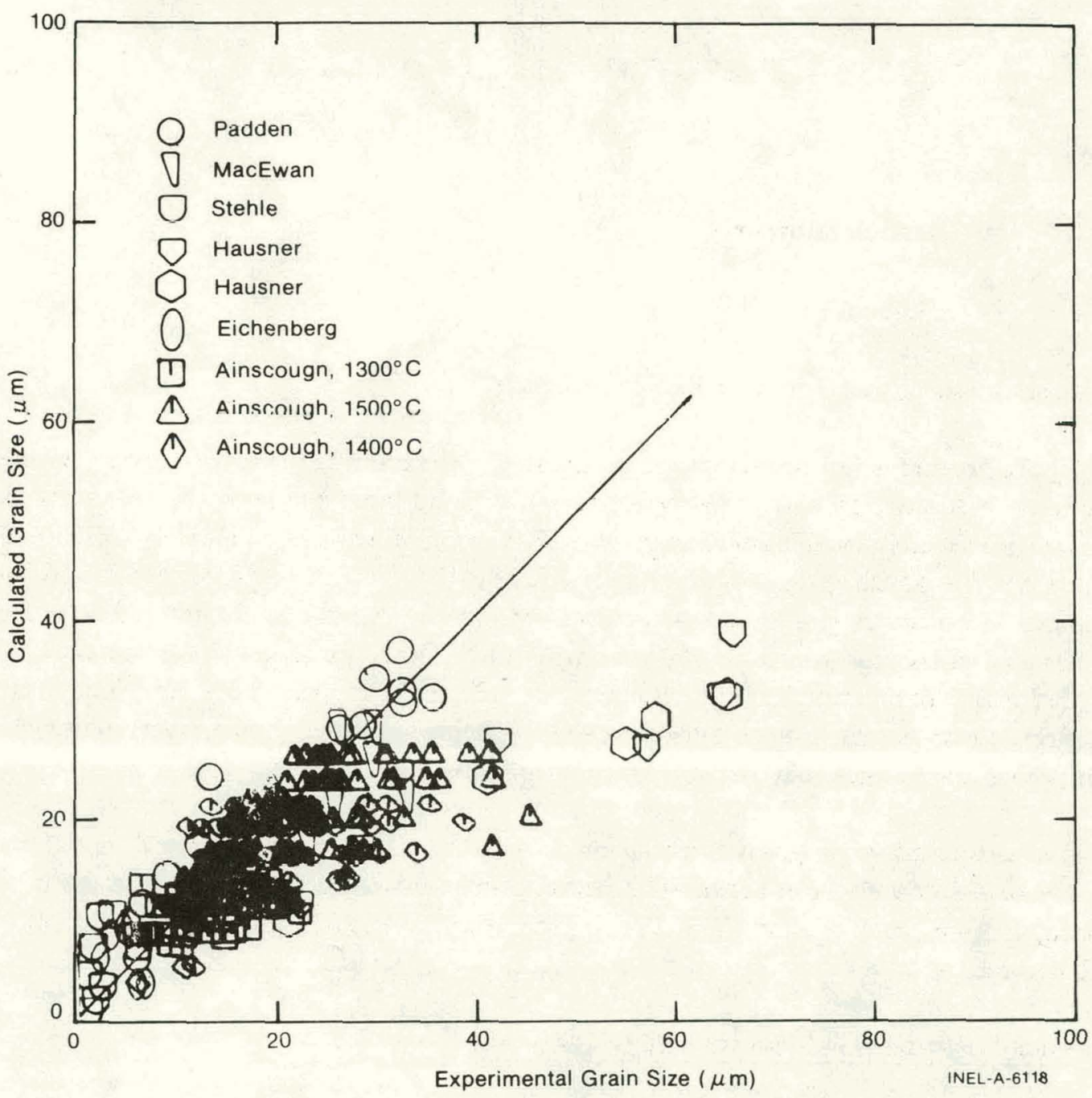

Fig. A-10.4 Comparison of Equation (A-10.16) with experimental data for $\mathrm{UO}_{2}$ grain growth.

Columnar grains apparently form by pore migration due to vapor transport and subsequent crystal growth where the rate controlling mechanism is the crystal growth. Conservatively low measurements of the columnar grain boundary velocity show the rates to be between 0.01 to $1 \mu \mathrm{m} / \mathrm{s}$ for temperatures between 1900 and $2450^{\circ} \mathrm{C}^{[\mathrm{A}-10.29]}$. For a fuel radius of $0.51 \mathrm{~cm}$, a time between 1.4 and 141 hours would be required for columnar grain formation, corresponding to the fastest and slowest rates of columnar grain formation. Thus the formation of columnar grains occurs very rapidly once the threshold temperature is exceeded.

Since the rates of columnar grain movement are very ill-defined and the constants in the various published models are difficult to evaluate, a theoretical model is not very useful. However, the published equations do show that a threshold temperature should exist for the 
formation of columnar grains and that this temperature should be a function of time, decreasing with an increase in time. Christensen $[\mathrm{A}-10.33]$ measured threshold temperature as a function of time and derived the following relationship:

$$
1 / T=3.435 \times 10^{-5} \log _{10} t+3.47 \times 10^{-4}
$$

where

$$
\begin{aligned}
& \mathrm{T}=\text { temperature }(\mathrm{K}) \\
& \mathrm{t}=\operatorname{time}(\mathrm{s}) .
\end{aligned}
$$

This is the model chosen for the FRESTR subcode.

In the formation of columnar grains, most of the sintering porosity moves towards the fuel center, but some of this porosity is lett in the boundaries between the columnar grains. Based on postirradiation examinations of pellet microstructures, a density of $98 \%$ TD is assumed for the density of the columnar grain zonel A-10.34]. Therefore, the model for the formation of columnar grains consists of an estimate of the threshold temperature for the formation of columnar grains as a function of time. Then, for areas of the fuel that exceed this threshold temperature, the density is assumed to be $98 \%$ TD. The porosity corresponding to the difference between the $98 \%$ density value and the initial density of the fuel is placed instantaneously in the central hole of the fuel.

The equiaxed grain growth equation is assumed to apply over the entire fuel region from the fuel surface to the radius of column grain formation. However, in regions of low fuel temperature, such as near the pellet surface, essentially no change in grain structure will be calculated.

\subsection{Fuel Restructuring Subcode FRESTR Listing}

A FORTRAIN listing of the FRESTR subroutine is shown in Table A-10.II.

\subsection{References}

A-10.1. D. R. DeHalas and G. R. Horn, "Evolution of Uranium Dioxide Structure During Irradiation of Fuel Rods," Journal of Nuclear Materials, 8 (1963) pp 207-220.

A-10.2. F. A. Nichols, "Theory of Grain Growth in Porous Compacts," Journal of Applied Physics, 37 (1966) pp 4599-4602.

A-10.3. M. V. Speight and G. W. Greenwood, "Grain Boundary Mobility and Its Effects in Materials Containing Inert Gases," Philosophical Magazine, 9 (1964) pp 683-688.

A-10.4. W. D. Kingery and B. Francois, "Grain Growth in Porous Compacts," Journal of the American Ceramic Society, 48 (1965) pp 546-547. 
TABLE A-10.II

LISTING OF THE FRESTR SUBCODE

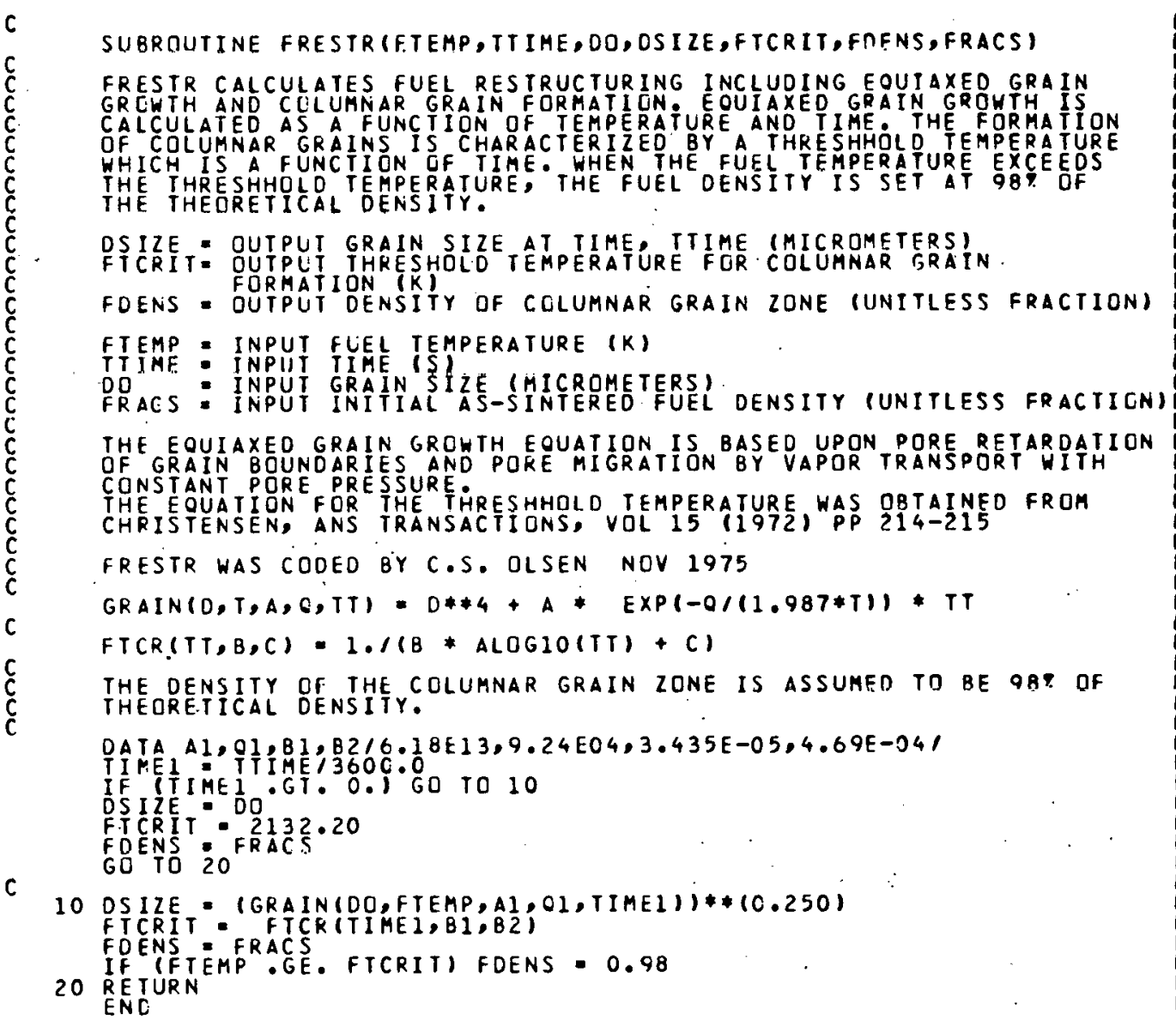

FRSRO010 FRSROO20 FRSROO48 FRSR0050 FRSROO6O FRSRO070 FRSROOBO FRSROOOO FRSRÓló FR RSROI 20 RSROI30 FRSRO140 RSRO150 FRSRO160 FRSRO180 FRSROI90 FRSROZOO FRSRO2 20 FRSRO230 FRSRO2 40 FRSROL50 FRSRO260 FRSRO270 RSRO280 RSRO 300 RSRO310 FRSRO320 RRSRO 330 FRSRO 350 FRSRO360 FRSR0370 RRSRO380 FRSRO390 RSR0 400 R SRO 410 RSRO 420 RRSRO 438 FRSRO 440 FRSRO 460 FRSRO470 RSRO480

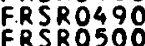

A-10.5. M. F. Lyons et al, Analysis of $\mathrm{UO}_{2}$ Grain Growth Data from Out-of-Pile Experiments, GEAP-4411 (November 1963).

A-10.6. J. R. MacEwan, Grain Growth in Sintered Uranium Dioxide, AECL-1184 (CRFD-999), Atomic Energy Commission of Canada Limited (January 1961).

A-10.7. T. R. Padden, "Behavior of Uranium Oxide as a Reactor Fuel," Proceedings of 2nd International Conference on Peaceful Uses of'Atomic Energy, Volume 6, Paper P/2404, (September 1958) pp 569-586.

A-10.8. H. Stehle, Paper Presentation at Joint Meeting of the Deutsche Gesellschaft für Metallkunde and the Deutsche Keramische Gesellschaft, November 8-9, 1962. 
FRESTR

A-10.9. H. Hausner, $\mathrm{UO}_{2}$ Grain Growth and Melting Studies, High Performance $\mathrm{UO}_{2}$ Program Quarterly Progress Reports, GEAP-3771-5, 3771-6, 3771-7 (1962-1963).

A-10.10. J. D. Eichenberg, et al, Effects of Irradiation on Bulk $\mathrm{UO}_{2}$, WAPD-183 (October 1957).

A-10.11. U. Runfors et al, "Sintering of Uranium Dioxide," Proceedings of 2nd International Conference on Peaceful Uses of Atomic Energy, Volume 6, Paper P/142, September 1958, p 605.

A-10.12. J. B. Ainscough et al, "Isothermal Grain Growth Kinetics in Sintered $\mathrm{UO}_{2}$ Pellets," Journal of Nuclear Matertals, 49 (1973/1974) pp 117-128.

A-10.13. J. E. Burke, "Some Factors Affecting the Rate of Grain Growth in Metals," Transactions of the American Institute of Metallurgical Engineers, 180 (1949) pp 73-91.

A-10.14. J. P. MacEwan and V. B. Lawson, "Grain Growth in Sintered Uranium Dioxide: II, Columnar Grain Growth," Journal of the American Ceramic Society, 45 (1962) pp 42-46.

A-10.15. J. A. Christensen, "In-Pile Void Migration in Uranium Dioxide," Transactions of the American Nuclear Society, 8 (1965) pp 44-45.

A-10.16. J. A. Christensen, "Columnar Grain Growth in Oxide Fuels," Transactions of the American Nuclear Society, 15 (1972) pp 214-215.

A-10.17..P. F. Sens, "The Kinetics of Pore Movement in $\mathrm{UO}_{2}$ Fuel Rods," Journal of Nuclear Matertals, 43 (1972) pp 293-307.

A-10.18. F. A. Nichols, "Movement of Pores in Solids," Journal of Metals (1969) pp 19-27.

A-10.19. P. G. Shewmon, "The Movement of Small Inclusions in Solids, by a Temperature Gradient," Transactions of the American Institute of Metallurgical Engineers, 230 (1964) pp 1134-1137.

A-10.20. F. A. Nichols, "Kinetics of Diffusional Motion of Pores in Solids," Journal of Nuclear Materials, 30 (1969) pp 143-165.

A-10.21. E. E. Gruber, "Calculated Size Distributions for Gas Bubble Migration and Coalescenence in Solids," Journal of Applied Physics, 38 (1967) pp 243-250.

A-10.22. F. A. Nichols, "Pore Migration in Ceramic Fuel Elements," Journal of Nuclear Materials, 27 (1968) pp 137-146. 
A-10.23. F. A. Nichols, "Pore Migration in Ceramic Fuel Elements," Journal of Nuclear Malerials, 22 (1967) pp 214-222.

A-10.24. G. N. Lewis et al, Thermodynamics, Second Edition, New York: McGraw Hill Book Co., 1961.

A-10.25. M. V. Speight, "The Migration of Gas Bubbles in Material Subject to a Temperature Gradient," Journal of Nuclear Materials, 13 (1964) pp 207-209.

A-10.26. W. Oldfield and A. J. Markworth, "The Theory of Bubble Migration Applied to Irradiated Materials," Material Science and Engineering, 4 (1969) pp 353-366.

A-10.27: G. K. Williamson and R. M. Cornell, "The Behavior of Fission Product Gases in Uranium Dioxide," Journal of Nuclear Materials, 13 (1.964) pn 2.78-280.

A-10.28. M. E. Gulden, "Migration of Gas Bubbles in Irradiated Uranium Dioxide," Journal of Nuclear Materials, 23 (1967) pp 30-36.

A-10.29. W. Oldfield and J. B. Brown Jr., "Bubble Migration in $\mathrm{UO}_{2}-\mathrm{A}$ Study Using a Laser Image Furnace," Materials Science and Engineering, 6 (1970) pp 361-370.

A-10.30. L. C. Michels and R. B. Poeppel, "In-Pile Migration of Fission Product Inclusions in Mixed-Oxide Fuels," Journal of Applied Physics, 44 (1973) pp 1003-1008.

A-10.31. C. Ronchi and C. Sari, "Properties of Lenticular Pores in $\mathrm{UO}_{2},(\mathrm{U}, \mathrm{Pu}) \mathrm{O}_{2}$ and $\mathrm{PuO}_{2}$," Journal of Nuclear Materials, 50 (1974) pp 91-97.

A-10.32. B. J. Buescher and R. O. Meyer, "Thermal Gradient Migration of Helium Bubbles in Uranium Dioxide," Journal of Nuclear Materials, 48 (1973) pp 143-156.

A-10.33. J. A. Christensen, "Columnar Grain Growth in Oxide Fuels," Transactions of the American Nuclear Society, 15 (1972) pp 214-215.

A-10.34. R. D. Leggett et al, "Central Void Size in Irradiated Mixed-Oxide Fuel Pins," Transactions of the American Nuclear Society, (1973) pp 175-176.

\section{FUEL DENSIFICATION (FUDENS)}

During the first few thousand hours of reactor operation, some $\mathrm{UO}_{2}$ and $(\mathrm{U}, \mathrm{Pu}) \mathrm{O}_{2}$ fuels densify at temperatures below normal sintering temperatures. The code FUDENS calculates the extent of $\mathrm{UO}_{2}$ and $(\mathrm{U}, \mathrm{Pu}) \mathrm{O}_{2}$ in-pile densification as a function of burnup, fuel temperature, and the density change found during a resintering test or the initial density and sintering temperature used while fabricating the fuel pellets. 


\subsection{Summary}

The code. allows a choice between two methods to calculate the maximum density change during irradiation. Use of the density change seen during a resintering test $\left(1700^{\circ} \mathrm{C}\right.$ for more than 24 hours) in a laboratory furnace is the preferred method for the calculation. If a resintering density change is not input, the code uses the initial unirradiated density of the fuel and the fuel fabrication sintering temperature for the calculations. The above inputs are used in the following equations to calculate the maximum length change occurring duing irradiation.

If a positive value for the resintering density change is input:

$$
\begin{aligned}
& \left(\frac{\Delta L}{L}\right)_{m}=(0.001) \text { RSNTR, when FTEMP }<1000 \mathrm{~K} \\
& \left(\frac{\Delta L}{L}\right)_{m}=(0.00285) \text { RSNTR, whell FTEMP } \geq 1000 \mathrm{~K} .
\end{aligned}
$$

If a zero or negative value for the resintering density change is input:

$$
\begin{aligned}
& \left(\frac{\Delta L}{l}\right)_{m}=\frac{22.2(100-\text { DENS })}{(\text { TSINT }-2073)} \text {, when FTEMP }<1000 \mathrm{~K} \\
& \left(\frac{\Delta L}{L}\right)_{m}=66.6 \frac{6(100-\text { DENS })}{(\text { TSINT }-1453)}, \text { when FTEMP } \geq 1000 \mathrm{~K}
\end{aligned}
$$

where

$$
\begin{array}{ll}
\left(\frac{\Delta \mathrm{L}}{\mathrm{L}}\right)_{\mathrm{m}}= & \begin{array}{l}
\text { maximum dimension change of fuel duc to } \\
\text { irradiation (percent) }
\end{array} \\
\text { DFNS }= & \text { percent theoretical density } \\
\text { FTEMP }= & \text { fuel temperature }(\mathrm{K}) \\
\text { TSINT }= & \text { sintering temperature }(\mathrm{K}) \\
\text { RSNTR }= & \text { resintered fuel density change }\left(\mathrm{kg} / \mathrm{m}^{3}\right) .
\end{array}
$$

The rate of densification as a function of burnup is calculated by the code using Equation (A-11.5):

$$
\left|\frac{\Delta L}{L}\right|=\left|\left(\frac{\Delta L}{L}\right)_{m}\right|-\exp [-3(F B U+B)]-2.0 \exp [-35(F B U+B)]
$$


where

$$
\begin{aligned}
& \left|\frac{\Delta L}{L}\right|=\quad \text { the absolute value of the radial dimension change of } \\
& \text { the fuel due to irradiation (percent) } \\
& \mid\left(\frac{\Delta \mathrm{L}}{\mathrm{L}}{ }_{\mathrm{m}} \mid=\quad \begin{array}{l}
\text { the absolute value of the maximum dimension change } \\
\text { of the fuel due to irradiation (percent) }
\end{array}\right. \\
& \mathrm{FBU}=\text { fuel burnup }(\mathrm{MWd} / \mathrm{kgU}) \\
& \text { B = a constant determincd by the code to fit the } \\
& \text { boundary conditions } \frac{\Delta L}{L}=0 \text { when } F B U=0 \text {. }
\end{aligned}
$$

\section{$11.2 \mathrm{UO}_{2}$ and Mixed Oxide Densification Data and Models}

The sintering of cold pressed $\mathrm{UO}_{2}$ powder compacts may be divided usefully into three regimes: (a) the formation of necks between particles, (b) the decrease of interconnected porosity, and (c) the subsequent volume reduction of isolated pores $[A-11.1]$. The last stage begins when about 92 to $95 \%$ theoretical density is reached. The porosity in fuels which is less than about $92 \%$ theoretically dense and which have been sintered at low temperatures is open and located along grain edges. The closed porosity in low density materials sintered at low temperatures is also located along grain boundaries. However, at higher sintering temperatures accelerated grain growth occurs and the closed porosity may be found inside the grains even in low density compacts ${ }^{[A-11.2]}$. The in-reactor densification phenomenon involves the third sintering regime in which fine isolated closed porosity (located either at grain boundaries or within the grains) is annihilated.

11.2.1 $\mathrm{UO}_{2}$ and Mixed Oxide Densification Data. An Edison Electric Institute/ Electric Power Research Institute (EEI/EPRI) project[A-11.3] recently concluded a comprehensive study of $\mathrm{UO}_{2}$ fuel densification. The fuel was tested in the RAFT (Radially Adjustable Facility Tubes) of the General Electric Test Reactor (GETR) ${ }^{[a]}$. The preirradiation and postirradiation physical properties are reported on fuel subjected to burnups of up to $3.5 \mathrm{MWd} / \mathrm{kgU}$. The study [A-11.4] concluded that irradiation-induced densification can be correlated with fuel microstructure, i.e., the largest in-reactor density changes occurred for those fuel types having a combination of the smallest pore size, the largest volume percent of porosity less than $1 \mu \mathrm{m}$ in diameter, the smallest initial grain size, and the lowest initial density. The volume fraction of porosity less than $1 \mu \mathrm{m}$ in diameter contributed significantly to densification of the fuel types studied; density increases were accompanied by a significant decrease in the volume fraction of pores in this size range. The volume fraction of pores ranging in diameter from 1 to $10 \mu \mathrm{m}$ initially increased with

[a] Located in Pleasanton, California. 


\section{FUDENS}

densification; but with continued densification, the volume of these pores decreased. Significant density increases occurred during irradiation with only minimal increases in grain size.

Analysis of thc EPRI data also shows that pellets located in low burnup, low fissiun rate regions densify less than pellets irradiated to the same burnup but in higher fission rate and temperature positions (see rigúre A-1 1.1). At the higher fission rates and temperatures, densification occurs rapidly and pellets approach maximum densities at a burnup of about $1 \mathrm{MWd} / \mathrm{kgl}$. $\Lambda$ t the lower fission rates, densification appcars to be increasing with burnups of ?. $\mathrm{MWd} / \mathrm{kgIT}$.

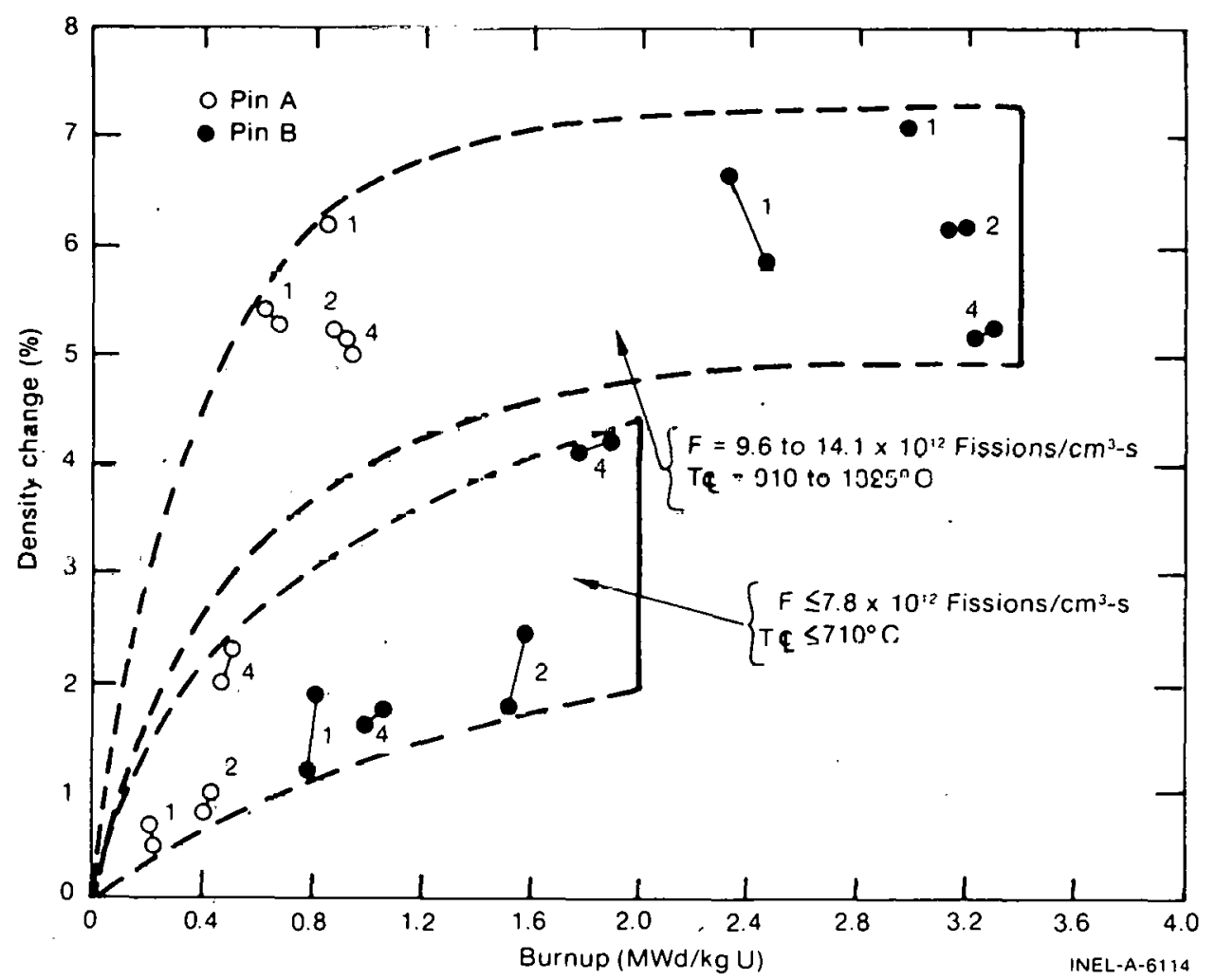

Fig. A-11.1 The effert of burnup and fission rate on the density change for EPRI fuol types 1, 2, and 4.

Kolstad et al $[\mathrm{A}-11.5]$ measured the fuel stack length change of $\mathrm{UO}_{2}$ in the Halden HBWR reactor ${ }^{[a]}$. The physical variables of fuel densities $(87,92$, and $95 \%$ TD), fabrication sintering temperatures, irradiation power levels, and fuel-cladding gap sizes were used to study irradiation-induced densification. The axial length change was measured at time intervals during the irradiation of the rods. The axial length change, as a function of burnup (see Figure A-11.2) for different power levels, did not depend on reactor power levels or fuel temperatures. Hanevik et al[A-11.6] proposed that this may be attributed to the fact that the outer edges (shoulder) of the pellet would be within 200 to $300^{\circ} \mathrm{C}$ of each other at both power levels. Since the outer edges of the pellet are much colder than its center

[a] Test reactor located in Halden, Norway. 

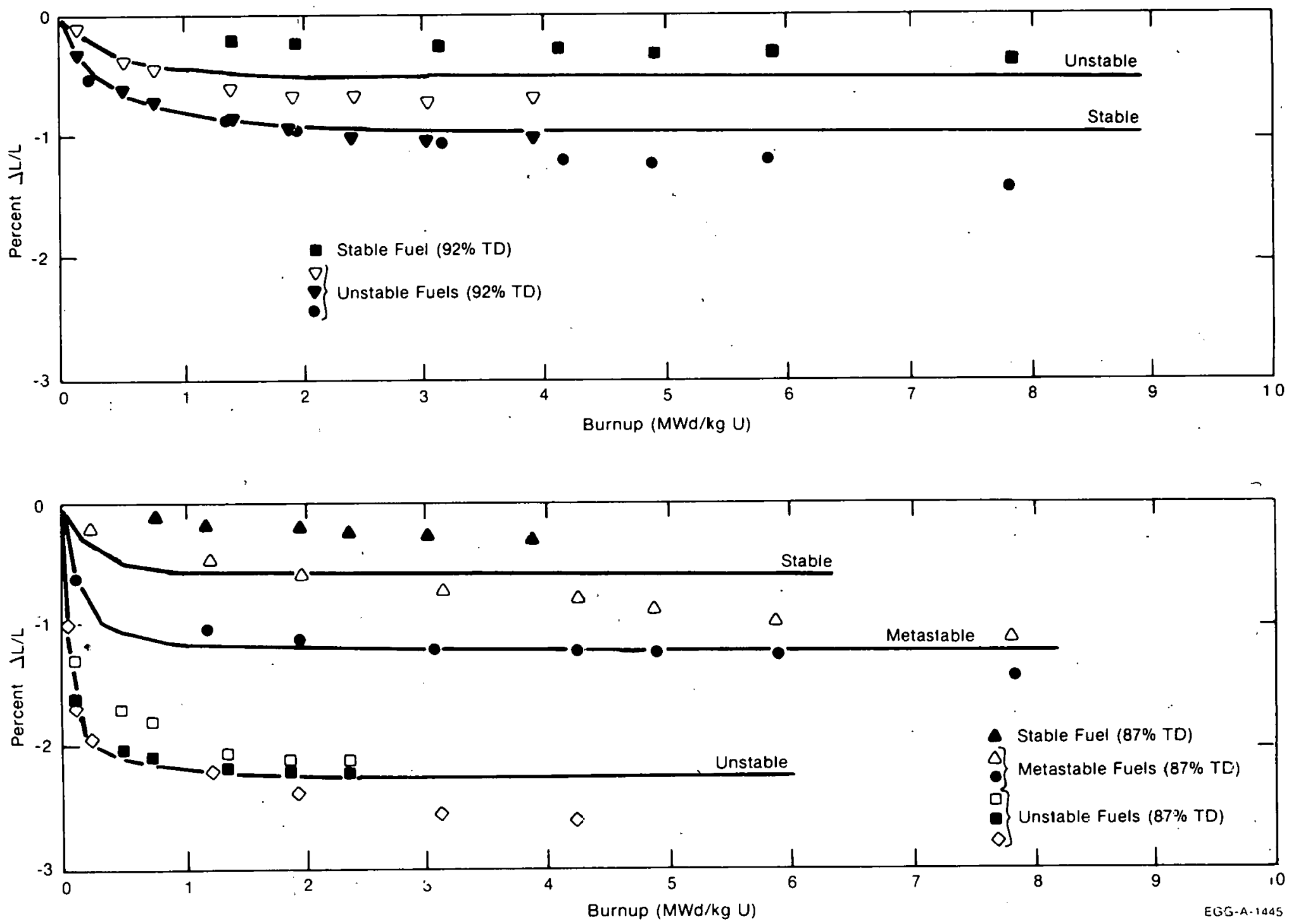

Fig. A-11.2 Change in fuel stack length of Halden fuel as a function of burmup. 


\section{FUDENS}

section, the axial in-reactor length change measurements are probably a measurement of the shrinkage in these regions (i.e., low temperature irradiation densification). The amount of fuel stack length change of the Halden fuel was found to depend mainly on out-of-pile thermal fuel slability, initial density, and burnup.

Collins and Hargreaves $[$ A-1 1-7] contrasted measurements of out-of-pile sintering rates at temperatures greater than $1600 \mathrm{~K}$ with the sintering rates of fuel irradiated in the Windscale Advanced Gas-Cooled Reactor (WAGR) ${ }^{[a]}$. The observed out-of-pile densification was attributed to the sintering of grain boundary porosity and was characterized by an activation energy of $2.9 \times 10^{5} \mathrm{~J} / \mathrm{mol}$ for grain boundary diffusion. Extrapolation of these results to the approximate $1000 \mathrm{~K}$ temperatures of the in-pile material indicated that negligible thermal sintering would be expected after a few hundred hours at this temperature. In addition, no evidence of sintering was observed in out-of-pile annealing tests at $1173 \mathrm{~K}$ and a pressure of $2.06 \mathrm{MPa}$. However, fuel irradiated to less than $0.3 \%$ burnup at fuel temperatures between 1000 and $1100 \mathrm{~K}$ experienced significant reductions in the pellet diameters. This shrinkage was attributed to irradiation-induced sintering which decreased the initial fuel porosity volume. Pores with diameters less than $3 \mu \mathrm{m}$ were reported by Collins and Hargreaves to be the major source of increased density. Pores larger than $100 \mu \mathrm{m}$ were reported stable during irradiation at temperatures below $1500 \mathrm{~K}$.

Ferrari et al ${ }^{[A-11.8]}$ measured $\mathrm{UO}_{2}$ fuel pellet densification in commercial reactors; using both moveable in-core flux detectors and postirradiation examination of selected test rods. The densification rate of the fuel was reported to occur rapidly during the early stages of irradiation and then slow or even stop after about 6 to $10 \mathrm{MWd} / \mathrm{kgU}$, as shown by Figure A-1 1.3. These results are consistent with the measurements of Rolstad et al. For the given density (92\% TD), the extent of densification was reported to vary significantly with microstructure, but no details of the microstructure were reported.

- Ferrari et al. reported that power levels between 4.9 and $55.8 \mathrm{~kW} / \mathrm{m}$ did not significantly affect densification. This result is in agreement with Rolstad et al. The axial shrinkage was suggested to be controlled by densification in the shoulder of the fuel pellets, a region of the fuel pellets which generally operates at temperatures below $800^{\circ} \mathrm{C}$. These lemperatures are too low for in-pile densification to be attributed to thermal mechanisms. fierrari et al proposed that the kinetics of densification are compatible with irradiationenhanced diffusion processes.

Metallographic measurements on the fuel studied by Ferrari et al indicated that the irradiation-enhanced densification was associated with the disappearance of fine pores and that pore shrinkage significantly decreased with increasing pore size. These results correspond to the EPRI findings. Ferrari et al suggest that densification could be reduced through both microstructural control of the fuel pellet and a reduction of the fine porosity content. Both of these factors are influenced by the pellet fabrication process, especially

[a] A prototypic, power-productive reactor in Windscale, Cumberland, England. 


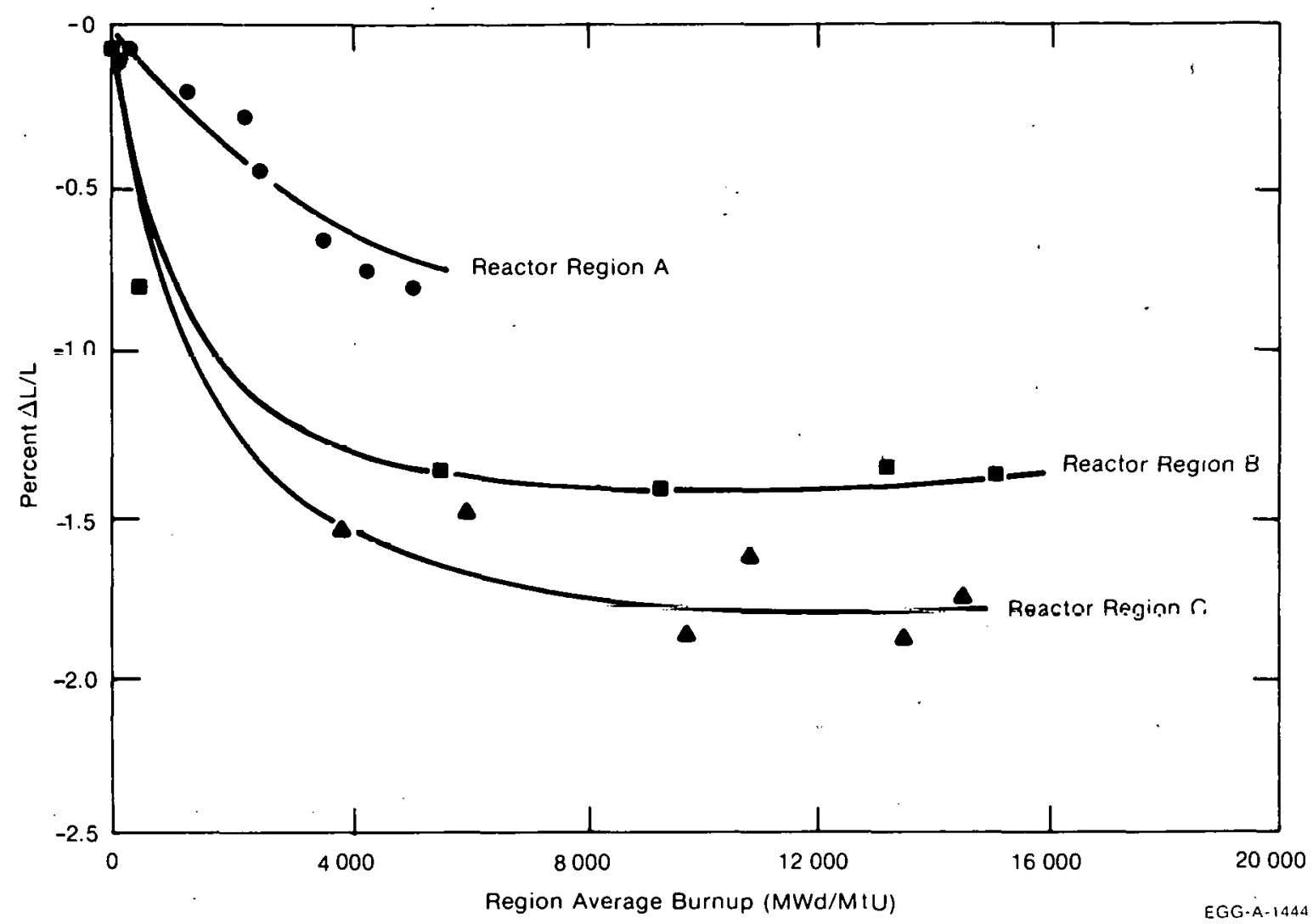

Fig. A-11.3 Fuel stack length changes for $92 \% \mathrm{TD} \mathrm{UO}_{2}$ processed by different techniques.

sintering temperature and the use of so-called "pore formers". Ferrari et al reported that experimental fuel of $89 \%$ theoretical density (TD) has been made and demonstrated to be relatively stable in the Saxton reactor ${ }^{[a]}$.

Heal et al ${ }^{[A-11.9]}$ reported that by controlling the pore size they have developed $\mathrm{UO}_{2}$ fuel which does not densify significantly. They calculated that shrinkage of the pores would continue until the internal pressure of trapped gas in the pores matched the surface tension forces causing shrinkage. Their calculations show no pore shrinkage with voids of $20 \mu \mathrm{m}$ or greater. Even a $10-\mu \mathrm{m}$ void is expected to shrink only 6 to $7 \mu \mathrm{m}$ before gas stabilization occurs. Voids of $1.0 \mu \mathrm{m}$ or less, however, shrink to $0.2 \mu \mathrm{m}$ or less before gas stabilization occurs, causing considerable densification. Fuel pellets fabricated with porosity sizes greater than $25 \mu \mathrm{m}$ were irradiated by Heal et al to $1.4 \times 10^{26}$ fissions $/ \mathrm{m}^{3}$ with center temperatures up to $1600^{\circ} \mathrm{C}$. Postirradiation examination of these pellets showed significantly less than $1 \%$ volume densification.

Ross [A-11.10] has shown that fuel after an irradiation of $2 \times 10^{25}$ fissions $/ \mathrm{m}^{3}$ has lost most pores with radii less than $0.5 \mu \mathrm{m}$. He found that fuels with burnups even as low as $2 \times 10^{24}$ fissions $/ \mathrm{m}^{3}$ had removed most pores with radii less than $0.3 \mu \mathrm{m}$.

[a] Experimental reactor located in Saxton, Pennsylvania. 
Burton and Reynolds [A-11.11] measured the shrinkage of fuel pellets, during the final stage of out-of-pile sintering of $96.5 \% \mathrm{TD} \mathrm{UO}_{2}$ with isolated porosity located at grain boundaries. The density change as a function of time was measured for three specimens at different temperatures. The densification rate was initially large but it decreased to a much slower rate at longer times. 'The shapes of these curves are very similar to those for the in-pile densification of $\mathrm{UO}_{2}$; however, in-pile densification occurs at much lower temperatures. This reduction in the sintering rate with time can arise for several reasons: (a) grain boundaries may migratc away from cavities during annealing, thus removing short dillusiun pallis of vacancies away from cavitles, (b) when significant entrapped gas is present, cavities may slirink until they become stabilized as the internal gas pressure becomes equal to the surface tension of the cavity as proposed by Heal et al, and (c) the number of cavities can become progressively reduced as densification proceeds. The first and second reasinns were rejected by Burton and Reynolds because the majority of the cavities in their samples remained on grain boundaries during sintering, and smaller cavities sintered to closure. Therefore, Burton and Reynolds suggested that the reduction in the sintering rate with time is only due to the progressive reduction in the number of cavities.

The reported irradiation-induced densification data indicate that it is affected by porosity and pore size distribution, fuel density, and irradiation temperature. The lack of a temperature dependence of the fuel densification data by Ferrariet al and Rolstad et al is probably a result of the measurement technique (i.e., measurement of the length change in the low temperature. pelle.t e.dges).

11.2.2 Survey of Densification Models. Densification models proposed by Rolstad[A-11.5], Meyer[A-11.12], Collins and Hargreaves[A-11.7], Voglewede and Dochwat $[A-11.13]$, Stehle and Assmann[A-11.14], Marlowe[A-11.15], Hull and Kimmer[A-11.16], and MacEwen and Hastings [A-11.7] are reviewed in this section.

Rolstad et al used two equations to correlate their data. The first equation below predicts the magnitude of shortening $\left(\frac{\wedge \mathrm{I}_{\mathrm{w}}}{\mathrm{L}}\right)_{\mathrm{m}}$ as a function of the percent theoretical density (DENS) and sintering temperature in degrees centigrade. (TSINT) at a burnup of $5000 \mathrm{MWd} / \mathrm{MtUO}_{2}$ :

$$
\left(\frac{\Delta L}{L}\right)_{m}=22.2 \frac{(100-D E N S)}{(\text { TSINT }-1780)}
$$

The effect of burnup was introduced through the use of a master curve created by shifting all curves vertically to agreement at $5000 \mathrm{MWd} / \mathrm{MtU}$ and then horizontally to achieve the best agreement at the low burnup portion of the curves. The master curve is described as follows:

$$
\frac{\Delta L}{L}=3.0-0.93 \exp (-B U)-2.07 \exp (-35 B U)
$$


wherc

$$
\begin{aligned}
& \frac{\Delta \mathrm{L}}{\mathrm{L}}=\text { the percent shrinkage of the fuel } \\
& \mathrm{BU}=\text { the burnup }(\mathrm{MWd} / \mathrm{kgU}) .
\end{aligned}
$$

This equation results in a rapid length change at low burnups $(<1 \mathrm{MWd} / \mathrm{kgU})$ and small length change at higher burnup levels. Very little additional densification is calculated after a burnup of 5000 to $6000 \mathrm{MWd} / \mathrm{kgU}$.

Meyer ${ }^{[A-11.12]}$ developed a conservative model for licensing purposes. The model is based primarily on the results obtained from a resintering test of the fuel at $1700^{\circ} \mathrm{C}$ for 24 hours. The resulting density change is used in the model as the maximum densification $(\triangle \rho$ max) incurred during irradiation. The model is defined by the following cquations.

For fuels that densify less than $4 \% \mathrm{TD}$,

$$
\begin{aligned}
& \Delta \rho=0 \text { for } 0<\mathrm{BU}<1728 \mathrm{MWs} / \mathrm{kgU} \\
& \Delta p=\mathrm{m} \log (\mathrm{BU})+\mathrm{b} \quad \text { for } 1728<\mathrm{BU}<172800 \mathrm{MWs} / \mathrm{kgU} \\
& \Delta \rho=\Delta \rho_{\max } \text { for } \mathrm{BU}>172800 \mathrm{MWs} / \mathrm{kgU} .
\end{aligned}
$$

where the coefficients $m$ and $b$ are found from

$$
\begin{aligned}
0 & =m \log (1728)+b \\
\Delta p_{\text {max }} & =m \log (172800)+b
\end{aligned}
$$

and $\Delta \rho \cdot$ max $_{\text {is }}$ ise estimated in-reactor maximum density change.

For very unstable fuels that densify more than $4 \% \mathrm{TD}$,

$$
\begin{aligned}
& \Delta \rho=0 \text { for } 0<\mathrm{BU}<432 \mathrm{MWs} / \mathrm{kgU} \\
& \Delta \rho=m \log (\mathrm{BU})+\mathrm{b} \quad \text { for } 432<\mathrm{BU}<43200 \mathrm{MWs} / \mathrm{kgU} \\
& \Delta \rho=\Delta \rho_{\max } \quad \text { for } \mathrm{BU}>43200 \mathrm{MWs} / \mathrm{kqU}
\end{aligned}
$$

where the coefficients $m$ and $b$ are found from

$$
\begin{aligned}
0 & =m \log (432)+b \\
\Delta \rho_{\max } & =\log (43200)+b
\end{aligned}
$$


where

$$
\begin{array}{ll}
\Delta \rho=\text { change in density } \\
\mathrm{BU}=\text { maximum in } \mathrm{MWs} / \mathrm{kgL} \\
\Delta \rho_{\max }=: \quad \text { consity change possible } \\
\mathrm{m} \quad=\quad \text { constant. }
\end{array}
$$

This model is very useful as a licensing model which calculatès the maximum irradiationinduced densification. Meyer reports that the $1700^{\circ} \mathrm{C} / 24$ hour resintering densification in his model adequately bounds all in-reactor densitication data at their disposal.

From the fuel sintering measurement in the WAGR, Collins and Hargreaves arrived at the empirical expression for the volume change of porosity as a function of burnup:

$$
V=A V_{0} \exp (-S I)+(1-A) \cdot V_{0}
$$

where

$$
\begin{aligned}
& \mathrm{V}=\text { fuel porosity at burnup I } \\
& \mathrm{I}=\text { fuel burnup (MWs/kgU) } \\
& \mathrm{V}_{\mathrm{O}}=\text { percent of initial porosity of the fuel } \\
& \mathrm{A}=\text { a constant between } 0.5 \text { and } 0.6 \\
& \mathrm{~S}=2 \times 10^{-3} \text { for temperatures } \geqslant 1000 \mathrm{~K} \text { or } \\
& \mathrm{S}=\sim 10^{-4} \text { for temperatures }<1000 \mathrm{~K} .
\end{aligned}
$$

Collins and Hargreaves further suggested that a complete description of the densification rate of uranium dioxide under irradiation demands a knowledge of the initial size distribution of the as-manufactured porosity in addition to the total volume of porosity because of the differing sintering rates of pores of different sizes. However, the morphology of the porosity in the $\mathrm{UO}_{2}$ fuel they used was not determined.

J. C. Voglewede and S. C. Dochwat $[A-11.13]$ developed an equation for final stage densification of mixed oxides fuels based on EBR-II ${ }^{[a]}$ reactor data. It is a semiempirical approach based on porosity, stress, and temperature:

[a] The Experimental Breeder Reactor, operated by Argonne National Laboratory, Idaho National Engineering Laboratory, Idaho Falls, Idaho. 


$$
(1 / v) d v / d t=k(P / 1-P)^{m} \sigma^{n} \exp (-Q / R T)
$$

where

$\begin{array}{rlrl}(1 / \mathrm{v}) \frac{\mathrm{dv}}{\mathrm{dt}} & = & & \text { densification rate } \mathrm{hr}^{-1} \\ \mathrm{k} & = & 2.0 \times 10^{10} \\ \mathrm{p} & = & \text { fractional porosity } \\ \mathrm{m} & = & : 2.4 . \\ \sigma & = & \text { stress }\left(\mathrm{kg} / \mathrm{cm}^{2}\right) \\ \mathrm{n} & = & 4 / 3 \\ \mathrm{Q} & = & 4.605 \times 10^{5} \mathrm{~J} / \mathrm{mol} \\ \mathrm{R} & = & \text { gas constant } \\ \mathrm{T} & = & \text { temperature }(\mathrm{K}) .\end{array}$

The model was based on Argonne National Laboratory data of $\mathrm{UO}_{2}-25$ wt $\% \mathrm{PuO}_{2}$ sintered pellets under stresses of 100 to $800 \mathrm{~kg} / \mathrm{cm}^{2}$.

Stehle and Assmann ${ }^{[A-11.14]}$ proposed a vacancy controlled densification model as a function of initial fuel porosity, fission rate, initial pore radius, fuel temperature, and vacancy diffusion. Their model is summarized by the equation:

$$
\frac{d r}{d t}=\frac{1 / 3 \omega \lambda F\left(C_{s}-C_{t}\right)}{1+\left(\frac{\omega \lambda F}{3 D_{v}}\right)\left(\frac{r R_{g}}{R}\right)}
$$

where

$$
\begin{aligned}
& \omega=\text { pore volume lost after each fission event } \\
& \mathrm{t}=\text { time } \\
& \lambda=\text { fission spike length } \\
& \mathrm{F}=\text { fission rate } \\
& \mathrm{r}=\text { pore radius }
\end{aligned}
$$




$$
\begin{aligned}
& \mathrm{R}_{\mathrm{g}}=\text { grain radius } \\
& \mathrm{D}_{\mathrm{v}}=\text { vacancy diffusion coefficient } \\
& \mathrm{R}=\text { distance tetween vacancy sink and pore center } \\
& \mathrm{C}_{\mathrm{S}}=\text { vacancy saturation concentration } \\
& \mathrm{C}_{\mathrm{t}}=\text { steidly stute vacancy concentration. }
\end{aligned}
$$

Equation (A-11.14) considers pores of only one diameter; therefore, application of this equation to practical engineering problems requires that the cquation be integrated over the pore sizes existing in the fuel. The Stehle and Assmann approach predicts that irradiation-induced fuel densification is temperature dependent because of the dependence of $D_{v}$ on temperature. The authors used approximate values for $D_{v}$ and found that the densification rate should change at approximately $750^{\circ} \mathrm{C}$. This corresponds very well with the experimental results found in the EPRI densification study.

Marlowe $[A-11.15]$ proposed a model for diffusion-controlled densification and modified the model to include fuel swelling contributions to the density changes as well as an irradiation-induced diffusivity which provides atomic mobility for grain growth densification. His model is expressed by the following equation:

$$
\rho=\rho_{0} \exp (-\dot{S} \dot{F} t)+\frac{M}{A} \exp \left[-S\left(\frac{G_{0}^{3}}{A D}+\dot{F} t\right)\right] \ln \left(1+\frac{A D \dot{F} t}{G_{0}{ }^{3}}\right)
$$

where

$$
\begin{aligned}
& S=\text { fractional volumetric fuel swelling per unit s.x pnsure } \\
& S_{\mathrm{r}_{0}}=\text { initial grain size } \\
& \mathrm{M}=\begin{array}{l}
\text { densification rate constant for the matcrial prior to } \\
\text { irradiation } \mathrm{M}=\left(\mathrm{G}^{3} / \mathrm{D}\right) \mathrm{d} \rho / \mathrm{dt}
\end{array} \\
& \mathrm{A}=\text { grain growth rate constant for the material prior to } \\
& \dot{\mathrm{F}}=\text { irradiation } \mathrm{A}=3 \mathrm{G}^{2}\left(\mathrm{dG}^{3} / \mathrm{dt}\right) \\
& \mathrm{t}=\text { irsion rate per unit volume } \\
& \mathrm{D}=\text { diffusion coefficient }
\end{aligned}
$$


$\therefore \rho_{\mathrm{O}} \quad=\quad$ initial pellet density (\%TD)

$\mathrm{G}=$ grain size as a function of time during thermal tests $(\mathrm{cm})$.

This model is based on densification and grain growth rate parameters, which must be determined experimentally for any particular fuel. The parameters, $\mathrm{M}$ and $\mathrm{A}$, strongly affect the predicted in-reactor densification behavior through grain size modification. Because the model allows complete pore elimination and, in fact, densities greater than theoretical for the matrix material, an upper limit to the density must be calculated to limit the densification change as calculated by Equation (A-10.15). The limit is calculated by

$$
\rho_{\max }=\frac{1}{1+\mathrm{SFt}} .
$$

Hull and Rimmer $[A-11.16]$ proposed a model using a porosity distribution which quantitatively predicts the density change as a function of time:

$$
\frac{d V}{d t}=\frac{k w D_{g b}}{T X}
$$

where

$$
\begin{aligned}
& \mathrm{V}=\text { volume } \\
& \mathrm{t}=\text { time } \\
& \mathrm{w}=\text { grain boundary width } \\
& \mathrm{D}_{\mathrm{gb}}=\text { grain boundary self-diffusivity } \\
& \mathrm{X}=\text { mean cavity spacing on the grain boundary } \\
& \mathrm{T}=\text { temperature } \\
& \mathrm{k}=\text { constant. }
\end{aligned}
$$

Hull and Rimmer reported reasonably good agreement with the Burton and Reynolds data despite the approximations required to evaluate this equation and the errors in determining the porosity distribution of the samples. Both the shape of the predicted curve and the absolute magnitude of the values were reported to be in good agreement, demonstrating that the decrease in sintering rate with time is associated only with the progressive reduction in the number of cavities. However, the calculation assumed a constant cavity spacing for each time step in changing from one volume size to the next. The similarity between the out-of-pile and in-pile densification strongly suggests the importance of pore size distribution and volume for in-reactor densification. 
MacEwen and Hastings [A-11.17] developed a model describing the rate change of pore diameter based on the time dependence of vacancy and interstitial concentrations, fission gas concentrations, and internal pore pressures. Tiwo equations were used. One describes the diametral change of pores on the grain boundaries and the other describes intergranular pore shrinkage. Use of their model requires interstitial and vacancy concentrations, internal pore pressures, and interstitial and vacancy jump frequencies. The model is thus difficult to use in engineering applications with the present in-reactor fuel data base.

Fuel densification models proposed by the authors in References A-11.11 and A-11.13 through A-11.17 attempted to correlate fuel densification with fundamental material properties. These theoretical or semiempircal approaches will eventually be the preferred modeling techniques but current versions of, these models must be based on estimates of such material properties as diffusion coefficients, void concentrations, jump frequencies, etc., which are not sufficiently well defined to be used to predict in-reactor densification.

As R. O. Meyer has pointed out in his review, the use of complicated theoretical approaches is not justified unless such a model can be supported with material property data which allow significantly better predictions than fully empirical correlations. It is the. author's conclusion that an empirical approach similar to the Meyer model is best for. modcling densification at the present.

\subsection{FUDENS Model Development}

The relation between densification and burnup suggested by Rolstad et al [ Equation (A-11.7)] has been adopted in the FUDENS code. Densification is assumed to consist of a. rapidly varying component [represented by the term $-2.0 \exp [-35(\mathrm{FBU}+\mathrm{B})]$ in Equation $(A-11.5)]$ and $\cdot a$ slowly varying component [ represented by the term $\exp [-3(F B U+B)]$ in Equation (A-11.5)]. The expression was adopted because it successfully. describes the burnup dependence of both the original Rolstad et al data and recent EPRI data: Comparisons of the model predictions with the data will be presented later in this section.

The term $\left(\frac{\Delta \mathrm{L}}{\mathrm{L}}\right)$ of Equation $(\Lambda-11.5)$ determines the maximum in-reactor densification. Four different expressions [Equations (A-11:1) to (A-11:4)] are used by the FUDENS code to determine a number for this term. When a measurement of fuel densification during a resintering test at $1700^{\circ} \mathrm{C}$ is available; this measurement is the basis of the model's prediction for the maximum in-pile shrinkage. The resintering density change found during a resintering test at $1700^{\circ} \mathrm{C}$ for at least 24 hours is the most appropriate basis to use in calculating the maximum in-pile densification because in-pile densification and thermal resintering are both dependent on porosity removal. However, Meyer's $[\mathrm{A}-11.12]$ assumption that the change in length during a resintering test is equal to the maximum in-pile densification is conservative at best for densification as required for the FUDENS code. The maximum irradiation-induced densification calculated by FUDENS is therefore a fraction of the density change found during a resintering test, i.e., $94 \%$ of the resintering density change at temperatures greater than $1000 \mathrm{~K}$ and $33 \%$ for temperatures below $1000 \mathrm{~K}$. 
If resintering test data are not available, the FUDENS model reverts to thc cxpression suggested by Rolstad et al [Equation (A-11.3)]. This expression provides a reasonable estimate of the in-pile densification, but unlike resintering tests, it cannot account for variations in pore size distribution.

Constants in the expressions used by FUDENS for maximum in-pile shrinkage were determined separately for high $(>1000 \mathrm{~K})$ and low temperatures. The separate expressions were used because a temperature dependence was found in the EPRI data ${ }^{[A-11.3]}$ and because of the irregular relation between the Halden data and the EPRI data sets. The Rolstad et al model, which predicts the Halden data well, fits the EPRI low temperature data but not the high temperature EPRI data. Hanevik et al suggested the Halden data was probably a measurement of the densification of fuel pellet edges, i.e., the cooler regions of the pellet. The Rolstad model is assumed by the FUDENS code to apply to low temperature densification, and the high temperature densification is assumed to be three times as large.

The constants in Equations (A-11.1) to (A-11.4) were determined by inspection to provide the best fit to the maximum density change of the EPRI data. Model predictions and the data base are shown in Figures A-11.2 and A-11.4. Mixed oxide fuel is assumed to densify in the same manner as $\mathrm{UO}_{2}$ due to lack of data to show otherwise.

\subsection{Fuel Densification Subcode FUDENS Listing}

A FORTRAN listing of the subcode FUDENS is presented in Table A-11.I.

\subsection{References}

A-11.1. W. Beere, "The Sintering and Morphology of Interconnected Porosity in $\mathrm{UO}_{2}$ Power Compacts," Journal of Materials Science, 5 (1973) pp 1717-1724.

A-11.2. W. M. Armstrong, W. R. Irvine, R. H. Martinson, "Creep Deformation of Stoichiometric Uranium Dioxide," Journal of 'Nuclear Materials, 7 (1962) pp 133-141.

A-1 1.3. D. W. Brite et al, EEI/EPRI Fuel Densification Project, Research Project 131 Final Report (Revised June 1975).

A-11.4. M. D. Freshley et al, "The Effect of Pellet Characteristics and Irradiation - Conditions on $\mathrm{UO}_{2}$ Fuel Densification," ANS/CNA Topical Meeting on Commercial Núclear Fuel - Current Technology, Toronto, Canada, April 1975.

A-11.5. E. Rolstad et al, "Measurements of the Length Changes of $\mathrm{UO}_{2}$ Fuel Pellets During Irradiation," Enlarged HPG Meeting on Computer Control and Fuel Research, June 4-7, 1974. 

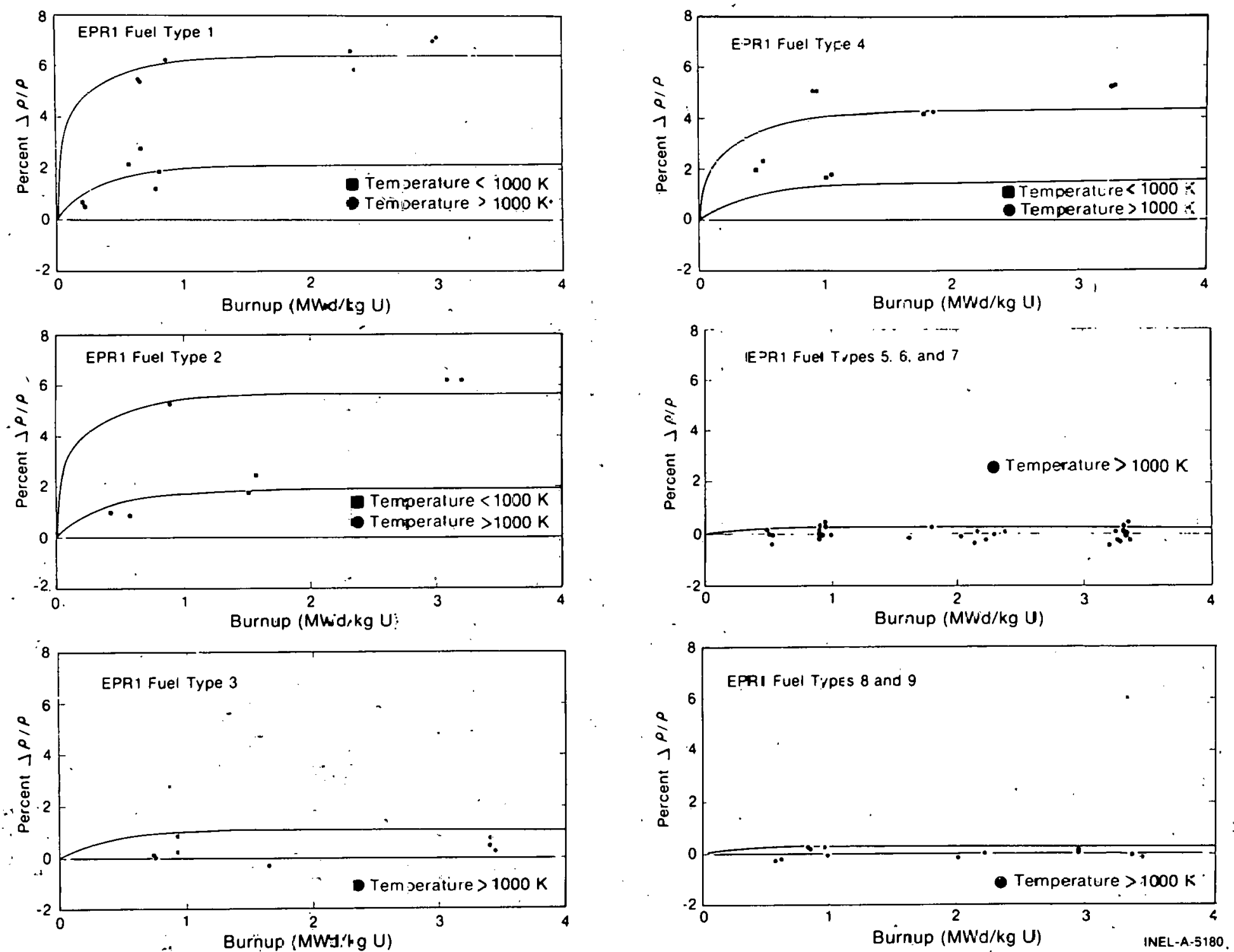

Fig. A-11.4 FUDENs calculations using EPRI fuel fabrication parameters and resintering values correlated with experimental EPRI in-piie data. 
FUDENS

TABLE A-11. I

I ISTING OF THE FUDENS SUBCODE

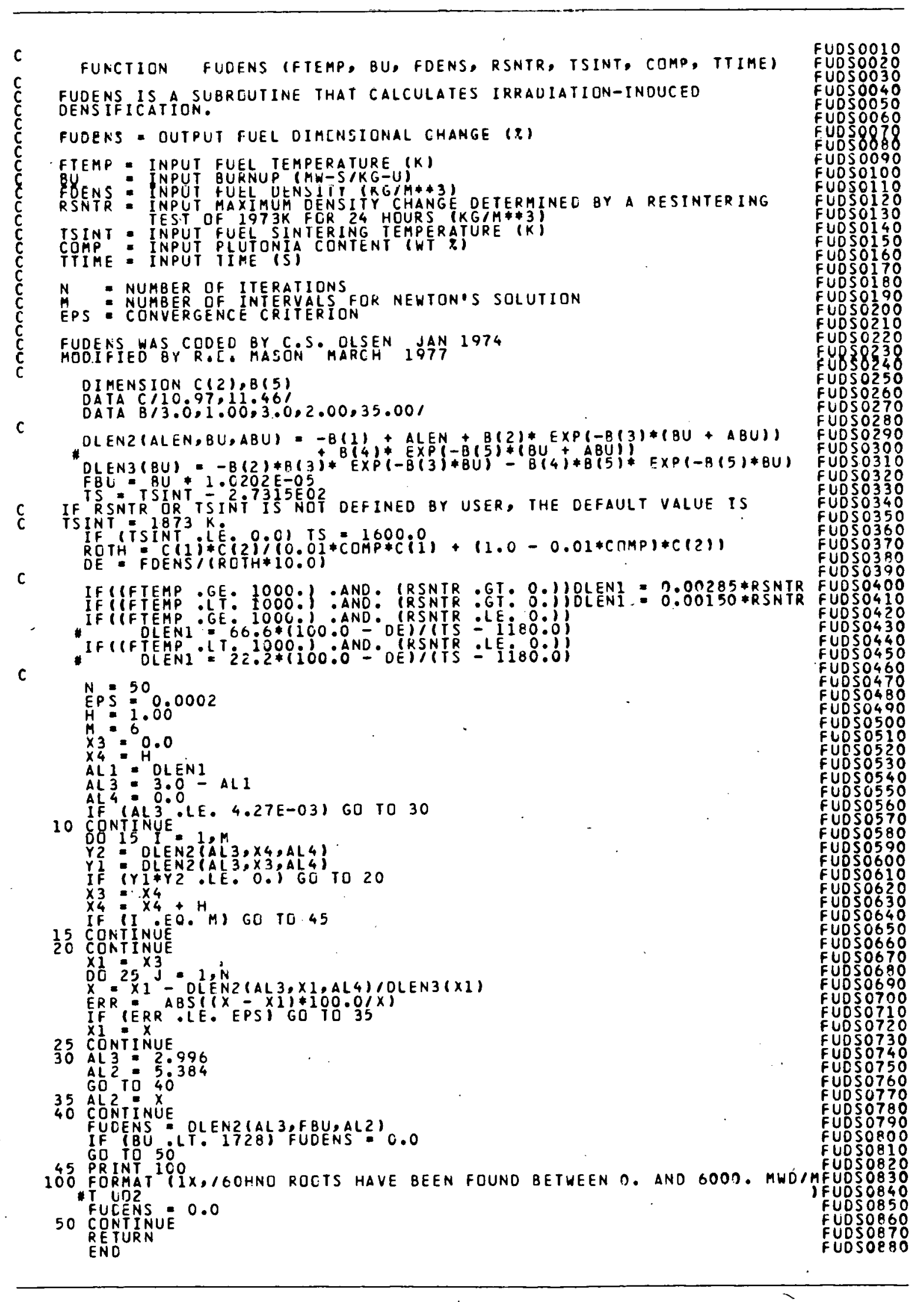


A-11.6. A. Hancvik et al, "In-Reactor Measurements of Fuel Stack Shortening," BNES Nuclear Fuel Performance Conference, London, October 15-19, 1973, paper no. 89.

A-11.7. D. A. Collins and R. Härgreaves, "Performance-Limiting Phenomena in Irradiated $\mathrm{UO}_{2}, "$ BNES Nuclear Fuel Performance Conference, London, October 15-19, 1973, paper no. 50.

A-11.8. H. M. Fcrrari ct al, "Fuel Densification Lxpenence in Westinghouse P'ressurized Water Reactors," BNES Nuclear Fuel Performance Conference, London, October 15-19, 1973, paper no. 54 .

A-11.9. T. J. Heal et al, "Devclopment of Stable Density $\mathrm{UO}_{2}$ Fuel," BNES Nuclear Fuel Performance Conference, London, October 15-19, 1.973, paper no. 52.

A-1 1:10. A. M. Ross, "Irradiation Behavior of Fission Gas Bubbles and Sintering Pores in $\mathrm{UO}_{2}$," Journal of Nuclear Materials (April 1969) pp 134-142.

A-11.11. B. Burton and G. L. Reynolds, "The Sintering of Grain Boundary Cavities in Uranium Dioxide,".Journal of Nuclear Materials, 45 (1972/73) pp 10-14.

A-11.12. R. O. Meyer, The Analysis of Fuel Densification, Office of Nuclear Reactor Regulation, U.S. Nuclear Regulatory Commission NUREG-0085 (July 1976).

A-11.13. J. C. Voglewede and S. C. Dochwat, Reactor Development Program Progress Report, ANL-RDP-33 (December 1974) pp 5-1 through 5-2.

A-1 1.14. H. Stehle and H. Assmann, "The Dependence of In-Reactor $\mathrm{UO}_{2}$ Densification on Temperature and Microstructure," Journal of Nuclear Materials, 52 (1974) pp 303-308.

A-11.15. M. O. Marlowe, "Predicting In-Reactor Densification Behavior of UO," Trans" actions of the American Nuclear Society, 17 (November 1973) pp 166-169.

A-11.16. D. Hull and D. E. Rimmer, "The Growth of Grain-Boundary Voids Under Stress," Philosophical Magazine, 4 (1959) p. 673.

A-11.17. S. R. MacEwen and I. J. Hastings, "A Model for In-Reactor Densification of $\mathrm{UO}_{2}$," The Philosophical Magazine 31, 1 (January 1975) pp 135-143.

A-11.18. R. W. Hamming, Introduction to Applied Numerical Analysis, New York: McGraw-Hill Book Company, Inc. (1971). 


\section{FISSION GAS RELEASE (FGASRL)}

During the irradiation of light water reactor fuel rods, gaseous fission products arc produced in the fuel and slowly released to the various void volumes in the rods. The released fission gases degrade the initial fill gas thermal conductivity (thereby changing the thermal response of the fuel rods) and increase the fuel rod internal pressure. In this section a correlation is described for the fractional tission gas release from oxide fuels duinig normal (steady state) operation. The correlation is based on the work of Weisman et al $[A-12.1]$ and is semiempirical, employing an equation derived from first principlcs and empirical constants. The constants were evaluated by comparing data from seven sources with code predictions using the FRAP-S2[A-12.2] computer code and the MATPRO cracked pellet gap conductance model. The constants reported here are, therefore, slightly different than the constants originally reported by Weisman et al. The model is inlended as a simplificd alternative to the more detailed prediction which will be availablc when the routine

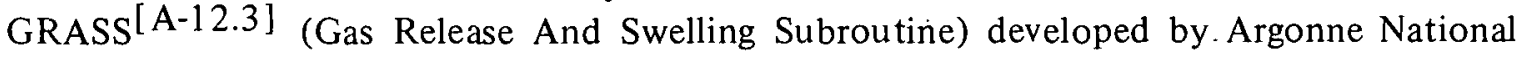
Laboratory is incorporated into FRAP.

\subsection{Summary}

Fractional release is given as a function of time, temperature, and burnup by Equation (A-12.1) below:

$$
F=1-\left(1-k^{\prime}\right) \frac{1-\exp (-k t)}{k t}
$$

with

$$
\begin{gathered}
k=\exp \left(-14800 T^{-1}-9.575\right) \text { and } \\
k^{\prime}=\exp (-6920 / T+33.95-0.338 \text { DEN })
\end{gathered}
$$

where

$$
\begin{aligned}
& \mathrm{F}=\text { fractional gas release } \\
& \mathrm{k}^{\prime}=\begin{array}{l}
\text { the fraction of fission gas that escapes without being } \\
\text { trapped }
\end{array} \\
& \mathrm{k}=\quad \begin{array}{l}
\text { the probability of trapped particle release per unit } \\
\text { time multiplied by } \mathrm{k}^{\prime}
\end{array} \\
& \mathrm{T} \quad=\quad \text { temperature (K) } \\
& \mathrm{t} \quad=\quad \text { time since startup (s) } \\
& \mathrm{DEN}=\text { percent theoretical density of the fuel. }
\end{aligned}
$$


If $\mathrm{T}<935 \mathrm{~K}$, then $\mathrm{T}$ is set equal to $935 \mathrm{~K}$.

The expressions for $\mathrm{k}$ and $\mathrm{k}^{\prime}$ have been obtained by fine-tuning the basic model, as discussed in Section A-12.2, to the temperature distribution generated by the FRAP code, which is discussed in Scction A-12.3. The uncertainty of the correlation for fractional release is dealt with in Section A-12.4, and an extension of the model to variable power-time histories is suggested in Section A-12.5. Additional parameters which influence gas release are briefly reviewed in Section A-12.6 and a listing of the subroutine is presented in Section A-12..7.

\subsection{Analytical Model}

The analytical model is that developed by Weisman et al $[A-12.1]$. It gives gas release as a function of temperature, time at temperature, and fuel theoretical density. The model considers gas release to be determined by the escape of gas from the fuel matrix and the release of trapped gas from grain boundaries or dislocations.

If $k^{\prime \prime}$ is the fraction of gas that escapes without being trapped, then $\mathrm{dn}_{1}$, the number of moles of gas released directly in timc $\mathrm{dt}$ is $\mathrm{k}^{\prime} \mathrm{pdt}$, where $\mathrm{p}$ is the gas production rate. If the probability of trapped particle release per unit time is $\mathrm{k}^{\prime \prime}$ and the number of moles trapped is $C$, then the trapped moles released in $d t$ is $d n_{2}=k^{\prime \prime} C d t$. Only a fraction $k^{\prime}$ of this gas released from traps reaches the surface. Thus the total gas released during $\mathrm{dt}$ is

$$
d n=d n_{1}+k^{\prime} d n_{2}=k^{\prime} p d t+k^{\prime} k^{\prime \prime} C d t .
$$

$C$ must equal the number of moles of gas produced minus the number released, i.e., $C=(\rho t-n)$. Making this substitution into Equation (A-12.3):

$$
d n=k^{\prime} p d t+k^{\prime} k^{\prime \prime} p t d t-k^{\prime} k^{\prime \prime} n d t \text {. }
$$

Letting $k^{\prime} k^{\prime \prime}=k$ and rearranging:

$$
\frac{d n}{d t}+k n=k \cdot n+k \cdot p t
$$

If $\mathrm{k}$ and $\mathrm{k}^{\prime}$ are independent of $\mathrm{t}$, as they should be, then Equation (A-12.5) is a common form of differential equation which can be solved by multiplying by the "integrating factor" $\mathrm{e}^{\mathrm{kt}}$ as follows:

$$
\begin{gathered}
{\left[\frac{d n}{d t}+k n\right] e^{k t}=k^{\prime} p e^{k t}+k p t e^{k t}} \\
\frac{d\left(n e^{k t}\right)}{d t}=k^{\prime} p e^{k t}+k p t e^{k t} .
\end{gathered}
$$


Equation (A-12.6b) may be integrated over the limits $(t=0, n=0)$ to $(t=t, n=n)$ where $t$ is the duration of the time step and $n$ is the number of moles of fission gas released in the time step. The quantity $n$ is zero when $t$ is zero because no gas has been released during the time step at the very beginning of the step.

$$
\begin{gathered}
\int_{0}^{n e^{k t}} d\left(n e^{k t}\right) \doteq \int_{0}^{t} k^{\prime} p e^{k t} d t+\int_{0}^{t} k p t e^{k t} d t \\
n e^{k t}=\left.\frac{k^{\prime} p e^{k t}}{k}\right|_{0} ^{t}+\left.\frac{p e^{k t}}{k}(k t-1)\right|_{0} ^{t} .
\end{gathered}
$$

The various integrals are tabulated in most tables of integrals, such as Dwight ${ }^{\text {A }-12.4]}$. Evaluating the expressions in Equation (A-12.7b) and solving for $n$ gives

$$
n=\frac{k^{\prime} p}{k}\left(1-e^{-k t}\right)-\frac{p}{k}\left(1-e^{-k t}\right)+p t
$$

or

$$
n=p\left[t-\frac{1}{k}\left(1-k^{\prime}\right)(1-\exp (-k t))\right]
$$

At constant power, the total fraction release is:

$$
F=\frac{n}{p t}=1:\left(1-k^{i}\right) \frac{1-\exp (-k t)}{k t}
$$

which is Equation (A-12.1).

\subsection{Evaluation of Constants}

Following Weisman et al, expressions for $\mathrm{k}$ and $\mathrm{k}^{\prime}$ have been evaluated from the literature assuming they have an Arrhenius temperature dependence. This functional form seems reasonable because gas release is quite small at low temperatures $[A-12.5, A-12.6]$ but shows a strong temperature dependence $[A-12.6-A-12.9]$ at higher temperatures.

As discussed below, the evaluation uses FRAP-S predictions for temperatures and reported measurements of temperatures.

12.3.1 Use of the FRAP-S Temperature Distribution. The FRAP-S code treats temperatures which vary axially and radially by dividing the fuel rod into 11 radial increments and up to as many as 15 axial increments. 
At each axial and radial station the code calculates the temperature, the fission gas production, and finally fission gas release. The production and release are then summed over the entire rod, and the ratio of the totals is used to express the rod-averaged fraction release. The heavier fission gases mix with the fill gas between the fuel and the cladding, degrading its thermal conductivity and thus reducing the heat transfer to the coolant, which in turn affects the rod's temperature profile. Therefore it is necessary to carry out gas release and temperature iterations at each power level until convergence is obtained.

12.3.2 Data Survcy. The dath 11sed for the rcfincment of the model was taken from the report of Beyer and Hann [A-12.9]. These authors were particularly careful to select fuel pin data which were from in-pile experiments, contained nearly stoichiometric fuel $(\mathrm{O} / \mathrm{M}=2 \pm 0.005)^{\circ}$ and $\sim 95 \%$ or more $\mathrm{TD}$, had constant power histories, relatively flat axial power profiles, and had good surface and centerline temperature determinations. They considered 46 experiments from 7 different sources $[A-12.10-A-12.16]$. Four of these 46 points were not used in this modeling effort because they referred to fuel which had an axial hole in the center, which is not typical of normal LWR fuel,

The expressions found for $k$ and $k^{\prime}$ are:

$$
\begin{gathered}
k=\exp \left(-14800 T^{-1}-9.575\right) \\
k^{\prime}=\exp (-6920 / T+33.95-0.338 \text { DEN })
\end{gathered}
$$

where

$$
\begin{aligned}
& \mathrm{T}=\text { temperature }(\mathrm{K}) \\
& \mathrm{DEN}=\text { percent theoretical density of the fuel. }
\end{aligned}
$$

The constants in Equations (A-12.10) and (A-12.11) were determined by running the FRAP-S code with different values for the parameters and comparing the calculated results with dalia from the Beyer and Hann ${ }^{\lceil\mathrm{A}-12.9]}$ report.

\subsection{Evaluation of Model Uncertainty}

The fractional release calculated by Equation (A-12.1) in conjuction with Equations (A-12.10) and (A-12.11) was checked against all the data selected. The comparison between the measured values and those predicted in this way is shown in Figure A-12.1. The standard deviation between measured and predicted values was $7 \%$, that is, if the measured gas release was $50 \%$, the one standard deviation limits are 43 and $57 \%$. All but one of the points falling outside the one standard deviation limits occur when the gas release is greater than $30 \%$, and the model consistently underpredicts in this region. All these points are from experiments where there was a large thermal gradient from the fuel centerline to surface. Since this is a circumstance where one would expect fuel cracking, a possible explanation for this might be the gas escaped through cracks and, in the interest of simplicity, this model does not include the effects of cracking. 


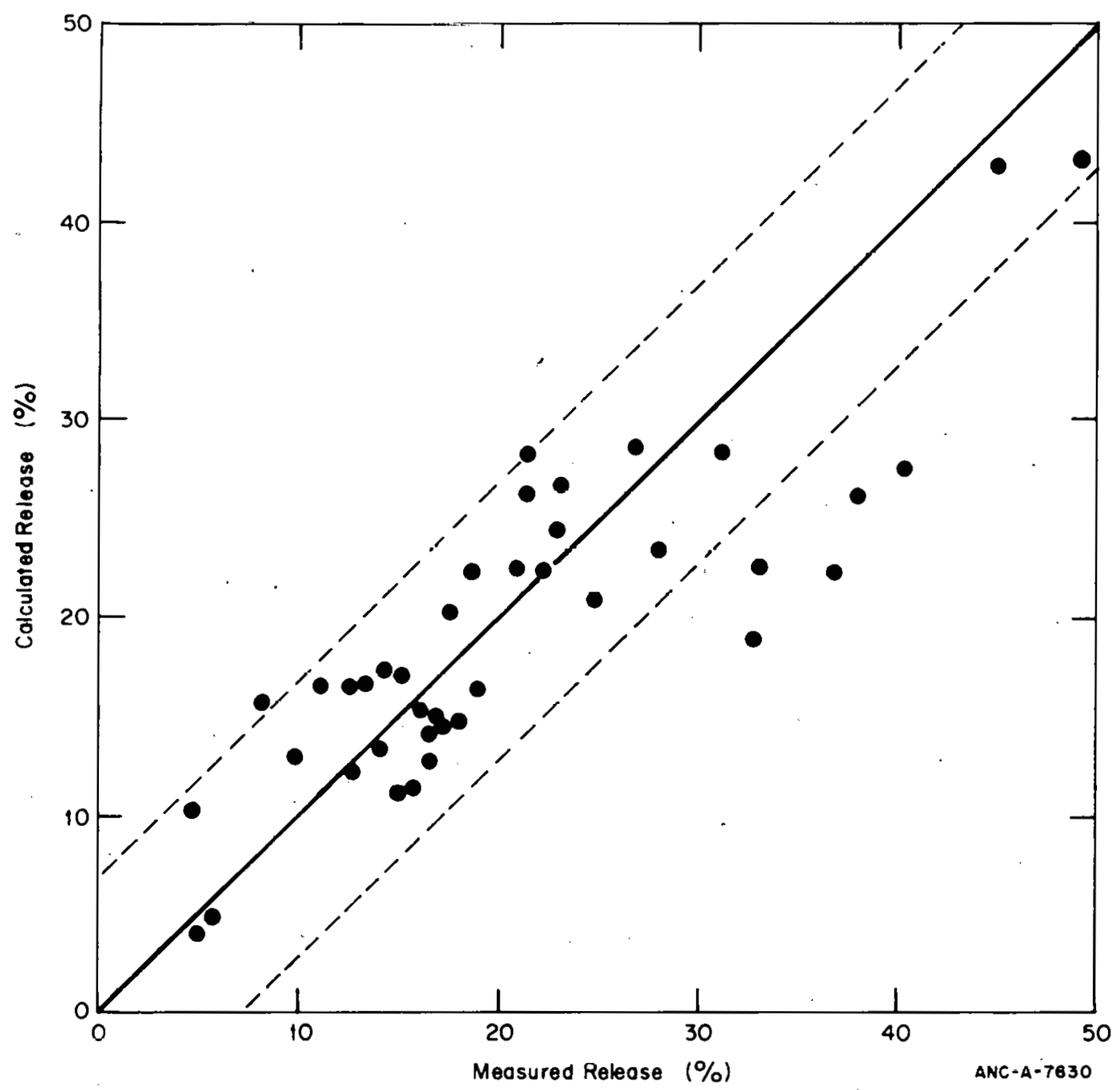

Fig. A-12.1 Calculated versus measured gas release percentages for the data points from R. M. Carroll et al.

\subsection{Extension of the Model to Variable Power-Time Hisluries}

The model presented above was developed for fuel pins with constant power-time histories. The model can be used to approximate the gas release from fuel pins with variable power-time histories by assuming reactor operation is described by a series of constant power steps. The number of moles released, $\Delta n_{i}$, during the ith power-time interval, is then

$$
\begin{aligned}
\Delta n_{i}= & n_{i}-n_{i-1}=p_{i}\left[\wedge t_{i}-\frac{1-k^{\prime}}{k_{i}}\left(1-\exp \left(-k_{i} \Delta t_{i}\right)\right)\right] \\
& +c_{i-1}\left[1-\exp \left(-k_{i} \Delta t_{i}\right)\right] .
\end{aligned}
$$

The first two terms of Equation (A-12.12) are analogous to Equation (A-12.1) and represent the release during the interval $\Delta t_{i}$, had the initial gas concentration been zero. 
FGASR I.

The last term is the additional release due to previously produccd gas. Since the total release from time zero is $\sum_{i} \Delta n_{i}$, the fractional release is

$$
F=\left[\sum_{i=1}^{m} \Delta n_{i}\right] /\left[\sum_{i=1}^{m} p_{i} \Delta t_{i}\right]
$$

where

$\mathrm{m}=$ the number of constant power steps.

Results obtained using Equation (A-12.13) werc not verificd with FRAP-S runs as part nf this effort.

\subsection{Additional Parameters Which Influeince Gàs Release}

Even though it is generally agreed that gas release increases, with burnup $[\mathrm{A}-12.9, \mathrm{~A}-12.17, \Lambda-12.18]$ [or time at power as shown in Equation $(\mathrm{A}-12.1)]$ and temperature ${ }^{[A-12.6-A-12.9]}$ and is inversely proportional to density $[A-12.6, A-12.17]$, there are several other factors which have an effect but which are not explicitly included in the present model because their importance and even dircction (causing an incrcasc or a decrease) are matters of disagreement. They are listed here and briefly discussed for completeness as well as to point out areas where more experimental work is needed.

12.6.1 Irradiation Effects. Carroll $[\mathrm{A}-12.5, \mathrm{~A}-12.7]$ reported that gas release decreased with increasing radiation density. In a later paper $[A-12.8]$ he reported this inhibiting effect occurs only at high irradiation levels. Soulhier ${ }^{[A-12.6]}$ reported that gas . release is independent of irradiation level.

12.6.2 Stoichiometry. Bailey $[A-12.17]$ reported that gas release is independent of stoichiometry, while Beyer and $\operatorname{Hann}^{[A .12 .9]}$ noted greater gas release with hyperstoichiometric fuel than with stoichiometric fuel.

12.6.3 Cracking. This is very important since gas often escapes from the fuel interior via cracks, but again there are contradictory reports. The Argonne National Laboratory quarterly for January-March, 1976 $[\mathrm{A}-12.19]$ reported that the effects of cracking are not well documented. Burley and Freshley $[A-12.20]$ claimed that most of the gas is released during shutdown power cycling, when changes in temperature would be expected to cause fuel cracking. Carroll [A-12.21] claimed that thermal cracking during irradiation can increase the external surface area by an order of magnitude. Since gas must escape from an external surface, this is an effect worth consideration.

These additional factors are listed not as criticisms of the model presented, since they are considered to some extent by virtue of the model's empirical nature, but rather as 
reminders that future experimental rcports should include these items in their fuel characterizations so that modelers can more easily assess their importance.

12.7 Fission Gas Release Subcode FGASRL Listing

A FORTRAN listing of the subcode FGASRL is given in Table A-12.I.

TABLE $A=12 . I$

LISTING OF THE FGASRL SUBCODE

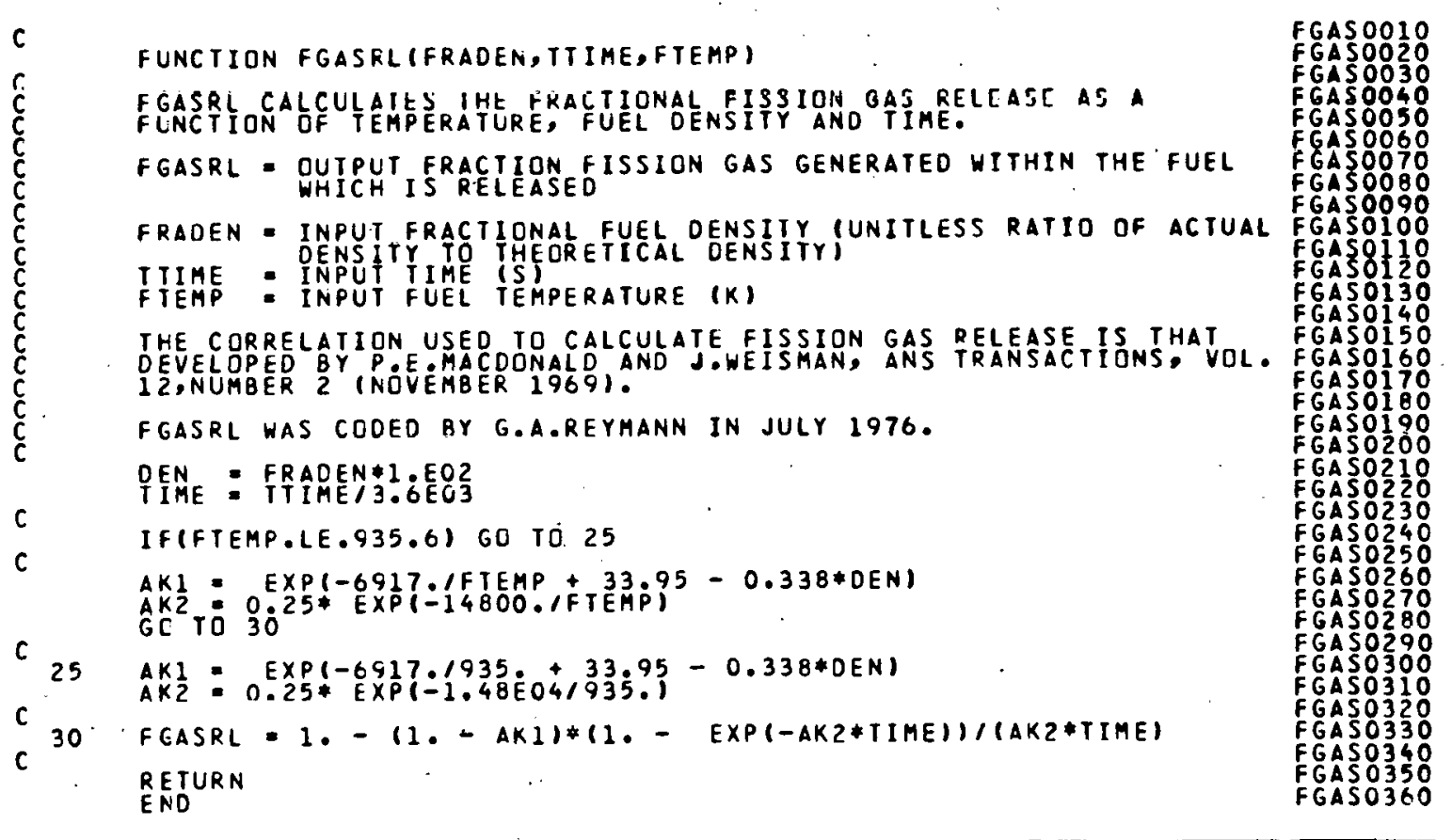

\subsection{References}

A-12.1. J. Weisman et al, "Fission Gas Release from $\mathrm{UO}_{2}$ Fuel Rods with Time Varying Power Histories," Transactions of the American Nuclear Society, 12 (1969) pp 900-901.

A-12.2. J. A. Dearien et al, FRAP-S2: A Computer Code for Steady State Analysis of Oxide Fuel Rods - Vol. I-Analytical Models and Input Manual, TREE-NUREG-1107 (July 1977).

A-12.3. R. B. Poeppel, "An Advanced Gas Release and Swelling Subroutine," Proceedings of the ANS Conference on Fast Reactor Fuel Element Technology, Hinsdale, Ill. (1976) pp 311-326. 
FGASRL

A-12.4. H. B. Dwight, Tables of Integrals and Other Mathematical Data, New York: The MacMillan Co., (1961).

A-12.5. R. M. Carroll, "Fission-Gas Behavior in Fuel Materials," Nuclear Safety, 8, 4 (Summer 1967) pp 345-353.

A-12.6. R. Soulhier, "Fission-Gas Release from $\mathrm{UO}_{2}$ During Irradiation up to $2,000^{\circ} \mathrm{C}$," Nuclear Applications, 2 (April 1966).

A-12.7. R. M. Carroll and O. Sisman, "In-Pile Fission-Gas Release from Single Crystal $\mathrm{UO}_{2}$," Nuclear Science and Engineering, 21 (19.65) pp 147-158.

A-12.8. R. M. Carroll et al, "Fission Density, Burnup, and Temperature Effects on Fission-Gas Release from $\mathrm{UO}_{2}$," Nuclear Science and Engineering, 38 (1969) pp 143-155.

A-12.9. C. E. Beyer and C. R. Hann, Prediction of Fission Gas Release from $\mathrm{UO}_{2}$ Fuel, BNWL-1 876 (November 1974).

A-12:10. J. P: Stora and P. Chenebault,'Programme Cyrano-Mesure de l'initegrale de conductibilite thermique d' $\mathrm{UO}_{2}$ frittc jusqu'a $2,3.00^{\circ} \mathrm{C}$-.. Evolution des gas de fission a puissance constante. CEA-R-3618 (1968).

A-12.11. J. A. Ainscough, An Assessment of the IFA-116 and 117 Irradiations from Data Obtained from the In-Reactor Instrumentation, HPR-129 (April 1971).

A-12.12. E. De Meulemeester et al, "Review of Work Carried out by BELGONCLEAIRE and CEA on the Improvement and Verification of the Computer Code with the Aid of In-Pile Experimental Results," British Nuclear Energy Society International

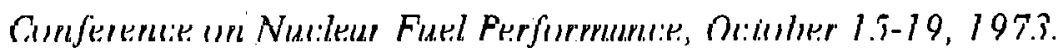

i-12.13." M: J. F. Notely et al, Mcasurcments of the Fission Product Gas Prossurcs Devcloped in $\mathrm{UO}_{2}$ Fuel Elements.During Operation, AECL-2662 (1966).

A-12.14. M. J. F. Notely and J. R. MacEwan, The Effect of $U_{2} O_{2}$ Density of Fission Product Gas Release and Sheath Expansion, CRNL Report AECL-2230 (1965).

A-12.15. M. J. F. Notely et al, Zircaloy Sheathed $\mathrm{UO}_{2}$ Fuel Elements Irradiated at Values of $\int k d \theta$ Between 40 and $83 w / \mathrm{cm}$, AECL-1676 (December 1962).

A-12.16. Jean-Claude Janvier et al, Irradiation of Uranium Dioxide in a Resistant Cladding Effects of Initial Diametral Gap on Overall Behavior, CEA-R-3358 (October 1967). 
A-12.17. W. E. Bailey et al, "Effect of Temperature and Burnup on Fission-Gas Release in Mixed Oxide Fuel," Journal of the American Ceramic Society, 49 (1970).

A-12.18. H. Mikailoff, "Effect of Density and Stoichiometry on Oxide Fuels Behavior," Journal of the American Ceramic Society, 49 (1970).

A-12.19. C. R. Kennedy et al, Cracking and Healing Behavior of $\mathrm{UO}_{2}$ as Related to Pellet-Cladding Mechanical Interaction, ANL-76-1 10 (July 1976).

A-12.20. T. B. Burley and M. D. Freshley, "Internal Gas Pressure Behavior in Mixed-Oxide Fuel Rods During Irradiation," Nuclear Applications and Technology 9, (August 1970).

A-12.21. R. M. Carroll, "Fission Product Release from $\mathrm{UO}_{2}, "$ Nuclear Safety, 4(1) (1962).

\section{CESIUM AND IODINE RELEASE (CESIOD)}

Cesium and iodine isotopes are produced in significant quantities by the fission of U-235 and Pu-239. The quantities of thesc isotopes released in the fuel rod gap are of interest in describing possible chemical attack of cladding by fission products and fission product release in the event of cladding integrity loss.

The CESIOD subcode was programmed because of publications containing the assumption that all the iodine and cesium produced by fission is available to attack zircaloy cladding $[A-13.1]$. The subcode does not provide a realistic description of iodine release because it does not consider chemical interactions between iodine and other fission products. It does, however, represent some improvement over the assumption that all of the fission-produced iodine is released from a ceramic oxide fuel matrix and attacks the cladding. In view of the uncertainty caused by chemical interactions, no effort has been made to incorporate the latest values of fission yields or nonfission effects on isotope production.

\subsection{Summary}

Cesium and iodine releases are modeled separately for each isotope since the decay rates of the different isotopes require separate treatments. Moreover, the approximations used to model long- and short-lived isotopes are different. Long-lived isotopes accumulate in the fuel in proportion to the burnup and are released by diffusion to the gap. Short-lived isotopes achieve a steady state in which their rate of release to the fuel rod gap is balanced by the decay rates of the isotopes in the fuel and in the gap. The concentration of short-lived isotopes is proportional to the rate of burnup. 
The input data required by the subcode are:

(1) Net fuel burnup (MWs/kg fuel)

(2) Net time at operating temperature (s)

(3) Maximum fuel temperature attained during operation prior to the constant-power (or time) step considered (K)

(4) Burnup increase durng the constant-power (or time) step considered (MWs/kg fuel)

(5) Duration of the step considered (s)

(6) Fuel density $\left(\mathrm{kg} / \mathrm{m}^{3}\right)$

(7) Fuel temperature at the mesh point considered (K)

(8) .Percent $\mathrm{PuO}_{2}$ content of the fuel (used unly to define fuel melt).

For the long-lived iodine and cesium isotopes (I-127, I-129, Cs-133, Cs-135, and Cs-137) the expression used to predict thc release of the isotope to the fuel rod gap is

$$
R_{i}=C_{i} B \cdot\left(\frac{4}{a} \sqrt{\frac{D t}{\pi}}-\frac{3 D t}{2 a^{2}}\right)
$$

where

$R_{i}=$ the specific isotope yield ( $\mathrm{kg}$ of the isotope $/ \mathrm{kg}$ fuel)

$\mathrm{C}_{\mathrm{i}}=$ the fission yield of the isotope ( $\mathrm{kg}$ of isotope/MWs), this constant is provided by the subroutine

$\mathrm{B}=\operatorname{burnup}(\mathrm{MWs} / \mathrm{kg}$ fuel)

$\mathrm{D}=$ diffusion coefficient for the isotope in fuel $\left(\mathrm{m}^{2} / \mathrm{s}\right)$, this constant is calculated by the subroutine from the input maximum temperature

a = diffusion distance for gas rclcasc ( $\mathrm{m})$, this constant is estimated by the subroutine from the input fuel density

$\mathrm{t}=$ time since the beginning of irradiation (s). 
For the short-lived iodine and cesium isotopes produced in quantity in light water reactors (I-131, I-132, I-133, I-134, I-135, and Cs-138) the expression used to predict the quantity of the isotope available in the steady state condition is

$$
R_{i}=\frac{\Delta B}{\Delta t} \frac{1}{1.732 \times 10^{10}} Y_{i} M_{i} \frac{\frac{3}{a} \sqrt{D \lambda_{i}}}{\left(\frac{3}{a} \sqrt{D \lambda_{i}}+\lambda_{i}\right) \lambda_{i}}
$$

where the symbols not defined in conjunction with Equation (A-13.1) are

$$
\begin{aligned}
& \Delta \mathrm{B}^{\prime}=\text { burnup during the step considered (MWs/kg fuel) } \\
& \Delta \mathrm{t}=\text { duration of the burnup step considered (s) } \\
& \mathrm{Y}_{\mathrm{i}}=\text { tission yield of the isotope (atoms o[ } \mathrm{i}_{\text {th }} \text { isotope/fission) } \\
& \mathrm{M}_{\mathrm{i}}=\text { atomic weight of the isotope } \\
& \lambda_{\mathrm{i}}=\text { the decay constant of the isotope }\left(\mathrm{s}^{-1}\right) .
\end{aligned}
$$

The diffusion coefficient in Equations (A-13.1) and (A-13.2) is calculated with an exponential expression which is truncated at low temperatures:

$$
\begin{array}{ll}
D=6.6 \times 10^{-6} \exp \left(\frac{-36086}{T}\right) & \text { for } T>1134.054 \mathrm{~K} \\
D=10^{-19} & \text { for } T \leq 1134.054 \mathrm{~K}
\end{array}
$$

where

$$
\begin{aligned}
& \mathrm{T}= \text { the maximum fuel temperature }(\mathrm{K}) \text { when } \mathrm{D} \text { is used in } \\
& \text { Equation }(\mathrm{A}-13.1) \text { or } \\
& \mathrm{T}= \\
& \quad \text { the current fuel temperature when } \mathrm{D} \text { is used in Equation } \\
&(\mathrm{A}-13.2) .
\end{aligned}
$$

A value for the diffusion distance, $a$, in Equations (A-13.1) and (A-13.2) is obtained from an empirical fit to measured values of effective open surface areas per volume of fuel as determined from gas absorption experiments. The correlation is presented in Section A:-13.2.1.

The basis for the model is discussed in Section A-13.2. Section A-13.3 is a review of the predictions of the model. A listing of the CESIOD code is provided in Section A-13.4. 


\subsection{Devclopment of the Model}

At fuel temperatures above $1000 \mathrm{~K}$, gaseous fission products become sufficiently mobile to migrate out of the $\mathrm{UO}_{2}$ lattice in a complex series of processes [A-13.2, A-13.3]. In the simplest useful appruach to model this process the fuel is treated as a collection of spheres, Fick's law is used to describe the diffusion of fission gases from the $\mathrm{UO}_{2}$ lattice, and the surface area per fuel volume (or, the effective radius of the spheres) is estimated from gas absorption measurements. This simple approach has been adopted to model the release of cerium und iodine to the fucl rod gap because a mule suphisticated treatment of the diffusion process is not justified without including complex chemical effects. Exact models for the amounts of cesium and iodine in the rod gap would require-consideration of the chemical interactions of cesium, iodine, zirconium, and oxygen as well as the details of the diffusion and gas release mechanism.

13.2.1 Derivation of the Mathematical Expressions. The equation which describes the release of stable or long-lived isntones hy diffusion is [A-13.3, A-13.4]:

$$
\frac{\partial \eta}{\partial t}=-D \nabla^{2} \cdot \eta+\gamma \cdot \frac{d f}{d t}
$$

where:

$$
\begin{aligned}
& \text { \%. } \quad \begin{array}{l}
\text { rumber of atoms of an isotope per unit volume of tuel } \\
\left(\text { atoms } / \mathrm{m}^{3}\right)
\end{array} \\
& \mathrm{t}=\text { time (s) } \\
& \mathrm{D}=\text { diffusion coefficient for the isotope }\left(\mathrm{m}^{2} / \mathrm{s}\right) \\
& \mathrm{Y}=\text { fission yield of the isotope (atoms of isotope/fission) } \\
& \left.\frac{\mathrm{df}}{\mathrm{dt}}=\text { fissinn rate of the fuel (atoms fiecioned } / \mathrm{m}^{3} \cdot \mathrm{s}\right) \text {, detcrmincd: }
\end{aligned}
$$

Since $\mathrm{Y} \frac{\mathrm{dr}}{\mathrm{dt}}$ represents the production rate of the isotopes; the fraction of the isotopes which is released from a sphere of radius " $a$ " ( $a=$ diffüsion distance for gas release. . ) is $[A-13.3]$

$$
R=\frac{4 \pi a^{2} \int_{0}^{t}\left(-D \cdot \frac{\partial n}{\partial r}\right) a d t^{\prime}}{\frac{4}{3} \pi a^{3} y \int_{0}^{t} \frac{d f}{d \cdot t^{\prime}} d t^{\prime}}
$$


where

$$
\begin{array}{ll}
\mathrm{R} & = \\
\left(-\mathrm{D} \frac{\partial \eta}{\partial \mathrm{r}}\right)_{\mathrm{a}}= & \text { the released fraction (unitless) } \\
& \begin{array}{l}
\text { the radial flux of isotope atoms obtained from } \\
\text { Equation }(\mathrm{A} \cdot 13.5)\left(\text { atoms } / \mathrm{m}^{2}\right) .
\end{array}
\end{array}
$$

The other symbols have been defined previously.

Equations (A-13.4) and (A-13.5) can be combined to find an expression for R. The resultant expression is $[\mathrm{A}-13.4, \mathrm{~A}-13.5]$

$$
R=1-\frac{6 a^{2}}{90 D t}+\frac{6 a^{2}}{\pi^{4} D t}\left[\sum_{m=1}^{\infty} \frac{1}{m^{4}} \exp -\left(\frac{-m^{2} \pi^{2} D t}{a^{2}}\right)\right]
$$

or, for $\frac{\pi^{2} \mathrm{Dt}}{\mathrm{a}^{2}}<1$

$$
R \simeq \frac{4}{a} \sqrt{\frac{D t}{\pi}}-\frac{3 D t}{2 a^{2}} .
$$

Multiplication of the release fraction $(R)$ by the fission yield of an isotope $\left(C_{i}\right)$ and the burnup (B) produces Equation (A-13.1) for the specific isotope yield of a long-lived isotope into the fuel rod gap. Expressions used for the diffusion coefficient (D) and the diffusion distance required for gas release (a) are discussed in Section A-13.2.2.

When the isotope is short-lived, the decay rate of the material in the $\mathrm{UO}_{2}$ matrix and in the fuel rod gap must be considered. The rate of change of the number of isotope atoms in the fuel rod gap is the difference between the rate of isotope release from the $\mathrm{UO}_{2}$ matrix and the rate of decay of isotope atoms in the gap.

$$
\frac{d M}{d t}=\nu N-\lambda M
$$

where

$$
\begin{aligned}
& \mathrm{M}=\text { number of isotope atoms in the fuel rod gap } \\
& \mathrm{t}=\text { time (s) } \\
& \nu=\text { escape rate coefficient }\left(\mathrm{s}^{-1}\right) \\
& \mathrm{N}=\text { number of isotope atoms in the } \mathrm{UO}_{2} \text { matrix } \\
& \lambda=\text { decay constant of the isotope }\left(\mathrm{s}^{-1}\right) .
\end{aligned}
$$


The rate of change of the number of isotope atoms inside the $\mathrm{UO}_{2}$ matix is the production rate less the rate of isotope release from the $\mathrm{UO}_{2}$ matrix and the rate of decay of isotope atoms in the $\mathrm{UO}_{2}$ matrix

$$
\frac{d N}{d t}=Y \frac{d f}{d t} V-v N-\lambda N
$$

where

$$
\mathrm{V}=\text { volume of the } \mathrm{UO}_{2} \text { matrix }\left(\mathrm{m}^{3}\right)
$$

and the other symbols have been defined in conjunction with Equations (A-13.4) and (A-13.8).

When the steady state is achieved $\frac{\mathrm{dM}}{\mathrm{dt}}$ and $\frac{\mathrm{dN}}{\mathrm{dt}}$ are both zero. Equations (A-13.8) and $(A-13.9)$ thus imply that the steady state value of $M$ (denoted by $M_{S}$ ) is

$$
M_{S}=\frac{v}{d} \frac{\gamma \frac{d f}{d t} V}{v+d}
$$

If the escape rate coefficients were known experimentally, Equation (A-13.10) would be sufficient to model the number of atoms of each isotope in the gap. Since sufficient experimental data are not available, the approach used for this model is to estimate an escape rate coefficient with the collection-of-spheres idea that was used for long-lived isotopes. The diffusion equation for the steady state (constant isotope concentration in the $\mathrm{UO}_{2}$ matrix) is

$$
0=D \nabla^{2} \eta+\gamma \frac{d f}{d t}-\lambda \eta
$$

where

$$
\begin{aligned}
& \eta=\begin{array}{l}
\text { number of atoms of the isotope per unit volume of fuel } \\
\left(\text { atoms } / \mathrm{m}^{3}\right)
\end{array} \\
& \mathrm{t}=\text { time (s) } \\
& \mathrm{D}=\text { diffusion coefficient for the isotope }\left(\mathrm{m}^{2} / \mathrm{s}\right) \\
& \mathrm{Y}=\text { fission yield of the isotope (atoms of isotope } / \text { fission) } \\
& \left.\frac{\mathrm{df}}{\mathrm{dt}}=\text { fission rate of the fuel (atoms fissioned } / \mathrm{m}^{3} \cdot \mathrm{s}\right) \\
& \lambda=\text { decay constant of the isotope }\left(\mathrm{s}^{-1}\right) .
\end{aligned}
$$


The quantity of interest for finding $\nu$ is the ratio, $F$, of the isolupe release rate to the isotope production rate. The ratio for a sphere of radius $a$ is

$$
F=\frac{4 \pi a^{2}\left(-D \frac{\partial \eta}{\partial r}\right) a}{\frac{4}{3} \pi a^{3} y \frac{d f}{d t}}
$$

Equations (A-13.11) and (A-13.12) can be combincd to find an cxpression for R. The resultant expression is $[\mathrm{A}-13.3]$

$$
F=\frac{3 D}{\lambda a^{2}}\left[\left(\frac{\lambda a^{2}}{D}\right)^{1 / 2} \operatorname{coth}\left(\frac{\lambda a^{2}}{D}\right)^{1 / 2}-1\right] .
$$

For $\frac{\lambda \mathrm{a}^{2}}{\mathrm{D}} \gg>1$, Equation (A-13.10) reduces to the form used in the model described here:

$$
F \simeq \frac{3}{a} \sqrt{\frac{D}{\lambda}}
$$

The ratio, $\mathrm{F}$, of the isotope release rate to the isotope production rate may also be written in terms of the escape rate coefficient

$$
F=\frac{v N}{Y \frac{d f}{d t} V}
$$

If the steady state form of Equation (A-13-9) is used to find an approximate expression for $\mathrm{N}$ when $\lambda \gg>\nu$, and if the resultant expression for $\mathrm{N}$ is substituted into Equation (A-13.15) one finds

$$
F \approx \frac{\nu}{\lambda}
$$

Finally, from Equations (A-13.14) and (A-13.16)

$$
v \approx \frac{3}{a} \sqrt{D \lambda}
$$

which is the result obtained by Belle $[\mathrm{A}-13.4]$.

Substitution of the approximate value of $\nu$ from Equation (A-13.7) into Equation (A-13.10), conversion of the fission rate $\frac{\mathrm{df}}{\mathrm{dt}}$ to a burnup rate, and conversion of $M$ to kilograms of isotope per $\mathrm{m}^{3}$ of fuel results in Equation (A-13.2). This equation is the one used in the model for the release of the short-lived isotopes of cesium and iodine.

13.2.2 Correlations for Material Constants Used in the Model. This section discusses the correlations used to obtain the diffusion coefficient for isotopes in the fuel, the diffusion radius for gas release, and the fission yields of the isotopes modeled. 
The correlation for the diffusion coefficient used with the model [Equation (A-13.3)] is the empirical expression recommended by Belle on page 512 of his review [A-13.4]. Recent results have not been used because improved values for the diffusion coefficient are simply not relevant until the improved techniques developed for the modeling of $\mathrm{Xe}$ and $\mathrm{Kr}$ can be adopted to provide significant improvement of the basic expressions for the release of cesium and iodine.

The correlation used for the diffusion radius is

$$
a=3(T D) \cdot 10^{[20.61-T D(67.9-46 T D)]}
$$

where

TD = fractional fuel density (ratio of actual density to theoretical density).

The expression is taken from the correlation for free surface area per unit volume recommended in Figure 9.18 of Belle's review $[$ A-13.4] . Belle's figure is: reproduced as 'Figure A-1:3.1 of this report. 1 he data are est1mates based; on;gas absorption measurements

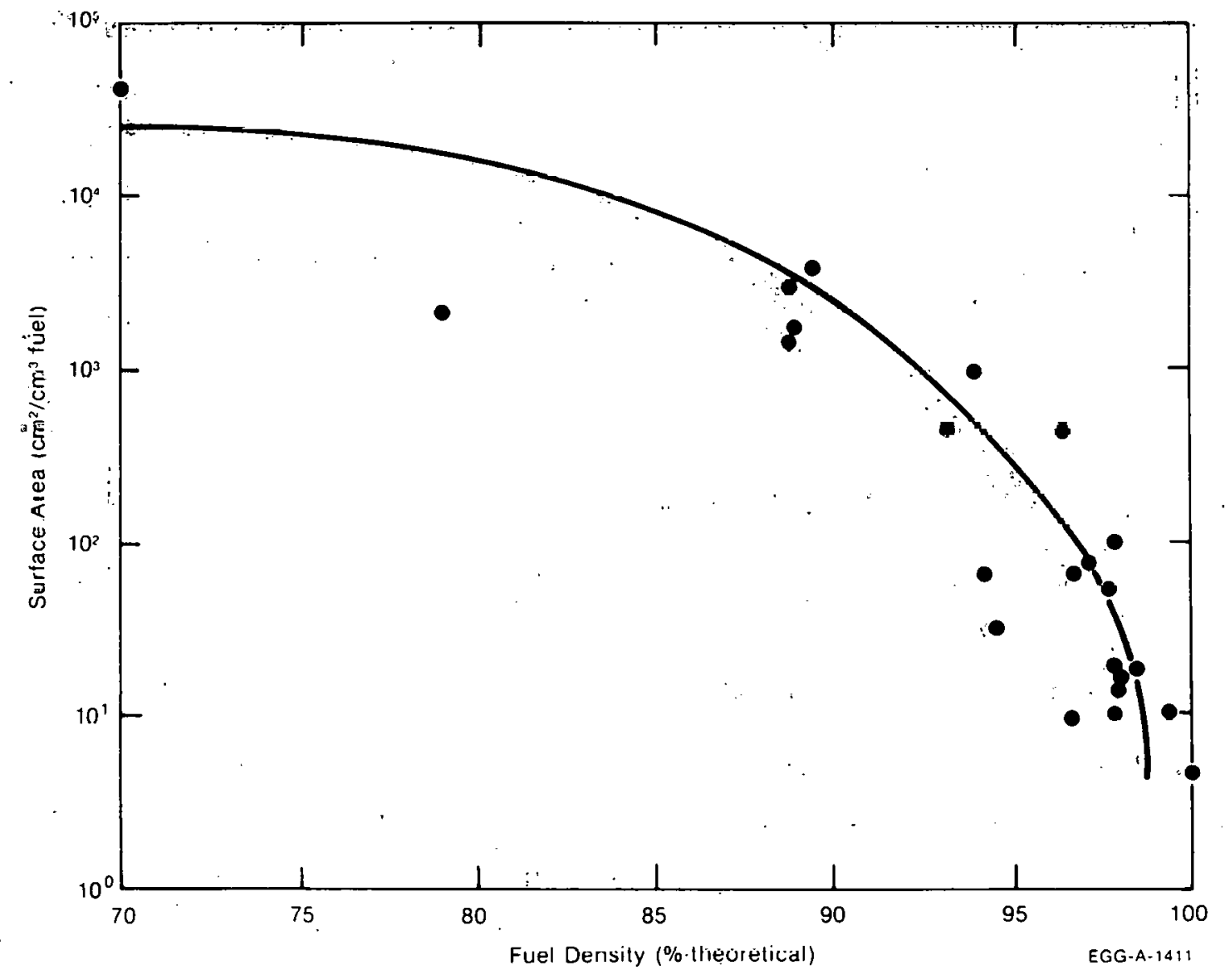

Fig. A-13.1 Surface area per unit volume recommended by Belle. 
with fuels of varying theoretical densities. Although considerable scatter is exhibited by the estimates, the trend toward smaller free surface area with higher density fuel is clear.

Expressions for the fission yields of the various isotopes are based on the early work of Katcoff $[\mathrm{A}-13.6]$. Since the products of fission have excess neutrons, they undergo a series of $\beta^{-}$decays in chains of constant mass number until a stable isotope is produced. The decay chains for mass numbers 127 and 138 and thermal fission of U-235 are reproduced in Figures A-13.2 and A-13.3. Decay chains for thermal fission of Pu-239 are similar. The Mass No.

127.

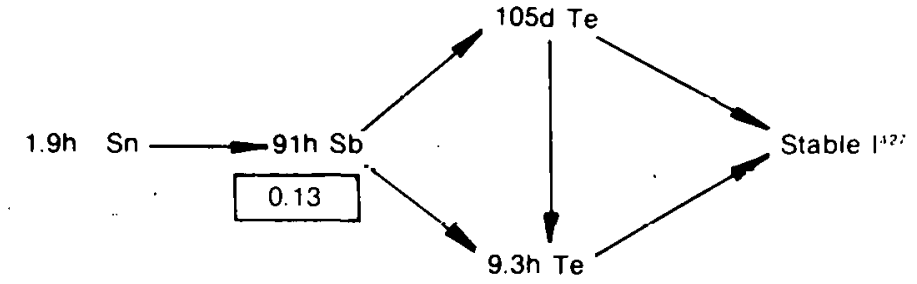

128.

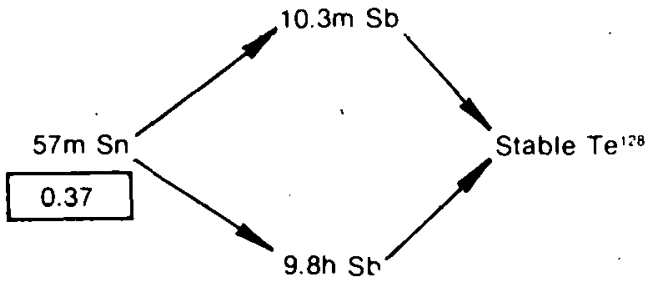

129.

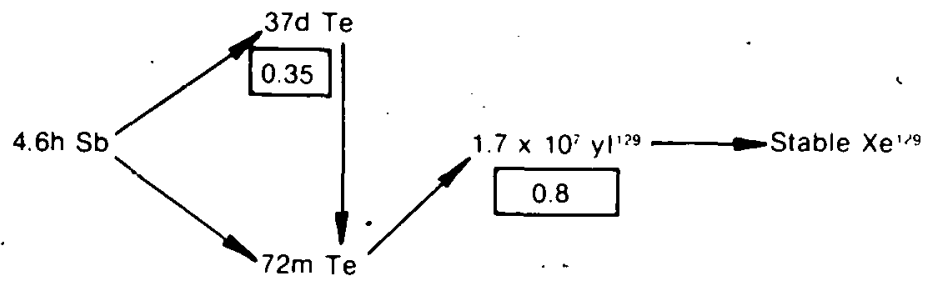

130.

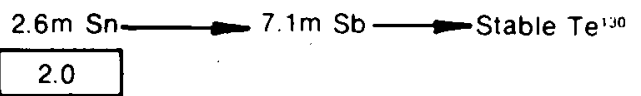

131.

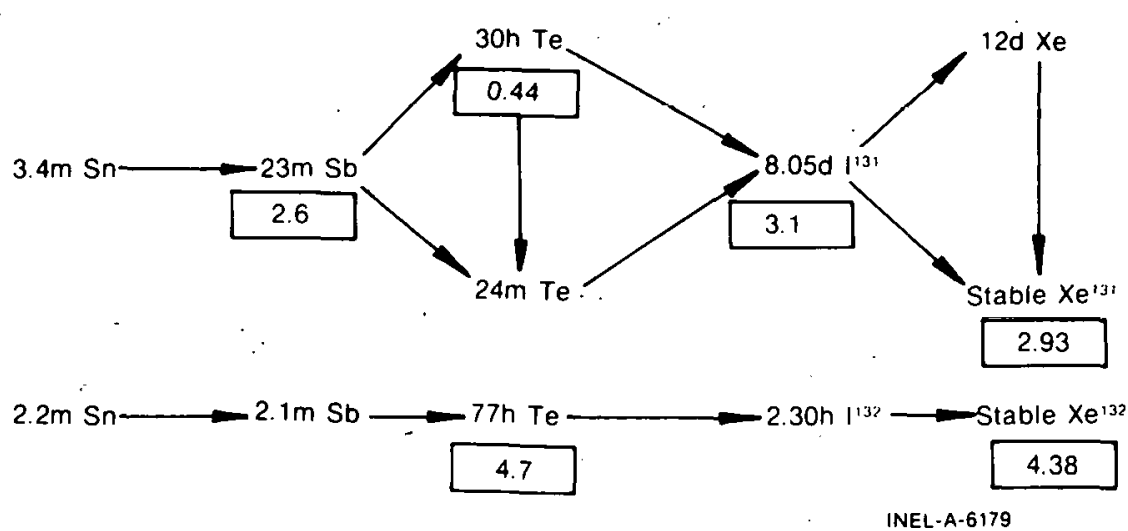

Fig. A-13.2 Fission chains for mass numbers 127-132 from the thermal fission of U-235. 
Mass

Number

133.

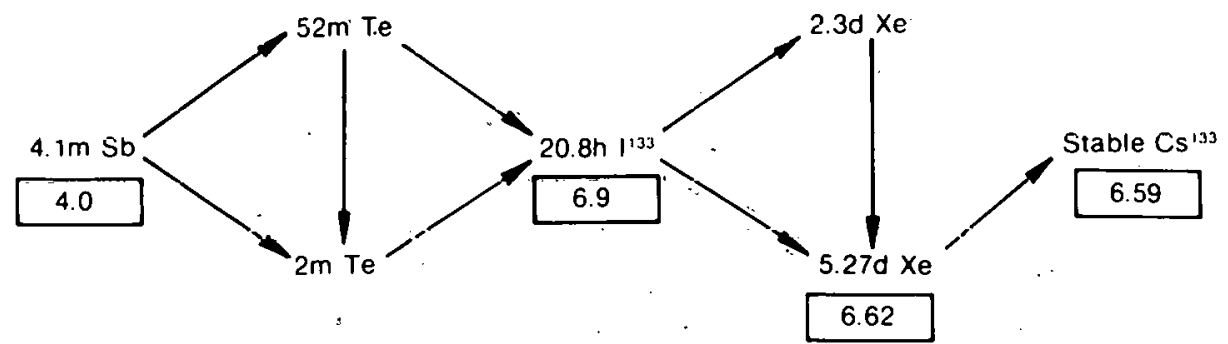

134.

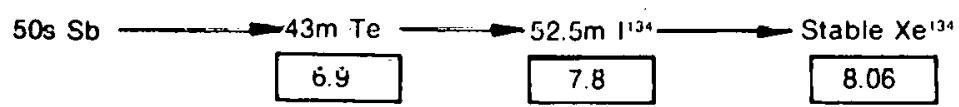

135.
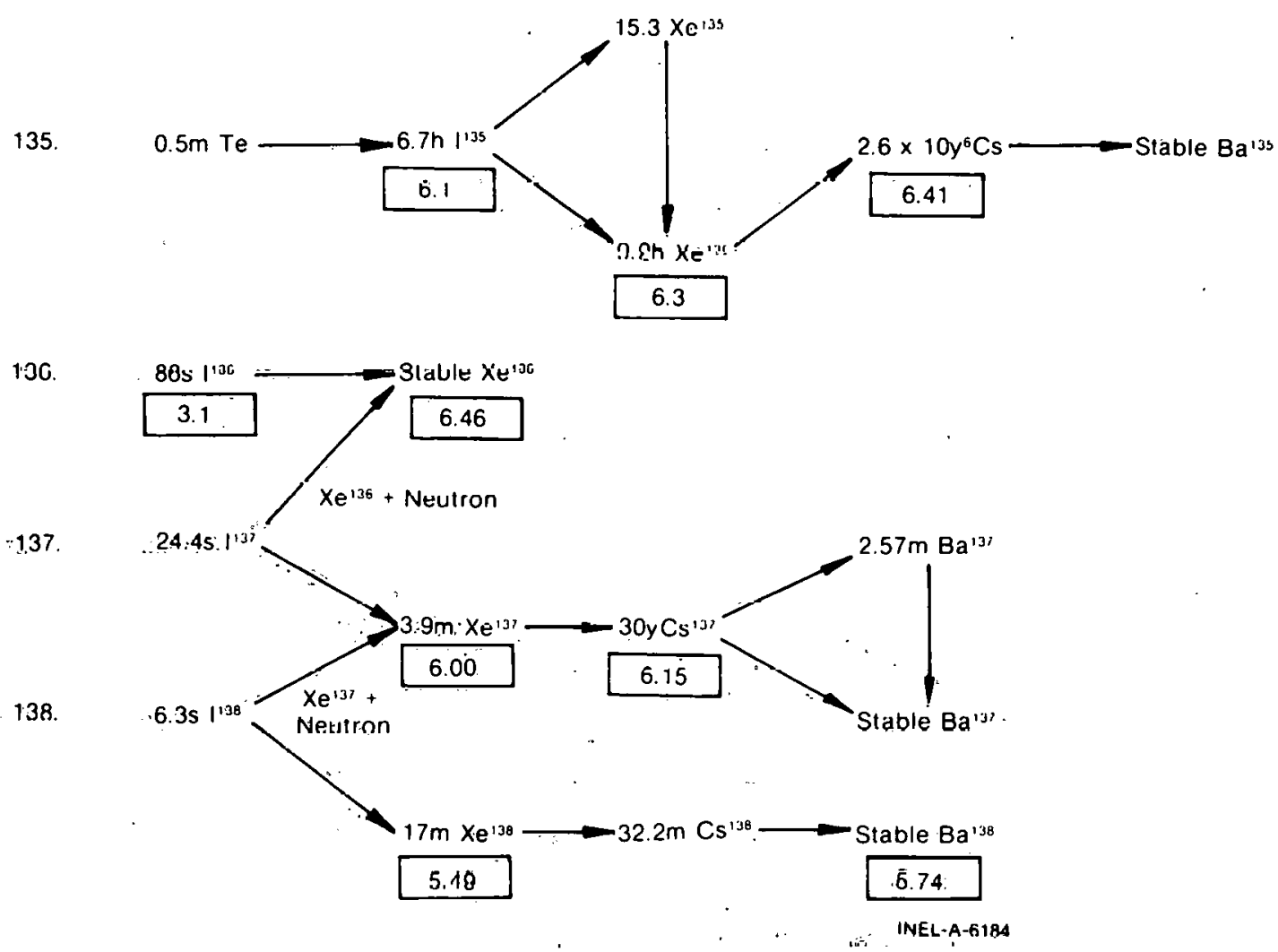

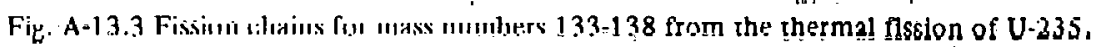

half-life of each chain member is indicated in front of the element's chemical symbol; and the chain yields in percent yield per fission are indicated by the box symbol at those points in the chain where they have been measured. At points where significant neutron decay exists, such as the decay of I-137 by neutron emission to form Xe-136, the yields vary significantly along the chain.

The yields for stable and long-lived isotopes of iodine and cesium are summarized in Table A-13.I. The conversion of the values of percent yield given in Figures A-13.2 and A-13.3 yields in kilograms of isotope per megawatt seconds for use in Equation (A-13.1) is given in Equation (A-13.19):

$$
c_{i}=\frac{Y_{i} \dot{M}_{j} 10^{-2}}{N_{a} E_{f}}
$$


TABLE A-13.I

FISSION YIELDS OF STABLE AND LONG-LIVED ISOTOPES
OF IODINE AND CESIUM

\begin{tabular}{lccc}
\hline Isotope & Half-Life & $\frac{\begin{array}{c}\text { Yield } \\
(\%)\end{array}}{\text { I-127 }}$ & $\begin{array}{c}\text { Stable } \\
\text { Yield } \\
(\mathrm{kg} / \mathrm{MWs})\end{array}$ \\
Cs-129 & $1.7 \times 10^{7}$ years & 0.13 & $9.50 \times 10^{-12}$ \\
Cs-135 & Stable & 0.8 & $5.94 \times 10^{-11}$ \\
Cs-137 & $2.6 \times 10^{6}$ years & 6.59 & $5.04 \times 10^{-10}$ \\
\hline
\end{tabular}

where

$$
\begin{aligned}
& \mathrm{C}_{\mathrm{i}}=\text { the fission yield of isotope } \mathrm{i}(\mathrm{kg} / \mathrm{MWs} \text { fission energy) } \\
& \mathrm{Y}_{\mathrm{i}}=\text { fission yield of isotope } \mathrm{i} \text { (percent per fission) } \\
& \mathrm{M}_{\mathrm{i}}=\text { mole weight of isotope } \mathrm{i}(\mathrm{kg} / \mathrm{mol}) \\
& \mathrm{N}_{\mathrm{a}}=\text { Avogadro's number (atoms } / \mathrm{mol} \text { ) } \\
& \mathrm{E}_{\mathrm{f}}=\text {. energy per fusion (MWs/fusion). }
\end{aligned}
$$

The fission yields for short-lived isotopes of iodine and cesium are summarized in Table A-13.II. Since the conversion from atoms released per fission to kilograms released per burnup rate is contained explicitly in Equation (A-13.2), the fission yields for short-lived isotopes are not converted to units of $\mathrm{kg} / \mathrm{MWs}$ fussion energy as they were in Table A-13.I.

Several short-lived isotopes of iodine and cesium are not included in Table A-13.1I or in the model. They are iodine isotopes with mass numbers 130,128 , and 126 or less; cesium isotopes with mass numbers 136,134, and 132 or less. The previous isotopes are not included because the relevant decay chain is terminated by a stable isotope before the isotope is produced. The other omissions are based on the very short half-lives of the isotopes which have been omitted. For very short half-lives the large decay constants obtained from the relation will cause very small amounts of the isotope in question to be present in the steady state.

$$
\dot{\lambda}_{i}=\frac{\ln \cdot 2}{\text { half-life }}
$$


TABLE A-13.1I

FISSION YIELDS OF SHORT-LIVED ISOTOPES

OF IODINE AND CESIUM

\begin{tabular}{|c|c|c|c|}
\hline Isotope & Hal'f-Life & $\begin{array}{l}\text { Decay Constant } \\
\left(\mathrm{s}^{-1}\right) \\
\end{array}$ & $\begin{array}{c}\text { Yield } \\
\text { (unitless fraction) }\end{array}$ \\
\hline$I-131$ & 8.05 days & $9.97 \times 10^{-7}$ & $3.1 \times 10^{-2}$ \\
\hline$I-132$ & 2.30 hours & $9.17 \times 10^{-6}$ & $4.3 \times 10^{-2}$ \\
\hline$I-133$ & 20.8 hours & $8.37 \times 10^{-5}$ & $6.9 \times 10^{-2}$ \\
\hline$I-134$ & 52.5 minutes & $2.22 \times 10^{-4}$ & $7.9 \times 10^{-2}$ \\
\hline$I-135$ & 6.7 hours & $2.87 \times 10^{-5}$ & $6.1 \times 10^{12}$ \\
\hline$C_{s}-1.38$ & 32.2 minutes & $3.59 \times 10^{-4}$ & $6.6 \times 10^{-2}$ \\
\hline
\end{tabular}

\subsection{Model Calculations and Comparison with Experimentạl-Data}

Figure A-13.4 illustrates model predictions for iodine and cesium releases from $97 \%$ dense fuel as a function of fuel temperature for a burnup of $2.6 \times 10^{5} \mathrm{MWs} / \mathrm{kgU}$ at one tenth year and a burnup rate of $3 \times 10^{6} \mathrm{MWs} / \mathrm{kgU}$ per year. The mass of cesium released is approximately ten times as large as the mass of iodine released. and both quantities increase rapidly as the fuel temperature increases. Two of the important components of the iodine release are shown separatcly. I-129 is a long-lived isotope so its contribution will increase with increasing burnup. I-131 is a short-lived isotope whose concentration in the gap is a function of the burnup rate. The step increase in the release of I-129 (from $0.8 \times 10^{=5} \mathrm{~kg}$ $1-129 / \mathrm{kg}$ fuel to $1.1 \times 10^{-5} \mathrm{~kg} \mathrm{I}-129 / \mathrm{kg}$ fuel) at $3100 \mathrm{~K}$ is caused by the assumption that tontal relcass of ling-lived isotones orsurs at fiel melt.

Figure A-13.5 illustrates the change in the predicted release of iodine when fuels of varying density are considered. Total iodine release at $1400 \mathrm{~K}$ for a burnup of $2.6 \times 10^{6} \mathrm{MWs} / \mathrm{kgU}$ at one year and a burnup rate of $3 \times 10^{6} \mathrm{MWs} / \mathrm{kgU}$ per year are shown for fuel densities ranging between 90 and $98 \%$ of theoretical density. Although the factor of 40 decrease in the iodine release is a large effect, the most important variable in determining the release of iodine (and cesium) is the temperature of the fuel.

No direct measurements of the amounts of cesium and iodine outside of the fuel matrix have been found. However, rod average escape rate coefficients determined from resin and loop water activities have been reported from tests of defected rods $[A-13.7]$. The escape rate coefficients reported and the escape rate coefficients predicted by Equation 


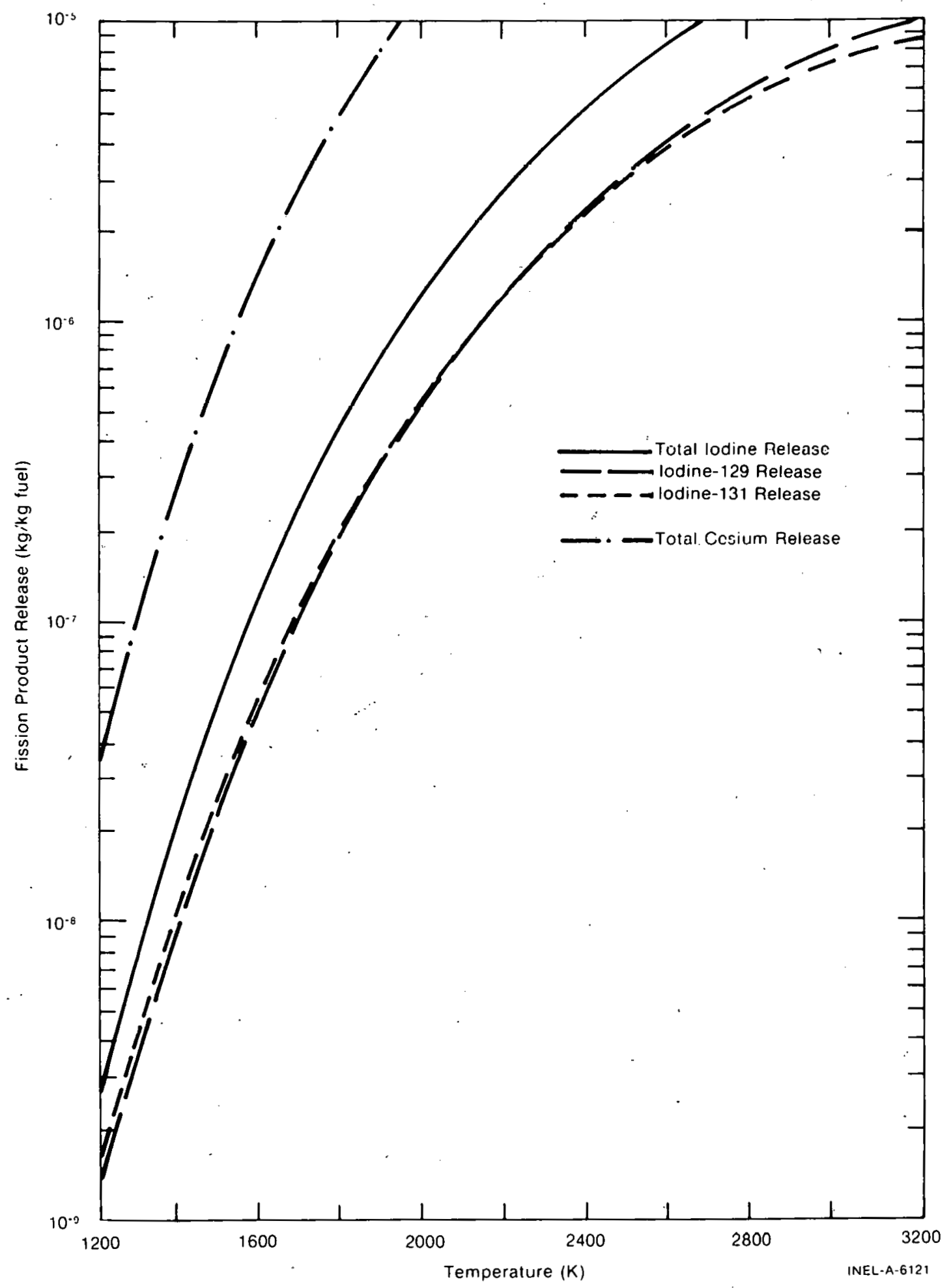

Fig. A-13.4 Model calculations for iodine and cesium releases from $97 \%$ dense fuel as a function of temperature for a burnup of $2.6 \times 10^{5} \mathrm{MWs} / \mathrm{kgU}$ at 0.1 year and a burnup rate of $3 \times 10^{6} \mathrm{MWs} / \mathrm{kgU}$ per year. 


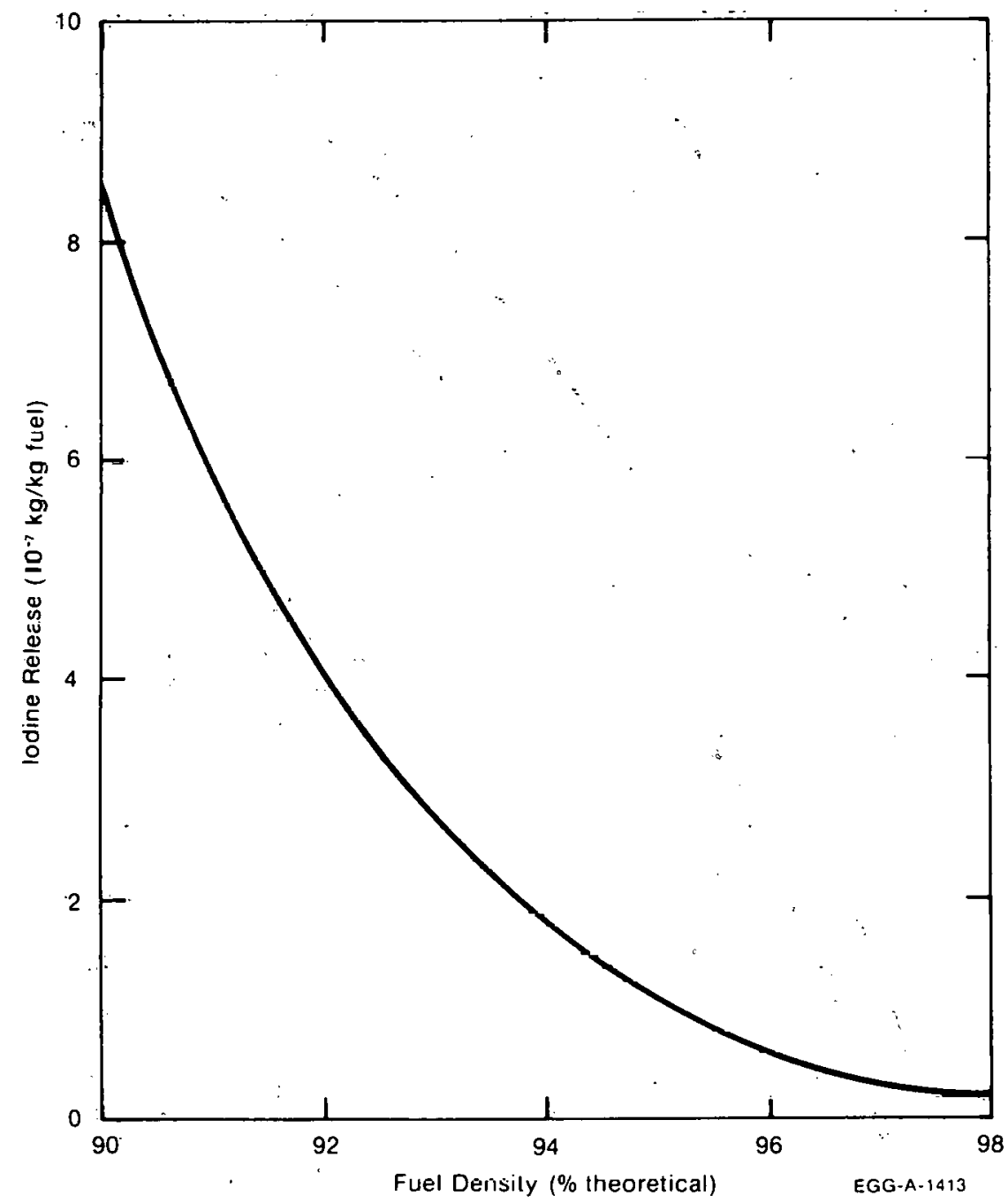

Fig. A-13.5 Iodine release from fuels of varying density with $2 \times 10^{6} \mathrm{MWs} / \mathrm{kgU}$ burnup at one year and a burnup rate of $3 \times 10^{6} \mathrm{MWs} / \mathrm{kgll}$ ner year.

(A-13.14) are compared in Tahle A-13.III Sinne the temperature distribution within the fuel rods is not known, estimates of the fuel centerline temperature and the rod average diffusion constant suggested by Belle on page 521 of his review $[\mathrm{A}-13.4]$ have been used in Equation (A-13.13). Belle's expression is

$$
\sqrt{D_{t}}=\frac{1}{6}\left(\sqrt{D_{c}}+4 \sqrt{D_{m}}+\sqrt{D_{s}}\right)
$$

where

$$
\begin{aligned}
& D_{t}=\text { the average diffusion coefficient for the rod }\left(\mathrm{m}^{2} / \mathrm{s}\right) \\
& \mathrm{D}_{\mathrm{s}}=\begin{array}{l}
\text { the diffusion constant at the fuel surface temperature } \\
\left(\mathrm{m}^{2} / \mathrm{s}\right)
\end{array}
\end{aligned}
$$


COMPARISON OF MODEL PREDICTIONS FOR ESCAPE RATE COEFFICIENTS

WITH VALUES REPORTED IN WCAP-TM- 159

\begin{tabular}{|c|c|c|c|c|}
\hline $\begin{array}{c}\text { Center line } \\
\text { Temperature } \\
(K) \\
\end{array}$ & Fuel Density & Isotope & WCAP-TM-159 & $\begin{array}{c}\nu \\
\text { Model } \\
\end{array}$ \\
\hline 685 & 0.934 & $I-131$ & $6.14 \times 10^{-10}$ & $1.62 \times 10^{-10}$ \\
\hline 685 & 0.934 & $I-131$ & $1.63 \times 10^{-9}$ & $1.62 \times 10^{-10}$ \\
\hline 685 & 0.934 & $\cdot I-1.33$ & $2.21 \times 10^{-9}$ & $1.48 \times 10^{-9}$ \\
\hline 685 & 0.934 & Cs -138 & $9.42 \times 10^{-9}$ & $4.17 \times 10^{-10}$ \\
\hline 1535 & 0.934 & $I-131$ & $6.08 \times 10^{-10}$ & $1.87 \times 10^{-9}$ \\
\hline 1535 & $-\quad 0.934$ & $I-131$ & $1.90 \times 10^{-9}$ & $1.87 \times 10^{-9}$ \\
\hline 1535 & 0.934 & $I-131$ & $1.78 \times 10^{-9}$ & $1.87 \times 10^{-9}$ \\
\hline 1535 & 0.934 & $I-133$ & $3.83 \times 10^{-9}$ & $1.70 \times 10^{-8}$ \\
\hline 15.3 .5 & 0.934 & $C s-138$ & $2.23 \times 10^{-7}$ & $4.78 \times 10^{-7}$ \\
\hline 1535 & 0.934 & Cs -138 & $1.63 \times 10^{-7}$ & $4.78 \times 10^{-7}$ \\
\hline 1800 & 0.974 & $I-131$ & $2.24 \times 10^{-9}$ & $1.54 \times 10^{-9}$ \\
\hline 1800 & 0.974 & $I-131$ & $5.78 \times 10^{-10}$ & $1.54 \times 10^{-9}$ \\
\hline . 1800 & 0.974 & $I-131$ & $2.93 \times 10^{-10}$ & $1.54 \times 10^{-9}$ \\
\hline 1800 & 0.974 & $C s-138$ & $1.28 \times 10^{-7}$ & $3.96 \times 10^{-7}$ \\
\hline 1800 & 0.974 & $C s-138$ & $6.58 \times 10^{-8}$ & $3.96 \times 10^{-7}$ \\
\hline
\end{tabular}
$\mathrm{D}_{\mathrm{m}}=$ the diffusion constant at the median fuel temperature $\left(\mathrm{m}^{2} / \mathrm{s}\right)$
$\mathrm{D}_{\mathrm{c}}=$ the diffusion constant at the fuel center temperature $\left(\mathrm{m}^{2} / \mathrm{s}\right)$.

The model underpredicts the low temperature escape rates, possibly because diffusion is not the dominant release mechanism at $685 \mathrm{~K}$. At the two higher temperatures the model predictions for I-131 fall within the scatter of the data, the one value measured for I-133 is one fifth the value predicted by the model and the model predictions for Cs-138 are about 3 times the values reported. 
13.4 Cesium and Iodine Release Subcode CESIOD Listing

The FORTRAN subcode CESIOD is listed in Table A-13.IV.

\section{$13.5^{\circ}$ References}

A-13.1. R. Van der Schaff, Zirconium in Nuclear Applications, ASTM-STP551 (August $1974), \mathrm{pp} 479-494$.

A-13.2. J. Rest, "Modeling of Fission-Gas Behavior During Steady-State and: Transient Conditions," Light-Water-Reactor Sufely Rescarch Program: Quarterly Progress Report April-June 1976, ANL-76-87, pp 8-17.

A-13.3. D. R. Olander, Fundamental Aspects of Nuclear Reactor Fuel Elements, ERDA Report TID-26711-P1 (April 1976).

A-13.4. J. Belle (ed.), Uranium Dioxide: Properties and Nuclear Applications, TID-75:46 U.S. Government Printing Office Washington, D:C. (1961):

A-13.5. A: H: Booth; A Method of Calculating Fission-Gas Diffusion from $\mathrm{UO}_{2}$ Fuel and Its Application to the X-2-f Loop Test; CRDC-721: (September 1957).

A-13:6: S. Katcoff, "Fission Product Yields from. Neutron-Induced: Fission," Nucleonics 18, 11, (Noyember 1960) pp 201-208.

A-13.7. R. Ehrenrerch, Radiochemistry of the PWR Fuel Material Cycling Tests (WAPD-29-1 and -2) in the WAPE-29 VH-3 Loop of the Materials Testing Reactor, WAPD-TM-1 59 (November 1959). 
TABLE A-13. IV

LISTING OF THE CESIOD SUBCODE
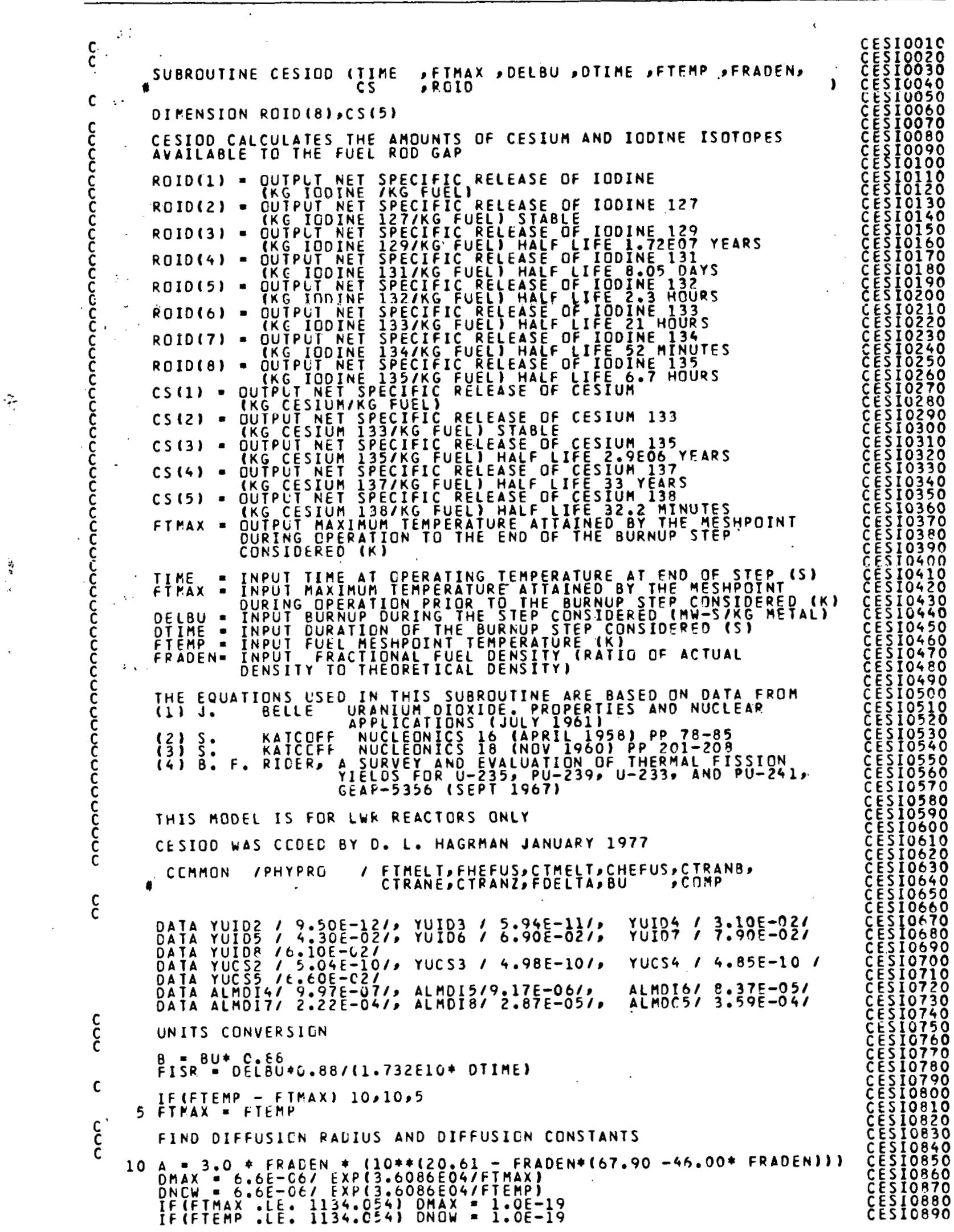
CESIOD

TABLE A-13.IV (continued)

C C FINO ESCAPE RATE COEFFICIENTS

ANUIS $=3.0 *(10 N O W * A(M O I 4) * 0.5) 1 A$

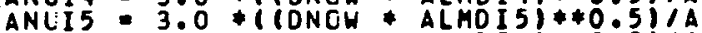

ANUI6 $=3.0 *($ IONOW $*$ ALMDI 6$) * 0.5) / A$

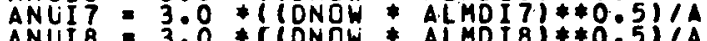

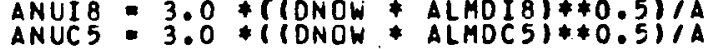

$c$
c
$c$
$c$

FINO SPECIFIT RELEASE FOR LONG LIVEO ISOTIRES

CHECK FOR FUEL MELT

21 IF (FTMAX - LT FIMGLT) GO TO 20

21 ROID(2): YUIDL:

CS $(2)=Y U C 52 * B$

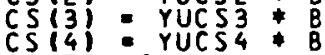

$c$
$c$
$c$

GO TO 25

SHECIFIC KELEASES WITHUUT TELI rúlLüW

CHECK TO SEE If RELEASE FRACTION IS GRETAER THAN ONE

$20 \mathrm{~F}=2.257$ * (CMAX * TIME)*0.5) / A - $1.5 *$ DMAX * TIME/(A*2)

IF IF.GT. 1.01 GO TO 21

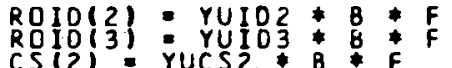

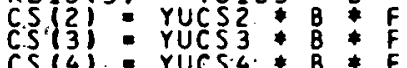

C. FINO SPECIFIC RELEASES FOR SHORT LIVEO ISOTOPES

25 ROID (4) = FISR * 131 * YUID4 *ANUI4 /(IANUI4 + ALMOI4)* ALMOI4) ROID (5) a FISR * 132 * YUID5 * ANUI5 / (ANUI5 + ALMDI5)* AL MOI5 ROIO(b) - FISR * 133 * YUIUO * ANUIG / ICANUIG + ALMDIGI* ALMOIG

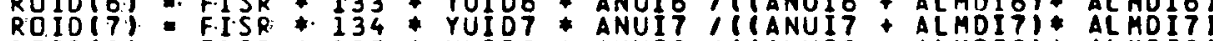

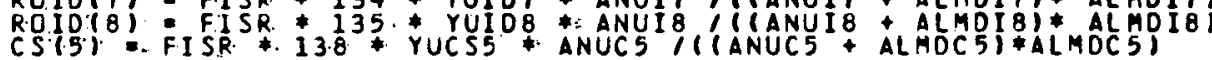

C CALCULATE SUMS

ROIO(1) $=R O I O(2)+R O I D(3)+R O I O(4)+R O I D(5)+R O I O(6)$

CS $(1) \cdot \operatorname{CS}(2)+C S(3)+C S(4)+\operatorname{CS}(5)$

RET TOR

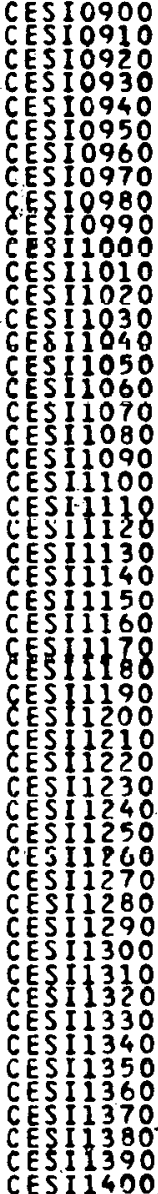




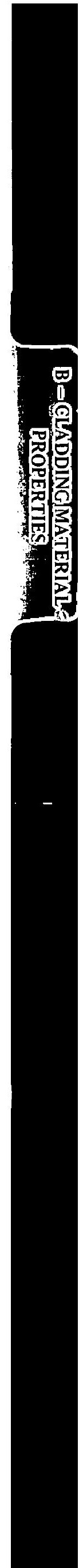


APPENDIX B

CLADDING MATERIAL PROPERTIES 
THIS PAGE

\section{WAS INTENTIONALLY \\ LEFT BLANK}




\section{APPENDIX B}

\section{CLADDING MATERIAL PROPERTIES}

Nineteen material properties of light water leactor cladding (zircaloy -2 or 4 ) have been modeled for inclusion in MATPRO - Version 10. Modeling approaches range from a choice of experimental, data with linear interpolation or extrapolation or both to a semiempirical expression suggested by theory.

All nineteen properties are modeled as a function of the cladding temperature. In addition such variables as flux, fluence, cold work, stress; time, and impurity content are used as arguments. Each model description characterizing a material property includes a listing of a FORTRAN subcode to enable users to independently program and utilize the correlations in the description. Some of the subcodes are interconnected, employing in part identical or very similar correlations (for example, strain versus stress, stress versus strain, and cladding ultimate strength), and some subcodes call upon others such as the physical properties subcode, PHYPRO, but all information needed to run a given subcode is contained.

\section{CLADDING SPECIFIC HEAT (CCP) AND THE EFFECT OF}

\section{HYDRIDE SOLUTION ON CLADDING SPECIFIC HEAT (CHSCP)}

Two function subcodcs are used to describe the apparent specific heat of the zircaloys. The first, CCP, describes the true specific heat of the alloys and the second, CHSCP, describes the apparent addition to the specific heat because of energy used in hydride solution. Uncertainty estimates have been determined for values returned by each function.

CCP requires only temperature as input, while CHSCP requires both temperature and the concentration of hydrogen. The hydrogen concentration may be supplied directly by the user or it may be calculated by the MATPRO function CHUPTK.

\section{$1.1 \quad$ Specific Heat}

For the alpha phase of the zircaloys (temperature less than $1090 \mathrm{~K}$ ), CCP returns linear interpolations for the points listed in Table B-1.I. (Linear interpolation is computed by the subcode POLATE described in Appendix D).

The table is based on precise data taken by Brooks and Stansbury [B-1.1] with a zircaloy-2 sample that had been vacuum annealed at $1075 \mathrm{~K}$ to remove hydrogen. The 
TABLE B-1. I

SPECIFIC HEAT CAPACITY AS A

FIINCTION OF TEMPERATURE - ALPHA PHASE

Temperature $(k)$

300

400

640

1090
Specific Heat $(\mathrm{J} / \mathrm{kg} \cdot \mathrm{K})$

281

302

331

375

standard error $^{[a]}$ of the CCP interpolation (that is, the precision of the fit to the data) was based on the 90 points in the data base and was found to be temperature dependent. For the 57 data points between 300 and $800 \mathrm{~K}$ it is $1.1 \mathrm{~J} / \mathrm{kg} \cdot \mathrm{K}$ and between 800 and $1090 \mathrm{~K}$ it is $2.8 \mathrm{~J} / \mathrm{kg} \mathrm{K}$.

For temperatures from 1090 to $1300 \mathrm{~K}$ (where Brooks and Stansbury do not report results) values-of specific heat proposed by Deem and Eldridge ${ }^{[\mathrm{B}-1.2]}$ are adopted by MATPRO. The Deem and Eldridge values, shown in Table B-1.II, are based on their measurements of enthalpy and temperature which provide considerably less precise specific heat data than the results of Brooks and Stansbury $[\mathrm{B}-1: 1]$.

The standard error as estimated by the Deem and Eldridge data in the region 1090 through $1310 \mathrm{~K}$ is $10.7 \mathrm{~J} / \mathrm{kg} \cdot \mathrm{K}$. Again, this standard error is a measure only of the precision of the fit since only a single data source is employed.

The specific heat as calculated by $\mathrm{CCP}$ is shown in Figure B-1.1. Figures B-1.2 and B-1.3 also show the CCP prediction using an expanded scale at lower temperatures and illustrating the base data freni Brouks and Stanisbury as well as alpha-phase data from Deem and Eldridge that were not used in constructing CCP.

At temperatures.up to $900 \mathrm{~K}$, the Brooks and Stansbury data agree with the Deem and Eldridge data within $3 \%$. Above the alpha + beta to beta transformation temperature (about $1250 \mathrm{~K}$ ) and up to about $1320 \mathrm{~K}$, a constant value of $355.7 \mathrm{~J} / \mathrm{kg} \cdot \mathrm{K}$ was reported by Deem and Eldridge. This value agrees well with a value of 365.3 reported by Coughlin and King ${ }^{[B-1.3]}$ for pure beta zirconium.

[a] The standard error is estimated for a data set by the expression: [sum of squared residuals/(number of residuals minus degrees of freedom) $]^{1 / 2}$. 
Temperature $(K)$

1093

1113

1133

1153

1173

1193

1213

1233

1248
Specific Heat $(\mathrm{J} / \mathrm{kg} \cdot \mathrm{K})$

502

590

615

719

816

770

619

469

356

The estimated standard error of CCP for data consisting of a random sample from all zircaloy-2 and zircaloy-4 claddings is also shown in Figures B-1.2 and B-1.3. This standard error is discussed in Section B-1.3 after the discussion of the effect of hydride solution.

\subsection{Effect of Hydride Solution}

Values returned by the function CHSCP for the addition to the specific heat due to energy used in solution of hydrides are

$$
C H S C P=\frac{A B C}{T^{2}}\left[\exp \left(\frac{-B}{T}\right)\right]\left[\exp \left(\frac{T-T S O L}{0.02 T S O L}\right)+1\right]^{-1}
$$

where

$$
\begin{array}{ll}
\text { CHSCP } & =\begin{array}{l}
\text { addition to true specific heat due to hydride } \\
\text { solution }(\mathrm{J} / \mathrm{kg} \cdot \mathrm{K})
\end{array} \\
\mathrm{T} \quad & \text { cladding temperature }
\end{array}
$$




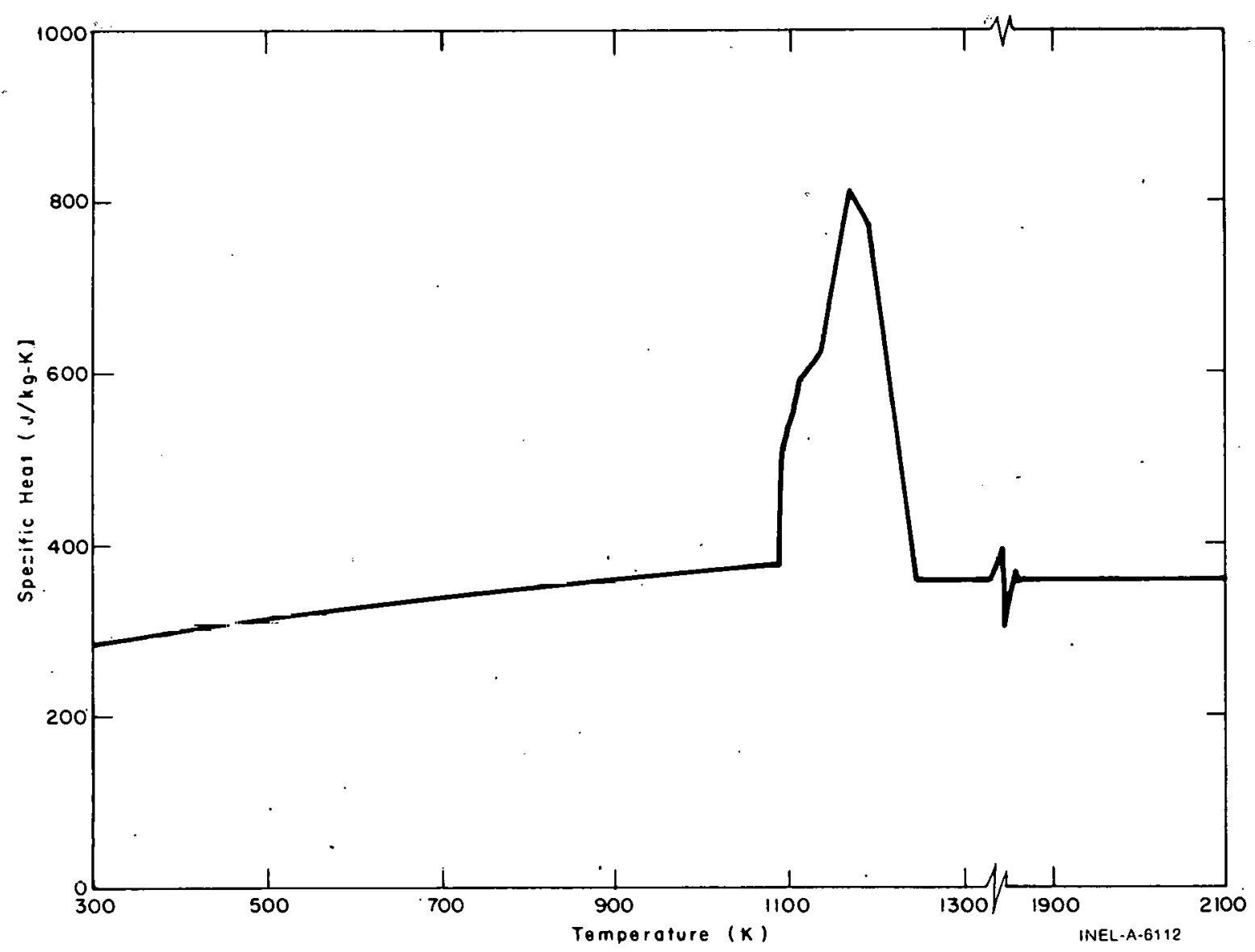

Fig. B-1.1 Specific heat of zircaloys as calculated by CCP for alloys without hydrides.

TSOL $=$ minimum temperature for complete solution of the hydrogen concentration as determined with Equation (B-1.2) (K)
$\mathrm{A}=1.332 \times 10^{5}$ (ppm hydrogen $)$
$\mathrm{B} \quad=\quad 4.401 \times 10^{3}(\mathrm{~K})$
$\mathrm{C}=45: 70(\mathrm{~J} / \mathrm{kg} \cdot \mathrm{ppm}$ hydrogen $)$

TSOL, the minimum temperature required for complete solution of the hydrogen present in the cladding, is determined from the expression

$$
\mathrm{TSOL}=\frac{\mathrm{B}}{\ln \left(\frac{\bar{A}}{\mathrm{H}}\right)}
$$




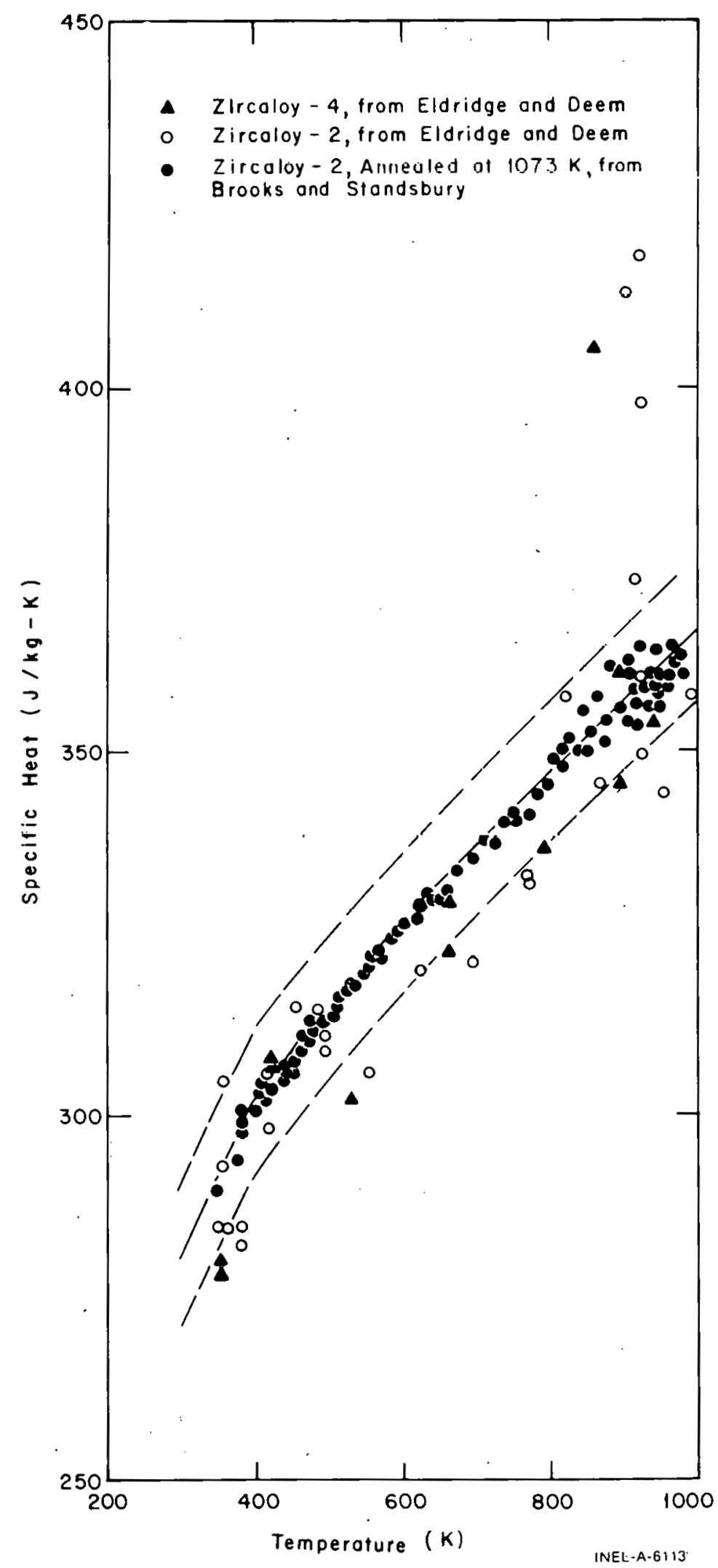

Fig. B-1.2 Available data, MATPRO expressions for specific heat, and estimated uncertainty of the MATPRO expression for temperatures from 300 to $1000 \mathrm{~K}$. 


\section{CCP/CHSCP}

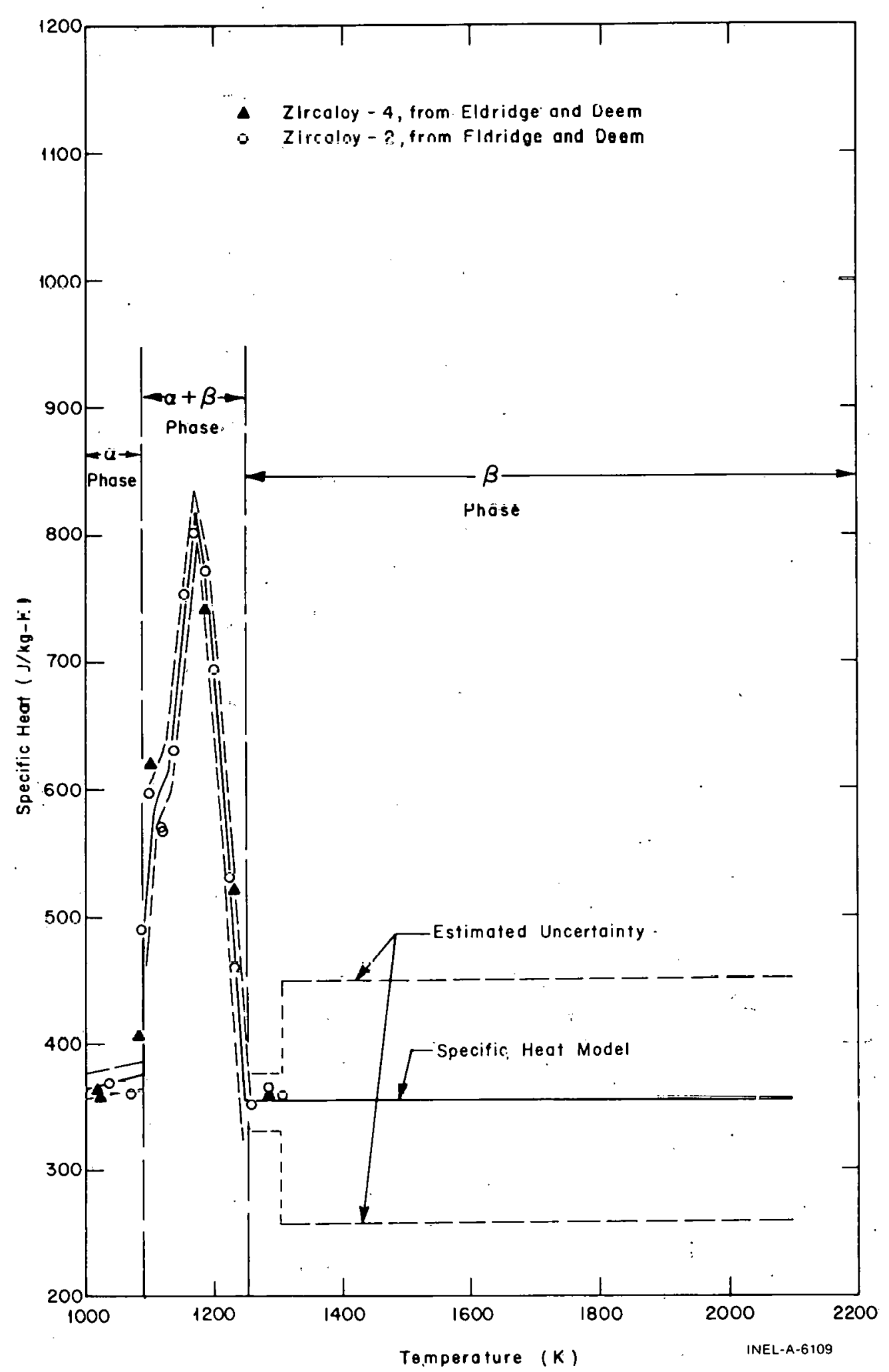

Fig. B-1.3 Available data, MATPRO expressions for specific heat,, and estimated uncertainty of the MATPRO expression for temperatures from 1000 to $2100 \mathrm{~K}$. 
where
$\mathrm{A}$ and $\mathrm{B}=$
constants given in conjunction with Equation
(B-1.1)
$\mathrm{H}=$ hydrogen concentration in ppm by weight.

A value of $\mathrm{H}$ can be detcrmined in either of two ways. A positive input by the user will be used directly, and a zero or negative input value for $\mathrm{H}$ will cause the remaining input arguments of CHSCP to be used with the function CHUPTK (Appendix B, Section 17) to calculate the hydrogen concentration.

Equations (B-1.1 and B-1.2) are based on data reported by Scott ${ }^{[B-1.4]}$ for zirconium with and without intentional additions of hydrogen. For temperatures below $830 \mathrm{~K}$, Scott (Figure 16 of Reference B-1.4) finds the logarithm of the terminal solubility of hydrogen in zirconium to be proportional to temperature. Below the temperature TSOL, when hydrides are not completely dissolved:

$$
\text { Energy to dissolve hydride }=\text { constant } \times \exp \left(\frac{\text { negative constant }}{\text { temperature }}\right) \text {. }
$$

It is assumed in this expression that the terminal solubility will be attained as long as undissolved hydrogen is present. The heat of solution per gram atom of hydrogen may be taken as the average of two values given by Scott (Table VII of Reference B-1.4). Equation (B-1.1) results from differentiation of this expression with respect to temperature and multiplication by the empirical factor $\left[\exp \left(\frac{\mathrm{T}-\mathrm{TSOL}}{0.02 \mathrm{TSOL}}\right)+1\right]^{-1}$ to express the fact that the data do not show an instant termination of hydride solution with increasing temperature.

Figure B-1.4 illustrates Scott's data for two samples of iodide zirconium and a single sample of zirconium intentionally doped with approximately $300 \mathrm{ppm}$ of hydrogen. The two iodide zirconium samples apparently contained some hydrogen and were fit by the MATPRO correlation [Equation (B-1.2)] assuming they contained 28 ppm hydrogen. Figure B-1.4 also shows the MATPRO correlation assuming $300 \mathrm{ppm}$ hydrogen and the curve recommended by Scott for pure zirconium.

\subsection{Uncertainties in Specific Heat Predictions}

The systematic crror (the cstimated variation between values obtained with different samples) is larger than the imprecision in the base data of CCP and CHSCP.

The standard error of CCP, reflecting the systematic error for a random sample of cladding zircaloys, is estimated to be $\pm 10 \mathrm{~J} / \mathrm{kg} \cdot \mathrm{K}( \pm 3 \%)$ in the alpha phase. This value is based on the difference between values of specific heat estimated by Deem and Eldridge 


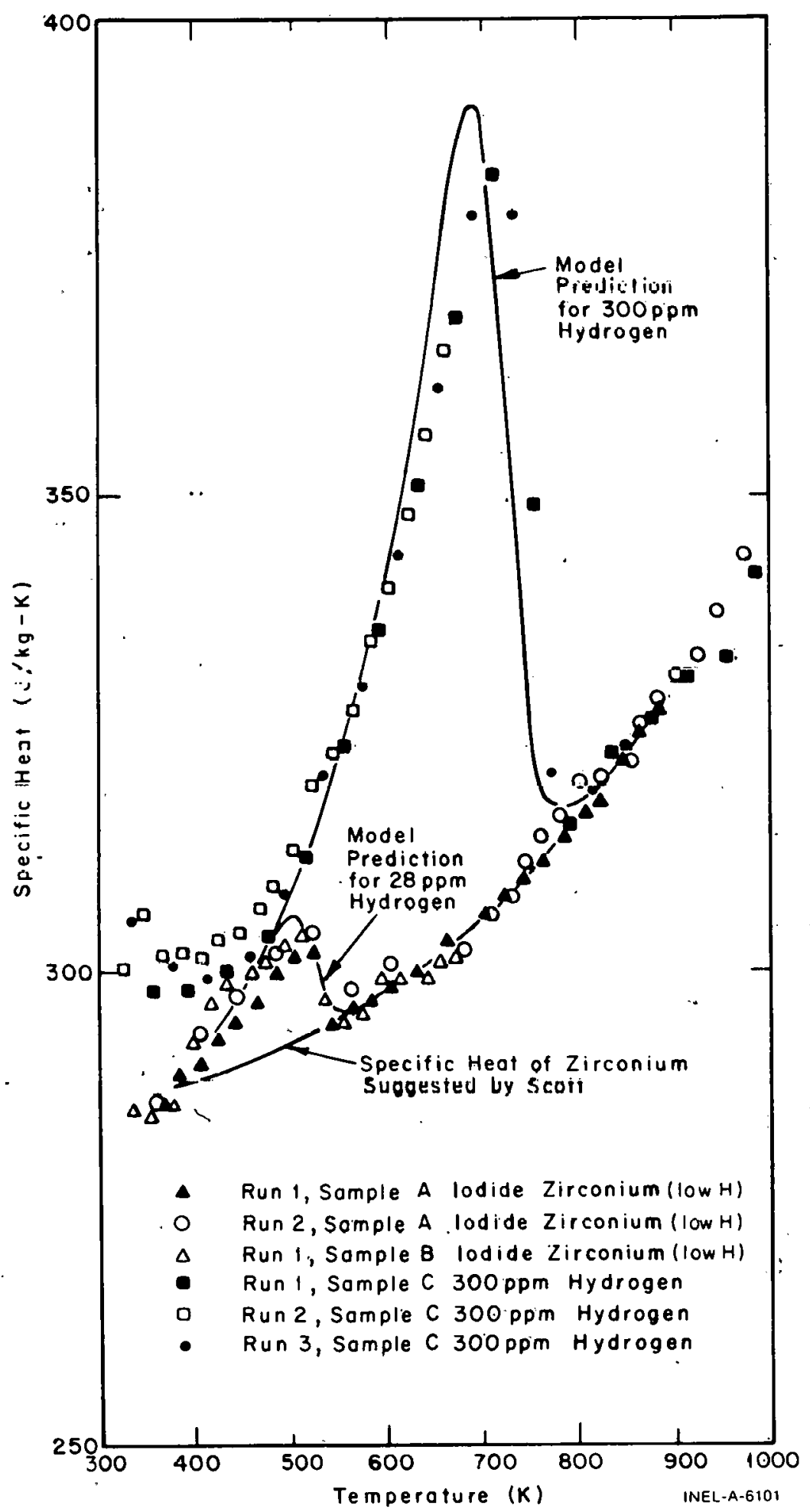

Fig. B-1.4 Data base for MATPRO prediction of the effect of hydride solution on specific heat, Scott's proposed curve for specific heat of zirconium, and the MATPRO predictions for the effect of $28 \mathrm{ppm}$ and $300 \mathrm{ppm}$ of hydrogen on the spccific heat curve. 
from their data ${ }^{[B-1.2]}$ and the more precise dala lium one samplc of zircaloy-2 used by MATPRO. In the alpha-beta phase region and the beta region to $1300 \mathrm{~K}$ a crudely estimated standard error of $25 \mathrm{~J} / \mathrm{kg} \cdot \mathrm{K}$ is assigned to $\mathrm{CCP}$, based on the decreased precision of the mcasurements and on the lack of any confirming data in this temperature range. For temperatures above $1300 \mathrm{~K}$, the only basis for the assumed constant value of specific heat is 1he prediction of the Debyo model of heat capacity for temperatures above the Debye temperature. Since no data are available, a standard error of $\pm 100 \mathrm{~J} / \mathrm{kg} \cdot \mathrm{K}$ is listed.

The basis for the estimate of the standard error of CHSCP over a random sample of cladding zircaloys is shown in Figure B-1.5, which compares MATPRO predictions for several concentrations of hydrogen with a curve published by Brooks and Stansbury [B-1.1] for the specific heal of zircaloy-2 tested without prior heat treatment. The unpublished data are reported to be within $1 \%$ of this curve and the MATPRO prediction is as far as $3 \%$ $(10 \mathrm{~J} / \mathrm{kg} \cdot \mathrm{K})$ below the reported curve. Since the prediction of CCP in this temperature range is based on precise data $( \pm 1.1 \mathrm{~J} / \mathrm{kg} \cdot \mathrm{K})$ taken with vacuum annealed samples of the same alloy, shown by a dashed line in Figure B-1.5, most of the discrepancy (between the dashed line and the $28 \mathrm{ppm} \mathrm{H}$ solid line) is presumed to be due to errors inherent in the application by CHSCP of the zirconium data of Scott to zircaloys. $\Lambda$ standard error of $50 \%$ in the hydrogen-induced increment to apparent specific heat is therefore assigned to the model.

The uncertainties in CCP are summarized in Table B-1.III.

The standard error in CHSCP (the addition to specific heat due to hydride solution) is taken to be $\pm 50 \%$.

1.4 Cladding Specific Heat Subcode CCP and Effect of Hydride Solution Subcode CHSCP Listings

The FORTRAN subcodes CCP and CHSCP are listed in Tables B-1.IV and.B-1.V.

\subsection{References}

B-1.1. C. E. Brooks and E. E. Stansbury, "The Specific Heat of Zircaloy-2 from 50 to $700^{\circ} \mathrm{C}$," Journal of Nuclear Materials, 18 (1966) p 223.

B-1.2. E. A. Eldrige and H. W. Deem, Specific Heats and Heats of Trarisformation of Zircaloy-2 and Low Nickel Zircaloy-2, USAEC BM1-1803 (May 31, 1967).

B-1.3. J. P. Coughlin and E. G. King, "High-Temperature Heat Contents of Some Zirconium-Containing Substances," Journal of the American Chemical Society, 72 (1950) p 2262.

B-1.4. J. Scott, A Calorimetric Investigation of Zirconium, Titanium, and Zirconium Alloys from 60 to $960^{\circ} \mathrm{C}$, Ph.D. Thesis, University of Tennessee (1957). 


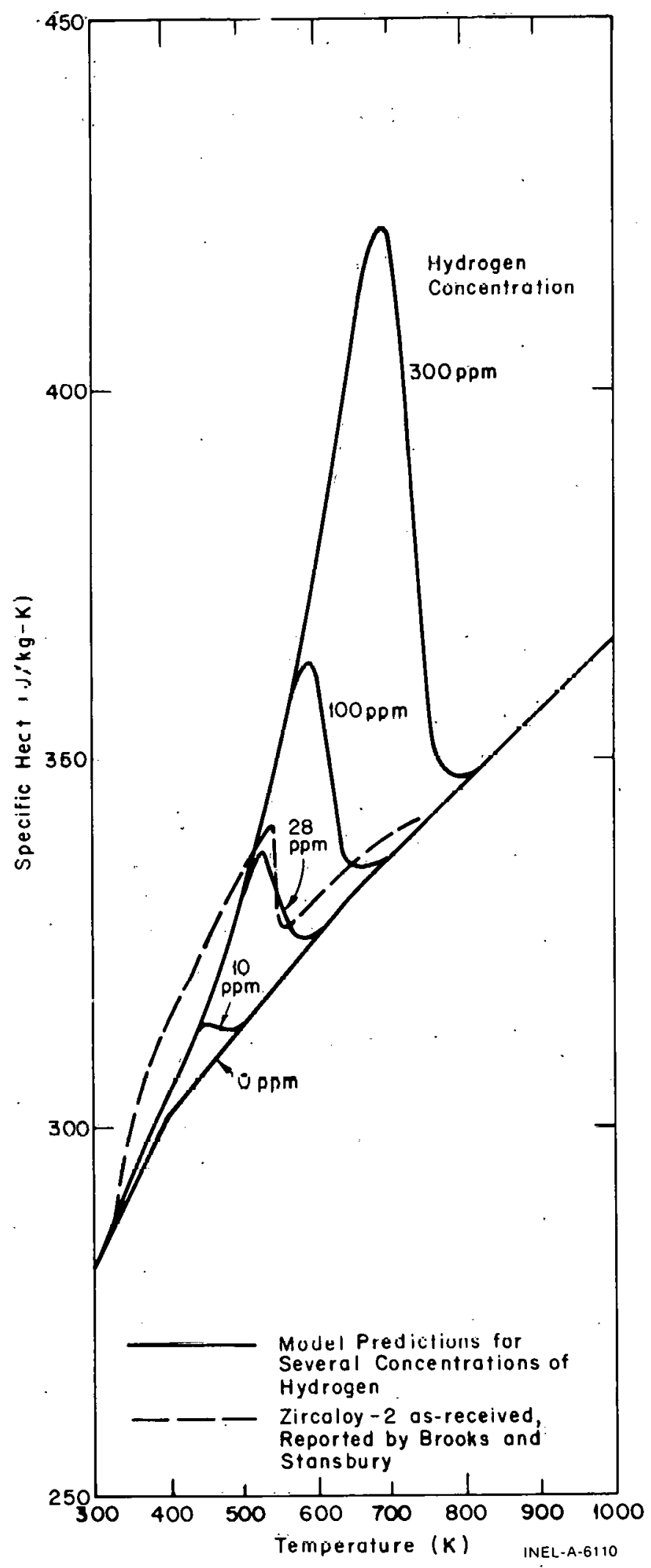

Fig. B-1 .5 MATPRO predictions for apparent zircaloy specific heat for several hydrogen concentrations compared with one curve measured with as-received zircaloy-2. 
TABLE B-1.III

UNCERTAINTIES IN SPECIFIC HEAT OF ZIRCALOY

Temperature Range

$300<T<1090 \mathrm{~K}$

$1090<T<1300 \mathrm{~K}$

$T<1300 \mathrm{~K}$
Standard Error in CCP

$$
\begin{aligned}
& \pm 10 \cdot \mathrm{J} / \mathrm{kg} \cdot \mathrm{K} \\
& \pm 25 \mathrm{~J} / \mathrm{kg} \cdot \mathrm{K} \\
& \pm 100 \mathrm{~J} / \mathrm{kg} \cdot \mathrm{K}
\end{aligned}
$$

TABLE B-1.IV

LISTING OF THE CCP SUBCODE .

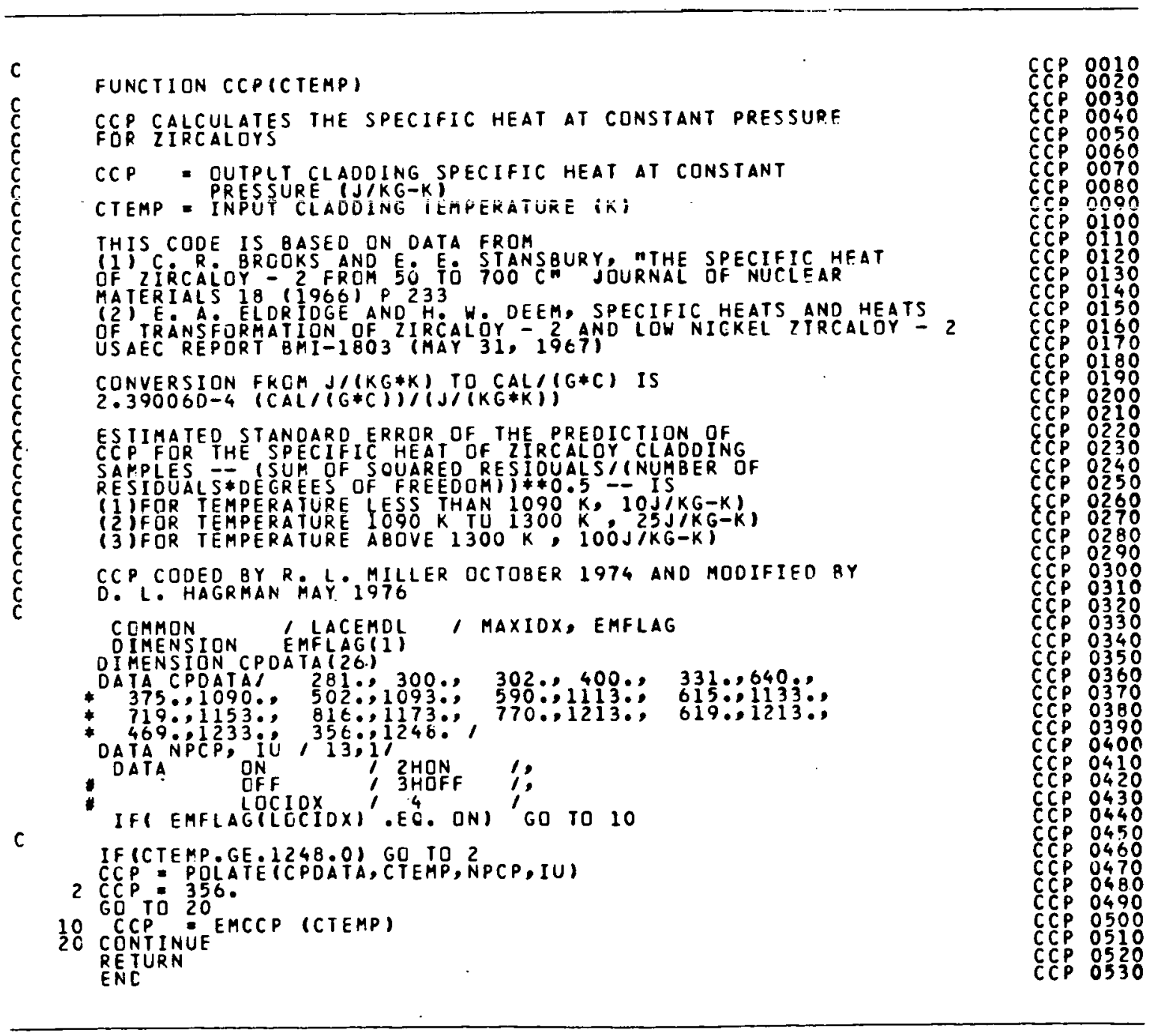




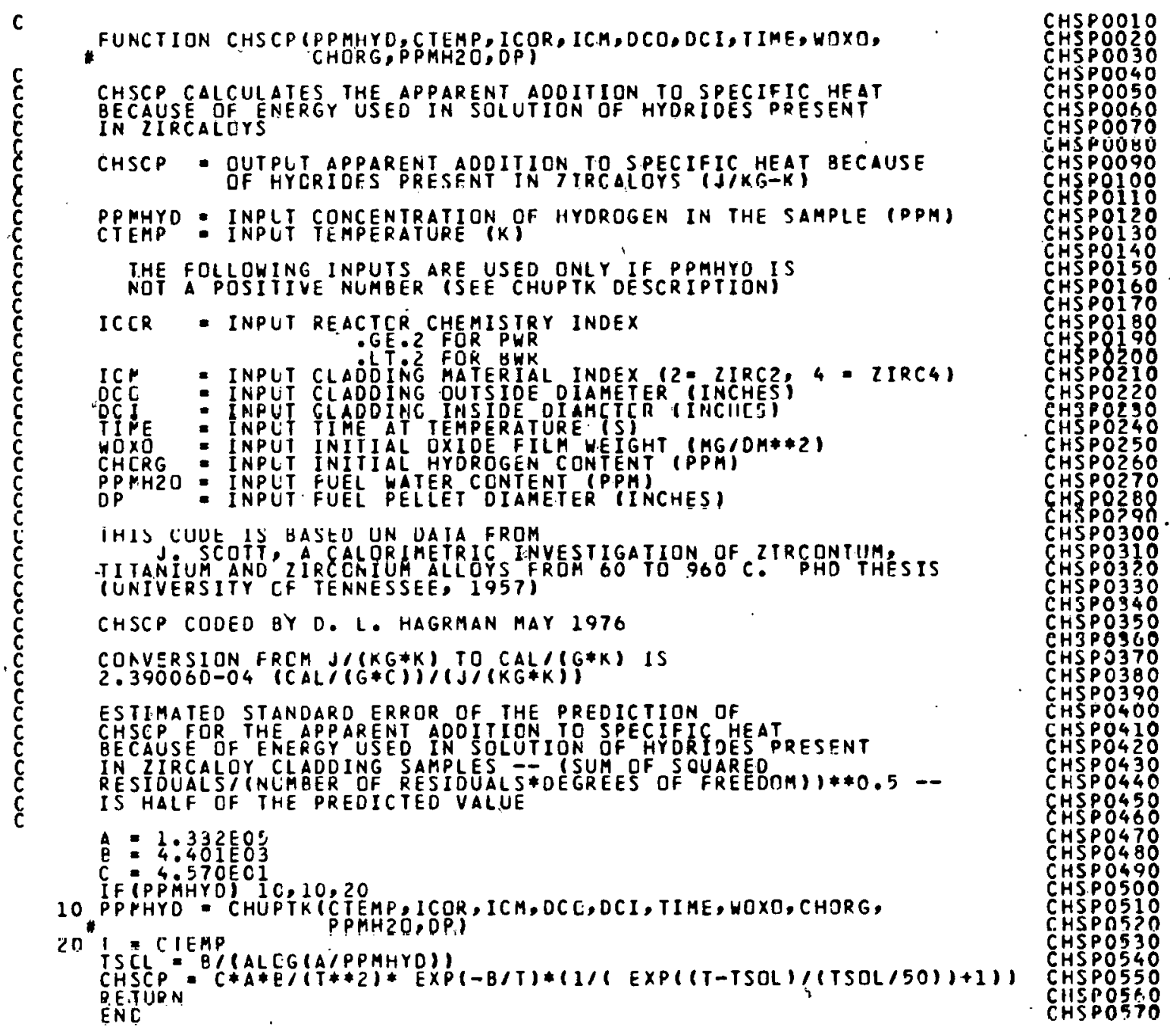

\section{CLADDING THERMAL CONDUCTIVITY (CTHCON)}

An expression has been developed for the thermal conductivity of zircaloy- 2 and -4 based on the pooled data from eight reports. This expression and the uncertainty in the correlation are presented in this section.

\subsection{Summary}

The thermal conductivity of alloys is primarily a function of temperature. Other characteristics such as residual stress levels, crystal orientation, and minor composition 
differences (zircaloy- 2 versus zircaloy- 4 , for example) may have a secondary influence on thermal conductivity. Considering only temperature as the defining parameter, the thermal conductivity of zircaloy and its uncertainty are found to be:

$$
\begin{gathered}
k=7.51+2.09 \times 10^{-2} \mathrm{~T}-1.45 \times 10^{-5} \mathrm{~T}^{2}+7.67 \times 10^{-9} \mathrm{~T}^{3} \\
\sigma_{k}=1.01
\end{gathered}
$$

where

$$
\begin{aligned}
& \mathrm{k}=\text { thermal conductivity of zircaloy }(\mathrm{W} / \mathrm{m} \cdot \mathrm{K}) \\
& \mathrm{T}=\text { temperature }(\mathrm{K}) \\
& \sigma_{\mathrm{k}}=\text { standard deviation }(\mathrm{W} / \mathrm{m} \cdot \mathrm{K}) .
\end{aligned}
$$

This equation predicts $\mathrm{k}$ very well from room temperature to the data limit of about $1800 \mathrm{~K}$ and may be extrapolated with some confidence to the melting point. The standard deviation of the data with respect to this correlation $\left(\sigma_{\mathrm{k}}\right)$ appears to be temperature independent over the data range $\left(0-1500^{\circ} \mathrm{C}\right.$, Figure B-2.1). Regression analysis indicates that one standard deviation for each of the constants in Equation (B-2.1) is 20 to $30 \%$ of the value of the constant.

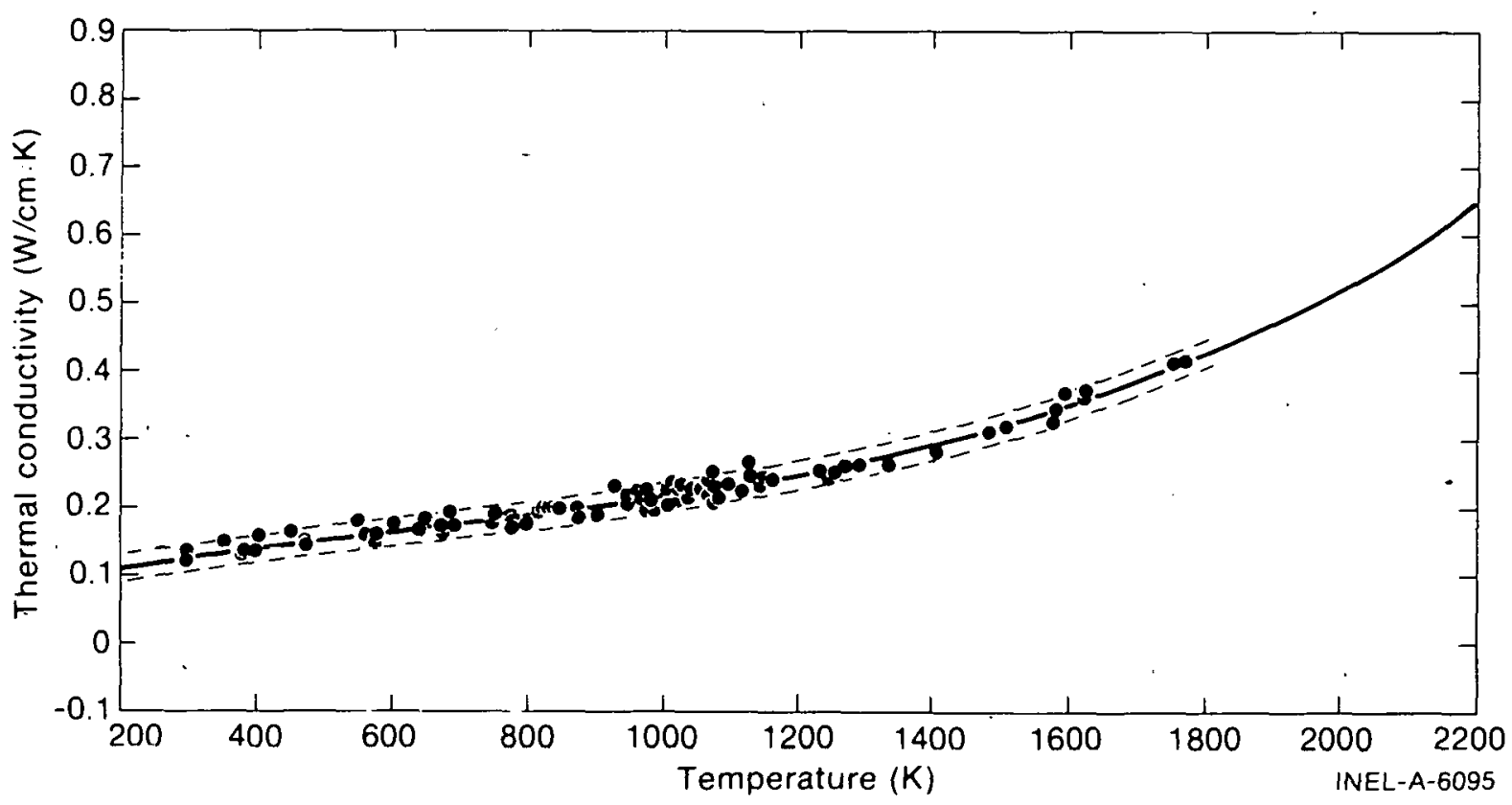

Fig. B-2.1 Thermal conductivity data, least-squares fit, and the two standard deviation limits. 


\section{$\cdot$ CTHCON}

\subsection{Survey and Analysis of Available Data}

Thermal conductivity data of the zircaloy alloys have been reported by Anderson[B-2.1], Chirigos ct al[B-2.2], Feith[B-2.3], Lucks and Deem ${ }^{[B-2.4]}$, Powers $[B-2.5]$ and Scott $[B-2.6]$. These data are presented in Tahle, B-2.I.

Anderson [B-2.1] reported thermal conductivity data for zircaloy-2 in the temperature range of about 380 to $872 \mathrm{~K}$. Chirigos et al ${ }^{[\mathrm{B}-2.2]}$ reported thermal conductivity data for zircolny $A$ in the temperature range of about 370 to $1125 \mathrm{~K}$. Feith ${ }^{[\mathrm{B}-2.3]}$ studied the thermal conductivity of zircaloy -4 in the temperature range of about 640 to $1770 \mathrm{~K}$. Lucks and Deem $[\mathrm{B}-2.4]$ measured the thermal conductivity of zircaloy-2 in the temperature range of about 290 to $1075 \mathrm{~K}$. Powers $[\mathrm{B}-2.5]$ reported three sets of thermal conductivity data for zircaloy taken from BMI letter reports. These data cover both zircaloy-2 and -4 over temperature ranges of approximately 300 to $1000 \mathrm{~K}$. Scott ${ }^{[\mathrm{B}-2.6]}$ reported the thermal conductivity of zircaloy 4 in the temperature range of about 400 to $1060 \mathrm{~K}$. Numerical values of his data were reported by Touloukian et al ${ }^{[\mathrm{B}-2.7]}$.

\subsection{Model Formulation Considering All Available Data}

The data reported in Section 2.2 refer to zircaloy- 2 and zircaloy-4 having various textures and pretest histories. The alloy chemistry and heat transfer properties of zircaloy- 2 and -4 are similar enough to consider them to be a single material. The differences in thermal conductivity between the materials appears to be of the same magnitude as the statistical scatter in the data.

Texture may have an effect in the alpha phase temperature region. Zircaloy crystallizes in the hexagonal close packed configuration in the low temperature alpha-phase and there may be some difference in the thermal conductivity along the prismatic and basal directions. At higher temperalures the material is body centered cubic and will not exhibit texture effects. In any case, contributions to the thermal conductivity due to texture are probably well within the scatter of the experimental data used to develop models for this property.

2.3.1 Thermal Conductivity Model. All of the available data for thermal conductivity of zircaloy -2 and -4 (approximately 120 data points) were combined and analyzed using a least squares polynomial fit of the third degree. The equation is

$$
k=7.51+2.09 \times 10^{-2} \mathrm{~T}-1.45 \times 10^{-5} \mathrm{~T}^{2}+7.67 \times 10^{-9} \mathrm{~T}^{3}
$$

where

$$
\begin{aligned}
& \mathrm{K}=\text { zircaloy thermal conductivity }(\mathrm{W} / \mathrm{m} \cdot \mathrm{K}) \\
& \mathrm{T}=\text { temperature of cladding }(\mathrm{K}) .
\end{aligned}
$$

This relation and the data are shown in Figure B-2.1. 
TABLE B-?.I

\section{ZIRCALOY THERMAL CONDUCTIVITY DATA BASE}

\begin{tabular}{|c|c|c|c|c|c|}
\hline $\begin{array}{c}\text { Temperature } \\
(\mathrm{K})\end{array}$ & $\begin{array}{l}\text { Thermal } \\
\text { Conductivity } \\
(\mathrm{W} / \mathrm{m} \cdot \mathrm{K}) \\
\end{array}$ & $\begin{array}{l}\text { Calculated } \\
\text { Thermal } \\
\text { Conductivity } \\
(\mathrm{W} / \mathrm{m} \cdot \mathrm{K}) \\
\end{array}$ & $\begin{array}{c}\text { Difference Between } \\
\text { Calculated and } \\
\text { Experimental Thermal } \\
\text { Conductivity } \\
\end{array}$ & Reference & Material \\
\hline $\begin{array}{ll}3.803999 \mathrm{E} & 02 \\
4.692998 \mathrm{E} & 02 \\
5.775999 \mathrm{E} & 02 \\
6.858999 \mathrm{E} & 02 \\
7.747998 \mathrm{E} & 02 \\
8.720000 \mathrm{E} & 02\end{array}$ & $\begin{array}{l}1.350000 E+01 \\
1.443000 E+01 \\
1.568000 E+01 \\
1.709999 E+01 \\
1.842000 E+01 \\
1.991000 E+01\end{array}$ & $\begin{array}{l}1.350512 \mathrm{E}+01 \\
1.441734 \mathrm{E}+01 \\
1.568544 \mathrm{E}+01 \\
1.711505 \mathrm{E}+01 \\
1.840124 \mathrm{E}+01 \\
1.991579 \mathrm{E}+01\end{array}$ & $\begin{array}{r}-5.117511 \mathrm{E}-03 \\
1.266061 \mathrm{E}-02 \\
-5.446908 \mathrm{E}-03 \\
-1.505824 \mathrm{E}-02 \\
1.875766 \mathrm{E}-02 \\
-5.795612 \mathrm{E}-03\end{array}$ & 1 & $\mathrm{Zr}-2$ \\
\hline $\begin{array}{ll}3.732000 \mathrm{E} & 02 \\
4.732000 \mathrm{E} & 02 \\
5.732000 \mathrm{E} & 02 \\
6.732000 \mathrm{E} & 02 \\
7.732000 \mathrm{E} & 02 \\
8.732000 \mathrm{E} & 02 \\
9.732000 \mathrm{E} & 02 \\
1.073200 \mathrm{E} & 03 \\
1.123200 \mathrm{E} & 03\end{array}$ & $\begin{array}{l}1.360000 E+01 \\
1.429999 E+01 \\
1.520000 E+01 \\
1.640000 E+01 \\
1.799999 E+01 \\
2.010000 E 101 \\
2.250000 E+01 \\
2.520000 E+01 \\
2.660000 E+01\end{array}$ & $\begin{array}{l}1.364614 \mathrm{E}+01 \\
1.422713 \mathrm{E}+01 \\
1.515939 \mathrm{E}+01 \\
1.644490 \mathrm{E}+01 \\
1.808563 \mathrm{E}+01 \\
2.008353 \mathrm{E}+01 \\
2.244059 \mathrm{E}+01 \\
2.515877 \mathrm{E}+01 \\
2.665389 \mathrm{E}+01\end{array}$ & $\begin{array}{r}-4.614268 \mathrm{E}-02 \\
7.286 / 96 \mathrm{E}-\mathrm{UL} \\
4.060403 \mathrm{E}-02 \\
-4.490390 \mathrm{E}-02 \\
-8.563132 \mathrm{E}-02 \\
1.616126 \mathrm{E}-02 \\
5.940534 \mathrm{E}-02 \\
4.122970 \mathrm{E}-02 \\
-5.389336 \mathrm{E}-04\end{array}$ & 2 & $2 r-4$ \\
\hline $\begin{array}{ll}6.422000 E & 02 \\
6.782000 E & 02 \\
7.462000 E & 02 \\
7.802000 E & 02 \\
8.002000 E & 02 \\
8.192000 E & 02 \\
8.332000 E & 02 \\
8.472000 E & 02 \\
8.502000 E & 02 \\
9.022000 E & 02 \\
9.252000 E & 02 \\
9.432000 E & 02 \\
9.462000 E & 02 \\
9.602000 E & 02 \\
9.632000 E & 02 \\
9.692000 E & 02 \\
9.812000 E & 02 \\
1.005200 E & 02 \\
1.012200 E & 03 \\
1.019200 E & 03 \\
1.021200 E & 03 \\
1.023200 E & 03 \\
1.025200 E & 03 \\
1.035200 E & 03 \\
1.037200 E & 03 \\
1.040200 E & 03 \\
1.054200 E & 03 \\
1.063200 E & 03 \\
1.066200 E & 03 \\
1.079200 E & 03 \\
1.093200 E & 03 \\
1.112200 E & 03 \\
1.128200 E & 03 \\
1.139200 E & 03\end{array}$ & $\begin{array}{l}1.630000 E+01 \\
1.610000 E+01 \\
1.760000 E+01 \\
1.840000 \mathrm{~F}+01 \\
1.770000 E+01 \\
1.980000 E+01 \\
2.010000 E+01 \\
1.960000 E+01 \\
2.000000 E+01 \\
1.900000 E+01 \\
2.309999 E+01 \\
2.180000 E+01 \\
2.040000 E+01 \\
2.210000 E+01 \\
2.150000 E+01 \\
2.140000 E+01 \\
2.120000 E+01 \\
2.290000 E+01 \\
2.359999 E+01 \\
2.110000 E+01 \\
2.120000 E+01 \\
2.260000 E+01 \\
2.320000 E+01 \\
2.180000 E+01 \\
2.250000 E+01 \\
2.290000 E+01 \\
2.270000 E+01 \\
2.399999 E+01 \\
2.169999 E+01 \\
2.140000 E+01 \\
2.330000 E+01 \\
2.250000 E+01 \\
2.449999 E+01 \\
2.309999 E+01\end{array}$ & $\begin{array}{l}1.583062 \mathrm{E}+01 \\
1.663987 \mathrm{E}+01 \\
1.800242 \mathrm{E}+01 \\
1.861384 \mathrm{E}+01 \\
1.895492 \mathrm{E}+01 \\
1.926751 \mathrm{E}+01 \\
1.949130 \mathrm{E}+01 \\
1.970998 \mathrm{E}+01 \\
1.975622 \mathrm{E}+01 \\
2.052728 \mathrm{E}+01 \\
2.085328 \mathrm{E}+01 \\
2.110363 \mathrm{E}+01 \\
2.114502 \mathrm{E}+01 \\
2.133705 \mathrm{E}+01 \\
2.137799 \mathrm{E}+01 \\
2.145969 \mathrm{E}+01 \\
2.162242 \mathrm{E}+01 \\
2.194615 \mathrm{E}+01 \\
2.204036 \mathrm{E}+01 \\
2.213456 \mathrm{E}+01 \\
2.216148 \mathrm{E}+01 \\
2.218841 \mathrm{E}+01 \\
2.221534 \mathrm{E}+01 \\
2.235013 \mathrm{E}+01 \\
2.237712 \mathrm{E}+01 \\
2.241763 \mathrm{E}+01 \\
2.260723 \mathrm{E}+01 \\
2.272971 \mathrm{E}+01 \\
2.277066 \mathrm{E}+01 \\
2.294897 \mathrm{E}+01 \\
2.314282 \mathrm{E}+01 \\
2.340962 \mathrm{E}+01 \\
2.363828 \mathrm{E}+01 \\
2.379793 \mathrm{E}+01\end{array}$ & $\begin{array}{r}4.693743 \mathrm{E}-01 \\
-5.398758 \mathrm{E}-01 \\
-4.024241 \mathrm{E}-01 \\
-2.138442 \mathrm{E}-01 \\
-1.254923 \mathrm{E}-00 \\
5.324852 \mathrm{E}-01 \\
6.086987 \mathrm{E}-01 \\
-1.099844 \mathrm{E}-01 \\
2.437815 \mathrm{E}-01 \\
-1.527285 \mathrm{E}-00 \\
2.246710 \mathrm{E}-00 \\
6.963659 \mathrm{E}-01 \\
-7.450175 \mathrm{E}-01 \\
7.629428 \mathrm{E}-01 \\
1.220028 \mathrm{E}-01 \\
-5.968902 \mathrm{E}-02 \\
-4.224248 \mathrm{E}-01 \\
9.538498 \mathrm{E}-01 \\
1.659638 \mathrm{E}-00 \\
-1.034563 \mathrm{E}-00 \\
-9.614855 \mathrm{E}-01 \\
4.115880 \mathrm{E}-01 \\
9.846602 \mathrm{E}-01 \\
-5.501281 \mathrm{E}-01 \\
1.228767 \mathrm{E}-01 \\
4.823629 \mathrm{E}-01 \\
9.276604 \mathrm{E}-02 \\
1.270283 \mathrm{E}-00 \\
-1.070669 \mathrm{E}-00 \\
-1.548976 \mathrm{E}-00 \\
1.571744 \mathrm{E}-01 \\
-9.096269 \mathrm{E}-01 \\
8.617133 \mathrm{E}-01 \\
-6.979313 \mathrm{E}-01\end{array}$ & 3 & $Z r-4$ \\
\hline
\end{tabular}




\section{CTHCON}

TABLE B-2.I (continued)

\begin{tabular}{|c|c|c|c|c|c|}
\hline $\begin{array}{c}\text { Tempera ture } \\
(\mathrm{K})\end{array}$ & $\begin{array}{l}\text { Thermal } \\
\text { Conductivity } \\
(\mathrm{W} / \mathrm{m} \cdot \mathrm{K})\end{array}$ & $\begin{array}{l}\text { Calculatad } \\
\text { Thermal } \\
\text { Conductivity } \\
(\mathrm{W} / \mathrm{m} \cdot \mathrm{K}) \\
\end{array}$ & $\begin{array}{c}\text { Difference Detween } \\
\text { Calculated and } \\
\text { Experimental Therma } 7 \\
\text { Conductivity } \\
\end{array}$ & Reference & Material \\
\hline $\begin{array}{ll}1.152200 E & 03 \\
1.16120 U E & U 3 \\
1.232200 E & 03 \\
1.243200 E & 03 \\
1.253200 E & 03 \\
1.269200 E & 03 \\
1.289200 E & 03 \\
1.331200 E & 03 \\
1.101200 E & 03 \\
1.404200 E & 03 \\
1.484200 \mathrm{O} & 03 \\
1.508200 \mathrm{E} & 03 \\
1.576200 \mathrm{E} & 03 \\
1.581200 \mathrm{E} & 03 \\
1.594200 \mathrm{E} & 03 \\
1.624200 \mathrm{E} & 03 \\
1.625200 \mathrm{E} & 03 \\
1.755200 \mathrm{E} & 03 \\
1.771200 \mathrm{E} & 03\end{array}$ & 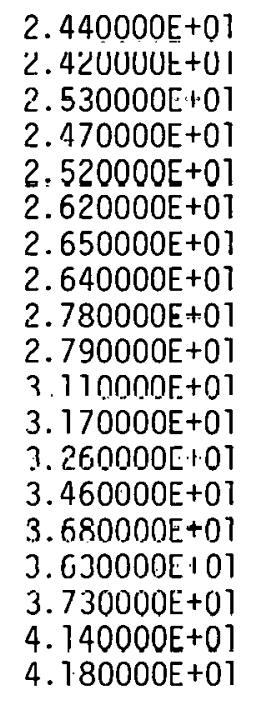 & $\begin{array}{l}2.398947 \mathrm{E}+01 \\
2.412405 \mathrm{E}+01 \\
2.525523[+01 \\
2.544350 \mathrm{E}+01 \\
2.561815 \mathrm{E}+01 \\
2.590489 \mathrm{E}+01 \\
2.627675 \mathrm{E}+01 \\
2.711114 \mathrm{E}+01 \\
2.868773 \mathrm{E}+01 \\
2.876116 \mathrm{E}+01 \\
3.091833 \mathrm{E}+01 \\
3.164731 \mathrm{E}+01 \\
3.394377 \mathrm{E} 101 \\
3.412697 \mathrm{E}+01 \\
3.461295 \mathrm{E}+01 \\
3.578927 \mathrm{E}+01 \\
3.582984 \mathrm{E}+01 \\
4.191110 \mathrm{E}+01 \\
4.277872 \mathrm{E}+01\end{array}$ & $\begin{array}{r}4.105307 \mathrm{E}-01 \\
1.595182 \mathrm{E}-02 \\
4.476639[-02 \\
-7.435016 \mathrm{E}-01 \\
-4.181534 \mathrm{E}-01 \\
2.951047 \mathrm{E}-01 \\
2.232487 \mathrm{E}-01 \\
-7.111352 \mathrm{E}-01 \\
-8.877888 \mathrm{E} 01 \\
-8.611653 \mathrm{E}-01 \\
1.816643 \mathrm{E}-01 \\
5.269211 \mathrm{E}-02 \\
-1.343776 \mathrm{E}=00 \\
4.730280 \mathrm{E}-01 \\
2.187051 \mathrm{E}-00 \\
5.107228 \mathrm{E}=01 \\
1.470160 \mathrm{E}-00 \\
-5.711024 \mathrm{E}-01 \\
-9.787221 \mathrm{E}-01\end{array}$ & $\begin{array}{l}{ }^{3} \\
\text { (contin- } \\
\text { ued) }\end{array}$ & $\begin{array}{l}\text { Zr-4 } \\
\text { (contin- } \\
\text { ued) }\end{array}$ \\
\hline $\begin{array}{ll}2.932000 \mathrm{E} & 02 \\
3.732000 \mathrm{E} & 02 \\
4.732000 \mathrm{E} & 02 \\
5.732000 \mathrm{E} & 02 \\
6.732000 \mathrm{E} & 02 \\
7.732000 \mathrm{E} & 02 \\
8.732000 \mathrm{E} & 02 \\
9.732000 \mathrm{E} & 02 \\
1.073200 \mathrm{E} & 03\end{array}$ & $\begin{array}{l}1.260000 \mathrm{E}+01 \\
1.339999 \mathrm{E}+01 \\
1.450000 \mathrm{E}+01 \\
1.560000 \mathrm{E}+01 \\
1.700000 \mathrm{E}+01 \\
1.840000 \mathrm{E}+01 \\
1.989999 \mathrm{E}+01 \\
2.150000 \mathrm{E}+01 \\
2.309999 \mathrm{E}+01\end{array}$ & $\begin{array}{l}1.258311 E+01 \\
1.339247 E+01 \\
1.449228 E+01 \\
1.568999 E+01 \\
1.698560 E+01 \\
1.837911 E+01 \\
1.987052 E+01 \\
2.145983 E+01 \\
2.314704 E+01\end{array}$ & $\begin{array}{r}1.688629 \mathrm{E}-02 \\
7.52137 .4 \mathrm{E}-03 \\
7.714730 \mathrm{E}-03 \\
-8.999747 \mathrm{E}-02 \\
1.439280 \mathrm{E}-02 \\
2.088348 \mathrm{E}-02 \\
2.947326 \mathrm{E}-02 \\
4.016811 \mathrm{E}-02 \\
-4.704257 \mathrm{E}-02\end{array}$ & 4 & $2 r-2$ \\
\hline $\begin{array}{ll}3.732000 E & 02 \\
4.732000 E & 02 \\
5.732000 E & 02 \\
6.132 U U U E & \text { UL } \\
7.732000 E & 02 \\
0.732000 E & 02 \\
9.732000 E & 02 \\
1.073200 E & 03\end{array}$ & $\begin{array}{l}1.411000 E+01 \\
1.479999 E+01 \\
1.532000 E+01 \\
1.601000 E+01 \\
1.705000 E+01 \\
1.017999[101 \\
1.942000 E+01 \\
2.077000 E+01\end{array}$ & $\begin{array}{l}1.416576 \mathrm{E}+01 \\
1.467827 \mathrm{E}+01 \\
1.562 .14 \mathrm{E}+01 \\
1.611515 \mathrm{E}+01 \\
1.705104 \mathrm{E}+01 \\
1.813956 \mathrm{E}+01 \\
1.988649 \mathrm{E}+01 \\
2.079757 \mathrm{E}+01\end{array}$ & $\begin{array}{r}-5.575651 \mathrm{E}-02 \\
1.217291 \mathrm{E}-01 \\
-\hat{0} .146581 \mathrm{~F}-0.3 \\
-1.051500 \mathrm{E}-01 \\
-1.038127 \mathrm{E}-03 \\
4.043032 \mathrm{E}-02 \\
3.350747 \mathrm{E}-02 \\
-2.757572 \mathrm{E}-02\end{array}$ & 5 & $\mathrm{Zr}-2$ \\
\hline $\begin{array}{ll}2.932000 \mathrm{E} & 02 \\
3.732000 \mathrm{E} & 02 \\
4.732000 \mathrm{E} & 02 \\
5.732000 \mathrm{E} & 02 \\
6.732000 \mathrm{E} & 02 \\
7.732000 \mathrm{E} & 02 \\
8.732000 \mathrm{E} & 02 \\
9.732000 \mathrm{E} & 02 \\
1.073200 \mathrm{E} & 03\end{array}$ & $\begin{array}{l}1.255000 E+01 \\
1.329000 E+01 \\
1.436999 E+01 \\
1.558000 E+01 \\
1.688000 E+01 \\
1.842000 E+01 \\
1.991000 E+01 \\
2.151999 E+01 \\
2.302000 E+01\end{array}$ & $\begin{array}{l}1.248179 \mathrm{E}+01 \\
1.330684 \mathrm{E}+01 \\
1.442380 \mathrm{E}+01 \\
1.563591 \mathrm{E}+01 \\
1.694317 \mathrm{E}+01 \\
1.834560 \mathrm{E}+01 \\
1.984317 \mathrm{E}+01 \\
2.143591 \mathrm{E}+01 \\
2.312379 \mathrm{E}+01\end{array}$ & $\begin{array}{r}6.820639 \mathrm{E}-02 \\
-1.684216 \mathrm{E}-02 \\
-5.380283 \mathrm{E}-02 \\
-5.590934 \mathrm{E}-02 \\
-6.317429 \mathrm{E}-02 \\
7.440336 \mathrm{E}-02 \\
6.682319 \mathrm{E}-02 \\
8.408958 \mathrm{E}-02 \\
-1.037939 \mathrm{E}-01\end{array}$ & 5 & $\mathrm{Zr}-4$ \\
\hline
\end{tabular}


TABLE B-2.I (continued)

\begin{tabular}{|c|c|c|c|c|c|}
\hline $\begin{array}{c}\text { Temperature } \\
(\mathrm{K})\end{array}$ & $\begin{array}{l}\text { Thermal } \\
\text { Conductivity } \\
(\mathrm{W} / \mathrm{m} \cdot \mathrm{K})\end{array}$ & $\begin{array}{l}\text { Calculated } \\
\text { Thermal } \\
\text { Conductivity } \\
(\mathrm{W} / \mathrm{m} \cdot \mathrm{K}) \\
\end{array}$ & $\begin{array}{c}\text { Difference Between } \\
\text { Calculated and } \\
\text { Experimenta] Thermal } \\
\text { Conductivity } \\
\end{array}$ & Reference & Material \\
\hline $\begin{array}{ll}2.932000 \mathrm{E} & 02 \\
3.732000 \mathrm{E} & 02 \\
4.732000 \mathrm{E} & 02 \\
5.732000 \mathrm{E} & 02 \\
6.732000 \mathrm{E} & 02 \\
7.732000 \mathrm{E} & 02 \\
8.7 .320 \mathrm{NOE} & 02 \\
9.732000 \mathrm{E} & 02\end{array}$ & $\begin{array}{l}1.342000 \mathrm{E}+01 \\
1.367000 \mathrm{E}+01 \\
1.416000 \mathrm{E}+01 \\
1.513000 \mathrm{E}+01 \\
1.639000 \mathrm{E}+01 \\
1.799999 \mathrm{E}+01 \\
2.017000 \mathrm{E}+01 \\
2.255000 \mathrm{E}+01\end{array}$ & $\begin{array}{l}1.345513 \mathrm{E}+01 \\
1.362336 \mathrm{E}+01 \\
1.417187 \mathrm{E}+01 \\
1.509616 \mathrm{E}+01 \\
1.639625 \mathrm{E}+01 \\
1.807213 \mathrm{E}+01 \\
2.012380 \mathrm{E}+01 \\
2.255126 \mathrm{E}+\mathrm{U1}\end{array}$ & $\begin{array}{r}-3.513338 \mathrm{E}-02 \\
4.663263 \mathrm{E}-02 \\
-1.187387 \mathrm{E}-02 \\
3.383048 \mathrm{E}-02 \\
-6.256034 \mathrm{E}-03 \\
-7.213538 \mathrm{E}-02 \\
4.619744 \mathrm{E}-02 \\
-1.261909 \mathrm{E}-03\end{array}$ & $\begin{array}{c}5 \\
\text { (contin- } \\
\text { ued) }\end{array}$ & $\begin{array}{l}2 r-4 \\
\text { (contin- } \\
\text { ued) }\end{array}$ \\
\hline $\begin{array}{ll}4.032000 \mathrm{E} & 02 \\
4.520999 \mathrm{E} & 02 \\
4.765000 \mathrm{E} & 02 \\
5.465000 \mathrm{E} & 02 \\
5.575999 \mathrm{E} & 02 \\
6.025999 \mathrm{E} & 02 \\
6.458999 \mathrm{E} & 02 \\
6.820999 \mathrm{E} & 02 \\
6.942998 \mathrm{E} & 02 \\
7.532000 \mathrm{E} & 02 \\
7.702998 \mathrm{E} & 02 \\
8.120999 \mathrm{E} & 02 \\
8.265000 \mathrm{E} & 02 \\
9.820999 \mathrm{E} & 02 \\
1.000900 \mathrm{E} & 03 \\
1.058100 \mathrm{E} & 03\end{array}$ & $\begin{array}{l}1.560000 E+01 \\
1.630000 E+01 \\
1.450000 E+01 \\
1.830000 E+01 \\
1.580000 E+01 \\
1.760000 E+01 \\
1.849999 E+01 \\
1.920000 E+01 \\
1.709999 E+01 \\
1.890000 E+01 \\
1.890000 E+01 \\
1.960000 E+01 \\
2.010000 E+01 \\
1.970000 E+01 \\
2.029999 E+01 \\
2.169999 E+01\end{array}$ & $\begin{array}{l}1.514388 \mathrm{E}+01 \\
1.579137 \mathrm{E}+01 \\
1.609721 \mathrm{E}+01 \\
1.691515 \mathrm{E}+01 . \\
1.703718 \mathrm{E}+01 \\
1.751180 \mathrm{E}+01 \\
1.793977 \mathrm{E}+01 \\
1.827756 \mathrm{E}+01 \\
1.838754 \mathrm{E}+01 \\
1.889315 \mathrm{E}+01 \\
1.903257 \mathrm{E}+01 \\
1.936077 \mathrm{E}+01 \\
1.946995 \mathrm{E}+01 \\
2.054782 \mathrm{E}+01 \\
2.066822 \mathrm{E}+01 \\
2.102598 \mathrm{E}+01\end{array}$ & $\begin{array}{r}4.561126 \mathrm{E}-01 \\
5.086254 \mathrm{E}-01 \\
-1.597214 \mathrm{E}-00 \\
1.384844 \mathrm{E}-00 \\
-1.237180 \mathrm{E}-00 \\
8.820030 \mathrm{E}-02 \\
5.602218 \mathrm{E}-01 \\
9.224340 \mathrm{E}-01 \\
-1.287547 \mathrm{E}-00 \\
6.849899 \mathrm{E}-03 \\
-1.325797 \mathrm{E}-01 \\
2.392254 \mathrm{E}-01 \\
6.300464 \mathrm{E}-01 \\
-8.478280 \mathrm{E}-01 \\
-3.682205 \mathrm{E}-01 \\
6.740101 \mathrm{E}-01\end{array}$ & 6,7 & $2 r-4$ \\
\hline
\end{tabular}

2.3.2 Uncertainty in Model. The standard deviation of the 120 data points with respect to Equation (B-2.3) is $1.01 \mathrm{~W} / \mathrm{m} \cdot \mathrm{K}$. Thirty-two of the points fall outside of plus or minus one standard deviation from the curve. Four points fall outside of plus or minus two standard deviations (Figure B-2.1). The standard deviations of the coefficients of Equation (B-2.3) are about 20 to $30 \%$ of the absolute value of the coefficients.

The standard deviation is small enough so that the user may havc considerable confidence in the model. Jensen ${ }^{[B-2.8]}$ performed a parametric analysis of several variables involved in estimation of fuel and cladding temperatures. Both steady state and transient analyses showed that variations of $\pm 20 \%$ resulted in calculated cladding temperature variations of about $2.8 \mathrm{~K}$. Fuel centerline temperatures are more sensitive to cladding thermal conductivity and showed variations of $28 \mathrm{~K}$. Similar findings were reported by Korber and Unger ${ }^{[B-2.9]}$. 


\section{CTHCON}

\subsection{Cladding 'lhermal Conductivity Subcode CTHCON Listing}

A FORTRAN listing of the thermal conductivity model CTHCON is presented in Tablc B-2.II. The uncertainly in the model is mentioned, but will be programmed in a separatc subcode with other uncertuinties for usc in scnsitivity analyses.

TABLE B-2. II

LISTING OF THE CTHCON SUBCODC
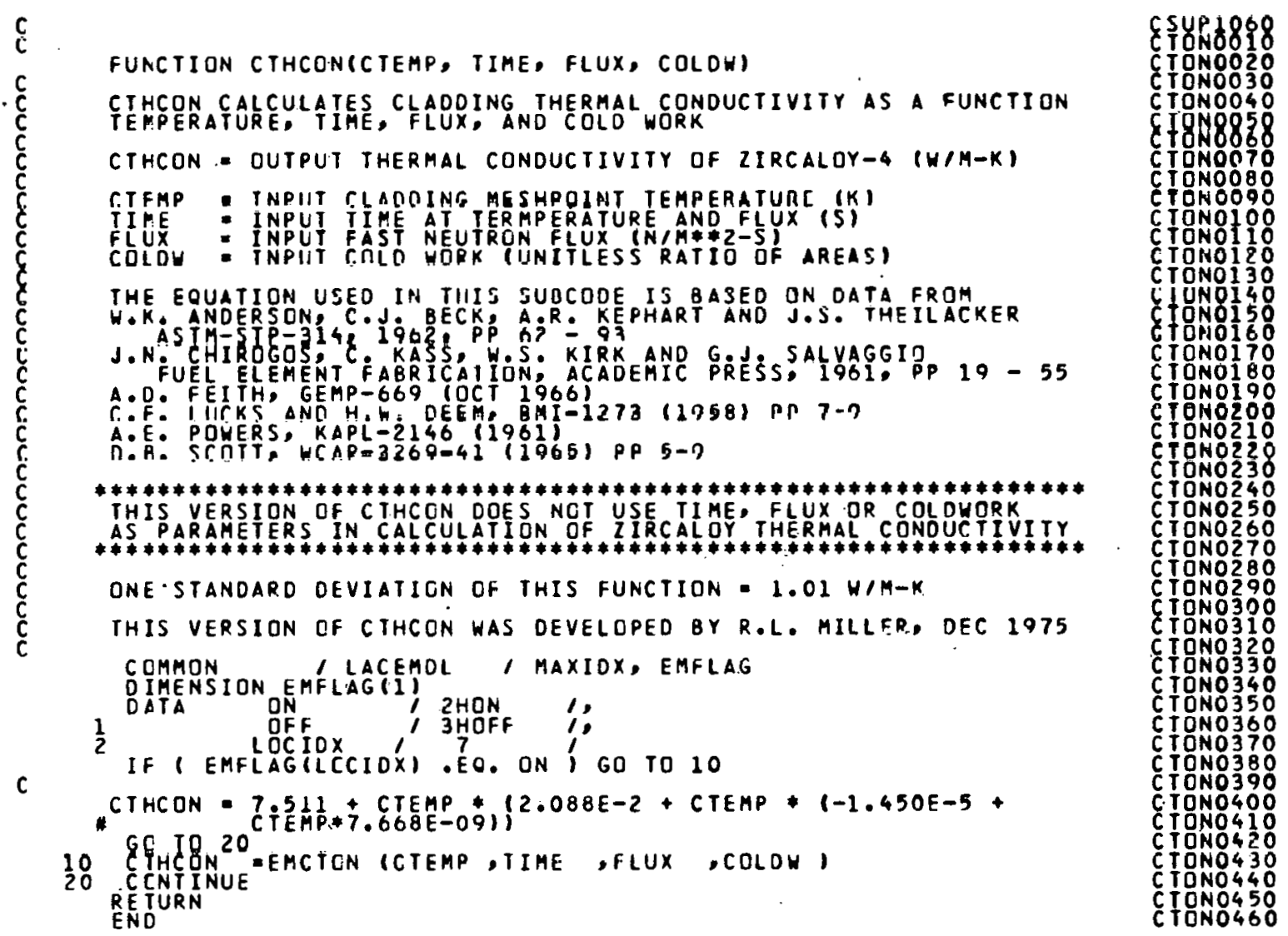

\subsection{References}

B-2.1. W. K. Anderson, C. J. Beck, A. R. Kephart, and J. S. Theilacker "Zirconium Alloys," Reactor Structural Materials: Engineering Properties as Affected by Nuclear Reactor Service, ASTM-STP-314 (1962) pp 62-93.

B-2.2. J. N. Chirigos et al, "Development of Zircaloy-4," Fuel Element Fabrication, New York: Academic Press, 1961 pp 19-55. 
B-2.3. A. D. Feith, Thermal Conductivity and Electrical Resistivity of Zircaloy-4, USAEC GEMP-669 (October 1966).

B-2.4. C. F. Lucks and H. W. Deem, Progress Relating to Civilian Applications During June, 1958, R. W. Dayton and C. R. Tipton, Jr., (eds.), USAEC BMI-1273 (1958) pp 7-9.

B-2.5. A. E. Powers, Application of the Ewing Equation for Calculating Thermal Conductivity from Electrical Conductivity, USAEC KAPL-2146 (April 7,1961).

B-2.6. D. B. Scott, Physical and Mechanical Properties of Zircaloy 2 and 4, USAEC WCAP-3269-41 (May 1965) pp 5, 9.

B-2.7. Y. S. Toulouklan, R. W. Puwell, C. Y'. Hu, P. G. Klemens, Thermophysical Properties of Matter, Volume 1, Thermal Conductivity, New York: Plenum Press, 1970, pp 888-889.

B-2.8. S. E. Jensen, Pururnetric Studies of Fuel Pin Temperature Response, USAEC IDO-17295 (February 1969)

B-2.9. H. Korber and H. E. Unger, "Sensitivity Study on Core Heatup and Meltdown by Variation of Heat Conductivity and Thermal Emissivity," Transactions of the American Nuclear Society, 18 (1974) pp 234-235.

\section{CLADDING SURFACE EMISSIVITY (ZOEMIS)}

One of the important modes of heat transfer to and from cladding surfaces during an abnormal transient is radiant heat transfer. Since the energy radiated is directly proportional to the emissivity of the inner and outer cladding surfaces, surface emissivity is important in descriptions of abnormal transients.

\subsection{Summary}

Surface emissivities are significantly affected by surface layers on the cladding. For cladding with thin oxide coatings, the oxide surface represents only a few wave lengths of near infrared radiation and is partly transparent. Oxide thickness is an important parameter for these thin coatings. Thicker oxide layers are opaque so the oxide thickness is not as important as the nature of the outer oxide surface. This surface is affected by temperature and by the chemical environment. The effect of temperature has been modeled but variations in crud on the external cladding surface and chemical reaction products on the inside surface are not modeled explicitly. 
The model for emissivity was constructcd by considering measured emissivities reported by several investigators $[\mathrm{B}-3.1-\mathrm{B}-3.3]$. Expressions used to predict the emissivity of zircaloy cladding surfaces are summarized below.

When the cladding surface temperature has not exceeded $1500 \mathrm{~K}$, emissivities are modeled by Equations (B-3.1a) and (B-3.1b). For oxide layer thicknesses less than $3.88 \times 10^{-6} \mathrm{~m}$

$$
\varepsilon_{1}=0.325+0.1246 \times 10^{6} d
$$

for oxide layer thicknesses of $3.88 \times 10^{-6} \mathrm{~m}$ or greatcr ${ }^{[a]}$

$$
\varepsilon_{1}=0.808642-50.0 \mathrm{~d}
$$

whøre

$$
\begin{aligned}
& \epsilon_{i}=\text { hemispherical emissivity (unitless) } \\
& \dot{d}=\text { oxide layer thickness }(m) .
\end{aligned}
$$

When the maximum cladding temperature has exceeded $1500 \mathrm{~K}$, emissivity is taken to be the larger of 0.325 and

$$
\varepsilon_{2}=\varepsilon_{1} \exp [(1500-T) / 300]
$$

where

$\epsilon_{1}=$ value for emissivity obtained from Equation (B-3.1)

$\mathrm{T}=$ maximum cladding temperature $(\mathrm{K})$.

The standard error expected from the use of Equation (B-3.1) to predict emissivity in a reactor when cladding surface temperature has never exceeded $1500 \mathrm{~K}$ is

$$
\sigma_{1}= \pm 0.1
$$

When cladding temperature has exceeded $1500 \mathrm{~K}$, the expected standard error is estimated by considering the value $\sigma_{2}$ in the expression

$$
\sigma_{2}= \pm 0.1 \exp [(T-1500) / 300] \text {. }
$$

[a] The use of six significant figures in Equation (B-3.1b) ensures an exact match of the values of $\epsilon_{1}$ at $\mathrm{d}=3.88 \times 10^{-6} \mathrm{~m}$. 
If Equations (B-3.3b) and (B-3.2) predict values of $\epsilon_{2} \pm \sigma_{2}$ which fall inside the range of physically possible values of emissivity $(0.0-1.0)$, the value $\sigma_{2}$ is returned as the expected standard error. If the prediction $\epsilon_{2}+\sigma_{2}$ is greater than 1 or if $\epsilon_{2}-\sigma_{2}$ is less than 0 , the standard error of Equation (B-3.3b) is modified to limit $\epsilon_{2}+\sigma_{2}$ at 1 and/or $\epsilon_{2}-\sigma_{2}$ at 0 .

The following subsection is a review of the available data on cladding emissivity. The approach used to formulate the model for emissivity is described in Section B-3.3 and Section B-3.4 is a discussion of the uncertainty of the model for cladding emissivity. A listing of the subroutine ZOEMIS is presented in Section B-3.5. References are contained in Section B-3.6.

\subsection{Literature Review}

Measurements of zircaloy-2 emissivities as a function of temperature and dissolved oxygen content were reported by Lemmon $[$ B-3.1]. The measurements utilized the hole-in-tube method and were carried out in vacuum. Data from samples with an oxide film were reported but the nonoxidizing environment of the sample during emissivity measurements caused the emissivity to change with ilme. Mureuver, lite llickiresses of the oxide films were not reported. The Lemmon data were not used in formulating the ZOEMIS subcode because the unknown oxide thickness probably influenced the values of emissivity and because of the complications caused by the vacuum environment.

The emissivity of zircaloy 4 was reported by Juenke and Sjodahl ${ }^{[B-3.2]}$ from measurements on oxldized zircaluy in vacuuin dind from mcasurcments in steam during the isothermal growth of oxide films. These authors reported a decrease in the emissivity measured in vacuum which they attributed to the formation of a metallic phase in the oxide. This metallic phase did not form in the presence of steam. The data taken in steam were used in constructing ZOEMIS because the steam environment is similar to an abnormal reactor environment.

Figure B-3.1 is a reproduction of the Juenke and Sjodahl steam data. The data suggest that emissivity decreases when oxide films become very thick (long times or high temperatures). In fact, Juenke and Sjodahl expect the total emissivity of very thick films to approach 0.3 or 0.4 which are characteristic of pure $\mathrm{ZrO}_{2}$. However, the decrease in emissivity at temperatures greater than about $1200^{\circ} \mathrm{C}$ is greater than one would predict from oxide layer thickness alone. The correlation of this emissivity data with oxide layer thickness is discussed in Section B-3.3.

Juenke and Sjodahl's data do not include very thin oxide films but they do report that the total emittance rises almost instantaneously from about 0.2 to 0.7 with the introduction of steam. Data relevant to thin films are discussed below.

The emissivity of oxide films measured in air at temperatures in the range 100 to $400^{\circ} \mathrm{C}$ were reported by Murphy and Havelock ${ }^{[\mathrm{B}-3.3]}$ and are reproduced in Table B-3.I. The emissivities are not strongly dependent on temperature but they do increase rapidly with oxide thickness for the thin oxide layers measured. The one value of emissivity measured with an oxide thickness of $94 \times 10^{-6} \mathrm{~m}$ is important because the oxide was 
ZOEMIS.

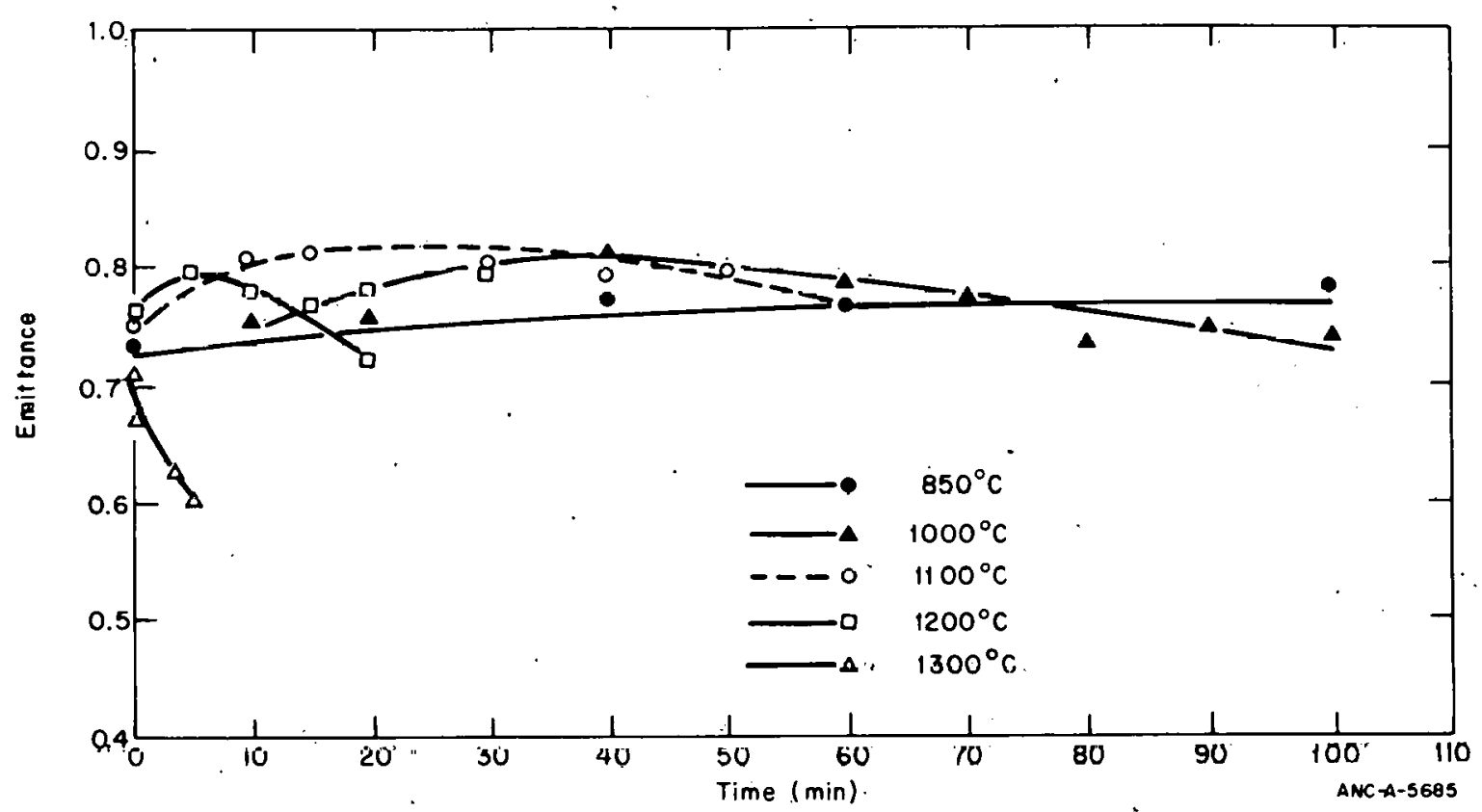

Fig. B-3.1 Total hemispherıcal emittance of zircaloy-4 versus time at temperature in steam.

TABLE B-3.I

EMISSIVITY OF THIN OXIDE FILMS AS REPORTED BY MURPHY AND HAVELOCK

\begin{tabular}{|c|c|c|c|c|c|c|}
\hline \multirow[b]{2}{*}{ Surface: Condition } & \multirow{2}{*}{$\begin{array}{l}\text { Oxide } \\
\text { Thickness } \\
(\mu \mathrm{m}) \\
\end{array}$} & \multicolumn{5}{|c|}{ Emissivity } \\
\hline & & $100^{\circ} \mathrm{C}$ & $150^{\circ} \mathrm{C}$ & $200^{\circ} \mathrm{C}$ & $300^{\circ} \mathrm{C}$ & $400^{\circ} \mathrm{C}$ \\
\hline $\begin{array}{l}\text { Pick.led }+2 \text { days } \\
\text { in air at } 400^{\circ} \mathrm{C}\end{array}$ & $0.9:$ & 0.424 & 0.474 & 0.416 & 0.434 & 0.433 \\
\hline $\begin{array}{l}\text { Pickled }+10 \text { days } \\
\text { in air at } 400^{\circ} \mathrm{C}^{-}\end{array}$ & 1.48 & 0.521 & 0.542 & 0.557 & 0.588 & -- \\
\hline $\begin{array}{l}\text { Pickled }+55 \text { days } \\
\text { in } 400^{\circ} \mathrm{C} \text { steam } \\
\text { under a pressure } \\
\text { of } 10.4 \mathrm{MPa}\end{array}$ & 2.3 & -- & 0.582 & 0.599 & 0.620 & -- \\
\hline $\begin{array}{l}\text { Pickled }+30 \text { days } \\
\text { in air at } 400^{\circ} \mathrm{C} \\
+73 \text { days in air } \\
\text { at } 500^{\circ} \mathrm{C}\end{array}$ & 94. & -- & 0.748 & -- & -- & -- \\
\hline
\end{tabular}


approximately thirty times the thickness assuciated with the transition from "black" oxide layers to "white" oxide layers. The emissivity of this oxide, which was described as "white". by the authors, has a measured emissivity characteristic of surfaces which are black in the infrared region of the spectrum. Since (a) the Murphy and Havelock data were taken in an oxidizing environment and (b) the emissivity of the $94 \times 10^{-6} \mathrm{~m}$ oxide film agrecs with the emissivity of films measured in steam, all of the Murphy and Havelock data were used in the formulation of ZOEMIS.

Additional data were reported by T. B. Burgoyne and A. Garlick at the OECD-CSNI meeting on the Behavior of Water Reactor Fuel Elements under Accident Conditions in Spinad, Norway, on September 13-16, 1976. Using a hot-filament calorimeter, these authors measured the emissivity of zircaloy-2 cladding surfaces coated with uniform oxide, nodular oxide, and crud. The emissivities were measured in vacuum. However, the following arguments are presented in favor of including some of these data in the data base of ZOEMIS: (a) a significant decrease in emissivity was not noticed with initial oxide thicknesses greater than $10^{-5} \mathrm{~m}$ until the samples were heated above approximately $800^{\circ} \mathrm{C}$ (the alpha-beta phase transition of zircaloy); (b) the low temperature values of emissivity measured with uniform oxides correspond closely to values measured in steam; and (c) the data taken with nodular and crud coated surfaces are representative of in-reactor surfaces not represented in other data. Data from Burgoyne and Garlick which did not show the sudden decrease in emissivity, characteristic of the change caused by a vacuum environment, were used in ZOEMIS. Table B-3.II is a summary of the measurements used.

\subsection{Development of the Model}

Near infrared radiation has a wavelength of $1 \times 10^{-6} \mathrm{~m}$. Oxide films up to a few wavelengths thick should be partly transparent to infrared radiation and should therefore have emissivities strongly dependent on oxide thickness. The emissivity versus oxide thickness data of Murphy and Havelock ${ }^{[\mathrm{B}-3.3]}$ were fit with standard least squares residual analysis to deduce Equation (B-3.1b).

The equation for the emissivity of oxide films thicker than $4 \times 10^{-6} \mathrm{~m}$ is based on the data of Burgoyne and Garlick, Juenke and Sjodahl ${ }^{[B-3.2]}$ and one measurement from Murphy and Havelock ${ }^{[B-3.3]}$ as discussed in Section B-3.2. Oxide thicknesses were calculated from the time and temperatures reported by Juenke and Sjodahl using the correlation published by Cathcart $[\mathrm{B}-3.4]$ :

$$
X=\left[2.25 \times 10^{-6} \exp (-18063 / . T) t\right]^{1 / 2}
$$

where

$$
\begin{aligned}
& \mathrm{X}=\text { the oxide layer thickness }(\mathrm{m}) \\
& \mathrm{T}=\text { temperature }(\mathrm{K}) \\
& \mathrm{t}=\text { time at temperature }(\mathrm{s})
\end{aligned}
$$


TABLE B-3. II

\section{EMISSIVITY DATA FROM BURGOYNE AND GARLICK}

\begin{tabular}{|c|c|c|c|}
\hline Cladding Surface & $\begin{array}{l}\text { Surface Layer } \\
\text { Thickness ( } \mathrm{mm})\end{array}$ & $\begin{array}{c}\text { Measurement Temperature } \\
(\mathrm{K})\end{array}$ & $\begin{array}{l}\text { Emissivity } \\
\text { (unitless) } \\
\end{array}$ \\
\hline Uniform $0 x i d e$ & $\begin{array}{r}10 \\
10 \\
10 \\
10 \\
10 \\
10 \\
10\end{array}$ & $\begin{array}{r}735 \\
805 \\
876 \\
885 \\
978 \\
986 \\
1.072\end{array}$ & $\begin{array}{l}0.748 \\
0.770 \\
0.773 \\
0.773 \\
0.774 \\
0.767 \\
0.797\end{array}$ \\
\hline Uniform Oxide & $\begin{array}{r}28 \\
28 \\
28 \\
28 \\
28\end{array}$ & $\begin{array}{r}784 \\
884 \\
987 \\
1080\end{array}$ & $\begin{array}{l}0.834 \\
0.818 \\
0.832 \\
0.829\end{array}$ \\
\hline Nodular Oxide & $\begin{array}{l}130 \\
130 \\
130 \\
130 \\
130 \\
130 \\
130 \\
130 \\
130\end{array}$ & $\begin{array}{r}654 \\
769 \\
775 \\
868 \\
885 \\
965 \\
975 \\
1066 \\
1149\end{array}$ & $\begin{array}{l}0.860 \\
0.845 \\
0.857 \\
0.849 \\
0.850 \\
0.849 \\
0.837 \\
0.866 \\
0.841\end{array}$ \\
\hline Crud & $\begin{array}{l}35 \\
35 \\
35 \\
35 \\
35 \\
35 \\
35 \\
35\end{array}$ & $\begin{array}{l}677 \\
683 \\
769 \\
777 \\
87.0 \\
876 \\
966 \\
977\end{array}$ & $\begin{array}{l}0.918 \\
0.930 \\
0.890 \\
0.000 \\
0.899 \\
0.888 \\
0.913 \\
0.903\end{array}$ \\
\hline
\end{tabular}

Table B-3.III lists the emissivity, time, and temperature reported by Juenke and Sjodahl together with the oxide thickness predicted using Equation (B-3.4). Values of emissivity and oxide layer thickness from Tables B-3.I, B-3.II, and B-3.III for oxide layers thicker than $4 \times 10^{-6} \mathrm{~m}$ were used to establish Equation (B-3.1 b).

Figure B-3.2 is a comparison of the curves generated by Equations (B-3.1 a) and (B-3.1 b) with the data base used to derive these equations. Predicted values of emissivity increase rapidly until the surface oxide layer thickness is $3.88 \times 10^{-6} \mathrm{~m}$ then decrease very slowly with increasing surface layer thickness. 
TABLE B-3. I I I

\section{EMISSIVITY VERSUS OXIDE THICKNESS FROM JUENKE AND SJODAHL'S DATA}

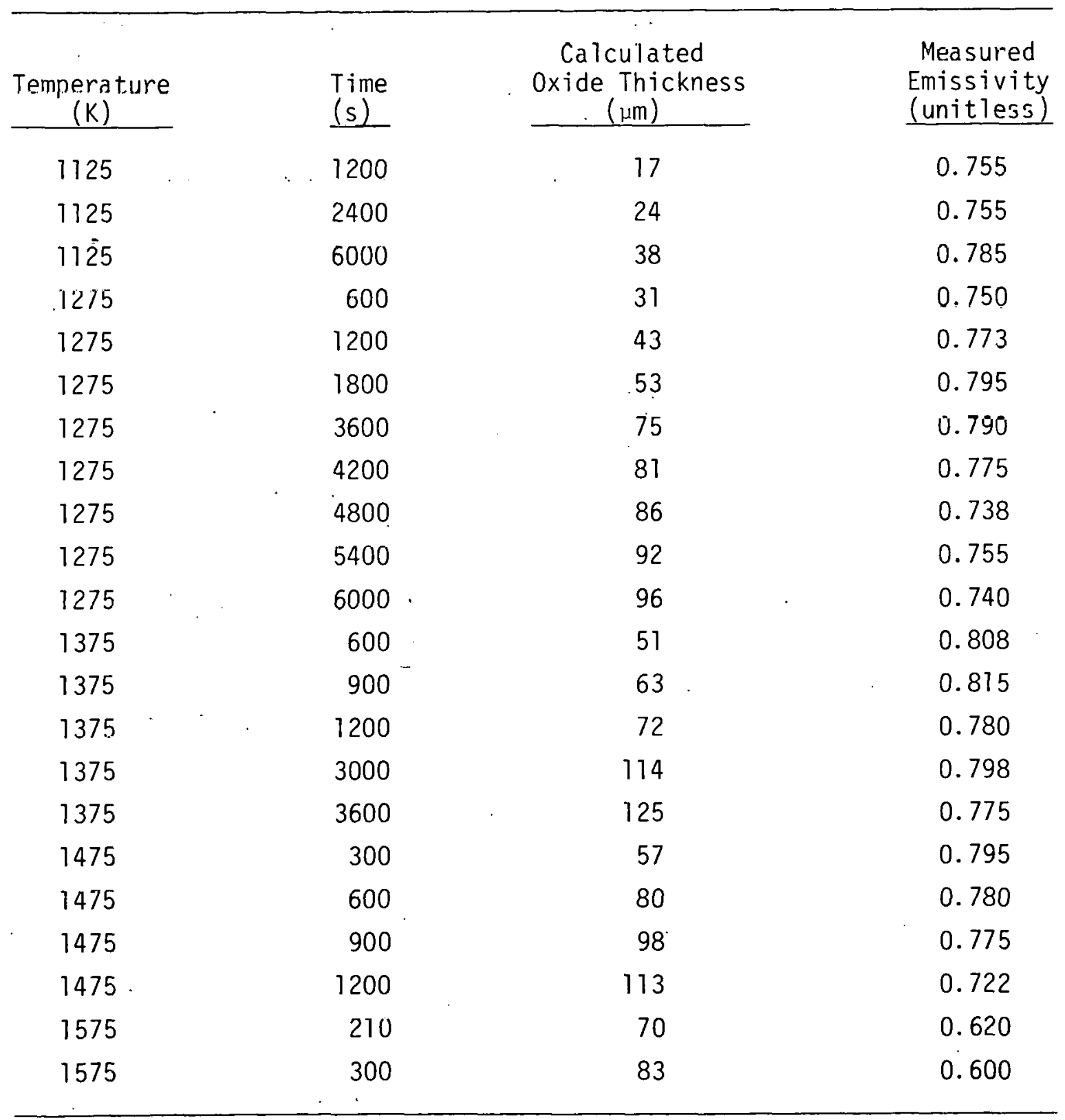

The values of emissivity measured by Juenke and Sjodahl at $1575 \mathrm{~K}(0.62$ and 0.60$)$ are significantly below the measured emissivities at lower temperatures. Since thicker oxide films were formed at lower temperatures, the low emissivity is not due to the thickness of the oxide film. Moreover, the low values of emissivities measured by Juenke and Sjodahl at high temperature are supported by posttest observations of cladding surfaces which have been at high temperatures $[\mathrm{B}-3.5]$. Cladding surfaces which experienced film boiling and 


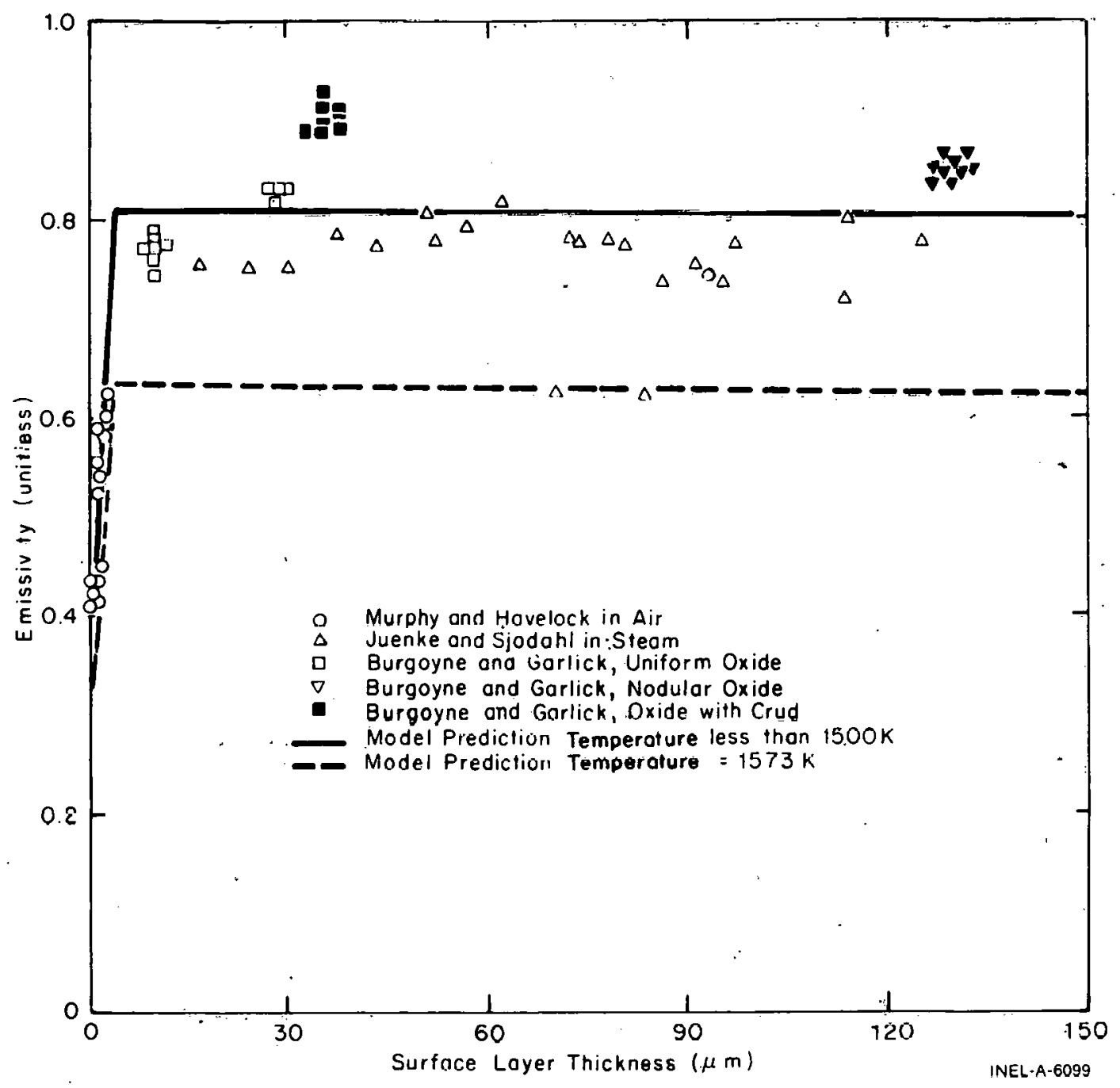

Fig. B-3.2 ZOEMIS calculations compared with the dạta base of the mndcl.

therefure high lemperatures, showed spalled oxide and somewhat whiter oxide surfaces in the region of the film boiling. The observations reported (Reference B-3.5) and the fact that the trend toward lower values of emissivity at higher temperatures was reported by Juenke and Sjodahl at 1475 and $1575 \mathrm{~K}$ implies that lower values of cladding surface emissivity are likely at temperatures above approximately $1500 \mathrm{~K}$. This trend in the limited data has been included in ZOEMIS by (a) adding a multiplicative factor to the expression for emissivity:

$$
\exp [(1500-T) / 300]
$$

where

$$
\mathrm{T}=\begin{aligned}
& \text { the greater of } 1500 \mathrm{~K} \text { and the maximum cladding } \\
& \text { temperature }
\end{aligned}
$$


and (b) limiting the minimum value of emissivity to 0.325 , which is the value pledicted by the model for zero oxide thickness.

\subsection{Uncertainty}

The standard enuis obtained with Equations (B-3.1a) and (B-3.1h) and the data base used to develop these Equations are listed in Table B-3.IV.

TABLE B-3. IV

STANDARD ERRORS OF MODEL PREDICTIONS

\begin{tabular}{|c|c|}
\hline Surface Description & $\begin{array}{c}\text { Emissivity } \\
\text { Standard Errur } \\
\end{array}$ \\
\hline oxide films $<3.88 \times 10^{-6} \mathrm{~m}$ & \pm 0.04 \\
\hline Pure oxide films $>3.88 \times 10^{-\sigma_{m}}$ & \pm 0.05 \\
\hline $\begin{array}{l}\text { Oxide films including samples with } \\
\text { nodular oxides and crud }\end{array}$ & \pm 0.07 \\
\hline
\end{tabular}

Standard errors shown in Tahle B-3.IV for oxide layers without the complicating features of nodular oxides or surface crud are consistent with measurement errors of $\pm 3 \%$ estimated by Lemmon ${ }^{[B-3.1]}$. However, the model is intended to predict the emissivity of cladding surfaces with crud or $\mathrm{UO}_{2}$ fission products as well as the oxide layer. The data from Burgoyne and Garlick (illustrated in Figure B-3.2) suggested that crud layers introduced a systemmatic error of approximately \pm 0.1 . The value of \pm 0.1 is therefore included in ZOEMIS as the best estimate for the standard error of the model prediction for emissivity during abnormal reactor operation at temperatures below $1500 \mathrm{~K}$.

The uncertainty of the prediction for emissivities above $1500 \mathrm{~K}$ is difficult to estimate. Equation (B-3.3b) was selected as a reasonable expression for the expected standard error of Equation (B-3.2), simply because the expression \pm 0.1 $\exp [-(1500$ - maximum cladding temperature $) / 300]$ predicts a standard error approximately equal to the change in emissivity caused by the empirical multiplicative factor of Equation (B-3.5).

In Figure B-3.3, the data base and model predictions of Figure B-3.2 are repeated. The standard error expected with LOEMIS for temperatures beluw $1500 \mathrm{~K}$ is shown by the cross-hatched area centered on the solid line. The cross-hatched area centered on the dashed line shows the standard error estimated for temperatures of $1573 \mathrm{~K}$.

\subsection{Cladding Surface Emissivity Subcode ZOEMIS Listing}

A FORTRAN listing of the subcode ZOEMIS is presented in Table B-3.V. 


\section{ZOEMIS}

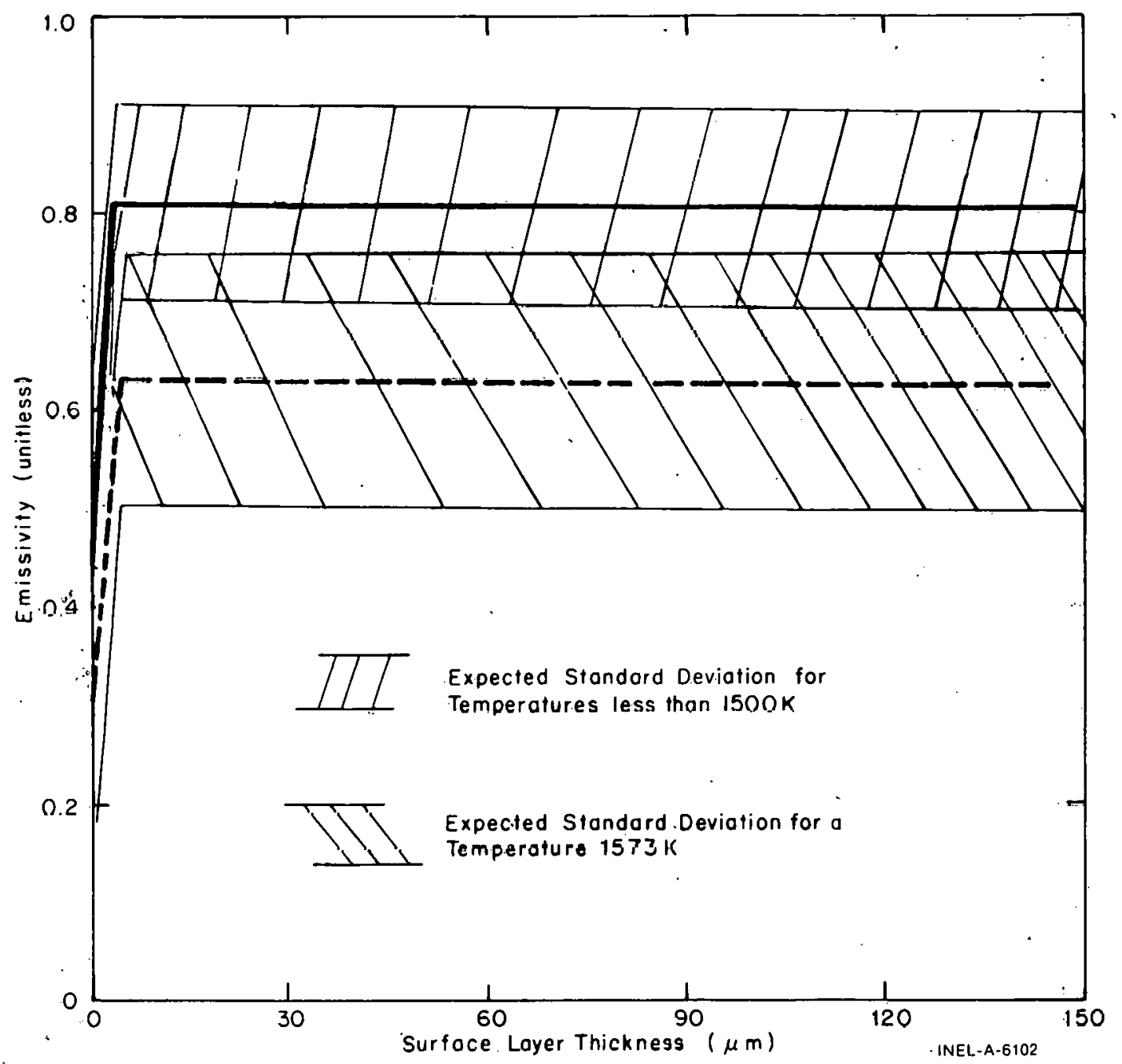

Fig. B-3.3 Expected standard errors of emissivity for temperatures below $1500 \mathrm{~K}$ and at $157,3 \mathrm{~K}$.

\subsection{Refferences}

B.3-1. A. W. Lemmon, Jr., Studies Relating to the Reaction Between Zirconium arid Waler at High Temperatures, BMI-1 154 (January 1957).

B-3.2. E. F. Juenke and L. H Sjodahl, "Physical and Mechanical Properties: Emittance Measurements", AEC Fuels and Materials Development Program, USAEC GEMP-1008 (1968) pp 239-242.

B-3.3: E. V. Murphy and F. Havelock, "Emissivity of Zirconium Alloys in Air in the Temperature Range $100-400^{\circ} \mathrm{C} "$, Journal of Nuclear Materials, 60, (1976) pp 167-176. 
IABLE B-3.V

\section{LISTING OF THE ZOEMIS SUBCODE}

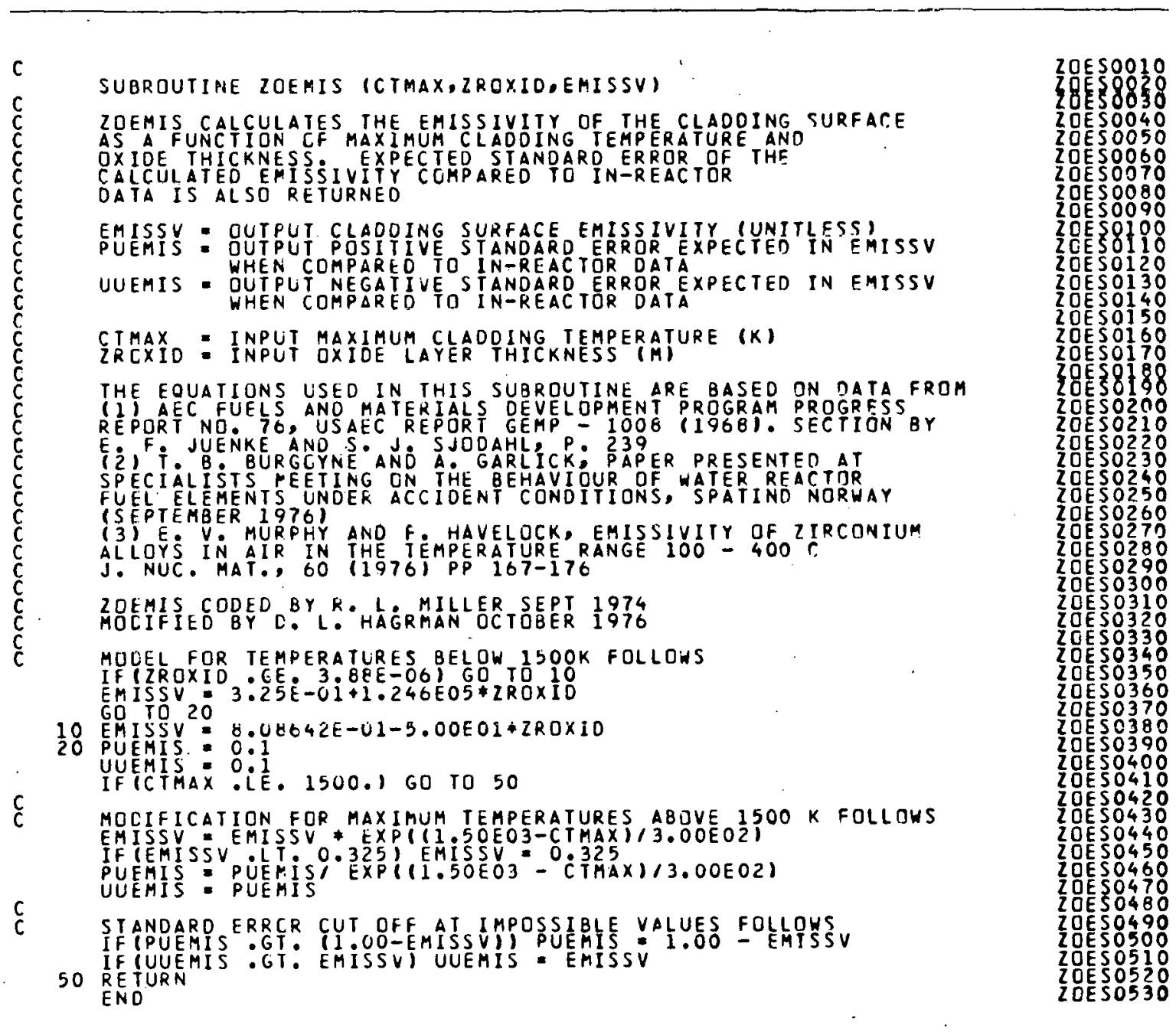

B-3.4. J. V. Cathcart, Quarterly Progress Report on the Zirconium Metal-Water Oxidation Kinetics Program Sponsored by the NRC Division of Reactor Safety Research for April - June 1976, ORNL/NUREG-TM-41 (August 1976).

B-3.5. Quarterly Technical Progress Report on Water Reactor Safety Programs Sponsored by the Nuclear Regulatory Commission's Division of Reactor Safety Research, October - December-1975, ANCR-NUREG-1301 (May 1976) p 67. 


\section{ZIRCONIUM DIOXIDE THERMAL CONDUCTIVITY (ZOTCON)}

The transfer of heat from fuel pellet to coolant depends partly on the thermal conductivity of the oxide layer that forms on the rod surface. Accurate predictions of fuel rod temperature profiles require knowledge of the oxide thermal conductivity.

Kingery et al $[\mathrm{B}-4.1]$ reported the thermal conductivity of zirconium dioxide stabilized with calcium oxide over the temperature range 100 to $1400^{\circ} \mathrm{C}$. A least squares analysis of his data resulted in the correlation

$$
\begin{aligned}
k=1.96 & -2.41 \times 10^{-4} \mathrm{~T}+6.43 \times 10^{-7} \mathrm{~T}^{2} \\
& -1.95 \times 10^{-10} \mathrm{~T}^{3}
\end{aligned}
$$

where

$$
\begin{aligned}
& \mathrm{k}=\text { zirconium dioxide thermal conductivity }(\mathrm{W} / \mathrm{m} \cdot \mathrm{K}) \\
& \mathrm{T}=\text { temperature }(\mathrm{K}) .
\end{aligned}
$$

This correlation and its supporting data are shown in Figure B-4.1. Equation (B-4.1) is used in the ZOTCON subroutine for calculating zirconium dioxide thermal conductivity.

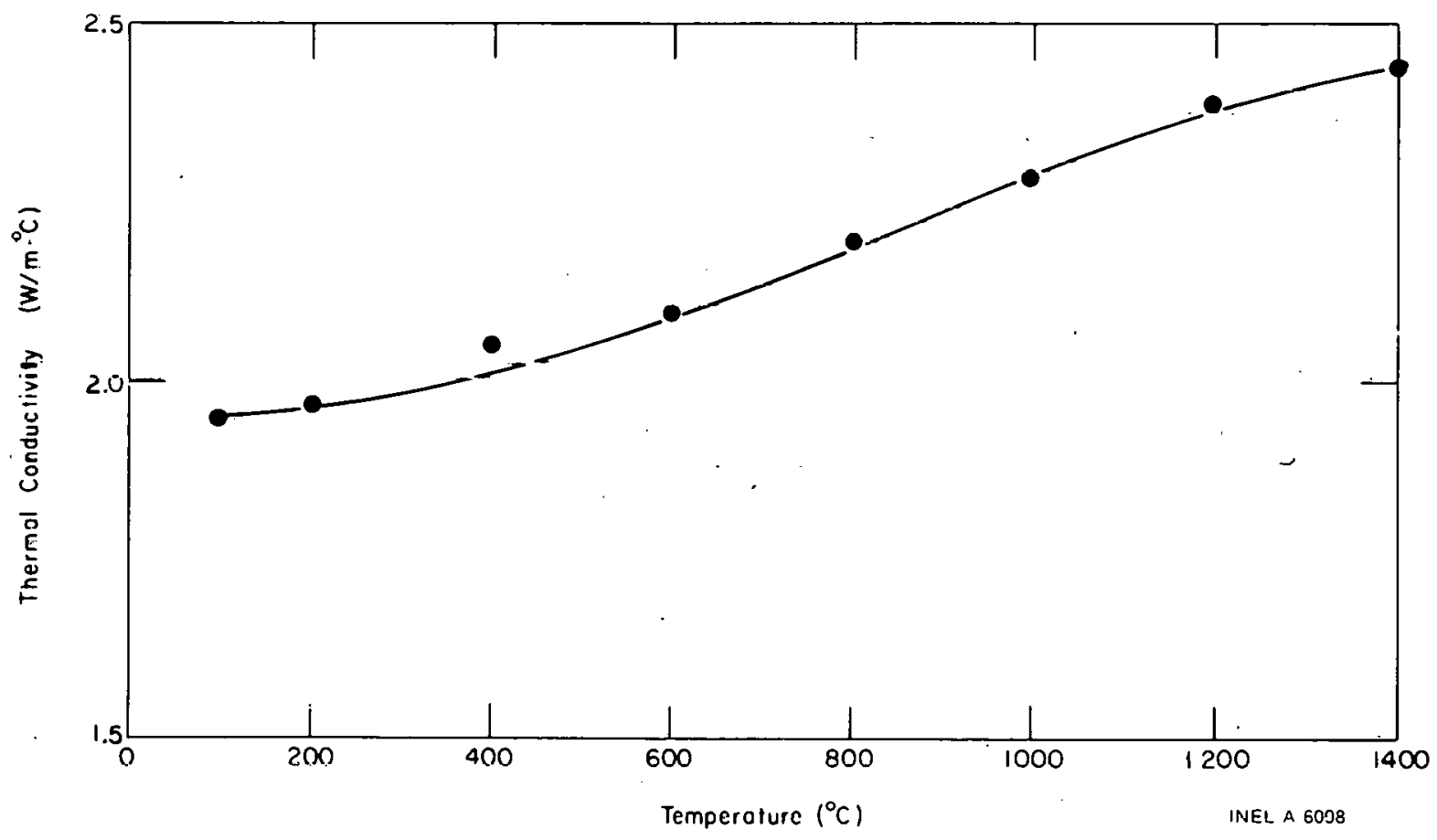

Fig. B-4.1 Thermal conductivity of zirconium dioxide as a function of temperature as calculated by the ZOTCON subcode.

Maki[B-4.2] and Lapshov and Bashkatov [B-4.3] have also reported the thermal conductivity of zirconium dioxide films. Maki's data, presented in Table B-4.I, cover a much smaller temperature range, show a strong temperature dependence, and generally exhibit 
TABLE B-4. I

THERMAL CONDUCTIVITY OF ZIRCONIUM DIOXIDE FROM MAKI ${ }^{[B-4.2]}$

\begin{tabular}{|c|c|c|c|c|}
\hline Specimen & $\begin{array}{l}\text { Linear } \\
\text { Heat Rate } \\
(\mathrm{kW} / \mathrm{m}) \\
\end{array}$ & $\begin{array}{c}\text { Coolant } \\
\text { Tempera ture } \\
(\mathrm{K}) \\
\end{array}$ & $\begin{array}{c}\text { Temperature } \\
\text { Ins ide Tube } \\
\text { (K) } \\
\end{array}$ & $\begin{array}{l}\text { Apparent } \\
\text { Thermal } \\
\text { Conductivity } \\
(\mathrm{W} / \mathrm{m} \cdot \mathrm{K}) \\
\end{array}$ \\
\hline 2 & $\begin{array}{r}8.08 \\
16.78 \\
29.25 \\
29.36 \\
36.19\end{array}$ & $\begin{array}{l}383.5 \\
413.3 \\
473.5 \\
522.1 \\
571.1\end{array}$ & $\begin{array}{r}415.9 \\
446.8 \\
502.6 \\
545.5 \\
597.5\end{array}$ & $\begin{array}{r}0.76 \\
5.14 \\
6.73 \\
16.20 \\
94.10\end{array}$ \\
\hline 3 & $\begin{array}{r}8.68 \\
16.87 \\
30.67 \\
28.09 \\
39.29\end{array}$ & $\begin{array}{l}383.9 \\
424.8 \\
473.0 \\
522.1 \\
593.2\end{array}$ & $\begin{array}{l}425.6 \\
459.1 \\
512.8 \\
551.2 \\
608.2\end{array}$ & $\begin{array}{l}0.88 \\
1.81 \\
3.26 \\
3.96 \\
6.33\end{array}$ \\
\hline 4 & $\begin{array}{r}8.65 \\
16.83 \\
28.72 \\
28.87 \\
38.33\end{array}$ & $\begin{array}{l}383.4 \\
424.4 \\
473.2 \\
523.1 \\
572.7\end{array}$ & $\begin{array}{l}418.7 \\
449.1 \\
501.9 \\
547.7 \\
602.8\end{array}$ & $\begin{array}{l}0.70 \\
4.78 \\
6.35 \\
5.41 \\
5.45\end{array}$ \\
\hline 5 & $\begin{array}{r}7.62 \\
15.94 \\
29.29 \\
27.75 \\
35.55\end{array}$ & $\begin{array}{l}383.0 \\
424.3 \\
473.8 \\
522.1 \\
573.0\end{array}$ & $\begin{array}{l}417.6 \\
450.4 \\
507.0 \\
530.8 \\
604.7\end{array}$ & $\begin{array}{l}1.07 \\
4.50 \\
5.76 \\
6.11 \\
6.27\end{array}$ \\
\hline 6 & $\begin{array}{r}8.10 \\
17.17 \\
27.72 \\
29.59 \\
41.43\end{array}$ & $\begin{array}{l}383.2 \\
424.2 \\
473.7 \\
522.2 \\
572.8\end{array}$ & $\begin{array}{l}416.2 \\
451.1 \\
504.6 \\
522.0 \\
609.7\end{array}$ & $\begin{array}{l}1.20 \\
3.95 \\
4.10 \\
3.12 \\
4.00\end{array}$ \\
\hline
\end{tabular}

larger values of thermal conductivity than the data of Kingery et al. Lapshov and Bashkatov experimented with films formed by plasma sputtering of zirconium dioxide on tungsten substrates. Although their data, shown in Figure B-4.2, cover the range of 300 to $1500^{\circ} \mathrm{C}$, the data exhibit much greater scatter and are substantially smaller in value than those of both References B-4.1 and B-4.2. The reason for the discrepancy between the data of Lapshov and Bashkatov and that of Kingery et al and Maki may be due to the fact that the sputtered or sprayed coatings are quite porous, poorly consolidated, and not very adherent . to the tungsten substrate.

\subsection{Zirconium Dioxide Thermal Conductivity Subcode ZOTCON Listing}

A FORTRAN listing of the ZOTCON subcode is given Table B-4.II. 


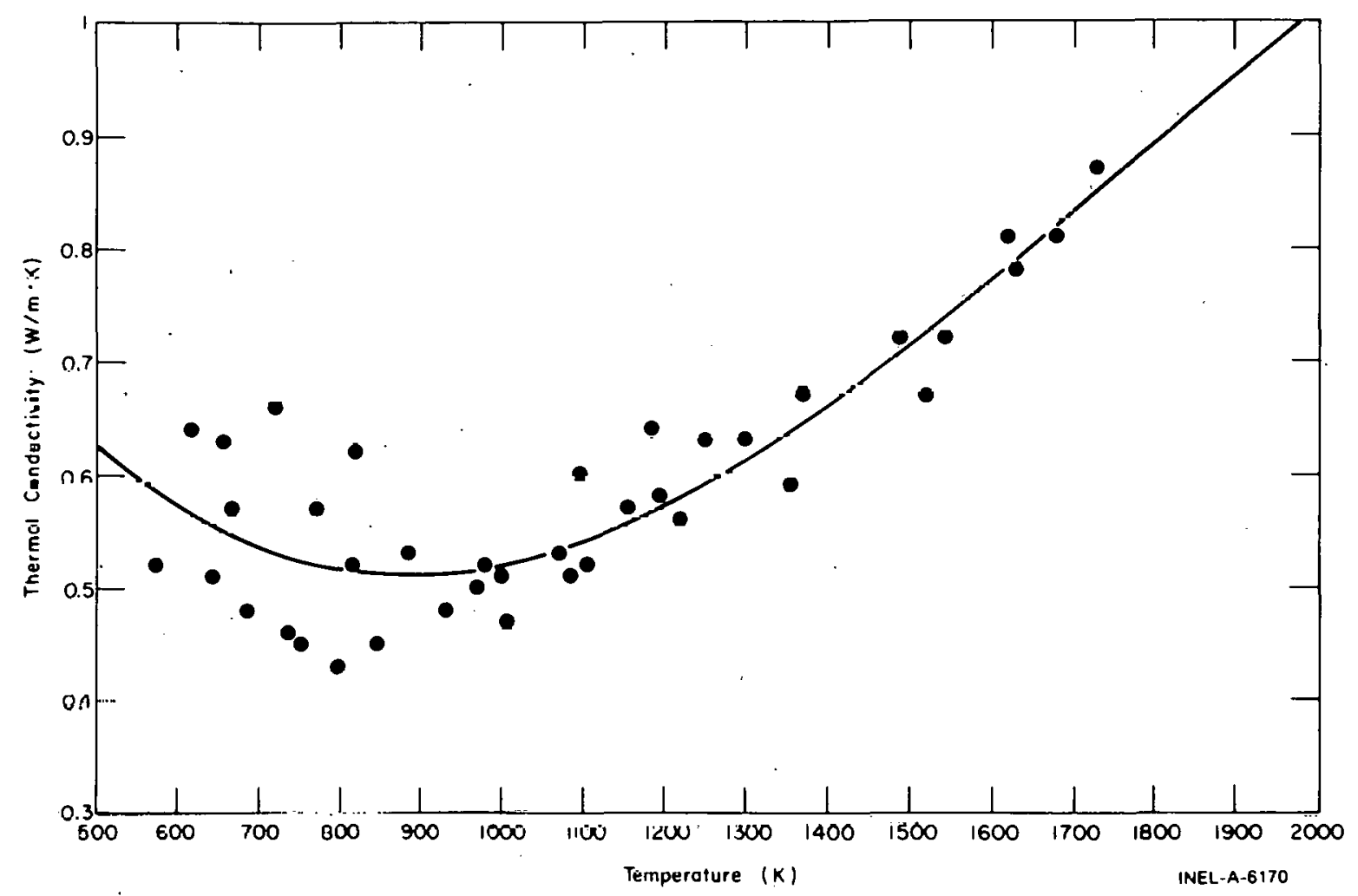

Fig. B-4.2 Temperature dependence of the thermal conductivity of zirconium dioxide according to Lapshov and Boshkatov, showing the liend line.

TABLE B-4. I I

LISTING OF THE ZOTCON SUBCODE

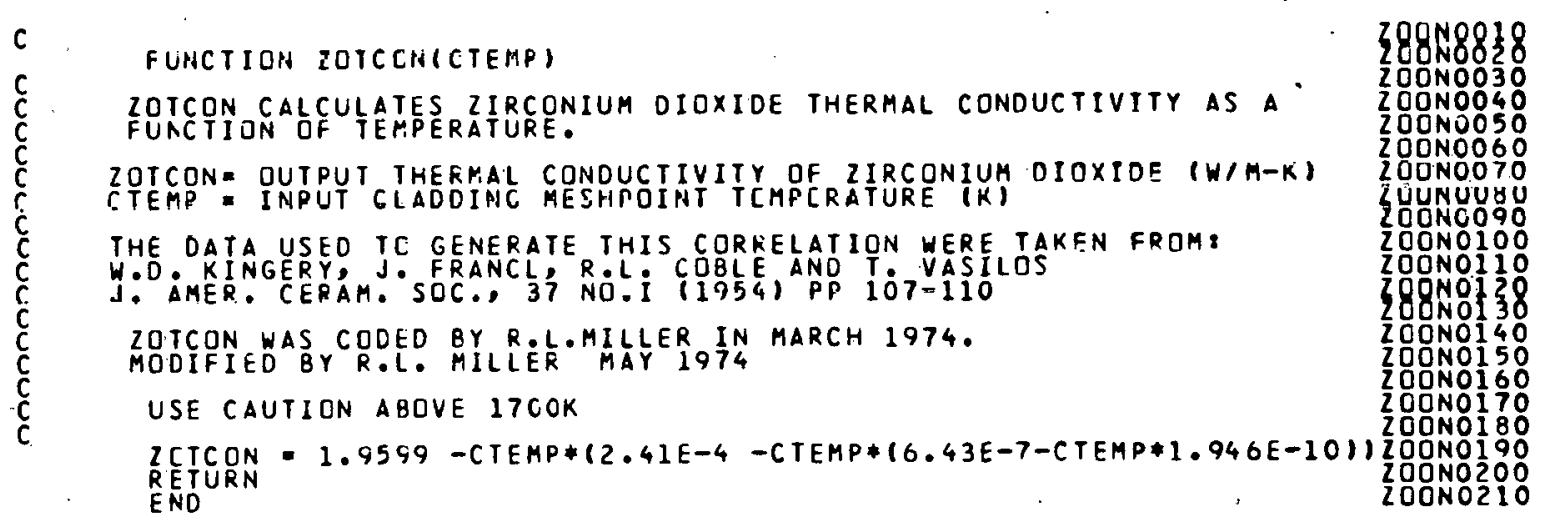

\subsection{References}

B-4.1. W. D. Kingery et al, "Thermal Conductivity: X, Data for Several Pure Oxide Materials Corrected to Zero Porosity," Journal of the American Ceramic Society, 37 (1954) pp 107-110. 
B-4.2. H. Maki, "Heat Transfer Characteristics of Zircaloy-2 Oxide Film." Journal of Nuclear Science and Technology, 10 (1973) pp 107-175.

B-4.3. V. N. Lapshov and A. V. Bashkatov, "Thermal Conductivity of Coatings of Zirconium Dioxide Applied by the Plasma Sputtering Method," Heat Transfer, Soviet Research, 5 (1973) pp 19-22.

\section{CLADDING AXIAL THERMAL EXPANSION (CATHEX)}

Correlations for the axial thermal expansion of zircaloy cladding and the uncertainties in these correlations are presented in this section. The assumption is made that zircaloy- 2 and zircaloy- 4 may be described by the same correlations. This assumption is justified by the large scatter in the data.

\subsection{Summary}

This model is divided into three sections: alpha phase, transition phase, and beta phase. From room temperature to $1073 \mathrm{~K}$, the following correlation was developed from a least squares fit to the poolcd data of three sources $[\mathrm{B}-5.1, \mathrm{~B}-5.2, \mathrm{~B}-5.3]$ :

$$
\frac{\Delta L}{L_{0}}=-1.238 \times 10^{-3}+4.441 \times 10^{-6} \mathrm{~T}
$$

for $300<\mathrm{T}<1073 \mathrm{~K}$

where

$\mathrm{T}=$ temperature $(\mathrm{K})$.

For the region between 1073 and $1273 \mathrm{~K}$, including the transition region, there are very few data and only those of Scott $[\mathrm{B}-5.1]$ are considered. In this range, the values for expansion are obtained through linear interpolation of Scott's data by means of the subroutine POLATE. For the beta phase the correlation used is

$$
\frac{\Delta L}{L_{0}}=-1.1 \times 10^{-2}+9.7 \times 10^{-6} \mathrm{~T}
$$

for $1273<\mathrm{T}<\mathrm{T}_{\text {melting }}$

The uncertainties in the model are largely due to both unspecified texture variations and lack of data at higher temperatures. The uncertainties are expressed as a percentage of total expansion and are:

$$
\begin{aligned}
& +10 \% \text { for } 300<T<1073 K \\
& \left.\begin{array}{r}
+100 \% \\
-50 \%
\end{array}\right\} \text { for } T>1073 \mathrm{~K} \text {. }
\end{aligned}
$$




\section{CATHEX}

\subsection{Derivation ol CATHEX Model}

Thermal expansion correlations are required to estimate geometry changes in the cladding as a function of temperature. For calculational continuity in accident analyses, the correlations must span the range from room temperature to the melting temperature of the cladding. Due to the strong texture (preferred crystallographic orientation) of cold-worked zircaloy, the thermal expansion is different in the axial and radial directions. The directions which may exhibit differences in texture for rolled plate and drawn tubing are shown in Figure B-5.1. Since much of the existing data are for plate specimens rather than for tubing, it is useful to consider analogous directions for plate and tubing even though it cannot be assumed that textures in analogous directions are identical. For example, the textures and the thermal expansion in the axial direction of tubing and the longitudinal direction of rolled plate are similar, as are those of the long transverse direction in rolled plate and the circumferential direction of tubing, and the radial direction of tubing and the short transverse direction of plate.
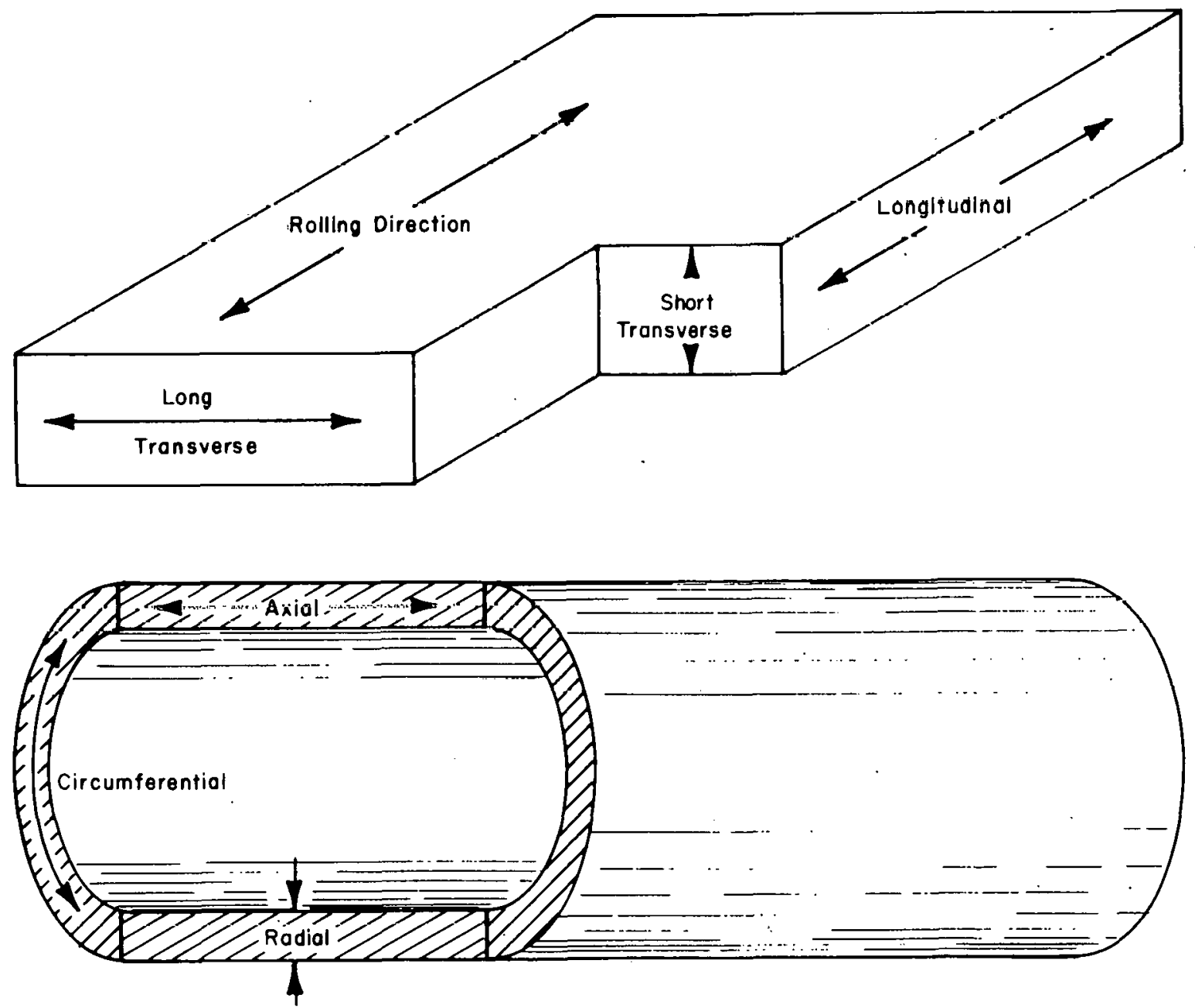

$A N C-A-4033$

Fig. B-5.1 Nomenclature used to describe directions in rolled plate and drawn tubing. 
5.2.1 Survey of Available Data. A papcr by Mchan and Cutler $[\mathrm{B}-5.4]$ contains results covering the temperature range from room temperature to $1273 \mathrm{~K}$. They found no anisotropic effects, and report that not all the data obtained were included, because in most cases the samples were cycled into and out of the beta phase (above $1273 \mathrm{~K}$ ) at least twice to obtain "thermal stability", and the expansion data were taken on the third run. This is unfortunate, because a single excursion into the beta phase apparently reduces anisotropic effects, even when the sample is later returned to the alpha phase ${ }^{\lfloor B-5.2\rfloor}$. Therefore, Mehan and Cutler failed to use their most significant results, those of the first runs, and their data are not included in the model.

$\operatorname{Scott}^{[B-5.1]}$, Kearns ${ }^{[B-5.2]}$, and Mehan and Wiesinger ${ }^{[B-5.3]}$ have published zircaloy thermal expansion data which do exhibit anisotropy. Of these, only Scott has data covering the temperature range where the transition from the alpha to beta phase takes placc. Mehan and Wiesinger's data are for zircaloy -2 plate, Kearns' are for zircaloy-4 plate, and Scott's are for zircaloy-4 tubing.

5.2.2 Cladding Axial Thermal Expansion Model in the Alpha Phase. A least squares analysis of the data from the sources used shows that when the thermal expansion is expressed as a linear function of temperature, the standard deviation from the data base is not substantially larger than that resulting when a cubic temperature dependence is used. Therefore, for simplicity, a linear equation is used in this temperature range. The expression is

$$
\frac{\Delta L}{L_{0}}=-1.238 \times 10^{-3}+4.441 \times 10^{-6} \mathrm{~T}
$$

for $300<\mathrm{T}<1073 \mathrm{~K}$

where

$$
\begin{aligned}
& \mathrm{T}=\text { temperature }(\mathrm{K}) \\
& \mathrm{L}_{\mathrm{O}}=\text { length at approximately } 300 \mathrm{~K} \\
& \Delta \mathrm{L}=\text { change in length resulting from thermal expansion }(\mathrm{m}) .
\end{aligned}
$$

A least squares fit to the data was made without constraint conditions since the expansion coefficient is the item of most interest, even though this approach does not give $\Delta L=0$ at the base temperature.

Equation (B-5.3) has a standard deviation of $1.35 \times 10^{-4}$ from its data base, with the largest deviations occurring at higher temperatures. However, this data base is very small, containing only 35 points, and other data, specifically that of Mehan and Cutler and of Kearns using samples with different textures, exhibit greater scatter, and texture variations from sample to sample can be quite large. Kearns ${ }^{[B-5.2]}$ even suggests that the amount of thermal expansion may be used as a measure of texture. Since the absolute value of the deviation between the curve given by Equation (B-5.3) and the data from Mehan and Cutler 


\section{CATHEX}

increases with temperature, a percentage uncertainty is more meaningful than a single-valucd tolerance or standard deviation. Placing uncertainty limits of $\pm 20 \%$ on Equation (B-5.3) for alpha-phase zircaloy includes most of the available data.

5.2.3 Cladding Axial Thermal Expansion During the Alpha-Beta-Phase Transition. Starting at about $1083 \mathrm{~K}$, zircaloy undergoes a phase transition which ends at approximately $1244 \mathrm{~K}$. Below $1083 \mathrm{~K}$ it normally has a hexagonal close-packed structure, called the alpha-phase; and above $1244 \mathrm{~K}$ it -normally has a body-centered cubic structure, called the

i beta-phase. During the alpha-beta transition, there is a distinct contraction which is partially reversed on cooling back to the alpha phase. The amount of expansion during cooling is, however, not necessarily equal to the amount of contraction which occurred during heating. Furthermore, after having been through the transition and cooled to room temperature again, the sample usually has a length different than the original. This change in length may be an increase ${ }^{[\mathrm{B}-5.3]}$ or a decrease ${ }^{[\mathrm{B}-5.1]}$ - the controlling factors are not yet defined. Because of this ambiguity, as well as the texture uncertainty which occurs after cycling to the beta phase and returning, only that thermal expansion which occurs during the first excursion of the as-received tubing from alpha to beta phase is modeled in this section.

Of the sources used to formulate this model, only that of Scott ${ }^{[B-5.1]}$ includes data for this region, and he lists only six points. It does not seem reasonable to try to find an analytical form using such a limited data base, and therefore a smooth curve was drawn through Scott's data and points taken from the curve were used to generate a data table describing the thermal expansion in this temperature range. Interpolation in this data set is accomplished through the use of the linear interpolation subroutine POLATE.

The values of $\frac{\Delta L}{L_{O}}$ returned by the MATPRO subcode CATHEX for temperatures in the transition region are about half as big as those reported by Mehan and Cutler ${ }^{[\mathrm{B}-5.4]}$, the only other source including data at these temperatures (not included in this model's data base for reasons given in Section B-5.2.1). Until more data are available, the upper uncertainty limit in this region is therefore assumed to be $100 \%$ of the CATHEX value. It is also difficult to assess the lower uncertainty limit, but $100 \%$ is too large since that would include the posstbllity of a contraction during the alpha-beta phase transition completely canceling the expansion which occurred in the alpha phase. Such a large contraction has never been reported by Mehan and Cutler, Scott, or investigators of pure zirconium ${ }^{\text {B-5.5; B-5.6] }}$. At present it seems that assuming a lower uncertainty limit of $50 \%$ is reasonable.

5.2.4 Cladding Axial Thermal Expansion in the Beta Phase. For beta-phase zircaloy, there are no data available. Therefore, above $1273 \mathrm{~K}$ the assumption was made that the coefficient of thermal expansion of zircaloy was the same as that for zirconium. A constant value for this coefticient of $9.7 \times 10^{-6} \mathrm{~K}^{-1}$ is reported by Lustman and Kerze [B-5.6] $^{\text {and }}$ also characterizes the data of Skinner and Johnston ${ }^{[\mathrm{B}-5.5]}$. This yields the following correlation for zircaloy:

$$
\frac{\Delta L}{L_{0}}=-1.1 \times 10^{-2}+9.7 \times 10^{-6} \mathrm{~T}
$$


for $1273<\mathrm{T}<2098 \mathrm{~K}$

where

$\mathrm{T}=$ temperature $(\mathrm{K})$.

The constants are given to only two significant figures due to the lack of a data base.

The uncertainties in this temperature region are assumed to be the same as those for the transition region, i.e., $+100 \%$ and $-50 \%$.

The results of these correlations and the points from the data base ale presented in Figure B-5.2.

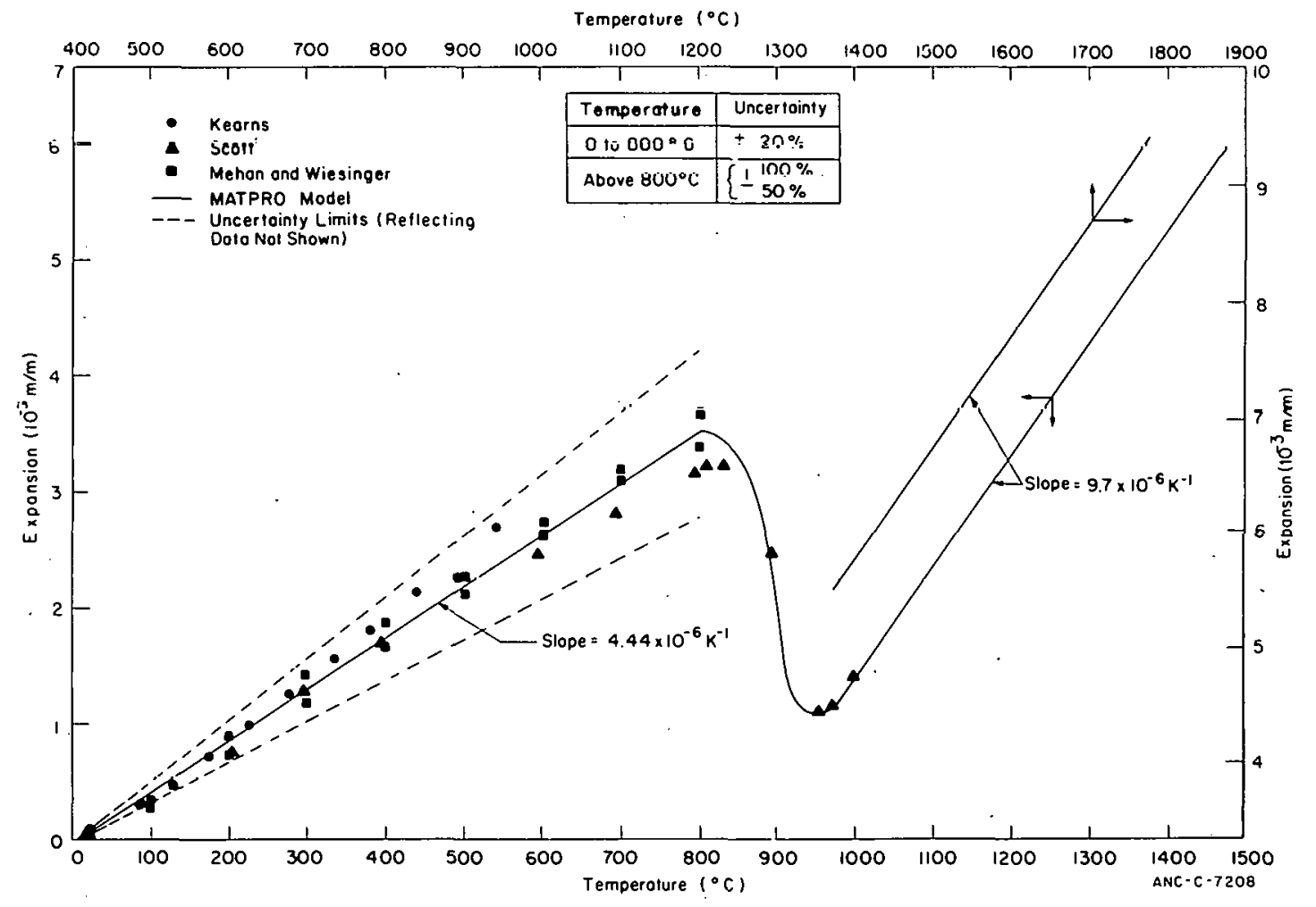

Fig. B-5.2 Axial thermal expansion of zircaloy tubing as calculated by CATHEX, including data base and estimated low-temperature uncertainty limits.

\subsection{Cladding Axial Thermal Expansion Subcode CATHEX Listing}

The FORTRAN listing of the subcode CATHEX is presented in Table B-5.I.

\section{$5.4 \quad$ References}

B-5.1. D. B. Scott, Physical and Mechanical Properties. of: Zircaloy-2 and -4, USAEC WCAP-3269-41 (May 1965) pp 8-12. 
TABLE B-5. I

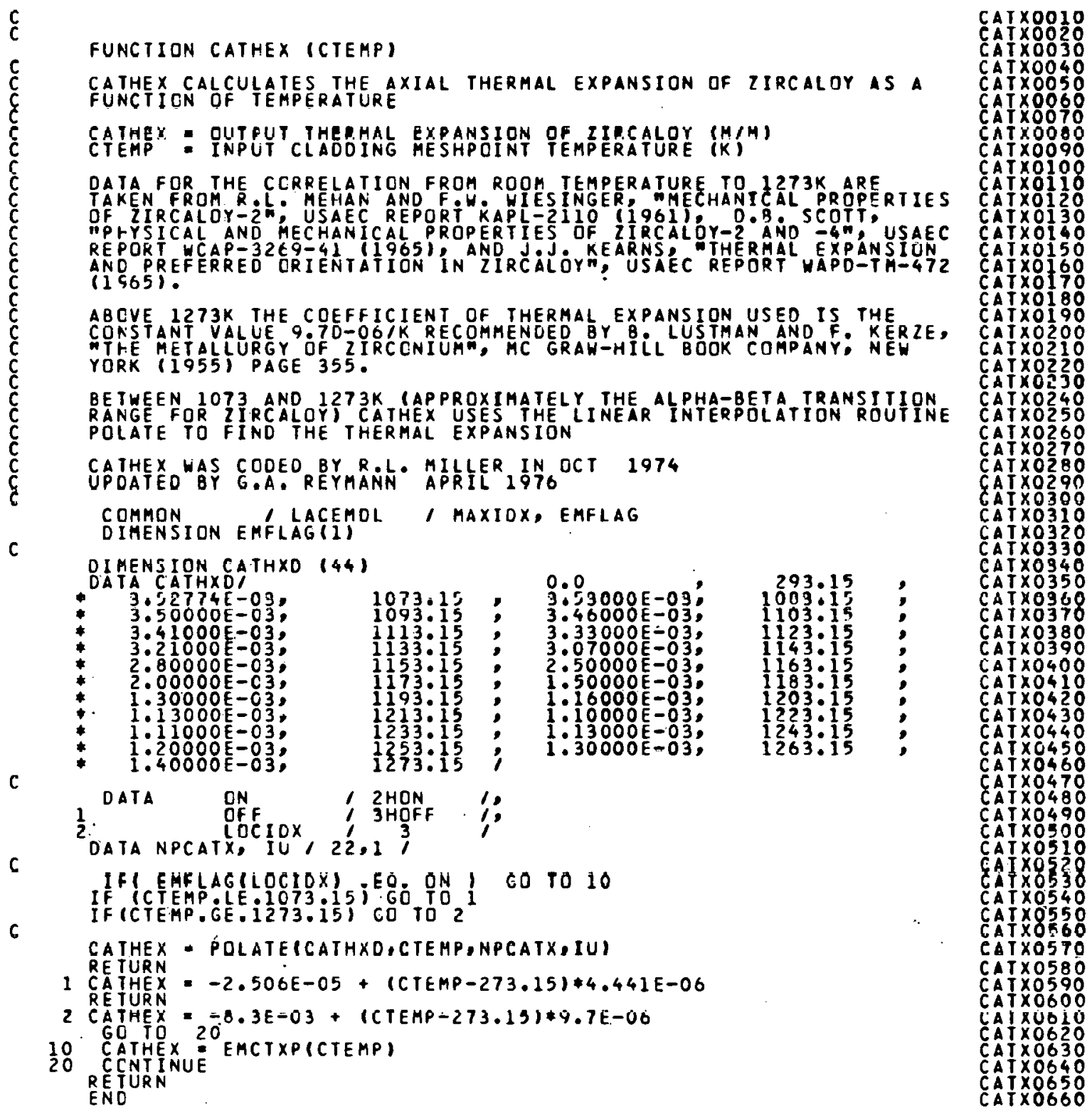

B-5.2. J. J. Kearns, Thermal Expansion and Preferred Orientation in Zircaloy, USAEC WAPD-TM-472 (1965).

B-5.3. R. L. Mehan and F. W. Wiesinger, Mechanical Properties of Zircaloy-2, USAEC KAPL-2110 (February 1961). 
CDTHEX

B-5.4. R. L. Melian and G. L. Cutler, Thermal Expansion of Zircaloy' 2 Between Room Temperature and $1,000^{\circ} \mathrm{C}$, USAEC KAPL-RLM-15 (1958).

B-5.5. G. B. Skinner and U. L. Johnston, "Thermal Expansion of Zirconium Between $298 \mathrm{~K}$ and 1,600 K", Journal of Chemistry and Physics, 2I (August 1953) pp 1383-1384.

B-5.6. B. Lustman and F. Kerze, Jr., The Metallurgy of Zirconium, New York: McGraw-Hill Book Company, Inc., 1955 p 355.

\section{CLADDING DIAMETRAL THERMAL EXPANSION (CDTHEX)}

In this section, correlations for the diametral thermal expansion of zircaloy cladding and the uncertainties in these correlations are presented.

\subsection{Summary}

As with the axial thermal expansion model CATHEX, the temperature range for CDTHEX is divided into three sections: the alpha-phase region, the transition region, and the beta-phase region. The assumption is made that zircaloy- 2 and zircaloy- 4 are similar enough in their thermal expansion properties to be described by the same correlations. Also the same sources of data are used $[\mathrm{B}-6.1, \mathrm{~B}-6.2, \mathrm{~B}-6.3]$ as in the CATHEX model.

For room temperature to the beginning of the transition:

$$
\frac{\Delta \mathrm{D}}{\mathrm{D}_{\mathrm{O}}}=-2.073 \times 10^{-3}+6.721 \times 10^{-6} \mathrm{~T}
$$

for $300<\mathrm{T}<1073 \mathrm{~K}$.

The assumption is made that the diametral thermal expansion is parallel to the CATHEX thermal expansion curve (shown in Figure B-5.2) from about $1.073 \mathrm{~K}$ to a temperature at which the beta phase is well formed, about $1273 \mathrm{~K}$. This assumption was used to generate a data table to describe the thermal expansion of zircaloy from 1073 to $1273 \mathrm{~K}$. CDTHEX then employs the subroutine POLATE to linearly interpolate between points in the data set.

For the beta phase the correlation is

$$
\frac{\Delta D}{D_{0}}=-9.4 \times 10^{-3}+9.7 \times 10^{-6} \mathrm{~T}
$$

for $1273 \mathrm{~K} .<\mathrm{T}<\mathrm{T}_{\text {melting }}$. 


\section{CDTHEX}

The uncertainties in the model are largely due both to unspecified texture variations and to lack of data at higher temperatures. The uncertainties are expressed as a percentage of the total expansion and are

$$
\begin{aligned}
& +10 \% \text { for } 300<T<1073 K \\
& \left.\begin{array}{r}
+100 \% \\
-50 \%
\end{array}\right\} \text { for } T>107.3 \mathrm{~K} \text { : }
\end{aligned}
$$

\subsection{Derivation of CDTHEX Model -}

The diametral expansion of tubing is a combination of circumferential and radial expansion. The circumferential direction of tubing and the long transverse direction of rolled plate: specimens are similar in texture and expansion properties, as are the radial direction of tubing and the short transverse direction of plate (see Figure B-5.1 of the axial thermal expansion discussion). However, the thickness of the tubing wall is so small compared with the diameter of the tubing that the radial contribution need not be considered. Therefore, the long transverse direction of plate may be used to model diametral expansion of tubing without serious error.

6.2.1 Survey of Available Data. The same. sources as. were used to model axial thermal expansion are used in this section. Again, the data of Mehan and Cutler [ $B \cdot 6.4]$ vere neglected because they observed no anisotropic effects and their samples were subjected to heat treatment not typical of as-received zircaloy tubing.

6.2.2 Cladding Diametral Thermal Expansion in the Alpha Phase. A least squares analysis of possible polynominal fits to the data base chosen, shows that expressing $\frac{\Delta \mathrm{D}}{\mathrm{D}_{\mathrm{o}}}$ as a linear function of the temperature gives a standard deviation from the data. which is not significantly different than that resulting from a higher order fit. Therefore, the linear equation given below was chosen to represent the thermal expansion

$$
\frac{\Delta D}{D_{0}}=-2.073 \times 10^{-3}, 6.721 \times 10^{6} \mathrm{~T}
$$

for $300<\mathrm{T}<1073 \mathrm{~K}$.

where

$$
\begin{aligned}
& \mathrm{T}=\text { temperature }(\mathrm{K}) \\
& \mathrm{D}_{\mathrm{O}}=\text { diameter at approximately } 300 \mathrm{~K} \\
& \Delta \mathrm{D}=\text { change in diameter resulting from thermal expansion }(\mathrm{m}) .
\end{aligned}
$$

A least squares fit to the data was made without constraint conditions since the expansion coefficient is the item of most interest, even though this approach does not give $\Delta \mathrm{D}=0$ at the base temperature. 
Since the scatter of the data generally grows with increasing temperature, a single value for a standard deviation or for error limits does not give a particularly representative or useful idea of the uncertainty associated with the correlation expressed by Equation (B-6.3). Rather, it was found that the percentage deviation was more constant over the temperature range, with a value of about $\pm 10 \%$ of the calculated value including nearly all of the data base.

6.2.3 Cladding Diametral Thermal Expansion During the Alphid to Beta Pliase Transition. There are no diametral data available in the temperature range from 1073 to $1273 \mathrm{~K}$, where the zircaloy phase transition occurs. Therefore, the assumption is made that the diametral thermal expansion is parallel to the axial thermal expansion curve shown in Figure B-5.2. The curve resulting from this assumption was used to gencrate a data table to be used by the subroutine POLATE for linear interpolation.

The uncertainty of the results returned in this temperature range is difficult to estimate. Until there are data available, the values used in CATHEX will be assumed to apply horc as wcll, i.e., an upper uncertainty limit of $100 \%$ of the CDTHEX value, and a lower limit of $50 \%$.

6.2.4 Cladding Diametral Thermal Expansion in the Beta Phase. For the beta phase (above approximately $1244 \mathrm{~K}$ ), there are again no data available. Thus the assumption was made that the coefficient of thermal expansion for zircaloy is the same as that for zirconium as quoted in Lustman and Kerze ${ }^{[\mathrm{B}-6.5]}$. Using this value and adding a constant to obtain agreement at $1273 \mathrm{~K}$, the following correlation is obtained:

$$
\frac{\Delta D}{D_{0}}=-9.4 \times 10^{-3}+9.7 \times 10^{-6} \mathrm{~T}
$$

for $1273<\mathrm{T}<2098 \mathrm{~K}$.

As before, the constants in Equation (B-6.4) are given only to two significant figures because of the lack of a data base, and the uncertainty limits are assumed to be $+100 \%$ and $-50 \%$ of the CDTHEX value for $\triangle \mathrm{D} / \mathrm{D}_{\mathrm{O}}$.

The results of these correlations and the data base points are presented in Figure B-6.1. The predictions of CDTHEX and CATHEX are compared in Figure B-6.2.

\subsection{Cladding Diametral Thermal Expansion Subcode CDTHEX Listing}

The FORTRAN listing of the subcode CDTHEX is presented in Table B-6.I.

\subsection{References}

B-6.1. D. B. Scott, Physical and Mechanical Properties of Zircaloy-2 and -4, USAEC WCAP-3269-41 (May 1965) pp 8-12. 


\section{CDTHEX}

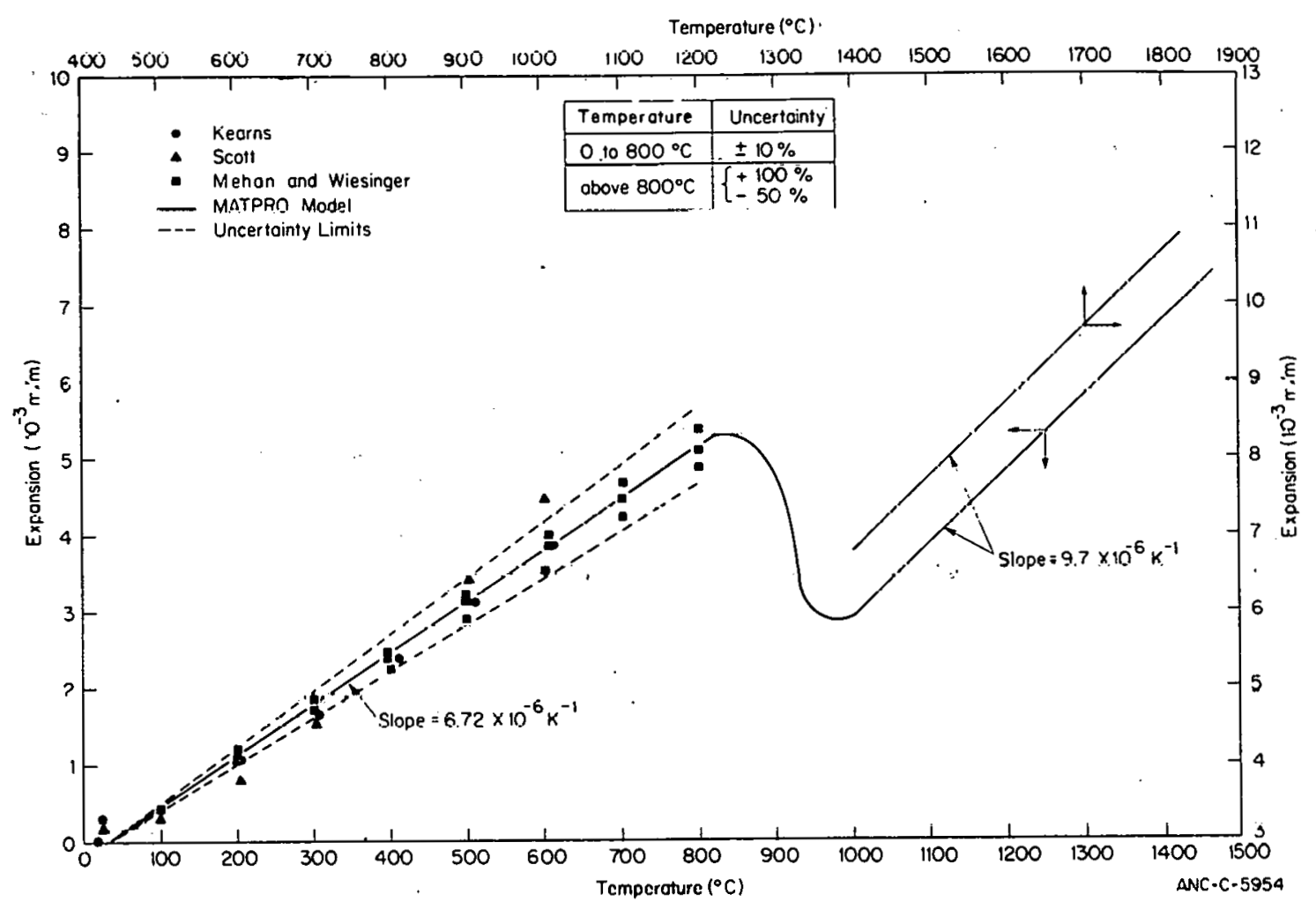

Fig. B-6.1 Diametral thermal expansion of zircaloy tubing as calculated by CDTHEX, including data base and luw-temperature uncertainty limits.

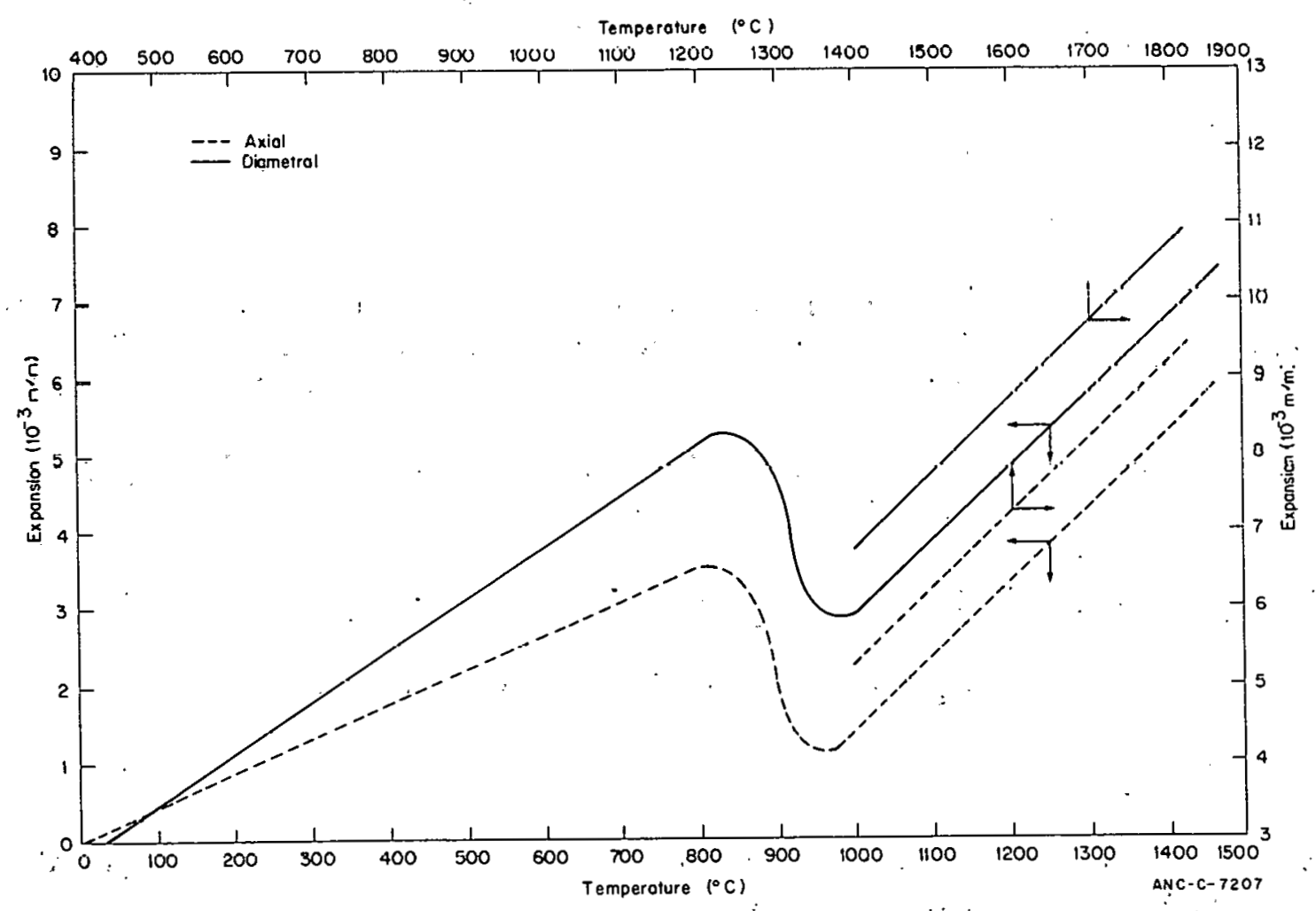

Fig. B-6.2 Comparison of the diametral thermal expansion of zircaloy tubing as calculated by CDTHEX with the axial thermal expansion of tubing as calculated by CATHEX. 
CDTHEX

TABLE B-6. I

\section{LISTING OF THE CDTHEX SUBCODE}

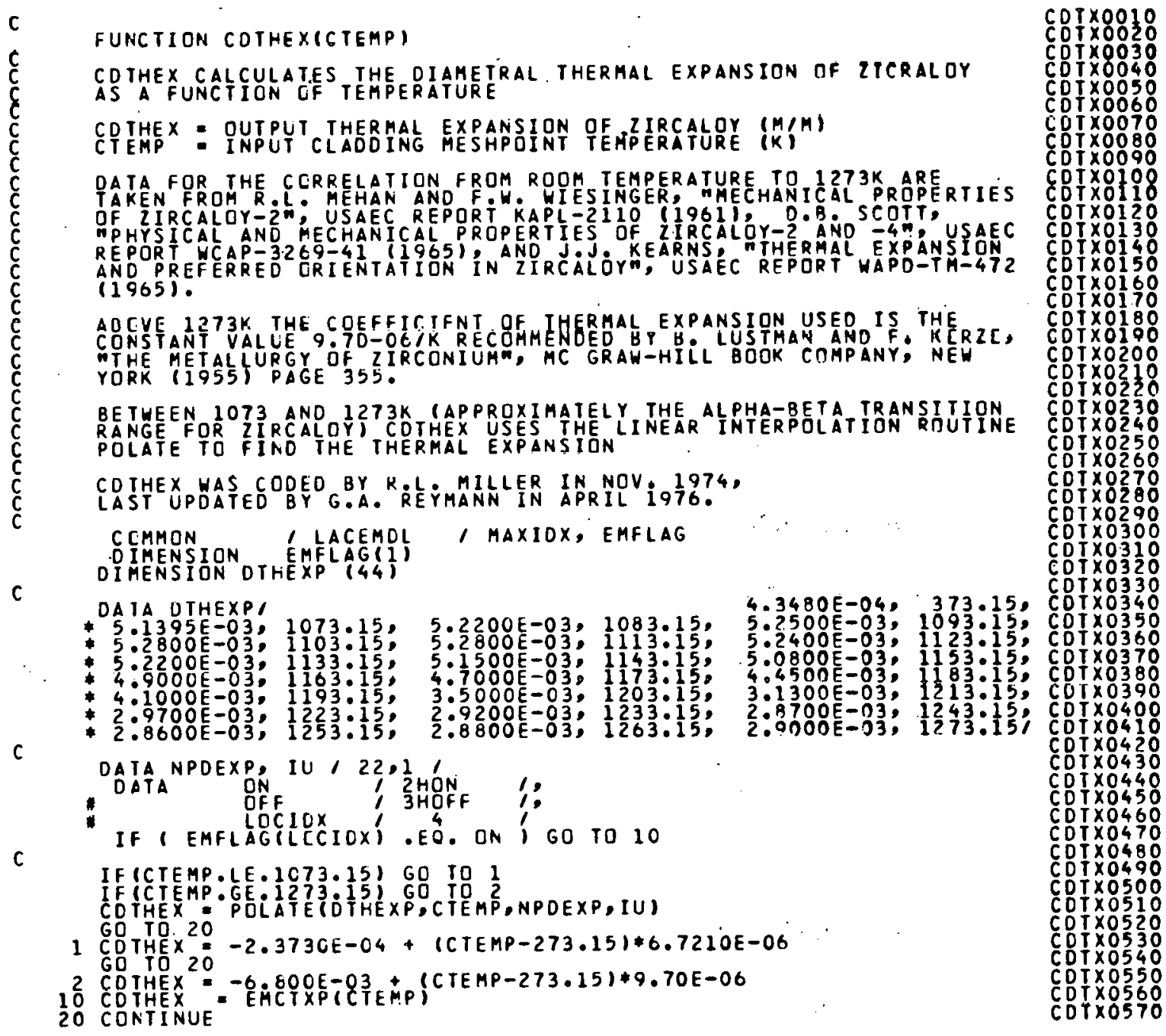

B-6.2. J. J. Kearns, Thermal Exparision and Preferred Orientation In Zircaloy, USAEC. WAPD-TM-472 (1965).

B-6.3. R. L. Mehan and F. W. Wiesinger, Mechanical Properties of Zircaloy-2, USAEC KAPL-2110 (February 1961).

B-6.4. R. L. Mehan and G. L. Cutler, Thermal Expansion of Zircaloy-2 Between Room Temperature and $1,000^{\circ} \mathrm{C}$, USAEC KAPL-M-RLM-15 (1958).

B-6.5. B. Lustman and F. Kerze, Jr., The Metallurgy of Zirconium, New York: McGraw-Hill Book Company, Inc., (1955) p 355. 


\section{CLADDING ELASTIC MODULUS (CELMOD)}

The modulus of elasticity is requircd to calculate inieclianical properties of zircaloy cladding at stresses less than the yield stress. The elastic modulus is defined by Hooke's law as the ralio of stress to strain for stresses below the yield point. The data available are for unirradiated material and span the range from room temperature to about $1073 \mathrm{~K}$, although they are less reliable above $673 \mathrm{~K}$.

Busby [B-7.1] reported values of the elastic modulus for zircaloy-4 between 297 and $644 \mathrm{~K}$ for five combinations of cold work and heat treatment. Too few data were reported to allow separation of the contribution of cold work and heat treatment from the effects of temperature, howcver. A linear least squares fit of Busby's data resulted in the correlation:

$$
E=1.178 \times 10^{11}-6.394 \times 10^{7} \mathrm{~T}
$$

where

$$
\begin{aligned}
& \mathrm{E}=\mathrm{Y}^{\prime} \text { enily's mudulus (Pa') } \\
& \mathrm{T}=\text { temperaturc (K). }
\end{aligned}
$$

Spasic et al ${ }^{[B-7.2]}$ studied the elastic modulus of zircaloy-2 in the unirradiated condition from room tempcrature to $673 \mathrm{~K}$. They reported the correlation

$$
E=8.25 E_{0} T^{-0.369}
$$

where

$$
\begin{aligned}
& \therefore \mathrm{E}-\text { Young's modulus (Pa) } \\
& \mathrm{T}=\text { temperature }(\mathrm{K}) \\
& \mathrm{E}_{\mathrm{O}}{ }^{\cdot}=\text { experimental value of Young's modulus at room tempera- } \\
& \text { ture }(300 \mathrm{~K}) 1.01 \times 10^{11} \mathrm{~Pa} \text {. }
\end{aligned}
$$

The Spasic et al data are reported to fall within $\pm 3 \%$ of their calculated curve ${ }^{[B-7.2]}$. Their correlation [Equation (B-7.2)] and supporting data are shown in Figure B-7.1. The elastic modulus calculated by this correlation decreases slowly after about $900 \mathrm{~K}$ and is probably not valid much beyond the limits of its data base. The material used by Spasic et al was not characterized as to amount of cold work, and the assumption is made that unirradiated material in the annealed condition was used in the tests.

Mehan $[B-7.3]$ and Mehan and Wiesinger ${ }^{[B-7.4]}$ reported elastic modulus data in the range of room temperature to $1089 \mathrm{~K}$. These data were gathered on unirradiated, 
CELMOD

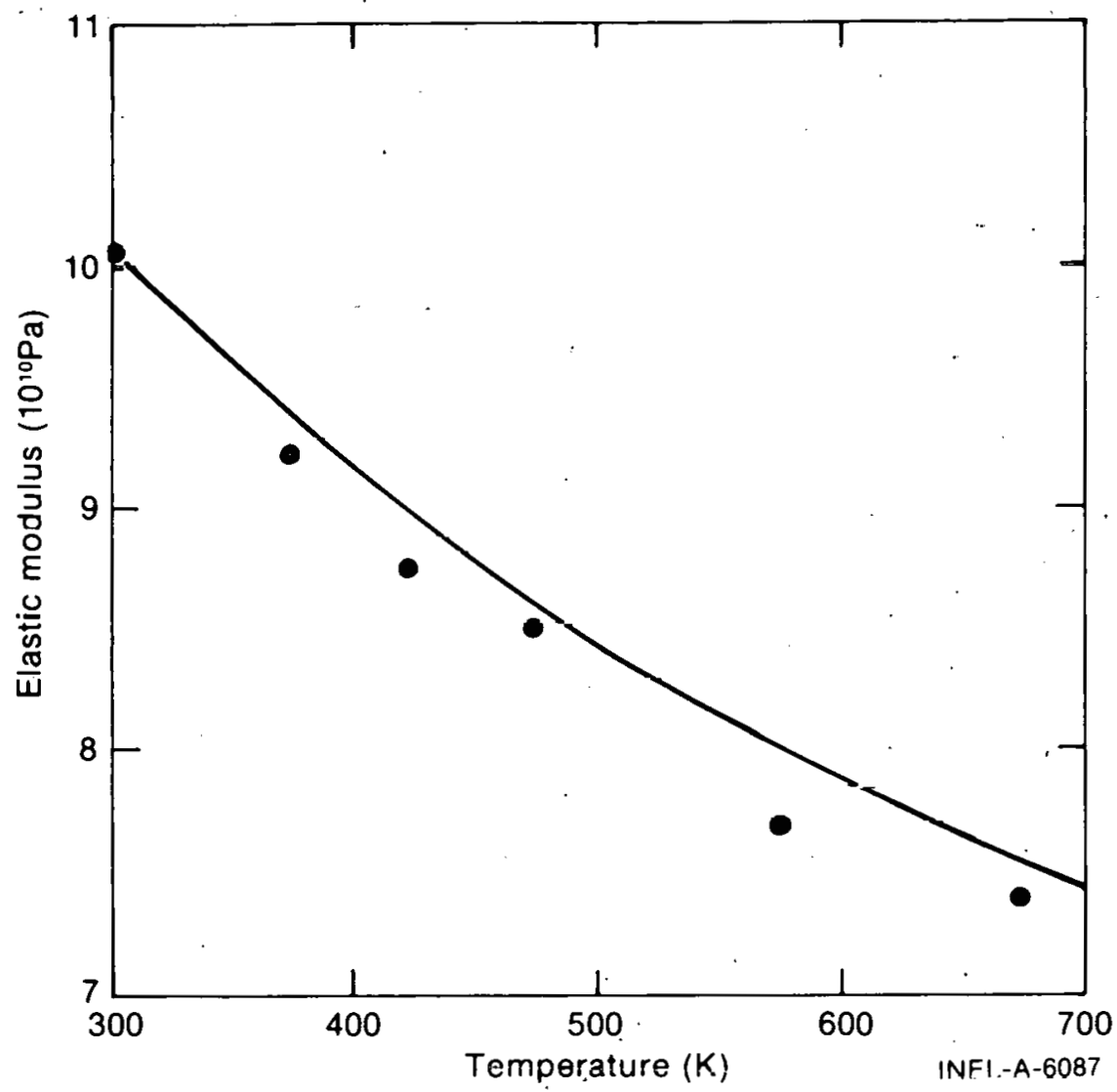

Fig. B-7.1 Elastic modulus of zircaloy-2 as a function of temperature showing the data and correlation of Spasic et al.

vacuum-annealed zircaloy-2. Brassfield et al ${ }^{[B-7.5]}$ reported the following correlation ${ }^{[a]}$ of Mehan and Wiesinger's[B-7.4] data:

$$
E=1.12 \times 10^{11}-5.67 \times 10^{7} \mathrm{~T}
$$

where

$$
\begin{aligned}
& \mathrm{E}=\text { Young's modulus }(\mathrm{Pa}) \\
& \mathrm{T}=\text { temperature }(\mathrm{K}) .
\end{aligned}
$$

This correlation is shown in Figure B-7.2.

In the temperature range over which the data base of the preceding correlations overlap, the agreement is within about $10 \%$. The CELMOD correlation is a linear relation of

[a] Equation (B-7.3) has different coefficients from those quoted in Reference B-7.5 because it has been converted to SI units. 


\section{CELMOD}

the elastic modulus as a function of temperature based on the pooled data from the preceding sources. The relation is

$$
E=1.148 \times 10^{11}-5.99 \times 10^{7} \mathrm{~T}
$$

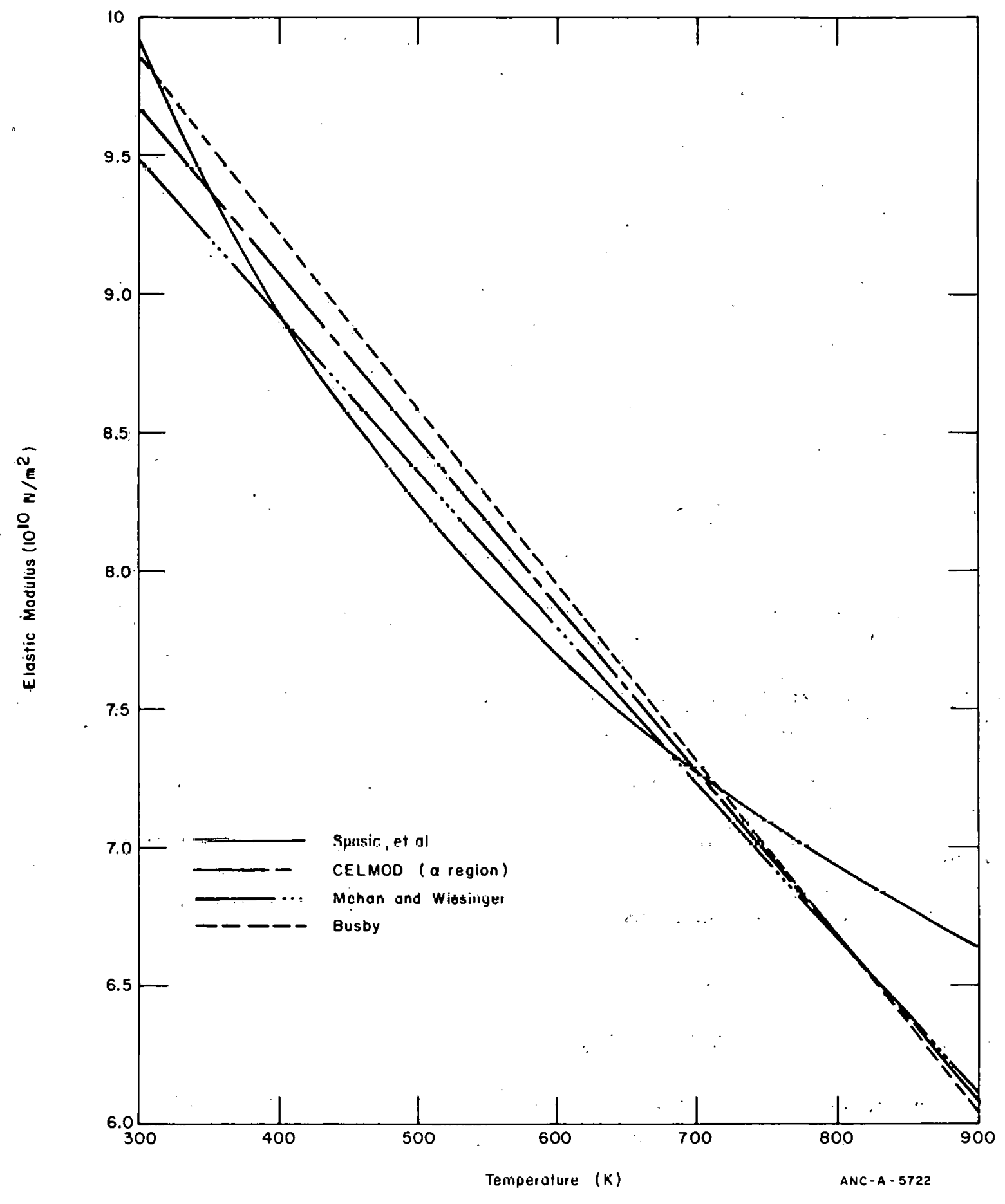

Fig. B-7.2 Zircaloy elastic modulus as a function of temperature showing the correlation of Busby, Spasic et al, Mehan and Wiesinger, and CELMOD for the $\alpha$-phase for zircaloy. 
for $300<\mathrm{I}^{\prime}<1135 \mathrm{~K}$

where

$$
\begin{aligned}
\mathrm{E} & =\text { Young's modulus }(\mathrm{Pa}) \\
\mathrm{T} & =\text { temperature }(\mathrm{K}) .
\end{aligned}
$$

This function is used to represent the elastic modulus of zircaloy-4 in the alpha-phase region (that is, in the region up to $1083 \mathrm{~K}$ ) and thus involves an extrapolation over a considerable temperature range. This relation is plotted in Figure B-7.2 along with the correlations from which it was derived.

Another extrapolation was made frum llie value at $1135 \mathrm{~K}$ to about zcro at the melting point. This extrapolation is used to represent the elastic modulus in the beta-phase region and is given by

$$
E=1.005 \times 10^{11}-4.725 \times 10^{7} \mathrm{~T}
$$

for $1135<\mathrm{T}<\mathrm{T}$ melting

where

$$
\begin{aligned}
& \mathrm{E} \quad=\text { Young's modulus }(\mathrm{Pa}) \\
& \mathrm{T}=\text { temperature }(\mathrm{K}) .
\end{aligned}
$$

This relation is shown in Figure B-7.3 along with the correlation for the alpha-phase region.

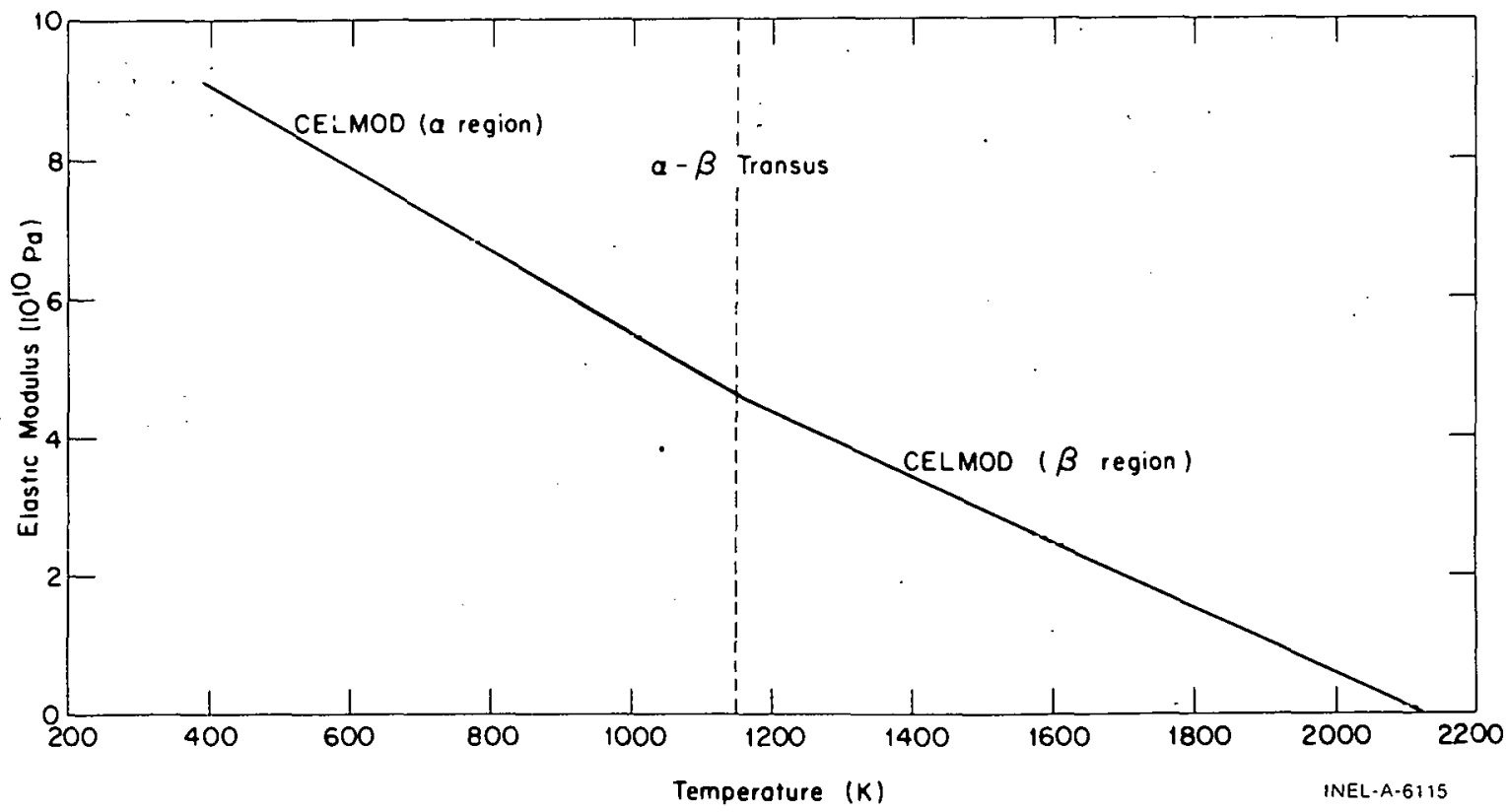

Fig. B-7.3 Elastic modulus of zircaloy as a function of temperature as calculated by the CELMOD subcode. 
The change in the elastic modulus in the alpha-beta transition region is unknown. The extrapolation of the elastic modulus from the alpha-beta transition region to the melting point is for calculational convenience, and large uncertainties exist in values calculated using the code in the beta-phase region.

7.1 Cladding. Elastic Modulus Subcode CELMOD Listing

A FORTRAN listing of the subcode CELMOD is presented in Table B-7.I.

TABLE B-7.I

\section{LISTING OF THE CELMOD SUBCODE}

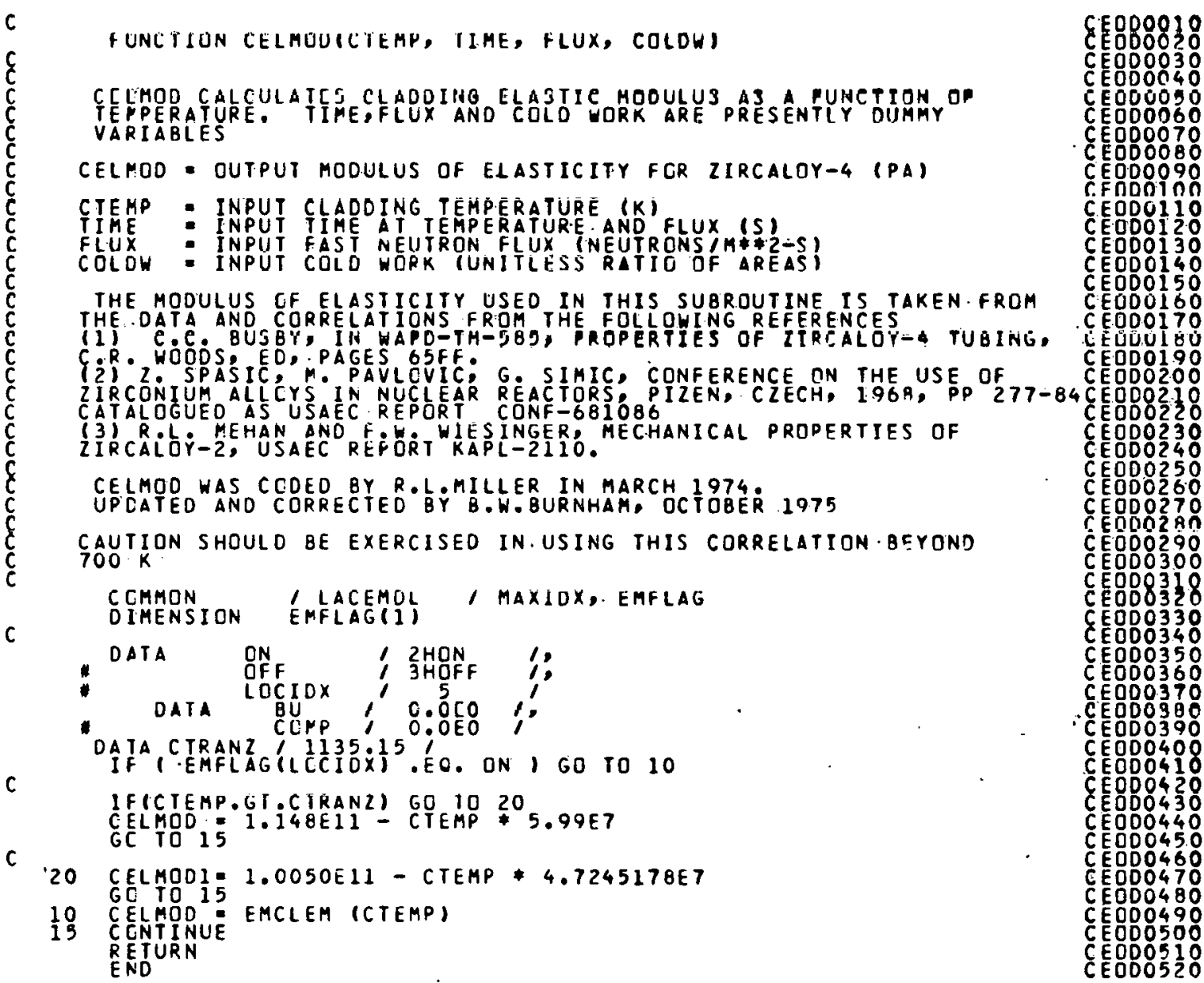

\subsection{References}

B-7.1. C. C. Bushy and C. R. Woods (eds.), Properties of Zircaloy-4 Tubing, USAEC WAPD-TM-585 (December 1966) p 65ff. 
B-7.2. Z. Spasic, M. Pavlovic, and G. Simis, Conference on the Use of Zirconium Alloys in Nuclear Reactors, Marianste Lazne, Czechloslovakia, October 1-3, 1968, USAEC CONF-681086 (1968) pp 277-284.

B-7.3. R. L. Mehan, Modulus of Elasticity of Zircaloy-2 Between Room Temperature and $1000^{\circ} \mathrm{F}$, USAEC'KAPL-M-RLM-16 (July 1958).

B-7.4. R. L. Mehan and F. W. Wiesinger, Mechanical Properties of Zircaloy-2, USAEC KAPL-21 10 (February 1961) pp 11-12.

B-7.5. H. C. Brassfield et al, Recommended Property and Reaction Kinetics Data for Use in Evaluating a Light Water-Cooled Reactor Loss-of-Coolant Accidcnt Involving Zircaloy-4 or 304-SS-Clad UO,, USAEC GEMP-482 (April 1968).

\section{CLADDING STRESS VERSUS STRAIN (CSTRES AND CSIGMA)}

The subroutine CSTRES calculates cladding true and engineering stress as a function of true strain, true strain rate, cladding temperature, maximum previous cladding temperature, cold work, and fast ncutron flucncc. A sccond subcode, CSIGMA, is provided which returns only the expression for true stress.

\subsection{Summary}

This section is intended to serve as an introduction to the common features of all the plastic deformation subcodes in MATPRO as well as the particular features of CSTRES and CSIGMA. All input strain or stress values are assumed by MATPRO mechanical property routines to be true strain ${ }^{[a]}$ or true stress ${ }^{[b]}$ values. With the exception of the function CSIGMA, MATPRO output values are given both as true and engineering values of stress or strain. In CSTRES true stress is converted to engineering stress by using the constant volume approximation:

$$
\begin{aligned}
\text { engineering stress }[\mathrm{c}] & =\frac{\text { true stress }}{1+\text { engineering strain }} \\
& =\frac{\text { true stress }}{\exp (\text { true strain })} .
\end{aligned}
$$

[a] True strain $=$ the change in length divided by length at the instant of change integrated from the original to the final length $=\int_{L_{O}}^{L} \frac{d \ell}{\ell}$.

[b] True stress $=$ force per $u$ nit cross sectional area with the area determined at the instant of measurement of the force.

[c] Engineering stress $=$ force per unit cross sectional area with the area determined when force was zero. 
Two different equations are used in MATPRO to relate true stress to true strain. In the clastic rcgion, Hooke's law is used:

$$
\sigma=E \varepsilon
$$

where

$$
\begin{aligned}
& v=\text { true stress } \\
& \epsilon \quad=\text { true strain } \\
& \mathrm{E}=\begin{array}{l}
\text { the modulus of elasticity (calculated by CELMOD as a } \\
\text { function of temperature). }
\end{array}
\end{aligned}
$$

In the plastic region the relation is

$$
\dot{\sigma}=k \varepsilon^{n}\left(\frac{\dot{\varepsilon}}{10^{-3} / s}\right)^{m}
$$

where

$$
\begin{aligned}
& \mathrm{K}=\text { strength coefficient }(\mathrm{Pa}) \\
& \mathrm{n}=\text { strain rate hardening exponent (dimensionless) } \\
& \mathrm{m}=\text { strain rate sensitivity exponent (dimensionlcss) } \\
& \dot{\epsilon} \quad-\quad \text { true siliaim late }
\end{aligned}
$$

The transition from the elastic to the plastic region is defined to be at the nonzero intersection of the curves prealicled by Equations.(B-8.2) and (B=8.3).

Effects of cladding temperature, in-reactor annealing, cold work, and irradiation on mechanical properties are expressed as changes in the strength coefficient, $\mathrm{K}$, the strain hardening exponent, $\mathrm{n}$, and the strain rate sensitivity constant, $\mathrm{m}$, of Equation (B-8.3). For fully annealed material, the temperature and strain rate dependent values of $n$ and $K$ are as follows.

[a] For input values of $\dot{\epsilon}$ outside the range of $10^{-5}$ to $10^{-1} / \mathrm{s}$ the input value $\dot{\epsilon}$ is replaced by the closest value in this range. 
Values of $n$ are lound with the correlations:

for $\mathrm{T}<850 \mathrm{~K}$ :

$$
n=-1.86 \times 10^{-2}+T\left[7.110 \times 10^{-4}-T\left(7.721 \times 10^{-7}\right)\right\rfloor
$$

for $\mathrm{T} \geqslant 850 \mathrm{~K}$ :

$$
n=0.027908
$$

Values of $\mathrm{K}$ are found with the correlations:

for $T \leqslant 794.9814 \mathrm{~K}$ :

$$
K=1.0750 \times 10^{9}-9.996 \times 10^{5} \times T
$$

for $\mathrm{T}>794.9814 \mathrm{~K}$ :

$$
\begin{aligned}
K= & \exp \left[3.417 \times 10^{1}+T\left(-2.6630 \times 10^{-2}+T\left(1.1569 \times 10^{-5}\right.\right.\right. \\
& \left.\left.\left.-1.7111 \times 10^{-9} \mathrm{~T}\right)\right)\right]
\end{aligned}
$$

Values of $\mathrm{m}$ for all material are given as follows:

for $\mathrm{T} \leqslant 730 \mathrm{~K}$ :

$$
\mathrm{m}=0.02
$$

for $730 \mathrm{~K}<\mathrm{T}<750 \mathrm{~K}$ :

$$
m=-2.9191625+4.02625 \times 10^{-3} \times T
$$

for $750 \mathrm{~K} \leqslant \mathrm{~T} \leqslant 1090 \mathrm{~K}$ :

$$
m=-6.47 \times 10^{-2}+2.203 \times 10^{-4} \mathrm{~T}
$$

for $1090 \mathrm{~K}<\mathrm{T} \leqslant 1172.5 \mathrm{~K}$ :

$$
\begin{aligned}
m= & -6.47 \times 10^{-2}+2.203 \times 10^{-4} \mathrm{~T} \\
+ & \left\{\begin{array}{c}
0 \text { if } \dot{\varepsilon} \geq 6.34 \times 10^{-3} / \mathrm{s} \\
6.78 \times 10^{-2} \ln \left(6.34 \times 10^{-3} / \dot{\varepsilon}\right) \times[(T-1090) / 82.5] \\
\text { if } \dot{\varepsilon}<6.34 \times 10^{-3} / \mathrm{s}
\end{array}\right\}
\end{aligned}
$$

(B-8.6d) 
for $1172.5 \mathrm{~K}<\mathrm{T}<125.5 \mathrm{~K}$ :

$$
\begin{aligned}
\mathrm{m}= & -6.47 \times 10^{-2}+2.203 \times 10^{-4} \mathrm{~T} . \\
& +\left\{\begin{array}{c}
0 \text { if } \dot{\varepsilon} \geq 6.34 \times 10^{-3} / \mathrm{s} \\
6.78 \times 10^{-2} \ln \left(6.34 \times 10^{-3} / \dot{\varepsilon}\right) \times[(1255-\mathrm{T}) / 82.5] \\
\text { if } \dot{\varepsilon}<6.34 \times 10^{-3} / \mathrm{s}
\end{array}\right\}
\end{aligned}
$$

$r$

$(\mathrm{B}-8.6 \mathrm{\theta})$

for $1255 \mathrm{~K} \leqslant \mathrm{~T}$ :

$$
m=-6.47 \times 10^{-2}+2.203 \times 10^{-4} \mathrm{~T}
$$

where

$$
\begin{aligned}
& \mathrm{T} \quad=\quad \text { temperature }(\mathrm{K}) \\
& \dot{c} \quad-\quad \text { truc } 3 \text { train ratc }\left(3^{-1}\right) .
\end{aligned}
$$

These expressions are discussed in conjunction with Figures B-8.1, B-8:2, and B-8:3 of Section: $B=8: 2$.

For irradiated and cold-worked cladding which has remained at temperatures below $550 \mathrm{~K}$, the change in the strength coefficient is described by multiplying the values for annealed materials by:

$$
\left[1-0.546 \times \text { cold } \text { work }^{[a]}\right] .
$$

Similarly, the work hardening exponent is multiplied by a factor $\mathrm{Y}$ which expresses the effect of cold work on $\mathrm{n}$ and a factor $\mathrm{Z}$ which expresses the effect of irradiation on $\mathrm{n}$. 'lhe analy tical expresscions for $Y$ and $L$ are:

$$
\begin{aligned}
& Y \equiv 0.847 \exp (-39.2 \operatorname{coLOW})+\dot{0} .153 \\
&+\operatorname{COLDW}\left(-9.16 \times 10^{-2}+0.229 \operatorname{coLDW}\right) \\
& Z=\exp \left[-(\phi t)^{1 / 3} /\left(3.73 \times 10^{7}+2 \times 10^{8} \text { COLDW }\right)\right]
\end{aligned}
$$

where

$$
\text { COLDW }=\quad \text { cold work (fraction of cross sectional area reduction) }
$$

[a] Fraction of cross sectional area reduction. 


$$
\begin{aligned}
\phi & = & \text { fast neutron flux }\left(\mathrm{n} / \mathrm{m}^{2} \cdot \mathrm{s}\right) \\
\mathrm{t} & = & \text { time at flux }(\mathrm{s}) .
\end{aligned}
$$

Graphs of the analytical expressions for Equation (B-8.7) and $\mathrm{YZ}$ at typical values of $\phi \mathrm{t}$ are shown in Figures B-8.5 and B-8.6 of Section B-8.3.

Changes in the strength coefficient and strain hardening exponent caused by cold work and irradiation are assumed to anneal permanently as a function of temperature. Changes due to annealing of irradiation damage are presumed to occur in the temperature range from 550 to $700 \mathrm{~K}$ and are approximated by replacing the fluence in Equation (B-8.9) by

$$
\frac{700 \mathrm{~K}-\text { Maximum Cladding Temperature }}{100 \mathrm{~K}}
$$

times the original fluence when the maximum cladding temperature is between 550 and $700 \mathrm{~K}$. Annealing of cold work effects is presumed to occur over the temperature range frum 775 to $850 \mathrm{~K}$ and is incorporated into the modcl by rcplacing the expression for cold work by

$$
\frac{850 \mathrm{~K}-\text { Maximum Cladding Temperature }}{75 \mathrm{~K}}
$$

times the original value for cold work whenever the maximum cladding temperature is between 775 and $850 \mathrm{~K}$. For previous maximum temperatures greater than $850 \mathrm{~K}$, the cladding is presumed to have been annealed.

No specific provision is included in the model for stress relief or other heat treatments which are not implied by maximum cladding temperature. For material which has been stress-relieved at temperatures higher than the first maximum cladding temperature input the "equivalent cold work" can be input to approximate the state of the material.

The development of the expressions for $\mathrm{m}, \mathrm{K}$, and $\mathrm{n}$ as functions of temperature is discussed in the following section. Section B-8.3 is a description of the modification of the expressions for $\mathrm{K}$ and $\mathrm{n}$ to include effects of irradiation, cold work, and annealing. The output of CSTRES is illustrated in Section B-8.4; however, a comparison of model predictions and experimental data is reserved for the CMLIMT subroutine which predicts the values of yield and ultimate strength that are most often quoted in the literature.

\subsection{Temperature Dependence of $\mathrm{m}, \mathrm{K}$, and $\mathrm{n}$}

The strain rate sensitivity constant, $m$, of zircaloy-2 and zircaloy -4 was evaluated with data obtained from References B-8.1 through B-8.4. The values of $m$ which are plotted in Figure B-8.1, at temperatures higher than $900 \mathrm{~K}$, were given by Reference B-8.2 as a function of engineering strain for strain rate changes centered around $10^{-3} / \mathrm{s}$. No significant dependence on strain was indicated, so $\mathrm{m}$ is modeled without strain dependence. Outside 


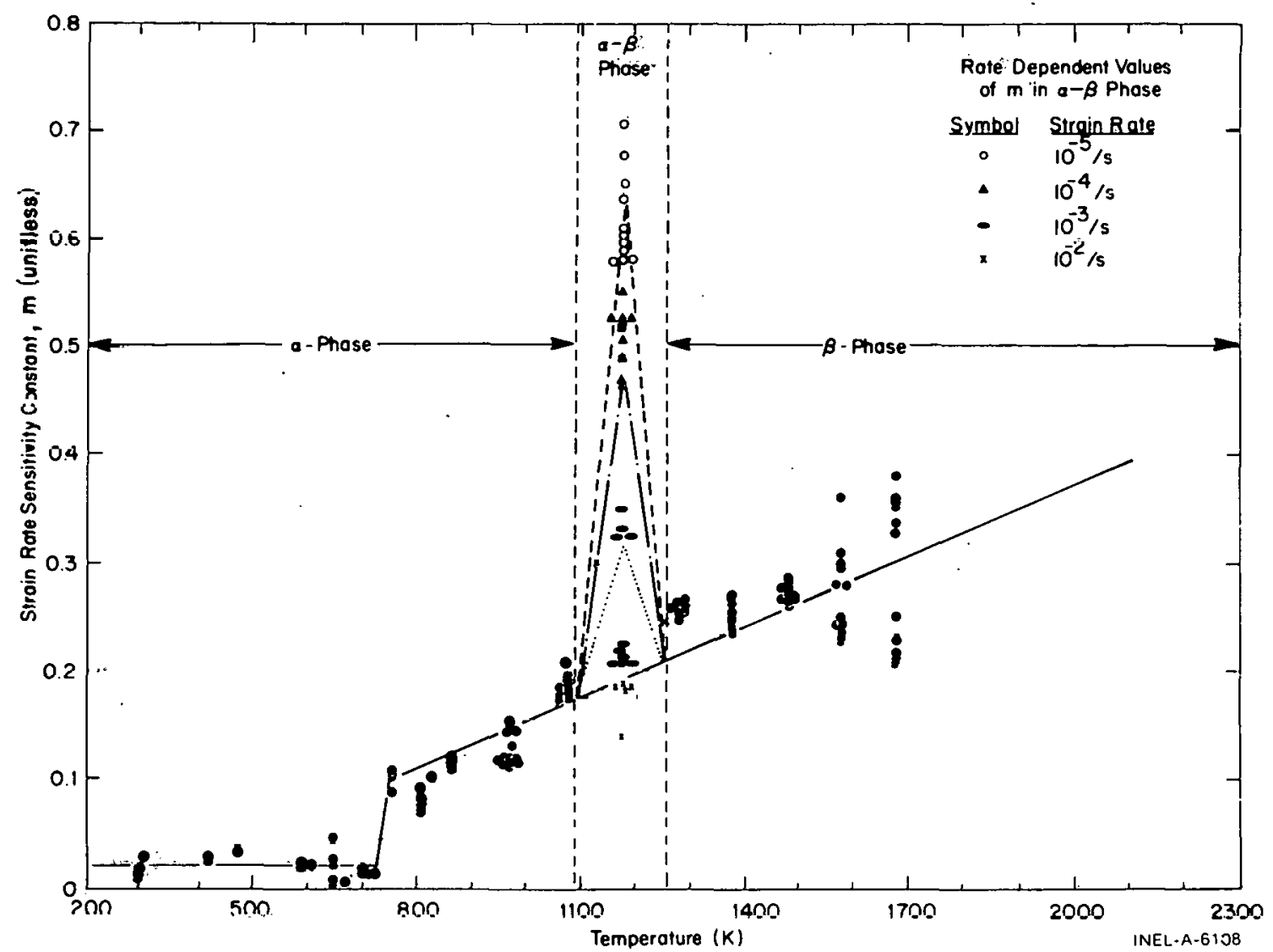

Fig. B=8:1 Values of strain rate sensitivity constant and data base as a function of temperature and strain rate used by MATPRO mechanical properties routines.

the alpha-bcta phase transition region (taken as $1090 \mathrm{~K}$ to $1255 \mathrm{~K}$ ) no significant dependence of $\mathrm{m}$ ' on strain rate was observed either. Within the alpha-beta transition region, the value of $m$ was a strong function of the strain rate.

In the MATPRO plastic deformation models, values of $m$ from data taken at temperatures below $730 \mathrm{~K}$ are approximated with a constant, $\mathrm{m}=0.02$, while data for tempcratures above $750 \mathrm{~K}$ and outside the alpha beta phase are represonted by a linear function of temperature. The linear function, $\mathrm{m}=0.0647+2.203 \times 10^{-4} \mathrm{~T}$ is illustrated in Figure B-8.1 along with the data. It should be noted that a distinction between data from zircaloy-2 and zircaloy 4 became evident at the two highest test temperatures. The lower group of points at $15 \% 3$ and $16 \% 3 \mathrm{~K}$ are trom zircaloy-2. It this trend continues at higher temperatures or is identified as due to the higher oxygen concentration of zircaloy- 2 , the strain rate sensitivity constant may have to be expressed as a function of oxygen concentration in the high temperature region of the beta phase.

- Values of $m$ in the alpha-beta transition region were also obtained from data presented in Reference B-8.2. The strain rate dependent values measured at $1173 \mathrm{~K}$ were assumed to reflect an additive increase in $\mathrm{m}$ due to the mixed phases. When the increase is plotted against the logarithm of the strain rate, the effect of varying strain rates on $\mathrm{m}$ can be closely approximated by a straight line of the form:

$$
\Delta m=0.1253+0.1562 \log _{10}\left(\frac{10^{-3} / \mathrm{s}}{\text { STRAIN RATE }}\right)
$$


which was obtained by a least squares fit to the data. The fit is illustrated in Figure B-8.2. For strain rates outside the range $10^{-5} / \mathrm{s}$ to $6.34 \times 10^{-3} / \mathrm{s}$ the change in $\mathrm{m}$ is taken to be equal to its value at the nearest point of this range of values.

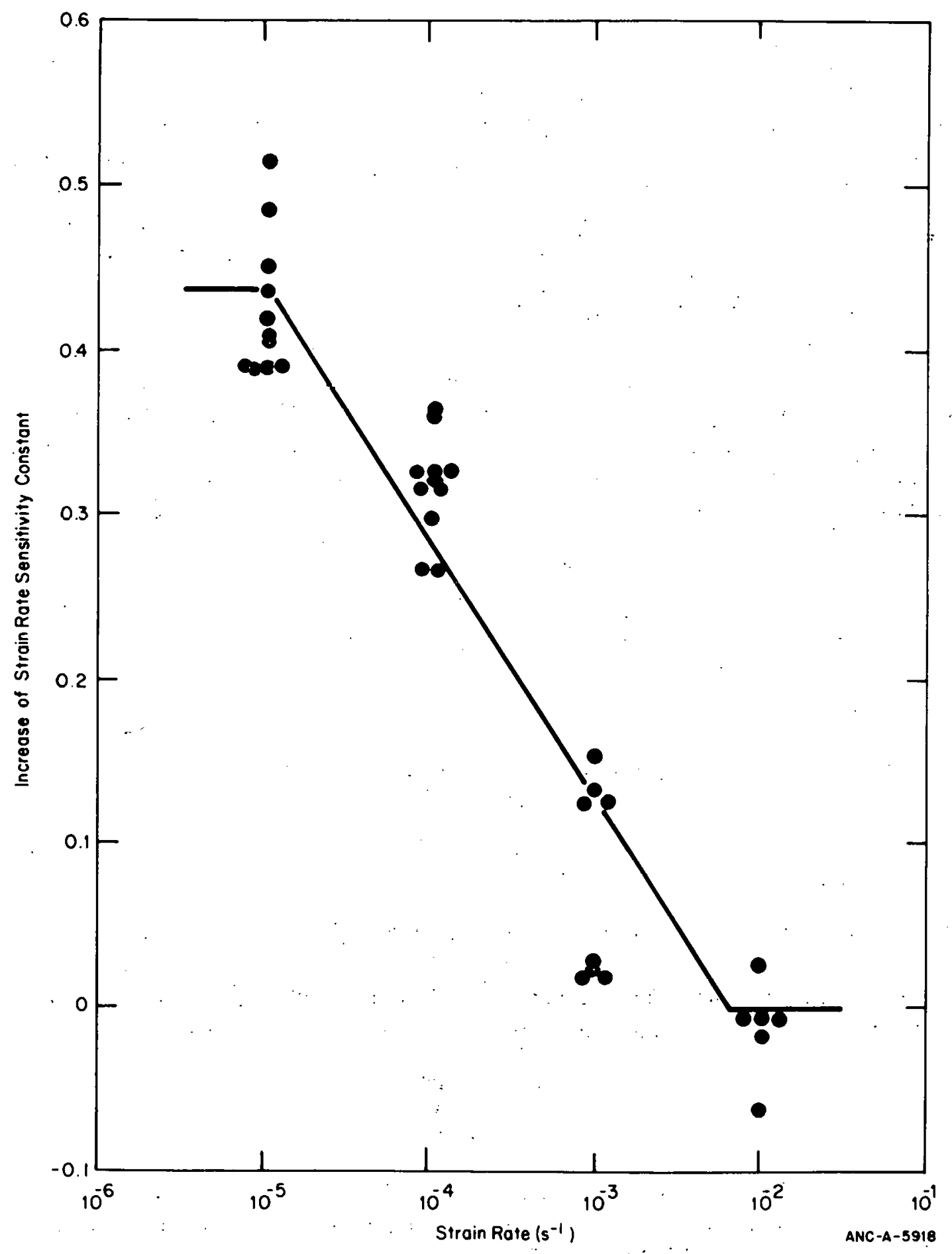

Fig. B-8.2 Increase in the strain sensitivity constant at $1173 \mathrm{~K}$ as a function of strain rate shown with the expression used for this increase in MATPRO. 
In the present model it is assumed that the value of m increases linearly from its value at the edges of the alpha-beta transition region to a maximum at $1173 \mathrm{~K}$ in the center of the region as shown in Figure B-8.1. Further data on values of $m$ as a function of temperature and strain rate in the alpha-beta transition region will be required if this crude expression is to be refined.

Values for $\mathrm{K}$ and $\mathrm{n}$ as a function of temperature from room temperature to 775 kelvins are based on data from tensile tests on zircaloy 4 tubes ${ }^{[B-8.1]}$. The effects of varying amounts of cold work and stress relief in the tubing tested were included by using the models described in the next section for changes in $\mathrm{K}$ due to cold work and annealing prior to: determining the temperature dependence of K. Similarly the effects of different strain rates were taken into account with the model discussed in previous paragraphs of this section [a]. The data for $K$, modified to represent annealed tubing, are shown in Figure B-8.3 along with the least squares fit polynomial used to describe the complex behavior of the 64 data points below 794.9814 kelvins.

Values of $\mathrm{K}$ above 755 kelvins were calculated from ultimate tensile strength (presumed $=$ maximum engineering strength) of $\cdot$ Reference B-8.5 and Reference B-8.3. In order to estimate $\mathrm{K}$ it is assumed in Equation (B-8.3) that $\epsilon=\mathrm{n}$ when the engineering stress is maximum $[\mathrm{b}]$. Thus Equation (B-8.3) at maximum engineering stress can be rewritten using Equation.(B-8.1) to give:

$$
K=\frac{\sigma_{u l t i m a t e}}{n^{n}\left(\frac{\dot{\varepsilon}}{10^{-3} / s}\right)^{m}}=\frac{S_{\max } \exp (n)}{n^{n}\left(\frac{\dot{\varepsilon}}{10^{-3} / s}\right)^{m}}
$$

where

$$
\begin{array}{ll}
S_{\max }= & \begin{array}{l}
\text { the maximum engineering stress as defined } \\
\text { in Fulutilon (B-8.1) }
\end{array} \\
\sigma_{\text {ultimate }}= & \text { the ultimate tensile strength. }
\end{array}
$$

The other symbols are defined in conjunction with Equation (B-8.3).

[a] Strain rate and annealing effects were removed from $\mathrm{K}$ as follows: First, $\mathrm{K}^{\prime}$ as given by. Reference B-8.1 for use in the expression $\sigma=K^{\prime} \epsilon^{n}$ was redefined to be equal to.

$$
K^{\prime}=K\left(\frac{\dot{\varepsilon}}{10^{-3 / s}}\right)^{m i} \text {. }
$$

Then the fractional change in $\mathrm{K}$ expected from varying amounts of cold work and anncaling was removed to give values for the $\mathrm{K}$ of annealed tubing consistent with the model adopted by MATPRO for the effects of cold work and annealing.

[b] For a discussion of this assumption see page 34 of Reference B-8.7. 


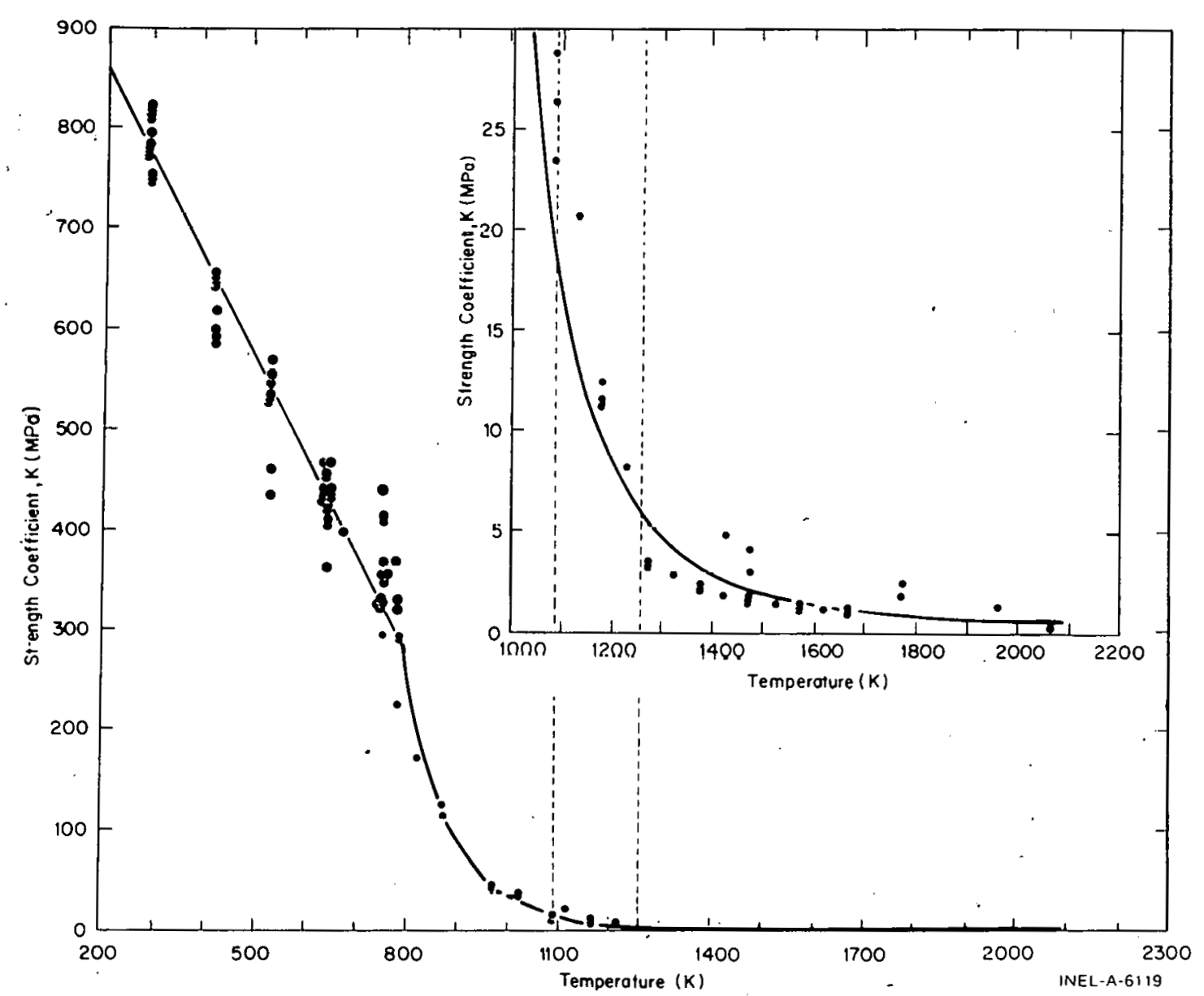

Fig. B-8.3 Data for K, modified to represent annealed tubing with the analytical expressions used in MATPRO to represent $\mathrm{K}$ as a function of temperature.

The expression for $\mathrm{n}$ as a function of temperature is based on a least squares fit to data reported in Reference B-8.1. Effects of cold work and an incomplete anneal on the values of $n$ are approximated simply by multiplying the fit to data taken with $70 \%$ coldworked and stress-relieved material by a factor of 1.38 in order to approximate values of $n$ obtained with fully annealed zircaloy. Figure B-8.4 shows the base data from stress relieved tubes and the curves generated by the expressions used to represent both the stress-relieved value of $\mathrm{n}$ (left side scale) and annealed values of $\mathrm{n}$ (right side scale).

Above $755 \mathrm{~K}$ the value of $\mathrm{n}$ would be expected to decrease to zero near the alpha-beta phase transition. However, recent results $[\mathrm{B}-8.7, \mathrm{~B}-8.8]$ have indicated that the behavior may be more complex. In the current mechanical properties model the quadratic expression which was fit to data from 300 to $755 \mathrm{~K}$ is continued to $850 \mathrm{~K}$ where the value of $\mathrm{n}$ is 0.028 for annealed zircaloy. Above this temperature, $n$ is assumed to be constant and equal to 0.028 . The present version of MATPRO does not set $n=0$ because several of the FRAP codes $[\mathrm{B}-8.9, \mathrm{~B}-8.10]$ which use MATPRO become unstable for very small values of $n$. 


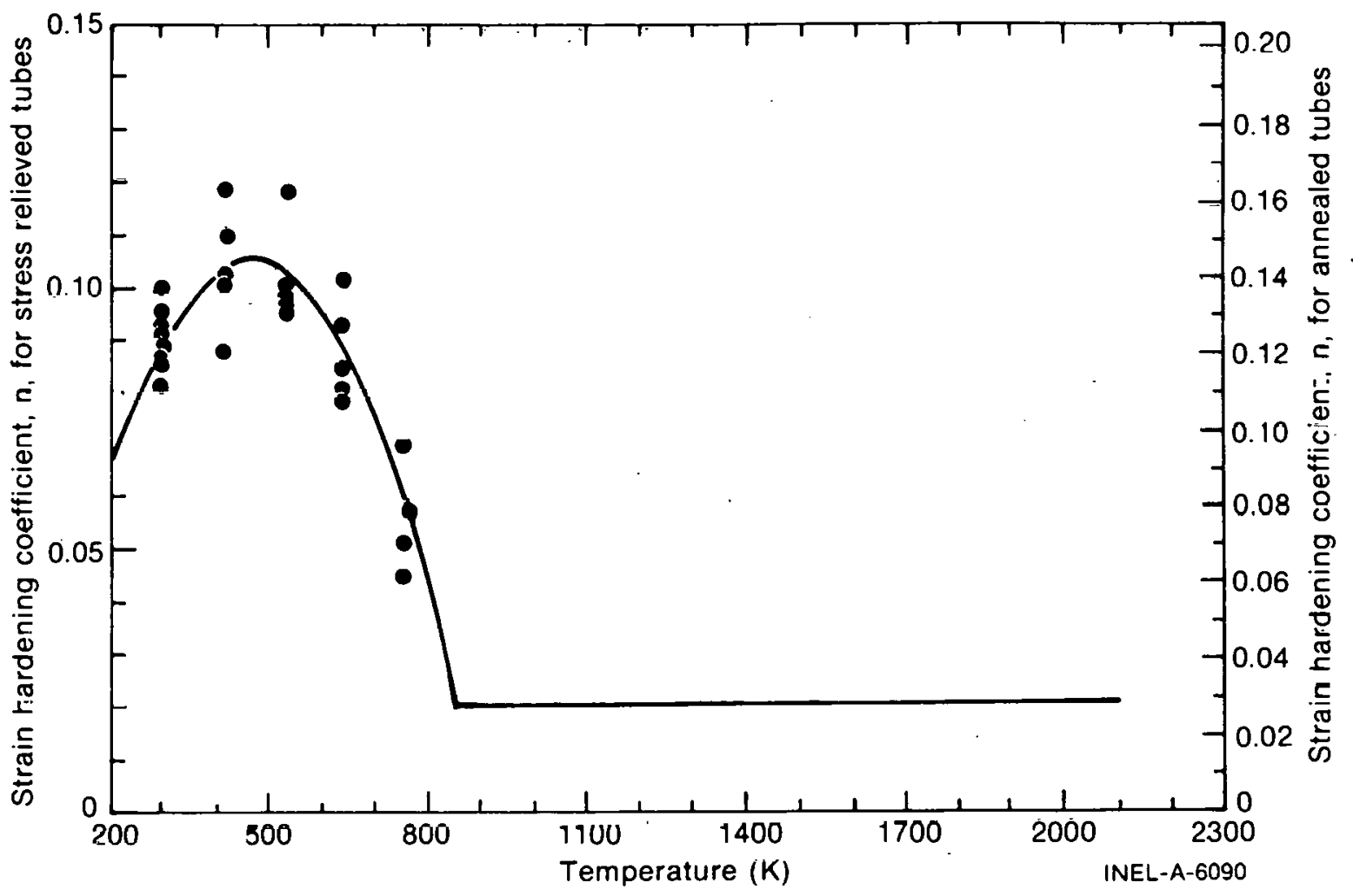

Fig. B-8.4 Base data and the expression used to represent the strain hardening exponent for annealed tubes.

\subsection{Effects of Irradiation, Cold Work, and Annealing}

Extensive testing to determine the effect of irradiation and cold work on zircaloy mechanical properties at room temperatures has been carried out by Bement ${ }^{[\mathrm{B}-8.6]}$. Unfortunately, published tests at high temperatures $[\mathrm{B}-8.11 \mathrm{~B}-8.13]$ do not yet include a similar series of tcsts in a single supply of material. Thus variation in mechanical properties due to uncharacterized differences in the materials such as different textures ${ }^{[B-8.14]}$ or different grain sizes [B 8.13], have caused considerable scatter among the high temperature data. It was thcrcfore decided to base the present model primarily on the data from Refererice B-8.6, using ratios to describe the complex effects of irradiation and cold work.

8.3.1 Effects of Cold Work on the Strength Coefficient. Values of a strength coefficient $[\mathrm{a}]$ from Reference B-8.6 are plotted in Figure B-8.5. Although texture effects are evident in annealed material and irradiation does tend to increase the strength coefficient slightly, the dominant correlation is a linear increase in the strength coefficient with cold work. A linear least squares fit yields the room temperature correlation for the strength coefficient $\mathrm{K}^{\prime}$, (MPa):

$$
K^{\prime}=624.4+341 . \text { COLDW }=624.4(1+0.546 \text { COLDW })
$$

[a] Defined in conjunction with the equation $\sigma=\mathrm{K}^{\prime} \epsilon^{\mathrm{n}}$ and therefore somewhat lower than the values represented in Figure B-8.3. 


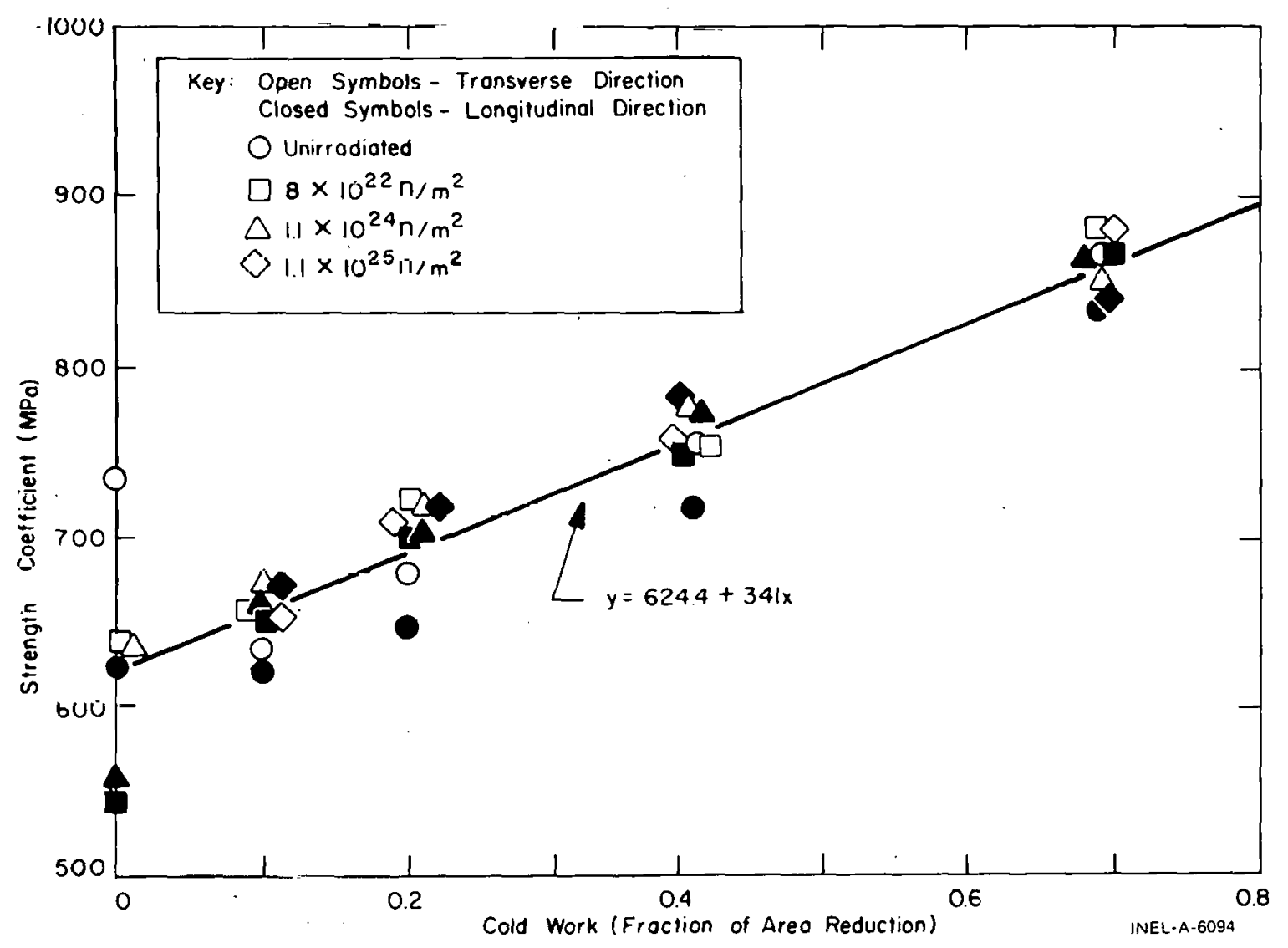

Fig. B-8.5 Data and least-squares fit to strength coefficients as a function of cold work and irradiation at ambient temperature.

where

$$
\text { COLDW }=\quad \text { the cladding cold work }
$$

In order to estimate the effect of temperature on this correlation, values of the strength coefficient determined from the limited data from References B-8.11 and B-8.12 at temperatures of 553 and $573 \mathrm{~K}$ were also fit to a straight line with the resultant correlation:

$$
K^{\prime}=373+238 \text { COLDW }=373(1+0.64 \text { COLDW }) \text {. }
$$

Comparison of the two results shows that they are consistent with a temperature dependent expression of the form:

$$
K^{\prime}=K^{\prime}(T)[1+\text { constant COLDW }]
$$

where

$$
\begin{aligned}
K^{\prime}(T)=\quad \text { the temperature dependent function describing the } \\
\text { behavior of the strength coefficient of annealed } \\
\text { zircaloy [Equation }(B-8.4)]
\end{aligned}
$$




\section{CSTRES/CSIGMA}

The form of Equation (B-8.14) has therefore been assumed. The constant coefficient of the cold work term is taken to be the value 0.55 as determined at room temperature since the room temperature data exhibit much less scatter than the high temperature data which were taken from several different sources.

8.3.2 Effect of Cold Work on the Strain Hardening Exponent. Figure B-8.6 illustrates the effect of cold work and irradiation on the strain hardening exponent, $n$, as determined at room temperature in Reference B-8.6. The strain hardening exponent of unirradiated materlal shown in Figure B-8.6 can be described by the empirical relation

$$
n=0.111 \exp (-39.2 \text { COLDW })+0.03(\text { COLDW })^{2}-0.12(\text { COLDW })+0.021 \text {. }
$$

This expression is essentially a decreasing exponential function for small values of cold work and a slowly increasing parabola for large values of cold work.

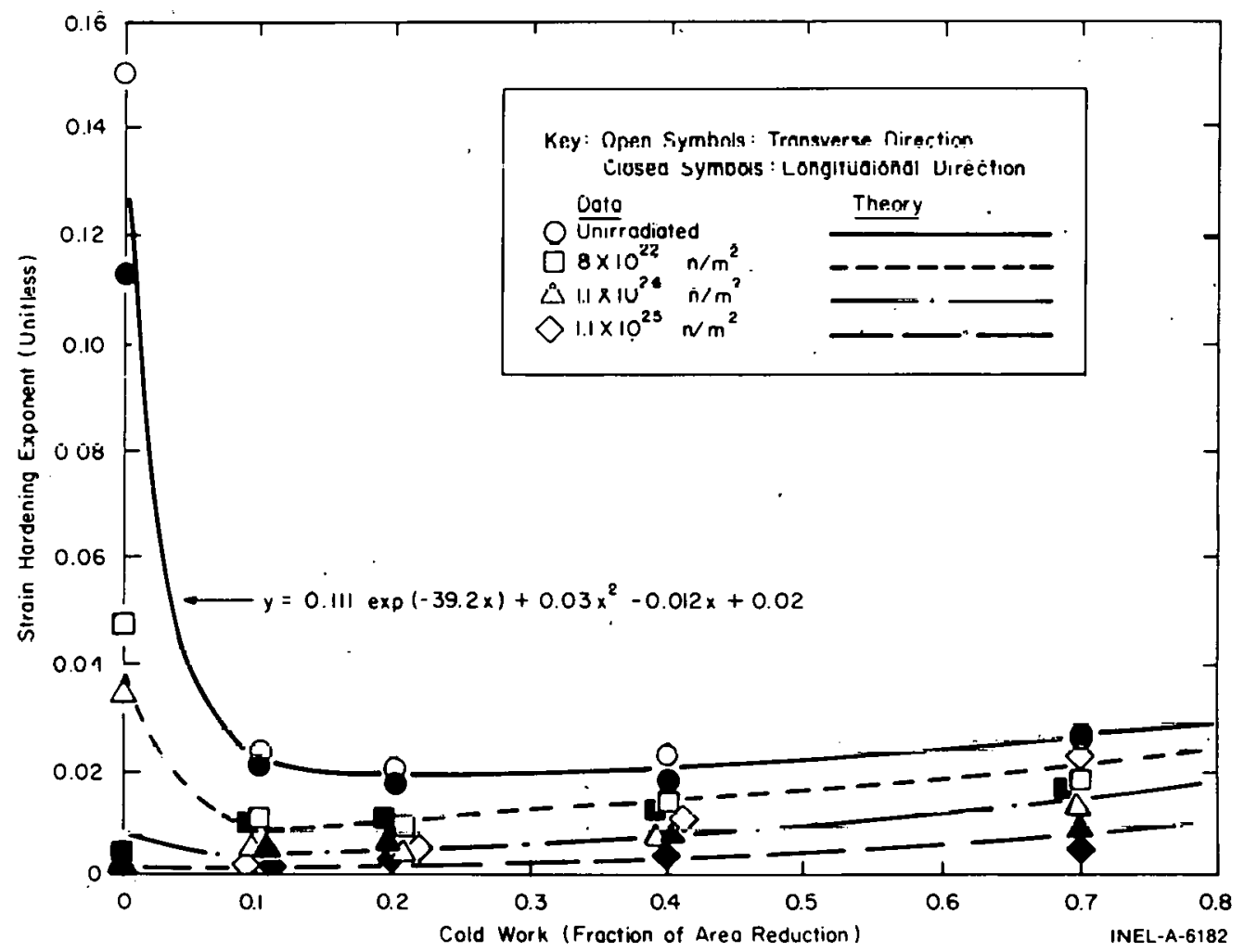

Fig. B-8.6 Data and analytical functions for strain hardening coefficient as a function of cold work and irradiation at ambient temperature.

At higher temperatures, trends exhibited by the limited and scattered values of $n$ (which have been obtained at $553 \mathrm{~K}^{[\mathrm{B}-8.11]}$ and $573 \mathrm{~K}^{[\mathrm{B}-8.12]}$ ) are consistent with the assumption that the fractional changes in $\mathrm{n}$ with cold work are similar to the fractional changes in $\mathrm{n}$ at room temperature. Thus the following functional relationship is assumed for the present model:

$$
n(\text { temperature, cold work })=n(\text { temperature }) \frac{n(\text { cold Work })}{n(\text { at } 0 \text { cold Work })} \cdot
$$


When the expression for $\mathrm{n}$ as a function of cold work, given by Equation (B-8.15), is substituted into Equation (B-8.16), then for unirradiated zircaloy:

$n=n(T)\left[\frac{0.111 \exp [-39.2(\text { COLDW })]+0.03(\text { COLDW })^{2}-0.012(\text { COLDW })+0.021}{0.132}\right]$

where $n(T)$ is given by Equation (B-8.4).

8.3.3 Effects of Irradiation on $\mathrm{K}$ and $\mathrm{n}$. The effect of irradiation on the strength coefficient was illustrated in Figure B-8.5. Although irradiation tends to increase the strength coefficient, the increase is small and the data show no consistent pattern. Effects of irradiation on the strength coefficient are therefore not modeled.

The effect of irradiation on the size of the strain hardening exponent, $\mathrm{n}$, is complex. Figure B-8.6 shows that the fractional change in $n$ due to irradiation at $333 \mathrm{~K}$ is large in annealed material and somewhat less in material that has been heavily cold worked. Furthermore, the effect of irradiation is highly nonlinear. Increasing amounts of irradiation produce continually decreasing changes in $\mathrm{n}$.

These features are described empirically in the irradiation model by expressing the ratic of the value of $n$ after irradiation to the value of $n$ before irradiation as an exponential multiplier with a moderating cold work dependent term in the argument of the exponent. The strain hardening exponent of irradiated material is then

$$
n=n(\text { unirradiated }) \exp \left[-(\text { fluence })^{1 / 3} /(A+B \text { COLDW })\right]
$$

where

$$
\begin{aligned}
& \left.A=3.73 \times 10^{7} \text { (neutrons } / \mathrm{m}^{2}\right)^{1 / 3} \\
& \left.B=2.0 \times 10^{8} \text { (neutrons } / \mathrm{m}^{2}\right)^{1 / 3}
\end{aligned}
$$

and n(unirradiated) is defined in Equation (B-8.17).

This model is assumed to be valid up to thermal annealing temperatures [B-8.10].

8.3.4 Thermal Annealing of Cold Work and Irradiation Damage. Only crude estimates of the effects of thermal anneding on cold work and irradiation-induced changes are available in the literature. Pickman ${ }^{[\mathrm{B}-8.15]}$ has commented that most irradiation effects anneal out at $653 \mathrm{~K}$, and Reference B-8.12 shows annealing curves for irradiation damage which demonstrate annealing at about $700 \mathrm{~K}$. The comparison of ultimate tensile strength data on stress-relieved tubing with tensile strength data from annealed material [B-8.5] shows that differences due to cold work which are present at $700 \mathrm{~K}$ are completely annealed out at $866 \mathrm{~K}$. Thus cold work and irradiation effects anneal over different temperature ranges. 


\section{CSTRES/CSIGMA}

The limited data on the effects of annealing are approximated by "turning off" the irradiation effects (i.e., the fluence) as a linear function of maximum temperatures between 550 and $700 \mathrm{~K}$. Similarly the cold work is "turned off" over the range from 775 to $850 \mathrm{~K}$. The minimum temperature was then determined to be consistent with the linear model developed in Section B-8.3.3 for the cffects of cold work on $K^{\prime}$, with the values of $K^{\prime}$ for $70 \%$ cold-worked tubes which had been stress relieved at $783 \mathrm{~K}^{[\mathrm{B}-8.1]}$, and with values of $\mathrm{K}^{\prime}$ lor the tubes which had been annealed at $922 \mathrm{~K}^{[\mathrm{B}-8.1]}$. The model is preliminary, both because the temperature dependence of annealing is approximate and because no considerntion is given to the time spent at maximum lemperaturc.

\subsection{Examples of CSTRES Output}

Predicted values for true and engineering stress as a function of true strain at several temperatures and a strain rate of $10^{-3} / \mathrm{s}$ are presented in Figure B-8.7. The figure represents fully annealed tubing, and the stress at 300 and $600 \mathrm{~K}$ is noticeably less than the stress predicted for cold-worked and stress-relieved tubing normally uscd in pressurized water reactors.

Figure B-8.8 illustrates predicted effects of cold work and irradiation on the true stress-true strain curve at $600 \mathrm{~K}$ and a strain rate of $10^{-3} / \mathrm{s}$. Yield points and rupture points as predicted by the subroutine CMLIMT are included in the figure only to complete the illustration. The subroutines CSTRES and CSIGMA will calculate and return stresses even if the input strain is larger than the rupture strain. However, in CSTRES, values of stress are limited to a maximum of 1.01 times the values predicted for a strain of unity.

The predicted effect of strain rate is illustrated by Figure B-8.9 which presents true stresses predicted for strain rates from $10^{-5}$ to $10^{-1} / \mathrm{s}$ at $900 \mathrm{~K}$. For strain rates outside these limits, CSTRES defaults to the nearest strain rate within this range, so the curves for strain rates of $10^{-5}$ to $10^{-1} / \mathrm{s}$ bound the predicted values of true stress at $900 \mathrm{~K}$. The relation between temperature and strain rate effects can be estimated by noting that the strain rate sensitivity constant predicted at $900 \mathrm{~K}$ by CSTRES is 0.134 . The predicted strain rate sensitivity constant increases with increasing temperature to values of nearly 0.4 at the melting point and to values of 0.63 for low strain rates at the center of the alpha-beta phase transition (see Figure B-8.1).

\subsection{Cladding Stress Subcodes CSTRES and CSIGMA Listings}

Listings of the FORTRAN subcodes CSIGMA for calculating true stress and CSTRES for calculating both true and engineering stress as a function of true strain are given in Tables B-8.I and B-8.II respectively.

\section{$8.6 \underline{\text { References }}$}

B-8.1. C. C. Busby, "Longitudinal Uniaxial Tensile and Compressive Properties," Properties of Zircaloy-4 Tubing, WAPD-TM-585 (December 1966). 


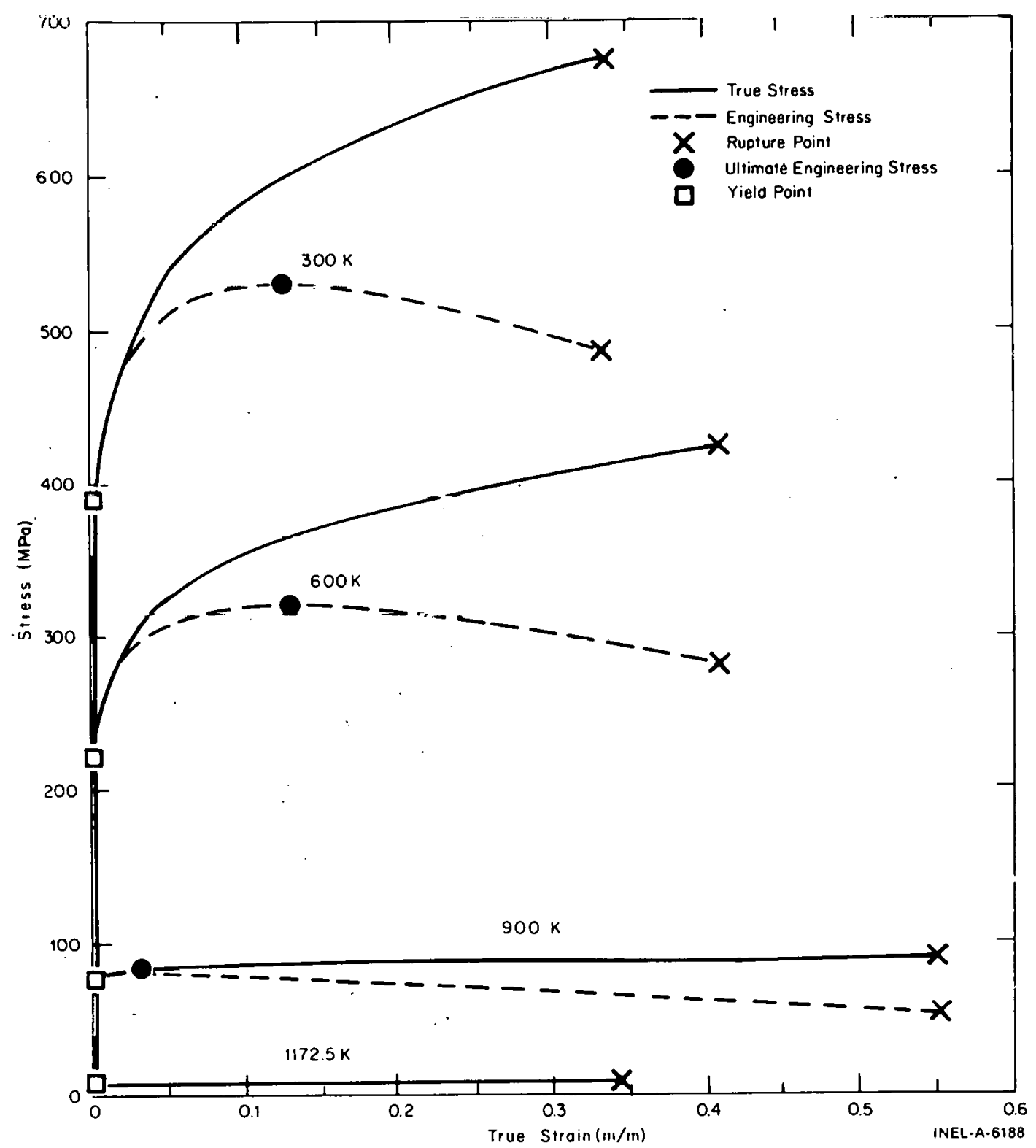

Fig. B-8.7 Predicted values of true and engineering stress as a function of true strain at a strain rate of $10^{-3} / \mathrm{s}$ and several temperatures.

B-8.2. H. M. Chung, A. M. Garde, T. F. Kassner, Light-Water-Reactor Safety Research Program: Quarterly Progress Report, April-June 1975, ANL-75-58 (June 13, 1975).

B-8.3. R. L. Mchan and F. W. Wiesinger, Mechanical Properties of Zircaloy-2, KAPL 2110 (February 1, 1961).

B-8.4. D. Lee and W. A. Backofen, "Superplasticity in Some Titanium and Zirconium Alloys," Transactions of the Metallurgical Society of AIME,239 (July 1967) pp 1034-1040. 


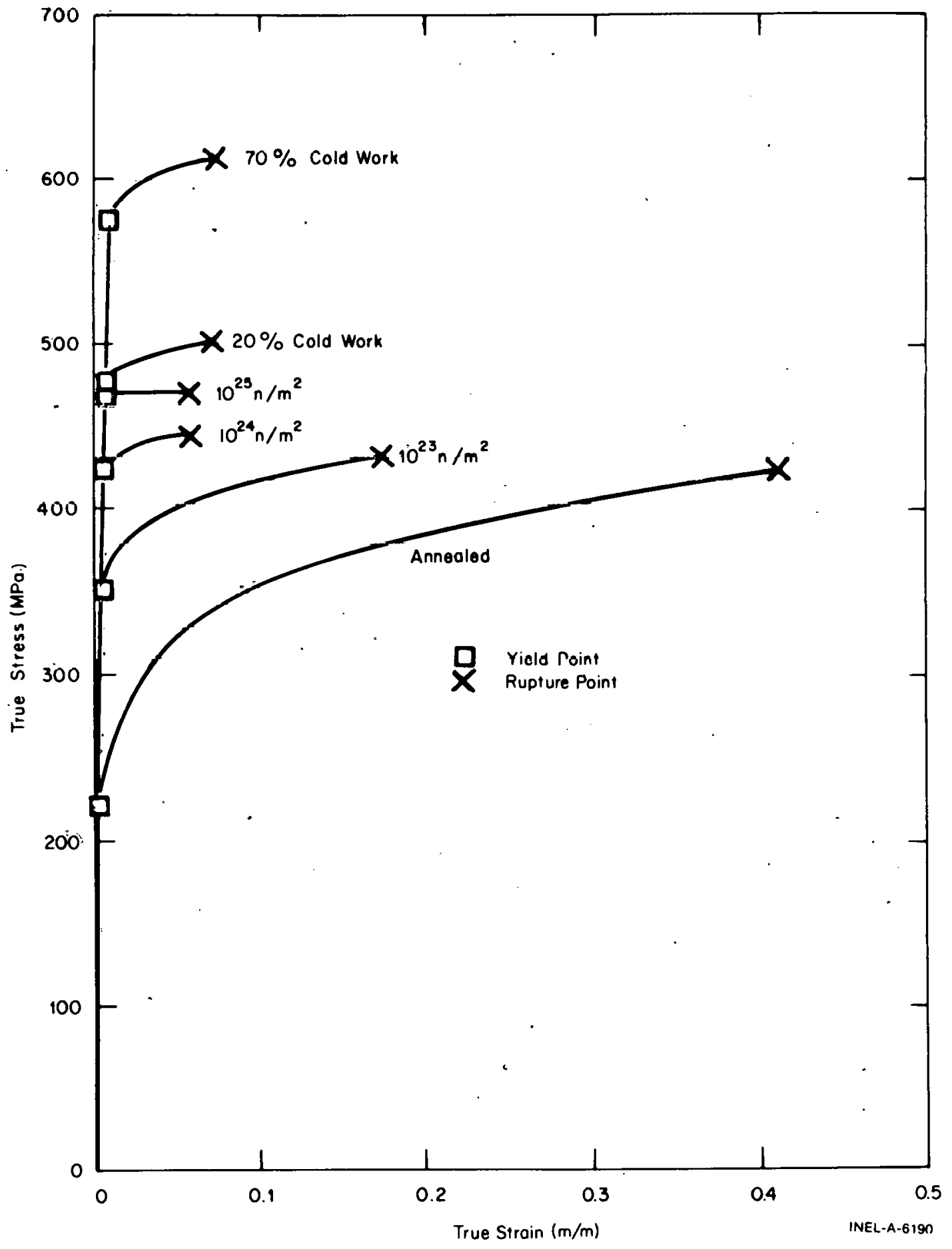

Fig. B-8.8 Effects of cold work or irradiation on true stress predicted by CSTRES at a temperature of $600 \mathrm{~K}$ and a strain rate of $10^{-3} / \mathrm{s}$. 


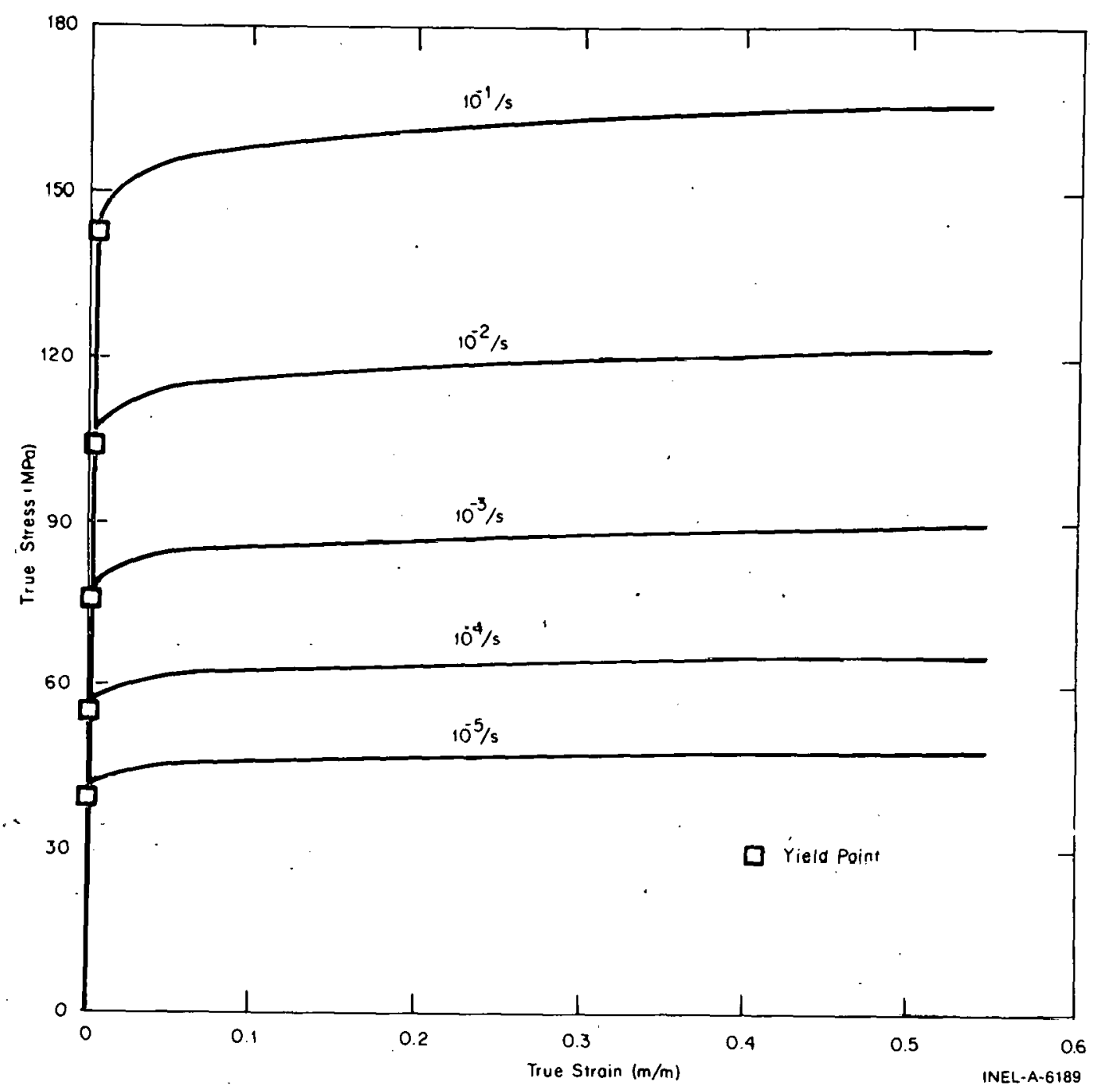

Fig. B-8.9 True stress versus true strain for several constant strain rates at $900 \mathrm{~K}$.

B-8.5. H. C. Brassfield et al, Recommended Property and Reaction Kinetics Data for Use in Evaluating a Light-Water Cooled Reactor Loss-of-Coolant Incident Involving Zircaloy-4 or 304-SS-Clad $\mathrm{UO}_{2}$, USAEC GEMP-482 (April 1968).

B-8.6. A. L. Bement, Jr., Effects of Cold-Work and Neutron Irradiation on the Tensile Properties of Zircaloy-2, HW-74955 (April 1.963).

B-8.7. H. M. Chung, A. M. Garde, T. F. Kassner, Light-Water-Reactor Safety Research Program: Quarterly Progress Report, January-March, 1975, ANL-75-28 (June 12, 1975).

B-8.8. H. M. Chung, A. M. Garde, T. F. Kassner, Light-Water-Reactor Safety Research Program: Quarterly Progress Report, July-September 1975 ANL-75-72. 


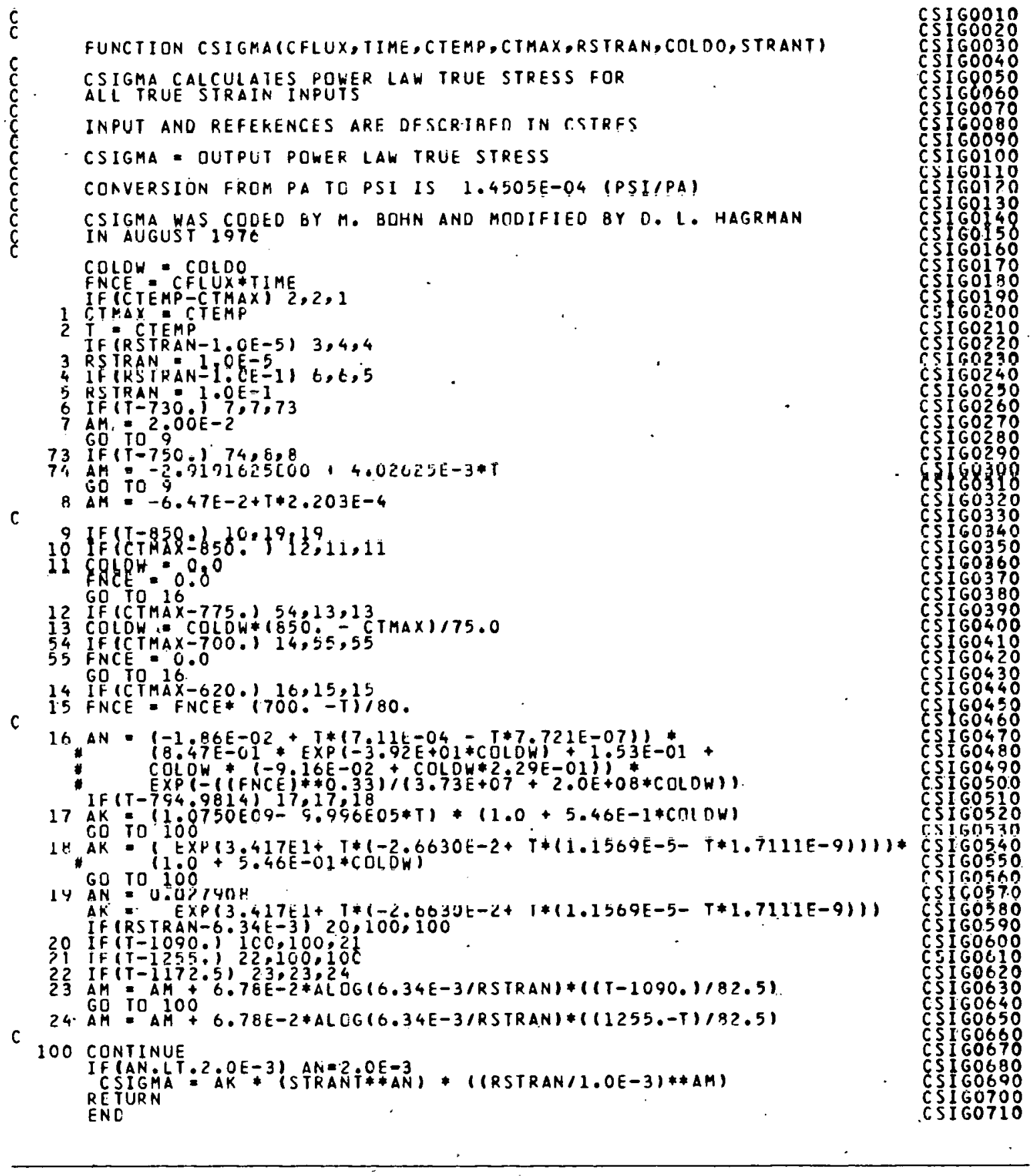




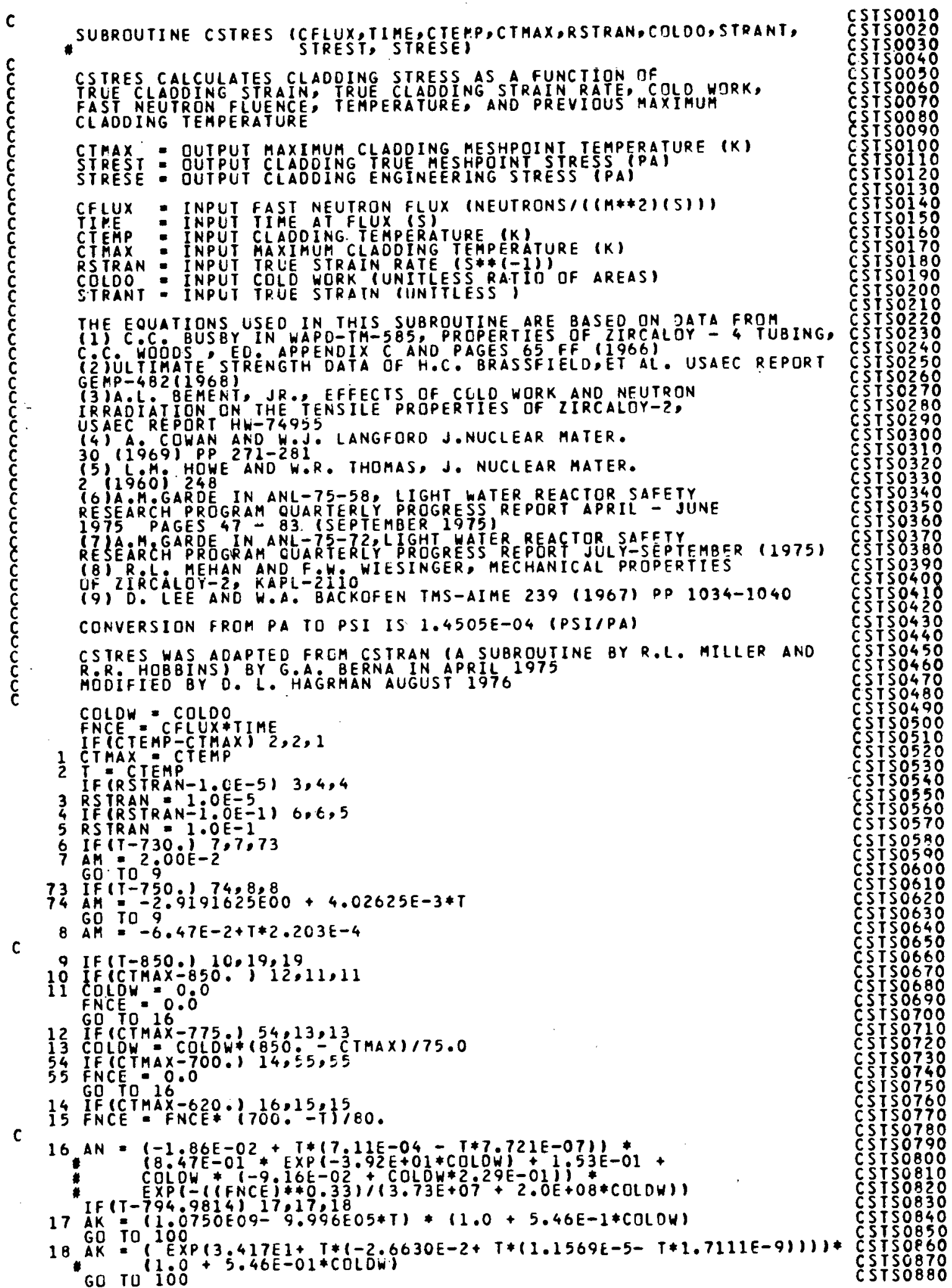




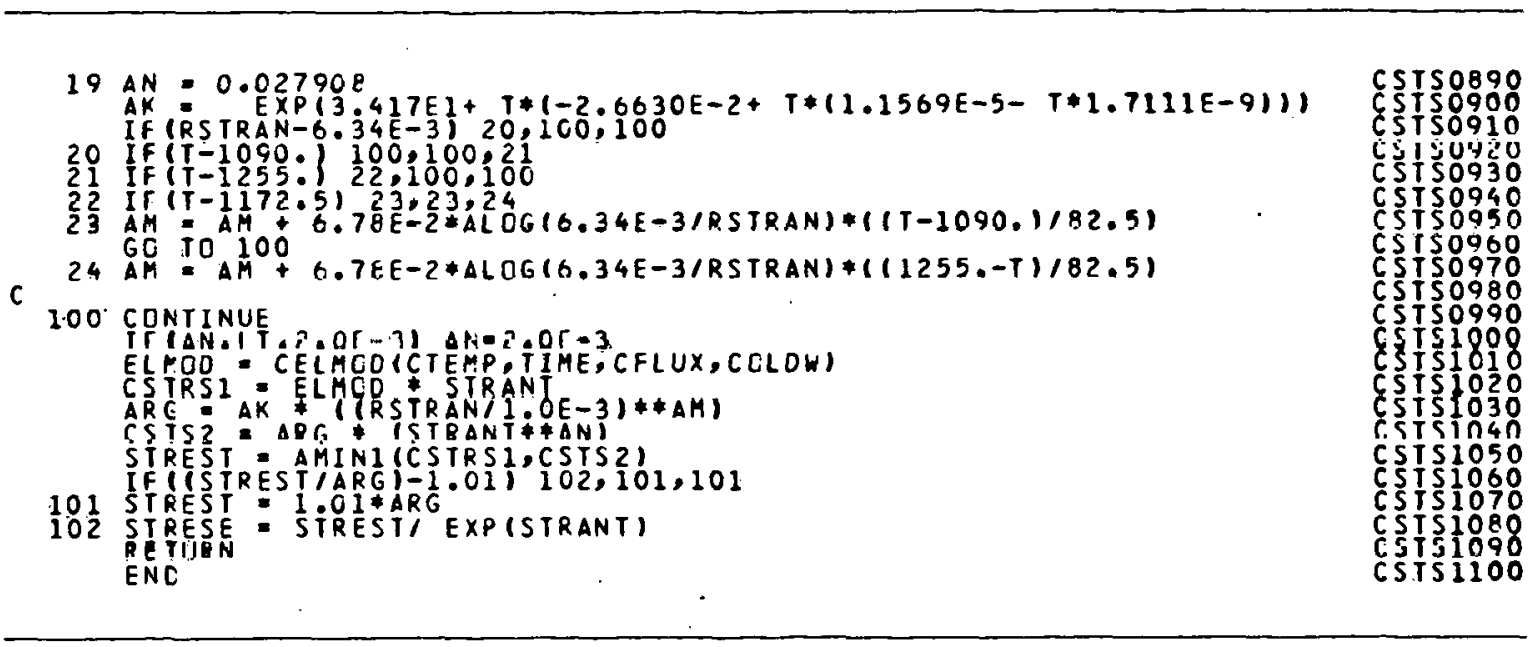

B-8.9. J. A. Dearien et al, FRAP-T2: A Computer Code for Transient Ánalysis of Oxide Fuel Rods, TREE-NUREG-1040 (March 1977).

B-8.10. J. A. Dearien et al, FRAP-S2: A Computer Code for the Steady State Analysis of Oxide Fuel Rods, TREE-NUREG-1 107 (July 1977).

B-8.11. A. Cowan and W. J. Langford, "Effects of Hydrogen and Neutron Irradiation on the Failure of Flawed Zircaloy-2 Pressure Tubes," Journal of Nuclear Materials, 30 (1969) pp 271-281.

B-8.12. L. M. Howe and W. R. Thomas, "The Effects of Neutron Irradiation on the Tensile Properties of Zircaloy-2,"Journal of Nuclear Materials, 2 (1960) p 248-260.

B-8.13. G. J. Salvaggio, "Effects of Irradiation on Mechanical Properties," Properties of Zirculuy-4 Tubiny, WAPD-TM-585 (December 1966).

B-8.14. G. F. Fieger and D. Lee, "Strength and Ductility of Neutron Irradiated and Textured Zircaloy-2", in Zirconium in Nuclear Applications, ASTM-STP-551 (1973) pp 355-369.

B-8.15. D. O. Pickman, "Properties of Zircaloy Cladding," Nuclear Engineering and Design, 21, (1972) pp 21 2-236. 


\section{CLADDING STRAIN VERSUS STRLSS (C'SI'RAN)}

In this subroutine, strain is calculated as a function of true stress, true stress rate of change, cladding temperature, maximum previous cladding temperature, cold work, and fast neutron fluence. Both elastic and plastic stress-strain curves are consistent with the relations used in CSTRES and CSIGMA.

\subsection{Summary}

In CSTRAN all input values of stress are assumed to be true stress ${ }^{[a]}$ and the output values are true strain $[\mathrm{b}]$ which are converted to engineering strain ${ }^{[c]}$ by using the expression:

$$
\text { engineering strain }=\exp (\text { true strain })-1 \text {. }
$$

Both true and engineering strain are returned as output.

Two different equations are used to relate true strain to true stress. In the elastic region, Hooke's law is used:

$$
\varepsilon=\frac{\sigma}{E}
$$

where

$$
\begin{array}{lll}
\epsilon \quad & \text { true strain } \\
\sigma \quad= & \text { true stress } \\
\mathrm{E} & =\text { modulus of elasticity (calculated by CELMOD). }
\end{array}
$$

In the plastic region the relation

$$
\varepsilon=\left[\frac{\sigma}{k\left(\frac{\dot{\varepsilon}}{10^{3} / \mathrm{s}}\right)^{\mathrm{m}}}\right]^{\frac{1}{\mathrm{n}}}
$$

[a] True stress $=$ force per unit cross sectional area with the area determined at the instant of measurement (of the force).

[b] True strain = change in length divided by the length at the instant of change and integrated from initial to final length $\int_{L_{O}} \frac{\mathrm{d} \ell}{\ell}$.

[c] Engineering strain = change in length divided by the original length. 
where

$$
\begin{aligned}
& \mathrm{K}=\text { the strength coefficient }^{[\mathrm{a}]} \\
& \mathrm{n} \quad=\text { the strain hardening exponent } \\
& \dot{\epsilon} \quad=\quad \text { the true strain rate } \\
& \mathrm{m} \quad=\quad \text { the strain rate sensitivity constant }
\end{aligned}
$$

The transition from the elastic to the plastic region is defined to be the nonzero intersection of the curves resulting from Equations (B-9.2) and (B-9.3).

The method used in CSTRAN to determine $\dot{\epsilon}$ of Equation (B-9.3) is selected by user specification of an integer value for the variable KINDOR (kind of rate). A value of 1 instructs the subrouline to assume that $\dot{\sigma}$ represents a constant stress rate, and a value of 2 causes tho oubroutine to assumc and ealeulate a cunstanl sliain! late currespunding to the input value of $\dot{\sigma}$. A value of 3 causes CSTRAN to assume the given strain rate and ignore the input stress rate. For codes which employ time steps, the option KINDOR $=3$ with strain rate determined from the two previous solutions for strain is the preferred use of CSTRAN because this approach bypasses the complex steps necessary to estimate strain rate from stress ratc.

When the strain rate cannot be input from previous time steps, it is calculated from the solution of the time derivative of Equation (B-9.3) with strain rate assumed constant. For constant stress rates, the strain rate solutions assuming $\ddot{\epsilon}=0$ are used to estimate the strain rate. Details of the calculation of strain rate for both the constant strain rate case and the correction for constant stress rates are discussed in Section B-9.2.

For truc strain rates between $10^{-5} / \mathrm{s}$ and $6.35 \times 10^{-3} / \mathrm{s}$ in the temperalure range 1090 to $1255 \mathrm{~K}$ the strain rate sensitivity constant, $\mathrm{m}$, in Equation (B-9.3) is a function of $\dot{\epsilon}$ and:a more involved approach is needed to tind $\dot{\epsilon}$ and $m$, from the available input. In this temperature region (the alpha-beta phase transition), an iteration procedure is used in conjunction with the time derivative of Equation (B-9.3) to obtain values for $\dot{\epsilon}$ and $m$ when $\dot{\epsilon}$ is not input. Details of the iteration procedure are discussed in Section B-9.2.

Effects of cladding temperature, in-reactor annealing, cold work and, irradiation on mechanical properties are expressed as changes in the strength coefficient, $K$, the strain hardening exponent, $\mathrm{n}$, and the strain rate sensitivity constant, $\mathrm{m}$, of Equation (B-9.3).

[a] Expressions for these constants are discussed in the description of CSTRES and CSIGMA.

[b] Values of $\dot{\epsilon}$ are limited to the range of $10^{-5} / \mathrm{s}$ to $10^{-1} / \mathrm{s}$. 
'l'hese effects and the expressions for $\mathrm{K}, \mathrm{il}$, and $\mathrm{m}$ as a function of temperaturs, cold work, and irradiation are the same as discussed in the description of CSTRES in Section B-8.

\subsection{Computation of Strain Rate When It Is Not Input}

In order to ohtain an expression for $\dot{\epsilon}$ from input values of $\sigma$ and $\dot{\sigma}$ the time derivative of Equation (B-9.3) is used:

$$
\dot{\varepsilon}=\frac{1}{n}\left[\frac{\sigma}{k\left(\frac{\dot{\varepsilon}}{10^{-3}}\right)}\right]^{\frac{1}{n}}\left[\frac{\dot{\sigma}}{\sigma}-\frac{m}{\dot{\varepsilon}}\right] .
$$

For constant strain rate the second term, -m $\ddot{\epsilon} / \dot{\epsilon}$, is zero and the resultant expression in $\dot{\epsilon}$ carl be reduced to $[$ a]

$$
\dot{c}=10^{-3}\left[\left(\frac{10^{3}}{n}\right)\left(\frac{\dot{\sigma}}{K}\right)\right]^{\frac{1}{1+\frac{m}{n}}}\left(\frac{\sigma}{k}\right)^{\frac{1-n}{n+m}}
$$

which is the expression used in CSTRAN for finding the strain rate when a constant strain rate is assumed.

When $\ddot{\epsilon}$ is not zero the second term of Equation (B-9.4), -m $\ddot{\epsilon} / \dot{\epsilon}$, is approximated with constant strain rate values of $\dot{\epsilon}$ obtained from Equation (B-9.5) as follows: Constant strain rate values of $\dot{\epsilon}$ and $\epsilon$ are found with input values of $\sigma$ and $\dot{\sigma}$. Then $\epsilon$ is increased by $5 \%$, the corresponding new value of $\sigma$ is found with the expressions used in CSTRES, and Fquation (B-9.5) is again used to find $\dot{\epsilon}$ for the new value of $\sigma$ and the (presumed) constant value of $\dot{\sigma}$. Finally, $\ddot{\epsilon}$ is taken to be the change in the constant strain rate values of $\dot{\epsilon}$ divided by the time between the two values $[\mathrm{b}]^{\circ}$ and the appropriate correction term, -mö̈$/ \dot{\epsilon}$, is added to $\dot{\sigma}$ in Equation (B-9.4) before determining a constant stress rate value for $\dot{\epsilon}$ with Equation (B-9.5).

It should be noted that the term $-m \ddot{\epsilon} / \dot{\epsilon}$ in Equation (B-9.4) is a strictly mathematical description of the changing stress-strain contribution to $\dot{\epsilon}$. This version of MATPRO does not contain any information about the physical effects of nonconstant strain rates since the entire data base used to construct the stress-strain curves is taken from constant strain rate tests.

[a] A more concise lorm of the expression, $n \dot{n} / \mathrm{e}=\dot{\sigma} / \sigma$, is useful for checking the consistency of CSTRAN and CSTRES predictions but is of no direct use in the computation of strain rate because the strain is not known.

[b] For constant stress rate the time between the two values is

$$
\frac{\sigma_{\text {at }} 1.05 \varepsilon-\sigma_{\text {at } \varepsilon}}{\dot{\sigma}} \text {. }
$$


In the temperature range 1090 to $1255 \mathrm{~K}$ (the alpha-beta phase transition region), $\mathrm{m}$ in Equation (B-9.3) is a function of $\dot{\epsilon}$, so a more involved approach is needed. As discussed in conjunction with the CSTRES subroutine, the expression for $m$ is of the form:

$$
\dot{m}=f(T)+g(\dot{\varepsilon})
$$

where

$$
g(\dot{\epsilon})=\quad \begin{aligned}
& \text { zero for } \dot{\epsilon} \text { larger than } 6.35 \times 10^{-3} / \mathrm{s} \text { and increases with } . . \\
& \text { decreasing } \dot{\epsilon} \text {. }
\end{aligned}
$$

In order to find $m$, CSTRAN starts by using Equation (B-9:5) to find the value of $\dot{\epsilon}$ corresponding to the low value $m=f(1)$. This value of $\dot{\epsilon}$ is then used ${ }^{[a]}$ to find a revised value of $\mathrm{m}$ with Equation (B-9.6). The process is repeated through five iterations and the correction for constant stress rate discussed in the previous two paragraphs is applied at each iteration when the constant strés śs rate option is specified.

\subsection{Examples of CSTRAN Expressions}

Predicted values of true and engineering strain as a function of true stress at several temperatures are presented in Figure B-9.1: Predictions of the deformation behavior of fully annealed tubing at a constant strain rate of $10^{-3} / \mathrm{s}$ are presented. which correspond to the curves.of Figure B-8.8 in the description of CSTRES in Section B-8.

Figure B-9.2 illustrates the effect of different rates of stress at $900 \mathrm{~K}$. Solid curves represent $\cdot$ stress rates which vary to cause constant strain rates of $10^{-5}, 10^{-3}$, and $10^{-1} / \mathrm{s}$. The dashed curves illustrate the predicted strains for four different constant values of stress ratc. A discontinuity in the curves for constant stress rates of $10^{2} \mathrm{MPa} / \mathrm{s}$ and higher.is causcd by the artificial limit of $10^{-1} / \mathrm{s}$ imposed on all strain rates.

\subsection{Cladding Strain Subcode CSTRAN Listing}

A listing of the FORTRAN subcode CSTRAN used for calculating strain as a function of stress is given in Table B-9.I.

[a] Unless $\dot{\epsilon}$ should fall outside the range of $10^{-5} / \mathrm{s}$ to $10^{-1} / \mathrm{s}$. If $\dot{\epsilon}$ is outside this range, the nearest limit of the range is substituted for $\dot{\epsilon}$. 
CSTRAN

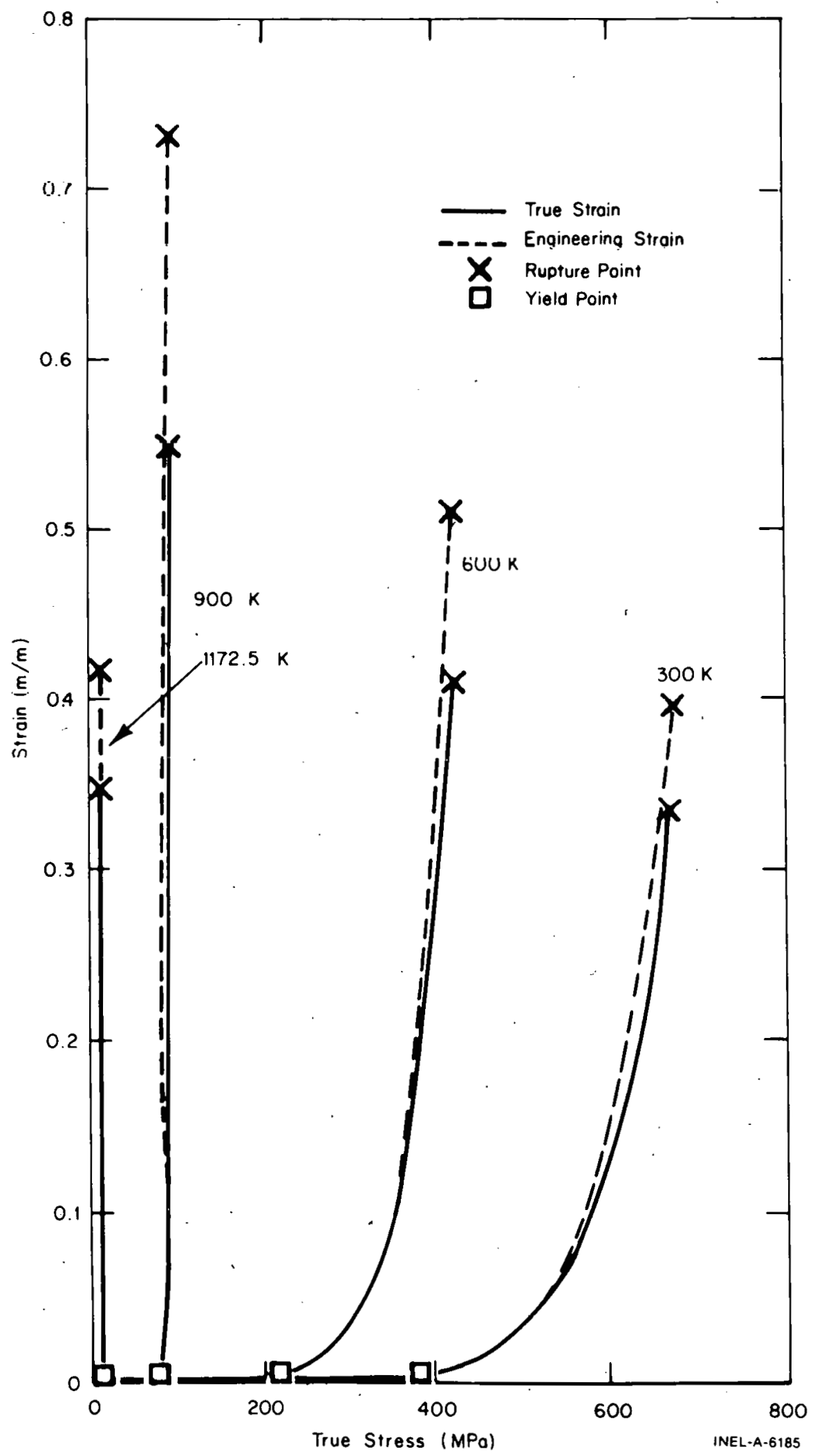

Fig. B-9.1 Values of true and engineering strain calculated by CSTRAN at several temperatures and a constant strain rate of $10^{-3} / \mathrm{s}$. 


\section{- CSTRAAN}

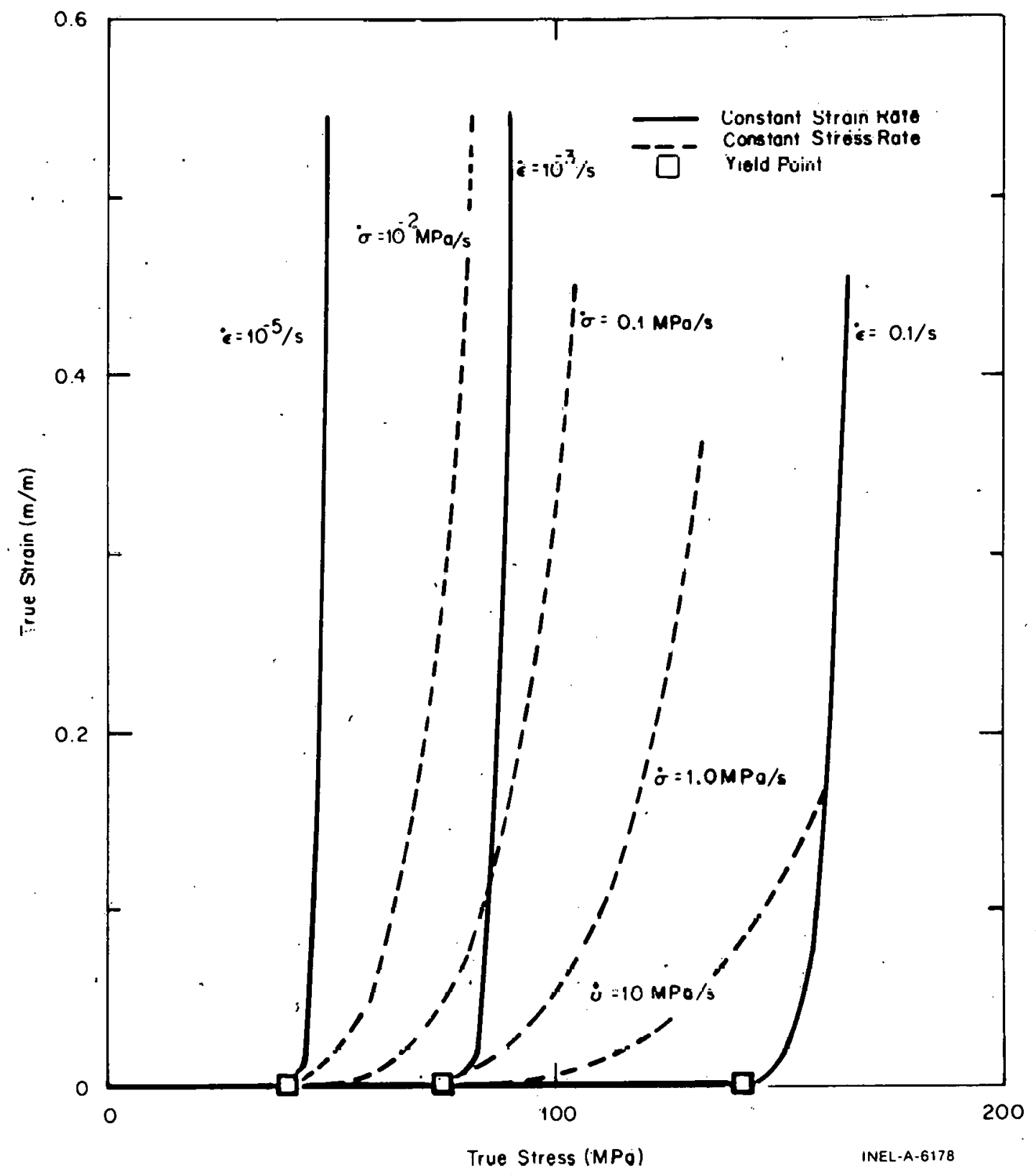

Fig. B-9.2 Effect of different constant rates of stress and strain on the values of true strain calculated by CSTRAN at $900 \mathrm{~K}$. 
TABLE B-9. I

LISTING OF THE CSTRAN SUBCODE

SUBRUUTINE CSTRAN ICFLUX,TIME,CTEMP,CTMAX,COLDO, KINDOR, STREST,

CSTRAN CALCULATES CLADOING STRAIN AS A FUNCTION DF

TRUE CLADDING STRESS, TRUE CLAODING STRESS RATE, COLD HORK, CLAT NEUTRORON FLUENCE

CTYAX : OUTPUT MAXIMUM TEMPERATURE (K)

RSTRAN: DUTPUT TRUE STRAIN RATE (S* + $(-1)$

STRANT : DUTPUT TRUE STRAIN IMIM)

CFLUX - INPUT FAST NEUTRON FLUX (NEUTRONS/ $(1 M *+2)(S) 1)$

TIME : INPUT IIME AT FIUX (S) INPUT CLADDING TEMPERATURE (K)

CIEMP : INPUT CLAOMUG CLAODING TEMTCRATURE (K)

CIMAX : INPUT HAXIMUH CLAODING TLMRERATURE IK

KINOOR = INPUT KIND OF RATE INDEX

1 : CONSTANI SIRESS RATE FROM INPUT STRESS RATE

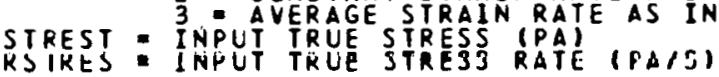

THE EOUATIONS USED IN THIS SUBRDUTINE ARE BASED ON DATA FROA

(1) C.C. BUSEY IN WAPD-TM-5B5, PROPERTIES OF ZIRCALOY - 4 TUBING, i JULTIMATE STRENGTH DATA DF H.C. BRASSFIELD,ET AL. USAFC REPORT GEPP-4B211968)

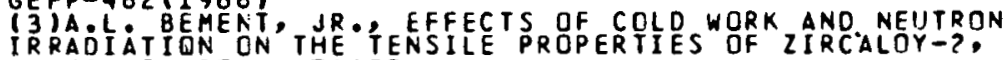

USAEC REPORT HW-74955

$(4)$ A. COWAN AND W.J. LANGFDRD J.NUCLEAR MATER.

$30271-281$ (1) 969$)$

$11960 \mathrm{i} 248$

M.R. THLMAS, J. NUCLEAR MATER.

TOA.M.GARDE IN ANL-75-58, LIGHT WATER REACTOR SAFETY

RESEARCH PROGRAM QUARTERLY PROGRESS REPORT APRIL - JUNE

1975 PAGES $47-83$ (SEPTEMBER 1975 )

(7)A.M.GARDE IN ANL-75-72,LIGHT WATER REACTOR SAFETY

RE SEARCH PROGRAM QUARTERLY PROGRESS REPORT JULY-SEPTEMBER

(8) R. L MEHAN AND F.W.WIESINGER, MECHANICAL PROPERTIES

(9) D. LEE ANO W.A. BACKOFEN TMS-AIME 239 1034-1040 (1967)

CONVERSION FROM PA TC PSI IS $1.4535 E-04$ (PSI/PA)

CSTRAN GRIGINALLY COOEO BY RL MILLER ANO PR HCBBINS MARCH 1974

COLDW - COLDO

FNCE CFLUX TIME

IF (CTEMP-CTMAX) $2,2,2$

1 CTMAX CTEMP

2 TIFTTEMP

7 IF TT-730: $7,7,7,73$

73 IF TT-750:1 $74,8,8$

74 AM E-2.919162EEOO + 4.02625E-3*T

$8 A M=-6.47 E-2+1 * 2.203 E-4$

9 If (T-850:\} 10, i9: i9:1,11

11 COLDW $=0.0$

$G 0$ TO 16

12 IF (CTMAX-775:) $54,13,13$ TMAX)/75.0

55 FNCE $=0.0$

$G \mathrm{GCE}=16$

14 IF ICTMAX-620.) $150,15,15,150$.

C

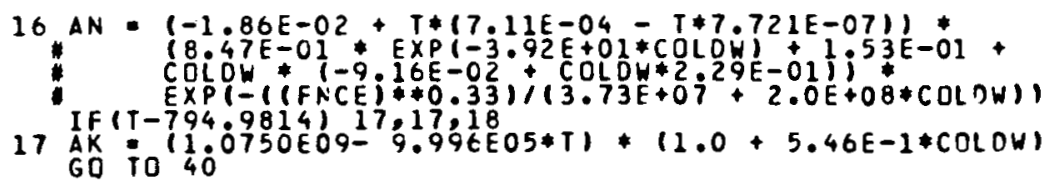

CSANOO10

CSANOO2O

CSANOO4O

C SANOO5O

C SANOOOO

SAN0080

¿ SANOOOO

CSANO100

CSANOIIO

CSANO 130

CSANOI 40

CSANOI 60

CSANO 170

CSANCI 80

CSANDIOO

CSANO200

CSANOZZO

C SANO230

C SANO240

CSANO250

C SANO270

C SANO2BO

C SANOZ9O

C SANO300

CSANO 320

CSANO330

CSANO 340

CSANO350

CSANO 370

CSANO 370
CSANU 380

CSANO390

CSANC 400

CSANO 110

CSANO 430

CSANO 440

CSANO450

C SANG 470

CSANC4

CSANO490

C SANO50O

C SANO510

C SANO520

CSANC530

C SANO 550

C SANOS6O

C SANO 580

C SANO 590

CSANO6OO

CSANO6O

CSANO 620

CSANOB 30

CSANO63\%

CSANO640

C SANO660

C SANO670

CSANOG8

C SANO69O

C SANO 700

C SANO710

CSANO 720

CSANO 730

CSANO 740

C SANO 750

CSANO76

CSANO 780

CSANO780
CSANO790

CSANO790

C SANOBOO

CSANOR2O

C SANO 830

CSANOB50 
C

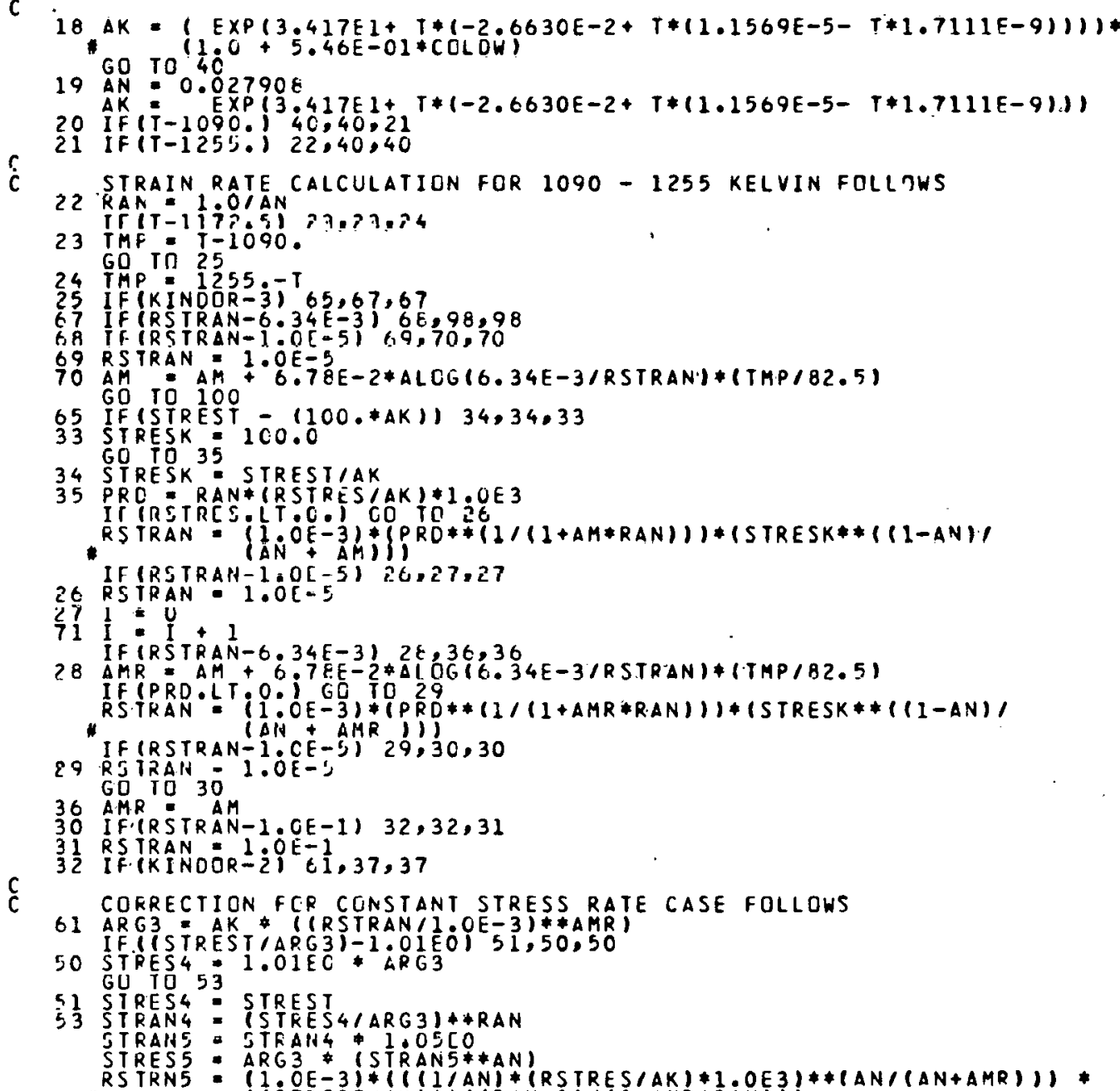


TAELE B-9.I (continued)

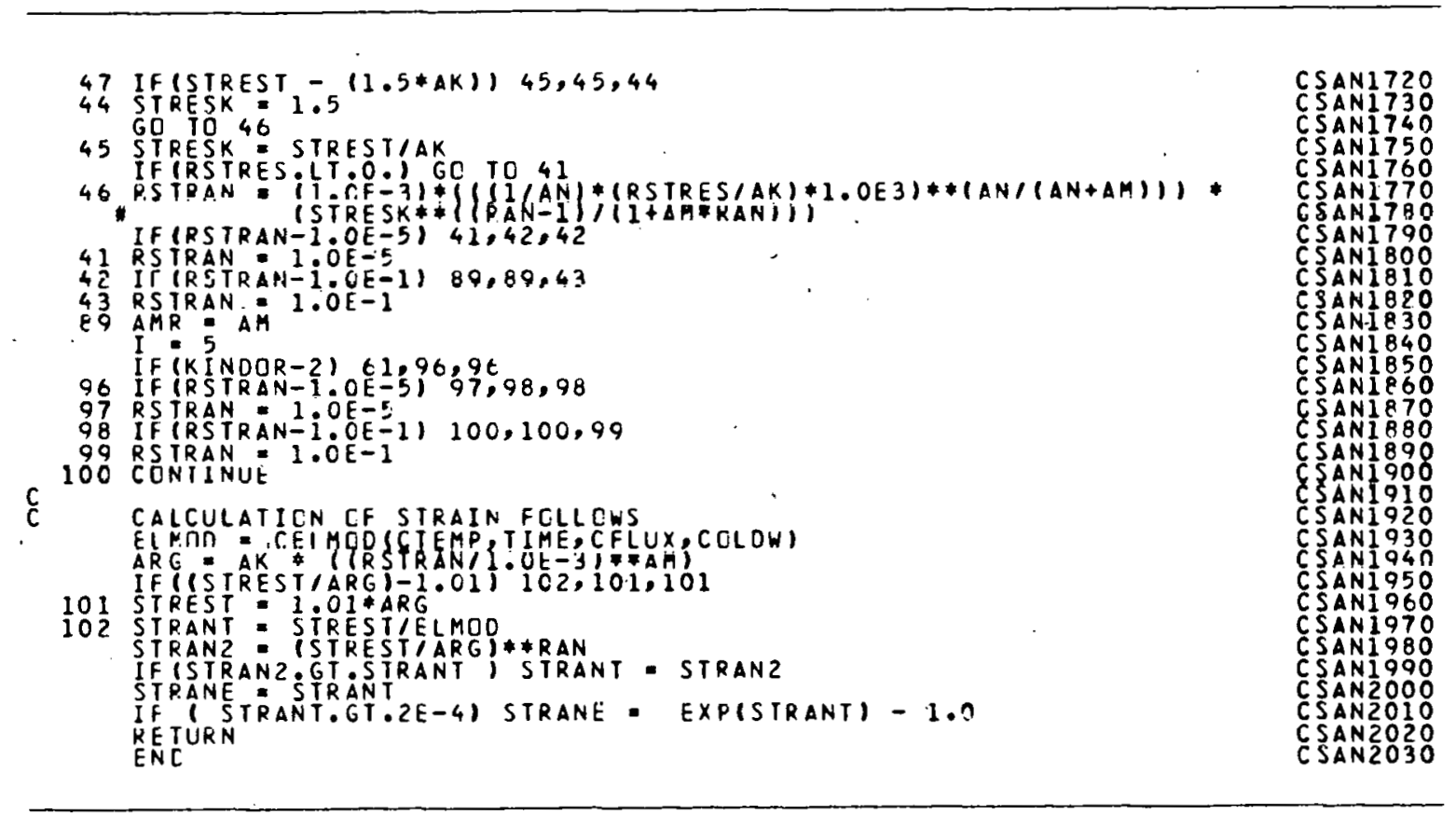

10. CLADDING MECHANICAL LIMITS (CMLIMT), CLADDING STRAIN

-AT RUPTURE (CSRUPT), AND CLADDING LOCAL STRAINS

$\underline{\text { AT RUPTURE (CLOCRP) }}$

Three subroutines are provided to describe zircaloy cladding mechanical limits, circumferential elongation at failure, and strain at rupture. The first, CMLIMT, calculates true and engineering values of strain at yield, instability strain, total circumferential strain at rupture, yield strength, and ultimate strength. The second, CSRUP'l', repeats the correlation for total circumferential strain at rupture and adds expressions for the uncertainty of the correlation. The third, CLOCRP, predicts local strains at failure of zircaloy cladding in the temperature range $1050-1370 \mathrm{~K}$. CMLIMT is designed for general use with fuel rod analysis programs while CSRUPT is designed specifically for use with subcodes which describe fuel rod integrity limits using a statistical approach. The CLOCRP subroutine is a preliminary code intended for use with models which predict local strains as a function of local temperature.

\subsection{Summary}

The required input information for CMLIMT is cladding temperature, maximum previous cladding temperature, cold work, fast neutron fluence ( $>1 \mathrm{Mev}$ ) and strain rate. The equations used by CMLIMT for true strain at yield, true yield strength, and true ultimate strength are: 


$$
\begin{aligned}
& \text { True Strain at Yiel] }=\left[\frac{K}{E}\left(\frac{\dot{\varepsilon}}{10^{-3}}\right)^{m}\right]^{\frac{1}{1-n}} \\
& \text { True Yield Strength }=\left[\frac{K}{E^{\prime \prime}}\left(\frac{\dot{\varepsilon}}{10^{-3}}\right)^{m}\right]^{\frac{1}{1-n}} \\
& \text { True Ultimate Strength }=k\left(\frac{\dot{\varepsilon}}{10^{-3}}\right)^{m} n^{n}
\end{aligned}
$$

where

$$
\begin{aligned}
& \mathrm{K}=\text { strength coefficient } \\
& \mathrm{n}=\text { strain hardening exponent } \\
& \dot{E} \quad-\quad \text { lruestrain rate }[a] \\
& \mathrm{m}=\quad \text { strain rate sensitivity exponent } \\
& \mathrm{E}=\text { Young's modulus. }
\end{aligned}
$$

The values of $\mathrm{K}, \mathrm{n}$, and $\mathrm{m}$ are calculated in CMLIMT from the input parameters as discussed in the description of CSTRES (Section B-8), $\mathrm{E}$ is obtained by calling the function CELMOD (Section B-7), and a value for $\dot{\epsilon}$ is required input information. The strain rate, $\dot{\epsilon}$, should be determined from values of strain closely spaced in time. Values of rate which are averaged over long periods of time may fail to provisle in groml dessirintion of the instantaneous etate of the material. rupture:

The following four correlations predict circumferential elongation of cladding at

for temperatures less than $1090 \mathrm{~K}$

$$
\text { STRRPE }=\left(0.198+4.16 \times 10^{-4} \mathrm{~T}+2.06 \times 10^{-7} \mathrm{~T}^{2}\right) \mathrm{R}
$$

[a] Values of $\dot{\epsilon}$ used by the subroutine are limited to the range $10^{-5}$ through $10^{-1} / \mathrm{s}$. 
for temperatures between 1090 and $1170 \mathrm{~K}^{[\mathrm{a}]}$

$$
\text { STRRPE }=9.06231055-7.491855 \times 10^{-3} \mathrm{~T}
$$

for temperatures between 1170 and $1600 \mathrm{~K}$

$$
\text { STRKPE }=-1.436+2.045 \times 10^{-3} \mathrm{~T}-4.82 \times 10^{-7} \mathrm{~T}^{2}
$$

for temperatures greater than $1600 \mathrm{~K}$

$$
\text { STRRPE }=0.60208
$$

where

$$
\begin{aligned}
& \text { STRRPE }=\quad \text { circumferential elongation at rupture i.e. (rup- } \\
& \text { ture circumference minus initial circum- } \\
& \text { ference divided by inital circumference) } \\
& \mathrm{T}=\quad \text { temperature at rupture }(\mathrm{K}) \\
& \mathrm{R}=\text { factor which accounts for the effects of } \\
& \text { irradiation and cold work on the circum- } \\
& \text { ferential elongation of zircaloy cladding at } \\
& \text { rupturc. }
\end{aligned}
$$

$\mathrm{R}$ equals 1 for annealed material and decreases with irradiation or cold work as described in Section B-10.3.

The instability strain for biaxial stress states returned by CMLIMT is one-fourth the circumferential elongation of unirradiated and annealed cladding

$$
\text { Instability Strain = STRRPE/R. }
$$

The expected standard error ${ }^{[b]}$ of the prediction for circumferential elongation is given by the following analytical expressions:

for temperatures less than $800 \mathrm{~K}$

$$
\sigma=\text { the smalier of } 0.08 \text { or the predicted value }
$$

[a] Use of several significant figures is required to avoid discontinuities in the expressions at the boundaries between different temperature regions.

[b] The standard error of a model is estimated with a set of data by the expression: (sum of squared residuals/number of residuals minus the number of degrees of freedom $)^{1 / 2}$. 
for temperatures between 800 and $1090 \mathrm{~K}$

$$
\sigma=(0.36 / 290)(T-800)+0.08
$$

fur tenperaluies belween 1090 and $1170 \mathrm{~K}$

$$
\sigma=-4.125 \times 10^{-3}(T-1090)+0.44
$$

for temperutures ubove $1170 \mathrm{~K}$

$$
0-0.11
$$

Both engineering and true values of stress and strain are returned by CMLIMT and CSRUPT. In order to obtain engineering strains or stresses from the values of true strain $\lfloor a\rfloor$ or true stress $[\mathrm{b}]$ in Equations (B-10.1) to (B-10.3) the true values are converted to engineering $\varepsilon$ tress $[\mathrm{C}]$ or engineering strain $[\mathrm{d}]$ using the relations

$$
\begin{aligned}
& \text { engineering stress }=\frac{\text { true stress }}{\exp (\text { true strain })} \\
& \text { engineering strain }=\exp (\text { true strain) }-1 .
\end{aligned}
$$

The inverse of Equation (B-10.8a),

$$
\text { true strain = en (engineering strain }+1 \text { ) }
$$

is used with the engineering strains from Equations (B-10.4) to obtain true strains at rupture.

Cladding local temperature is the only required input information for the local strain subcode (CLOCRP). For temperatures in $K$, true local radial (wall thickness) and true local circumferential strains at rupture are given by the correlations

$$
\text { . Circumferential strain }=-0.415+0.001368 \times \text { Temperature }(\mathrm{B}-10.9)
$$

[a] True strain = the change in length divided by the length at the instant of change and integrated from initial to final length $\int_{\mathrm{Lo}}^{\mathrm{L}} \frac{\mathrm{d} \ell}{\ell}$.

[b] True stress $=$ the force per unit cross sectional area with the area determined at the instant of measurement of the force.

[c] Engineering stress $=$ the force per unit cross sectional area with the area determined when the strain was zero.

[d] Engineering strain = the change in length divided by the original length. 


$$
\text { Radial strain }=-0.0107-0.001305 \times \text { Temperature. }
$$

Corresponding values of engineering strain are calculated with expression (B-10.8a). The CLOCRP subcode is preliminary since it is based only on seven cross sections of tubes burst between 1090 and $1320 \mathrm{~K}$. However, surprisingly consistent results were obtained with these few tests. Local circumferential and local radial (wall lhickness) strains at i upture are found to be closely approximated with linear functions of temperature. This implies that the pronounced minimum in average circumferential expansion during the alpha-beta phase transition is a localization of circumferential strain rather than a reduction of the local strain required for rupture. Since local circumferential strain and local radial strain are related during deformation and at rupture, either component of strain is a candidate for use as a failure criterion. Both strains to rupture are developed here, but the change is radial strain is based on simple direct measurements and is therefore the preferred criterion for failure when cladding wall thickness can be determined.

The following section describes the derivation of Equations (B-10.1) to (B-10.3). The determination of the correlations for circumferential rupture strains and biaxial instability strains, Equations (B-10.4) and (B-10.5), is discussed in Section B-10.3 and the expressions for the standard error of the rupture strains are discussed in Section B-10.4. The derivation of Equations (B-10.9) and (B-10.10) is discussed in Section B-10.5. Examples of the output of CMLIMT and CSRUPT are presented in Section B-10.6. A listing of the CMLIMT, CSRUPT, and CLOCRP subcodes is presented in Section B-10.7.

\subsection{Derivation of Expressions Used for Yield Points and Ultimate Strength}

The yield point is taken to be the nonzero intersection of the stress-strain curves given by Hooke's law for the elastic region

$$
\sigma=E \varepsilon
$$

and by the modified power law used in CSTRES and CSTRAN for the plastic region

$$
\sigma=k \varepsilon^{n}\left(\frac{\dot{\varepsilon}}{10^{-3}}\right)^{m}
$$

where the symbols in Equations (B-10.11) and (B-10.12) have been defined in Section B-10.1. Solution of these simultaneous equations gives the yield strain and yield strength described by Equations (B-10.1) and (B-10.2).

In the present model, plastic instability under uniaxial stress is assumed to begin at the point of maximum load (maximum engineering stress) which is in turn assumed to be at a true strain equal to the work hardening exponent. When a value of $n$ is substituted for $\epsilon$ in Equation (B-10.12), Equation (B-10.3) for ultimate strength is obtained. 


\section{CMLIMT/CSRUPT/CLOCRP}

\subsection{Derivation of Expressions Used for Strain at Rupture and Biaxial Instability Strains}

Equation (B-10.4a) with $\mathrm{R}=1$ for annealed tubing at temperatures below $1090 \mathrm{~K}$ was obtained from a least squares fit to data taken from tests in inert atmospheres $[\mathrm{B}-10.1-\mathrm{B}-10.4]$, since low temperature test results in steam have not yet been published. Data from References B-10.1 and B-10.4 are from isothermal tests on annealed tubes while the other two sources describe transient tests on cold-worked and stress-relieved tubes at temperatures which are sufficiently high to anneal the cold work effects.

For temperatures above $1090 \mathrm{~K}$ where the beta phase of zircaloy is expected to be present, Equations (B-10.4b), (B-10.4c) and (B-10.4d) are based on tests in steam environments $[\mathrm{B}-10.5 \cdot \mathrm{B}-10.8]$. The most conspicuous effect of the steam environment is the lack of the second maximum of circumferential clongation scen in incrt atmosphere data $[\mathrm{B}-10.2, \mathrm{~B}-10.3]$. In steam, the circumferential elongation is limited both by the localization of circumferential strain under axial cracks in the surface oxide layer and by the fact that temperatures vary substantially around the circumference ${ }^{[B-10.8]}$. Equation (B 10:1C) is a loast squares fit to the data in steam reported in References B-10.5 to B-10.8. Equation (B-10.4b) was constructed by inspection of the limited data in the region from 1090 to $1170 \mathrm{~K}$ (the first half of the alpha-beta transition region of zircaloy). The circumferential elongation to failure was set equal to a constant in Equation (B-10.4d) simply because of the lack of data. Analytical expressions for the circumferential elongation at rupture of cold-worked or irradiated cladding are obtained by multiplying the elongation of annealed cladding by the factor $\mathrm{R}$ used in Equation (B-10.4a). R is defined by

$$
R=P Q
$$

where

$$
\begin{aligned}
& \mathrm{P}=\text { all effects of cold work } \\
& \dot{Q}=\text { all effects of irradiation. }
\end{aligned}
$$

When annealing has not occurred, the values of $P$ and $Q$ are:

$$
P_{0}=\left[\frac{\exp (-21 \times \text { COLDW })+0.33}{1.33}\right]
$$

and

$$
Q_{0}=\left|\frac{1+2 \exp \left(- \text { FNCE } / 10^{23}\right)}{3}\right|
$$

where

$$
\begin{array}{ll}
\text { COLDW }= & \text { cold work (fraction of cross sectional area reduction) } \\
\text { FNCE }= & \text { fast neutron fluence (neutrons } \left./ \mathrm{m}^{2}\right) .
\end{array}
$$


Equations (B-10.14) and (B-10.15) are based on data of Reference B-10.9 from ternsile tests using flat plates because measurements of circumferential elongation to rupture as a function of irradiation and cold work in a single lot of tubing are not available. The axial elongation to failure in tensile tests is known to differ from circumferential deformation to rupture ${ }^{[B-10.10]}$. However, the ratio of circumferential strains of highly irradiated and annealed tubing is similar to the ratio of axial strains measured during tensile tests or irradiated and annealed material.

Figure B-10.1 compares the ratios obtained using the values of elongation at failure reported in Reference B-10.9 and the model based on these data [Equations (B-10.14) and (B-10.15)]. Cold work to an area reduction of 0.1 causes a drastic change in ductility but further cold work has little effect. Irradiation effects have become saturated by the time the fast neutron fluence is $10^{24}$ neutrons $/ \mathrm{m}^{2}$. Since typical end-of-life values of fast fluence are $4 \times 10^{25}$ nentrnns $/ \mathrm{m}^{2}$, mnst. of the change in strain to rupture of the cladding occurs at beginning-of-life.

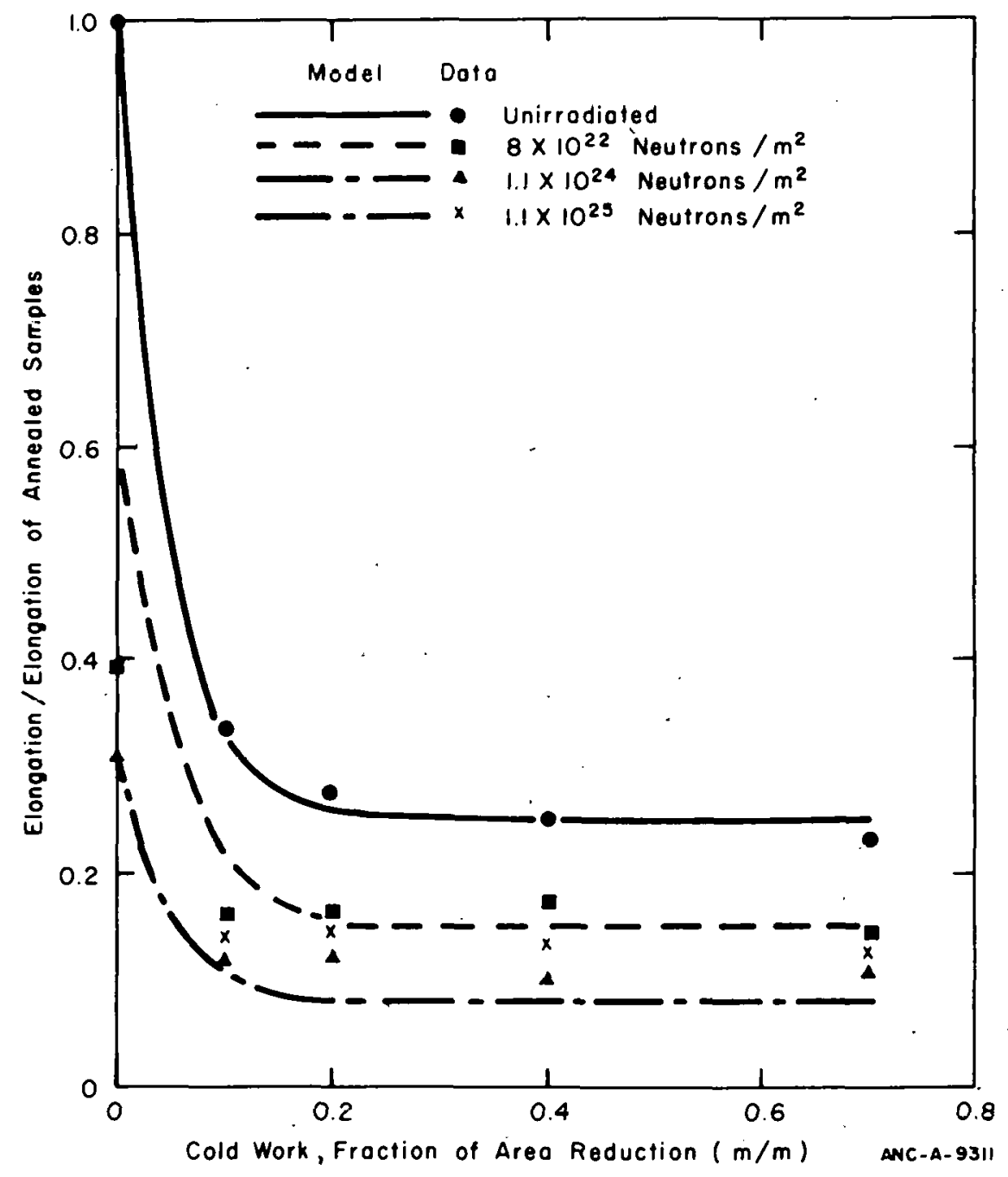

Fig. B-10.1 Ratios of elongation at failure for samples with varying amounts of cold work and fast neutron fluence to elongation at failure of an annealed sample. 


\section{CMLIMT/CSRUPT/CLOCRP}

The effect of annealing of irradiation damage on circumferential elongation is modeled by modifying the fluence dependent factor in Equations (B-10.14) and (B-10.15) to cause reduction of the effects of irradiation when the maximum cladding temperature has been in the range 620 to $700 \mathrm{~K}$. The expression for $\mathrm{Q}$ in Equation (B-10.13) is then

$$
Q=Q_{0}\left(\frac{700-\text { CTMAX }}{80}\right)+\left(\frac{\text { CTMAX }-620}{80}\right)
$$

where

$$
\begin{array}{ll}
\text { СТМ } \Lambda \mathrm{X} & =\text { previous maximum cladding temperaturc } \\
\mathrm{Q}_{\mathrm{N}} & =\quad \text { original Muence dependent faclor of Equation (B-10.15). }
\end{array}
$$

The model for the annealing of the effects of irradiation is based on recent burst tests $[D-10.10]$ of commercial fuel rods which show an increase in circumferential elongation beginning between the temperatues of 589 and $644 \mathrm{~K}$ and continuing to temperatures of $700 \mathrm{~K}$. It should be noted that these tests have also shown a significant strain rate effect at $644 \mathrm{~K}$ which has not yet been modeled.

The effect of annealing of cold work on circumferential elongation is modeled by modifying the cold-work dependent factor in Equation (B-10.13) over the temperature range 755 to $850 \mathrm{~K}$ so the factor is changed from its original value to 1 as temperature increases from 775 to $850 \mathrm{~K}$. The expression used is

$$
P=P_{0}\left(\frac{850-\text { CTMAX }}{75}\right)+\left(\frac{\text { CTMAX }-775}{75}\right)
$$

where

$$
\begin{array}{ll}
\dot{\mathrm{P}}= & \begin{array}{l}
\text { the cold work dependent factor in Equation } \\
(\mathrm{B}-10.13)
\end{array} \\
\text { CTMAX }= & \begin{array}{l}
\text { previous maximum cladding temperature }(\mathrm{K}) \\
\mathrm{P}_{\mathrm{O}}=
\end{array} \\
\begin{array}{l}
\text { the original cold work dependent factor of } \\
\text { Equation }(\mathrm{B}-10.14) .
\end{array}
\end{array}
$$

The model had to be based on the annealing behavior of the strength coefficient as discussed in CSTRES since no detailed observations characterizing the effect of annealing of cold work on circumferential elongation have been reported.

The correlation for the biaxial stress state instability strain [Equation (B-10.5)] is based on data reported in Figures III-20 and III-22 of Reference B-10.11. The data and the MATPRO correlation are reproduced in Figure B-10.2. Since the two figures of Reference B-10.11 refer to different heating rates and different applied constraints, no effort was made 


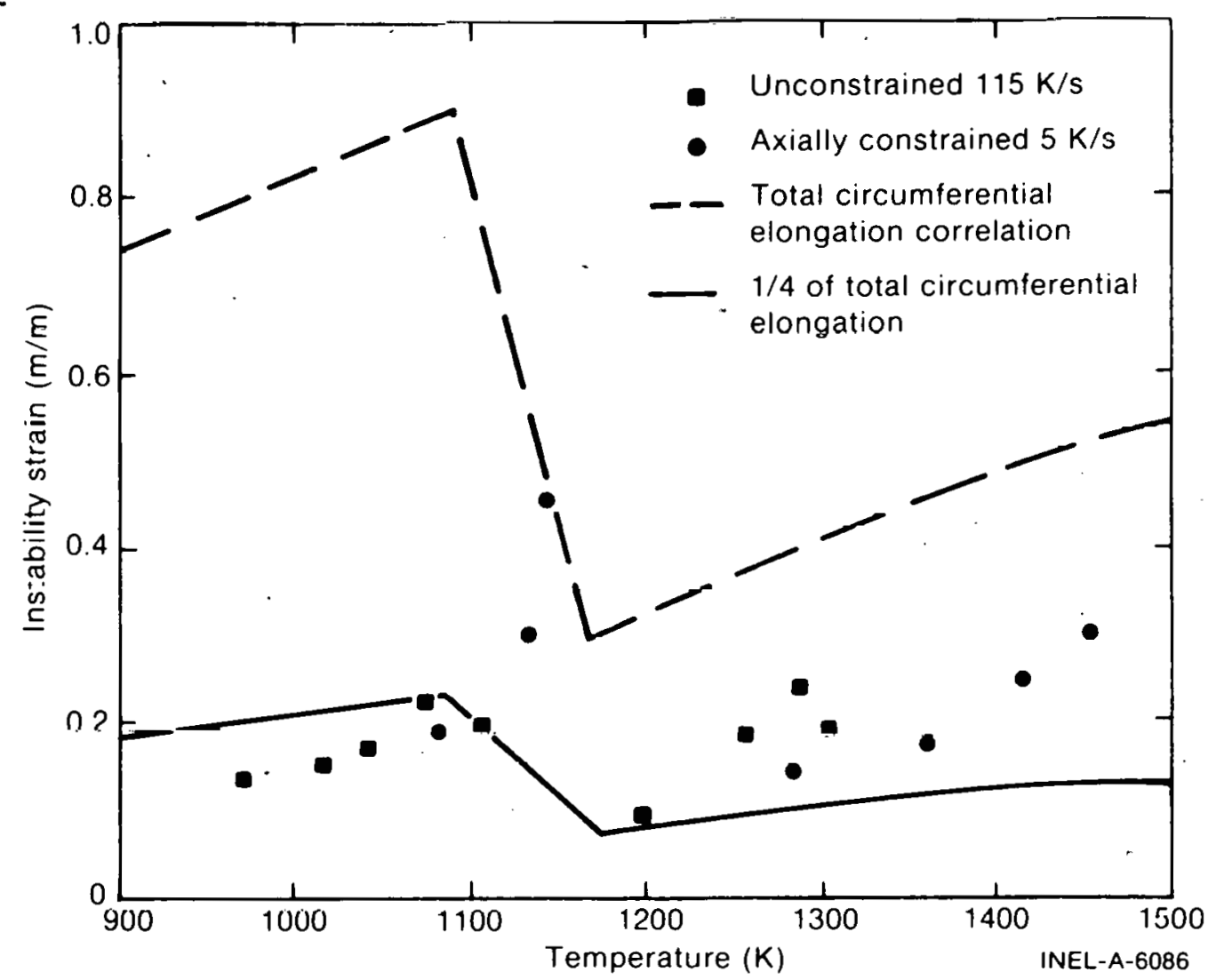

Fig. B-10.2 Measured values of instability strain from W. R. Smalley compared to the MATPRO correlation for total circumferential elongation.

to produce a careful correlation at this time. The data conform roughly to one-fourth the circumferential elongation at rupture predicted by Equations (B-10.4a) through (B-10.4c) and this value is used as a correlation for the biaxial instability strain.

\subsection{Uncertainty of the Prediction for Strain at Rupture}

Equations (B-10.6a) through (B-10.6d) are based on standard errors of the model as evaluated by its own data base. These results are listed in Table B-10-I.

TABLE B-10.I

STANDARD ERROR OF PREDICTED STRAINS AT RUPTURE

\begin{tabular}{|c|c|}
\hline Temperature Range (K) & Standard Erro \\
\hline $290-800$ & 0.082 \\
\hline $800-1090$ & 0.258 \\
\hline $1170-1600$ & 0.108 \\
\hline
\end{tabular}


Equations (B-10.6a) and (B-10.6d) state results listed in Table B-10.I. Equation (B-10.6b) was obtained by noting that the scatter of measured values of strain at rupture increases as the beginning of the alpha-beta transition is approached. The average value for the region from $800-1090 \mathrm{~K}, 0.26$, is assumed to apply to the middle of the temperature range $800-1090 \mathrm{~K}$, and the uncertainty is assumed to increase linearly up to $1090 \mathrm{~K}$. In the region from 1090 to $1170 \mathrm{~K}$ Equation (B-10.6c) was derived by assuming the uncertainty decreases from its value at $1090 \mathrm{~K}$ to the value found for data taken above $1170 \mathrm{~K}$.

\subsection{Derivation of Expressions Used for Local Strain}

Photographs of cross sections taken perpendicular to the axis of several zircaloy tubes burst at Argonne National Laboratory [B-10.11 - B-10.13] were used to determine strain components at cladding rupture. Expansion of the tubes was assumed to consist of two parts. The first part, uniform expansion, is assumed to be symmetric in the plane of the tubing cross section ${ }^{[a]}$ and the second part, ballooning, is assumed to consist of equal axial and circumferential strains localized on the side of the tube which burst. Neither of these assumptions has been verified, but neither is necessary to determine radial strains. The assumptions will affect only the relative values of circumferential and axial strains.

In order to find local uniform strains, the center of curvature of the side of the tube away from the burst was located by drawing chords on the side of the cross section opposite the burst and constructing perpendiculars to the chords, as illustrated in Figure B-10.3. The uniform circumferential strain was calculated by comparing the circumference of the circle constructed at the center of curvature to the circumference of the original tubing $[\mathrm{B}-10.12]$. Local strain was assumed to be equal to the average circumferential strain. Local radial strain during uniform deformation was computed from measurements of cladding wall thickness in the circular part of the cladding cross section and published values ${ }^{[B-10.12]}$ of the initial wall thickness. Local axial uniform strain was calculated using the incompressibillty relation [b]

$$
\exp \left(\varepsilon_{\theta}\right) \exp \left(e_{z}\right) \exp \left(f_{r}\right)=1
$$

wliete

$$
\begin{array}{ll}
\epsilon_{\theta}, \epsilon_{\mathrm{Z}}, \epsilon_{\mathrm{r}}= & \text { the circumferential, axial, and radial compo- } \\
\text { nents of local true strain. }
\end{array}
$$

[a] The assumption of symmetric deformation during the first part of these tests may be reasonable because circumferential variation in temperature should be minimized by the use of self-resistance heating.

[b] In terms of engineering strains, the relation is $\left(1+\mathrm{e}_{\theta}\right)\left(1+\mathrm{e}_{\mathrm{Z}}\right)\left(1+\mathrm{e}_{\mathrm{r}}\right)=1$ where $\mathrm{e}_{\theta}$, $e_{Z}$, and $e_{r}$ are the circumferential, axial, and radial components of local engineering strain. 


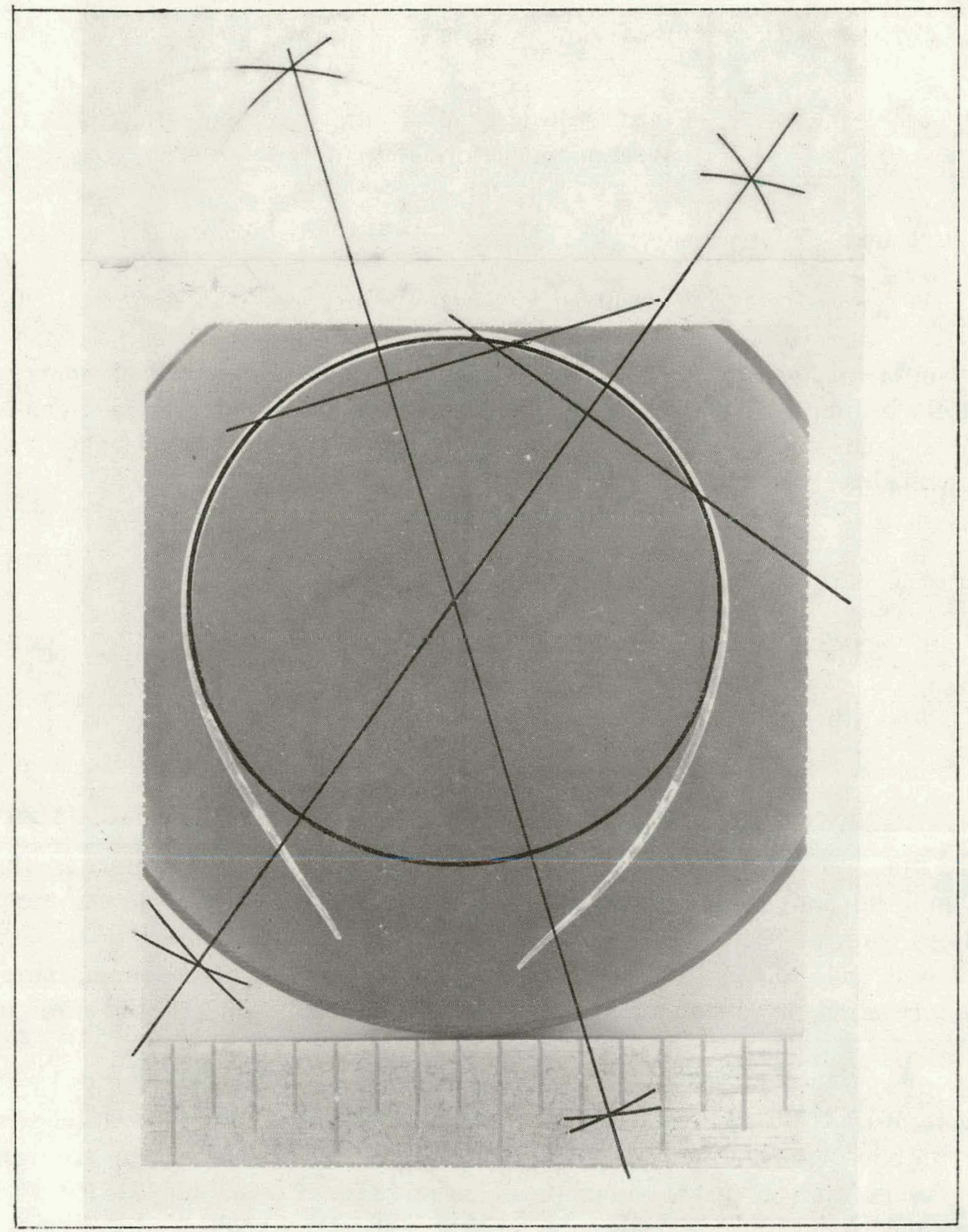

Fig. B-10.3 Cross section, perpendicular to the axis, of a zircaloy tube showing location of the center of curvature of the side opposite the burst region.

Strains during the ballooning part of the deformation were calculated by measuring the wall thickness adjacent to the burst ${ }^{[a]}$. The radial strain during the ballooning part is given by

$$
\varepsilon_{r}{ }^{\prime}=\ln \frac{W_{\text {burst }}}{W_{\text {uniform }}}
$$

[a] Most burst edges displayed a fracture-like line approximately 45 degrees from the radial direction. The wall thickness was measured adjacent to this line or, if the line could not be distinguished, $0.25 \mathrm{~mm}$ from the burst tear. 
where

$$
\begin{array}{ll}
\epsilon_{\mathrm{r}}^{\prime}= & \begin{array}{l}
\text { true local radial strain during the } \\
\text { ballooning deformation }
\end{array} \\
\mathrm{W}_{\text {burst }}= & \text { wall thickness adjacent to the burst } \\
\mathrm{W}_{\text {uniform }}= & \text { wall thickness after uniform deformation. }
\end{array}
$$

Since circumferential and axial strains are assumed to be equal during the ballooning part of the burst, the incompressibility relation can be used in conjunction with Equation (B-10.19) to find the axial and circumferential strains during ballooning. The incompressibility equation with equal axial and radial strains is

$$
\varepsilon_{\theta}^{\prime}=\frac{\varepsilon_{r}^{\prime}}{2}
$$

where

$$
\begin{aligned}
& c_{\dot{\theta}}{ }^{\prime}=\text { the true circumfcrential strain during ballounimg } \\
& \epsilon_{\mathrm{r}}{ }^{\prime}=\text { the true local radial strain during ballooning. }
\end{aligned}
$$

True strains are additive so the net local components of strain at rupture are the sum of the uniform and ballooning parts of each component. These sums, the burst temperatures, and the heating rates for seven bursts are shown in Table B-10.II. Although there is considerable scatter in the uniform and ballooning parts of the strain, there is an apparent correlation of both the net circumferential and net radial strains at rupture with temperature.

Figure B-10.4 illustrates the correlation of the components of true local strain at rupture with burst temperature. The axial strain components are included in the figure for reference despite the fact that this component has not been included in CLOCRP. The local circumferential strains at rupture increase linearly with temperature, and the local radial strains decrease (become more negative) with temperature. The predictions of Equations (B-10.9) and (B-10.10), which are used in CLOCRP to represent true local circumferential and radial strains, are also illustrated. These equations are linear least squares fits to the seven values of the circumferential and axial strains which are illustrated. The one test which was done at a heating rate of $5 \mathrm{~K} / \mathrm{s}$ does not deviate from the trend of the other tests which represent heating rates of approximately $115 \mathrm{~K} / \mathrm{s}$.

\subsection{Examples of CMLIMT and CSRUPT Output}

The effects of temperature, cold work, and fast neutron fluence on the value of engineering ultimate strength, $\mathrm{S}_{\mathrm{u}}$, predicted for a strain rate of $10^{-5} / \mathrm{s}$ are illustrated in 


\begin{tabular}{|c|c|c|c|c|c|c|}
\hline \multirow{2}{*}{ Burst } & \multirow[b]{2}{*}{$\begin{array}{l}\text { Temperature } \\
\text { (K) }\end{array}$} & \multirow[b]{2}{*}{$\begin{array}{l}\text { Heating Rate } \\
(\mathrm{K} / \mathrm{S})\end{array}$} & & \multicolumn{3}{|c|}{ True Strains } \\
\hline & & & & Circumferential & Radial & Axial \\
\hline & 1089 & 5 & $\begin{array}{l}\text { Uniform } \\
\text { Balloon } \\
\text { Total. }\end{array}$ & $\begin{array}{l}0.71 \\
0.41 \\
1.12\end{array}$ & $\begin{array}{r}-0.49 \\
-0.82 \\
-1.31\end{array}$ & $\begin{array}{r}-0.23 \\
0.41 \\
0.18\end{array}$ \\
\hline . & 1129 & 115 & $\begin{array}{l}\text { Uniform } \\
\text { Balloon } \\
\text { lotal }\end{array}$ & $\begin{array}{l}0.45 \\
0.55 \\
1.00\end{array}$ & $\begin{array}{l}-0.19 \\
-1.11 \\
-1.30\end{array}$ & $\begin{array}{r}-0.26 \\
0.55 \\
0.29\end{array}$ \\
\hline & 1138 & 115 & $\begin{array}{l}\text { Uniform } \\
\text { Balloon } \\
\text { Total }\end{array}$ & $\begin{array}{l}0.67 \\
0.64 \\
1.31\end{array}$ & $\begin{array}{l}-0.46 \\
-1.28 \\
-1.74\end{array}$ & $\begin{array}{r}-0.21 \\
0.64 \\
0.43\end{array}$ \\
\hline & 1164 & 115 & $\begin{array}{l}\text { Uniform } \\
\text { Balloon } \\
\text { Total }\end{array}$ & $\begin{array}{l}0.30 \\
0.77 \\
1.07\end{array}$ & $\begin{array}{l}-0.09 \\
-1.54 \\
-1.63\end{array}$ & $\begin{array}{r}-0.27 \\
0.77 \\
0.56\end{array}$ \\
\hline & 1278 & 130 & $\begin{array}{l}\text { Uni form } \\
\text { Ball oon } \\
\text { Total }\end{array}$ & $\begin{array}{l}0.67 \\
0.70 \\
1.37\end{array}$ & $\begin{array}{l}-0.33 \\
-1.40 \\
-1.73\end{array}$ & $\begin{array}{r}-0.34 \\
0.70 \\
0.36\end{array}$ \\
\hline & 1348 & 115 & $\begin{array}{l}\text { Uniform } \\
\text { Balloon } \\
\text { Total }\end{array}$ & $\begin{array}{l}0.72 \\
0.60 \\
1.32\end{array}$ & $\begin{array}{l}-0.43 \\
-1.20 \\
-1.63\end{array}$ & $\begin{array}{r}-0.29 \\
0.60 \\
0.31\end{array}$ \\
\hline & 1369 & 115 & $\begin{array}{l}\text { Uniform } \\
\text { Balloon } \\
\text { Total }\end{array}$ & $\begin{array}{l}0.85 \\
0.70 \\
1.55\end{array}$ & $\begin{array}{l}-0.45 \\
-1.40 \\
-1.85\end{array}$ & $\begin{array}{r}-0.40 \\
0.70 \\
0.30\end{array}$ \\
\hline
\end{tabular}

Figure B-10.5. At low temperatures, cold work and irradiation cause significant changes in $\mathrm{S}_{\mathrm{u}}$. However; the effect of irradiation is less significant when cold-worked tubing is irradiated. The sharp reduction of $S_{u}$ in the temperature range from 1090 to $1125 \mathrm{~K}$ (alpha-beta phase transition) is due to the low strain rate selected for the illustration and a relatively high value of the strain rate sensitivity constant, $m$, in this temperature range.

Figure B-10.6 presents a comparison of the CMLIMT predictions with values of ultimate strength measured at $630 \mathrm{~K}$ using cladding samples from fuel rods irradiated to high levels of fast neutron fluence in the Saxton reactor [B-10.14, B-10.15]. The strain rate of the Saxton tests was $8.3 \times 10^{-5} / \mathrm{s}$ and the cold work was "equivalent" to a $10 \%$ reduction of area ${ }^{[B-10.14]}$. Although the measured values exhibit much scatter about the predicted values, the mean is predicted by CMLIMT. 


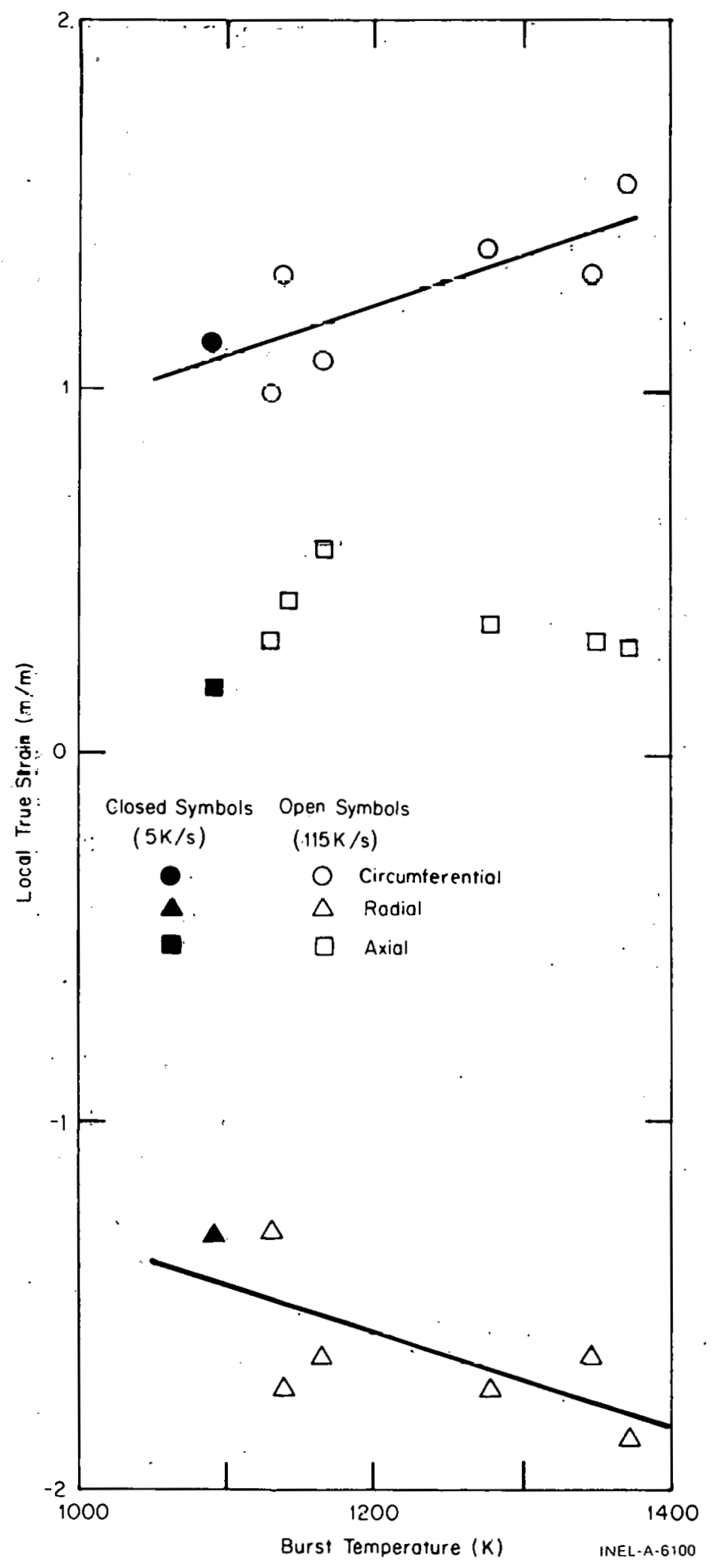

Fig. B-10.4 Graphic correlation of the components of true local strain at rupture with temperature. 

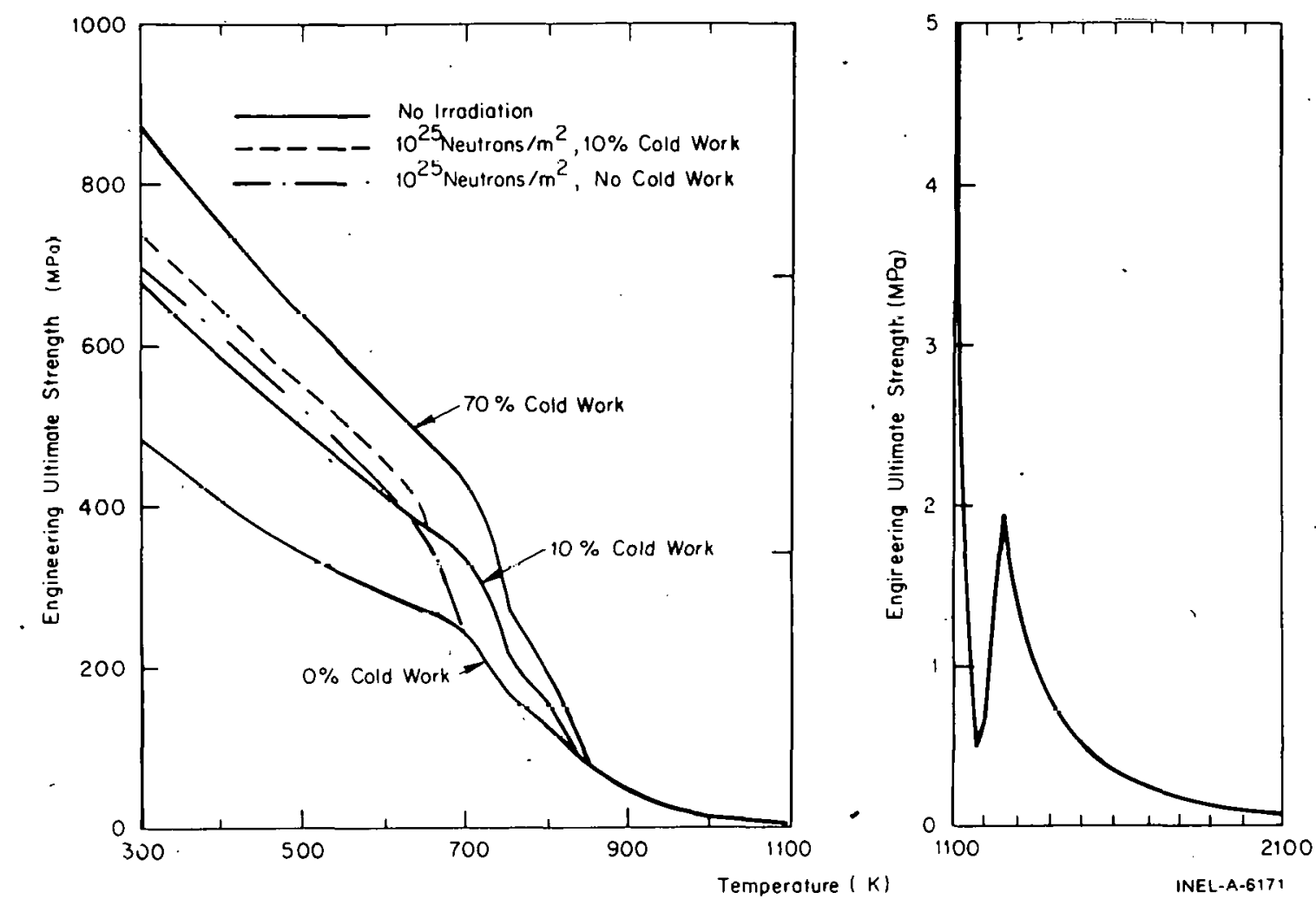

Fig. B-10.5 Engineering ultimate strength predicted by CMLIMT at a strain rate of $10^{-5} / \mathrm{s}$ as a function of temperature for several levels of cold work and typical fluences.

The predicted circumferential elongation at rupture for annealed zircaloy tubing and the data base used to derive the model are shown in Figure B-10.7. Dashed lines denote limits defined by the standard error of the prediction as estimated from its data base. Fractional elongation at failure increases with increasing temperatures until the alpha-beta transition begins and then decreases with temperature to a minimum of about 0.3 at $1200 \mathrm{~K}$. At temperatures above $1200 \mathrm{~K}$, the temperature gradients and steam environment cause strain to become localized and limit the elongation ratio to less than 0.75 .

The standard error of the prediction for annealed tubes remains constant to about $800 \mathrm{~K}$, increases rapidly to a maximum of \pm 0.44 at $1090 \mathrm{~K}$, and decreases to \pm 0.11 for temperatures above $1170 \mathrm{~K}$. It is expected that the correlation and the standard error determined' with this data base will apply to LWR abnormal or accident situations since (a) all of the data above $1090 \mathrm{~K}$ were taken in a steam environment, (b) most of the tubing tested contained internal mandrels to restrict axial deformation, and (c) the data from in-reactor tests are similar to the rest of the data base.

Irradiation and cold work strongly influence the circumferential elongation at rupture at temperatures less than $850 \mathrm{~K}$. Figure B-10.8 compares the model predictions for annealed cladding with prediction for cladding cold worked to 0.1 area reduction and then irradiated to a fast fluence of $10^{24}$ neutrons $/ \mathrm{m}^{2}$ or more. Test results obtained with irradiated 


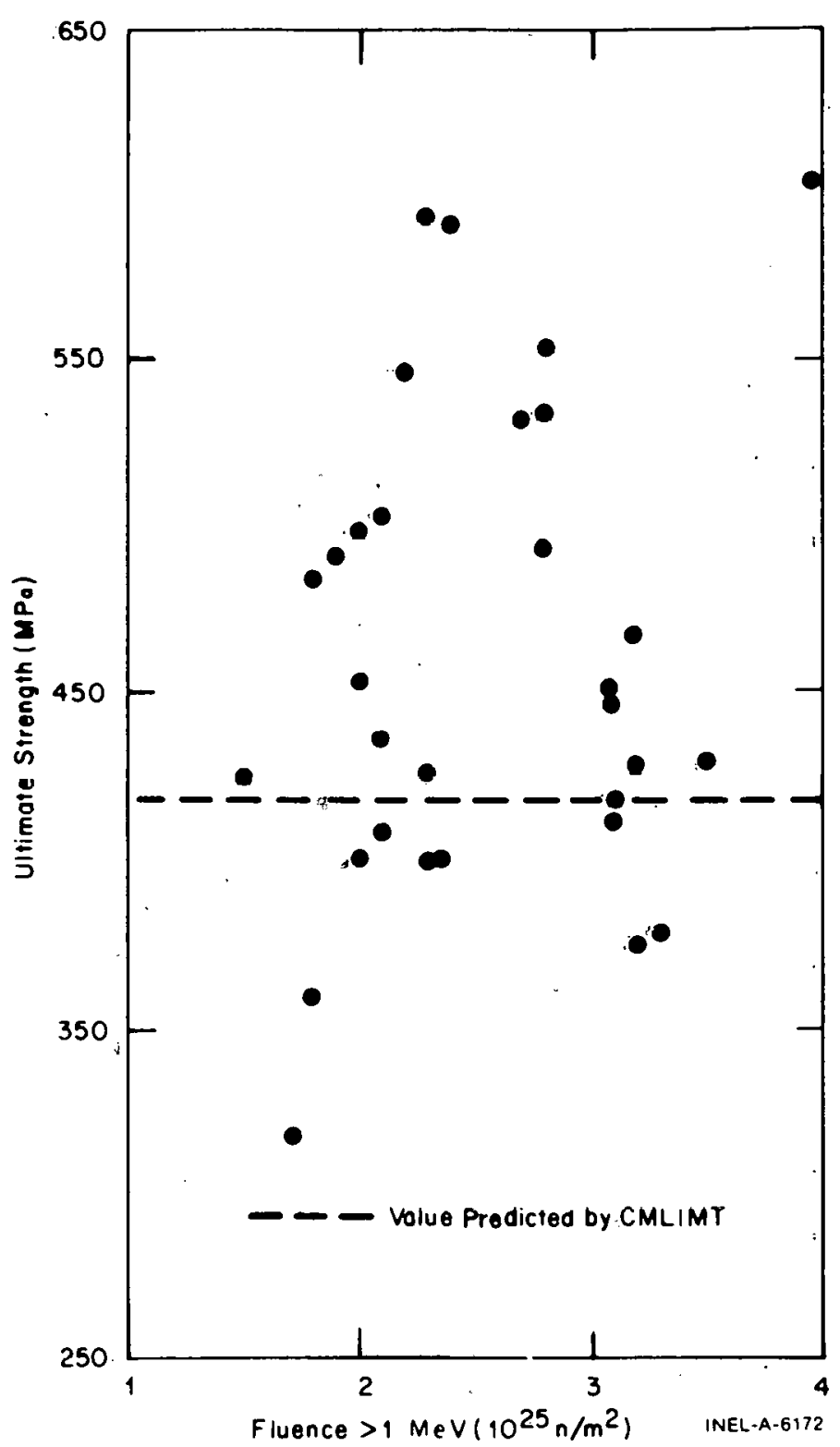

Fig. R-1 10.6 Measured values of ultimate strength at $630 \mathrm{~K}$ and a strain rate of $8 \times 10^{-5} / \varepsilon$ with Saxton cladding ae a funotion of fast neutron fluence compared to CMLIMT predictions for engineering ultimate strength.

cladding and the standard error predicted by the model are included in the figure. The large increases in elongation at 620 to $700 \mathrm{~K}$ and 775 to $850 \mathrm{~K}$ reflect annealing of irradiation damage and cold work, respectively.

10.7 Cladding Mechanical Limit CMLIMT, Cladding Strain at Rupture CSRUPT, and Cladding Local Strains at Rupture CLOCRP Subcode Listings

A listing of the FORTRAN subcode CMLIMT used for calculating strain at yield, instability strain, yield strength, ultimate strength, and strain to rupture is given in Table B-10.III. The listing of the subcode CSRUPT (which returns strain to rupture and the standard error expected with the correlation) is presented in Table B-10.IV and Table $\mathrm{B}-10 . \mathrm{V}$ is a listing of the CLOCRP subcode. 


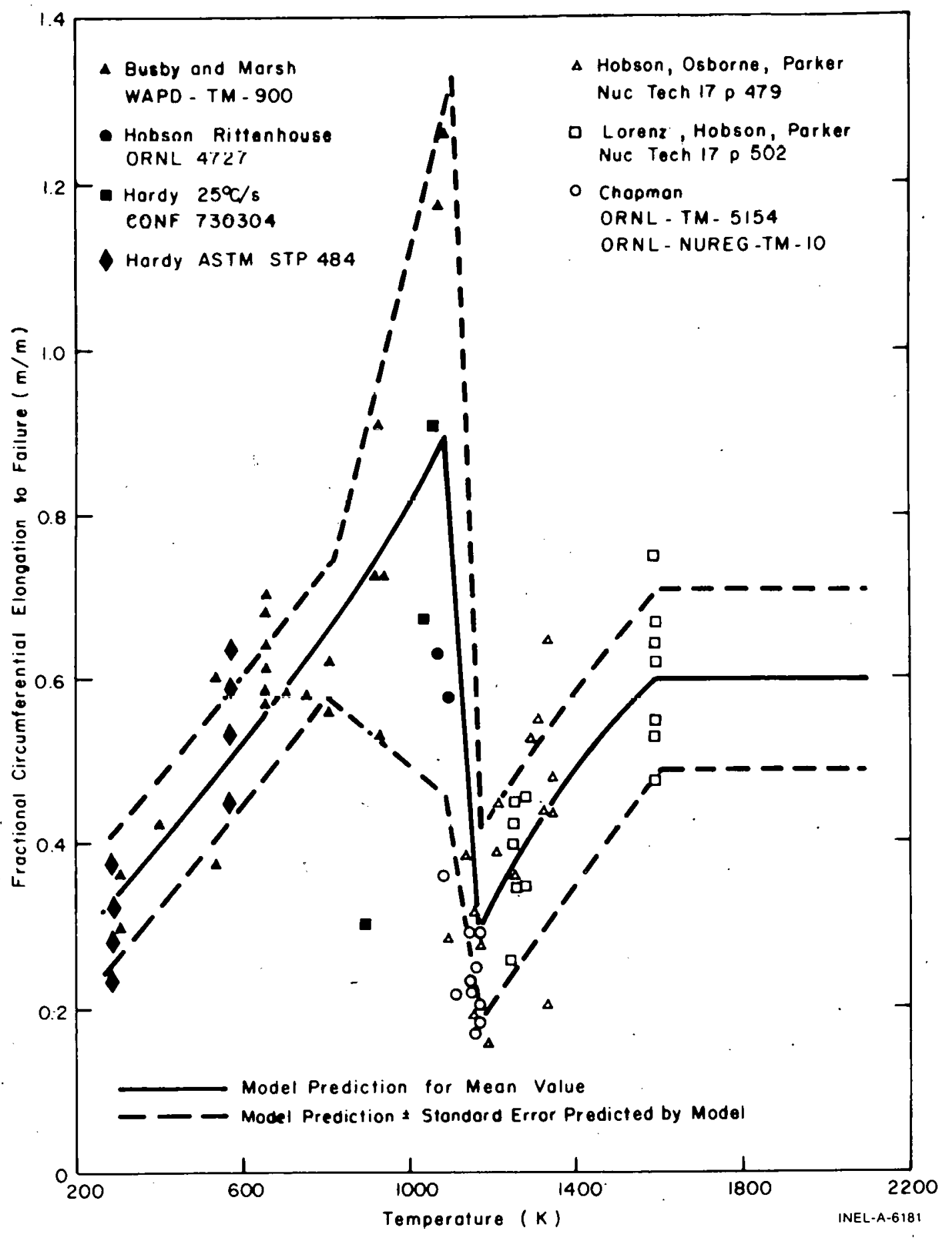

Fig. B-10.7 Predicted circumferential elongation at rupture, measured values, and standard error of new in-reactor data predicted as a function of temperature by the CSRUPT model for annealed tubing. 


\section{CMLIMT/CSRUPT/GLOCRP}

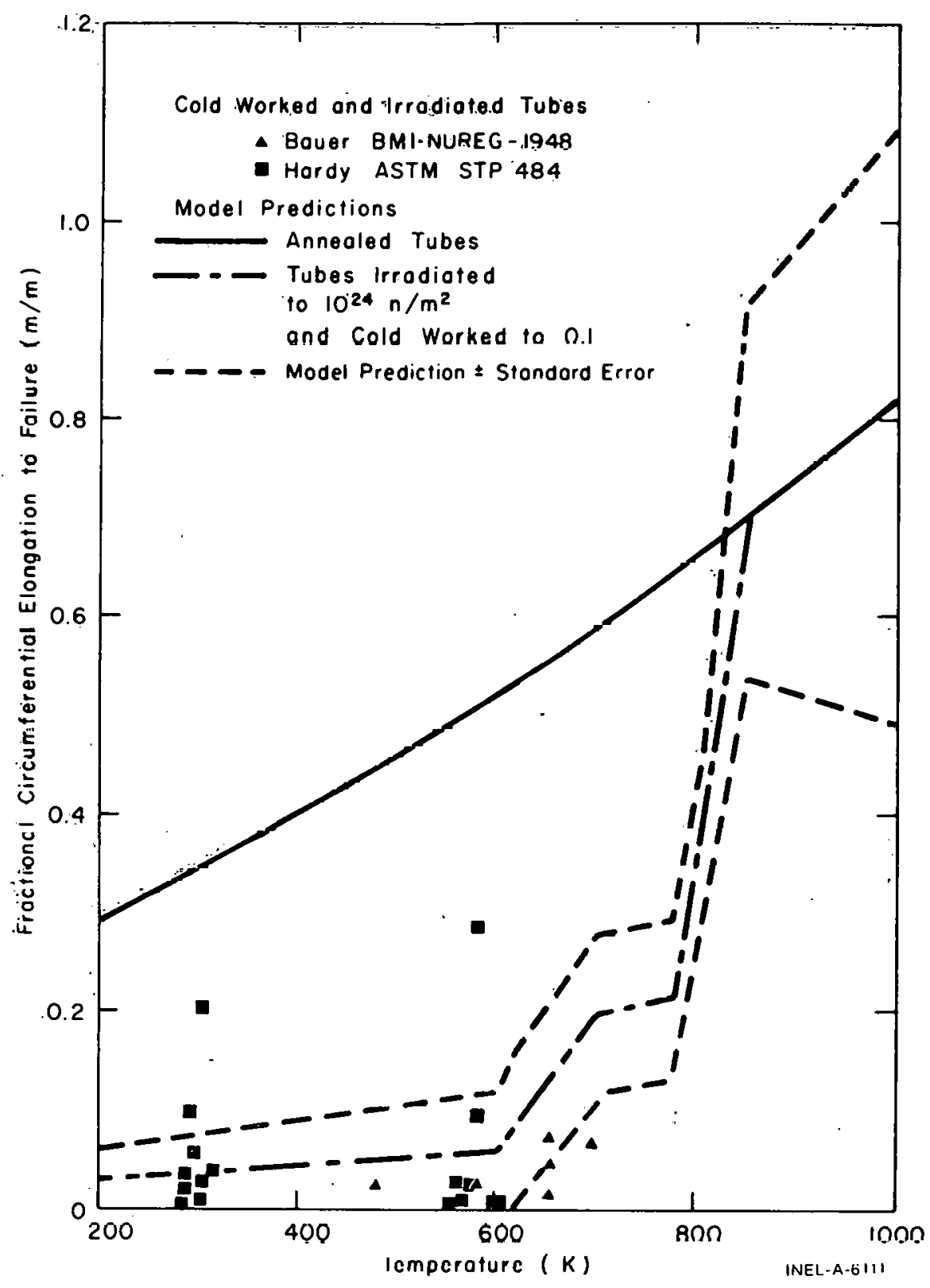

Fig. B-10.8 Predicted circumferential clongation at rupture of annealed cladding compared to predictions and measurements for cold-worked and irradiated cladding.

\subsection{References}

B-10.1. C. C. Busby and K. B. Marsh, High Temperature Deformation and Burst Characteristics of Recrystallized Zircaloy-4 Tubing, WAPD-TM-900 (January 1970).

B-10.2. D. G. Hardy, "High Temperature Expansion and Rupture Behavior of Zircaloy Tubing," Topical Meeting on Water Reactor Safety, Salt Lake City, American Nuclear Society, March 26-28, 1973, CONF-730304. 
TABLE B-10. II I

LISTING OF THE CMLIMT SUBCODE

SURRTHTINF CMI IMTICFLUX, TI HE ETEMP, C TMAX,RSTRAN, COL DO, STRNYT, - STRNYE, STRNUT, STRNUE, STRRPE, S\}RRPT, CYLDST, CYLUSE, CUL IS I, CUI TSE

CMLIMT CALCULATES STRESS AND STRAIN AT THE TRANSTTION BETYEEN COLD WORK, FAST NEUTRON FLUENCE, TEMPERATURE, AND PREVIDUS

HAXIMUA TEMPERATUREO

SIRNYT = OUIPLI TRUE SIRAIN ATYYIELD (M/M)

STRNYE: OUTPUT ENGINEERING STRAIN ATYYIELOMI

STRNUT: DUTPUT TRUE INSTABILITY STRAIN STRAIN (M/M)

STRRPE: DUTPUT ENGINEERING STRAINAT RUPTURE (M/M)

SIKRPI = DUTPUT TRUE STRAIN ATRUPTURE (M/M)

CYLDST = OUTPUT TRUE YIELD STRENGTH (PA)

CYLOSE: OUIPUT ENGINEERING YIELD STRENGTH (PA)

CULTSE - OUTPUT ENGINEERING ULTIMATE STRENGIH (TA)

CFLUX - INPUT FAST NEUTRON FLUX (NEUTRONS/( $(M * 2)(S))$ )

CFLUX: INPUT FAST NEUTRON ISI

IIPE : INPUT TIME AT FLUX (S) INT TEMPERATURE $(K)$

CTMAX - INPUI MAXIMUM CLADDING MESHPOINT TEMPERATURE (K)

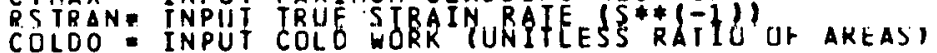

THE EQUATIONS USEO IN THIS SUBRQUTINE ARE BASEO ON OATA FROM

(1) C.C.BUSBY IN WAPO-TM-5B5, PROPERTIES QF ZIRCALOY - 4 TUBING Cं C. WODOS, EDOAPPENOIX C AND PAGES 65 FF (1966) USAEC REPORT GEMP-482(1968)

(3)A. BEMENT, JR, EFFECTS OF CCLD HORK AND NEUTRTN

IRRADIATION CN THE TENSILE RRCPERTIES OF ZIRCALOY-2,

USAEC REPORT HW-74955

(4) A. COHAN AND W.J. LANGFORD J.NUCLEAR MATER.

$3027 i-281$ (1)

IE, $271-28$ HOWE AHD H.R. THOHAS, d NUCLEAR MATER.

1 ' 1960 ; 248

IO 9608 GUS 4 YNO K B MARSH. HIGH TEMPERATURE DEFORMATION BUR ${ }^{\circ}$ CHARACER I I BAPD-TM-QOO (IG7O)

WAPO TM-9OOROY HIGH TEMPERATURE EXPANSION AND RUPTURE

BE OAY HAR IRCALOY TUBING IN TOPICAL MEETING ON

WATER REACTOR SAFETY CONF-7303 (1973)

(6 JODOHOBSON ANC P IL. RITTENHOUSE CDEFORAATION AND RUPTURE

I9) R.L. MEHAN AND F. W. WIESINGER. MECHANICAL PROPFRTIES

OF IIRCALOY-2, KAPL-Zi IO

(10)D. IEE AND H.A. BACKOFEN TMS-AIME 239 1034-1040 (1967)

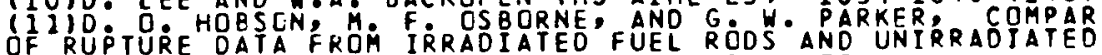

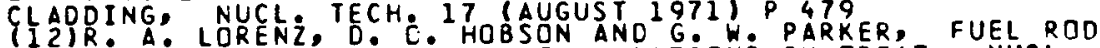

FAILURE UNOER LOSS CF COOLAN

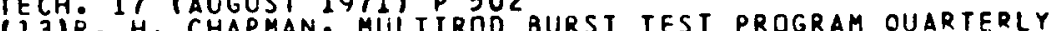

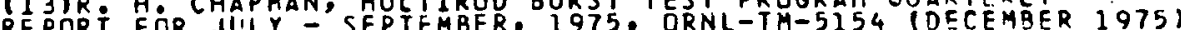

REPR FOR CHAPMAN, MULTIROD BURST'TEST PROGRAM OUARTERLY

I1 4)R H. HHAPMAN, MULTIROD BUR 975 , ORNL INUREGITM-IO (MAY 1976

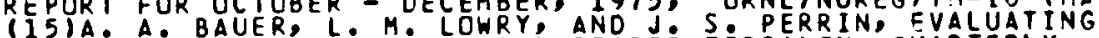

II 15 IA. A. BAUER, L. M. LOWRY'AAND J. S P PERRIN, OUYATUATY

STRENGTH AND DUCTILIY JAPARY THROUGH MARCH, 1976, BMI-NUREG-1948 (MARCH 1976 )

CODED BY DP LE: HAGRMAN JAANUARY 1976

FNCE - CFLUX $\$$ TIME

CCLOW $=$ COLDO

CTMAX) $2,2,1$

$\frac{1}{2}$ TTHAX E

IF (RSTRAN-1. OE-5) $3,4,4$

RSIRAN = 1. OE -5

IF (RSTRAN-I. OE-1) 6,6,5

RSTRAN $=1.0 \mathrm{E}-1$

6 If (T-730, $), 7,7,73$.

AM ${ }^{\circ} 0^{2} \cdot 90$

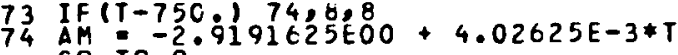

$G 0$ TO

$A M=-6.47 E-2+T * 2.203 E-4$

CML T0010 CML

CHLI0090

CMLTO100

CMLTO120

CMLTOI30

CALro140

EALTO150

C MLTOI70

CMLTO180

CMLTO200

CMLTO210

CHLTO230

CMLTO240

CMLTO260

CML TO270

CMLTO2BO

CMLTO290

CMLIO 310

CMLIO320

CMLTO330

CMLTO340

CMLTO360

CMLTO 380

CMLTO390

CMLTO400

CMLTO420

CMLIO430

CML 0440

CMLTO460

CML 10470

CMLTO480

CMLTO490

CHLTO510

CHLTO520

CMLTO5 300

CHLTO550

CML T0570

CMLTO580

ML

CMLTC610

CMLI0620

MLT0630

CMLTO64

CML

CMLTI0660

CMLI0680

CMLT0690

CMLTO700

CMLT0720

CMLT0730

CMLTO740

chitro7s

CMLTO 750

CMLT0780

CMLI0790

CMLTOBOO

CMLTOR10

CMLTOB 30

CHLTO\&40 
c

9 IF $(T-850) \quad 18.19,$.

10 If CCIMAX-800:; $12,11,11$

COLOE $=0.0^{\circ}$

$G 0$ TO 16

12 If (CIMAX-775, $54 ; 13,13$

13 COLDW $=$ COLOW $\$(850.5$ CTMAX)/75.0

55 FNCE $=0.0$

UU IU 16

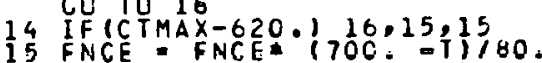

$16 A N=\left(-1.86 E-02+{ }^{*} * 17.11 E-04-T * 7.721 E-07\right) 1$ *

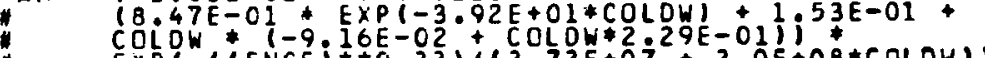

IF TT- $594,981,4) 17,17,18$

$17 A K=11.0750 E C 9-9.996 E 05 * T) * 11.0+5.46 E-1 *(\mathrm{CONW})$

GO TO 100

18 AK I I EXP(3.417E1+T*(-2.6630E-2+T*(1.1569E-5-T*1.7111E-9)1)1* GO $101188+5.46 E-01 *$ CCLDW)

19 AN $=0.027908$

AK : OEXP\{3.417E1+T*(-2.6630E-2+T*(1.1569E-5-T*1.7111E-9))

IF (RSTKAN=O. $34 \mathrm{E}=3\} 20 ; 100 ; 100$

20 IF (T-1C90.) $160,100,21$

21 IF $(T-1255:), 22,100,100$

22 IF (T- $\left.1 \frac{1}{2} T 2.3\right), 23,23,240(6.34 E-3 / R S T R A N)+((T-1090.1 / 82.5)$

$24 \triangle M=\Delta M+6.7 E E-2 * A L O G(6.34 E-3 / R S T R A N) *(1255 .-T) / 8 ? .5)$

c

100 CDNTINUE

IF (AN.LT.2.OE-3) AN=2.OE-3

ELMDO - CELMEDICTEMP, TIME, CFLUX, CCLDW)

c

LALCULATE STRA.IN AT TIELO

STRNYT=((AG) ELMOD)\$\#(1.0,1.0-AN))

C: CALCULATE STRAIN AT FUPTURE

$0=1: 0$

FNCE $1: 0$ CFLUX TIME

IF (T.GT. IC9CE) GC TO $201-04+T * 2.06 E-07)$

STRRPE (CTMAX TiT.R5O.) GE TO 201

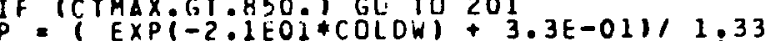

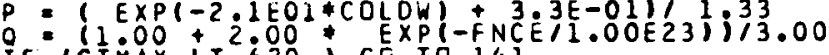

If (CTMAX.LT:E20,) GOTO 141

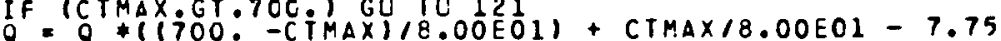

$12160 \quad T 0141$

IF ICIMAX.LT.775, GO TO 141

IF ICTMAX:LT.775:) GOTO 141

141 STRRPE STRRPE " $P$ "

201 PF $\{$.

STRRPE $90.06231055 E C C-T+7.491855 E-03$

$\left.301 \frac{1}{S T R R P E}=1-1.43 \in E C O+T * 12.045 E-03-T * 4.82 E-07\right)$

GO TO 501

C

$4 C 1$ STRRPE : 6.0206E-1

501 STRRPT

CYLDST: (AG) (ELMOD*AAN)**(1.0/(1.0-AN)

C CALCULATE ULTIMATE STRENGTH

CULYST : AG* IAN* ANTI

C

CALCULATE INSTABILITY STRAIN

STRNUT: ALOG 11.0 ; STRNUE)

KEIURN

END

CMLTOB5O

CHLT0870

CMLTOB8

CMLTO900

CMLTOQ10

CMLTO920

C.MLTC930

EMLTOS5O

CMLTO960

CMLTO980

CMLTO990

CMLT1000

CMLIIOZO

CMLT1030

CMLT1040

CMLT1050

CMLTIO60

CMLT 1080

CMLT1090

CMLTI100

CMLTII20

CHITI 130

CHE

MLIII60

CMLTII70

CMLII180

CMLII190

HLTI210

MLII220

MLII 40

CMLTI250

CMLT1270

CMLI 1280

MLI1290

CML 1300

CMLII320

CHLTI330

CMLTI 1340

CMLI 1360

C MLI 1370

C MLTI380

CMI 1400

CML T 1410

CMLI1.420

CHLT 440

EMLT 1450

MLI 1460

C 1480

CHLT1480

CMLT1500

CMLTIS10

CMLII520

c.

C MLII550

C

CMIT1580

CMLTI590

CMLT1600

CMLI1610

CMLT1620

CMLTI 1630

CMLI 1650

CMLT1660 

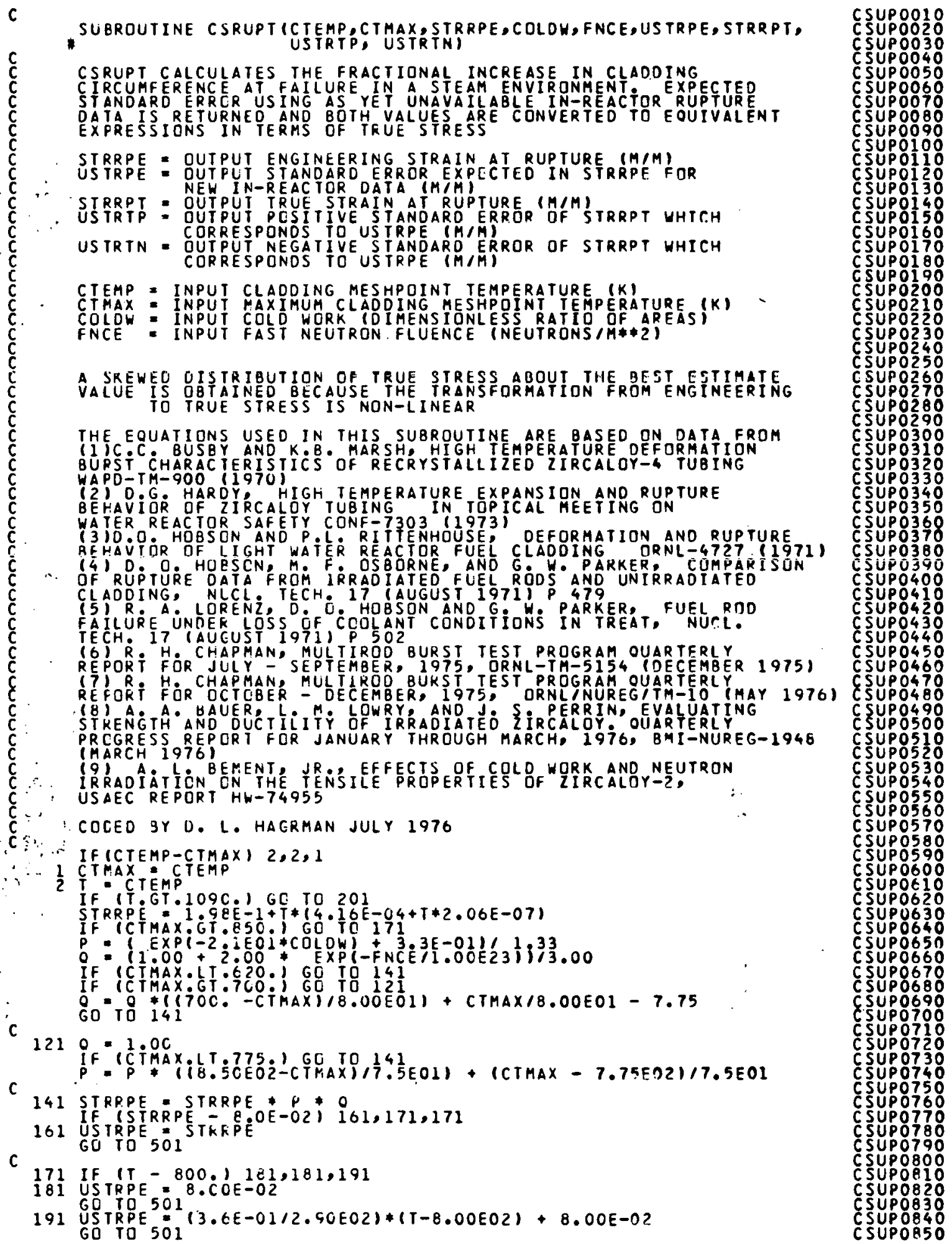
TABLE B-10. IV (continued)

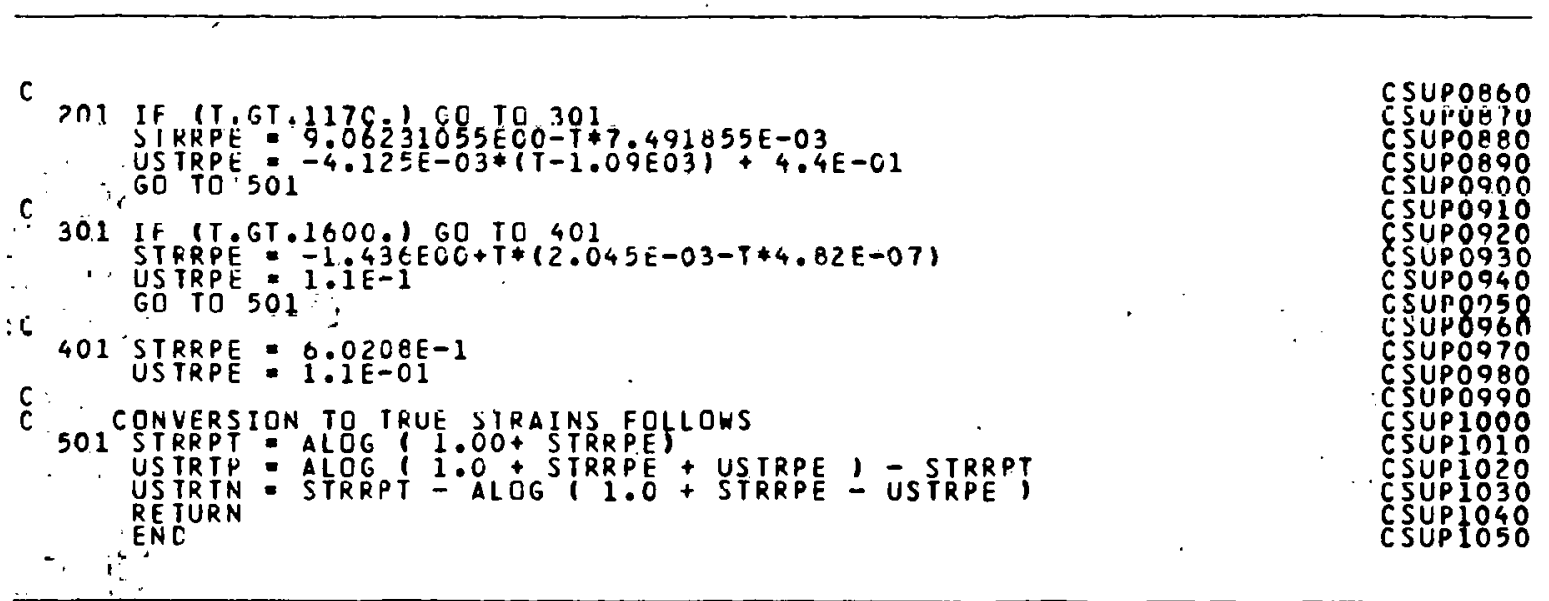

TABLE B-10.V

LISTING OF THE CLOCRP SUBCODE

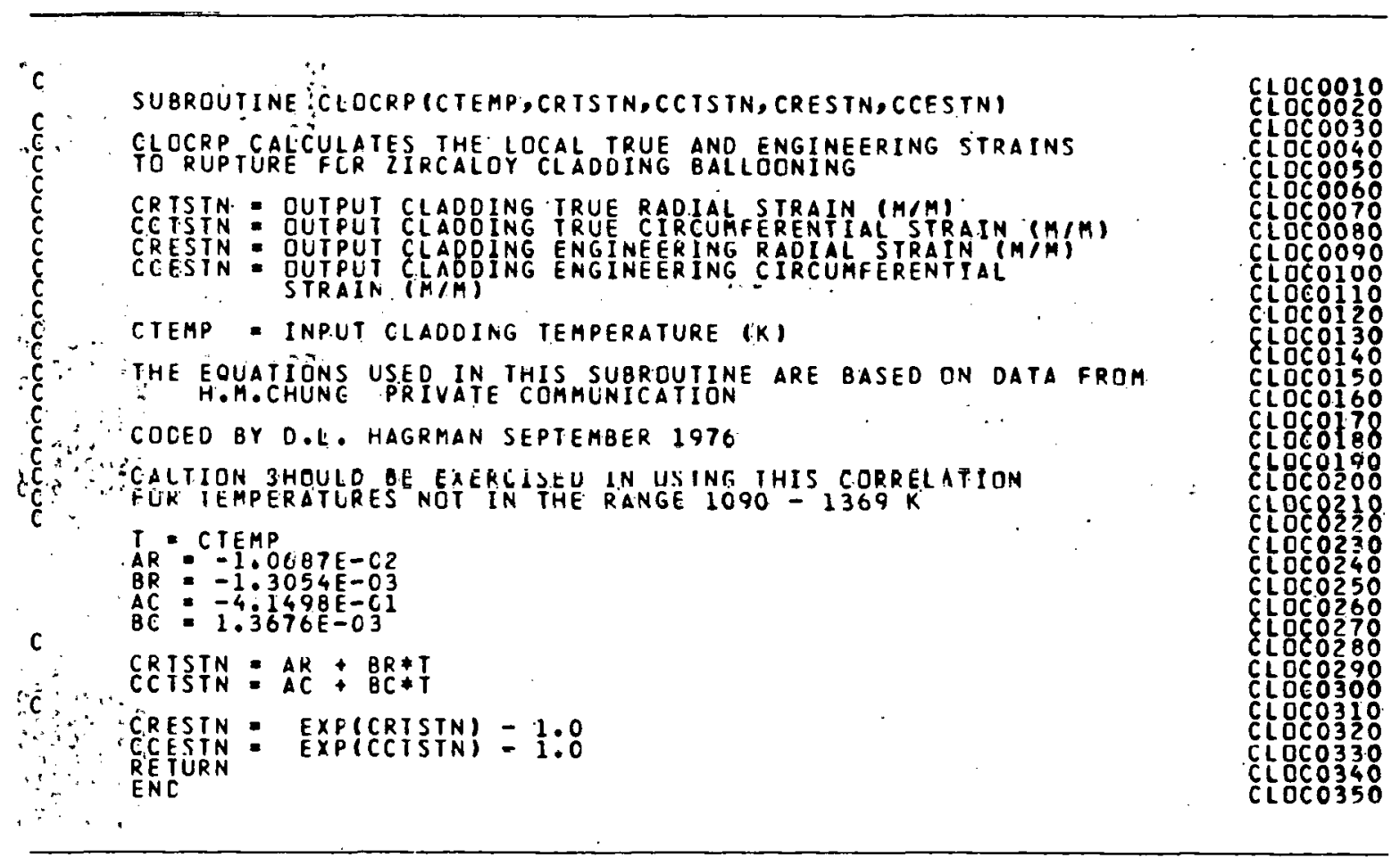


B-10.3. D. O. Hobson and P. L. Rittenhouse, Deformation and Rupture of Light-Water Reactor Fuel Cladding, ORNL-4727 (October 1971).

B-10.4. D. G. Hardy, "The Effect of Neutron Irradiation on the Mechanical Properties Zirconium Alloy Fuel Cladding in Uniaxial and Biaxial Tests," Irradiation Effects un Structurul Alloys For Nuclcar Rcactor Application, ASTM-STP-484, American Society for Testing and Materials (1970) pp 215-258.

B-10.5. D. O. Hobson, M. F. Osborne, G. W. Parker, "Comparison of Rupture Data From Irradiated Fuel Rods and Unirradiated Cladding," Nuclear Technology, 17 (August 1971) p 479.

B-10.6. R. A. Lorenz, D. O. Hobson, G. W. Parker, "Fuel Rod Failure Under Loss-of-Coolant Conditions in TREAT," Nuclear Technology, 17 (August 1971) p 502.

B-10.7. R. H. Chapman, Multirnd Rurst Test Program Quarterly Progress Report for July - September, 1975, ORNL-TM-5150 (December 1975).

B-10.8. R. H. Chapman, Multirod Burst Test Program Quarterly Progress. Report for October - December, 1975, ORNL/NUREG/TM-10 (May 1976).

B-10.9. A. L. Bement, Jr., Effects of Cold-Work and Neutron Irradiation on the Tensile Properties of Zircaloy-2 HW-74955 (April 1963).

B-10.10. A. A. Bauer, L. M. Lowry, J. S. Perrin, Evaluating Strength and Ductility of Irradiated Zircaloy, Quarterly Progress Report for January through March, 1976, BM1-NUREG1948 (March 1976).

B-10.11. H. M Chung, A. M Garde, T. F. Kassner, Light-Water-Reactor Safety Research Program: Quarterly Progress Report, January-March 1976, ANL-76-49 (June 1976).

B-10.12. H. M. Chung, A. M. Garde, T. F. Kassner, Light-Water-Reactor Safety Research Program: Quarterly Progress Report July-September 1975, ANL-75-72.

B-10.13. Light-Water-Reactor Safety Research Program: Quarterly Progress Report October-December 1975, ANL-76-15.

B-10.14. W. R. Smalley, Saxton Core II Fuel Performance Evaluation Part I: Materials, WCAP-3385-56 (1971).

B-10.15. W. R. Smalley, Saxton Core III Fuel Materials Performance, WCAP-3385-57 (1974). 
A correlation is presented in this section to describe the creepdown behavior of zircaloy cladding used in LWR reactors. The correlation is primarily based on data taken under actual PWR operating conditions.

\subsection{Introduction}

A significant barrier for heat transfer from a. fuel pellet to the coolant is the fuel-tu-cladding diametral gap. Any change in the width of this gap causes a change in fucl temperatures and stored energy. One way for the gap to change is by cladding creepdown, a process during wluich 'the cladding gradually moves in toward the fuel pellets. In extrcmc cases this results in ridging or "bambooing" of the cladding due to plastic deformation after contact with the hot fuel pellets, which may themselves have swelled, also nàrrowing the gap. This kind of deformation may result in the formation of cladding cracks leading to loss of sladiding intrgrity. The sorrelation developod hore will be used in füel perluninance computer models which determine fuel temperatures, fuel and cladding deformations, pcllct-cladding mechanical inleraction, and other irradiation induced behavior mechanisms which may occur during normal (steady state) uperation.

11.1.1 Factors Which Influence Creep Rate. Four factors are used in the correlation describing creep rate. They are: temperature, fast neutron flux $(>1 \mathrm{MeV})$, time at temperature, and circumferential stress. The model has been developed for the in-pile diametral creep of zircaloy- 2 or zircaloy 4 cladding under a biaxial stress. The model is not appropriate for and does not predict the results of out-of-pile tests, uniaxial tests, or tests conducted under irradiation conditions significantly different from LWR conditions.

It was assumed that the cladding temperature was constant for the entire time from start-up until the cnd-of-lifi of the rud. 'Tlis illay be a restrlction. It can be overcóme to some extent 'by taking constant temperature time steps, but this process also has its limitations, as disciussed in Section 11.s.

11.1.2 Creep Rate Correlation. The correlation used to describe the creep rate is:

$$
\dot{\varepsilon}=\frac{5.7 \times 10^{-12}\left(1+10^{8} \mathrm{~T}^{-7} \phi^{0.65}\right)\left(\sigma+710 \mathrm{e}^{4.97 \times 10^{-8} \sigma}\right)[\exp (-42000 / \mathrm{RT})]}{\sqrt{\mathrm{t}}}
$$

where

$$
\begin{aligned}
\dot{\epsilon} & =\text { diametral creep strain rate }\left(\mathrm{s}^{-1}\right) \\
\mathrm{T} & =\text { temperature }(\mathrm{K})
\end{aligned}
$$




$$
\begin{aligned}
\phi & =\text { fast neutron flux }(>1 \mathrm{MeV})\left(\text { neutrons } / \mathrm{m}^{2} \cdot \mathrm{s}\right) \\
\sigma & =\text { stress }(\mathrm{Pa}) \\
\mathrm{R} & =\text { universal gas constant }(8.3 .14 / \mathrm{mol} \cdot \mathrm{K}) \\
\mathrm{t} & =\text { time }(\mathrm{s}) .
\end{aligned}
$$

The data chosen as a basis for the correlation are discussed in Section B-11.2. Equation (B-11.1) is derived and discussed in Section B-11.3, a comparison of its predictions with data is made in Section B-11.4, its limitations discussed in Section B-11.5, and an estimate of its uncertainty made in Section B-1 1.6. The FOR'IRAN subcode CCRPR is listed in Section B-1 1.7.

\subsection{Data Survey}

While there is an impressive amount of creep data available, only a very few are chosen for consideration here. Many of the data conflict, and it is likely llial this is the result of differing experimental conditions, material geometries, or actual materials. To obtain a correlation which predicts creep under typical LWR conditions, the criteria outlined in Sections B-11.2.1 to -11.2.3 were applied for the selection of data.

11.2.1 Typical LWR Experimental Conditions. Only typical LWR operating conditions were considered. This exciudes ilie diata of Dressler et al $[\mathrm{B}-11.1]$ because the temperature was too low, the SGHWR ${ }^{[a]}$ data reported by D. S. Wood ${ }^{[B-11.2]}$ because an entirely different reactor system and fast flux spectrum was used, that of Yagee and Purohit ${ }^{[B-11.3]}$ and Gärtner and Stehle ${ }^{[B-11.11]}$ again due to a different type of reactor (gas-cooled and heavy water moderated, respectively) as wcll as many other results from gas and liquid metal cooled reactors.

Another condition for usage of experimental data was that the measurements were performed in-pile. Thus, other data sources such as Ibrahim and Coleman ${ }^{[B-11.4]}$, Fidleris $^{[B-11.5]}$, Stehle et al ${ }^{[B-11.9]}$, and Busby and White ${ }^{[B-11.10]}$ were excluded.

Such potential data sources as Azzarto et al ${ }^{\text {[B-11.6] }}$, Ross-Ross and Fidleris ${ }^{\text {[B-1 }}$ 1.7] and Fidleris ${ }^{[B-11.8]}$ were rejected because only uniaxial creep was considered in their experiments, whereas in normal reactor operation cladding experiences biaxial creep.

11.2.2 Tubular Specimen Geometry: Some creep experiments were conducted with plate specimens or segments cut from the cladding, rather than with actual tubular samples. Since the stress interactions inherent to tubular specimens are necessarily absent in such tests, data obtained from them are not considered in this report. Among such tests are those of Fidleris $[\mathrm{B}-11.5]$, Azzarto et al ${ }^{[\mathrm{B}-11.6]}$, Kreyns and Burkart ${ }^{[\mathrm{B}-11.12]}$, and Fidleris and Williams $\left.{ }^{[B-1} 1.13\right]$

[a] Steam generating heavy water reactor. 
11.2.3 LWR Cladding Materials. The; creep rate of zirconium based alloys depends on both the alloy's composition and the texture of various samples having the same composition. Since the correlation presented in this report is meant to describe zircaloy 4 or zircaloy-2 fuel pin cladding, other alloys have been largely excluded.

There is much creep data available for a zirconium alloy containing a small percentage of niobium; used extensively in the pressure tubes of Canadian CANDU reactors. The creep behavior of this alloy differs appreciably from that of zircaloy cladding. Therefore, data describing this material, including that of Ibrahim [B-11.14], Ells and Fidleris $[\mathrm{B}-11.15]$, Gilbert $^{[\mathrm{B}-11.16]}$, and Langford and Mooder ${ }^{[\mathrm{B}-11.17]}$, and many others have not been included. There is also much data available on the creep of zircaloy-2 pressure tubes. Although this material is identical to zircaloy fuel rod cladding in chemical composition, it differs in texture, as illustrated by the typical pole figures shown in Figure B-11.1 [a] . From these figures it is evident that the c-axes in the fuel cladding are oriented predominantly in the radial direction, while in pressure tubes their orientation tends to be intermediate between the radial and tangential directions with a slight preference for the tangential. The c-axes are perpendicular to the $(0001)$ basal planes in the unit cells of the zirconium hexagonal close-pack structure. In at least one instance, Kohn $[\mathrm{B}-11.18]$, it has been reported that this texture difference can cause the biaxial creep rates of the two materials to differ by a factor of ten. Kohn's data however, were obtained from zircaloy-2.5 wt \% Nb, and other data on zircaloy-2 cladding and zircaloy-2 pressure tubes do not indicate such an extreme dissimilarity. For example, Ibrahim ${ }^{[B-11.19]}$ shows that the creep rates of these two materials differ by only $20 \%$, with the fuel cladding having the greater rate in every case.

11.2.4 Data Used for Development of the Correlation. Only a few data were found to meet these extensive criteria. The best of these were from the Saxton Plutonium Project $[\mathrm{B}-11.20-\mathrm{B}-11.22]$ where many profilometry data were reported for different rods at varying axial locations and burnups. The rods were separated into groups of approximately the same burnup, and the cladding outside diameters wcre measured at various axial locations after 9750 hours of operating time. The data pertaining to these rods are presented in Table B-1:1.I. Because there are only five data in this set, it was possible.to fit them very well with a single correlation. However, a paper by Ibrahim [B-11.23] contains data which satisfy all the criteria except the last (Section B-11.2.3), having been taken from material with a texture similar to that of pressure tubes. These data are presented on Table B-11.II. In spite of this, these Ibrahim data were tried in the correlation developed for cladding, largely because they cover somewhat different temperature and stress ranges. It was found that for operating times comparable to those of the Saxton data the correlation predicted these pressure tube creep rates with reasonable accuracy if multiplied by a constant factor of 0.8 .

[a] The word "typical" is quite important. These figures illustrate only general differences between the two materials. It would be accurate to say there is a distinctive pole figure for every piece of zircaloy. 

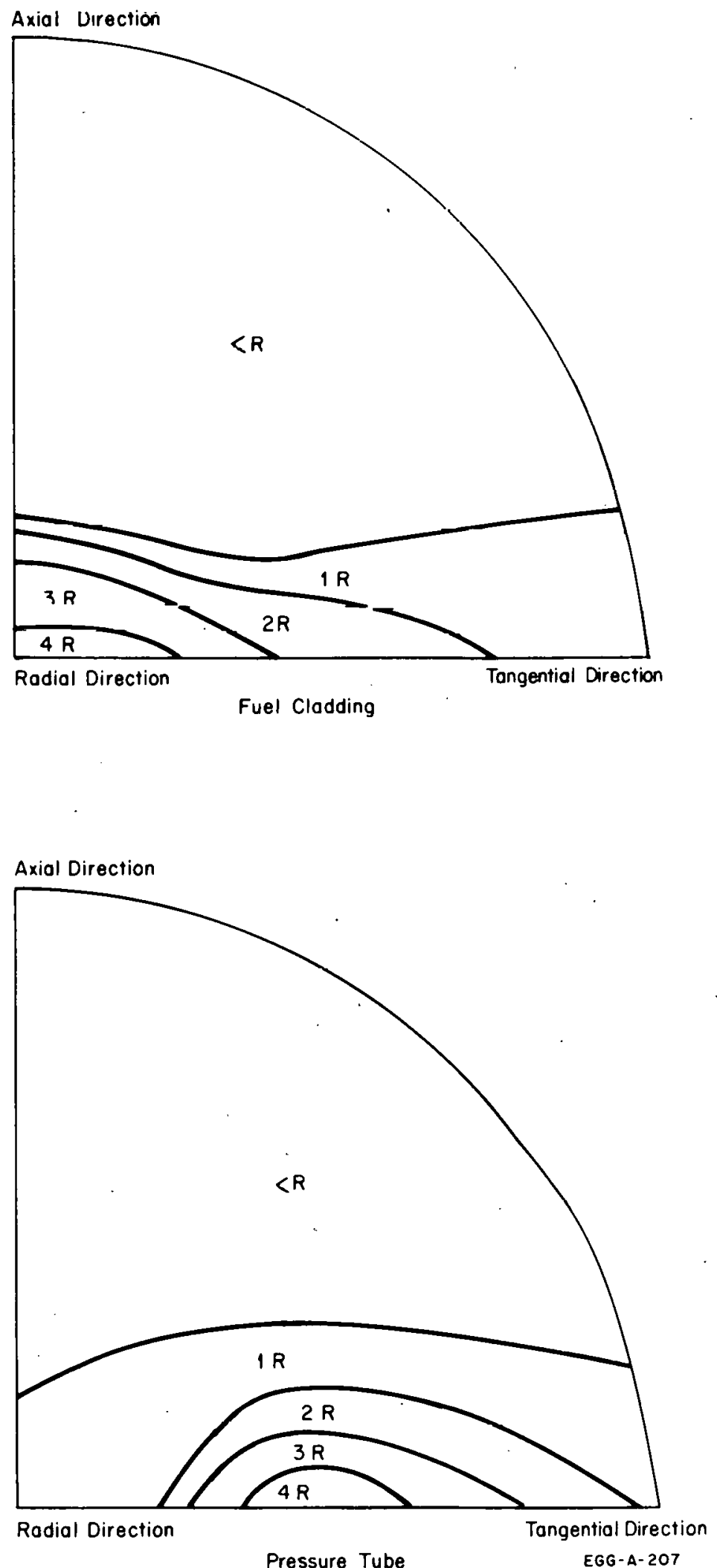

Fig. B-11.1 Typical pole figures showing texture differences between zircaloy pressure tubes and fuel rod cladding. 
TABLE. B-11.I

SAXTON RODS CREEPDOWN DATA AT 9750 HOURS $^{\text {[a] }}$

\begin{tabular}{|c|c|c|c|c|}
\hline $\begin{array}{c}\text { Rod Average } \\
\text { Power } \\
(\mathrm{kW} / \mathrm{m}) \\
\end{array}$ & $\begin{array}{c}\text { Initial } \\
\text { Backfill } \\
\text { Pressure } \\
(\mathrm{Pa}) \\
\end{array}$ & $\begin{array}{l}\text { Average } \\
\text { Cladding } \\
\text { Stress } \\
(\mathrm{MPa}) \\
\end{array}$ & $\begin{array}{c}\text { Average } \\
\text { Cladding } \\
\text { Temperature } \\
(\mathrm{K}) \\
\end{array}$ & $\begin{array}{c}\text { Measured } \\
\text { Creep Rate } \\
\left(\mathrm{s}^{-1}\right) \\
\end{array}$ \\
\hline 15.55 & $1.034 \times 10^{5}$ & 89.7 & 614 & $3.64 \times 10^{-11}$ \\
\hline 17.09 & $1.034 \times 10^{5}$ & 89.0 & 621 & $4.00 \times 10^{-11}$ \\
\hline 18.50 & $1.034 \times 10^{5}$ & 88.3 & 627 & $4.08 \times 10^{-11}$ \\
\hline 21.33 & $1.034 \times 10^{5}$ & 86.9 & 629 & $3.64 \times 10^{-11}$ \\
\hline 25.92 & $1.034 \times 10^{5}$ & 83.5 & 633 & $1.64 \times 10^{-11}$ \\
\hline
\end{tabular}

[a] All rods were in a fast flux $(>1 \mathrm{MeV})$ of $2.168 \times 10^{.17}$ neutrons $/ \mathrm{m}^{2} \cdot \mathrm{s}$.

TABLE B-11. II

IBRAHIM ${ }^{[B-1] .24]}$ PRESSURE TUBE CREEP DATA AT 10000 HOURS $[\mathrm{a} \cdot]$

$\begin{array}{cc}\begin{array}{c}\text { Average Cladding Stress } \\ (\text { Mila })\end{array} & \frac{\begin{array}{c}\text { Measured Creep Rate } \\ \left(\mathrm{s}^{-1}\right)\end{array}}{110} \\ 135 & \begin{array}{r}1.13 \times 10^{-11} \\ 171\end{array} \\ 203 & 2.78 \times 10^{-11} \\ 241 & 3.78 \times 10^{-11} \\ 260 & 6.75 \times 10^{-11} \\ & 1.00 \times 10^{-10}\end{array}$

[a] Cladding temperature was $536 \mathrm{~K}$ and fast neutron flux was $2.9 \times 10^{17}$ neutrons $/ m^{2} \cdot s$ in all cases. 


\subsection{Model Derivation}

The time dependence of the correlation presented here is of the same form as that proposed by Ibrahim [B-11.23]. Each of the four important parameters: time, stress, temperature, and fast flux are discussed. Often, authors whose data were rejected are cited in these sections because of the lack of data which meet the criteria and their arguments and correlations are qualitatively, if not quantitatively applicable.

11.3.1 Time Dependence. Ibrahim concludes that the total creep $(\epsilon)$ is adequately represented by:

$$
\varepsilon=\beta t^{I I I}
$$

where

$$
\begin{aligned}
& \beta=\begin{array}{l}
\text { constant if all other experimental parameters are held } \\
\text { constant and only time allowed to vary }
\end{array} \\
& \mathrm{t}=\text { time } \\
& \mathrm{m}=\text { a constant. }
\end{aligned}
$$

Creep with this strain-time relationship has been reported often in the literalure for mally different types of alloys $[\mathrm{B}-11.24]$. It is usually described as the result of work hardening. dominating over recovery. Ibrahim [B-11.23] discusses this at some length in his paper. In a fast flux environment, Ibrahim finds that the best value for $m$ is 0.468 . Kreyns and Burkart $[\mathrm{B}-11.12]$ find values for $\mathrm{m}$ ranging from 0.43 to 0.60 for their nontubular specimens of $50 \%$ cold-worked zircaloy-4. Ross-Ross and Fidleris [B-11.7] find an exponent ranging from 0.8 to 1 from their uniaxial data, while Fidleris ${ }^{[B-11.5]}$ estimates values from 0 to 0.33 . When Equation (B-11.2) is differentiated with respect to time to obtain $\dot{\epsilon}$, the time exponent is $(\mathrm{m}-1)$ which, in all the cases quoted above, will be either negative or zero. A negative value for $m$ indicates a creep rate continuously diminishing with time and an adequate equation was developed using $\mathrm{m}=0.5$, which means that $\dot{\epsilon} \propto 1 / \sqrt{\mathrm{t}}$.

11.3.2 Stress Dependence. It is clear that a high stress will give a high creep rate, but because of the anisotropy of zircaloy and the complex internal stress interactions within a stressed tubular specimen, this dependence is not necessarily linear, although several investigators have reported stress dependence as linear [B-11.7, B-11.12, B-11.25, B-11.26]. A variety of analytical expressions have been tried to model the stress dependence. Several authors use hyperbolic functions: (a) cosh $\left(1.67 \times 10^{-2} \sigma\right)$ by Wood [B-11.2], (b) $\sinh (\mathrm{A} \sigma)$ where $\mathrm{A}$ increases with temperature from $2.2 \times 10^{-3}$ at $1075 \mathrm{~K}$ to $9.8 \times 10^{-3}$ at $1367 \mathrm{~K}$ by Busby and White ${ }^{[\mathrm{B}-11.10]}$, (c) $\sinh (\mathrm{A} \sigma)$ where $\mathrm{A}$ is a detailed function of such things as dislocation spacing and mobility by Fidleris and Williams $[\mathrm{B}-11.13]$, and (d) sinh $\left(7.5 \times 10^{-5 \sigma}\right)$ by Pankaskie [B-11.27]. A quite popular form is $\dot{\epsilon} \propto \sigma^{\mathrm{n}}$ with $\mathrm{n} \neq 0$. This is used by (a) Coleman $[\mathrm{B}-11.28]$ where $90 \underset{<}{\sim} \mathrm{n} \underset{<}{\sim} 10$, (b) Kohn $[\mathrm{B}-11.18]$ where $5.3 \widetilde{\mathrm{n}} \widetilde{<}$; 
(c) Azzarto et al ${ }^{[B-11.6]}$ where $n \simeq 4$; (d.) Fidleris $[B-11: 8]$ where $n \approx 3$; (e) Wood and Atkins $[\mathrm{B}-11.29]$ where $10 \underset{<}{\sim} \sim 50$, and many others. Many of the data indicate that the strain rate is linear for relatively low stress, and then exhibits a stronger dependence as the stress increases. For example, Bernstein $[\mathrm{B}-11.30]$ found that the stress dependence of zircaloy-2 was proportional to $\sigma^{n}$, where $n=1$ at low stresses and increases to 4.5 to 5.5 at higher stresses. Nichols $[\mathrm{B}-11.31]$ provided more insight along these lines, hypothesizing the in-pile creep mechanisms and specifying their stress dependence. Some of the mechanisms identified by Nichols, in order of increasing stress are:

(1) Preferential alignment of vacancy and interstitial loops $(\dot{\epsilon} \propto \sigma)$

(2) Glide of dislocations $\left(\dot{\epsilon} \propto \sigma^{10}\right)$

(3) Radiation-enhanced glide of edge dislocations over radiation produced obstacles $\left(\dot{\epsilon} \propto \sigma\right.$ at low $\sigma$ to $\dot{\epsilon} \propto \sigma^{4}$ at high $\sigma$ )

(4) Destruction of radiation obstacles $\left(\dot{\epsilon} \propto \sigma^{100}\right)$.

This dramatic increase in the stress dependence suggests an exponential function, which is of course also described by the hyperbolic forms cited earlier. The data fit best to an expression of the form $\left(\sigma+\mathrm{Ae}^{-\beta \sigma}\right)$, where $\beta$ is small enough so that the linear stress dependence at low stresses ( $\sigma \simeq 200 \mathrm{MPa}$ ) is not disturbed, but the general increase in $\dot{\epsilon}$ with $\sigma$ at high stresses is properly reflected.

11.3.3 Fast Flux Dependence: Although most investigators agree that a fast flux environment enhances the zircaloy creep rate and that the enhancement is of the form $\phi^{\mathrm{a}}$, where $\phi$ is the fast flux, there is disagreement about the magnitude of the exponent $a$ : Fidleris $[B-11.32]$ gives a value for a of 1.0 and states that it might even be more. Duffin and Nichols [B-1 1.23], Piercy [B-11.34], Ross-Ross and Hunt ${ }^{[B-11.26]}$, and Ross-Ross and Fidleris $[\mathrm{B}=11.7]$ also suggest that $\dot{\epsilon}$ is directly proportional to the fast flux. Wood $^{[\mathrm{B}-11.2, \mathrm{~B}-11.29]}$ uses $\dot{\epsilon} \propto \phi^{0.85}, \mathrm{Kohn}{ }^{[\mathrm{B}-11.18]}$ uses $\phi^{0.65}$, and Gilbert [B-1 1.35] uses $\phi^{0.5}$. Ilowever, several authors have noted that irradiation-induced crecp is ovcrshadowed by thermally activated creep at high temperatures. Among these are Nichols $[\mathrm{B}-11.25, \mathrm{~B}-11.31]$, Pankaskie $^{[\mathrm{B}-11.27]}$, Fidleris and Williams ${ }^{[\mathrm{B}-11.13]}$, and Kohn ${ }^{[B-11.18]}$. Fidleris and Williams give the transition temperature as $523 \mathrm{~K}$ and Nichols as about $623 \mathrm{~K}$. Some authors, such as Pankaskie give two correlations, one for high temperature and one for low temperature, with the transition being between 600 and $625 \mathrm{~K}$. The most logical approach seems to be that of Kohn ${ }^{[\mathrm{B}-11.18]}$ who models the flux dependence in the form $\mathrm{K} \mathrm{T}^{-7} \phi^{0.65}$, where $\mathrm{K}$ is a fairly large constant to moderate the small numbers resulting from the $\mathrm{T}^{-7}$ term. This functional form has the virtue of cutting off the flux term at high temperatures as well as automatically accounting for the fact that the higher the flux level is, the higher the temperature must be to negate the effect of flux. The expression used in the correlation is $\left(1+10^{8} \mathrm{~T}^{-7} \phi^{0.65}\right)$. The exponent 0.65 was chosen because it gave the best fit to the data. The 1 is added to the temperature dependent term to provide calculational continuity at zero flux and to allow proper modeling of thermal creep at high temperatures. 
11.3.4 Temperature Dependence. In addition to the temperature dependence in the flux term, there is a creep activation energy to be overcome by thermal energies. This is modeled using an Arrhenius function. Because several creep mechanisms exist, authors have reported different values for this activation energy, ranging from over $10^{5} \mathrm{~J} / \mathrm{mol}[\mathrm{B}-11.18, \mathrm{~B}-11.11, \mathrm{~B}-11.30]$ to less than $10^{4} \mathrm{~J} / \mathrm{mol}[\mathrm{B}-11.12]$. Often, authors reported different activation energies in different temperature ranges $[\mathrm{B}-11.18, \mathrm{~B}-11.32]$, but in the interest of calculational simplicity only a single activation energy has been used here. The value giving the best fit was $4.2 \times 10^{4} \mathrm{~J} / \mathrm{mol}$.

11.3.5 Possible Factors Not Included. There are several other variables which may affect the creep rate but have not been included in the correlation. A few of these are discussed below.

Material Fabrication: The correlation was developed using Saxton cladding data. This cladding was highly cold worked then stress relieved at $825 \mathrm{~K}$ for two hours to give an "equivalent" cold work of $10 \%$ [B-11.36]. The fabrication history of a sample can influence the subsequent creep rate by as much as a factor of two or more. Ibrahim [B-11.23], Frenkel and Weisz ${ }^{[B-11.37]}$, and Kreyns and Burkart ${ }^{[B-11.12]}$ all agree that annealing increases the resistance of zircaloy to creep: However, Frenkel and Weisz found that the resistance increased with annealing temperature, while Kälström et al ${ }^{[\mathrm{B}-11.38]}$ found that the resistance was maximum after annealing at about $790 \mathrm{~K}$ and was less when annealed at higher or lower temperatures.

Previous Irradiation: There is general agreement $[\mathrm{B}-11.11, \mathrm{~B}-11.2 \overline{7}, \mathrm{~B}-11.32]$ that prior irradiation increases the resistance to creep, especially at high creep rates, but the information about this is not yet quantitative enough to include in a model.

Hydrogen Content: Gärtner and Stehle ${ }^{[B-11.11]}$ reported that hydrogen contents of as much as $100 \mathrm{ppm}$ at $673 \mathrm{~K}$ do not affect the creep rate. Very high concentrations of hydrogen could have an effect but relevent data are not available.

11.3.6 Creep Rate Correlation. As summarized in the introduction, the correlation used to model the creep rate is given by Equation (B-11.1):

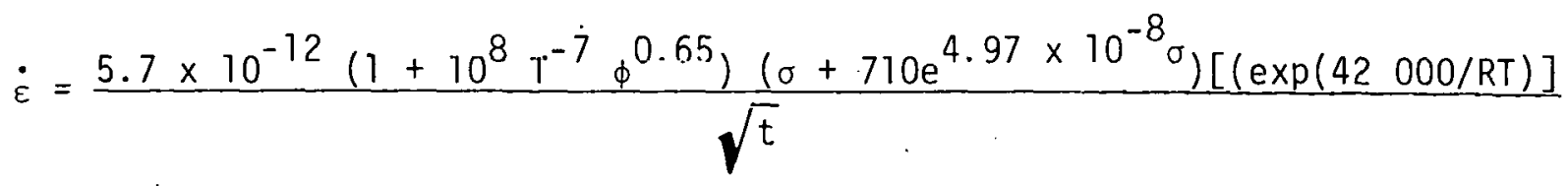

where

$$
\begin{aligned}
\dot{\epsilon} & =\text { diamteral creep strain rate }\left(\mathrm{s}^{-1}\right) \\
\mathrm{T} & =\text { temperature }(\mathrm{K}) \\
\phi & =\text { fast neutron flux }(>1 \mathrm{MeV})\left(\text { neutrons } / \mathrm{m}^{2} \cdot \mathrm{s}\right)
\end{aligned}
$$




$$
\begin{aligned}
\sigma^{*} & =\text { stress }(\mathrm{Pa}) \\
\mathrm{R} & =\text { universal gas constant }(8.314 \mathrm{~J} / \mathrm{mol} \cdot \mathrm{K}) \\
\mathrm{t} & =\operatorname{time}(\mathrm{s}) .
\end{aligned}
$$

The predictions of this equation for a typical PWR case are shown in Figure B-11.2 where total creep is plotted as a function of time up to $3.5 \times 10^{7} \mathrm{~s}(1.1$ years $)$ and for two different fluxcs.

\subsection{Comparison of Model Predictions with Experimental Data}

Within its range of validity as specified by the criteria of Section.B-11.2, Equation (B-11.1) does quite well. With a multiplicative prefactor of 0.8 ; it is also able to predict some pressure tube data to within experimental uncertainty. However, it does not do well at all with data that dn not fit most of the criteria listed.

11.4.1 Comparison with the Saxton Data. The most important data set, since it was the only one which met all of the criteria; is that gleaned from the Saxton reports $[\mathrm{B}-11.20-\mathrm{B}-11.22]$. A comparison with these data is shown in Figure $\mathrm{B}-11.3$, where the 627 and $629 \mathrm{~K}$ curves are approximated by a single line calculated for $628 \mathrm{~K}$. The $1 \mathrm{~K}$ difference between each of these two data and the curve does not cause any serious error for the purpose of comparison: The agreement between the calculated curves and the data is excellent for the three lowest temperatures, but at the two higher temperatures the correlation substantially overpredicts the creep rate. The discrepancy for these two data is not considered serious however, because many of the rods from which these data were taken showed pellel-cladding mechanical interaction (PCI). Since the creep rate was obtained by simply taking the total creep and dividing by the time in-pile, the cladding may not have . been creeping for an appreciable fraction of the time due to the PCI, thus giving unrealistically low creep rates. More of the $633 \mathrm{~K}$ rods showed PCI than the $629 \mathrm{~K}$ rods, which in turn showed more than twice that of the $627 \mathrm{~K}$ rods. The 614 and the $621 \mathrm{~K}$ rods showed no PCI. The predictions of the correlation are entirely in agreoment with thesc considerations.

Finally, it is worth reiterating that although only five points are used here, each of these actually represents the average from many rods, so the correlation is based on more than five measurements.

11.4.2 Comparison with Ibrahim Data. Ibrahim's zircaloy-2 data ${ }^{[B-11.23]}$ are another set which essentially meets the criteria. It is of typical PWR dimensions, biaxially stressed, and was taken in-pile. However, it is different from the Saxton data in that the rods were internally, rather than externally pressurized and the texture was typical of pressure tube material rather than of cladding material. The comparison of these data with the correlation is shown in Figure B-11.4. The solid line is the prediction of Equation (B-11.1) and somewhat overpredicts the creep rate. This is consistent with the observation of 


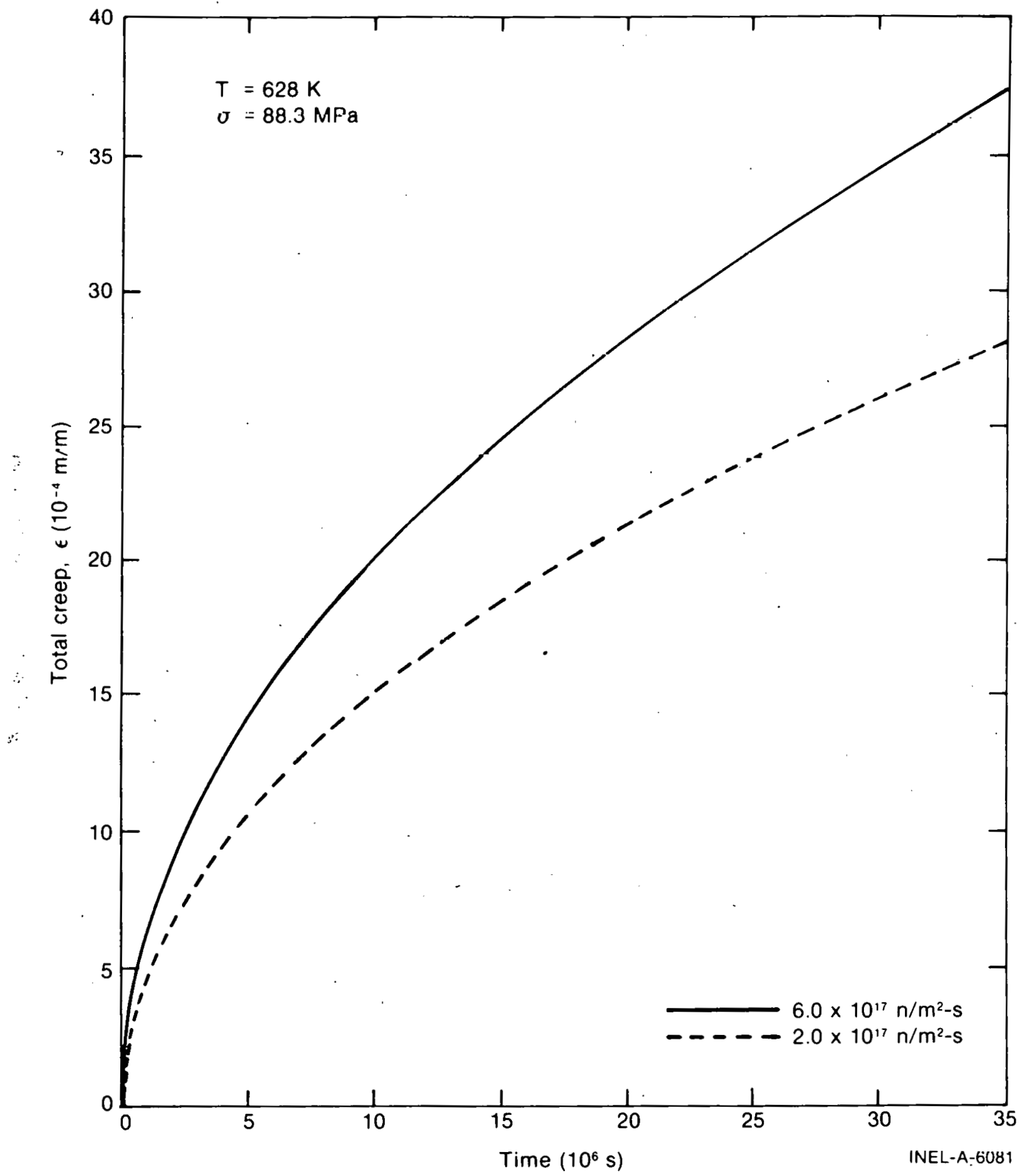

Fig. B-11.2 Total creep predicted by the cladding creep rate equation for typical PWR operating conditions and for two different flux levels, as a function of time. 


\section{CCRPR :}

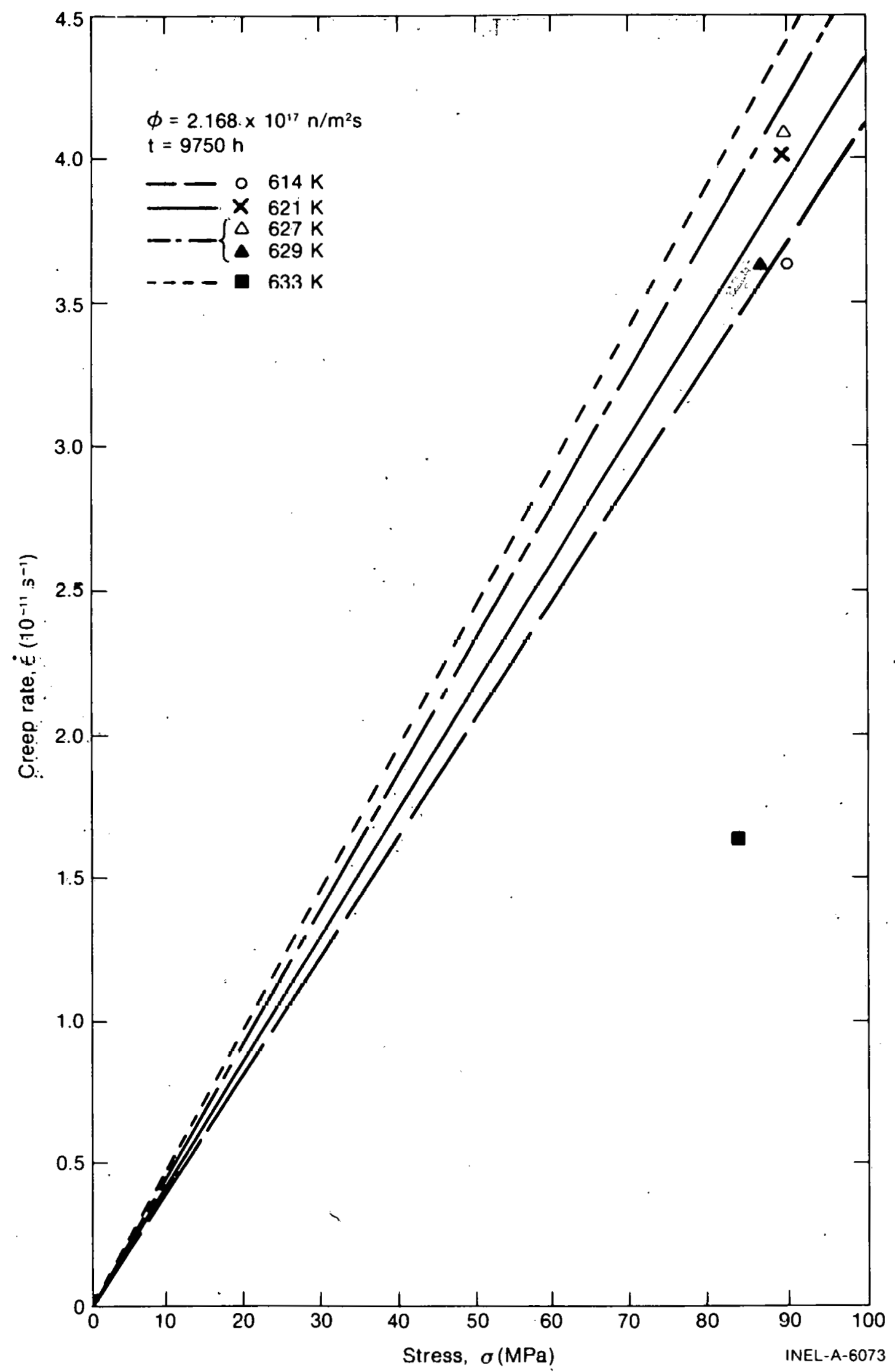

Fig. B-11.3 Comparison of the predictions of the cladding creep rate equation with the Saxton data. 


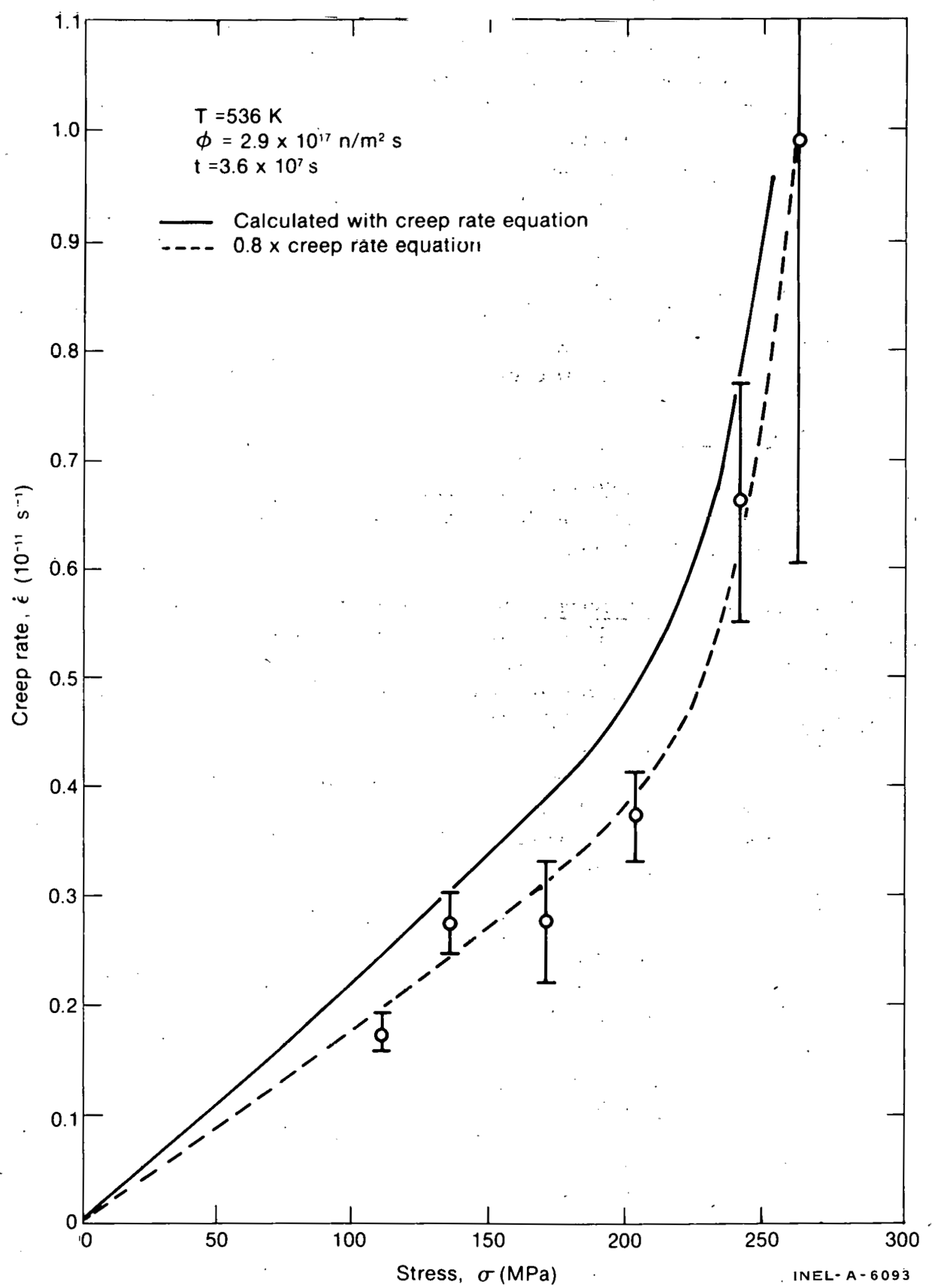

Fig. B-1 1.4 Comparison of Ibrahim's pressure tube data with the cladding creep rate equation. 
Kohn ${ }^{[B-11.18]}$ that pressure tubes do not creep as fast as cladding. The dashed line was calculated by multiplying Equation (B-11.1) by 0.8 and it fit the data quite well. In addition, Figure B-11.4 is useful in that it illustrates how the correlation predicts creep rate over a wider stress range. Specifically, it sliuws liuw the exponential part of the stress dependence causes a severe departure from a linear relationship between strain rate and stress beginning at a stress ol about $200 \mathrm{MPa}$, where the exponential term is $7.4 \%$ of the linear term. At $250 \mathrm{MPa}$, the exponential term is $71 \%$ of the linear term.

1.1.4.3 Comparison with Other Data. The correlation was tried with data from several other sources: Fidlcris[B-11.5, B-11.32], Ibrahim and Coleman[B-11.4], and Wouds[R-11 39]. Fur inusl of these data the corrclation was tound to be completely useless, predicting values which showed no systematic relationship to the data.

\subsection{Model Limitations}

Clearly, the model's validity is restricted to those materials which satisfy the criteria in Section B-1 1.2, since only data satisfying those criteria were used in its formulation. In addition there are other limitations.

11.5.1 Samples with Varying Degrees of Cold Work and Annealing. As outlined in. Section B-1 1.3.5, the data on which the stress dependence of this correlation is based were taken from material with a texture typical of pressure tube material. The specimens used by Ibrahim had significant cold work $(20 \%)$ and were not heat treated at as high a temperature as the Saxton tubing ( 673 versus $825 \mathrm{~K}$ for the Saxton tubes). While it is probable that the texture difference accounts for the necessity of adjusting Equation (B-11.1) to fit Ibrahim's data, the possibility that these differences in material treatment may also play a role cannot be eliminated until more complete data are available. Therefore, results obtained from the use of this correlation with materials of more than $20 \%$ cold work or having more complete annealing must be regarded as suspect.

11.5.2 Samples with Varying Irradiation Histories. The correlatinn was develnperd for samples which experienced a conistant fast flux level throughout their operating lifetimes. Changing irradiation levels can be handled by taking time steps and calculating the creep during the step as the product of creep rate given by Equation (B-11.1) and the duration of the time steps. However, there is evidence that prior irradiation can cause an increase in resistance to creep, so there is some doubt that the correlation will accurately predict creep rate if the fast flux is changed significantly during creepdown. Since the fast flux dependence is not particularly strong, this is probably not too serious.

11.5.3 Samples with Varying Temperature Histories. Some caution must be exercised because prior creep history is important. The creep rate after a change to a new temperature $\mathrm{T}$, at time $\mathrm{t}$, in operating life, might nol be the same as it would be at $\mathrm{t}$ had the sample been at temperature $T$ for its entire previous life. No data are available to assess the magnitude of this effect. 


\subsection{Uncertainties}

The lack of a more extensive data base makes the assignment of uncertainty limits very tentative. The error bars shown in Figure B-11.4 are Ibrahim's, presumably based on the uncertainty of his measurement. Error bars are absent from Figure B-11.3 because no similar data were avallable for thal case. The reasonablc agrcement between the correlation and these two data sets is encouraging, but a quite narrow range of the important variables is represented, especially with regard to time. It is possible that the predicted creep rates miay be in error by a factor of five for considerably different conditions. However, typical PWR operating conditions which the cladding might encounter will not differ radically from those of its data base, so an error of this magnitude is not probable. Other in-pile data, notably that of Fidlcris $[\mathrm{B}-11.8]$ for uniaxial creep, rarely differ by more than $100 \%$ from the correlations's predictions for temperatures around $600 \mathrm{~K}$ and for a wide range of fluxes and stresses (including zero flux). Therefore, it is probable that uncertainties of $+100 \%$ and $-90 \%$, are reasonable.

A listing of the FORTRAN subcode CCRPR is given in Table B-11.III.

\section{TABLE B-71. III}

\section{LISTING OF THE CCRPR SUBCOUEE}

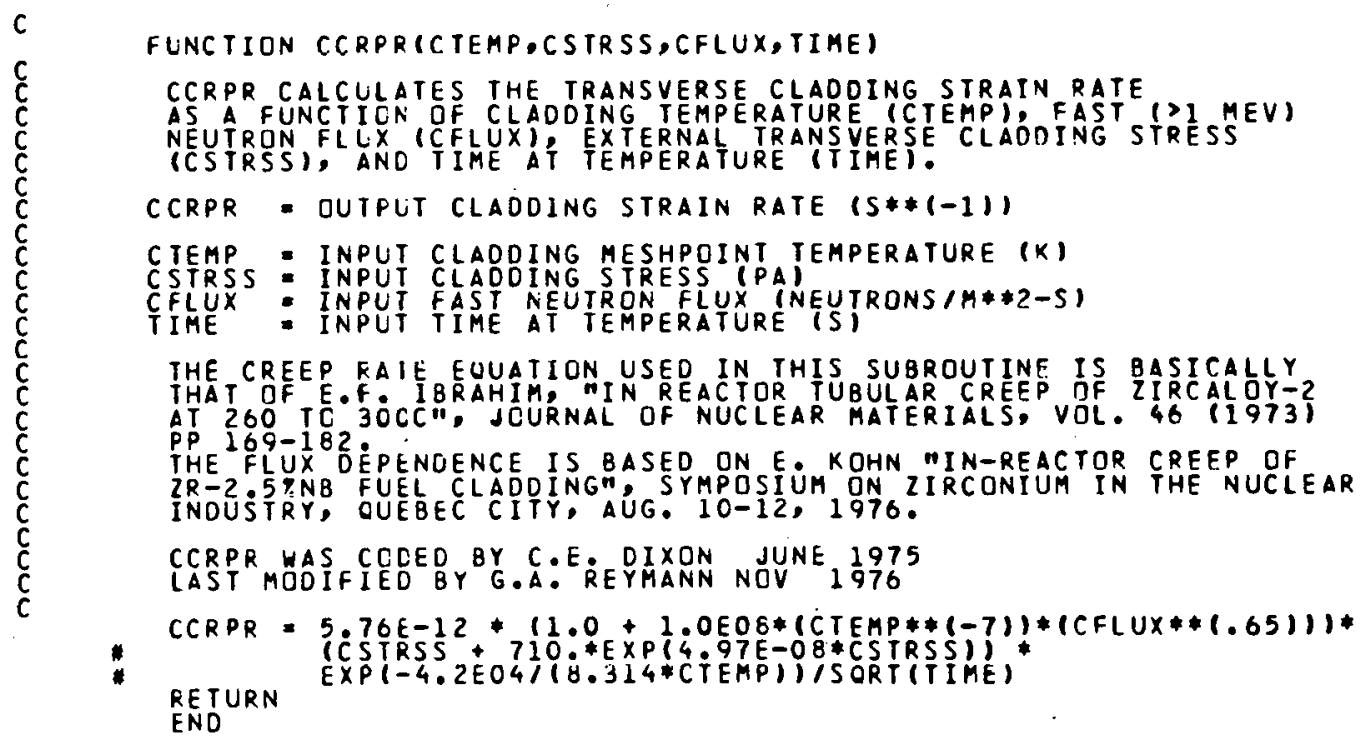

CCRPOO10 CCRPOO30 CCRPOO40 CCRPOO5O CCRPOO60 CCRPOOBO CRPO090 CCRPO100 CCRPOI2O CRPOI30 CCRPO140 CRPO160 CCRPOI70 CCRPOIBO CRPO190 CCRPO200 CRPO210 CRPOZ2O CCRPO230 CCRPO240 
CCRPR

\subsection{References}

B-11.1. G. Dressler et al, "Determination of Complete Plane Stress Yield of Zircaloy Tubing," Zirconium in Nuclear Applications ASTM-STP-551, Philadelphia, American Society for Testing and Materials, 1974, pp 72:103.

B-11.2. D. S. Wood, "Dose Dependence of Irradiation Creep of Zircaloy-2," Properties of Reactor Structural Alloys After Neutron or Particle Irradiation ASTM-STP-570, Philadelphia, American Socicty for Testing and Materials, 1975, pp 207.217.

B-1 1.3. F. L. Yagee and A. Purohit, "Biaxial Creep Characteristics of GCFR Cladding at 650" and 32.4-ksi Hoop Stress," Transactions of the American Nuclear Society, 22 (November 1975) p 182.

B-11.4. E. F. Ibrahim and C. E. Coleman, "Effect of Stress Sensitivity on Stress-Rupture Ductility of Zircaloy-2 and Zr-2.5 wt\% Nb," Canadian Metallurgical Quarterly, 12, 3 (1973) pp 285-287.

B-11.5. V. Fidleris, "The Effect of Texture and Strain Aging on Creep of Zircaloy-2," Applications Related Phenomena for Zirconium and Its Alloys ASTM-STP-458, Philadelphia, American Society for Testing and Materials, 1969, pp 1-17.

B-1 1.6. F. J. A.zzarto et al, "Unirradiated, In-Pile and Post-Irradiation Low Strain Rate Tensile Properties of Zircaloy-4," Journal of Nuclear Materials, 30 (1969) pp 208-218.

B-1 1.7. P. A. Ross-Ross and V. Fidleris, "Design Basis for Creep of Zirconium Alloy Components in a Fast Neutron Flux," International Conference on Creep and Fatigue in Elevated Temperature Applications, Philadelphia and Sheffield, UK (1973) pp 216.1-216.7.

B-11.8. V. Fidleris, "Uniaxial In-Reactor Creep of Zirconium Alloys," Journal of Nuclear Materials. 26 (1968) pp .51-76.

B-1 1.9. H. Stehle et al, (Preprint) "Mechanical Properties, Anistropy and Microstructure of Zircaloy Canning Tubes," Symposium on Zirconium in the Nuclcar Industry, Quebec City, August 10-12, 1976, ASTM-CNA/AIME, Kraftwerk Union (Germany).

B-11.10. C. C. Busby and L. S. White, Some High Temperature Mechanical Properties of Internally Pressurized Zircaloy-4 Tubing, WAPD-TM-1243 (February 1976).

B-11.11. M. Gärtner and H. Stehle, In-Pile Creep Behaviour of Zircaloy-4 Cladding Tubes at $400^{\circ} \mathrm{C}$, Siemens Aktiengesellschaft Reaktortechnik (September 1972). 
B-11.12. P. H. Krcyns and M. W. Burkart; "Radiation-Fnhanced Relaxation in Zircaioy-4 and $\mathrm{Zr} / 2.5 \mathrm{wt} \% \mathrm{Nb} / 0.5 \mathrm{wt} \%$ Cu Alloys," Journal of Nuclear Materials, 26 (1968) pp 87-104.

B-1 1.13. V. Fidleris and C. D. Williams, "Influence of Neutron Irradiation' of Zircaloy-2 at $300^{\circ} \mathrm{C}$," Journal of Electrochemical Technology, 4' (May-June 1966), pp 258-267.

B-11.14. E. F. Ibrahim, "In-Reactor Creep of Zirconium - 2.5 Nb. Tubes at $570 \mathrm{~K}$," Zirconium in Nuclear Applications ASTM-STP-55.1, Philadelphia; American Society for Testing and Materials, 1974, pp 249-262.

B-11.15. C. E. Ells and V. Fidleris, "Etfect of Neutron Irradiation on Tensile Properties of the Zirconium - 2.5 Weight Percent Niobium Alloy," Journal of Electrochemical Technology, 4 (May - June 1966), pp 268-274.

B-11.16. E. R. Gilbert, "In-Reactor Creep of Zr-2.5 wt\% Nb," Journal of Nuclear Materials, 26 (1968), pp 105-111.

B-11.17. W. J. Langford and L. E. J. Mooder, "Metallurgical Properties of Irradiated Cold-Worked of Zr-2.5 wt\% Nb Pressure Tubes," Journal of Nuclear Materials, 30 (1969), pp 292-302.

B-11.18. E. Kohn, "In-Reactor Creep of Zr-2.5 wt\% Nb Fuel Cladding," Symposium on Zirconium in the Nuclear Industry, Quebec City, August 10-12, 1976.

B-1 1.19. E. F. Ibrahim, "In-Reactor Creep of Zirconium-Alloy Tubes and Its Correlation. with Uniaxial Data," Applications-Related Phenomena for Zircaloy and Its Alloys, ASTM-STP-458, Philadelphia, American Society for Testing and Materials, 1969, pp 18-36.

B-11.20. W. R. Smalley, Saxton Plutonium Program: Semi Annual Progress Report for the Period Ending June 30, 1969, WCAP-3385-20 (October 1969).

B-1 1.21. T. E. Caye and W. R. Smalley, Saxton Plutonium Project, Quarterly Progress Report for the Period Ending December 31, 1970, WCAP-3385-26 (March 1970).

B-11.22. W. R. Smalley, Evaluation of Saxton Core III Fuel Materials Performance, WCAP-3385-57 (July 1974).

B-11.23. E. F. Ibrahim, "In-Reactor Tubular Creep of Zircaloy-2 at $260^{\circ} \mathrm{C}$ and $300^{\circ} \mathrm{C}$," Journal of Nuclear Materials, 46 (1973) pp 169-182.

B-1 1.24. H. Conrad, "Experimental Evaluation of Creep and Stress-Rupture," Mechanical Behavior of Materials at Elevated Temperatures, New York: McGraw-Hill, 1961, p 149. 
CCRPR

B-11.25. F. A. Nichols, "Theory of the Creep of Zircaloy During Neutron Irradiation," Journal of Nuclear Materials, 30 (1969) pp 249-270.

B-11.26. P. A. Ross-Ross and Hunt, "The In-Reactor Creep of Cold-Worked Zircaloy-2 and Zirconium-2.5 wt\% Niobium Pressure Tubes," Journal of Nuclear Materials, 26 (1968) pp 2-17.

B-11.27. P. J. Pankaskie, Irradiation Effects on the Mechanical Properties of Lirconium and Dilute Zirconium Alloys - A Review, BN-SA-618 (July 1976, updated November 1976).

B-1 1.28. C. E. Coleman, "Tertiary Creep in Cold-Worked Zircaloy-2," Journal of Nuclear Materials, 42 (1971), pp 180-190.

B-11.29. D. S. Wood and B. Watkins, "A Creep Limit Approach to the Design of Zircaloy-2 Reactor Pressure Tubes at $275^{\circ} \mathrm{C}$," Journal of Nuclear Materials, 41 (1971), pp 327-340.

B-11.30. M. Bernstein, "Diffusion Lreep in Zirconium and C'ertain Zirconium Alloys," Transactions of the Melallurgical Society of AIME, 239 (1969), pp 1518-1522.

B-11.31. F. A. Nichole, "On the Mechanisme of Irradiation Crecp in Zirconium-Base Alloys," Journal of Nuclear Materials, 37 (1970), pp 59-70.

B-11.32. V. Fidleris, "Uniaxial In-Reactor Creep of Zirconium Alloys," Journal of Nuclear Materials, 26 (1967), pp 51-76.

B-11.33. W. J. Duffin and F. A. Nichols, "The Effect of Irradiation on Diffusion-Controlled Creep Processes," Journal of Nuclear Materials, 45 (1972/1973), pp 302-316.

B-11.34. G. R..Pierey, "Mechanisms for the In-Reactor Creep of Zirconium Alloys," Journal of Nuclear Materials, 26 (1968'), pp 18-50.

B-11.35. E. R. Gilbert, "In-Reactor Creep of Reactor Materials," Reactor Technology, 14 (Fall 1971), pp 258-285.

B-1 1.36. W. R. Smalley, Saxton Core II Fuel Performance Evaluation Part I: Materials, WCAP-3385-56 (September 1971).

B-1 1.37. T. M. Frenkel and M. Weisz, "Effect of the Annealing Temperature on the Creep Strength of Cold-Worked Zircaloy-4 Cladding," Zirconium in Nuclear Applications ASTM-STP-551, Philadelphia, American Society for Testing and Materials, 1974, pp 140-144. 
B-1 1.38. K. Källström et al, "Creep Strength of Zircaloy Tubing at $400^{\circ} \mathrm{C}$ as Dependent on Metallurgical Structure and Texture," Zirconium in Nuclear Applications ASTM-STP-551, Philadelphia, American Society for Testing and Materials, 1974, pp 160-168.

B-11.39. C. R. Woods (ed.), Properties of Zircaloy-4 Tubing, WAPD-TM-585 (December 1966).

\section{CLADDING POISSON'S RATIO (CPOIR)}

Poisson's ratio is defined as the ratio of diametral to axial strain and is dimensionless. The theoretical value of Poisson's ratio for isotropic or ideal materials has been reported as 0.5 by Van Vlack $[\mathrm{B}-12.1], 0.25$ by Dieter $[\mathrm{B}-12.2]$, and 0.33 by Shanley $[\mathrm{B}-12.3]$. Dieter notes that most metals have a Poisson's ratio of about 0.33 .

Scott ${ }^{[B-12.4]}$, Shober et al ${ }^{[B-12.5]}$, and Johnson ${ }^{[B-12.6]}$ have reported experimental data for the Poisson's ratio of zircaloy. Scott reported data and a correlation for the Poisson's ratio of zircaloy 4 from about 21 to $400^{\circ} \mathrm{C}$ using annealed, unirradiated material. These data show a decrease in Poisson's ratio with increasing temperature. Shober reported values for Poisson's ratio of 0.368 to 0.380 at $27^{\circ} \mathrm{C}$ and 0.425 to 0.460 at $150^{\circ} \mathrm{C}$ using annealed, unirradiated zircaloy-2: that is, an increase in Poisson's ratio was reported for increasing temperature. Johnson reported values of Poisson's ratio of $0.325 \pm 0.015$ at room temperature for annealed, unirradiated zircaloy-2. Since Johnson's data were derived from shear modulus test data, they may be less applicable than the data of Scott and Shober et al. The data of Scott, Shober et al, and Johnson and the correlation of Scott are shown in Figure B-12.1. The cause of the differences between the reported data is not apparent, and a value judgment would be difficult to make or justify until more data or correlations become available.

Because Scott's data are more extensive, his correlation was used in the CPOIR subcode to estimate Poisson's ratio as a function of temperature; that is:

$$
\text { Poisson's ratio }=0.333-1.26 \times 10^{-4} \mathrm{~T} \text {. }
$$

where

$$
\mathrm{T}=\text { temperature }(\mathrm{K})
$$

Due to the relatively large data scatter and to the lack of data at higher temperatures, Poisson's ratio at temperatures above $670 \mathrm{~K}$ is assumed to be 0.248 , the value given by Equation (B-12.1) at $\mathrm{T}=670 \mathrm{~K}$. 


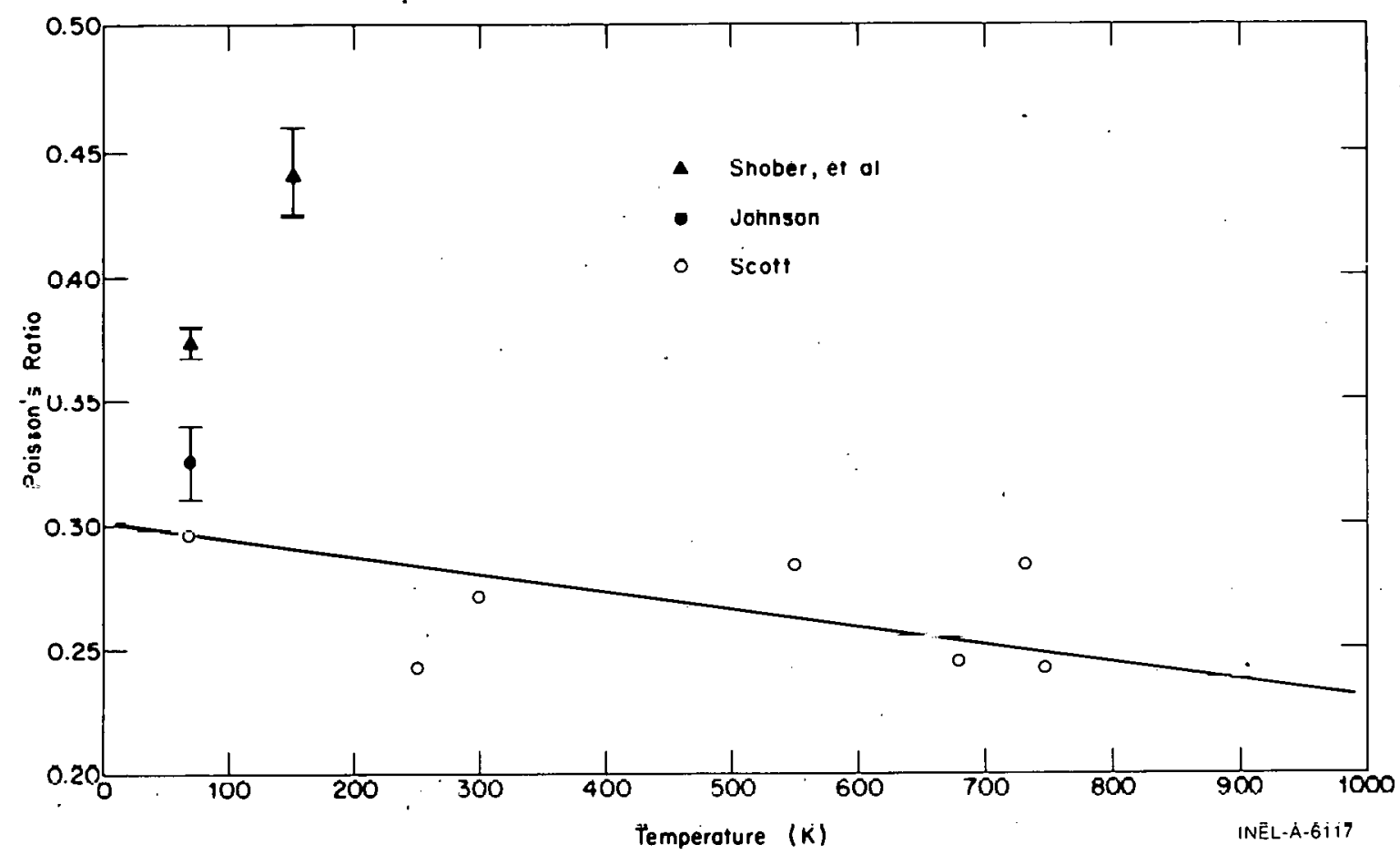

Fig. B-12.1 Temperature dependencc of Poisson's ratio for zircaloy as used in the CPOIR subcode.

12.1 Cladding Poisson's Ratio Subcode CPOIR Listing

The FORTRAN subcode CPOIR is listed in Table B-12.I.

\subsection{References}

B-12.1. L. H. Van Vlack, Materials Science for Engineers, Reading: Addison-Wesley rublishing Company, 19'/1, pp 19U-191.

B-12.2. G. E. Dieter, Jr., Mechanical Metallurgy, New York! McGraw-Hill Book Company, Inc., 1961, p 36.

B-12.3. F. R. Shanley, Strength of Materials, New York: McGraw-Hill Book Company, Inc., 1957, pp 138-139.

B-12.4. D. B. Scott, Physical and Mechanical Properties of Zircaloy-2 and -4, USAEC WCAP-3269-41 (May 1965).

A

B-12.5. F. R. Schober, J. A. Van Echo, L. L. Marsh, Jr., J. R. Keeler, The Mechanical Properties of Zirconium and Zircaloy-2, USAEC BMI-1 168 (February 1957).

B-12.6 R. E. Johnson, The Torsional Properties of Zircaloy-2 and Zircaloy-4, USAEC WAPD-BT-10 (October 1958) pp 49-56. 


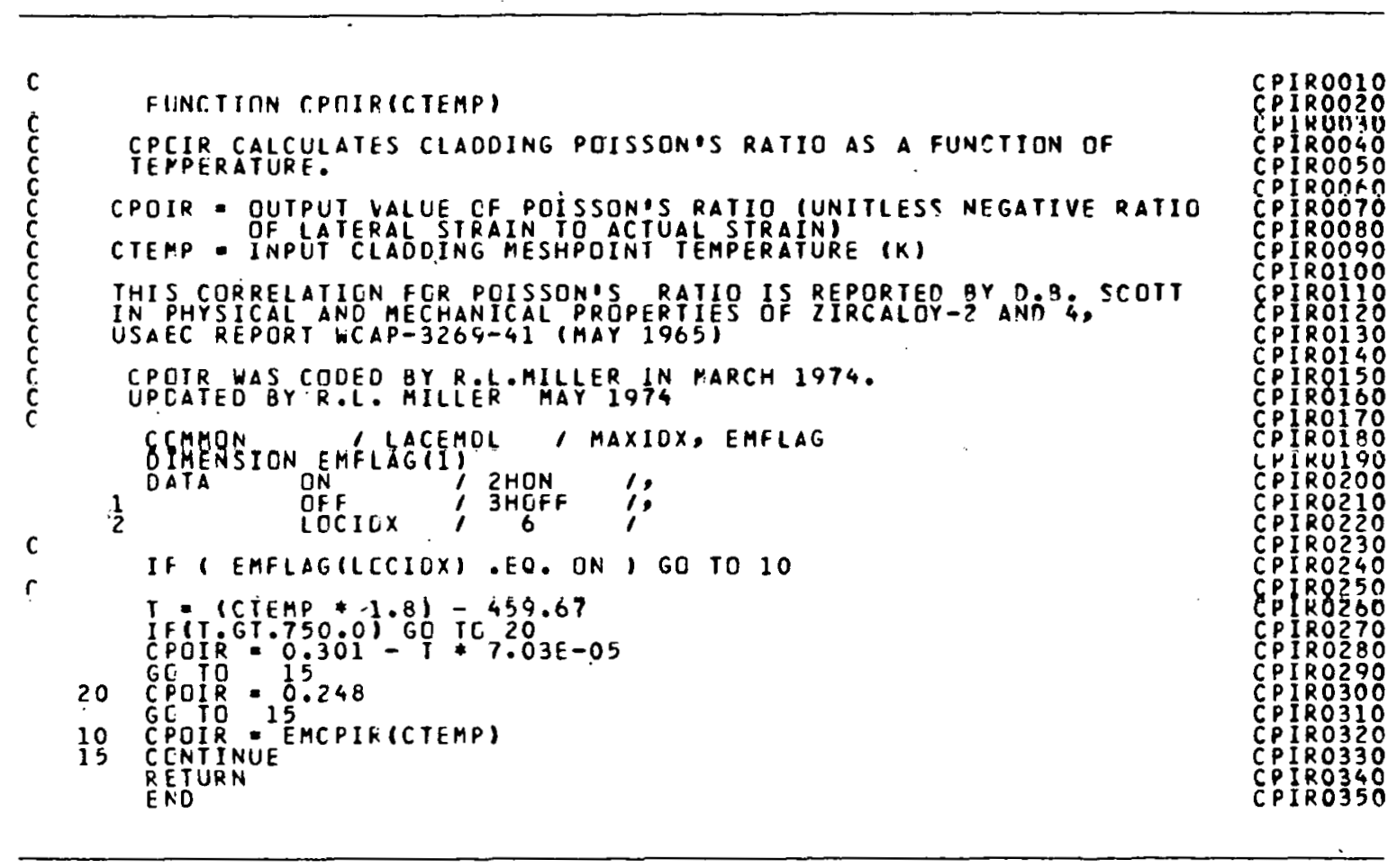

\section{CLADDING CYCLIC FATIGUE (CFATIG)}

The subcode CFATIG provides preliminary estimates of material constant in a format which is compatible with the use of fracture mechanics to model the effect of cyclic fatigue.

\subsection{Summary}

High cycle (nominally elastic strain) fatigue uses material constants in an equation of the following form.

For $\Delta K \geqslant 9.5 \times 10^{6} \mathrm{~N} / \mathrm{m}^{1.5}$

$$
\frac{d \ell}{d N}=B(\Delta K)^{m}
$$

for $\Delta \mathrm{K}<9.5 \times 10^{6} \mathrm{~N} / \mathrm{m}^{1.5}$

$$
\frac{\mathrm{d} \ell}{\mathrm{dN}}=0
$$


where

$\frac{\mathrm{d} \ell}{\mathrm{dN}}=$ the change in crack length per cycle $(\mathrm{m} / \mathrm{cycle})$

$\Delta \mathrm{K}=$ the stress intensity range $\mathrm{MN}\left(\mathrm{m}^{-1.5}\right)$

$\mathrm{B}, \mathrm{m}=\quad$ material parameters returned by the CFATIG code.

The exponent $\mathrm{m}$ is

$$
m=15-12 \exp \left(-\Phi / 10^{24}\right)
$$

where

$\Phi=$ the fast neutron fluence (neutrons $/ \mathrm{m}^{2}$ ).

'I'he parameter B in tquation ('B-13.1 a') is computed from the following expressions.

For fast neturon fluences less than $10^{25}$ neutrons $/ \mathrm{m}^{2}$

$$
B=2 \times 10^{-11}\left[15.531432^{12},\left[\exp \left(-\Phi / 10^{24}\right)-1\right]\right]
$$

for fast neutron fluences of $10^{25}$ neutrons $/ \mathrm{m}^{2}$ or more

$$
B=1.0165786 \times 10^{-25} .
$$

Inw cycle (plastic strain) fatigue uses material constants intended in the equation proposed by Tomkins [B-13.1].

$$
\frac{d \ell}{d N}=K(\Delta \varepsilon)^{1 / \alpha} \ell
$$

where

$$
\begin{aligned}
& \Delta \epsilon=\text { plastic strain amplitude (unitless) } \\
& \ell \quad=\quad \text { rrack lenglh (III) } \\
& \alpha, \mathrm{K}=\text { material parameters. }
\end{aligned}
$$

The value returned by CFATIG for the dimensionless material parameter $\mathrm{K}$ is 10.7 and the value for $\alpha$ is 0.6 . 


\subsection{Basis for High Cycle Fatigue Material Constants}

Constants for the description of high cycle crack propagation are based on data taken by V. S. Rao [B-13.2] and preliminary measurements by Walker and Kass $[\mathrm{B}-13.3]$. S-N (stress versus number of cyclcs to failure) data reported by O'Donnell and Langer [B-13.4] have not been incorporated in to the model because the effect of varying initial crack sizes is not known.

Rao's measurements of crack growth rates as a function of stress intensity (from Figure 4 of Reference B-13.2) are reproduced in Table B-13.I. The parameter $m$ in Equation (B-13.1 a) is equal to the slope of a plot of $\log \left(\frac{d l}{d N}\right)$ against $\log \Delta K$. The value of $m$ obtained from a lcast squares fit to a plot of the data of Table B-13.I is 3.3.

TABLE B-13.I

CRACK GROWTH RATE VERSUS STRESS INTENSITY

RANGE FROM RAO $[B-13.2\rceil$

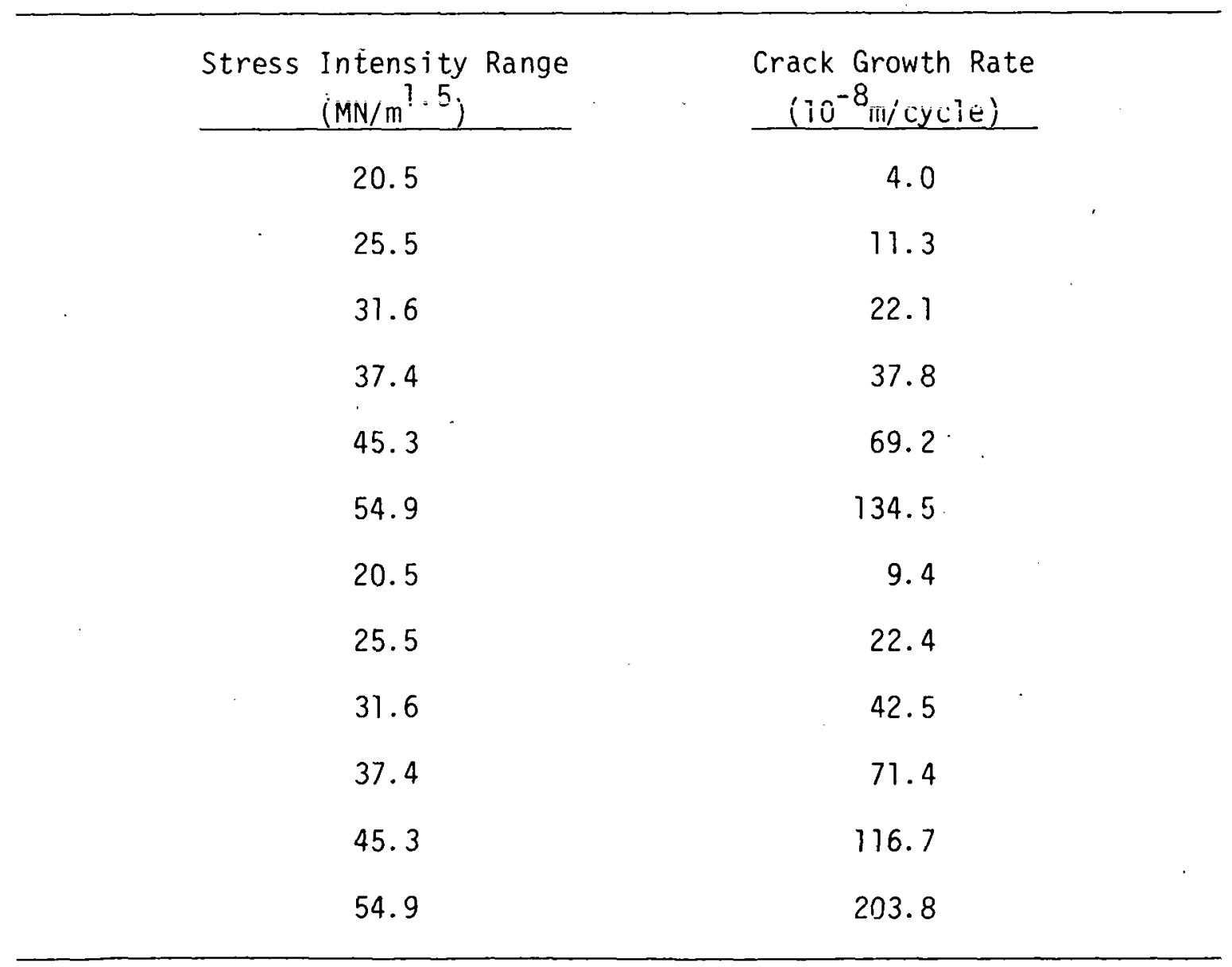


The preliminary data of Walker and Kass (Figure 9 of Reference B-13.2) were analyzed with the same approach used to analyze the data of Rao. The straight line used by Walker and Kass to summarize data from nonirradiated samples is equivalent to. a value of $m=2.8$ in Equation (B-13.1 a).

Walker and Kass also reported crack growth rate measurements from eleven samples which received fast neutron fluences from 5 to $19 \times 10^{24}$ neutrons $/ \mathrm{m}^{2}$. A linear least squares fit to a [log (stress intensity) versus log (crack growth rate)] plot of these measurements suggests that a value of $m=15.7$ in Equation (b-13.1 a) w,ould y.eld the best description of irradiated zircaloy.

The exponential form of Equation (B-13.2) is an estimate relating the values of $m=3$ for unirradiatcd zircaloy and $m=15$ for zircaloy irradiated to a fast neutron fluence of $10^{25}$ neutrons $/ \mathrm{m}^{2}$. A decreasing exponential is typical of the change of material constants with fluence.

Values of the parameter B for unirradiated zircaloy were determined by substituting measurements of crack growth rate and stress intensity range into Equation (B-13.1a) with $\mathrm{m}=3$. Values of $\mathrm{B}$ determined from the two sets of data shown in Table B-13.I were averaged to obtain values of 12.7 and $6 \times 10^{-30}$. Two additional estimates for the value of B werc obtained by repeating the "solution" of Equation (B.13.3) for B with Ran's measurements of crack growth rates at constant stress intensity (Figure 9 of Reference $\mathrm{B}-13.2)$. Analysis of data from these two samples yielded values of $\mathrm{B}=19.3 \times 10^{-30}$ and $\mathrm{B}=16 \times 10^{-30}$. A fifth estimate for $\mathrm{B}$ in unirradiated zircaloy was obtained using the Walker and Kass summary of their data with unirradiated material: Their straight line fit corresponds to a value of $B=48 \times 10^{-30}$.

The only data used to find B for irradiated zircaloy were the eleven measurements of crack growth rate and stress intensity factor range by Walker and Kass which were discussed earlier in this section. The average value of B from these data and Equation (B-13.1) with $\mathrm{m}=15$ was $\mathrm{B} 10^{-25}$.

The expression used to model B [Equation (B-13.3)] is a fit to the average of the five estimates for $B$ at zero fast neutron fluence and the one value of $B$ at fluences on the order of $10^{25}$ neutrons $/ \mathrm{m}^{2}$. The functional dependence of $B$ on fast neutron fluence is an estimate based on the data at zero and $10^{25}$ neutrons $/ \mathrm{m}^{2}$. The value of $B$ for fluences between $10^{24}$ and $10^{25}$ neutrons $/ \mathrm{m}^{2}$ has been determined to cause the predicted value of crack growth rate to remain constant at stress intensity factors of $15.531432 \mathrm{~N} / \mathrm{m}^{1.5}$.

The value $\Delta \mathrm{K}_{\min }=9.5 \mathrm{MN} / \mathrm{m}^{1.5}$ in Equation (B-13.1) is based on a test by Rao at this stress intensity range. No change in crack length was observed in this test. 


\subsection{Basis for Low Cycle Fatigue Material Constants.}

The values returned for the material parameters in Equation (B-13.4) are bascd on the data and analysis of K. Pettersson[B-13.5]. Pettersson has shown that Equation (B-13.4) can be integrated and expressed in the form of the Coffin-Manson relationship

$$
\Delta E=C N_{f}^{-\alpha}
$$

where

$$
\begin{aligned}
& \Delta \mathrm{E}=\text { plastic strain range } \\
& \mathrm{N}_{\mathrm{f}}=\text { number of cycles to failure } \\
& \mathrm{C}, \alpha=\text { material parameters. }
\end{aligned}
$$

The constant $\alpha$ is the same matenal paramèter as the conslant $\alpha$ in Equaliun (D-13.4). Pettersson shows that the constant $\mathrm{C}$ is related to the material constant $\mathrm{K}$ of Equation (B-13.4) by the following expressions:

for uniaxial straining

$$
c^{1 / \alpha}=\frac{\ln \left(\ell_{f} / \ell_{0}\right)}{K} \simeq \frac{4.83}{K} .
$$

For bend tests

$$
c^{1 / \alpha}=\frac{1}{k} \int_{l_{0 / t}}^{l_{f} / t} \frac{d x}{x(1-x)^{1 / \alpha}} \simeq \frac{6.26}{k}
$$

where

$$
\begin{aligned}
& \ell_{0}=\text { the initial-crack length }(\mathrm{m}) \\
& \ell_{\mathrm{f}}=\text { the final crack length }(\mathrm{m}) \\
& \mathrm{t}=\text { the specimen thickness }(\mathrm{m}) .
\end{aligned}
$$

The values of the constants $\alpha$ and $\log C$ which Pettersson reports from fits to his data are listed in Table B-13.II along with the value of the constant $\mathrm{K}$ obtained from Equation (B-13.7).

\subsection{Cladding Cyclic Fatigue Subcode CFATIG Listing}

A listing of the FORTRAN subcode CFATIG is provided in Table B-13.III. 


\begin{tabular}{cccc}
$\begin{array}{c}\text { Fast Fluence } \\
\left.\text { (neutrons } / \mathrm{m}^{2}\right)\end{array}$ & $\begin{array}{c}\alpha \\
\text { (unitiess) }\end{array}$ & $\begin{array}{c}\log \mathrm{C} \\
\text { (unitiess) }\end{array}$ & $\begin{array}{c}K \\
\text { (unitiess) }\end{array}$ \\
$1.3 \times 10^{24}$ & 0.60 & 1.87 & 10.3 \\
$2.6 \times 10^{24}$ & 0.64 & 1.96 & 11.7 \\
Average Values & 0.56 & 1.75 & 10.1 \\
\hline
\end{tabular}

TABLE B-13. III

LISTING OF THE CFATIG SUBCODE

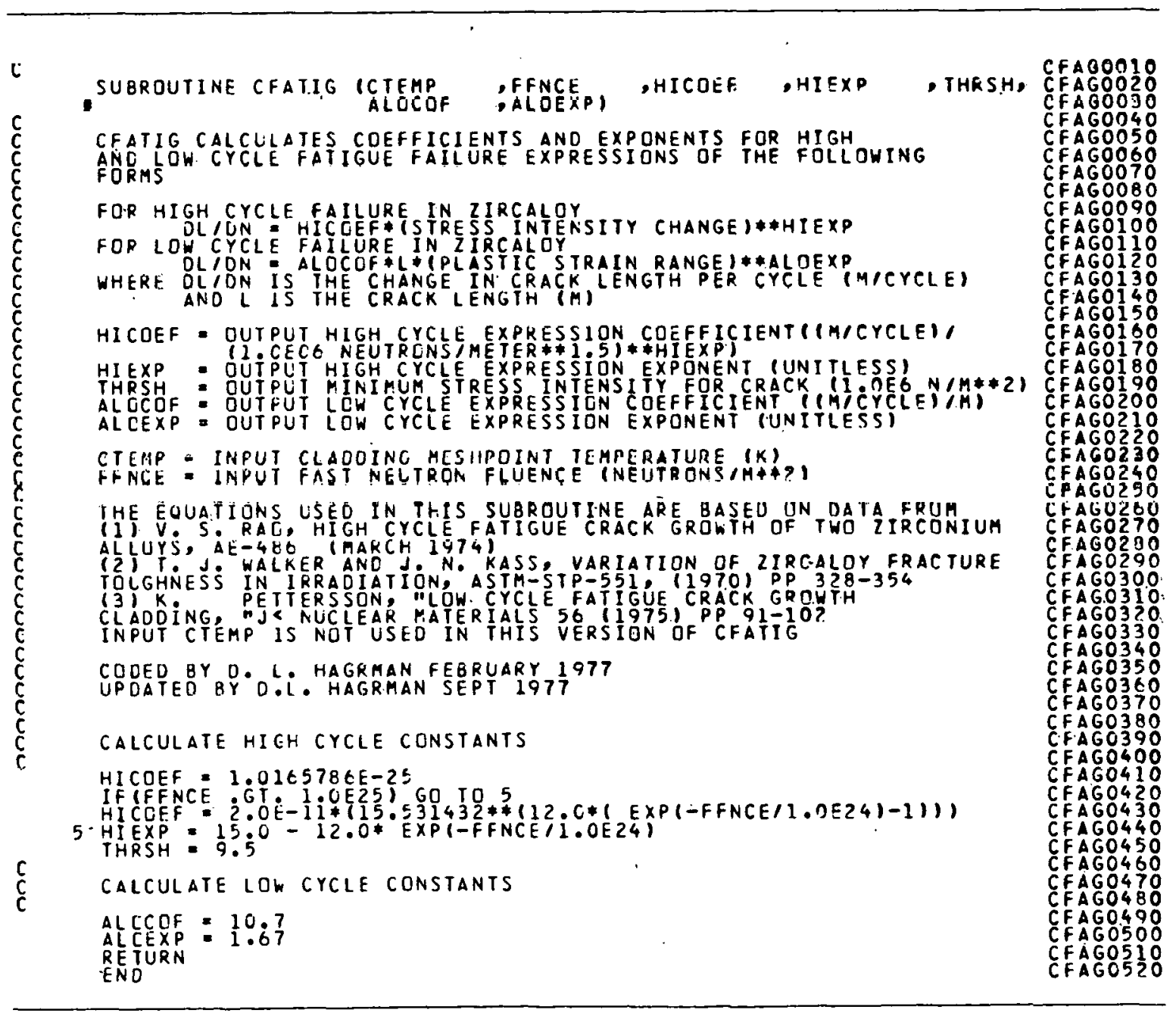




\subsection{References.}

:

B-13.1. B. Tomkins, "Fatigue Crack Propagation - An Analysis," Philosophical, 18 (1968) p 1041 .

B-13.2. V. S. Rau, High Cycle Futigue Crack Giowth of Two Zironium Alloys, ADa48G (March 1974).

B-13.3. T. J. Walker and J. N. Kass, "Variation of Zircaloy Fracture Toughness in Irradiation," Zirconium in Nuclear Applications, ASTM-STP-551, Philadelphia, Pennsylvania, American Society for Testing and Materials, 1974 pp 328-354.

B-13.4. W. J. O'Donnell and B. F. Langer, "Fatigue Design Basis for Zircaloy Components," Nuclear Sclence and Ëngineering, 20, 1 (1964).

B-13.5. K. Pettersson, "Low Cycle Fatigue Properties of Zircaloy Cladding," Journal of Nucloar Matorials, $56(1975) \mathrm{pp}, 91.102$.

\section{CLADDING MEYER HARDNESS (CMHARD)}

One of the parameters required for calculating fuel-to-cladding contact conductance is hardness. As the contact pressure between the two surfaces increases, the points of contact enlarge due to localized plastic deformation, and the solid-to-solid thermal conductance is improved. The Meyer hardness is used by Ross and Stoute ${ }^{[B-14.1]}$ in their heat transfer correlation as an indication of the hardness or resistance to deformation of the softer (zircaloy) material.

The Meyer hardness number is a measure of indentation hardness and is defined in conjunction with Meyer's law, $\mathrm{L}=\operatorname{ad}^{\mathrm{n}}$ where $\mathrm{L}$ is the load, $\mathrm{d}$ is the diameter of impression at the surface of a specimen in a static ball test, $\mathrm{n}$ is the Meyer work hardening coefficient, and $a$ is a material constant. The Meyer hardness number $(M H)$ is defined as $\left(4 \mathrm{~L} / \pi \mathrm{d}^{2}\right)$. Other hardness numbers are available (Brinell, Rockwell, etc.), and conversion from one to another is possible. However, the routine CMHARD was created to provide information required by the Ross and Stoute gap conductance model.

The hardness of zircaloy was assumed to be proportional to the yield strength of zircaloy:

$$
M H=M H_{R T}\left(\frac{Y S_{T}}{Y S_{R T}}\right) \text {. }
$$




\section{CMHARD}

wherc

$$
\begin{array}{ll}
\mathrm{MH} & =\begin{array}{l}
\text { Meyer hardness number at temperature of interest } \\
(\mathrm{Pa})
\end{array} \\
\mathrm{MH}_{\mathrm{RT}}= & \text { Meyer hard ness number at room temperature }(\mathrm{Pa}) \\
\mathrm{YS}_{\mathrm{RT}}= & \text { zircaloy yield strength at room temperature }(\mathrm{Pa}) \\
\mathrm{YS}_{\mathrm{T}}= & \begin{array}{l}
\text { 7ircalny yield strength at temperature of interest } \\
(\mathrm{Pa}) .
\end{array}
\end{array}
$$

Meyer hardness numhers for temperatures from 298 to $1000 \mathrm{~K}$ were determined by using the room temperature Meyer, hardness value presented by Ross and Stoute and the y1eld

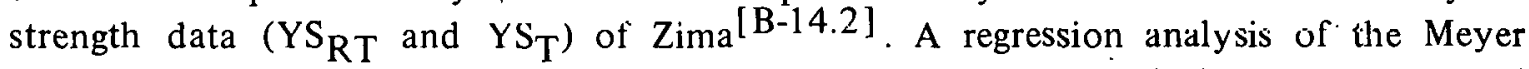
hardness values versus temperature was performed to obtain the analytical expression used in CMHARD for the temperature range of 298 to $1000 \mathrm{~K}$. The Meyer hardness number is assumed to take on constant values outside this temperature rarige. 'Ilite cunclation used in CMHARD is given by Equations (B-14.2) through (B-14.4).

For $\mathrm{T}<298 \mathrm{~K}$ :

$$
\mathrm{MH}=1.96 \times 10^{9} \mathrm{~Pa} \text {. }
$$

For $298<T<1000 \mathrm{~K}$ :

$$
\begin{aligned}
M H & =6.51 \times 10^{9}-2.36 \times 10^{7} \mathrm{~T}+3.29 \times 10^{4} \mathrm{~T}^{2} \\
& -15.68 \mathrm{~T}^{3} \mathrm{~Pa}
\end{aligned}
$$

where

$\mathrm{T}=$ temperature $(\mathrm{K})$.

For $\mathrm{T}>1000 \mathrm{~K}$ :

$$
\mathrm{MH}=1.0 \times 10^{8} \mathrm{~Pa} .
$$

Figure B-14.1 illustrates these relations.

\subsection{Cladding Meyer Hardness Subcode CMHARD Listing}

A listing of the FORTRAN subcode CMHARD is presented in Table B-14.I. 


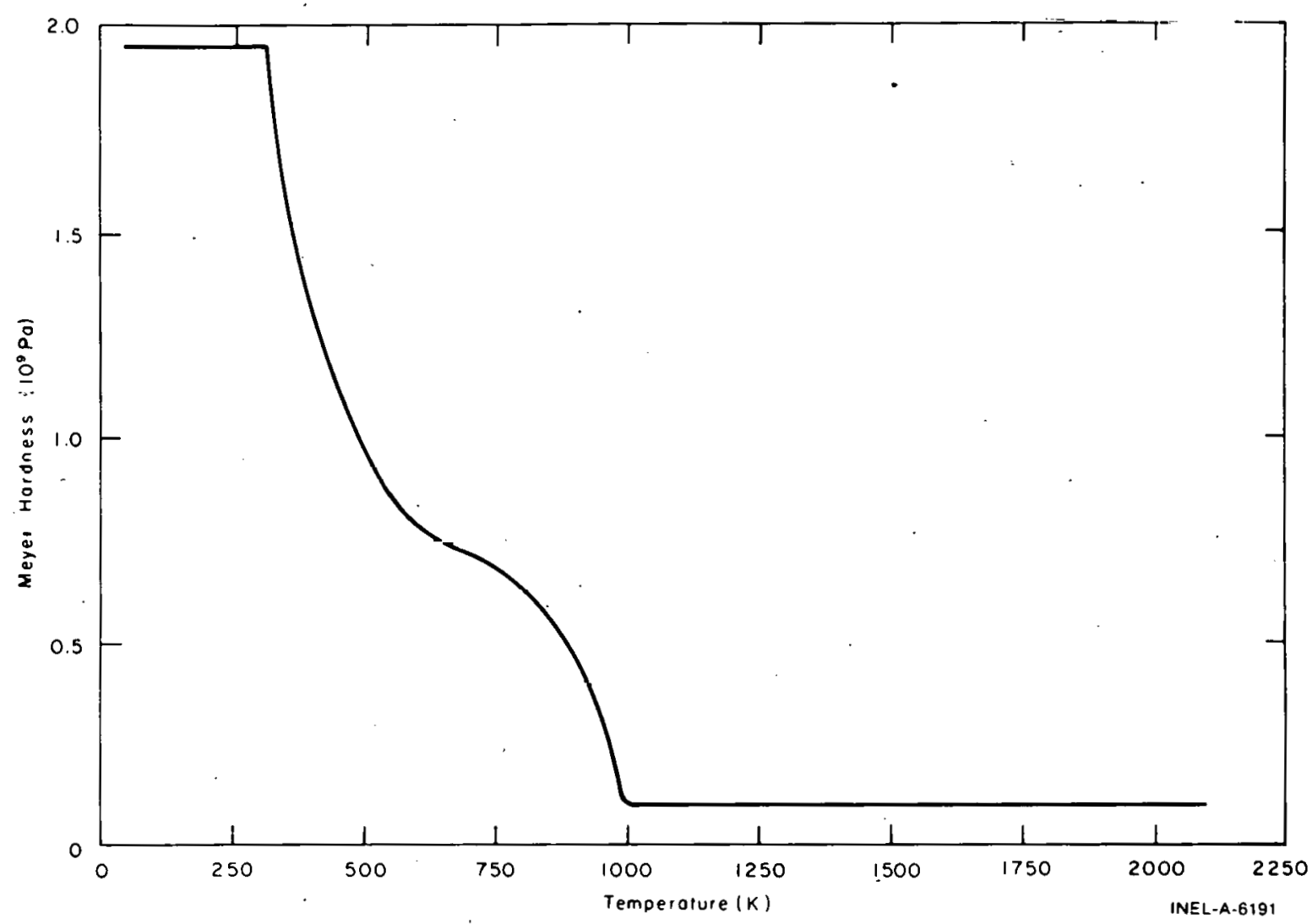

Fig. B-14.1 The CMHARD correlation for the Meyer hardness of zircaloy.

\subsection{References}

B-14.1. A. M. Ross and R. L. Stoute, Heat Transfer Coefficient Between $\mathrm{UO}_{2}$ and Zircaloy-2, AECL-1552 (June 1962).

B-14.2. G. E. Zima, A Review of the Properties of Zircaloy-2, HW-60908 (October 1959) p 61. 


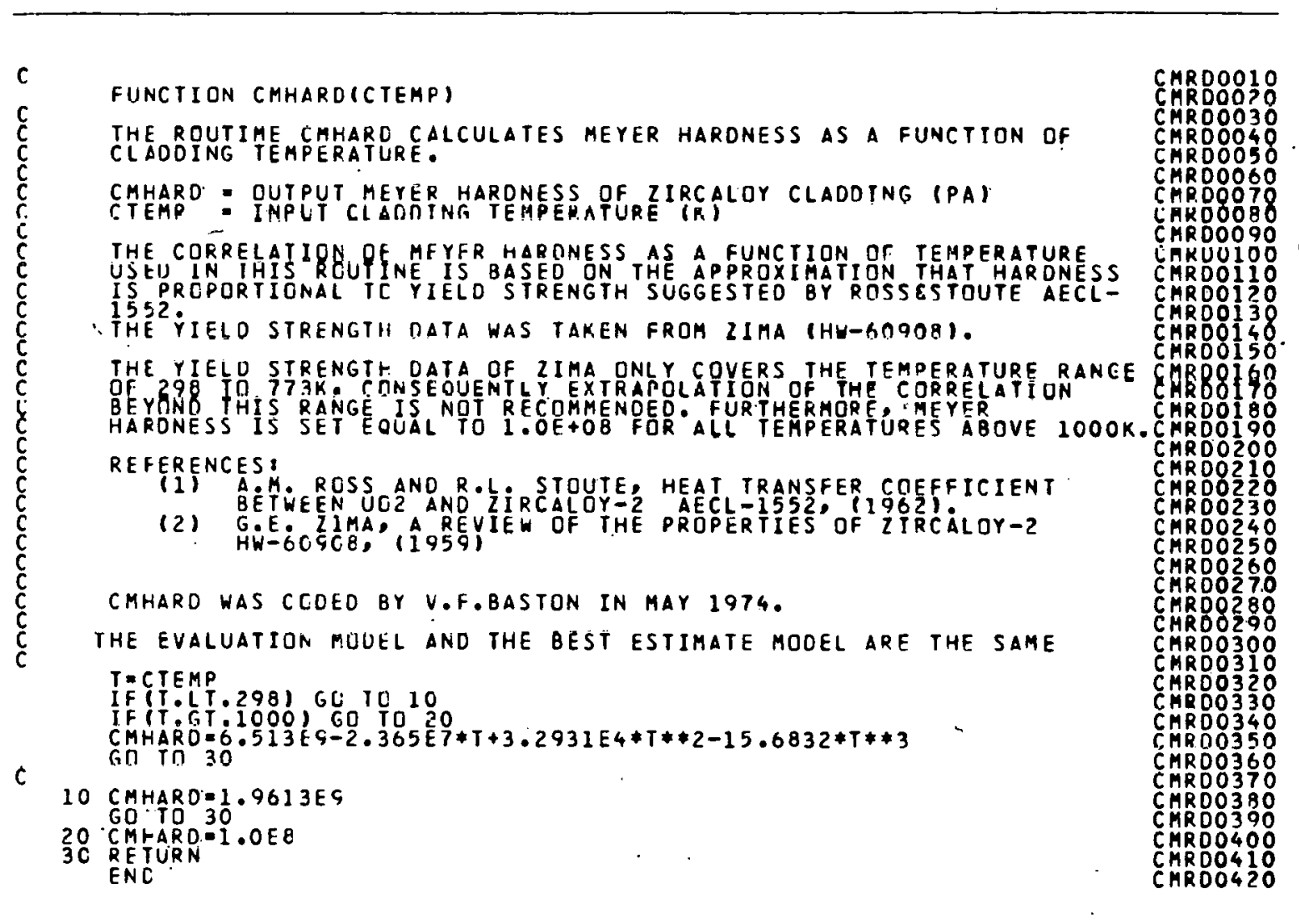

\section{CLADDING AXIAL GROWTH (CAGROW)}

$\Lambda$ model for calculating the fractional change in length of zircaloy tubes due to irradiation-induced growth is presented in this section. Effects of fast neutron fluence, tubing texture, cladding temperature, and cold work are included in the model, which applies equally well to zircaloy- 2 and zircaloy- 4 . The change in length of commercial fuel rods due to irradiation growth is small, however, it can represent a significant fraction of the clearance between the rod and the top and bottom assembly nozzles. Contact with the nozzles can cause rods to bow and possibly fail at points where rods contact each other.

\subsection{Summary}

The following equation has been developed to model the irradiation growth of zircaloy tubes at temperaturcs between 40 and $360^{\circ} \mathrm{C}$ (applying to the normal range for cladding temperatures in LWRs): 


$$
\frac{\Delta L}{L}=A[\exp (240.8 / T)] \quad[\phi t]^{1 / 2}\left[1-3 f_{z}\right][1+2.0 \mathrm{CW} \mid
$$

where

$$
\begin{aligned}
& \frac{\Delta \mathrm{L}}{\mathrm{L}}=\text { fractional change in length due to growth } \\
& \left.\mathrm{A}=1.407 \times 10^{-16} \text { (neutrons } / \mathrm{m}^{3}\right)^{-1 / 2} \\
& \mathrm{~T}=\text { cladding temperature }(\mathrm{K}) \\
& \phi \quad=\text { fast neutron flux }\left(\mathrm{n} / \mathrm{m}^{2} \cdot \mathrm{s}\right)(\mathrm{E}>1.0 \mathrm{MeV}) \\
& \mathrm{t}=\text { time (s) } \\
& \mathrm{f}_{\mathrm{z}}=\text { texture factor }{ }^{[\mathrm{a}]} \text { for the tubing axis } \\
& \mathrm{CW}=\text { cold work (fraction of cross-sectional area reduction). }
\end{aligned}
$$

Axial growth for temperatures below $40^{\circ} \mathrm{C}$ is approximated by using $\mathrm{T}=40^{\circ} \mathrm{C}$ in Equation $(\mathrm{B}-15.1)$ and growth above $360^{\circ} \mathrm{C}$ is approximated by using $\mathrm{T}=360^{\circ} \mathrm{C}$.

A comparison of values calculated by the CAGROW subroutine for fully annealed material with experimental results is presented in Figure B-15.1. Comparison with the data shown from cold-worked tubes was not possible because the exact anount of cold work was not reported.

\subsection{Background and Approach}

The irradiation growth of zircaloy cladding appears to be quite sensitive to texture. Therefore, the effects of texture were considered first and the data was normalized to a standard texture $\left(f_{z}=0.05\right)$ before considering other effects on axial growth. The model was developed further by modeling the effects of fluence and irradiation temperature on the growth of annealed specimens. Finally the effects of texture, fluence, and temperature were removed from the cold-worked specimen data using the model based on annealed specimens (the data were normalized to a texture of 0.05 , a fluence of $2 \times 10^{25} \mathrm{n} / \mathrm{m}^{2}$, and a temperature of $300^{\circ} \mathrm{C}$ ) and the effect of cold work modeled. It should be noted, however, that the effect of cold work may not be treated completely since the limited data base did not allow treatment of cold work and fluence, temperature, or texture interaction effects.

[a] $f_{z}$ is the effective fraction of cells aligned with their $<0001>$ axis parallel to the tubing axis as determined by $x$-ray diffraction analysis. $A$ Value of $f_{z}=0.05$ is typical $[B-15.1]$. 


\section{CAGROW:}

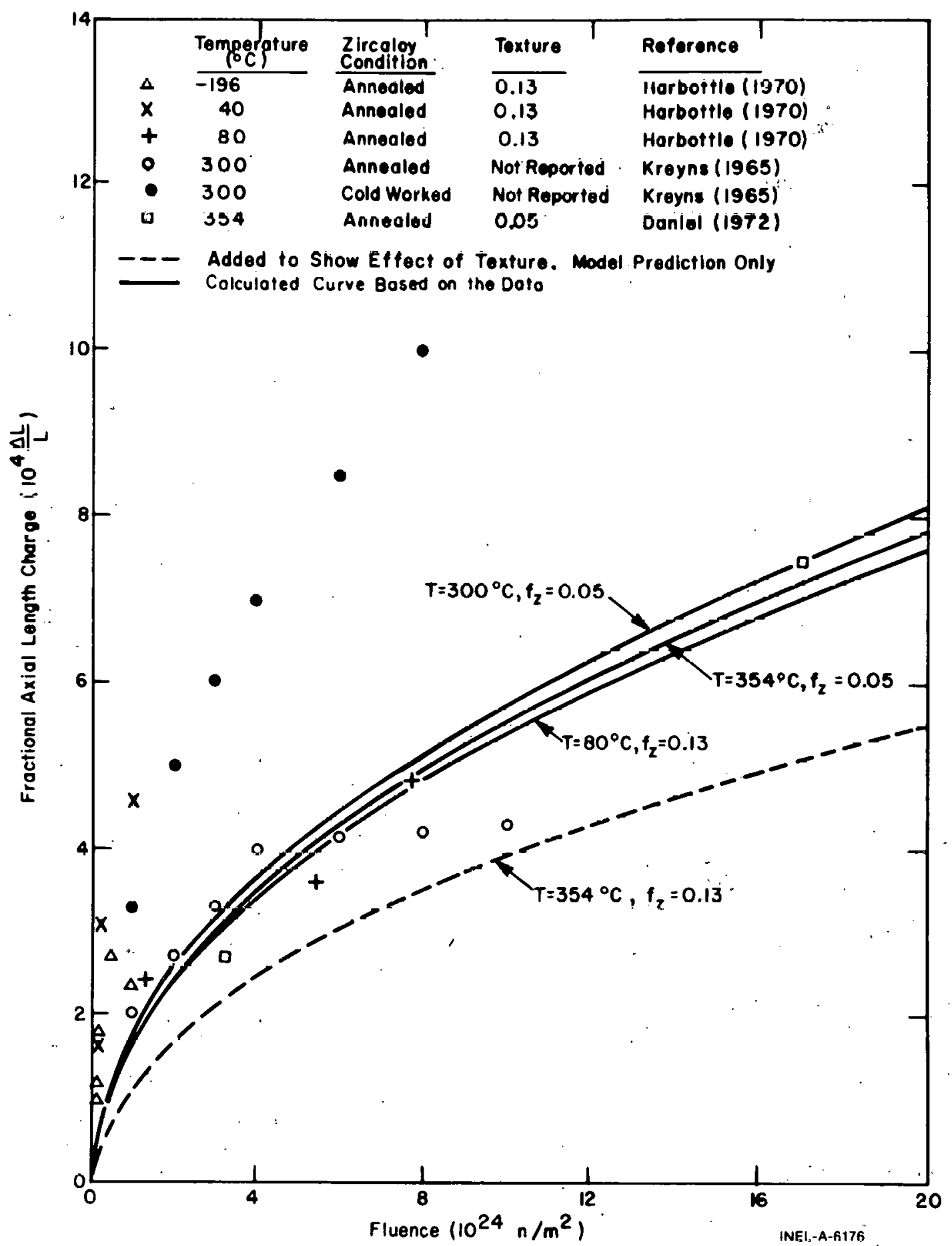

Fig. B-15.1 Model predictions and measured values of zircaloy tube axial growth as a function of fast.neutron fluence, irradiation temperature, cold work, and texture coefficient $f_{z}$. 
In this model it is assumed that fast neutron flux and temperature both affect the growth rate by varying the concentration of interstitials which are free to migrate and cause growth. Since theoretical considerations imply a complex relation between the temperature, fast neutron flux, time, and the rate of growth, an empirical approach was used to approximate these effects. It should be noted that this model employs only the product of flux and time (fluence), although the flux used to achieve a given fluence does have theoretical significance (see below).

An empirical approach was also used to model the effect of cold work on zircaloy tube growth. The limited data was fit using an independent factor of the form $(1+$ constant $x$ cold work $)$ - the least complex form consistent with the preliminary data reported to date. The main conclusion from the available data is that cold work increases the rate of growth at low fluence. At higher fluences, the growth rate of annealed tubing may decrease rapidly. Cold worked tubing continues to grow at higher fluences at nearly the rate established during early irradiation.

\subsection{Review of Experiment Data}

Samples of zirconium, zircaloy-2; and zircaloy-4 irradiated in a fast neutron flux $\left(\mathrm{E}>1 \mathrm{MeV}\right.$ ) to fluences of $10^{25} \mathrm{n} / \mathrm{m}^{2}$ show typical axial growth on the order of $0.1 \%$ of length or less. Since the effects of fuel-cladding mechanical interactions and pressure differentials across the cladding compete with the smaller effects of irradiation growth, the relatively plentiful data $[\mathrm{B}-15.2, \mathrm{~B}-15.3, \mathrm{~B}-15.4]$ are not directly useful in determining the change in cladding length due to irradiation growth. Data on thimble tubes or other structural elements relatively free of confounding effects would be useful, but none have been published. Table B-15.I summarizes the data which have been used for development of the model.

Early data on the irradiation induced axial growth of zircaloy-4 tubing at $300^{\circ} \mathrm{C}$ were obtained by Kreyns ${ }^{[B-15.5]}$. His experiments indicated that growth of cold worked tubing is proportional to the square root of the fast neutron fluence up to its maximum fluence $\left(10^{25} \mathrm{n} / \mathrm{m}^{2}\right)$. Growth of annealed tubing appeared to saturate at a fluence of $4 \times 10^{24} \mathrm{n} / \mathrm{m}^{2}$ and a fractional length change of $4 \times 10^{-4}$. However, subsequent data taken by other investigators have indicated that saturation is not determined by fluence or net growth.

Harbottle ${ }^{[B-15.6]}$ has reported the difference in growth strains of transverse and longitudinal strips cut from zircaloy- 2 pressure tubes. The strips were annealed and then irradiated at $-196,40$, and $80^{\circ} \mathrm{C}$. The basal pole texture was found to be $13 \%$ in the direction of the tube axis and $36 \%$ in the circumferential direction, both before and after the cutting and annealing process. Harbottle's differential growth strains were converted to absolute values of axial growth strains by using the equation

$$
\frac{1-3 f_{z}}{1-3 f_{\phi}}=\frac{\text { growth strain in axial direction }}{\text { growth strain in circumferential direction }}
$$




\section{CAGROW}

\section{TABLE B-15. I}

\section{MEASUREMENTS OF GROWTH IN ZIRCALOY TUBING}

\begin{tabular}{|c|c|c|c|c|c|c|}
\hline Siniorite & $\begin{array}{c}\Delta \mathrm{L} / \mathrm{L} \\
\left(10^{-4}\right)\end{array}$ & $\begin{array}{l}\text { Differential }[\mathrm{a}] \\
\mathrm{N} / 1\left(1 n^{-4}\right) \\
\end{array}$ & $\begin{array}{c}\begin{array}{c}\text { Fast } \\
\text { Fluence } \\
\left(1 n^{22} n / m^{2}\right) \\
\end{array} \\
\end{array}$ & - Mnterpint & $\begin{array}{l}\text { Fast Flux } \\
\left(1 n^{17} \mathrm{n} / \mathrm{m}^{2} \cdot q\right) \\
\end{array}$ & $\begin{array}{c}\text { Irradiation } \\
\text { Temperature } \\
\left({ }^{\circ} \mathrm{r} .\right) \\
\end{array}$ \\
\hline \multirow{13}{*}{$\begin{array}{l}\text { Kreyus, } \\
\text { reference } \\
\text { (B-15.5] }\end{array}$} & 2 & & 100 & Aniviéléd ziricaluy-4 & (?) & 300 \\
\hline & 2.7 & & 200 & & & \\
\hline & 3.3 & & 300 & & . & \\
\hline & 4.0 & & 400 & & & \\
\hline & 4.15 & & 600 & & & \\
\hline & 4.2 & & 800 & . & & \\
\hline & 4.3 & & 1000 & & & \\
\hline & 3.3 & & 100 & Cold-worked zircaloy 4 & (?) & 300 \\
\hline & 5 & & 200 & & & \\
\hline & 6 & & $3 n n$ & & & \\
\hline & 7 & & -400 & & & \\
\hline & 8.5 & & 600 & $\cdot$ & & \\
\hline & 10 & & 800 & & & $\cdot$ \\
\hline \multirow{13}{*}{$\begin{array}{l}\text { Daniel, } \\
\text { reference } \\
\text { [B-15.1 } \\
\quad 15.7] \\
\text { Harbottle, } \\
\text { reference } \\
\text { [B-15.6] }\end{array}$} & 2.7 & . & 310 & Annealed zircaloy-4 & 12.5 & 354 \\
\hline & 7.5 & & 1700 & . & & \\
\hline & & $1.2 \pm 0.2$ & 4.9 & Annealed ztrcaloy-2 & 3 & -196 \\
\hline & & $1.5 \pm 0.3$ & - $\quad 9.7$ & & & \\
\hline & & $2.3 \pm 0.3$ & 19 & & & \\
\hline & & $3.5+0.5$ & 50 & & & \\
\hline & & $3.0 \pm 0.1$ & 98 & & & \\
\hline & & $2.1 \pm 0.2$ & 8.2 & Annealed zircaloy-2 & 3 & 40 \\
\hline & & $4.0 \pm 0.2$ & 29 & & & \\
\hline & & $5.6 \pm 0.4$ & 100 & . & & \\
\hline & & $3.1 \pm 0.4$ & 130 & Annealed zircaloy-2 & 12 & 80 \\
\hline & & $4.7 \pm 0.4$ & 540 & & & \\
\hline & & $6.3 \pm 1.0$ & 770 & - & & \\
\hline
\end{tabular}

[a] Only the difference between longitudinal and transverse changes in length was reported. 
where

$$
\begin{aligned}
\mathrm{f}_{\mathrm{z}} \text { and } \mathrm{f}_{\theta}=\quad \text { the texture factors in the axial and circum- } \\
\text { ferential directions. }
\end{aligned}
$$

This equation is discussed in Section B-15.4.

A somewhat different approach was taken by Daniel [B-15.1, B-15.7] in a series of experiments which measured both diameter and length changes of fuel rods. The effects of fuel-cladding interactions and pressure differentials across the cladding on medsured changes in rod length could be separated from the effect of cladding growth since no fuel-cladding mechanical interaction was present in one experiment series. The separation was achieved by noting that the expected ratio of length to diameter changes is very different for fuel-cladding interactions, creep due to pressure differentials across the rod, and irradiation-induced growth. In particular, the fractional change in diameter due to growth was predicted to be very small for typical cladding diameters and textures. Therefore, a plot of the measured change in length as a function of the measured change in diameter at a single fluence could be used to determine the change in length due to growth by simply extrapolating to zero change in diameter with data which did not contain fuel-cladding mechanical interactions.

Daniel determined the fractional change in length at two values of fluence. His results $^{[a]}$ are partıcularly signiticant because they provide a measure of growth of annealed cladding at high fluence and they do not show the saturation which Kreyns ${ }^{[B-15.5]}$ observed.

\subsection{The Effect of Texture on Axial and Circumferential Growth}

Single crystal texture effects are related to polycrystalline growth. Growth is pictured simply as a reduction of the c-axis dimension of individual grains and an increase of the basal plane dimensions of the grains. The analysis is carried out with the help of an abstract picture of grains made up of schematic immobile unit cells which decrease their c-axis length by a fraction $n$ and increase their $a_{1}, a_{2}$, and $a_{3}$ axis lengths by a fraction $m$. Although the picture of changing unit cell size does not represent atomic behavior within the grain, the growth of the grain is reproduced by the abstract picture.

Figure B-15.2 illustrates the change in the axis lengths of the schematic unit cells. Growth of the three axes in the basal plane is assumed to be equal because of the symmetry of the lattice. The relation between the decrease of the c-axis dimension and the increase of the a-axes dimensions is dependent on the details of the atomic model used to describe growth. For models which imply that the volume of the grain (and schematic unit cell)

[a] A growth component of strain equal to $7.5 \times 10^{-4}$ at a fluence of $17 \times 10^{24} \mathrm{n} / \mathrm{m}^{2}$ and a growth strain of $2.7 \times 10^{-4}$ at a fluence $3.1 \times 10^{24} \mathrm{n} / \mathrm{m}^{2}$ were indicated by Daniel $[\mathrm{B}-15.1, \mathrm{~B}-15.7]$. 


\section{CAGROW}
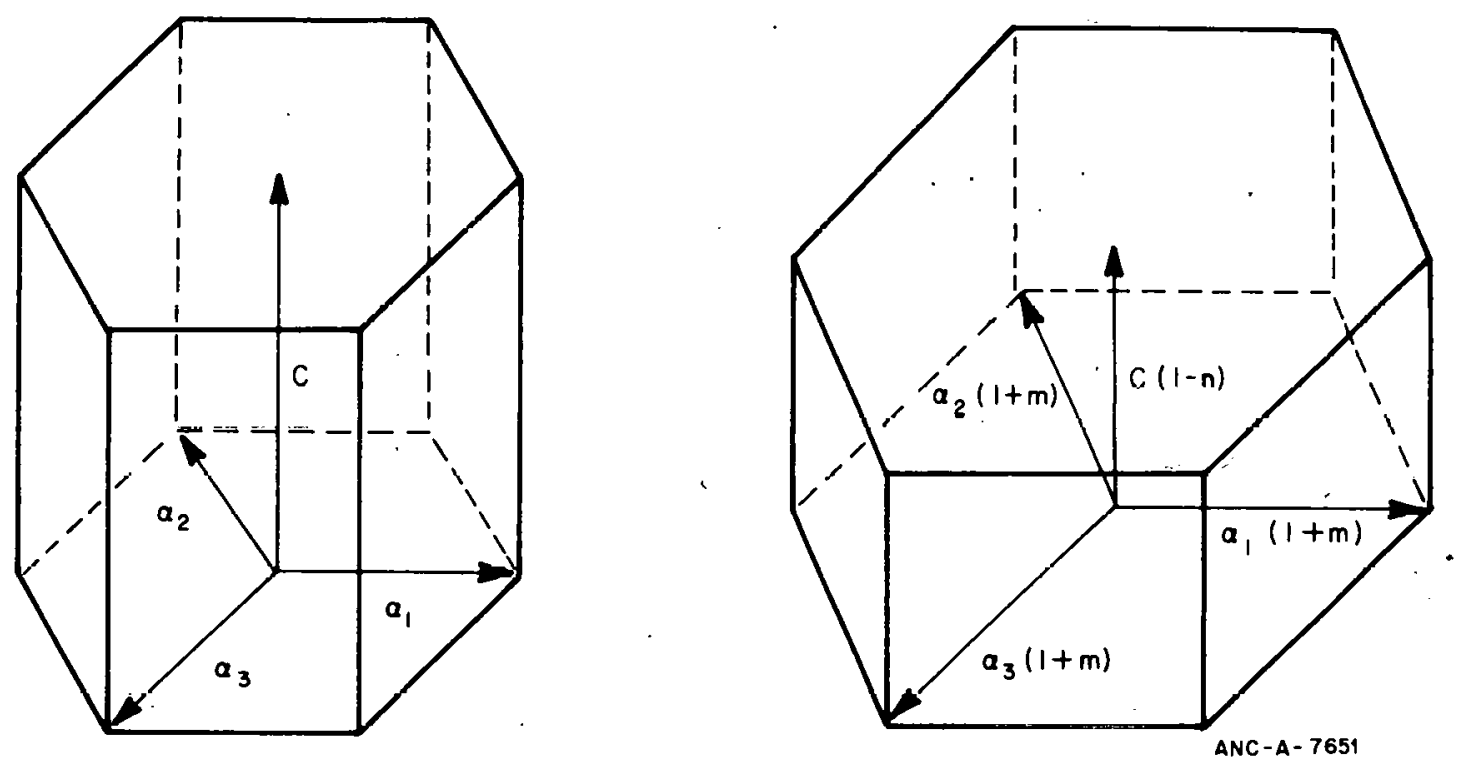

Fig. B-1 5.2 The growth of schematic unit cells in a grain.

remains constant, $(1+m)=(1-n)^{-1 / 2}$. This value for $1+m$ will be assumed at the last stage of the derivation of the effect of texture. It should be noted that the assumption is not made on the basis of a detailed atomic model. The constant-volume assumption is made on the basis of experimental evidence $[\mathrm{B}-15.8, \mathrm{~B}-15.9]$ and this evidence has been somewhat contradictory.

15.4.1 Use of the X-Ray Diffraction Orientations Parameter to Relate Single-Crystal Models to Polycrystalline Results. The effective fraction of grains aligned with their c-axis parallel to a reference direction (axial, circumferential, or radial direction of the tube) is usually taken to he an orientation parameter $[\mathrm{B}-15.10]$ which is'determined from $\mathrm{x}$-ray diffraction studies. This parameter is formally defined as the average of the squared cosine of the azimuthal angle betwecn the caxis of individual grains and the reference direction, weighted by the volume fraction $V_{i}$ occupied by cells at a given azimuthal angle $\theta_{i}$. That is:

$$
F=\frac{\sum_{i} V_{i} \cos ^{2} \theta_{i}}{\sum_{j} V_{j}}
$$

It is shown in Reference B-15.10 that polycrystalline bulk properties in a reference direction can he expressed as

$$
P_{\text {ref }}=f P_{\|}+(1-f) P_{\perp}
$$

if the property has the following characteristics (a)

$$
P_{n}=P_{\|} \cos ^{2} n+P \perp \sin ^{2} n
$$


where

$$
\begin{aligned}
& \mathrm{P}_{\eta}=\quad \text { the single crystal property in a direction at an angle } \eta \text { to } \\
& \mathrm{P}_{\|}=\text {the axis } \\
& \mathrm{P}_{\perp}=\text { the single crystal property perpendicular to the c-axis }
\end{aligned}
$$

and (b) the property in a reference direction of the polycrystalline sample is the volumeweighted summation of this property in its individual crystals.

A property of the schematic unit cells which satisfies condition (a) is the square of the distance between two points imbedded in the schematic unit cell. That is, if $\frac{-x}{2}, \frac{-y}{2}, \frac{-z}{2}$ and $\frac{x}{2}, \frac{y}{2}, \frac{z}{2}$ are coordinates of two points in the cell relative to an origin at the middle of the cell, the squared distance between the points is

$$
e^{2}=z^{2}+x^{2}+y^{2}
$$

or

$$
e^{2}=e_{0}^{2}(1-n)^{2} \cos ^{2} \theta+e_{0}^{\ddot{2}}(1+m)^{2} \sin ^{2} \theta
$$

where

$$
\begin{array}{ll}
\ell_{\mathrm{O}} & =\text { the distance between the points } \\
\mathrm{n} \text { and } \mathrm{m}= & \text { zero } \\
\theta \quad & \begin{array}{l}
\text { the angle between the c-axis and the line } \\
\text { between the points. }
\end{array}
\end{array}
$$

It is assumed here that conditon (b) of the previous paragraph is also satisfied.

Equations (B-15.4) and (B-15.5) can be used to express the fractional change in the distance between two points of polycrystalline sample. $\mathrm{P}_{\|}$and $\mathrm{P}_{\perp}$ of Equation (B-15.4) are identified as $\ell_{0}^{2}(1-m)^{2}$ and $\ell^{2}(1+m)^{2}$ in Equation B-15.5 so that $\ell^{2}$ (the square of the distance between points of polycrystalline sample) is

$$
\ell^{2}=f(1-n)^{2} \ell_{0}^{2}+(1-f)(1+m)^{2} \ell_{0}^{2} .
$$

The fractional change in length along the reference direction of a polycrystalline sample will then be 


$$
\frac{\Delta \ell}{\ell_{0}}=\frac{l-\ell_{0}}{\ell_{0}}=\sqrt{f(1-n)^{2}+(1-f)(1+m)^{2}}-1 .
$$

The parameters $\mathrm{n}$ and $\mathrm{m}$ represent the average fractional growth along the $\mathrm{c}$ - and $\mathrm{a}$-axis of single crystals. Since growth in zirconium alloys is typically less than $1 \%, \mathrm{n}$ and $\mathrm{m}$ are small numbers and a Taylor series expansion of the radical about $n=m .=0$ is possible. The expansion yields

$$
\frac{\Delta l}{\ell_{0}} \approx 1+m-(n+m) f+\text { terms of order } n^{2}, m^{2} \text {, and } n m \text {. }
$$

If $(1+m)$ is taken equal to $(1-n)^{-1 / 2}$ in order to impose the restriction of a constant volume on the grain, the Taylor series expansion yields

$$
\frac{\Delta \ell}{\ell_{0}} \approx \frac{n}{2}(1-3 f)+\text { terms of order } n^{2} \text {. }
$$

The assumption of constant volume is made here in lieu of a successful atomic level model for kinetics of growth.

15.4.2 Application of the Result of Scction B-15.4.1 to Measurements of Growth in Different Directions. Equations (B-15.8) and (B-15.9) have been derived without reference to any particular direction. Thus for the axial component of growth, $\frac{\Delta \ell}{\ell}$ is measured along the tubing axis and $f$ is the axial orientation parameter, $f_{\mathrm{z}}$. If a change in tubing circumference (or diameter of the tube since the diameter is $\pi^{-1}$ times the circumference) is being considered, $\frac{\Delta l}{\ell}$ is the fractional change in the tubing diameter or circumference, and $f$ is $f_{0}$, the tangential orientation parameter.

\subsection{Analysis of Irradiation-Induced Growth Factors Other than Texture}

The effects on irradiation growth by fast neutron fluence, irradiation temperature, and cold work :are analyzed in the following paragraphs. The fast neutron flux (in addition to fluence) and the residual stress in the tubing may affect growth (References B-15.6 and B-15.11) but no attempt has been made to include these effects due to lack of data. Also, no significant difference in the growth rates of zirconium, zircaloy-2, and zircaloy-4 has been reported, so no distinction between their growth rates has been incorporated into the model. As mentioned in Section B-15.2, the first step in developing the model was to account for differences in growth due to differences in texture. The factor $(1+3 f)$ of Equation (B-15.9) was used to adjust growth measured with arbitrary textures to values expected for $\mathrm{f}=0.05$. The results are illustrated in Figure B-15.3.

15.5.1 The Effect of Fast Neutron Fluence on Irradiation Growth.. Many investigators have treated the effect of fast fluence by fitting in the empirical expression

$$
\text { growth strain a }(\text { fluence })^{q}
$$




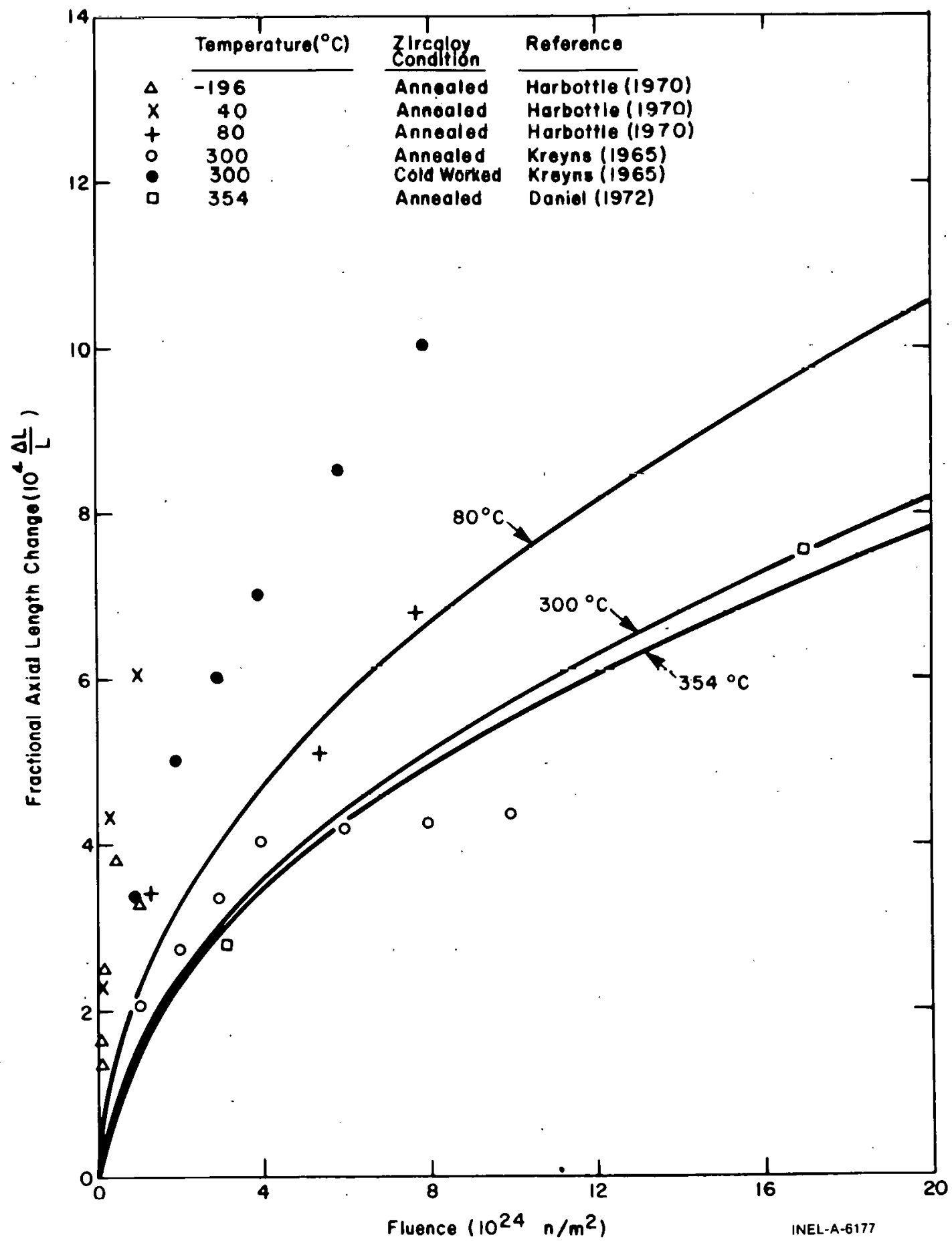

Fig. B-15.3 Model predictions and measured values of growth of zircaloy tubes adjusted to a common texture coefficient of $f_{Z}=0.05$. 
to the data $[B-15.6, B-15.8]$ with resultant values of $q$ in the range $0.3-0.8$. Although good agreement can be obtained by allowing the value of $q$ to vary for each set of data, the results of such empirical fits are somewhat misleading. Hesketh ${ }^{[B-15.12]}$ has derived a dependence on the square root of fluence $[q=0.5$ in Equation (B-15.10)] and data from individual irradiations have not demonstrated a clear departure (other than saturation effects) from this rule. This point is illustrated in Figure B-15.4 by showing a plot of axial growth as a function of the square root of the fluence.

Departures from an exponent of $\mathrm{q}=0.5$ would be indicated by curvature of the data in Figure B-15.4. Exxept for apparent saturation effects on annealed tubes at $300^{\circ} \mathrm{C}$, these departures are much less pronounced than differences due to different temperatures, fluences, and cold work. Moreover, there is a physical basis for expecting temperature and flux to modify the effect of a given fluence. Therefore, the exponent in Equation (B-15.10) is fixed in the model at 0.5 due primarily to the evidenco of Figure B-15.4.

15.5.2 The Effect of Temperature on Irradiation-Induced Growth. It has been suggested by Harbottle that growth is proportional to the instantaneuus concentration of interstitials. This implies that growth should be directly proportional to the rate of intersitial production (which is proportional to neutron flux $\phi$ ) and inversely proportional to the rate of interstitial removal [which is proportional to exp (-interstitial migration energy/R.T)]. In other words, the following expression fü gruwtl should apply:

$$
\frac{\Delta L}{L} \propto \phi \exp \left(E_{M} / R T\right)
$$

where

$$
\mathrm{E}_{\mathrm{M}}=\text { interstitial migration energy. }
$$

When Equation (B-15.11) is compared to data, it is found that $E_{M}$ varies with temperature (as expected) but that any simple variation of $E_{M}$ with temperature is not consistent with all experiments. A constant value for $F_{M}$ has been used in the model due to llese incunsistencies and because it has been suggested that the dependence of $E_{M}$ on temperature will be too complex $[\mathrm{B}-15.13]$ to evaluate with existing data. $\mathrm{E}_{\mathrm{M}}$ will actually change in poorly defined steps as the modes of interstitial migration change withincreasing temperature. However, Figures B-15.1, B-15.3, and B-15.4 indicate that there is a,relatively small temperature dependence in the normal operating temperature range for light water reactors. Use of a small and constant value for $E_{M}$ is therefore justified. A comparison of Equation (B-15.11) with the data shown in Figure B-15.4, then, results in the following correlation:

$$
\frac{\Delta L}{L} \propto \exp (240.8 / T)
$$

where

$$
\mathrm{T}=\text { temperature }(\mathrm{K}) \text {. }
$$




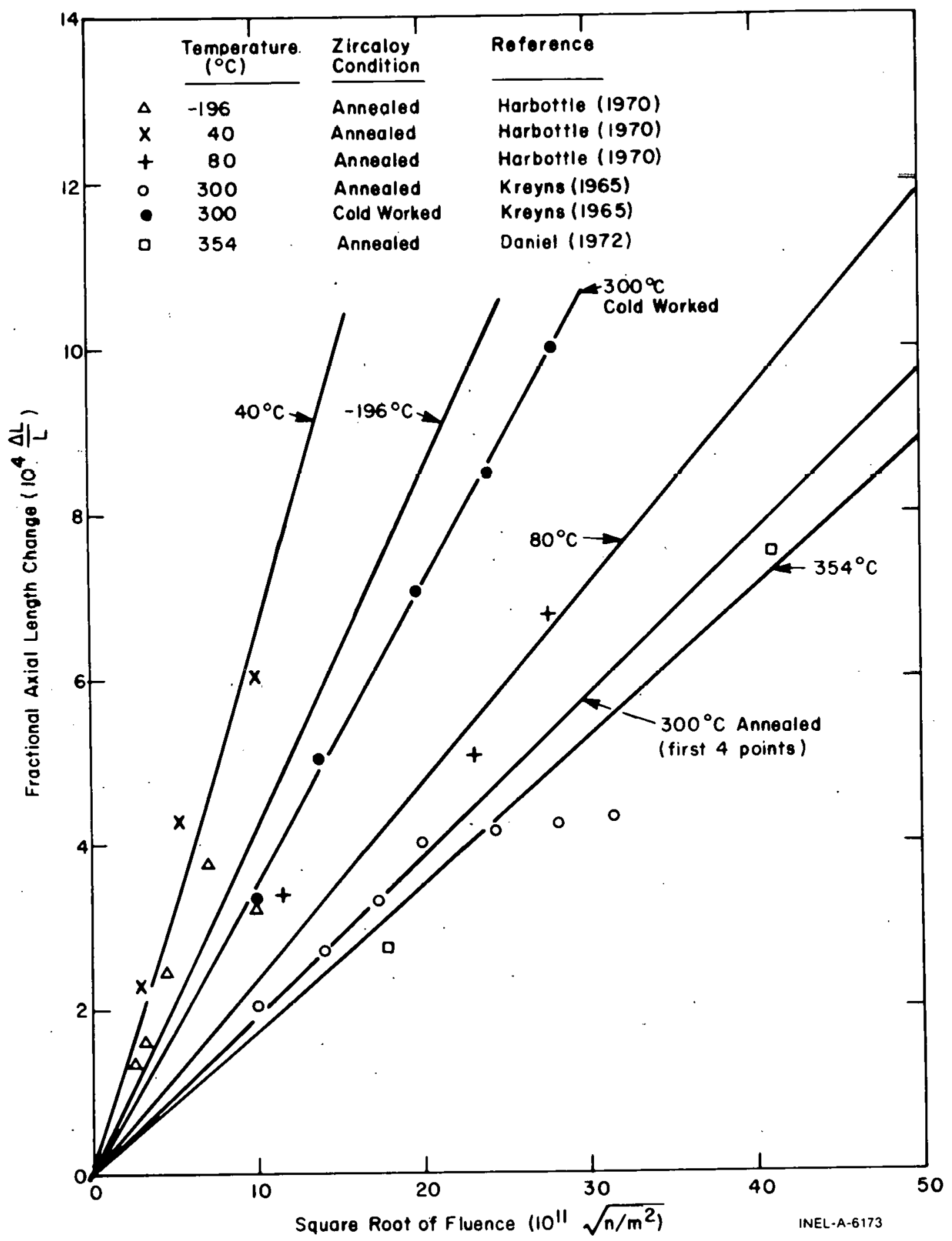

Fig. B-15.4 Zircaloy growth versus square root of fast neutron fluence for data adjusted to a common tube texture coefficient of $f_{Z}=0.05$ with linear least-squares fits. superimposed. 
The fast flux factor of Equation (B-15.11) has been incorporated in the constant $A$ of the full-expression for growth, Equation (B-15.1).

The detailed data comparisons made while deriving Equation (B-15.12) provide justification for the functional dependence shown. When Harbottle's [B 15.6] data tor growth under fast fluxes differing by a factor of two (at 40 and $80^{\circ} \mathrm{C}$ - See Table B-15.I) are compared, they are consistent with a value of $E_{m}=0.3 \mathrm{eV}$. This value of $E_{m}$ is reasonable. for atomic migration in that temperature range. When other data are examined, values of $\mathrm{L}_{\mathrm{m}}=0.075 \mathrm{eV}$ sesult at $-196^{n} \mathrm{C}$ and ul $\mathrm{E}_{\mathrm{m}}-0.517 \mathrm{eV}$ al $354^{\circ} \mathrm{C}$. 'This rainge ul values is alsu reasonable ${ }^{[B-15.14]}$ and so confidence may be assumed in the functional dependence given by Equations (B-15.11) and (B-15.12).

15.5.3 The Effect of Cold Work on Irradiation Growth. The obscrved cffects of cold work have not been successfully explained in detail in the literature. For the present model, general conclusions have been drawn from the available measurements and an empirical expression has been formed. The data taken by Kreyns on cold-worked zircaloy 4 tubes at $300^{\circ} \mathrm{C}$ agree very well with a square root of fluence dependency as shown in Figure B-15.5. In order to compare these results with those for annealed tubes, the annealed data shown in Figure B-15.4 were normalized to $300^{\circ} \mathrm{C}$ by use of Equation (B-15.12). Figure B-15.5 then indicates that the net effect of cold work is to increase the growth rate in the unsaturated range of fluence. Neither the dependence on the square root of the fluence nor the intercept at zero fluence are changed hy cold working the tubing.

The only available data on the effect of varying the amount of cold work are reported in Figure 19 of Reference B-15.8 which indicates the following approximate irradiation growth fractions in the longitudinal direction of zircaloy-4 plate specimens at $300^{\circ} \mathrm{C}$ (Table B-1 5.II). The data are reasonably consistent with a linear relationship between growth and cold work and have been incorporated into the model by assuming a factor of the form ( $1+\mathrm{D} \times$ cold work). Values of $\mathrm{D}$ determined from the data at the three different fluences are listed in Tahle B-1.5.III where

$$
D=\frac{1}{\text { cold work }}\left[\frac{\text { Growth with cold work }}{\text { Growth without cold work }}-1\right]=
$$

The value $D=2.0$, given by the data at the lower fluences, is used in the model since the measured values of growth with $0 \%$ cold work (Table B-15.II) show gross saturation effects similar to the effects apparent in the high fluence data of Kreyns. The model thus sacrifices a description of these gross saturation effects in order to fit the cold-work data and the majority of the annealed tubing data.

\subsection{Evaluation of the Model and Its Uncertainty}

The normalization of all the annealed data to identical conditions (texture coefficient $\mathrm{f}_{\mathrm{Z}}=0.05$, temperature at $300^{\circ} \mathrm{C}$ ) as shown in Figure B-15.5, provides a test of the model. The model predicts irradiation growth reasonably well except for data taken at fluences less 


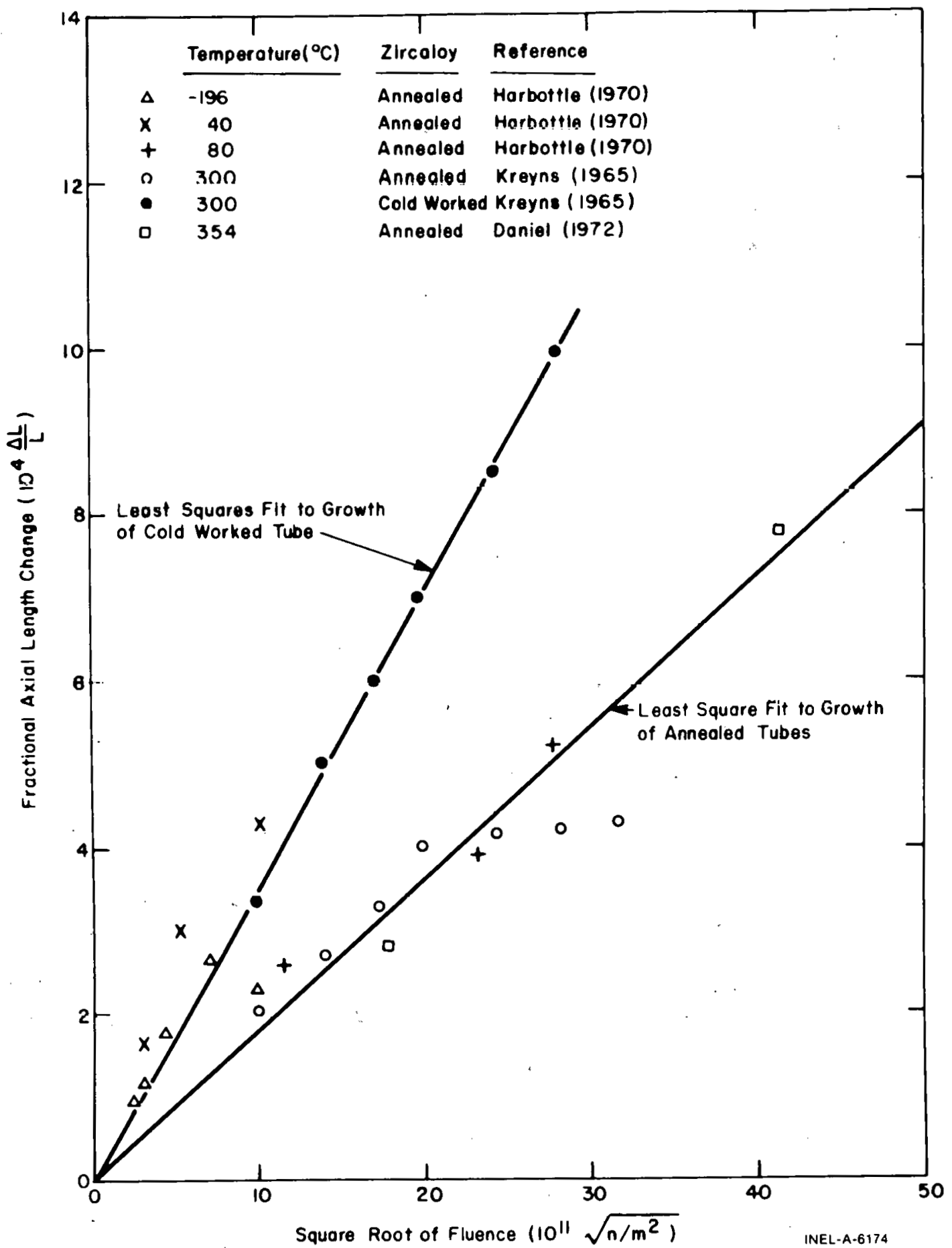

Fig. B-15.5 Zircaloy growth versus square root of fast neutron fluence for data adjusted to a common tube texture coefficient of $\mathrm{f}_{\mathrm{Z}}=0.05$ and to a common temperature of $300^{\circ} \mathrm{C}$, with linear least squares fits superimposed. 
TABLE B-15. II

ZIRCALOY GROWTH DATA AS A FUNCTION OF COLD WORK AND FLUENCE

\begin{tabular}{cccc}
\hline $\begin{array}{c}\text { Fast } \\
\text { F1 uence } \\
\left(10^{24} \mathrm{n} / \mathrm{m}^{2}\right)\end{array}$ & $\frac{0 \%}{14}$ & $\frac{20 \%}{7.8 \times 10^{-4}}$ & $\frac{78 \%}{17.4 \times 10^{-1}}$ \\
\cline { 2 - 4 } & $7.4 \times 10^{-4}$ & $11.7 \times 10^{-4}$ & $24.4 \times 10^{-4}$ \\
30 & $8.2 \times 10^{-4}$ & $17.3 \times 10^{-4}$ & $36.3 \times 10^{-4}$ \\
\hline
\end{tabular}

TABLE B-15. II I

DETERMINATON OF COLD WORK COEFFICIENT

Fast.

Fluence

$\left(10^{24} \mathrm{n} / \mathrm{m}^{2}\right)$

14

20

30
$\underline{D}$

1.7

2.0

3.8

than $10^{24}$ neutrons $/ \mathrm{m}^{2}$ and except for greater than normal saturation effects seen in some annealed samples. Figure B-15.1 leads to the same conclusion and also indicates the relative effects of the tcmpcraturc, tcxturc, and fluence variables as predicted by the model. [The factor $A$ used in Equation (B-15.1) for these curves was derived from a linear least squares fit to the data of Figure B-15.5].

Further refinement of the model to explain the relatively high growth measured at low fluence and to explain the gross saturation effects observed on some samples, has not been attempted. In the low fluence case there are competing processes that may explain the high values sometimes found, and there is no way to distinguish between them with additional data. These effects are:

(1) Stress relief causing additional length changes (Reference B-15.11) 
(2) Variation in fast flux causing different gruwth rates (Reference B-15.6)

(3) Variation in interstitial migration energy with temperature causing error in the temperature model (as discussed in Section B-15.5.2).

Similar problems exist with attempts to model the gross saturation effects observed in some experiments by Kreyns using tubing and by Fidleris ${ }^{[B-15.8]}$ using plate samples. There are sufficient data to indicate clearly that these saturation effects in growth are not simply a function of the fluence or the growth strain. However, few data are available to appraise correlations between saturation and other parameters.

An estimate of the uncerlainly can be ubtained by comparing prediction of the model with data which were not used in formulating the model. For example, the plate specimen data listed in Table B-15.II for $0 \%$ cold work (and $300^{\circ} \mathrm{C}$ ) were not used to formulate the predicted growth of annealed tubes. When these data are compared with the model predictions for annealed growth at $300^{\circ} \mathrm{C}$, a discrepancy of approximately $10 \%$ is found. This $10 \%$ discrepancy is consistent with the scatter of the data at fluences above $10^{24} \mathrm{n} / \mathrm{m}^{2}$ in Figure B-15.5 and thus represents a reasonable estimate of the model's uncertainty in the temperature range from 40 to $360^{\circ} \mathrm{C}$.

The uncertainty for temperatures outside of this range and for fluences less than

$10^{24} \mathrm{n} / \mathrm{m}^{2}$ may be substantially greater than $10 \%$. In the low fluence range, inspection of Figure B-15.5 suggests uncertainties on the order of $100 \%$. Such large discrepancies may be due to stress-relief effects $[\mathrm{B}-15.11]$. For temperatures much ou tside the range 40 to $360^{\circ} \mathrm{C}$ increased error will be caused by the presence of different modes of atomic interstitial or vacancy migration causing different rates of zircaloy growth.

\subsection{Cladding Axial Growth Subcode CAGROW Listing}

A listing of the FORTRAN subcode CAGROW is presented in Table B-15.IV.

\subsection{References}

B-15.1. R. C. Daniel, "In-Pile Dimensional Changes of Zircaloy-4 Tubing Having Low Hoop Stresses (Light Water Breeder Reactor Development Program)," Nuclear Technology, 14 (May 1972) pp 171-186.

B-15.2. W. R. Smalley, Evaluation of Saxton Core III Fuel Matcrials Performance WCAP-3385-57 (1974).

B-1 5.3. J. B. Melehan, Yankee Core Evaluation Program Quarterly Progress Report for the Period Ending September 30, 1969, WCAP-3017-6091 (December 1969). 


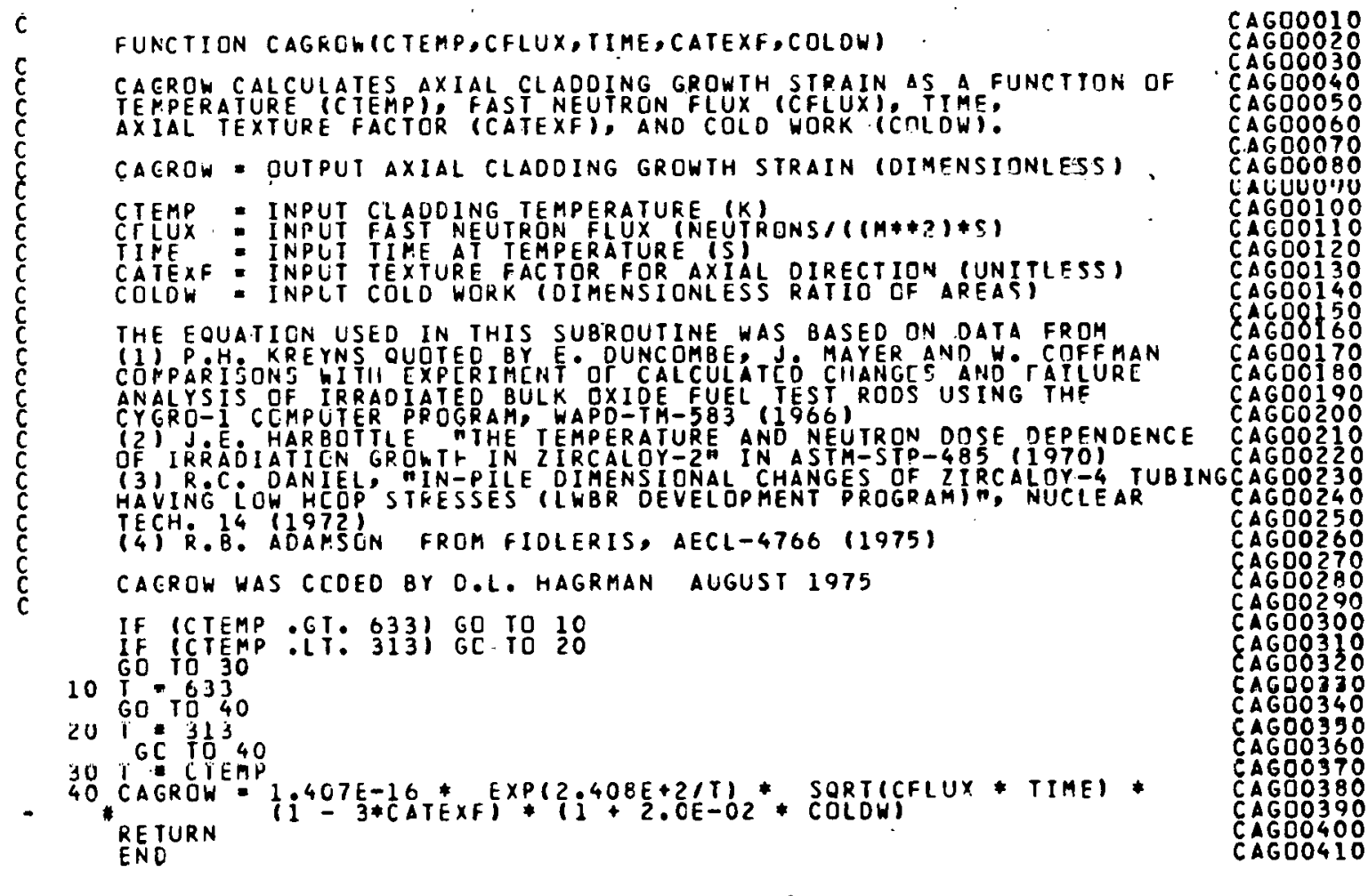

B-15.4. E. T. Laats and P. E. MacDonald, Halden Project Fuel Behavior Test Program Experimental Data. Report for Test Assemblies IFA-226 and IFA-239, NRC-OECD (March 1975).

B-15.5. P. H. Kreyns, quoted by E. Duncombe, J. E. Mayer, W. A. Coffman, Comparisons with Experiment of Calculated Changes and Failure Analysis of Irradiated Bulk Oxide Fuel Test Rods Using the CYGRO-1 Computer Program, WAPD-TM-583 (September 1966).

B-15.6. J. E. Harbottle, "The Temperature and Neutron Dose Dependence of Irradiation Growth in Zircaloy-2," Irradiation Effect on Structural Alloys for Nuclear Reactor Applications, ASTM-STP-485 (1970) pp 287-299.

B-15.7. R. Daniel, In-Pile Dimensional Changes of Zircaloy-4 Tubing Having Low Hoop Stresses (LWBR Development Program), WAPD-TM-973 (July 1971).

B-15.8. V. Fidleris, "Summary of Experimental Results on In-Reactor Creep and Irradiation Growth of Zirconium Alloys," Atomic Energy Review, 13 (1975) p 51. 
B-15.9. S. N. Buckley, "Discussion at Institute of Metals Spring Meeting," Journal of the Institute of Metals, 97 (1969) p 61.

B-15.10. J. J. Kearns, Thermal Expansion and Preferred Orientation in Zircaloy, WAPD-TM-472 (November 1965).

B-15.11. V. Fidleris, "The Effect of Cold-Work and Stress-Relieving on the Irradiation Growth Behavior of Zirconium Alloys," Journal of Nuclear Materials, 46 (1973) pp 356-360.

B-15.12. R. V. Hesketh "Non-linear Growth in Zircaloy-4," Journal of Nuclear Materials, $30(1969)$ pp $217-222$.

B-13.13. S. H. Bush, Irradiation Effects in Cladding and Structural Materials, New York: Rowman and Littlefield (1965) p 143.

B.15.14. A. Seeger and H. Mehren, "Analysis of Self-Diffusion and Equilibrium Measurements," Vacancies and Interstitials Metals, A. Seeger (ed.), New York: American Elsevien Publishing Co., Inc., 1970, p 892.

\section{CLADDING OXIDATION (CORROS AND CHITOX)}

The oxidation of zircaloy cladding is an important subject because zircaloy containing oxygen is more brittle than oxygen-free zircaloy and, therefore, has less ability to deform plastically under stress. Moreover, the oxidation reaction is exothermic and at high temperatures, such as might occur during a loss-of-coolant accident, the reaction may proceed rapidly enough so its heat can significantly influence the cladding temperature.

The correlations developed are used in safety analysis to determine the extent of the oxidation, to assess the strength of the cladding, and to predict the cladding temperature.

\subsection{Summary}

Low temperature oxidation is summarized in Section B-16.1.1 and high temperature oxidation is summarized in Section B-16.2.

16.1.1 Low Temperature Oxidation (CORROS). The subroutine CORROS returns'an expression for the thickness of the oxide layer on zircaloy cladding during typical reactor operation at temperatures of 250 to $400^{\circ} \mathrm{C}$. Required input values are temperature at the outer surface of the oxide, initial oxide film weight, length of time at the given temperature, type of reactor (BWR or PWR), heat flux across the oxide layer, and zircaloy oxide thermal conductivity. 
Cladding oxidation during normal LWR operation occurs in two stages depending on the oxide thickness and to some extent on the temperature of the oxide. For thin oxides the rate of oxidation is controlled by the entire oxide layer. When the oxide layer becomes thicker, a change of the outer portion occurs and further oxidation is controlled by the intact inner layer. The transiliun between slages is described in tcrms of thiclnowe of the oxide layer at transition which is given by

$$
X_{\text {TRAN }}=7.749 \times 10^{-6} \exp \left(\frac{-790}{T}\right)
$$

where

$$
\begin{array}{ll}
\mathrm{X}_{\text {TRAN }}= & \begin{array}{l}
\text { thickness of the oxide layer at transition point } \\
(\mathrm{m})\left(\text { typically } 1.9 \times 10^{-6} \mathrm{~m} \text { thick }\right)
\end{array} \\
\mathrm{T} . \quad & \text { temperature of the oxide-metal interface }(\mathrm{K}) .
\end{array}
$$

Values of the thickness of the oxide layer on the outside of the cladding are given by Equations (b-1.6.2a), (b-16.2b), and ( $B-16.2 c)$ for pretransllun and puslladisitiun uside films.

For pretransition oxide films:

$$
x_{P R E}=\left[4.976 \times 10^{-9} \mathrm{~A}[\mathrm{t}] \exp \left(\frac{-15660}{\mathrm{~T}}\right)+x_{0}^{3}\right]^{1 / 3}
$$

for posttransition oxide films when $\mathrm{X}_{\mathrm{O}}$, the intial oxide thickness, is less than $\mathrm{X}_{\text {TRAN }}$ :

$$
x_{\text {POST }}=82.88 \mathrm{~A}\left[t-t_{\text {TRAN }}\right] \exp \left(\frac{-14 \cdot 080}{T}\right)+x_{\text {TRAN }}
$$

and when $\mathrm{X}_{\mathrm{O}}$ is grealer than the transition thickncss:

$$
x_{\text {POST }}=82.88 \mathrm{~A}[\mathrm{t}] \exp \left(\frac{-14080}{\mathrm{~T}}\right)+x_{0}
$$

where

$$
\begin{array}{ll}
\dot{X}_{\text {TRAN }}= & \begin{array}{l}
\text { thickness of the oxide layer at the transition } \\
\text { point (Equation B-16.1). }
\end{array} \\
\mathrm{X}_{\text {PRE }}= & \begin{array}{l}
\text { thickness of the oxide layer when a pretransition } \\
\text { oxide film exists }(\mathrm{m}) .
\end{array} \\
\mathrm{X}_{\mathrm{POST}}=\quad \begin{array}{l}
\text { thickness of the oxide layer when the oxide film } \\
\text { is in the posttransition state }(\mathrm{m}) .
\end{array}
\end{array}
$$




\begin{tabular}{|c|c|c|}
\hline$x_{0}$ & $=$ & $\begin{array}{l}\text { initial thickness of the cladding oxide layer } \\
\text { expressed in meters. This term can be approxi- } \\
\text { mated as } X_{O}=0 \text { for etched cladding but it } \\
\text { becomes important if extensive prefilming has } \\
\text { occurred or if oxidation is carried out in several } \\
\text { steps which take place at different temperalures } \\
\text { or in different coolant chemistries. }\end{array}$ \\
\hline $\mathrm{t}$ & $=$ & time at temperature (days). \\
\hline A & $=$ & $\begin{array}{l}\text { a parameter describing enhancement of the } \\
\text { cladding oxidation rate in a reactor environ- } \\
\text { ment. Typical reactor chemistries and flux levels } \\
\text { result in a value of } A=1.5 \text { for a PWR and } 9 \text { for } \\
\text { a BWR. However, the factor is apparently. a } \\
\text { function of temperature, as discussed in Section } \\
\text { B-16.2.3. A value for A is delermined in the } \\
\text { subcode by user specification of BWR or PWR } \\
\text { chemistry with an input parameter ICOR. }\end{array}$ \\
\hline $\mathrm{T}$ & $=$ & $\begin{array}{l}\text { temperature of the oxide-metal interface calcu- } \\
\text { lated by the code from the input value of the } \\
\text { temperature at the outer oxide suirface, the heat } \\
\text { flux across the oxide and the thermal con- } \\
\text { ductivity of the oxide layer }(\mathrm{K}) \text {. }\end{array}$ \\
\hline${ }^{t}$ TRAN & $=$ & $\begin{array}{l}\text { time of transition between states (pre- and } \\
\text { posttransition). This time is calculated in the } \\
\text { code from the inverse of Equation B-16.2a. }\end{array}$ \\
\hline
\end{tabular}

The approach and general physical picture used to model low temperature oxidation are summarized in Section B-16.2.1. Section B-16.2.2 develops the basic out-of-pile model, and Section B-16.2.3 generalizes the basic model to in-pile environments. The model is compared with in-pile data in Section B-16.2.4. The subcode CORROS is presented in Section B-16.4.

16.1.2 High Temperature Oxidation (CHITOX). For the high temperature range $\left(1000\right.$ to $\left.1500^{\circ} \mathrm{C}\right)$ neither the flux level nor the coolant chemistry has an important influence on the extent of oxidation. At these temperatures the "coolant" has become steam, and oxidation proceeds much more rapidly than at operating temperatures. The only parameters used in the model are the time at the high temperature and the temperature. The correlations are used to calculate the $\mathrm{ZrO}_{2}$ and $\xi^{[a]}$ layer thicknesses formed

[a] The $\mathrm{ZrO}_{2}$ and oxygen-stabilized alpha layers together are called the $\xi$ layer. 
during a time step, the radial thicknesses of the unoxidized part of the cladding at the end of the step, and the heat released per meter per second due to the transformation of zirconium to zirconium dioxide.

The general features of high-temperature zircaloy oxidation are discussed in Section B-16-3.1. The selection of a data base for comparison with the correlations is discussed in Section B-16.3.2 and an evaluation of existing models with this data base is given in Section B-16.3.3. The corrclations chosen for the model based on this evaluation are those of C'alhuarl $[\mathrm{D}-16.1]$. The thickness of $\mathrm{ZrO}_{2}$ layer is discussed in Section $\mathrm{B}: 16.3 .4$ and is given by Equation (B-16.3):

$$
x_{2}=\left[x_{1}^{2}+2.25 \times 10^{-6} \exp (-18063 / T) D t\right]^{1 / 2} .
$$

where

$$
\begin{aligned}
& \mathrm{X}_{\mathrm{l}}=\text { the oxide thickness at the beginning of the time step (m) } \\
& \mathrm{X}_{2}=\text { the oxide thickness at the end of the timc step (m) } \\
& \mathrm{I}=\text { tempcrature (K) } \\
& \mathrm{Dt}=\text { duration of the time step (s). }
\end{aligned}
$$

Because an increase in volume occurs when zirconium changes to $\mathrm{ZrO}_{2}$, the radius of the remaining unoxidized zircaloy is not simply the original radius minus the thickness of the oxide layer. Rather this radius, designated by $R_{2}$, is given by:

$$
R_{2}=R_{0}-0.69 x_{2}
$$

where the new variables are:

$$
\begin{aligned}
& R_{0}=\text { outside diameter of the fuel rod before any oxidation } \\
& R_{2}=\begin{array}{l}
\text { outside diameter of the unoxidized part of the fuel rod at } \\
\text { the end of the time step }(\mathrm{m}) .
\end{array}
\end{aligned}
$$

Equation (B-16.4) is derived in Section B-16.3.5.

The rate of heat generation per meter in a rod of original radius $R_{o}$ due to the oxidation reaction is given by:

$$
Q=\left(r_{Z r}\right)(H R Z) 4.34 R_{0}\left(x_{2}-x_{1}\right) / D t
$$


where

$$
\begin{aligned}
& \mathrm{Q}=\text { rate of heat generation by the oxidation }(\mathrm{W} / \mathrm{m}) \\
& \rho_{\mathrm{Zr}}=\text { density of zirconium }\left(6.5 \times 10^{3} \mathrm{~kg} / \mathrm{m}^{3}\right) \\
& \mathrm{HRZ}=\text { heat of reaction per } \mathrm{kg} \text { of zirconium }\left(6.45 \times 10^{6} \mathrm{~J} / \mathrm{kg}\right) .
\end{aligned}
$$

The derivation of Equation (B-16.5) is given in Section B-16.3.6.

The $\xi$ layer thickness correlation given by Equation (B-16.6) is developed in Section B-16.3.7.

$$
x_{2}^{\prime}=\left[x_{1}^{\prime 2}+6.824 \times 10^{-5} \exp (-21000 / T) D t\right]^{1 / 2}
$$

where

$$
\begin{aligned}
& X_{1}^{\prime}=\text { the } \xi \text { thickness at the beginning of a time step (m) } \\
& X_{2}^{\prime}=\text { the } \xi \text { thickness at the end of a time step }(m) .
\end{aligned}
$$

In Section B-16.3.8 an approach to the oxidation kinetics during ballooning of the rod is discussed. Ballooning is especially important because as the rod surface area increases, the brittle oxide cracks and exposes unoxidized zircaloy, which according to the parabolic rate law will oxidize much more quickly than the neighboring oxidized areas and thus cause further thinning of the remaining ductile material which rapidly changes to oxide. The uncertainties in the correlations are discussed in Section B-16.3.9, and the computer subcode CHITOX is presented in Section B-16.4.

\subsection{Low Temperature Oxidation Model (CORROS)}

In this section a model is developed which describes the oxidation of zircaloy cladding at normal reactor operating temperatures $\left(250\right.$ to $\left.400^{\circ} \mathrm{C}\right)$.

16.2.1 Physical Picture Used in the Model. Investigators generally agree ${ }^{[\mathrm{B}-16.2 \text {, }}$ B-16.3] that oxidation of zirconium alloys by water in the temperature range from 250 to $400^{\circ} \mathrm{C}$ proceeds by the migration of oxygen vacancies from the oxide-metal interface through the oxide layer to the oxide-coolant surface (and the accompanying migration of oxygen in the opposite direction). The vacancies at the metal-oxide surface are generated by the large chemical affinity of zirconium for oxygen. Although the rate of oxidation is controlled in part by vacancy migration, the process of oxygen transfer from coolant to metal is not complete until the vacancy is annihilated by an oxygen ion at the oxide-coolant surface. Thus, the suggestion that in-pile oxidation rates are affected by the supply of oxygen ions or atoms at the surface is consistent with oxygen rate control by vacancy 
diffusion. In other words, the net flux of oxygen atoms into the metal is equal to the product of the vacancy flux times the probability that a vacancy will be annihilated by an oxygen atom, and that probability is affected by the supply of oxygen ions at the outer surface of the oxide whenever a competing mode for vacancy annihilation exists.

Detailed mechanisms for the posttransition time dependence of oxide growth have not been established in the literature [B-16.4, B-16.5]. Proposed mechanisms are discussed in conjunction with the models developed in Sections B-16.2.2 and B-16.2.3.

16.2.2 Out-of-Pile Basis for the Oxidation Model. An out-of-pile model is considered in this section because well characterized data[B-16.2] on oxidation as a function of time and temperature have been published only for out-of-pile corrosion. Principal features of the oxidation models are:

(1) The pretransition oxidation rate is time dependent and inversely proportional to the square of the (uniform) oxide thickness.

(2) The posttransition oxidation rate of a macroscopic surface is constant und proportional to the avcragc of the local rates determined by an intact inner oxide layer. Figure B-16.1 presents a srhematir pirture of the posttransition model of the nxide film.

Oxidation of materials which form a protective oxide layer is frequently found to conform to the assumption that the rate determining process is the diffusion of oxygen atoms across the oxide. In these metals, the flux of atoms arriving at the metal and thus the rate of oxidation are determincd by the concentration gradient across the oxide and are inversely proportional to the oxide thickness $[\mathrm{B}-16.6]$.

$$
\frac{d y}{d t^{\prime}}-\frac{k}{y}
$$

where

$$
\begin{aligned}
& \mathrm{y}=\text { oxide thıckness } \\
& \mathbf{t}^{\prime}=\text { time } \\
& \mathrm{k}=\text { a constant. }
\end{aligned}
$$

Integration of this equation from $y=0$ at $t^{\prime}=0$ to $y=X$ at $t^{\prime}=t$ yields a "parabolic" time dependence, $X=(2 \mathrm{~K} \mathrm{t})^{1 / 2}$ which is frequently observed experimentally.

A slight generalization in the derivation of "parabolic" oxidation produces a result consistent with the measured lime dependence of zircaloy corrosion. As discuissed, vacancy 


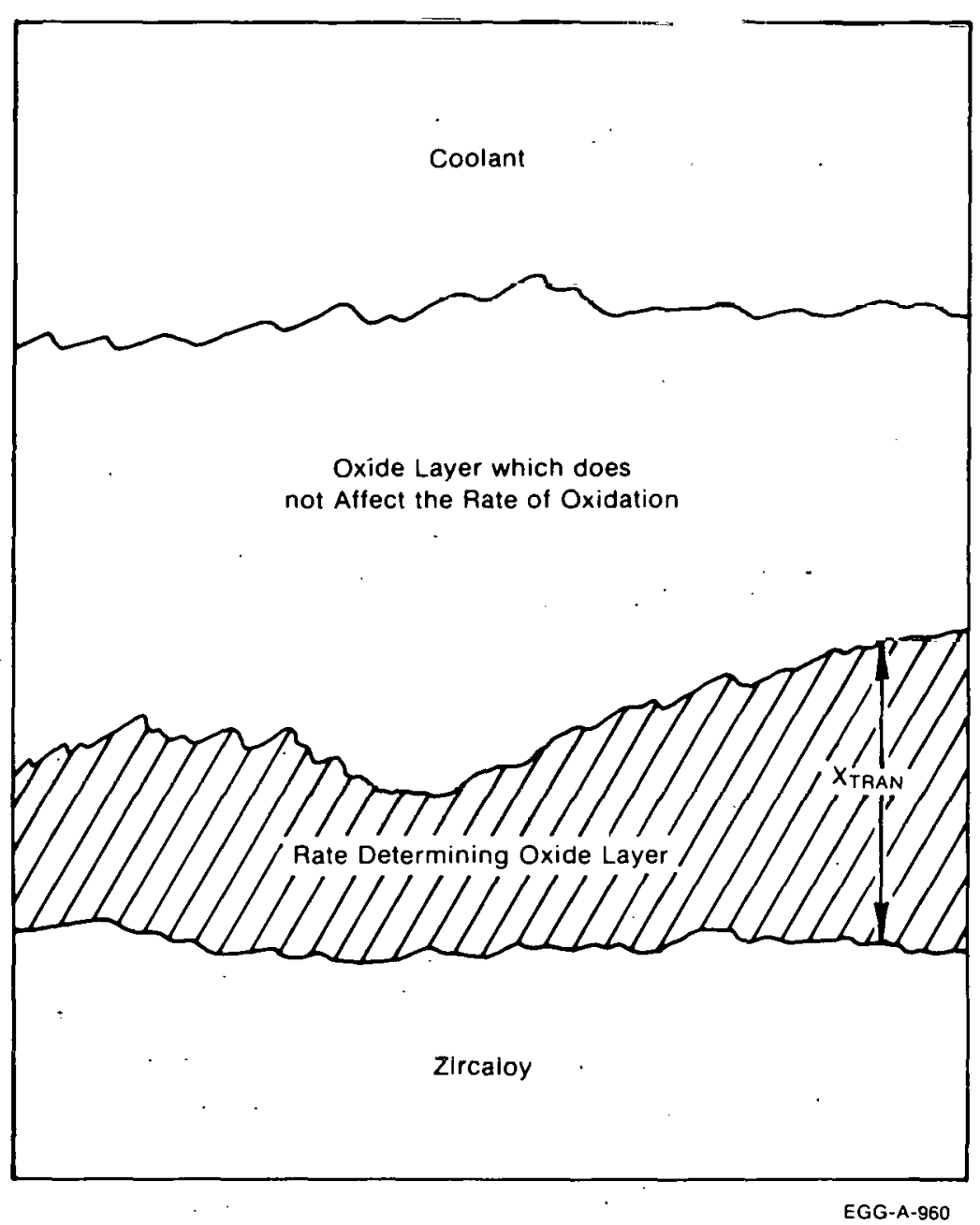

Fig. B-16.1 Schematic of posttransition oxide showing an intact rate-determining layer of varying thickness, with another oxide layer which does not affect the oxidation rate.

migration is one factor in the rate controlling mechanism. If the vacancies have a limited lifetime, the flux of vacancies arriving at the oxide-coolant surface will be proportional to the inverse of the time, $t_{\text {diffusion }}$, required for a vacancy to diffuse to the oxide-coolant surface. Since this time is proportional to the square of the average diffusion distance $\left(t_{\text {diffusion }} \propto y^{2}\right)$ the net vacancy flux arriving at the oxide-coolant surface and thus the rate of oxidation should be proportional to the inverse of the square of the oxide thickness which the vacancies must cross.

From the physical arguments of the last paragraph, the vacancy lifetime-limited rate of oxide growth should be $\frac{d y}{d t^{\prime}}=\frac{c}{y^{2}}$ where $c$ is not a function of time or oxide thickness. Integration of the rate equation from $y=X_{0}$ at $t^{\prime}=0$ to $y=X$ at $t^{\prime}=t$, gives $X=\left(3 c t+x_{0}^{3}\right)^{1 / 3}$.

The $t^{1 / 3}$ dependencc of the oxide layer was obtained directly from the assumption that the oxide growth is proportional to the inverse squared oxide thickness without specific 


\section{CORROS/CHITOX}

reference to the vacancy migration picture. If the concept of a temperature dependent vacancy concentration at the metal-oxide surface is introduced, the constant $c$ can be replaced with a temperature dependent form $c=R \exp \left(-T_{0} / T\right)$ where $R$ and $T_{0}$ are constants and $\mathrm{T}$ is the temperature of the oxide-metal interface. The rate of oxidation in the pretransition stage is then

$$
\frac{d y}{d t^{\prime}}=\frac{R \exp \left(-T_{0} / T\right)}{y^{2}}
$$

where

$$
y=\quad \text { the oxide layer thickness at time } t^{\prime} .
$$

Integration of Equation (B-16.8a) from $y=X_{0}$ at $t^{\prime}=0$ to $y=X$ at $t^{\prime}=t$ gives

$$
x=\left[3 R t \exp \left(-T_{0} / T\right)+x_{0}^{3}\right]^{1 / 3} \text {. }
$$

Posttransition oxidation is viewed in this section as a series of pretransition modes. An inner oxide layer with thickness that varies as a function of surface position is presumed to control the rate of oxidation until this inner layer grows to the transition thickness. At this time the inncr layer changes to an outer layer which does not affect the oxidation rate, and growth of a new inner layer begins. The representation is adopted because it successfully relates pretransition and posttransition oxidation rates (out-of-pile).

If the representation with an inner oxide film of varying thickness is correct, the rate controlling inner part of the oxide layer should join the outer layer at a thickness approximately equal to the transition thickness but at a time determined by local conditions. After several cycles the growth rates of the inner oxide layer at different locations on the surface of a Illacruscipic oxide fllm will be out of phase and the rate of growth of the entire surface film at any time (which is what is nhserver in most cxpcriments) will be the time average rale of growth at any one place on the surface.

$$
\frac{d y}{d t} \underset{\begin{array}{l}
\text { average } \\
\text { over } \\
\text { surface }
\end{array}}{\text { surfan }}=\frac{x_{\text {TRAN }}}{t_{\text {TRAN }_{0}}}=\frac{3 R \exp \left(-T_{0} / T\right)}{x_{\text {TRAN }}^{2}}
$$

where

$$
\begin{array}{ll}
\mathrm{X}_{\text {TRAN }}= & \text { the thickness of the oxide layer at transition } \\
\mathrm{t}_{\text {TRAN }_{\mathrm{O}}=} & \begin{array}{l}
\text { the time necessary for an oxide film to grow } \\
\text { from almost zero thickness to the transition } \\
\text { thickness, according to Equation (B-16.8B) }
\end{array}
\end{array}
$$




$\begin{array}{lll}\mathrm{T} & = & \text { temperature } \\ \mathrm{T}_{\mathrm{O}} & = & \text { constant } \\ \mathrm{R} & = & \text { constant. }\end{array}$

Empirical relations based on out-of-pile data are published in Reference B-16.3. These relations are as follows:

$$
\begin{aligned}
& \text { pretransition oxidation }=(27.1 \pm 0.8) 10^{3} t^{1 / 3} \exp \left(\frac{-5220}{T}\right) \\
& \text { posttransition oxidation }=\left(23.0 \pm 0.710^{8} \mathrm{t} \exp \left(\frac{-14400}{T}\right)\right. \\
& \text { weight gain at transition }=(123 \pm 4) \exp \left(\frac{-790}{T}\right)
\end{aligned}
$$

where

$$
\begin{array}{rlrl}
\text { oxidation } & = & & \text { weight gain in } \mathrm{mg} / \mathrm{dm}^{2} \\
\mathrm{~T} & = & & \text { temperature }(\mathrm{K}) \\
\mathrm{t} & = & \text { time in days. }
\end{array}
$$

Since the posttransition oxidation is viewed as being a series of pretransition modes which are separated by local loss of the inside oxide film, one would expect to obtain the pre- and posttransition oxidation rates with a single set of constants. In fact, the empirical constants determined by Van der Linde ${ }^{[\mathrm{B}-16.3]}$ for the pre- and posttransition oxidation rates [Equations (B-16.10) and (B-16.11)] can be reproduced with a single set of parameters, $\mathrm{T}_{\mathrm{O}}=14080 \mathrm{~K}, \mathrm{R}=1.659 \times 10^{-9} \frac{\mathrm{m}^{3}}{\mathrm{day}}$, and $\mathrm{X}_{\mathrm{TRAN}}=7.749 \times 10^{-6} \mathrm{~m} \exp (-790 / \mathrm{T})$. Oxidation rates obtained using these constants and Equations (B-16.8) and (B-16.9) are within the $\pm 4 \%$ error reported by. Van der Linde for oxidation rates obtained using Equations (B-16.10) and (B-16.11).

16.2.3 Generalization to an In-Pile Model. Prediction of in-pile corrosion is complicated because the important variables of local temperature and reactor chemistry are not always reported; thermal gradients exist across the oxide film (causing the oxide outer surface temperature to differ from the oxide-metal interface temperature), and data on the time dependence of corrosion are limited. If in-pile corrosion enhancement is due to irradiation damage of the oxide layer as has been suggested ${ }^{[B-16.7, B-16.8]}$, a new mechanism must be added to the present model. However, if the observed enhancements 


\section{CORROS/CHITOX}

result from an increased supply of oxygen atoms or oxygen ions as suggested by other workers[B-16.9], a simple change of the rate constant in the out-of-pile equation will describe the increased oxidation observed in reactors. Changes in oxidation due to in-pile shemical effects are incorporated into the present model with an enchancement factor $A$ which describes a multiplicative in-pile enhancement of the out-of-pile oxidation rate due to an increased supply of oxygen ions.

Rate equations for in-pile oxidation are thus:

for pretransition regime

$$
\left(\frac{d x}{d t}\right)_{\text {pre }}=\frac{A R \exp \left(-T_{0} / T\right)}{x^{2}}
$$

for posttransition regime

$$
\left(\frac{\mathrm{dX}}{\mathrm{dt}}\right)_{\text {post }}=\frac{3 \wedge \mathrm{R} \exp \left(-\mathrm{T}_{0} / T\right)}{x_{\text {TRAN }}^{2}} .
$$

The inlegraled forms of these equalions are:

$$
X_{P R E}=\left[3 A R t \exp \left(-T_{0} / T\right)+x_{0}^{3}\right]^{1 / 3}
$$

and

$$
x_{\text {PIST }}=\frac{3 / K\left(t-t_{\text {TRAN }}\right) \operatorname{cxp}\left(\dot{T}_{0} / T\right)}{x_{\text {TRNN }}^{2}}+x_{\text {TRAN }}
$$

if $X_{O}$ is less than $X_{\text {TRAN }}$, or if $X_{O}$ is greater than $X_{\text {TRAN }}$ :

$$
X_{\text {POST }}=\frac{3 \text { AR } t \exp \left(-T_{0} / T\right)}{x_{\text {TRAN }}^{2}}+x_{0} .
$$

An interesting result (and a good test of the theory if time dependent in-reactor data become available) is the fact that the rate enhancement factor $A$ does not result in a linear change in the oxide thickness for pretransition films. That is, al though the oxidation rate is enhanced by factor $A$, the pretransition oxide film thickness at a given time is merely $A^{1 / 3}$ as thick as it would have been without the in-pile enhancement. Since the posttransition oxidation is linear in time, both the rate and change in oxide thickness at a particular time are enhanced by factor $\mathrm{A}$. 
I he metal-oxide temperalue is computcd from the tempcrature at the ouler uxide surface, the heat flux across the oxide surface, and the thermal conductivity of the oxide layer by Equation (B-16.16):

$$
T=T_{C}+Q * X / K 02
$$

where

$$
\begin{aligned}
& \mathrm{T}=\text { temperature of the oxide-metal interface }(\mathrm{K}) \\
& \mathrm{T}_{\mathrm{C}}=\text { temperature of the outer surface of the oxide }(\mathrm{K}) \\
& \mathrm{Q}=\text { heat flux across the oxide layer }\left(\mathrm{W} / \mathrm{m}^{2}\right) \\
& \mathrm{X}=\text { oxide layer thickness }(\mathrm{m}) \\
& \mathrm{KO2}=\text { thermal conductivity of the oxide layer }(\mathrm{W} / \mathrm{m} \cdot \mathrm{K}) .
\end{aligned}
$$

Since the term $Q * X / K O 2$ normally is a small correction to the temperature of the outer oxide surface, the correction to the lemperature is approximated with an iteratinn. For the first, step $X$ is approximated as the initial oxide thickness. The oxide thickness is then computed with Equation (B-16.14) or Equation (B-16.15) and the resultant value is inserted for $\mathrm{X}$ in Equation (B-16.16).

An adequate data base for a careful prediction of oxidation enhancements in reactor environments is not available in spite of several past studies which have concentrated on the effects of dissolved oxygen $[\mathrm{B}-16.10, \mathrm{~B}-16.11]$, fast neutron flux ${ }^{[\mathrm{B}-16.11]}$, fast neutron fluence $^{[B-16.12]}$, and $\gamma$-irradiation ${ }^{[B-16.9]}$. As an interim measure, this model correlates the oxidation enhancement with only two of the more important variables: temperature and reactor environment.

(1) BWR Environments. Several authors $[B-16.8, B-16.9, B-16.13]$ report that oxidation enhancement increases rapidly with decreasing temperatures in BWR environments. Values of the enhancement factor A, proposed in References B-16.8 and B-16.13 are plotted in Figure B-16.2 along with an average value of $A=9$ found necessary to obtain a reasonable fit of the model developed here to the oxidation data presented in Reference B-16.14 and B-16.15 (pH 7 water with $30 \mathrm{ppm}$ oxygen content in the steam). It is recommended that the straight line sketched between these points be used to estimate the enhancement in a typical BWR environment, and an analy tical expression corresponding to this straight line has been programmed into CORROS using the expression

$$
A=4.840 \times 10^{5} \exp \left(-1.945 \times 10^{-2} \mathrm{~T}_{\mathrm{C}}\right)
$$

for $500<\mathrm{T}<673 \mathrm{~K}$ 
where

$\mathrm{A}=$ the enhancement factor
$\mathrm{T}_{\mathrm{C}}=$ the temperature at the outer oxide surface $(\mathrm{K})$.

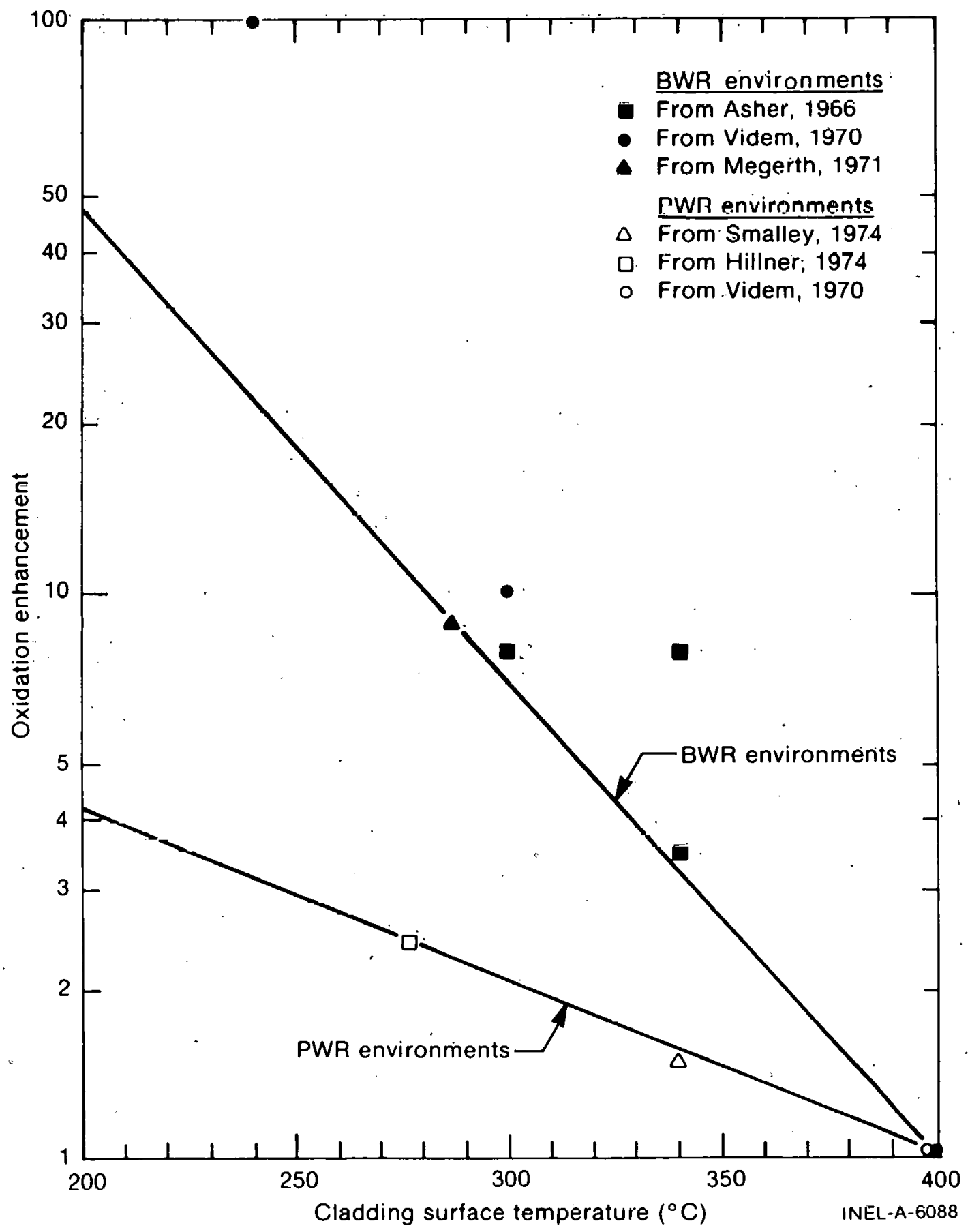

Fig. B-16.2 Estimates of enhancements over out-of-pile oxidation rates when cladding is irradiated in typical BWR and PWR environments. 
(2) PWR Environments. "Enhancement factors" have been reported to be about 2.4[B-16.16] for zircaloy-2 rods in the Shippingport PWR. A fit of Equation (B-16.2b) to values of oxide thickness rcported in Reference B-16.16 agreed with this value and a similar fit of the equation to values reported from Saxton. PWR rods $[B-16.17, B-16.18]$, resulted in a value of $A=1.5$. These values are also plotted in Figure B-16.2. The relatively small value of $A$ in PWR environmenls (which do not contain dissolved oxygen in the bulk coolant) is consistent with the picture of enhanced oxygen atom and ion supply rates due to ionization of dissolved oxygen. As in the case of BWR environments, the straight line sketched between these points is used by CORROS to estimate the enhancement in a typical PWR environment.

The equation for $500<\mathrm{T}<673 \mathrm{~K}$ is

$$
A=1.203 \times 10^{3} \exp \left(-7.118 \times 10^{-3} \mathrm{~T}_{\mathrm{C}}\right)
$$

where
$\mathrm{A}=$ the enhancement factor
$\mathrm{T}_{\mathrm{C}}=$ the temperature at the oxide-coolant surface $(\mathrm{K})$.

16.2.4 Comparison with In-Pile Data. The average value predictions of the model deveioped in this section are compared with the values reported for individual samples in Figures B-16.3 through B-16.5. There is considerable scatter in the data from individual rods, with maximum measured values of oxide thickness as large as twice the average values. In some cases, such as the Shippingport data of Figure B-16.3, variations are generally consistent with the idea that temperature variations are responsiblc. In other cases, such as the Saxton data of Figure B-16.4, variations are not explained solely by temperature variation and the cause is probably related to local variations in coolant quality or chemistry caused by nucleate boiling or to contaminants. Similarly, variations in coolant quality along the BWR rods could contribute to the large scatter in the BWR data of Figure B-16.5. Note that the duration of the pretransition period varies considerably in Figures B-16.3, B-16.4, and B-16.5. Figures B-16.3 and B-16.4 refer to PWRs with relatively low oxidation rate enhancements. However, the temperature is higher in the case of Figure B-16.4, producing a shorter pretransition period due to more rapid oxidation. Figure B-16.5 refers to a BWR, having low temperatures but large oxidation enhancement factors ( 9 in this case). This enhancement overwhelms the temperature effect and results in an even shorter pretransition period so that the relatively rapid posttransition oxidation is predicted to start early in the BWR.

\subsection{High Temperature Oxidation Model (CHITOX)}

The model developed in this section is somewhat simpler than that used for low temperature oxidation. This is partly because the calculations deal with layer thickness and heat generation rates, quantities which can be described with reasonable accuracy by 


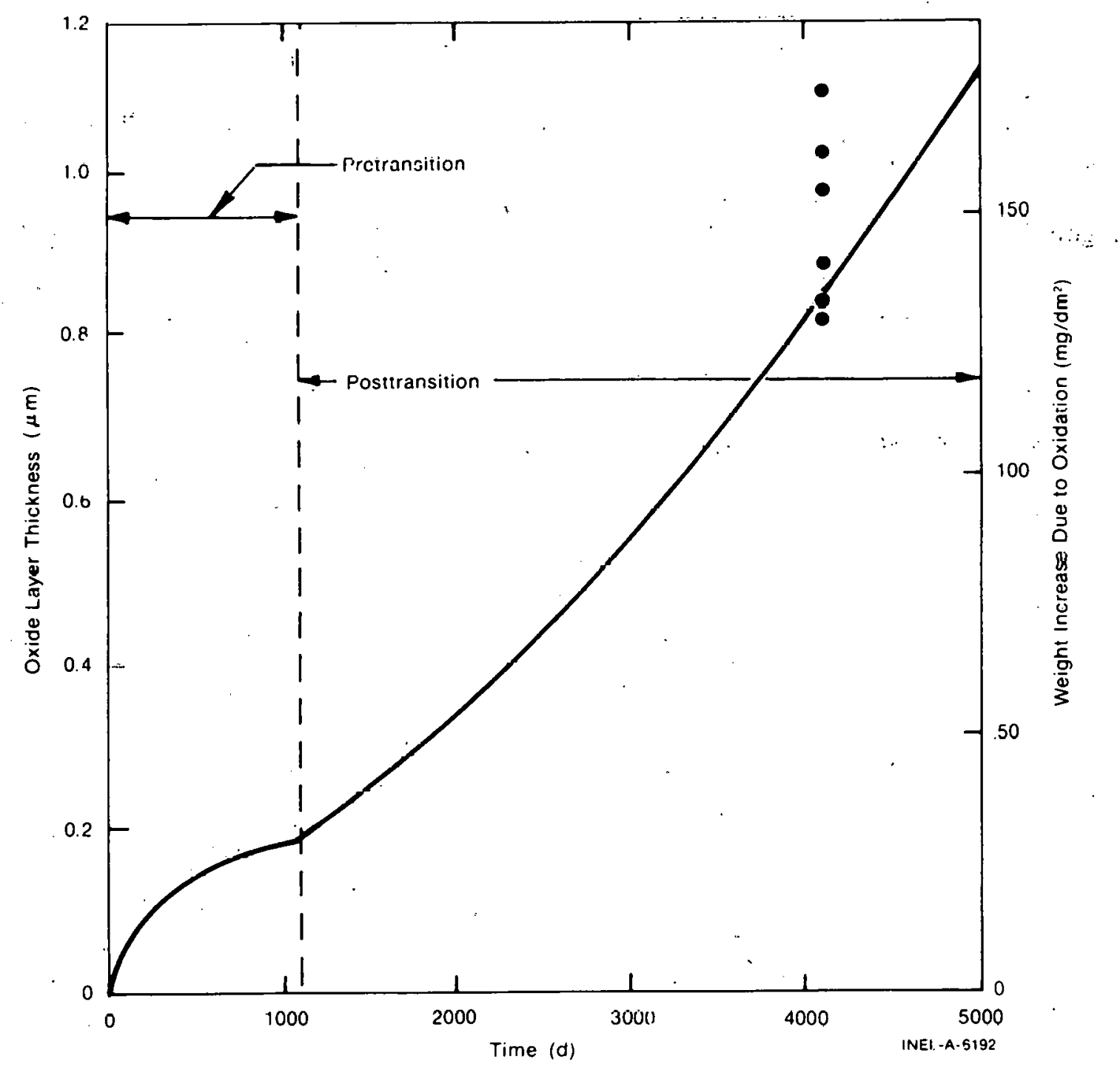

Fig. B-16.3 Comparison of the predicted oxide layer thickness with the base data from average values of six Shippingport zircạluy-2 ruds in:ä PWR eniviunument al $277^{\circ} \mathrm{C}$.

relatively simple correlations. The model has been developed for the temperature range 1000 to $1500^{\circ} \mathrm{C}$. For temperatures between 400 and $1000^{\circ} \mathrm{C}$ the oxide thickness is assumed to be that reached at $400^{\circ} \mathrm{C}$ using the subroutine CORROS. This is an approximation, but should be a good one since the contribution to oxide layer thickness during the time a reactor's fuel rods are in this temperature range is small.

16.3.1 General Features of High Temperature Zircaloy Oxidation. When zircaloy tubing is exposed to steam at temperatures above the alpha-beta transition temperature $(1244 \mathrm{~K})$, three different materials are present. On the outside, exposed to the steam, is a layer of $\mathrm{ZrO}_{2}$. Beneath this is a layer of "oxygen-stabilized alpha". This is zircaloy at a high enough temperature so that it should be in the beta phase, but which has the characteristic 


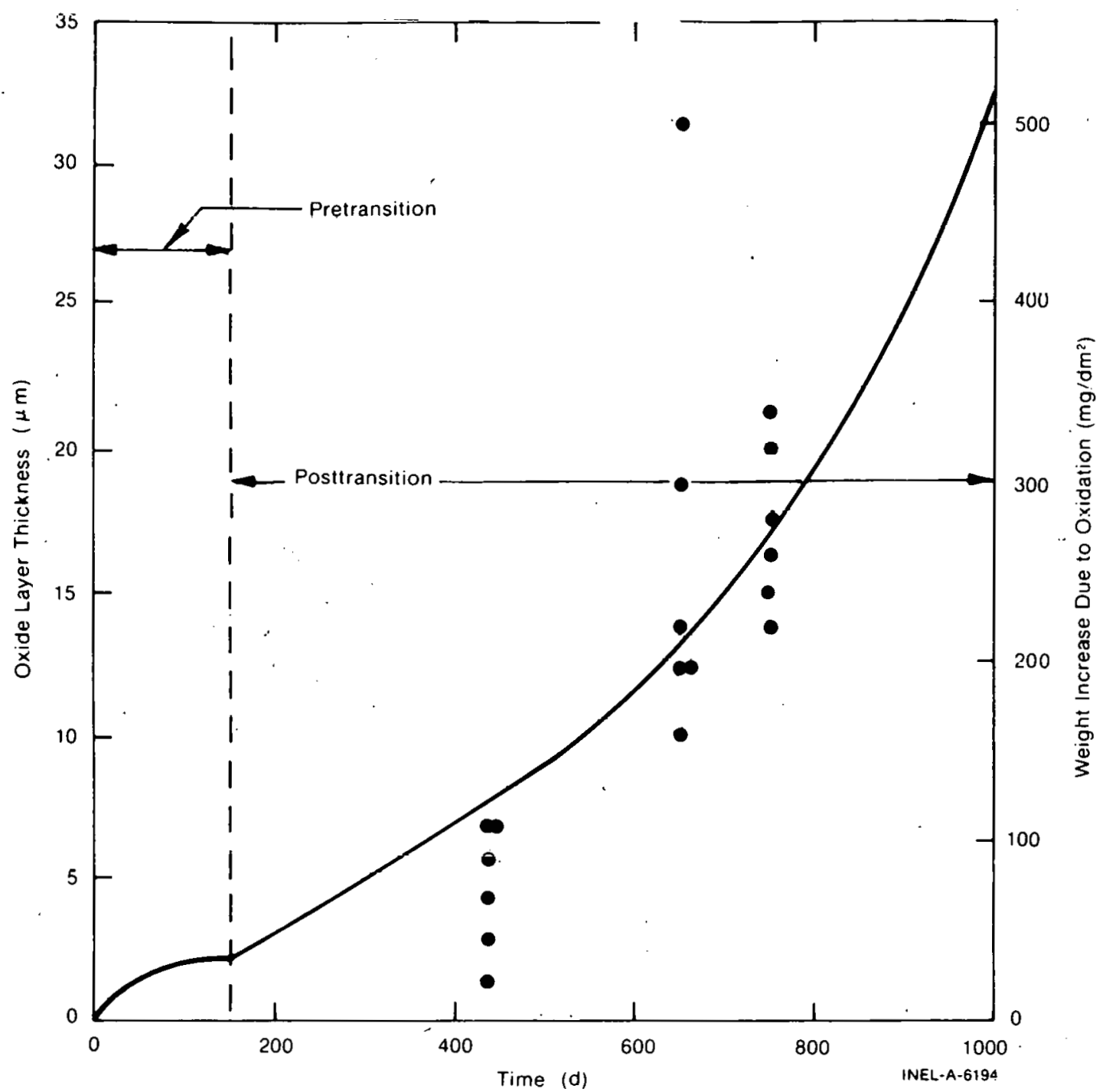

Fig. B-16.4 Comparison of the predicted oxide layer thickness with the base data from Saxton zircaloy 4 rods in a PWR at $340^{\circ} \mathrm{C}$.

alpha-phase hexagonal structure due to the presence of oxygen ${ }^{[a]}$. Beneath this is a layer of beta zircaloy, which may have some oxygen dissolved in it, but has not yet transformed to the alpha phase. In addition, at high oxygen concentrations, needle-like regions of alpha zircaloy may extend from the oxygen-stabilized alpha layer into the beta layer. These are called "alpha incursions" and are believed to form during cooling as a way of relieving excess oxygen concentration [B-16.16, B-16.17]. The key parameters for describing the oxidation reaction are the temperature and the time at temperature.

16.3.2 Selection of the Data Base. A data base consisting of 430 points for the $\mathrm{ZrO}_{2}$ layer and 377 points for the $\xi$ layer from 7 sources was assembled. The primary criteria for inclusion in this data base were:

[a] The $\mathrm{ZrO}_{2}$ and oxygen-stabilized alpha layers together are called the $\xi$ layer. 


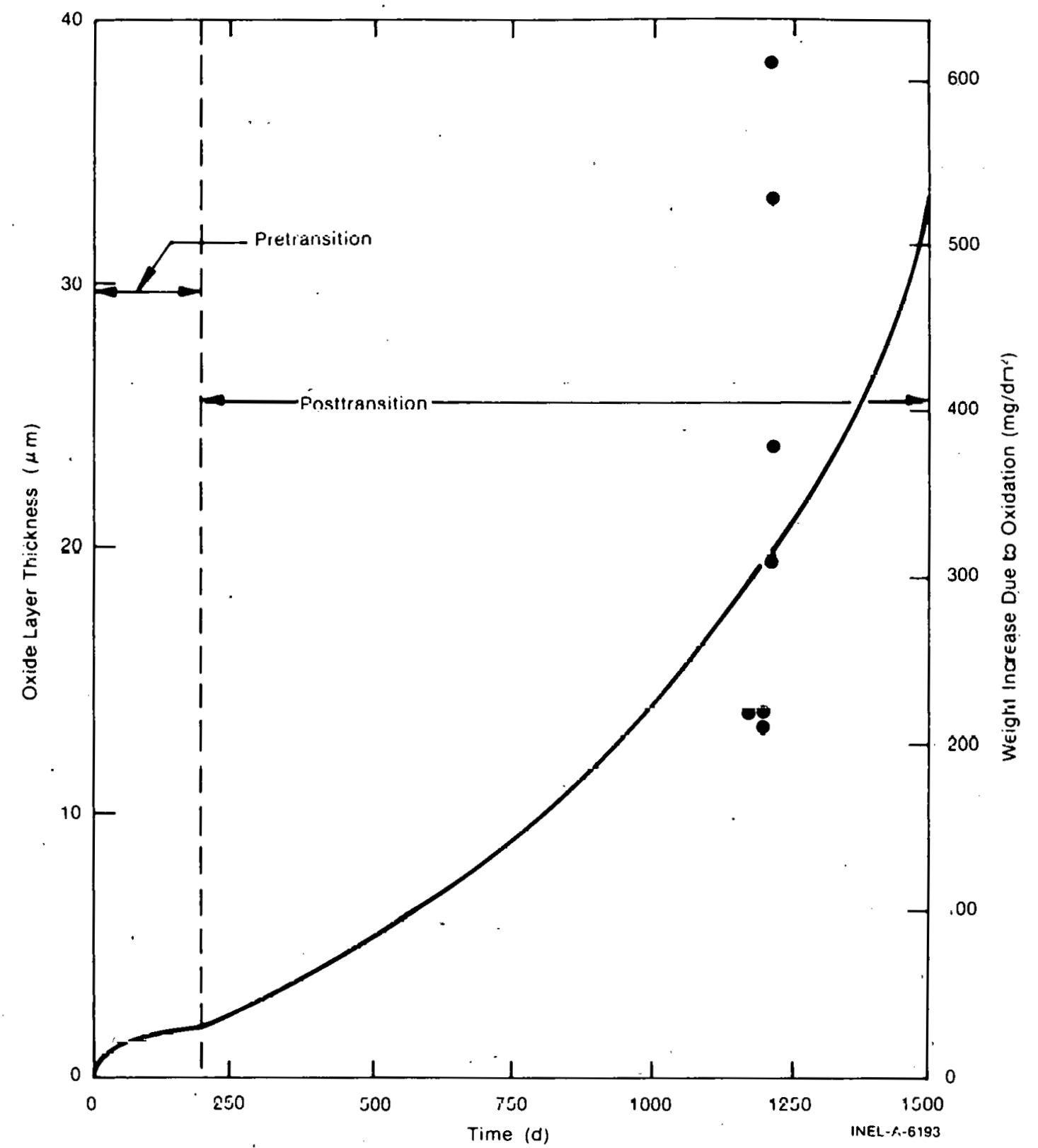

Fig. B-16.5 Comparison of the predicted oxide layer thickness with the base data from zircaloy-2 rods irradiated in the Vallecitos and Dresden BWRs at $286^{\circ} \mathrm{C}$.

(1) Good temperature characterization

(2) Tubular experimental samples of typical LWR dimensions

(3) Temperatures in the range 900 to $1500^{\circ} \mathrm{C}$.

Most of the data not used were excluded because they failed to satisfy the latter two criteria. For example, Baker and Just $[\mathrm{B}-16.18]$. studied molten zirconium spheres, while Hillner $[\mathrm{B}-16.19]$ examined rods which had been in operation in a PWR at temperatures 
below the range of interest $\left(300^{\circ} \mathrm{C}\right)$. Urquhart and Vermilyea ${ }^{[\mathrm{B}-16.20]}$ also used samples oxidized at a low temperature $\left(600^{\circ} \mathrm{C}\right.$ ), as did Bradhurst and Heuer $[\mathrm{B}-16.21]$ (500 to $700^{\circ} \mathrm{C}$ ). A great many satisfactory data are available and have been included. Perhaps the best of these are those from Cathcart $[\mathrm{B}-16.1, \mathrm{~B}-16.22-\mathrm{B}-16.24]$ who has carried out an extensive program with particular care. In addition, Biederman [B-16.17, B-16.25] and Hobson and Rittenhouse $[\mathrm{B}-16.26]$ also have some relevant results. The data base gathered from these authors is broad enough for model evaluations.

16.3.3 Evaluation of Existing Models. Many high temperature oxidation models already have been published. 'Ihe most common analytical form employs "parabolic kinetics" where the time rate of change of the layer thickness is inversely proportional to the thickness itself and the constant of proportionality is an Arrhenius function of tempcraturc.

Thus, in this scheme:

$$
\frac{d X^{\prime}}{d t}=\frac{1}{X^{\prime}} A^{\prime} \cdot \exp \left(-B^{\prime} / T\right)
$$

where

$$
\begin{aligned}
\mathrm{X}^{\prime} & =\text { layer thickness (either } \mathrm{ZrO}_{2} \text { or } \xi \text { layer) }(\mu \mathrm{m}) \\
\mathrm{t} & =\text { time (s) } \\
\mathrm{T} & =\text { temperature }(\mathrm{K}) \\
\mathrm{A}^{\prime} & =\text { constant characteristic of the particular model under } \\
\mathrm{B}^{\prime} & =\text { consideration } \\
& \text { constant characteristic of the particular model under }
\end{aligned}
$$

If Equation (B-16.19) is integrated with respect to time assuming isothermal conditions and zero initial oxidation, as was the case for the data used, then the layer thickness is given by Equation (B-16:20):

$$
X^{\prime}=A \exp (-B / T) \sqrt{t} \text {. }
$$

The $\mathrm{A}$ in Equation (B-16.20) is the square root of $2 \mathrm{~A}^{\prime}$ from Equation (B-16.19) and $\mathrm{B}$ is $\mathrm{B}^{\prime} / 2$.

Two sets of correlations of this type are considered: one for the $\mathrm{ZrO}_{2}$ layer and one for the $\xi$ layer. The layer thicknesses are the only outputs from these correlations. There are other quantities which may ultimately be of interest, such as oxygen concentrations in the 
various layers. Computation of quantities such as these will involve a more complicated routine, perhaps something resembling SIMTRAN ${ }^{[\mathrm{B}-16.27]}$ which has been developed at Oak Ridge National Laboratory and is currently being verified there.

The models compared are those of Urbanic [B-16.28], Biederman [B-16.17, B-16.25]. Baker and Just $[\mathrm{B}-16.18]$, and Cathcart $[\mathrm{B}-16.1]$ for $\mathrm{ZrO}_{2}$; and Lemmon $[\mathrm{B}-16.30]$, Hobson and Rittenhouse $\left[\mathrm{B}-16.26^{\prime}\right]$, Biederman, Cathcart $\left[\mathrm{B}-16.1 T^{2}\right.$, and Leistikow ${ }^{[a]}$ for the $\xi$ layer. In addition comparisons were made with the SIMTRAN code. This will be discussed at the end of this subsection.

The prediction of each correlation for each data point was found and the standard error for the correlation with the appropriate data set computed. The constapts A and B of Equation (B-16.20) for each correlation and its standard error are presented in Table B-16.I, The standard error is defined by Equation (B-16.21):

$$
\text { (Standard Error) }=\sqrt{\frac{\sum\left(x_{\text {meas }}-x_{c a l c}\right)^{2}}{N-1}}
$$

where

$$
\begin{array}{ll}
\mathrm{X}_{\text {meas }} & =\text { measured thickness } \\
\mathrm{X}_{\text {calc }}= & \text { calculated thickness } \\
\mathrm{N} & =\text { number of points in the data set. }
\end{array}
$$

It is clear from the standard errors listed. in Table B-16.I that for both the $\mathrm{ZrO}_{2}$ and the $\xi$ laycr Cathcart's correlations give the best fit to the data. These are therefore the ones used in the model.

In addition to all these models, the computer code SIMTRAN[B-16.27] was run on the Idaho National Engineering Laboratory computer for a range of cladding temperatures. SIMTRAN is a FORTRAN IV computcr program which solves SilMultanenusly the TRANsport equations for both heat and mass flow in a finite-geometry, moving-boundary systcm. Ne simple correlation can be given, but a description and listing may be found in Reference B-16.27. It is the most complicated of the models, being the only one to consider such factors as heat generated by the zirconium-water reaction, convective and radiative heat losses, and coolant temperature. The output includes layer thicknesses, dissolved oxygen contents, and temperature profiles. No attempt was made to run SIMTRAN for all the points in the data base. The primary reason for not doing this was that complete input information was not available from the data base to make the runs meaningful. Some runs were made with assumed values for the required input parameters, such as coolant

[a] S. Leistikow, GfK, Karlsruhe, Paper presented at the Third Water Reactor Safety Meeting, Gaithersburg, Maryland (September 29 - October 2, 1975). 
TABLE B-16.I

SUMMARY OF $\mathrm{ZrO}_{2}$ AND $\xi$ CORRELATIONS AND THEIR STANDARD

ERRORS FROM THE DATA BASES

\begin{tabular}{|c|c|c|c|c|}
\hline & Investigator & A & $B$ & Standard Error \\
\hline $\mathrm{ZrO}_{2}$ & $\begin{array}{l}\text { Urbanic }[\mathrm{a}] \\
\text { Biederman } \\
\text { Baker and Just } \\
\text { Cathcart }\end{array}$ & $\begin{array}{r}360.0 \\
364.4 \\
10 \quad 200.0 \\
1501.0\end{array}$ & $\begin{array}{r}6793 \\
7006 \\
11450 \\
9031\end{array}$ & $\begin{array}{r}10.57 \\
8.87 \\
19.88 \\
4.44\end{array}$ \\
\hline$\xi$ & $\begin{array}{l}\text { Lemmon } \\
\text { Hobson and Rittenhouse }[\mathrm{b}] \\
\text { Biederman } \\
\text { Cathcart } \\
\text { Leistikow }\end{array}$ & $\begin{array}{r}7080.0 \\
8412.0 \\
2118.5 \\
8261.0 \\
34 \quad 640.0\end{array}$ & $\begin{array}{rr}10 & 317 \\
10 & 330 \\
8461 \\
10 & 494 \\
12 & 360\end{array}$ & $\begin{array}{r}8.92 \\
13.53 \\
16.08 \\
7.90 \\
29.91\end{array}$ \\
\hline
\end{tabular}

[a] The Biederman correlations used here were developed from a least squares fit to a parabolic kinetics equation of data taken from the papers quoted. These papers describe a moving-boundary computer code apparently similar to SIMTRAN, but no listing of the code was available for use in this analysis.

[b] The correlation used in this model was developed by Pawel using data of Hobson and Rittenhouse.

temperature, heat transfer coefficients, surface emissivity, and the temperature of the surface to which the zircaloy is radiating. These runs showed that the layer thicknesses predicted by SIMTRAN are close to those predicted by Biederman for the $\mathrm{ZrO}_{2}$ layer and to those predicted by Hobson and Rittenhouse for the $\xi$ layer. However recent changes in the code, primarily in the diffusion constants for oxygen in the various zircaloy phases $^{[\mathrm{B}-16.30]}$ reportedly ${ }^{[\mathrm{a}]}$ makes the predictions of SIMTRAN in complete agreement with the models of Cathcart. This being the case, Cathcart's analytically simple parabolic kinetics models, which show the best agreement with the data base, are just as good and will be used until the more complete information supplied by SIMTRAN is required for more sophisticated analyses.

All of the data used in the data base were taken out-of-pile. There have been very few in-pile zircaloy-water reaction experiments conducted to date. One of these few cases is PCM-20 test series [B-16.31] where temperature ranges were estimated by examination of the postirradiation microstructure. The results of these are shown in Figure B-16.6. The

[a] S. Malang, Gesellschaft für Kernforschung (GfK), Karlsruhe, Germany, Private Communication (August 1976). 


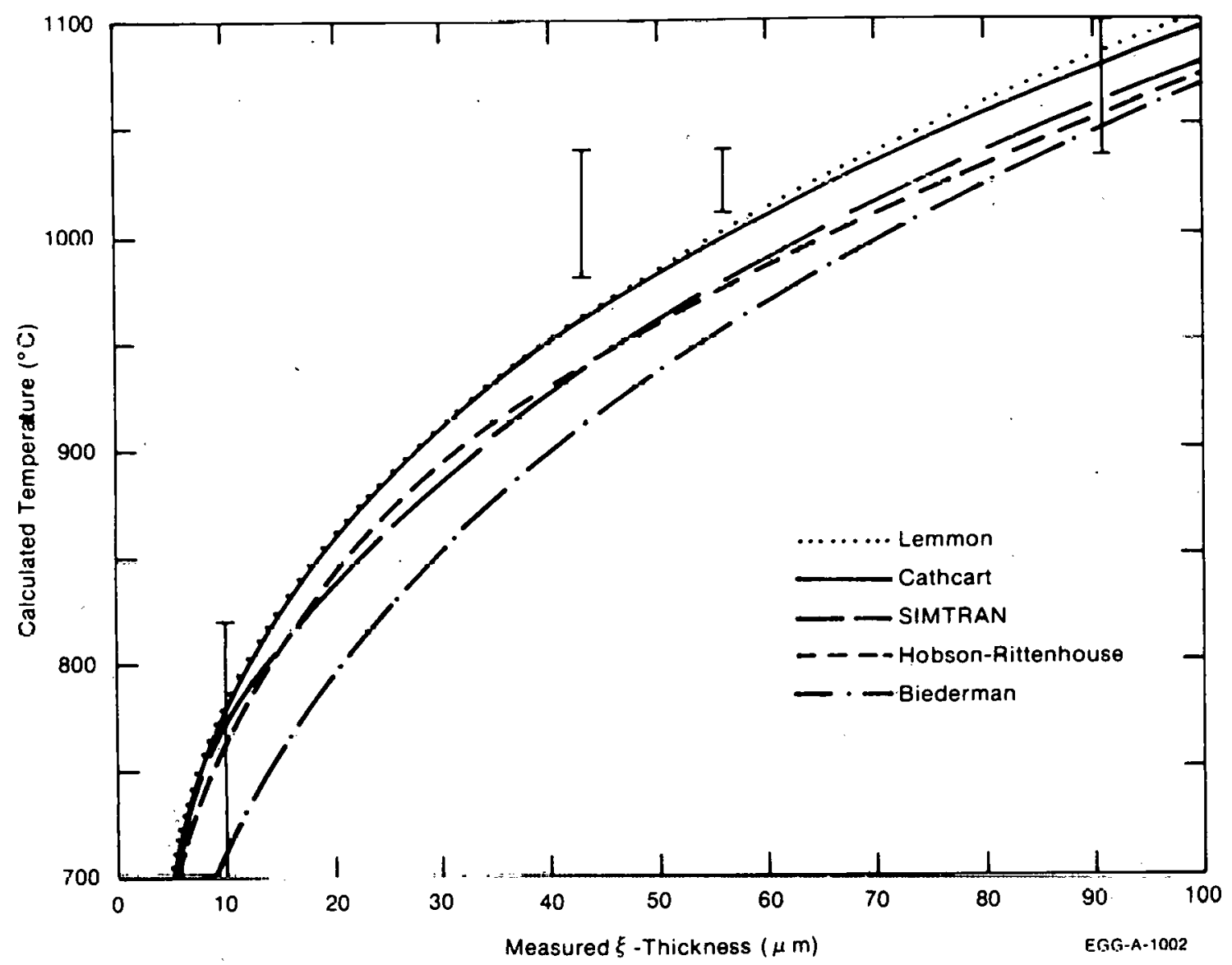

Fig. B-16.6 Calculated temperatures versus measured $\xi$ layer thickness with temperature estimates made from the microstructure.

curves were calculated using the various correlations. While no firm conclusion may be drawn from these data, it is at least apparent that the correlations make reasonable predictions of in-pile results even though based on data taken out-of-pile. equation

16.3.4 Oxide Jayer Model. The model is based on Cathcart's isothermal rate

$$
\frac{d X}{d t}=\frac{1.126 \times 10^{-6}}{X} \exp (-18063 / T)
$$

where

$$
\begin{aligned}
& \mathrm{X}=\text { thickness of oxide layer }(\mathrm{m}) \\
& \mathrm{t}=\text { time (s) } \\
& \mathrm{T}=\text { temperature }(\mathrm{K}) .
\end{aligned}
$$


To obtain a correlation for nonisothermal cases Equation (B-16.23) is integrated directly to find the change in oxide thickness during a time step starting at time $t_{1}$ and ending at time $t_{2}$.

$$
\int_{x_{1}}^{x_{2}} x 0 x=\int_{t_{1}}^{t_{2}} 1.126 \times 10^{-6} \exp (-18063 / T) d t
$$

where

$$
\begin{aligned}
& \mathrm{X}_{1}=\text { thickness of oxide layer at beginning of the time step } \\
& \mathrm{X}_{2}=\text { thickness of oxide layer at end of the time step. }
\end{aligned}
$$

If the temperature is constant during the time step, or if it is approximated as a constant equal to the average of the temperatures at the beginning and end of the step, then Equation (B-16.24) is easily integrated to beconne.

$$
x_{2}^{2}-x_{1}^{2}=2.25 \times 10^{-6} \exp (-18063 / T) \mathrm{Dt}
$$

where

Dt $=t_{2}-t_{1}$, the duration of the time step (s).

Finally the total oxide thickness at the end of the time step is given by Equation (B-16.26):

$$
x_{2}=\left[x_{1}^{2}=2.25 \times 10^{-6} \exp (-18063 / T) \mathrm{Dt}\right]^{1 / 2}
$$

A comparison of the oxide thickness predictions of Equation (B-16.26) with the data base for several different temperatures is shown in Figure B-16.7.

16.3.5 Outer Radius of the Unoxidized Part of the Cladding. When zirconium changes to $\mathrm{ZrO}_{2}$ there is an increase in volume. For this reason the outer radius of the unoxidized part of the fuel rod is greater than simply the original radius of the rod before there was any oxidation minus the thickness of the oxide. $\mathrm{ZrO}_{2}$ is composed of $74 \%$ zirconium by weight. To find the thickness of remaining zircaloy, refer to the simple drawing below:

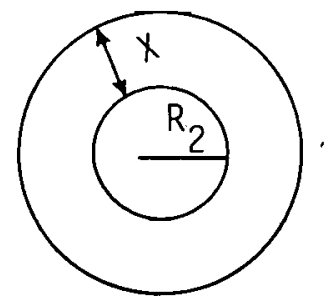




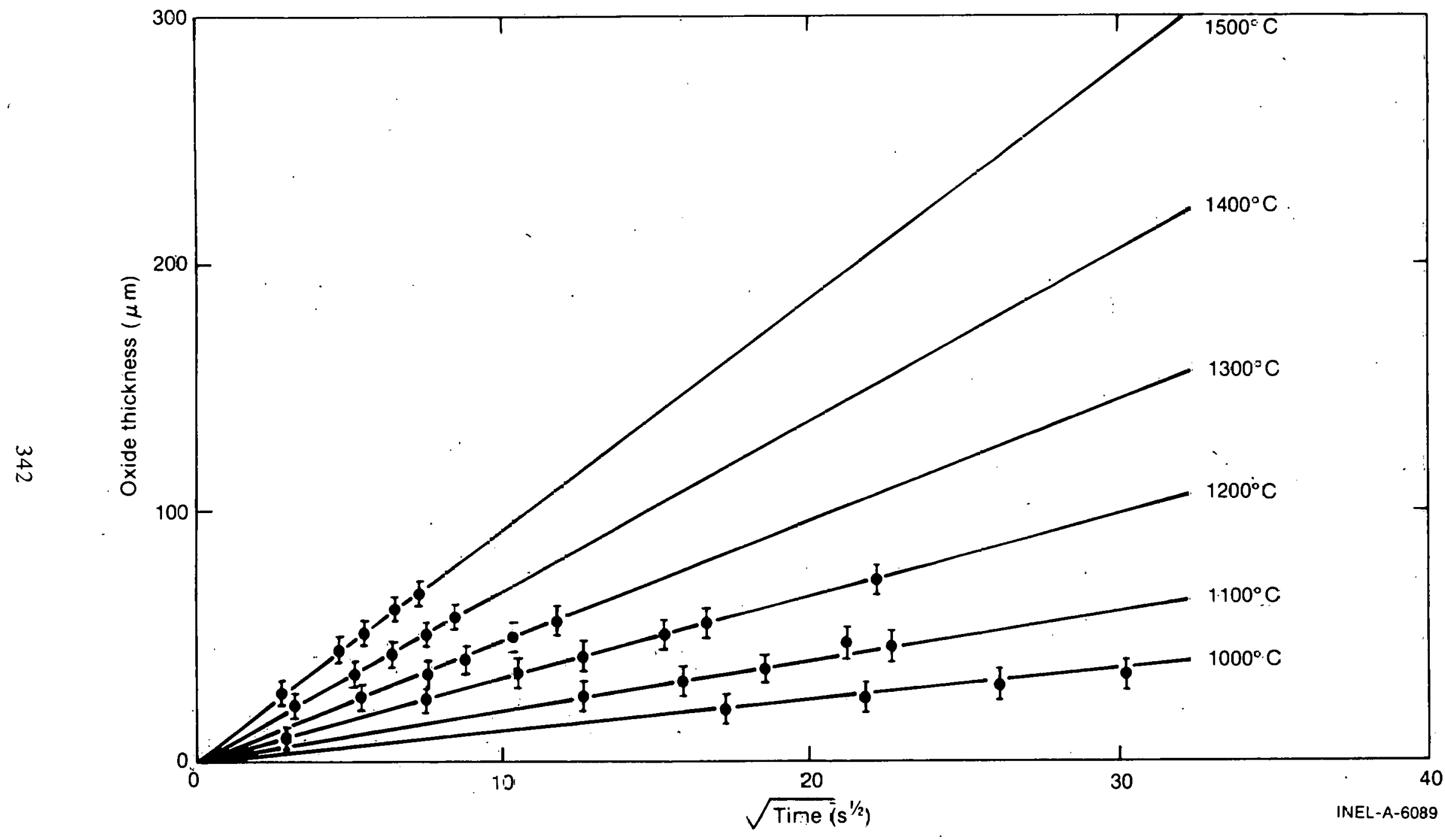

Fig. B-16.7 Comparison of calculated and measured $\mathrm{ZrO}_{2}$ thicknesses for six temperatures. 
where

$$
\mathrm{R}_{2}=\text { radius of remaining unoxidized zircaloy. }
$$

The mass of zirconium in the $\mathrm{ZrO}_{2}$ layer must equal the mass of zirconium used up in the oxidation. Making the assumption that all the expansion occurs in the radial direction:

$$
0.74 \pi\left(\rho_{\mathrm{ZrO}_{2}}\right) L\left[\left(R_{2}+x\right)^{2}-R_{2}^{2}\right]=\pi\left(\rho_{Z r}\right) L\left(R_{0}^{2}-R_{2}^{2}\right)
$$

where

$$
\begin{array}{ll}
\rho_{\mathrm{ZrO}_{2}} & =\text { density of } \mathrm{ZrO}_{2}\left(6.1 \times 10^{3} \mathrm{~kg} / \mathrm{m}^{3}\right) \\
\rho_{\mathrm{Zr}} & =\text { density of zirconium }\left(6.5 \times 10^{3} \mathrm{~kg} / \mathrm{m}^{3}\right) \\
\mathrm{X} & =\text { thickness of } \mathrm{ZrO}_{2} \text { laycr } \\
\mathrm{R}_{\mathrm{O}} & =\text { original radius of unoxidized tube (not shown) } \\
\mathrm{L} & =\text { the length of the rod }(\mathrm{m}) .
\end{array}
$$

Equation (D-16.27) mây then be expañded and rcarranged,

$$
0.74 \frac{\rho_{Z_{2} O_{2}}}{\rho_{Z r}}(X)\left(2 R_{2}+X\right)=\left(R_{0}-R_{2}\right)\left(R_{0}+R_{2}\right) .
$$

If at this point the approximation $\left(R_{o}+R_{2}\right) \sim\left(2 R_{2}+X\right)$ is made, then $\left(R_{0}-R_{2}\right)$, the change in zircaloy thickness due to the formation of an oxide layer of thickness $\mathrm{X}$, is given by

$$
R_{0}-R_{2}=0.74 \frac{\rho_{Z r O_{2}}}{\rho_{Z r}}(x)=0.69(x)
$$

or

$$
R_{2}=\left(R_{0}-0.69 x_{2}\right)
$$

Equation (B-16.30) is actually the correct one to use for the oxidation of zircaloy plate expanding only in the direction perpendicular to its surface. This derivation also neglects expansion of the unoxidized zirconium lattice due to dissolved oxygen.

16.3.6 Rate of Heat Generation in the Cladding Due to Oxidation. The volume of zirconium converted to $\mathrm{ZrO}_{2}$ during a time step for a cylindrical rod may be found with the help of Equation (B-16.30). The volume is 


$$
\Delta V=L \pi\left(R_{0}-0.69 x_{1}\right)^{2}-L \pi\left(R_{0}-0.69 x_{2}\right)^{2}
$$

where all the variables have been previously defined. Expanding and collecting similar terms gives

$$
\Delta V=L \pi 1.38\left[R_{0}-0.345\left(x_{2}+x_{1}\right)\right] \quad\left(x_{2}-x_{1}\right) .
$$

In Equation ( $\mathrm{B}-16.32) \mathrm{K}_{\mathrm{O}}$ is much greater than the term $0.345\left(\mathrm{X}_{2}+\mathrm{X}_{1}\right)$ because $\mathrm{R}_{\mathrm{O}}>>\mathrm{X}_{1} \approx \mathrm{X}_{2}$. In addition, neglecting the smaller term leads to a more conservative result, that is the calculation yields a greater volume of converted zircaloy. Therefore, approximating in Equation (B-16.32) by neglecting this smaller term:

$$
\Delta V=4.34 L\left(R_{0}\right)\left(x_{2}-x_{1}\right) \text {. }
$$

To obtain the heat generation rate per unit length per kilogram due to the conversion of zirconium to $\mathrm{ZiO}_{2}$, Equaliun (B-16.33) is multiplice hy the density of $\mathrm{Zr}$ and by the exulliermal lieal of réacllun per $\mathrm{kg}$ from the conversion, then divided by both the length of the rod and the duration of the time step. I'he result is given in Equation (B-16.34):

$$
Q=\frac{\left({ }^{\rho} Z r\right)(H R Z) 4.34 R_{0}\left(X_{2}-X_{1}\right)}{D t}
$$

where

$$
\begin{array}{ll}
Q= & \text { rate of heat generation per meter for a rod of initial radius } \\
& R_{\mathrm{O}}(\mathrm{W} / \mathrm{m})
\end{array}
$$

$\mathrm{HRZ}=$ heat of reaction per $\mathrm{kg}$ of zirconium $\left(6.45 \times 10^{6} \mathrm{~J} / \mathrm{kg}\right)$

$\rho_{\mathrm{Zr}}=$ density of zirconium $\left(6.50 \times 10^{3} \mathrm{~kg} / \mathrm{m}^{3}\right)$.

A plot of $Q$ versus temperature for a fuel rod where initial radius $R_{o}$ equals $6.25 \times 10^{-3} \mathrm{~m}$ is shown in Figure B-16.8 for various initial oxide thicknesses where $\mathrm{X}_{2}$ was calculated from Equation (B-16.26) with a time step of one s.

16.3.7 Xi Layer Model. The $\xi$ layer which is defined as the combined oxide and oxygen stabilized zircaloy layers. Like $\mathrm{ZrO}_{2}$, the oxygen-stabilized layer is less ductile than oxygen-free zircaloy, so the entire $\xi$ layer is of interest for safety analysis.

The model is based on Cathcart's $\xi$ layer rate equation:

$$
\frac{d X^{\prime}}{d t}=\frac{3.412 \times 10^{-5}}{X} \exp (-21000 / T)
$$




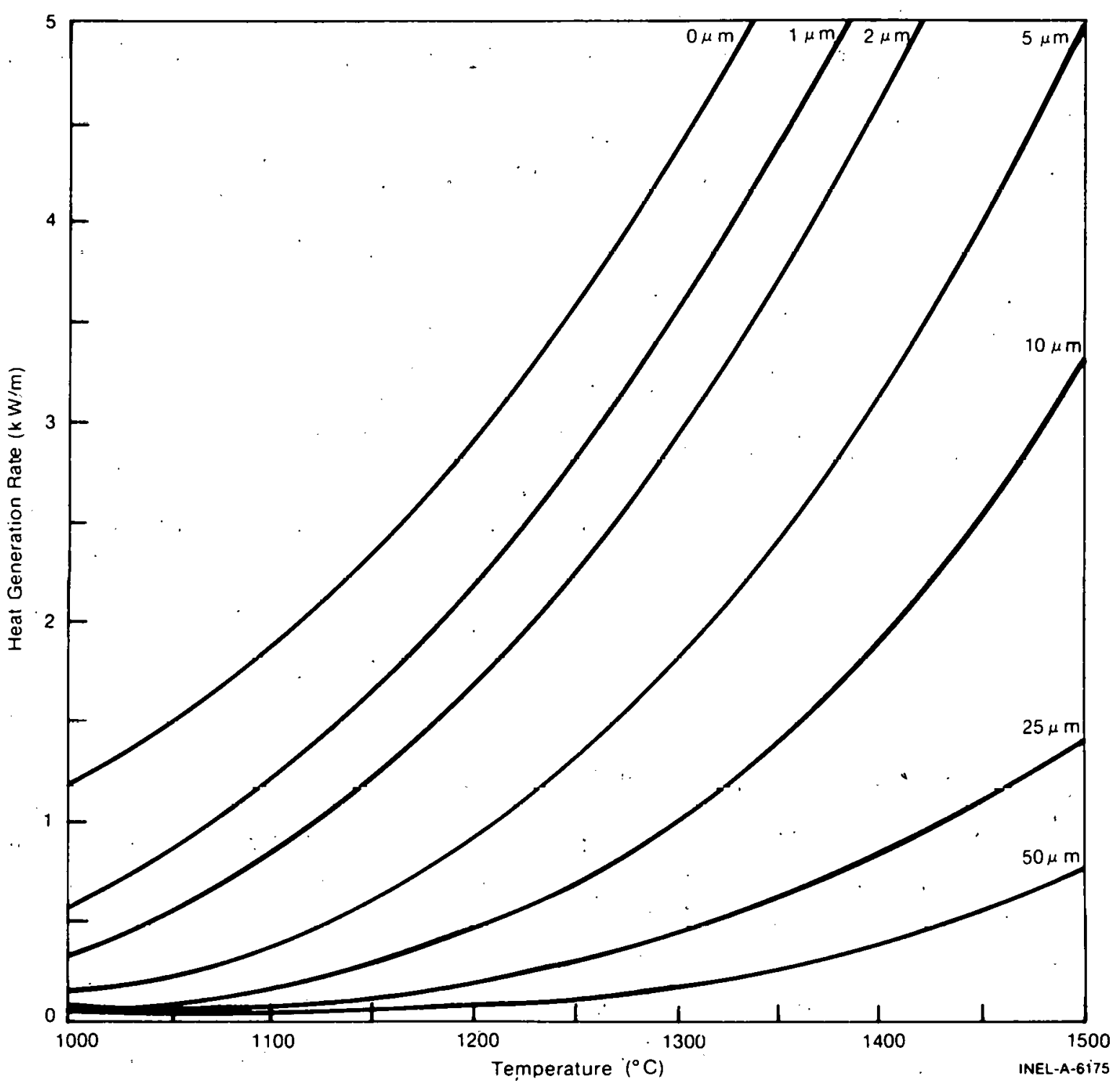

Fig. B-16.8 Heating rate per meter for a rod of initial diameter $1.25 \times 10^{-2} \mathrm{~m}$ as a function of temperature for various initial oxide thicknesses.

where

$$
\begin{aligned}
\mathrm{X}^{\prime} & =\text { thickness of the } \xi \text { layer }(\mathrm{m}) \\
\mathrm{t} & =\text { time (s) } \\
\mathrm{T} & =\text { temperature }(\mathrm{K}) .
\end{aligned}
$$

Following the procedure used for the oxide layer in Section B-16.2.3, Equation (B-16.35) is integrated to obtain an expression for the increase of the $\xi$ layer during a time step. 


$$
\int_{x_{1}}^{x_{2}} \dot{x} d x=\int_{t_{1}}^{t_{2}} 3.412 \times 10^{-5} \exp (-21000 / T) d t
$$

where

$$
\begin{aligned}
& \mathrm{t}_{1}=\quad \text { time at start of time step }(\mathrm{s}) \\
& \mathrm{x}_{1}=\quad \text { thickness of } \xi \text { layer at time } \mathrm{t}_{1},(\mathrm{~m}) \\
& \mathrm{t}_{2}=\quad \text { time at end of time step }(\mathrm{s}) \\
& \mathrm{x}_{2}^{\prime}=\quad \text { thickness of } \xi \text { layer at time } \mathrm{t}_{2}(\mathrm{~m}) .
\end{aligned}
$$

If the temperature is constant, or approximated as constant during the time step, then Equation (B-16.36) becomes

$$
x_{2}^{\prime}=\left[x_{1}^{\prime 2}+6.824 \times 10^{5} \exp (-21000 / T) D t\right]^{1 / 2}
$$

where.

$D t=t_{2}-t_{1}$, the duration of the time step (s).

A comparison of the predictions of Equation (B-16.37) with the $\xi$ layer data base for several different temperatures is shown in Figure B-16.9. It should be pointed out that the data base contains only isothermal data.

16.3.8 An Approach to Oxidation Kinetics During Ballooning. One of the important problems which must be dealt with in the computer simulation of reactor behavior is the performance of the reactor when there is plastic deformation of the cladding. A large, localized deformation is called a "balloon" and is important in the consideration of coolant flow blockage. Plastic deformation of the cladding is significant in oxidation kinetics. This is because the $\mathrm{ZrO}_{2}$ is very brittle, while the underlying unoxidized zircaloy is still ductile, so that when the zircaloy expands, the oxide cracks and exposes unoxidized zirconium which will then oxidize rapidly according to the parabolic rate law, Equation (B-16.23). In the course of this rapid oxidation of the freshly exposed zircaloy, its thickness is reduced with a consequent loss of strength. The rapid oxidation also heats the metal locally.

To treat this problem analytically in the code, it is necessary to account for changes in surface area. The net change in area during a time step may be found from the subcode BALOON which is part of the FRAP-T3 code ${ }^{[a]}$. In order to approximate the effect of

[a] FRAP-T3 is a version of the FRAP-T fuel behavior code, however, it is unpublished for public review, therefore, FRAP-T2 ${ }^{[B-16.32]}$ is referenced. 


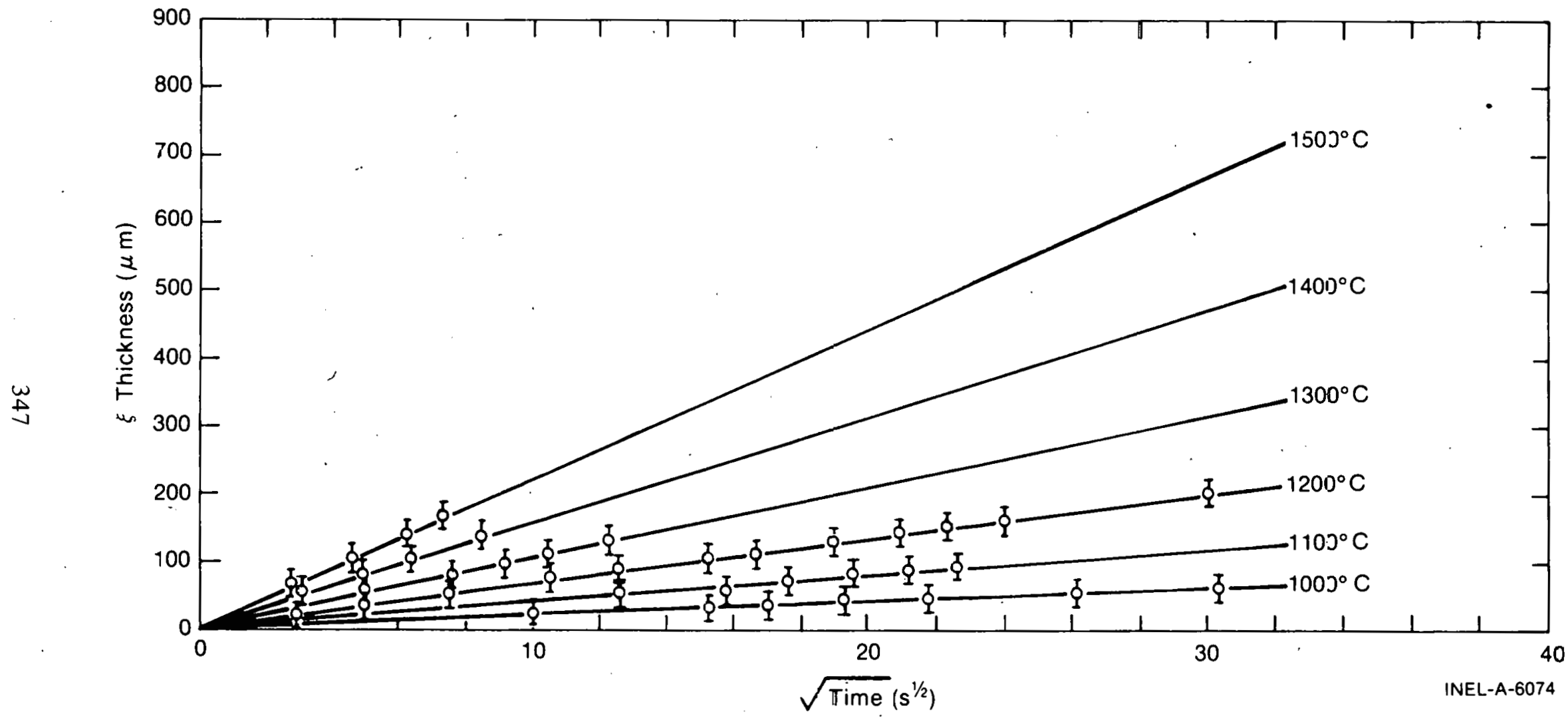

Fig. B-16.9 Comparison of calculated and mea:ured $\xi$ layer thicknesses for six temperatures. 


\section{CORROS/CHITOX}

increasing area, it is recommended that the new surface be treated in the next time step as unoxidized. The new surface oxidizes more rapidly than those areas which carried the previously formed oxide with them. As the ballooning proceeds, new unoxidized area will open up, and there will be several distinct areas, one for each time step during the ballooning process, with different oxide thicknesses and therefore oxidizing at different rates. For any area exposed by oxide cracking, the oxide thickness is given by Equation (B-16.26) with the initial oxide thickness set equal to zero at the time of the crack.

The change in thickness of the remaining unoxidized zircaloy during a time step may be found using a modification of Equation (B-16.30). This thickness, designated $\mathrm{X}_{\mathrm{zr}}$, is approximated by

$$
x_{z r}=\left(x_{z r}\right)_{i}-(0.69) x_{o x i d e}
$$

where

$$
\begin{aligned}
& \mathrm{X}_{\mathrm{zr}}=\quad \begin{array}{l}
\text { thickness of unoxidized zircaloy at the end of the time } \\
\text { step }(\mathrm{m})
\end{array} \\
& \left(\mathrm{X}_{\mathrm{zr}}\right)_{\mathrm{i}}=\begin{array}{l}
\text { initial thickncss of unoxidized zircaloy at the begin- } \\
\text { niing of the time stcp }(\mathrm{m})
\end{array}
\end{aligned}
$$

and $X_{\text {oxide }}$ is taken from Equation (B-16.26) using the length of the time step Dt for the time and $\mathrm{X}_{1}=0$.

16.3.9 Uncertainties in the Correlations in CHITOX. The standard errors given in Table B-16.I for the Cathcart correlations are for the entire data sets. These are relevant quantities for the comparison of correlations, but they can be misleading as uncertainty estimates for individual calculations both because the correlations may be better in some temperature regions than in others, and because a $4 \mu \mathrm{m}$ error represents a larger fractional error at $1000^{\circ} \mathrm{C}$ than at $1500^{\circ} \mathrm{C}$, for comparable times. As noted by Cathcart $[\mathrm{B}-16.1]$, the scatter in the data decreased as the temperature increased. He postulated that this was associated with the fact that at the higher temperatures the interfaces are better defined. For these reasons a percentage error is more useful and different percentages are appropriate for different temperature ranges. Table B-16.II shows the average uncertainty in the $\mathrm{ZrO}_{2}$ and $\xi$ layer thickness as calculated with Equations (B-16.26) and (B-16.37), respectively.

The approximation made in deriving Equation (B-16.30) for $\mathrm{R}_{\mathrm{O}}$, the radius of the unoxidized part of the cladding, results in negligible error. Most of the uncertainty in this equation results from the thickness term and is therefore the same as those in Table B-16.II. The approximation used in deriving Equation (B-16.34) for the heat generation rate is also negligible. 
TABLE B-16. II

UNCERTAINTIES IN CHITOX CORRELATIONS

$\begin{array}{ccc}\text { Layer } & \text { Percent Uncertainty } & \begin{array}{l}\text { Temperature } \\ \text { Range }\left({ }^{\circ} \mathrm{C}\right)\end{array} \\ { }_{2} & 17.5 & \mathrm{~T}<1250 \\ & 6.5 & \mathrm{~T}>1250 \\ \xi & 12.0 & \mathrm{~T}<1250 \\ & 4.3 & \mathrm{~T}>1250\end{array}$

16.4 Cladding Oxidation Subcodes CORROS and CHITOX Listings

The FORTRAN subcodes CORROS and CHITOX are presented in Tables B-16.III and B-16.IV respectively.

16.5 References

B-16.1. J. V. Cathcart, Quarterly Progress Report on the Zirconium Metal-Water Oxidation Kinctics Program Sponsored by the NRC Division of Reactor Safety Research for April - June 1976, ORNL/NUREG/TM-41 (August 1976).

B-16.2. E. Hillner, Hydrogen Absorption in Zircaloy During Aqueous Corrosion, Effect of Environment, WAPD-TM-411 (November 1964).

B-16.3. A. Van der Linde, Calculation of the Safe Life Time Expectancy of Zirconium Alloy Canning in the Fuel-Elements of the Nero Reactor, RCN-41 (July 1965).

B-16.4. B. Cox, "Comments on the Paper "The Influence of Oxide Stress on the Breakaway Oxidation of Zircaloy-2' by D. H. Bradhurst and P. M. Heuer," Journal of Nuclear Materials, 41 (1970) p 96.

B-16.5. D. H. Bradhurst and P. M. Heuer, "Reply to Comments by B. Cox on 'The Influence of Oxide Stress on the Breakaway Oxidation of Zircaloy-2,' " Journal of Nuclear Materials, 41 (1971) p 101.

B-16.6. W. Jost, Diffusion in Solids, Liquids, Gases, New York: Academic Press Inc., 1972, p 341 .

B-16.7. D. H. Bradhurst, P. J. Shirvington, P. M. Heuer, "The Effects of Radiation and Oxygen on the Aqueous Oxidation of Zirconium and its Nlloys at $290^{\circ} \mathrm{C}$," Journal of Nuclear Materials, 46 (1973) p 53. 


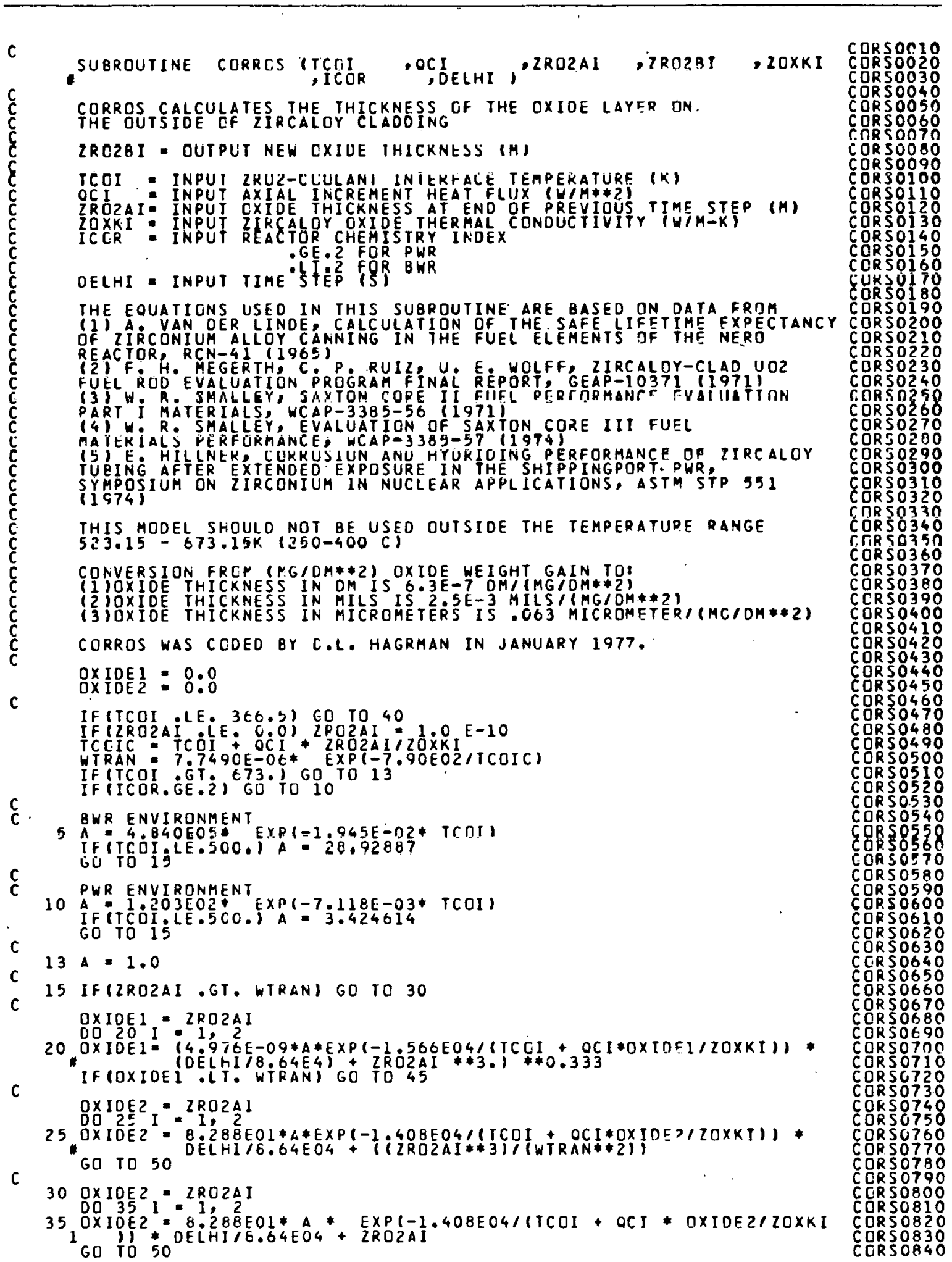


TABLE B-16.11 I (continued)

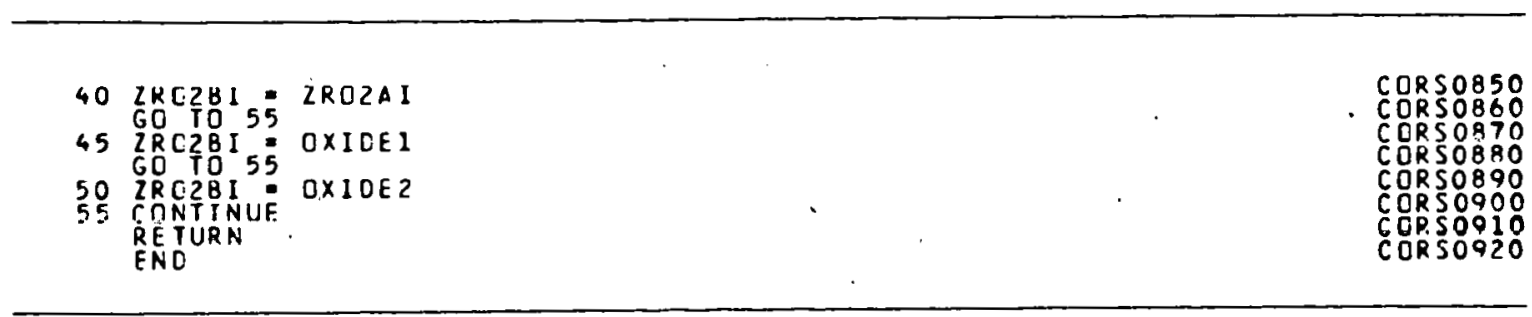

TABLE B-16. IV

LISTING OF THF R.HITOX SUBCODE

\begin{tabular}{|c|c|c|}
\hline & SUBRQUTINE CHITOX $(T 1, T 2, \times 2, \times 1, D T, \times 12, \times 1$ & \\
\hline & 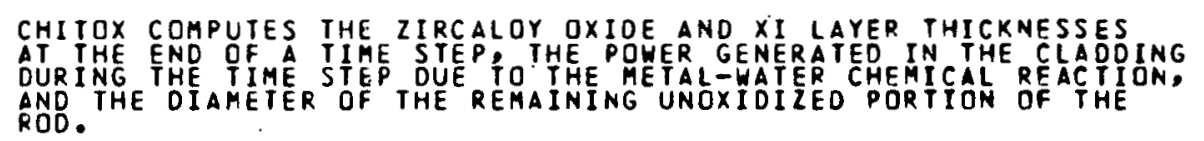 & $\begin{array}{l}C H C \\
C H C \\
C H C\end{array}$ \\
\hline & 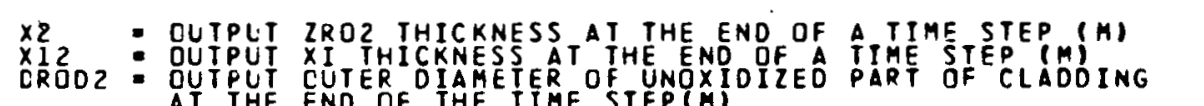 & choxol \\
\hline & AT THE END OF THE THME STEPPUE TO OISSOLVED OXYGEN IS & \\
\hline & $\begin{array}{l}\text { - OUTPUT RATE OF HEAT GENERATION,PER METER FOR A ROD OF } \\
\text { INITIAL OIAMETER DROO (WATTSIM) }\end{array}$ & 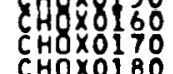 \\
\hline & 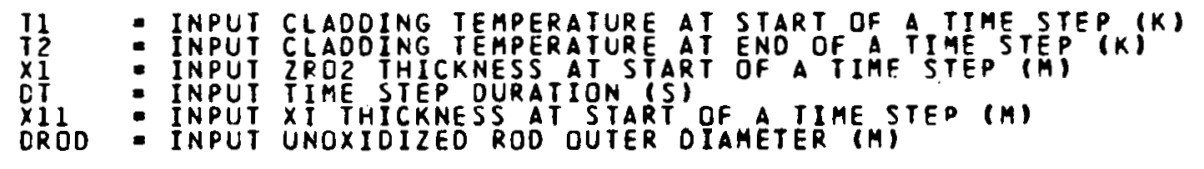 & $\begin{array}{l}1 \\
C H O X 0190 \\
C H O X 0200 \\
C H O X 0210 \\
C H D \times 0220 \\
C H O X 0230\end{array}$ \\
\hline & $\begin{array}{l}\text { THE CQRRELATIONS WERE DERIVEDFROM THE PARABOLIC RATE EOUATIONS } \\
\text { OF J.V. CATHCART, ORNLINUREGTTM-4I TAUGUSTIGTSI }\end{array}$ & \\
\hline & 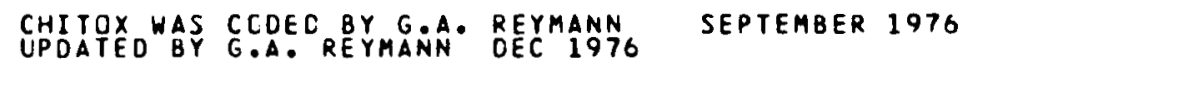 & $\begin{array}{l}10 \\
0 \\
0\end{array}$ \\
\hline & 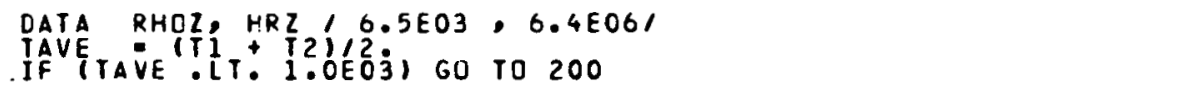 & 0350 \\
\hline & 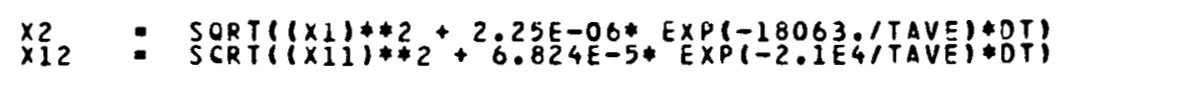 & \\
\hline 100 & 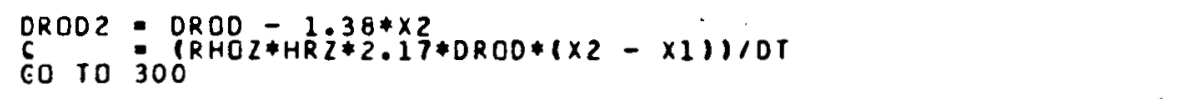 & 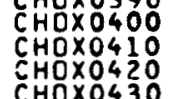 \\
\hline 200 & $\begin{array}{ll}x^{2} & =x_{1} \\
x 12 & 12 \\
60 & 12\end{array}$ & \\
\hline 300 & $\begin{array}{l}\text { RETURN } \\
\text { END }\end{array}$ & \\
\hline
\end{tabular}




\section{CORROS/CHITOX}

B-16.8. R. C. Asher et al, "Effects of Radiation on the Oxidation and Hydrogen Absorption of Zirconium Alloys in Steam," Electrochemical Technology, 4 (1966) p 231 .

B-16.9. L. Lunde and K. Videm "Effects of Surface Treatment on the Irradiation Enhancement of Corrosion of Zircaloy-2 in HBWR," Zirconium in Nuclear Applications, ASTM-STP-551 (1974) pp 514-526.

B-16.10. A. B. Johnson, Jr., "Effects of Nuclear Radiation on the Corrosion, Hydriding, and Oxide Properties of Six Zirconium Alloys," Applications-Related Phenomena for Zirconium and Its Alloys, ASTM-STP-458 (1969) pp 301-324.

B-16.11. W. A. Burns, Effects of Fast Neutron Irradiation, Fabrication History, and Water Oxygen on the Environmental Behavior of Zirconium Alloys, BNWL-88 (1965).

B-16.12. A. B. Johnson, Jr., and J. E. Irvin, Radiation-Enhanced Oxidation of Zircaloy-2 in pH-10 LiOH and $p H-10 \mathrm{NH}_{4} \mathrm{OH}$, BNWL-463 (1967).

B-16.13. K. Videm, "Properties of Zirconium Base Cladding Materials Corrosion and Hydrogen Pickup," Advanced Course on Limiting Aspects of Fuel Element Performance in Water Cooled Power Reactors at the Institute for Antomenergi in Kjeller, Norway, August $24-28,1970$.

B-16.14. F. H: Megerth, C. P Ruiz, U. E. Wolff, Zircaloy-Clad UO ${ }_{2}$ Fucl Rod Evaluation Program, GEAP-10371 (June 1971).

B-16.15. II. E. Williamson et al, AEC Fuel Cycle Program Examination of $\mathrm{UO}_{2}$ Fuel Rods Operated in the VBWR to 10,000 MWD/TU, GEAP-4597 (1965).

B-16.16. R. E. Pawel, "Oxygen Diffusion in Beta Zircaloy During Steam Oxidation," Ioumal of. Nuclear Materials, .50 (1974) pp 247-2.58.

B-16.17. R. R. Biederman and W. G. Dobson, "A Study of Zircaloy-Steam Oxidation Keaction Kinetics," Fifth :Interim Progress Keport, Worchester Polytechnic Institute (January 16, 1976 - April 15, 1976).

B-16.18. L. Baker and L. C. Just, Studies of Metal-Water Reactions at High Temperatures - III. Experimental and Theoretical Studies of the Zirconium-Water Reaction, ANL-6548, (May 1962).

B-16.19. E. Hillner, "Corrosion and Hydriding Performance of Zircaloy Tubing After Extended Exposure in the Shippingport Pressurized Water Reactor," Zirconium in Nuclear Applications ASTM-STP-551, Philadephia, American Society for Testing and Materials, 1974, pp 449-462. 
B-16.20. A. W. Urquhart and D. A. Vermilyea, "Characterization of Zircaloy Oxidation Films," Zirconium in' Nuclear Applications, ASTM-STP-551, Philadelphia, American Society for Testing and Materials, 1974, pp 463-478.

B-16.21. D. H. Bradhurst and P. M. Heuer, "The Influence of Oxide Stress on the Breakaway Oxidation of Zircaloy-2," Journal of Nuclear Materials, 37 (1970) pp $3.5-47$.

B-16.22. J. V. Cathcart, Quarterly Progress Report on the Zirconium Metal-Water Oxidation Kinetics Program Sponsored by the NRC Division of Reactor Safety Research for July - September 1975, ORNL-5148 (December 1975).

B-16.23. J. V. Cathcart, Quarterly Progress Report on the Zirconium Metal-Water Oxidation Kinetics Program Sponsored by the NRC Division of Reactor Safety Research for October - December 1975, ORNL/TM-5248 (March 1976).

B-16.24. J. V. Cathcart, Quarterly Progress Report on the Zirconium Metal-Water Oxidation Kinetics Progam Sponsored by the NRC Division of Reactor Safety Research for January - March 1976, ORNL/NUREG/TM-17, NRC-3 (May 1976).

B-16.25. R. R. Biederman and W. G. Dobson, "A Study of Zircaloy - Steam Oxidation Reaction Kinetics," Fourth Interim Progress Report, Worchester Polytechnic Institute (October 1, $19 \overline{7} 5$ - January 15, 1976).

B-16.26. D. O. Hobson and P. L. Rittenhouse, Embrittlement of Zircaloy-Clad Fuel Rods by Steam During LOCA Transients, ORNL-4758 (January 1972).

B-16.27. S. Malang, SIMTRANI-A Computer Code for the Simultaneous Calculation of Oxygen Distributions and Temperature Profiles in Zircaloy During Exposure to High Temperature Oxidizing Environments, ORNL-5083 (November 1975).

B-16.28. V. F. Urbanic, "Method for Estimating the Exposure Time and Temperature for Zircaloy Oxidation in Steam," Journal of Nuclear Materials, 59 (1976) pp 90-94.

B-16.29. A. W. Lemmon, Studies Relating to the Reaction Between Zirconium and Water at High Temperatures, BMI-1 154 (1957).

B-16.30. R. E. Pawel, Zirconium Metal-Water Oxidation Kinetics III. Oxygen Diffusion in Oxide and Alpha Zircaloy Phases, ORNL/NUREG-5 (October 1976).

B-16.31. T. G. Odekirk, Detailed Test Plan Report for P'BF Test Series PCM-20: The Behavior of Unirradiated PWR Fuel Rods Under Power-Cooling-Mismatch Conditions, ANCR-1095 (April 1974).

B-16.32. J. A. Dearien et al, FRAP-T2: A Computer Code for Transient Analysis of Oxide Fuel Rods, TREE-NUREG-1040 (March 197.7). 


\section{CLADDING HYDROGEN UPTAKE.(CHUPTK)}

This function returns the average weight fraction of hydrogen in zircaloy cladding during typical reactor operation at temperatures of 250 to $400^{\circ} \mathrm{C}$. Required input values are temperaturc at the oxide-metal interface, initial oxide film weight, time at flux and temperature, type of reactor (BWR - or PWR), cladding inside and outside diameters, initial hydrogen in cladding, fuel water content, fuel pellet diameter, and cladding material.

\subsection{Summary}

The average weight fraction of hydrogen in zircaloy cladding during steady state conditions is

$$
\mathrm{H}=\mathrm{H}_{0}+\mathrm{H}_{1}+\mathrm{H}_{\mathrm{C}}
$$

where

$$
\begin{aligned}
& \mathrm{H}=\text { net weight fraction of hydrogen in the cladding (ppIn). } \\
& \mathrm{II}_{\mathrm{O}}=\text { initial concentration of hydrogen in the cladding duc to } \\
& \text { inpurities introduced during manufacturing and auto- } \\
& \text { claving (ppm). Typical values are } 8-30
\end{aligned}
$$

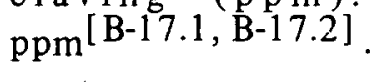

$$
\begin{aligned}
& \mathrm{H}_{1}=\text { concentration of hydrogen in the cladding due to internal } \\
& \text { outgassing of water absorbed by the fuel ( } \mathrm{ppm} \text { ). } \\
& \mathrm{H}_{\mathrm{C}}=\text { concentration of hydrogen in the cladding due to absorp- } \\
& \text { tion of hydrogen frum the cosilant ( } p \mu m) \text {. }
\end{aligned}
$$

$\mathrm{H}_{\mathrm{O}}$ is an input parameter. $\mathrm{H}_{1}$ is calculated by the routine using the input values for parts per million watcr vapor in the fucl, the input cladding dimensions, and the input fuel pellet diameter. CHUPTK assumes that all the hydrogen from the water vapor in the fuel is picked up by the cladding.

The primary consideration in determining $\mathrm{H}$ is the determination of a value for $\mathrm{H}_{\mathrm{c}}$. Analytical expressions for $\mathrm{H}_{\mathrm{C}}$ are divided into two parts, Equation (B-17.2a) for oxide films thinner than the transition thickness ${ }^{[a]}$ and Equation (B-17.2b) for oxide films which have

[a] Oxide film growth is discussed in conjunction with the description of the cladding oxidation subcode, CORROS. The terms pre- and posttransition refer to two different stages in the growth of the oxide film. A transition between the two stages occurs when the oxide film has added approximately $30 \mathrm{mg}$ of oxide per $\mathrm{dm}^{2}$ of oxide surface. 
grown beyond the transition thickness. In these equations, the variable $H$ has been converted from $\mathrm{mg} / \mathrm{dm}^{2}$ of hydrogen across the cladding surface to units of average parts per million by weight in the cladding.

$$
\begin{gathered}
H_{C}=\left[\frac{0.0154}{\tau}\right]\left[\frac{R}{8 A}\right]\left[X_{\text {PRE }}-X_{0}\right]=H_{C P R E} \\
H_{C}=H_{\text {TRAN }}+\left[\frac{0.0154}{\tau}\right]\left[\frac{2.27 B}{8 A}\right]\left[X_{\text {POST }}-X_{\text {TRAN }}\right]=H_{\text {CPOST }}
\end{gathered}
$$

where

$$
\begin{aligned}
& \mathrm{H}_{\mathrm{c}}=\text { weight fraction of hydrogen added to the } \\
& \text { cladding from the coolant (ppm by weight). } \\
& \mathrm{H}_{\text {TRAN }}=\quad \because \text { value of } \mathrm{H}_{\mathrm{C}} \text { at the transition weight of the oxide } \\
& \text { film (ppm by weight). } \\
& r \quad=\quad \text { cladding initial thickness }(\mathrm{m}) \text {. } \\
& \bar{B} \quad=\quad \text { iraction of hycorogen iberaled by tite reactioui } \\
& \text { with the coolant during pretransition corrosion } \\
& \text { (discussed in Section B-17.4). In this model, } \\
& B \text { includes any additional hydrogen input due to } \\
& \text { sources other than the expected out-of-pile } \\
& \text { reaction rate with water. } A \text { value for } B \text { is } \\
& \text { determined in the subcode according to the }
\end{aligned}
$$




\section{CHUPTK}

\begin{tabular}{|c|c|c|}
\hline$x_{0}$ & $=$ & $\begin{array}{l}\text { initial weight of the cladding oxide layer } \\
\text { expressed in } \mathrm{mg} / \mathrm{dm}^{2} \text { of oxygen which has } \\
\text { crossed the oxide surface. This term can be } \\
\text { approximated as } X_{0}=0 \text { for etched cladding, but } \\
\text { it becomes important if extensive prefilming is } \\
\text { carried out or if oxidation is carried out in } \\
\text { several steps which occur at different tempera- } \\
\text { tures or in different coolant chemistries. }\end{array}$ \\
\hline$x_{P R E}$ & $\equiv$ & $\begin{array}{l}\text { total weight of oxygen which has been absorbed } \\
\text { through the zircaloy surface when a pretran- } \\
\text { sition oxide film exists }\left(\mathrm{mg} / \mathrm{dm}^{2}\right) \text {. }\end{array}$ \\
\hline$X_{\text {TRAN }}$ & & $\begin{array}{l}\text { total weight of oxygen absorbed at transition } \\
\text { point }\left(\mathrm{mg} / \mathrm{dm}^{2} \text { ) (typically } 30 \mathrm{mg} / \mathrm{dm}^{2} \text { or } 0.08\right. \\
\text { tuil llick). }\end{array}$ \\
\hline $\mathrm{X}_{\mathrm{POST}}$ & $=$ & $\begin{array}{l}\text { total weight of oxygen which has been absorbed } \\
\text { through the zirconium surface when the oxide } \\
\text { film is in the posttransition state }\left(\mathrm{mg} / \mathrm{dm}^{2} \text { ). }\right.\end{array}$ \\
\hline
\end{tabular}

Expressions for $\mathrm{X}_{\mathrm{PRE}}, \mathrm{X}_{\mathrm{TRAN}}$, and $\mathrm{X}_{\mathrm{POST}}$ are calculated by the CHUPTK subcode using the expressions developed for CORROS (Section B-16 of this report) and the input information. $X_{O}$ is part of the required input information, but may usually be taken to be zero since typical prefilming values are $1 \mathrm{mg} / \mathrm{dm}^{2}$ and typical end-of-life values are hundreds of $\mathrm{mg} / \mathrm{dm}^{2}$.

The approach and general physical picture used to model hydrogen uptake are summarized in Section B-17.2. Section B-17.3 develops the basic out-of-pile model, and Section B-17.4 generalizes the basic model so that it represents in-pile hydrogen uptake behavior.

\subsection{Background and Approach}

It is generally agreed $[\mathrm{B}-17.3, \mathrm{~B}-17.4]$ that oxidation of zirconium alloys by water in the temperature range from 250 to $400^{\circ} \mathrm{C}$ proceeds by the migration of oxygen vacancies in the oxide layer. Charge and physical size considerations imply that the mechanism of introduction of hydrogen into the zirconium metal through an oxide film is by entry of neutral hydrogen atoms into oxygen vacancies in the lattice $\left(\mathrm{H}_{2}\right.$ is too large and $\mathrm{H}^{+}$is too positive). The constant ratio of hydrogen to oxygen (the "pick up fraction") which is added to the metal is explained as having been determined by the competition between possible subsequent reactions of the atomic hydrogen created by corrosion (the atomic hydrogen can combine to form a gas or enter into a surface vacancy in the oxide lattice). 
In this approach, the close relationship between the hydrogen weight gain and the oxygen weight gain from the coolant is viewed as a consequence of the fact that the oxygen and hydrogen usually come from a common source (the water molecule) and are transported to the metal by a common carrier (oxygen vacancies). The hydrogen pickup fraction is determined by the composition of the coolant-oxide surface. In particular, it is suspected that nickel oxicle from the nickel in zircaloy-2 absorbs atomic hydrogen at the surface of the oxide of this alloy and thereby enhances the fractional hydrogen uptake for zircaloy-2.

\subsection{Out-of-Pile Basis for the Model}

The in-pile model is based primarily on out-of-pile data because well characterized data on hydrogen uptake as a function of time and temperature have been published only for out-of-pile corrosion. At least two plausible suggestions for a hydrogen uptake model can be presented from the approach discussed in Section B-17.2. According to both of these suggestions, the dependent variable is the ratio of the corrosion-liberated hydrogen to oxygen which is absorbed by the metal, al though the independent variables differ. A brief summary of the two models, and a third less probable model follows.

17.3.1 Simple Probabilistic Hydrogen Pickup Model. In this model, the fraction of released hydrogen which is absorbed by the oxide surface is assumed to be proportional to the rate of appearance of oxide vacancies at the oxide-coolant interface. In the discussion of the cladding oxidation model, CORROS, it is shown that the vacancies appear at a rate proportional to the inverse of the square of the oxygen weight gain during the pretransition phase of oxidation. During the posttransition phase of oxidation, the surface averaged rate of appearance of oxide vacancies is constant and proportional to three times the inverse of the square of the weight of the oxide layer at transition. This model would ignore any details of the surface chemistry involved in the absorption of atomic hydrogen by the oxide vacancies.

17.3.2 Surface-Controlled Hydrogen Pickup Model. In this model, the fraction of released hydrogen which is absorbed by the oxide surface is a constant determined by the metallurgy of the oxide surface. The picture assumes that the effect of absorption of atomic hydrogen is dominant in the capture of hydrogen by the oxide film's outer surface.

17.3.3 Diffusion-Controlled Hydrogen Pickup Model. It is also conceivable that the time rate of hydrogen input into the metal is controlled by some as yet unconsidered independent diffusion process. In the case of diffusion-controlled hydrogen uptake, the net time rate of hydrogen pickup is proportional to the inverse thickness of the oxide layer.

The rate equations implied by the three alternate pictures are summarized in Table B-17.I. Pretransition expressions were formulated simply by writing down the mathematical equivalent of the descriptions above. Posttransition expressions for the hydrogen pickup fraction were derived by replacing powers of $X$ (proportional to the oxide thickness) in the pretransition expressions with powers of $\mathrm{X}$ averaged over a rate-determining oxide thickness 
CHUPTK

TABLEE B-17. I

RATE EQUATIONS FOR HYDROGEN UPTAKE

Pretransition Rates

Posttransition

(1) Simple Probabilistic Pickup Fraction Determination

$$
\frac{d H}{d X}=\frac{r}{x^{2}}
$$

$$
\frac{d H^{\prime}}{d X}=\frac{C}{x^{2}}=\frac{3 C}{X_{\text {TRAN }^{2}}}
$$

(2) Surface-Controlled Pickup Fraction Determination

$$
\frac{d H}{d X}=P
$$

$$
\frac{d H}{d X}=P
$$

(3) Diffusion-Controlled Time Rate

$$
\frac{d H}{d X}=\frac{Q}{X}
$$

$$
\frac{d H}{d X}=\frac{Q}{\bar{X}}=\frac{20}{X_{\text {TRAN }}}
$$

$H_{i} \quad=$ hydrngen weight. gain $\left(\mathrm{mg} / \mathrm{dm}^{2}\right)$

$x \quad=$ oxygen weight gain ( $\mathrm{mg} / \mathrm{dm}^{2}$, corresponds to oxide thickness)

t = time at temperature

$x_{\text {TRAN }}=$ the transition weight of the oxide 7ayer (mg/ $\mathrm{dm}^{2}$ )

$\overline{x^{2}}=$ the average of $x^{2}$ with values of $x$ distributed at random between 0 and the transition thickness, $x_{\text {TRAN }}\left(\mathrm{mg} / \mathrm{dm}^{2}\right)$.

$X$ = the space average of $X$ with values of $X$ distributed at random between 0 and the transition thickness $\left(\mathrm{mg} / \mathrm{dm}^{?}\right.$ )

$G, P, Q=$ constants

that randomly varies from zero to the transition thickness of the oxide film. A discussion of the posttransition oxide film and this approach to describing posttransition rates is included in the description of the cladding oxidation subcode CORROS in Section B-16.

When the three very different expressions for hydrogen uptake obtained with these models were integrated and compared with the pretransition data of Tables 7 and 9 of 
Reference $\mathrm{B}-17.3$, the pretransition data for zircaloy-2 and zircaloy-4 were found 10 conform best to the assumption that the rate is surface-controlled. The surface-controlled model is therefore used.

Comparison of experimental pretransition and posttransition hydrogen pickup fractions ${ }^{[B-17.3]}$ for zircaloy-2 show that the posttransition rate is about twice the pretransition rate. Although the simple surface-controlled hydrogen pickup model of Table B-17.I predicts equal pre- and posttransition pickup fractions, the model can be improved to account for the increased posttransition pickup. The hydrogen pickup rate is surface limited, thus, the increase in surface area represented by the nonuniform surface of the rate-determining oxide layer of the posttransition stage will increase the net absorption probability when the smooth surface of the pretransition regime is replaced by the rough posttransition surface. If this approach is correct, pre- and posttransition values of the constant hydrogen pickup rate will have ncarly the same ratio in all alloys as the values 0.75 and 0.33 reported in Reference B-17.4 for zircaloy-2.

The resultant expressions for the fractional pickup of hydrogen are:

$$
\begin{aligned}
& \text { for pretransition } \frac{d H}{d X}=\frac{B}{8} \\
& \text { for posttransition } \frac{d H}{d X}=\frac{2.27 B}{8}
\end{aligned}
$$

where $B$ is determined by the oxide surface metallurgy of the particular alloy (the presence or absence of nickel which absorbs atomic hydrogen, for example) and 8 accounts for the different weights of hydrogen and oxygen in water so that $\frac{\mathrm{dH}}{\mathrm{dx}}=\frac{1}{8}$ for complete "pickup."

\subsection{Generalization to an In-Pile Model}

Prediction of in-pile corrosion is complicated because important variables (local temperature and reactor chemistry) are not always reported and because data on the time dependence of corrosion are limited. Even relatively simple experiments such as inserting several unfueled zircaloy tubes (preferably with thermocouples at various positions along their axes) in to blank thimble tubes in operating reactors would provide needed information for modeling in-pile hydrogen uptake. Enhancement of hydrogen uptake fractions by the reactor environment is treated by determining the value of the pickup fraction $B$ for each reactor environment. Changes in the rate of hydrogen picked up which are caused by changes in the oxidation rate are described with the parameter A which is discussed in conjunction with the oxidation model, CORROS. Thus two parameters are specified to describe the two separate processes involved in determining the total rate of hydrogen uptake.

The basic equations for the fraction of hydrogen pickup with respect to the amount of oxygen pickup $(\mathrm{dH} / \mathrm{dX})$ are discussed at the end of Section B-17.3 [Equation (B-17.3a) 


\section{CHUPTK}

and (B-17.3b)]. Those equations reference out-of-pile oxidation. For in-pile pickup, the enhancement factor A must again be used. It is presumed that the effect which enhances the oxidation rate in the reactor does not enhance the rate of hydrogen uptake. Thus the enhancement of the oxidation rate hy a factor $A$ will decrease the fractional hydrogen uptake by a factor $\frac{1}{\mathrm{~A}}$.

The rate equations for in-pile oxidation and for fractional pickup of hydrogen are summarized in Equations (B-17.4a) and (B-1\%.4b) for both pre- and posttransition regines.

For the pretransition in pile regime:

$$
\cdot \frac{d H}{d X}=\frac{B}{8 A}
$$

for the posttransition innile, regime:

$$
\frac{d H}{d X}=\frac{2 \cdot 27 B}{8 A}
$$

The integrated lorm of these equations is given in Equations (B-17.5a) and (B-17.5b).

For llie pretuansition in-pile region:

$$
H=H_{0}=\frac{B}{8 A}\left(X_{P R E}-X_{0}\right)
$$

for the posttransition in-pile regime:

$$
H=H_{\text {TRAN }}+\frac{2 \cdot 27 B}{8 A}\left(X_{\text {POST }}-X_{\text {TRAN }}\right) \text {. }
$$

The subsrripts refer to the point of evaluation: $X_{0}$ is oxygen weight at time zero; the subscrlpt PRE intulies evalualivin during a pretransition oxide tlux; TR. $\Lambda N$ refere to the transition point; POST refers to the posttransition regime.

An out-of-pile value of the parameter B has been determined in Reference B-17.4 (from unpublished data) to be $B=0.33$ for zircaloy-2. For zircaloy -4 , a value of $B=0.12$ was obtained from Figure 12 of Reference B-17.3. The result is consistent with a value of $10 \%$ recommended by Reference B-17.4.

When values of $B$ were fit to the average hydrogen pickup values for the zircaloy- 4 rods in the Saxton $[B-17.5, B-17.6]$ reactor, an average value of $B=0.104 \pm 0.04$ was obtained. Thus the out-of-pile determined value of $B=0.12$ is apparently adequate for zircaloy 4 rods in PWRs. Since no data on zircaloy-4 cladding in a BWR are available, the PWR value, $B=0.12$, is returned for the unlikely case of zircaloy- 4 in a BWR. Values of B obtained by fitting the zircaloy-2 PWR hydrogen pickup reported in Reference B-17.2 
were $B=0.48 \pm 0.07$ while a fit to the BWR hydrogen pickup data on the zircaloy- 2 rods of Reference B-17.7 produced values of $B=0.29 \pm 0.06$. Since the PWR environment has an overpressure of hydrogen and it is known that hydrogen overpressures enhance the out-of-pile pickup fraction [B-17.3], it is suggested that difference in PWR and BWR values for $B$ with zircaloy-2 is an effect of the different environments.

\subsection{Cladding Hydrogen Uptake Subcode CHUPTK Listing}

A listing of the FORTRAN subcode CHUPTK is presented in Table B-17.II.

\subsection{References}

B-17.1. F. H. Megerth, C. P. Ruiz U. E. Wolff, Zircaloy-Clad $\mathrm{UO}_{2}$ Fuel Rod Evaluation Program, GEAP-10371 (June 1971).

B-17.2. E. Hillner, "Corrosion and Hydriding Performance of Zircaloy Tubing after Extended Exposure in the Shippingport PWR," Zirconium in Nuclear Applications, ASTM-STP-551 (1974) pp 449-462.

B-17.3. E. Hillner, Hydrogen Absorption in Zircaloy During Aqueous Corrosion, Effect of Environment, WAPD-TM-411 (November 1964).

Q-17.4. A. Van der Inde, Calculation of the Safe Life Time Expectancy of Zirconium Alloy Canning in the Fuel-Elements of the Nero Reactor, RCN-41 (July 1965).

B-17.5. W. R. Smalley, Saxton Core II Fuel Performace Evaluation, Part I: Materials, WCAP-3385-56 (July 1971).

B-17.6. W. R. Smalley, Saxton Core III Fuel Materials Performance, WCAP-3385-57 (July 1974).

B-17.7. H. E. Williamson, C. J. Baroch, J. P. Hoffmann, D. T. Ikeaye, AEC Fuel Cycle Program Examination of $\mathrm{UO}_{2}$ Fuel Rods Operated in the VBWR to 10,000 $M W D / T U$, GEAP-4597 (1965). 


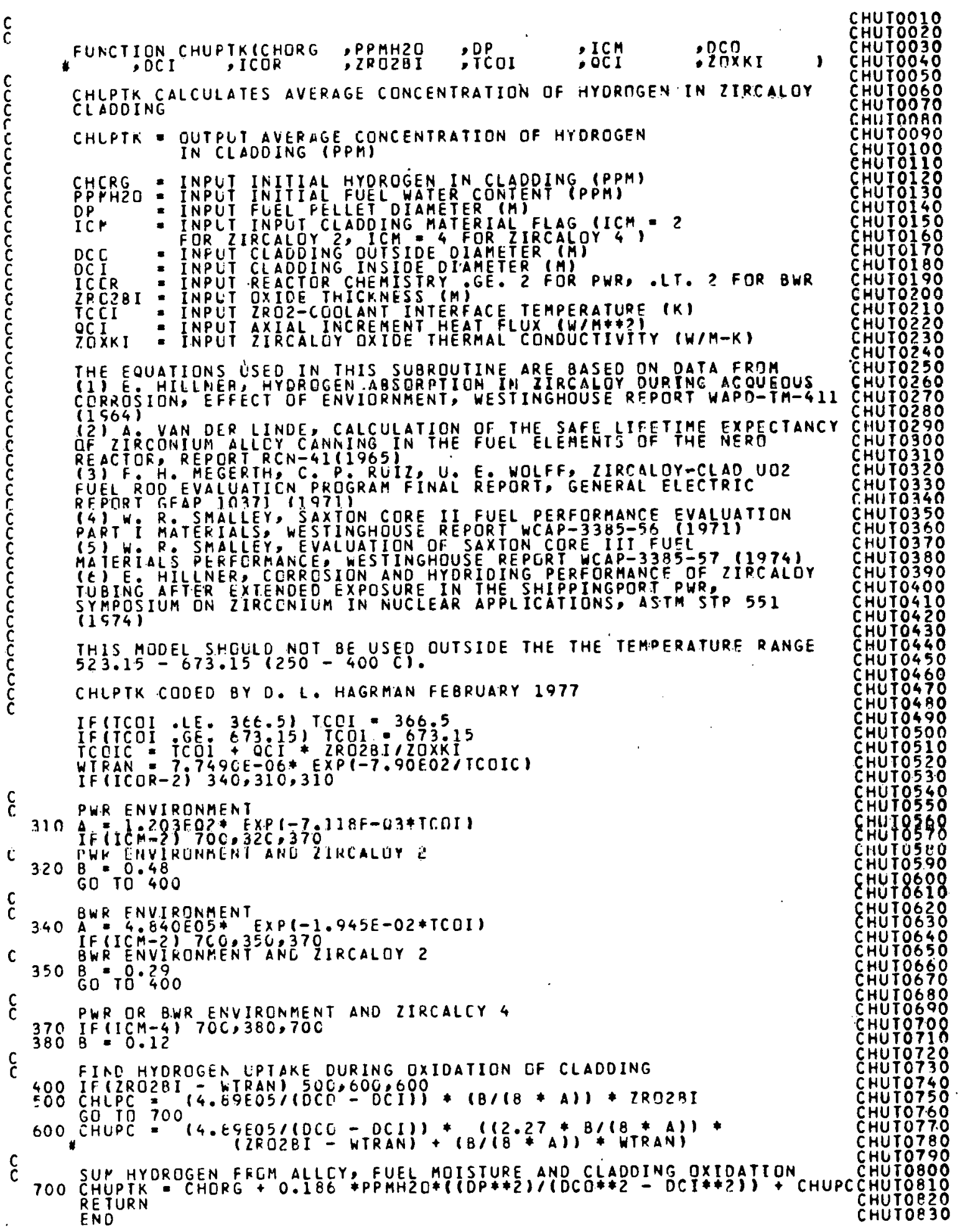


APPENDIX C

GAS AND FUEL ROD PROPERTIES 


\section{THIS PAGE}

WAS INTENTIONALLY

LEFT BLANK 


\section{APPENDIX C}

\section{GAS AND FUEL ROD PROPERTIES}

Two properties of the inlernal gas of light water reactors have been included in MATPRO - Version 10. The thermal conductivity of seven gases (and their mixture in any combination) is modeled, as is gas viscosity. Gas viscosity and thermal conductivity have been modeled as functions of both temperature and gas composition.

In addition a physical property subroutine (PHYPRO) is included in this appendix. This subroutine provides the melting temperatures and heats of fusion for light water reactor fuels and cladding, and also includes phase transformation temperatures for zircaloy cladding. A number of MATPRO models call upon this subroutine for needed data, some of which are given in PHYPRO as a function of burnup and plutonia content.

\section{GAS THERMAL CONDUCTIVITY (GTHCON)}

The cladding-fuel gap conductance is, in part, dependent on the thermal conductivity of the gap gas mixture. Thermal conductivity relations for seven gases have been taken from the literature as has a scheme for calculating the conductivity of mixtures of those gases. The thermal conductivities of the light gases, hydrogen and helium, have been adjusted to allow for imperfect energy transfer between solids and gas in the Knudsen flow regime.

\subsection{Conductivity of Gases and Gas Mixtures}

The relationship for calculating the thermal conductivity of a monatomic gas mixture is based on the work of Brokaw $[C-1.1]$ :

$$
k_{\text {mix }}=\sum_{i=1}^{n}\left(\frac{k_{i}}{1+\sum_{\substack{j=1 \\ j \neq 1}}^{n} \psi_{j j} \frac{x_{j}}{x_{i}}}\right)
$$

where

$$
\psi_{i j}=\phi_{i j}\left[1+2.41 \frac{\left(M_{i}-M_{j}\right)\left(M_{i}-0.142 M_{j}\right)}{\left(M_{i}+M_{j}\right)^{2}}\right]
$$




\section{GTHCON}

and

$$
\phi_{i j}=\frac{\left[1+\left(\begin{array}{l}
k_{i} \\
k_{i}
\end{array}\right)^{1 / 2}\left(\begin{array}{l}
M_{i} \\
M_{j}
\end{array}\right)^{1 / 4}\right]^{2}}{2^{3 / 2}\left(1+\frac{M_{i}}{M_{j}}\right)^{1 / 2}}
$$

and

$$
\begin{aligned}
& \mathrm{n}=\text { number of components in mixture } \\
& \mathrm{M}_{\mathrm{i}}=\text { molecular weight of the chemical species } \mathrm{i} \\
& \mathrm{x}_{\mathrm{i}}=\text { mole fraction of the chemical species } \mathrm{i} \\
& \mathrm{k}_{\mathrm{i}}=\text { thermal conductivity of the chemical species } \mathrm{i} .
\end{aligned}
$$

The thermal conductivity equations of the individual rare gases are based on the correlative work of Gandhi and Saxena ${ }^{[C-1.2]}$. The resulting expressions are ${ }^{[C-1.3]}$

$$
\begin{aligned}
& k_{\text {helium }}-3.366 \times 10^{-3} \mathrm{~T}^{0.668} \\
& k_{\text {argon }}=3.421 \times 10^{-4} \mathrm{~T} 0.701 \\
& k_{\text {xenon }}=4.0288 \times 10^{-5} \mathrm{~T}^{0.872} \\
& k_{\text {krypton }}=4.726 \times 10^{-5} \mathrm{~T}^{0.923}
\end{aligned}
$$

where

$$
\begin{aligned}
\mathrm{k} & =\text { thermal conductivity }(\mathrm{W} / \mathrm{m} \cdot \mathrm{K}) \\
\mathrm{T} & =\text { gas temperature }(\mathrm{K}) .
\end{aligned}
$$

In addition, the following conductivity equations for nitrogen, hydrogen, and steam $[\dot{C}-1.3, C-1.4]$ are used:

$$
\begin{aligned}
& k_{N_{2}}=2.091 \times 10^{-4} \mathrm{~T} 0.846 \\
& k_{H_{2}}=1.6355 \times 10^{-3} \mathrm{~T} 0.8213
\end{aligned}
$$




$$
\begin{aligned}
k_{\text {steam }}= & \left(-2.8516 \times 10^{-8}+9.424 \times 10^{-10} \mathrm{~T}\right. \\
& \left.-6.004 \times 10^{-14} \mathrm{~T}^{2}\right) \frac{\mathrm{P}}{\mathrm{T}}+\frac{1.009 \mathrm{P}^{2}}{\mathrm{~T}^{2}(\mathrm{~T}-27.3)^{4.2}} \\
& -8.4083 \times 10^{-3}-1.19998 \times 10^{-5} \mathrm{~T} \\
& -6.706 \times 10^{-8} \mathrm{~T}^{2}-4.51 \times 10^{-11} \mathrm{~T}^{3} .
\end{aligned}
$$

where

$$
\mathrm{P}=\text { gas pressure }\left(\mathrm{N} / \mathrm{m}^{2}\right) \text {. }
$$

The thermal conductivity of monatomic gases has been measured by a large number of workers. Gandhi and Saxena, through the facilities of the Thermophysical Properties Research Center of Purdue University, developed a consistent, correlated set of thermal conductivity data for each rare gas through careful evaluation of experimental techniques; review of viscosity data and kinetic theory, and intercomparison of various data. The data on which the Gandhi and Saxena analysis were based are: helium (References C-1.5 through C-1.22), argon (References C-1.5, C-1.9 through C-1.12, C-1.17 through C-1.21, C-1.23 through C-1.34), krypton (References C-1.9, C-1.14, C-1.17 through C-1.19, C-1.25 through C-1.28, C-1.30, and C-1.35), and xenon (References C-1.9, C-1.10, C-1.13, C-1.14, $\mathrm{C}-1.17$ through $\mathrm{C}-1.19, \mathrm{C}-1.27, \mathrm{C}-1.35$, and $\mathrm{C}-1.36$ ).

The equations based on the correlative work of Gandhi and Saxena have also been compared with the results of the review of experimental and theoretical rare gas conductivities published by Andrew and Calvert ${ }^{[C-1.37]}$. Little difference was noted.

Figure C-1.1 compares the conductivities of the xenon-helium mixture at $520^{\circ} \mathrm{C}$ (as a function of mole fraction) calculated by GTHCON with those measured and calculated by other investigators (References, $\mathrm{C}-1.1, \mathrm{C}-1.38$ through $\mathrm{C}-1.42$ as summarized in Reference C-1.37). The GTHCON values compare well with other published theoretical and experimental values.

\subsection{Conductivities in the Knudsen Domain}

The thermal conductivity of the gas mixture plays an important role in determining so-called "contact" gap conductance as well as "open" gap conductance in a fuel rod. When the mean free path of the gas molecules is greater than 0.01 times the characteristic dimension (gap), normal heat flow formulas become inaccurate. Heat transfer from a solid to a gas in this Knudsen domain is then dependent on an accommodation coefficient which is defined as the ratio of the actual energy interchange to the maximum possible energy interchange between a surface and a gas. Generally, the accommodation coefficient of a 


\section{GTHCON}

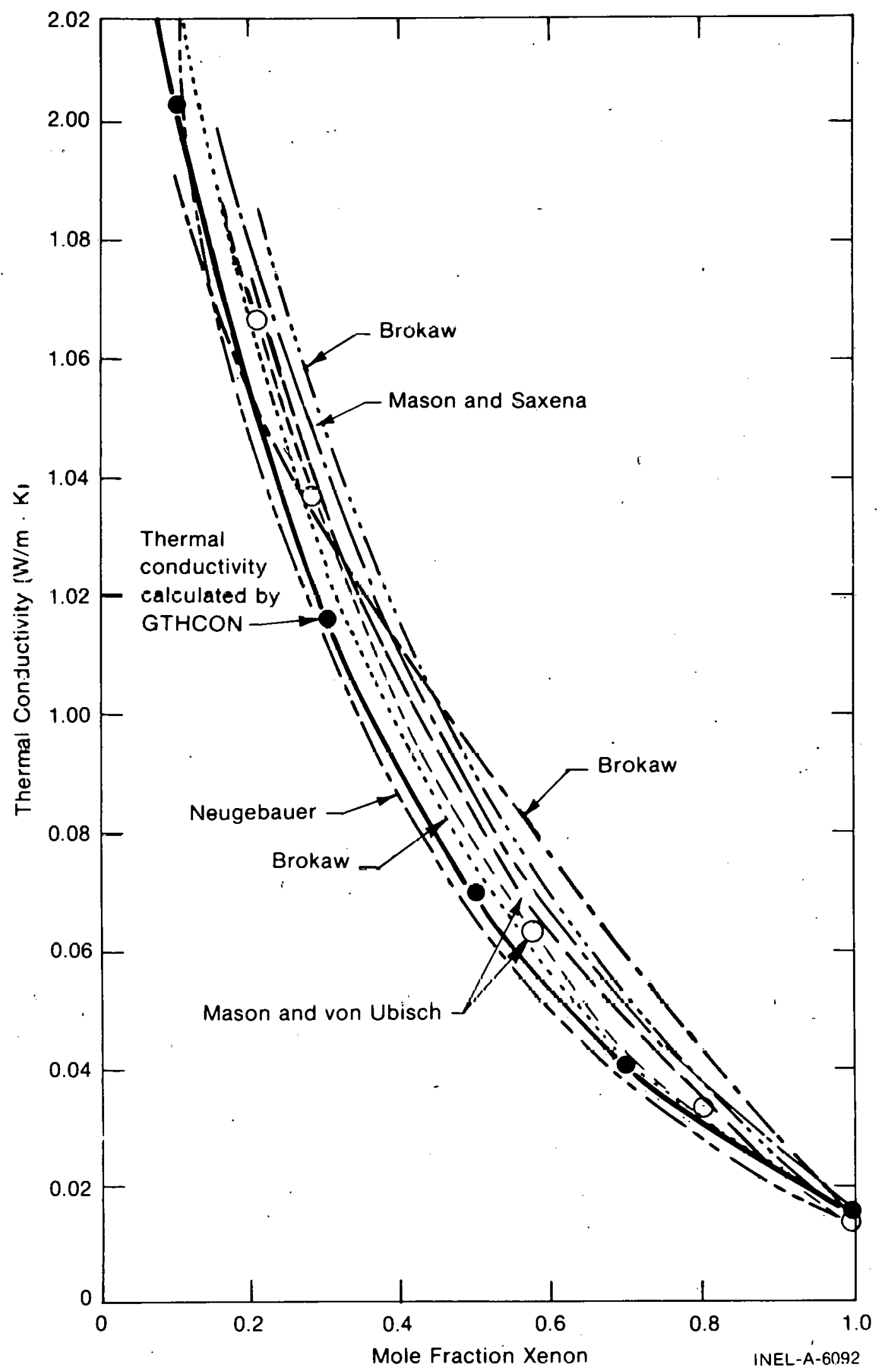

Fig. C-1.1 Thermal conductivity of xenon-helium mixtures at $520^{\circ} \mathrm{C}$. 
heavy gas such as argon or xenon is near unity and this effect can be neglected. But the effect cannot be neglected when the gap is filled with a light gas such as helium. Dean ${ }^{[C-1.43]}$ has presented the following factor by which the bulk thermal conductivity of the light gases, helium and hydrogen, should be divided when temperature drops are calculated in the Knudsen domain:

$$
f=1+\frac{\alpha_{1}+\alpha_{2}-\alpha_{1} \alpha_{2}}{\alpha_{1} \alpha_{2}} \frac{4}{c_{p}+c_{v}} \frac{k}{\mu} \frac{\lambda}{\zeta}
$$

where

$$
\begin{aligned}
& \alpha_{1}=\text { accommodation coefficient of the fuel }(\mathrm{J} / \mathrm{J}) \\
& \alpha_{2}=\text { accommodation coefficient of the cladding }(\mathrm{J} / \mathrm{J}) \\
& c_{p}=\text { constant pressure heat capacity }\left(\mathrm{J} / \mathrm{kg}^{\prime} \mathrm{K}\right) \\
& c_{\mathrm{v}}=\text { constant volume heat capacity }(\mathrm{J} / \mathrm{kg} \cdot \mathrm{K}) \\
& \mathrm{k}=\text { gas thermal conductivity }(\mathrm{W} / \mathrm{m} \cdot \mathrm{K}) \\
& \mu \quad=\text { gas viscosity }\left(\mathrm{N} \cdot \mathrm{sec} / \mathrm{m}^{2}\right) \\
& \lambda=\text { mean path }(\mathrm{m}) \\
& \zeta \quad=\text { characteristic dimension }(\mathrm{gap})(\mathrm{m}) .
\end{aligned}
$$

The mean path $(\lambda)$ can be written as

$$
\lambda=\frac{3 \mu}{\rho}\left[\frac{\pi M}{8 K T}\right]^{1 / 2}
$$

where

$$
\begin{aligned}
& \mu \quad=\text { gas viscosity }\left(\mathrm{N} \cdot \mathrm{sec} / \mathrm{m}^{2}\right) \\
& \mathrm{T}=\text { gas temperature }(\mathrm{K}) \\
& \mathrm{M}=\text { mass of the molecule }(\mathrm{kg}) \\
& \mathrm{K}=\text { Boltzman constant }\left(1.38 \times 10^{-23} \mathrm{~J} / \mathrm{K}\right) \\
& \rho \quad=\quad \text { density of gas }\left(\mathrm{kg} / \mathrm{m}^{3}\right) .
\end{aligned}
$$


If $\lambda$ is substituted in Equation $(C-1.11)$ and $c_{p}$ and $c_{v}$ are assumed to be temperature independent, then Equation (C-1.11) can be rewritten using the ideal gas law and the fact that $\rho=\mathrm{nM} / \mathrm{V}$ as

$$
f=1+c \frac{k \sqrt{T}}{P_{\zeta}}
$$

where

$$
\begin{aligned}
& \mathrm{k}=\text { thermal conductivity }(\mathrm{W} / \mathrm{m} \cdot \mathrm{K}) \\
& \mathrm{T}=\text { temperature }(\mathrm{K}) \\
& \mathrm{P}=\text { pressure }\left(\mathrm{N} / \mathrm{m}^{2}\right) \\
& \zeta \quad=\quad \text { characteristic dimension }(\mathrm{m}) \\
& \mathrm{C}=\text { empirical constant. }
\end{aligned}
$$

The characteristic dimension, $\zeta$, is essentially equal to the gap dimension and during pellet-to-cladding contact should be equal to the root mean square of the surface roughness, approximately $4.389 \times 10^{-6} \mathrm{~m}$ in most commercial fuel rods. A value for $\mathrm{C}$ of approximately $0.2103 \mathrm{~N}-\mathrm{K}^{1 / 2} / \mathrm{W}$ was determined in conjunction with the development of the cracked pellet gap conductance model discussed in Section C-3. C was determined by comparing fuel centerline temperature predictions with thermocouple measurements of centerline temperatures in helium-filled test rods with strong pellet-cladding mechanical interaction and high contract pressurc. These comparisons are presented in Section C-3.2.

Values for the thermal accommodation coeficients of the uranium oxide fuel and zircaloy cladding, $\alpha_{1}$ and $\alpha_{2}$, of approximately 0.3 and 0.07 , respectively, are obtained by equaling Equalions $(C-1.11)$ and $(C-1.13)$. Eckert and Drakell-1.44] have published thermal accommodation coefficients for glass (a ceramic) and helium of approximately 0.3 , as well as cuefricienls ranging frum 0.011 to approximately 0.2 for tungsten or nickel and helium. Thus the accommodation coefficient values determined by comparison of measured and predicted in-pile temperatures compare favorably with the limited thermal accommodation coefficient data published for similar materials.

The effect of heat transfer in the Knudsen domain on fuel temperatures is indicated in Figure C-1.2. Campbell and DesHaies ${ }^{[C-1.45]}$ performed an experiment in which the fuel rod internal gas pressure was reduced from about $15.2 \mathrm{MPa}$ during irradiation thereby allowing the cladding to collapse onto the fuel. Fuel temperatures near the pellet surface and cladding circumferential strain were continuously monitored. As the internal pressure was decreased, the gap width became smaller (as indicated in Figure C-1.2), the gap conductance increased, and the fuel surface temperature decreased. Further pressure reduction from about $1 \mathrm{MPa}$ results in increasingly imperfect energy exchange between the 


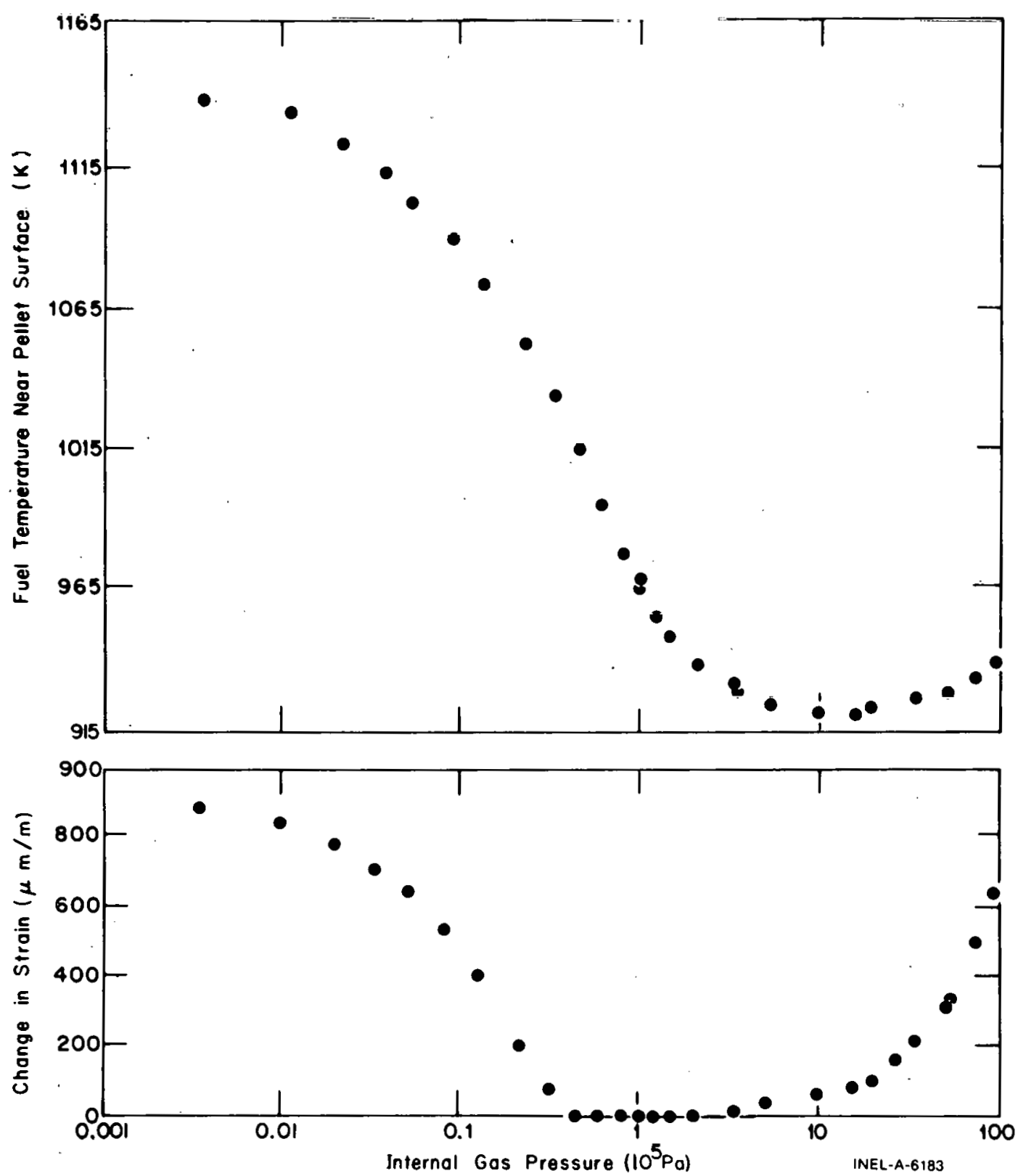

Fig. C-1.2 Effect of measured internal gas pressure on fuel temperatures near the pellet surface.

fill gas and the fuel and cladding, however. This effect more than compensates for the decreased gap width and the fuel temperature, and then the fuel radius is seen to increase. Continued reduction in fill gas pressure increased fuel temperatures until heat transfer through mating asperity points became dominant. At pressures below approximately $1000 \mathrm{~Pa}$, the heat transfer was primarily through contact conductance, and the temperatures stabilized.

\subsection{Gas Thermal Conductivity Subcode GTHCON Listing}

A listing of the FORTRAN subcode GTHCON is presented in Table C-1.I. 


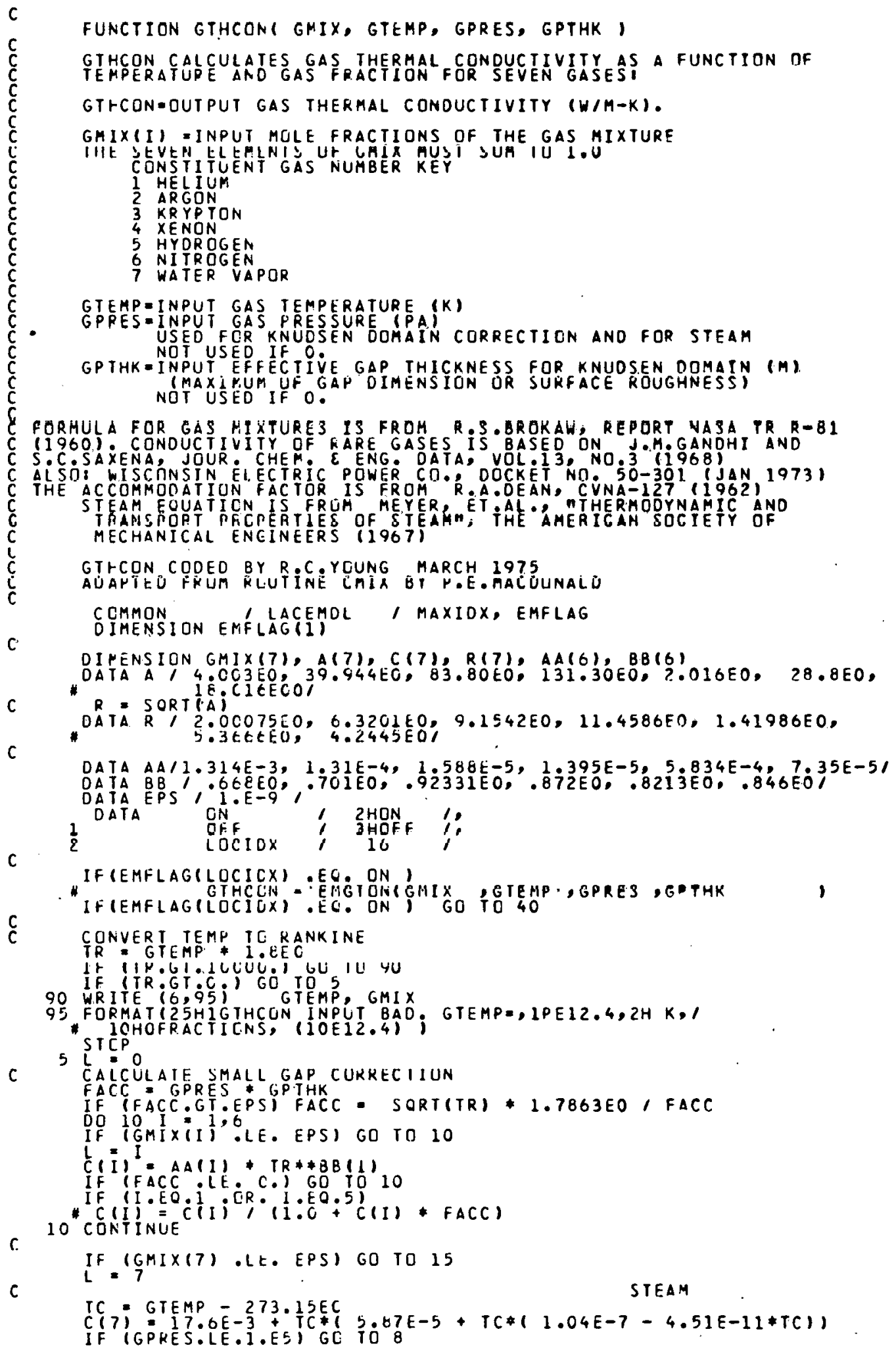




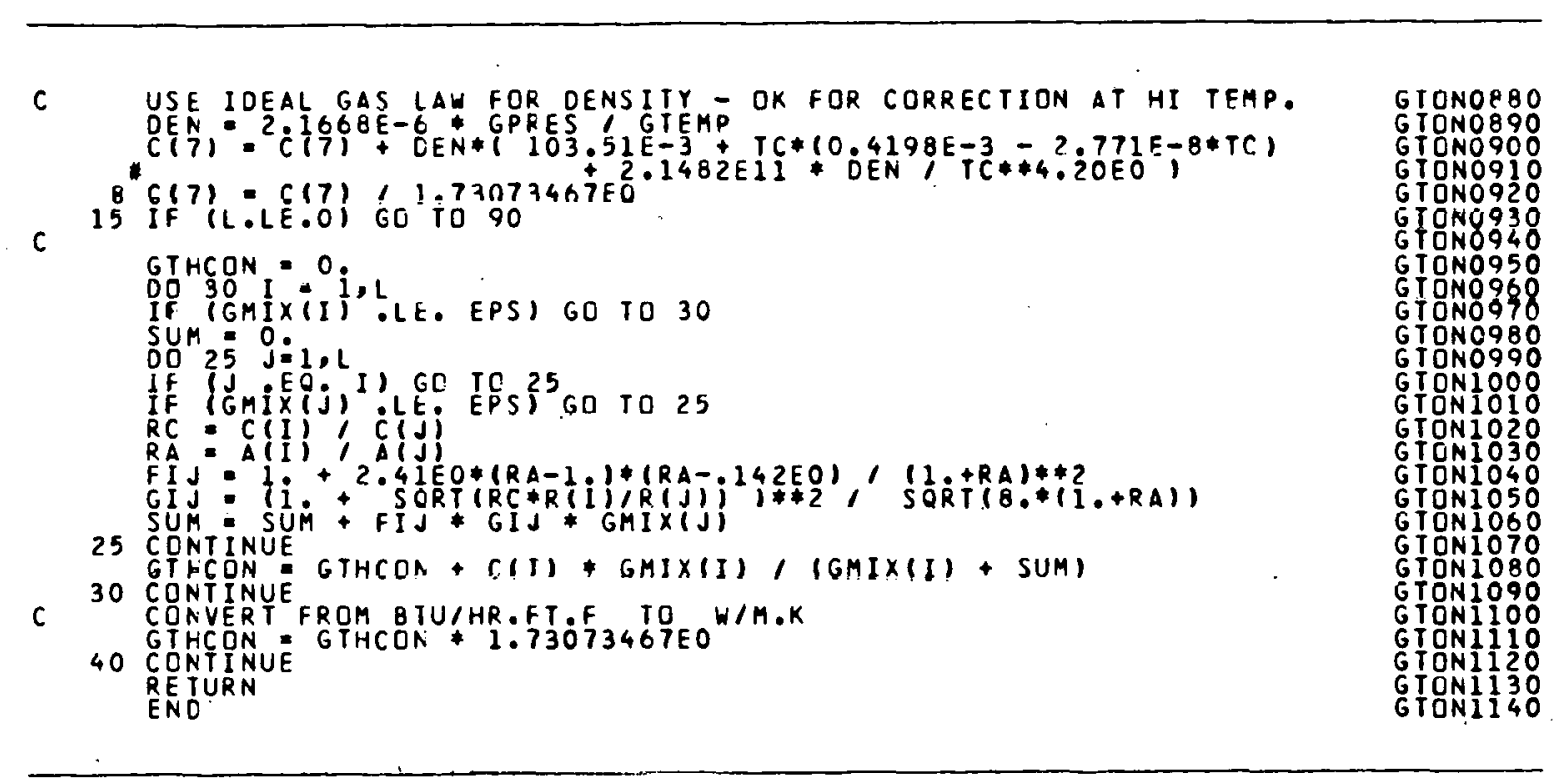

\subsection{References}

C-1.1. R. S. Brokaw, Alignment Charts for Transport Properties, Viscosity, Thermal Conductivity, and Diffusion Coefficients for Nonpolar Gases and Gas Mixtures at Low Density, Lewis Research Center, NASA-TR-R-81 (1960).

C-1.2. J. M. Gandhi and S. C. Saxena, "Correlated Thermal Conductivity Data of Rare Gases and Their Binary Mixtures at Ordinary Pressures," Joumal of Chemical and Engineering Data, 13, 3 (1968).

C-1.3. Wisconsin Electric Power Company, "Fuel Densification," Point Beach Nuclear Plant, Unit 2, Docket 50301-78 (December 1972).

C-1.4. Thermodynamic and Transport. Properties of Steam. New York: American Society of Mechanical Engineers, 1968.

C-1.5. H. Cheung, L. A. Bromley, C. R. Wilke, "Thermal Conductivity of Gas Mixtures," AIChE Journal 8 (1962) pp 221-228.

C-1.6. J. M. Davidson and J. F. Music, Experimental Thermal Conductivities of Gases and Gaseous Mix tures at Zero Degrees Centigrade, HW-29021 (July 1953).

C-1.7. R. S. Hansen, R. R. Frost, J., A. Murphy, "The Thermal Conductivity of Hydrogen-Helium Mixtures," Journal of Physical Chemistry, 68, 7 (1964) pp 2028-2029. 
C-1.8. H. L. Johnston and E. R. Grilly, "The Thermal Conductivities of Eight Common Gases Between $80^{\circ}$ and $380^{\circ} \mathrm{K}$," Journal of Chemical Physics, 14 (1946) pp 2.3.3-7.38.

C-1.9. W. G. Kannuluik and E. H. Carman, "The Thermal Conductivity of Rare Gases," Proceedings Physics Society London, B, 65 (September 1952) pp 701-709.

C-1.10. W. G. Kannuluik and L. H. Martin, "Thermal Conductivity of Fases at 0.6.," Proceedings of the Royal Society London, 144 (May 1934) pp 496-513.

C-1.11: F. F. Keyes, Project Squid, Massachusetts Institute of Technology, Cambridge, Technical Report, 37 (April 1, 1952) (as referenced in C-1.2).

C-1.12. J. M. Lcnoir and E. W. Comings. "Thermal Conductivity of Gases. Measurement at High Pressure," Chemical Engineering Progress, 47 (1951) pp 223-231.

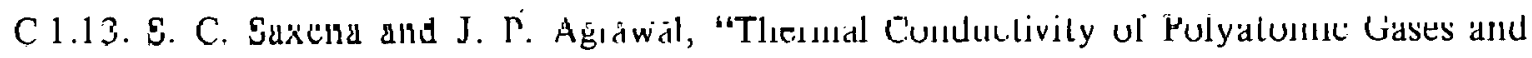
Relaxation Phenomena," .ournal of C'hemiral Physics, sh (1961) pp $2107-2113$.

C-1.14. B. N. Srivastava and A. K. Barua, "Thermal Conductivity of Binary Mixtures of Dialumic and Monnatomle Gásess," Journal of Cihemical Physics, 32 (1960) pp $429-435$.

(-1.15. Y. S. Touloukian (ed.), "Thermal Conductivity," Thermophysical Properties Research Center, Data Book, Volume 2, Chapter 1, Purdue University (1966).

C-1.16. L. B. Thomas and R. C. Golike, "A Comparative Study of Accommodation Coefficients by the l'emperature-Jump and Low-Pressure Methods and Thermal Conductivities of Helium, Neon, and Carbon Dioxide," Journal of Chemical Thysics, 2.2 (19.54) एم 300-305.

C-1.17. E. 'Thornton, "Visçosity and Thermal Conductivity of Rinary Fas Mixtures. Xenon-Krypton, X'cnon-Argon, Xenon-Neon, and Xenon-Helium," Proceedings of the Physics Society London, 76 (1960) pp 104-112; "Viscosity and Thermal Conductivity of Binary Gas Mixtures: Krypton-Argon, Krypton-Neon, and Krypton-Helium," Ibid., 77 (1961) pp 1166-1169.

C-1.18. E. Thornton and W. A. D. Baker, "Viscosity and Thermal Conductivity of Binary Gas Mixtures: Argon-Neon, Argon-Helium, and Neon-Helium," Proceedings of the Physics Society London, 80 (1962) pp 1171-1175.

C-1.19. H. von Ubisch, "The Thermal Conductivities of Mixtures of Rare Gases at $29^{\circ} \mathrm{C}$ and at $520^{\circ} \mathrm{C}, "$ Arkiv foer Fysik, 16, 7 (1959) pp 93-100. 
C-1.20. J. Wachsmuth, "Conduction of Heat in Mixtures of Argon and Helium," Physikalische Zeitschrift, 9 (April 1908) pp 235-240.

C-1.21. F. G. Waelbroech and P. Lucherbrodt, "Thermal Conductivities of Gases at Low 'Pressures. I. Monatomic Gases, Helium, and Argon," Journal of Chemical Physics, 28 (1958) pp 523-524.

C-1.22. R. E. Walker, N. deHaas, A. A. Westenberg, "New Method of Measuring Gas Thermal Conductivity," Physics of Fluids, 3 (May-June 1960) pp 482-483.

C-1.23. B. G. Dickins, "Effect of Accommodation on Heat Conduction through Gases," Proceedings of the Royal Society London, 143 (February 1934) pp 517-540.

C-1.24. W. C. Gardiner and K. L. Schafer, "Transport Phenomena in Gases and" Intermolecular Forces," Zeitschrift fur Elektrochemie, 60 (1956) pp 588-594.

C-1.25. F. G. Keyes, "Thermal Conductivity of Gases," Transactions of the American Society of Mechanical Engineers, 76 (1954) pp 809-816.

C-1.26. F. G. Keyes, "Thermal Conductivity of Gases," Transactions of the American Society of Mechanical Engineers, 77 (1955) pp 899-906.

C-1.27. K. L. Schafer and K. H. Grundler, "The Heat Transport in Quartz Power-Gas Mixtures, A Method for the Determination of the Thermal Conductivity of Gases at High Temperatures," Zeitschrift fur Elektrochemie, 63, 4 (1959) pp 449-453.

C-1.28. K. L. Schafer and F. W. Reiter, "Method for the Measurement of Heat Conductivity at $1100^{\circ} \mathrm{C}, "$ Zeitschrift fur Elektrochemie, 61 (1957) pp .1230-1235.

C-1.29. J. V. Sengers, PhD Dissertation, Amsterdam (1962) (as referenced in C-1.2).

C-1.30. B. N. Srivastava and S. C. Saxena, "Thermal Conductivity of Binary and Ternary Rare Gas Mixtures," Proceedings of the Physics Society of London, B, 70, 4 (April 1957) pp 369-378.

C-1.31. S. Weber, "Experimental Researches on the Thermal Conductivity of Gases," Annalen der Physik, 54, 4 (March 1917) pp 325-356.

C-1.32. S. Weber, "Heat Conductivity of Gases," Annalen der Physik, 82, (February 1927) pp 479-503.

C-1.33. L. S. Zaitseva, "An Experimental Investigation of the Heat Conductivity of Monatomic Gases Over Wide Temperature Intervals," Zhurnal Technicheskai Fisziki, 29, 4 (April 1959) pp 497-505. 


\section{GTHCON}

C-1.34. L. S. Zaitseva, "An Experimental Investigation of the Heat Conductivity of Monatomic Gases Over Wide Temperature Intervals," Soviet Physics - Technical Physics, 4, (April 1959) pp 444-450.

C-1.35. H. H. Landolt, Landolt-Bornstein P̈hysikalisch-Chemische Tabellen, Berlin: J. Springer, 1917.

C-1.36. A. K. Barua, "Thermal Conductivity of Eucken-Type Factor for the Binary Mixtures $\mathrm{H}-\mathrm{He}, \mathrm{H}-\mathrm{Ne}, \mathrm{H}-\mathrm{Kr}$ and $\mathrm{H}-\mathrm{Xe}$," Indian Journal of Physics, 34, 4 (1960) pp 169-183.

C-1.37. A. D. Andrew and C. S. Calvert, Thermal Conductivity and Viscosity of Neon, Helium, Argon, Xenon, and Their Binary Mixtures, General Electric Company, 'I'lD-246'36 (April 1966).

C-1.38. R. S. Brokaw, Approximate Formulas for Viscosity and Thermal Conductivity of Gas Mixtures, Lewis Research Center, NA'SA-TN-D-2502 (November 1964).

C-1.39. E. A. Mason and S. C. Saxena, "Approximate Formula for the Thermal Conductivity of Gas Mixtures," Physics of Fluids, 1, 5 (September-October 1958) pp 361-369.

C-1.40. F. J. Neugebauer, Collection of Heat-Transfer Properties of Gases at Moderate Pressures and Rules for Rapid Estimation of Missing Data, General Electric Company, 62 GL 54 (April 1962).

C-1.41. R. S. Brokaw, "Estimating Thermal Conductivities for Nonpolar Gas Mixtures Simple Empirical Method," Indian Journal of Engineering Chemistry, 47 (1955) pp 2398-2400.

C-1 42. E. A. Mason and H. von Ubisch, "Thermal Conductivities of Rare Gas Mixtures," Physics of Fluills, 3, 3 (May-Junt 1960) pp 355-361.

C-1.43. R. A. Dean, Thermal Contact Corductance Between $\mathrm{UO}_{2}$ and Zircaloy-2, Westinghouse Electric Company, CVNA-127 (May 1962).

C-1.44. E. R. G. Eckert and R. M. Drake, Analysis of Heat \& Mass Transfer, New York: McGraw-Hill Book Company, Inc., 1972.

C-1.45. F. R. Campbell and R. DesHaies, "The Effect of Gas Pressure on Fuel/Sheath Heat Transfer," Transactions of the American Nuclear Society, 21 (June 1975) p 380. 


\section{GAS VISCOSITY (GVISCO)}

Viscosity is an important parameter in describing the dynamic behavior of fluids. According to kinetic theory for a gas having a net mass motion, molecules tend to lose forward momentum due to proximity of stationary surfaces. 'l'his loss is described in terms of a viscosity, and it is pertinent to the flow of gas in a fuel-cladding gap as well as through a cladding rupture. In particular, the rate at which gas flows into the ballooning section of a fuel rod is inversely proportional to the fill gas viscosity for narrow gaps, becoming less dependent on the gas viscosity as the gap widens and flow becomes turbulent.

Bretsznajder $[C-2.1]$, Bird et al ${ }^{[C-2.2]}$, and Ilirschfelder et al ${ }^{[C-2.3]}$ have discussed in detail the functional relationships for viscosity, which in summary showed dependence on temperature, pressure, and gas composition. The formulation used in the routine GVISCO was taken from Bird et al and is

$$
\mu_{\operatorname{mix}}=\sum_{i=1}^{n} \frac{x_{i} \mu_{j}}{\sum_{j=1}^{n} x_{j} \Phi_{i j}}
$$

where

$$
\begin{aligned}
& \mu_{\text {mix }}=\text { viscosity of gas mix ture }(\mathrm{kg} / \mathrm{m} \cdot \mathrm{s}) \\
& \mathrm{n}=\text { number of chemical species in the mix ture } \\
& X_{\mathrm{i}}, X_{\mathrm{j}}=\text { the mole fractions of species } \mathrm{i} \text { and } \mathrm{j} \\
& \mu_{\mathrm{j}, \mu_{\mathrm{j}}}=\text { the viscosities of species } \mathrm{i} \text { and } \mathrm{j}(\mathrm{kg} / \mathrm{m} \cdot \mathrm{s})
\end{aligned}
$$

and $\Phi_{\mathrm{ij}}$ is a dimensionless parameter defined as

$$
\Phi_{i j}=\frac{1}{\sqrt{8}}\left(1+\frac{M_{i}}{M_{j}}\right)^{-1 / 2} \cdot\left[1+\left(\frac{\mu_{i}}{\mu_{j}}\right)^{1 / 2} \cdot\left(\frac{M_{j}}{M_{i}}\right)^{1 / 4}\right]^{2}
$$

where

$$
M_{i}, M_{j}=\quad \text { the molecular weights of species } i \text { and } j(\mathrm{~kg} / \mathrm{mol}) \text {. }
$$


The viscosity of a pure monatomic specics may be expressed as

$$
\mu_{i}=8.4411 \times 10^{-24} \frac{\sqrt{M T}}{\sigma^{2} k T / \varepsilon}
$$

where

$$
\begin{aligned}
& \mu_{\mathrm{i}} \quad=\text { viscosity of species } \mathrm{i}(\mathrm{kg} / \mathrm{m} \cdot \mathrm{s}) \\
& \mathrm{M} \quad=\text { molecular weight of species }(\mathrm{kg} / \mathrm{mol}) \\
& \sigma \quad=\text { the collision diameter }(\mathrm{m}) \\
& \mathrm{T} \quad=\text { absolute temperature }(\mathrm{K}) \\
& \epsilon \quad=\quad \text { the maximum energy of attraction between a pair of } \\
& \mathrm{k} \quad=\text { moleccules }(\mathrm{J} / \text { molecule })
\end{aligned}
$$

Bird et al states that Equations (C-2.1) through (C-2.3) are useful for computing viscosities of nonpolar gases and gas mixtures at low density from their tabulated values of the intermolecular force padaneters o and e. Figure C-2.1 shows the viscositics for threc different cases calculated from Equation (C-2.1): (a) helium only, (b) an equal molar mixture of helium and xenon, and (c) àn equal molar mixture of helium, argon, krypton, and xenon. The routine GVISCO currently allows seven gases to be considered: helium, argon, krypton, xenon, hydrogen, air, and steam. Additional nonpolar gases may be readily added to GVISCO if desired.

The viscosity of steam, $\mu_{\mathrm{s}}$, is taken from Meyer et al ${ }^{[C-2.4]}$ :

$$
\mu_{s}=\left((0.407 T=30.8) \times 10^{-7}\right)
$$

where

$$
\begin{aligned}
& \mu_{\mathrm{S}}=\text { viscosity of steam }(\mathrm{kg} / \mathrm{m} \cdot \mathrm{s}) \\
& \mathrm{T}=\text { tcmpcraturc }(\hat{\mathrm{K}}) .
\end{aligned}
$$

A density correction could be applied, but examination of tabular data indicates the correction is small at typical fuel rod temperatures.

\subsection{Gas Viscosity Subcode GVISCO Listing}

The listing of the FORTRAN subcode GVISCO used for calculating gas viscosity is presented in Table C-2.I. 


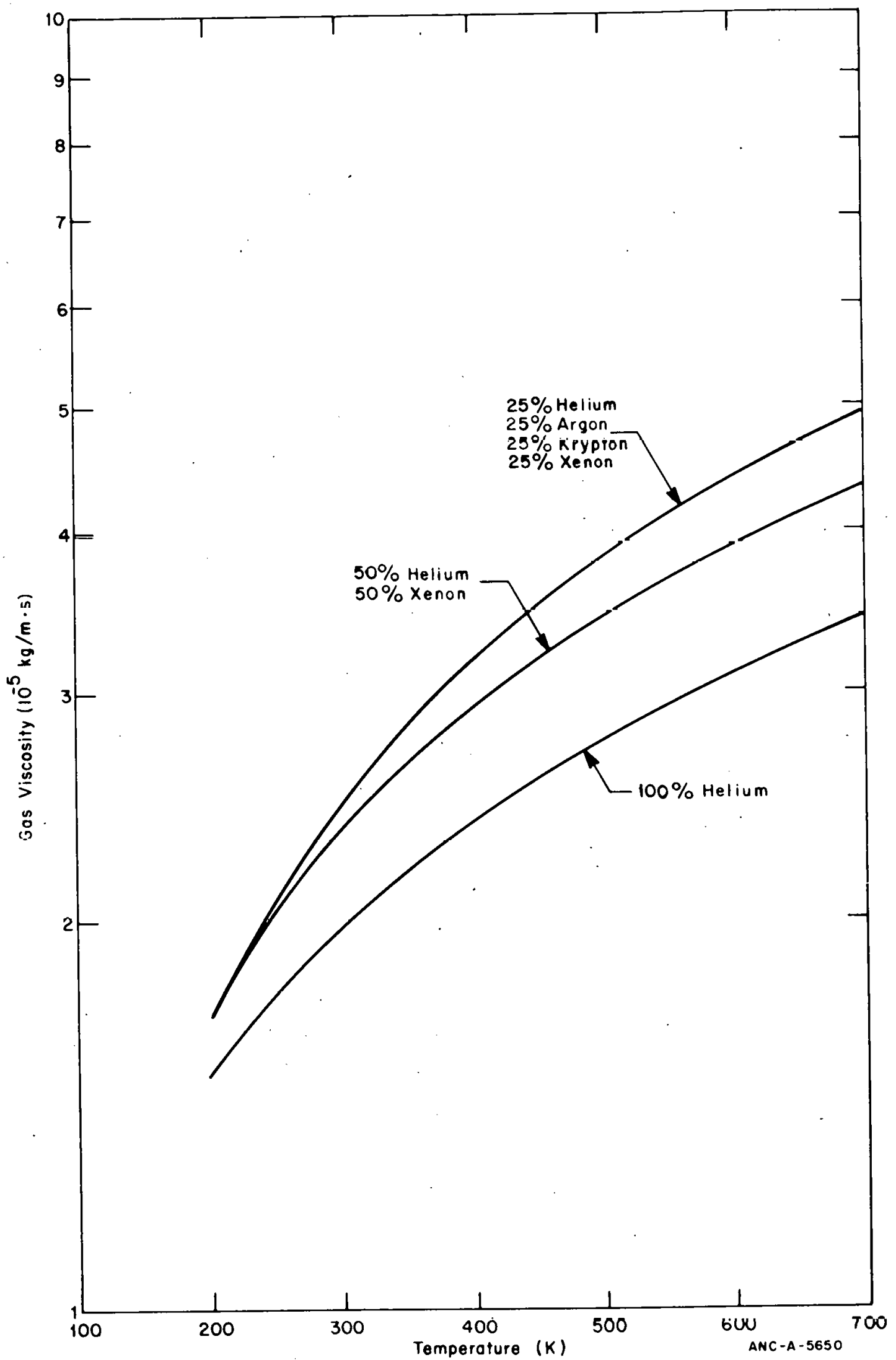

Fig. C-2.1 Gas viscosity as a function of temperature for pure helium, for a binary mixture of helium and xenon, and for an equal molar mixture of helium, argon, krypton, and xenon. 
GVISCO

TABLE C-2. I

LISTING OF THE GVISCO SUBCODE

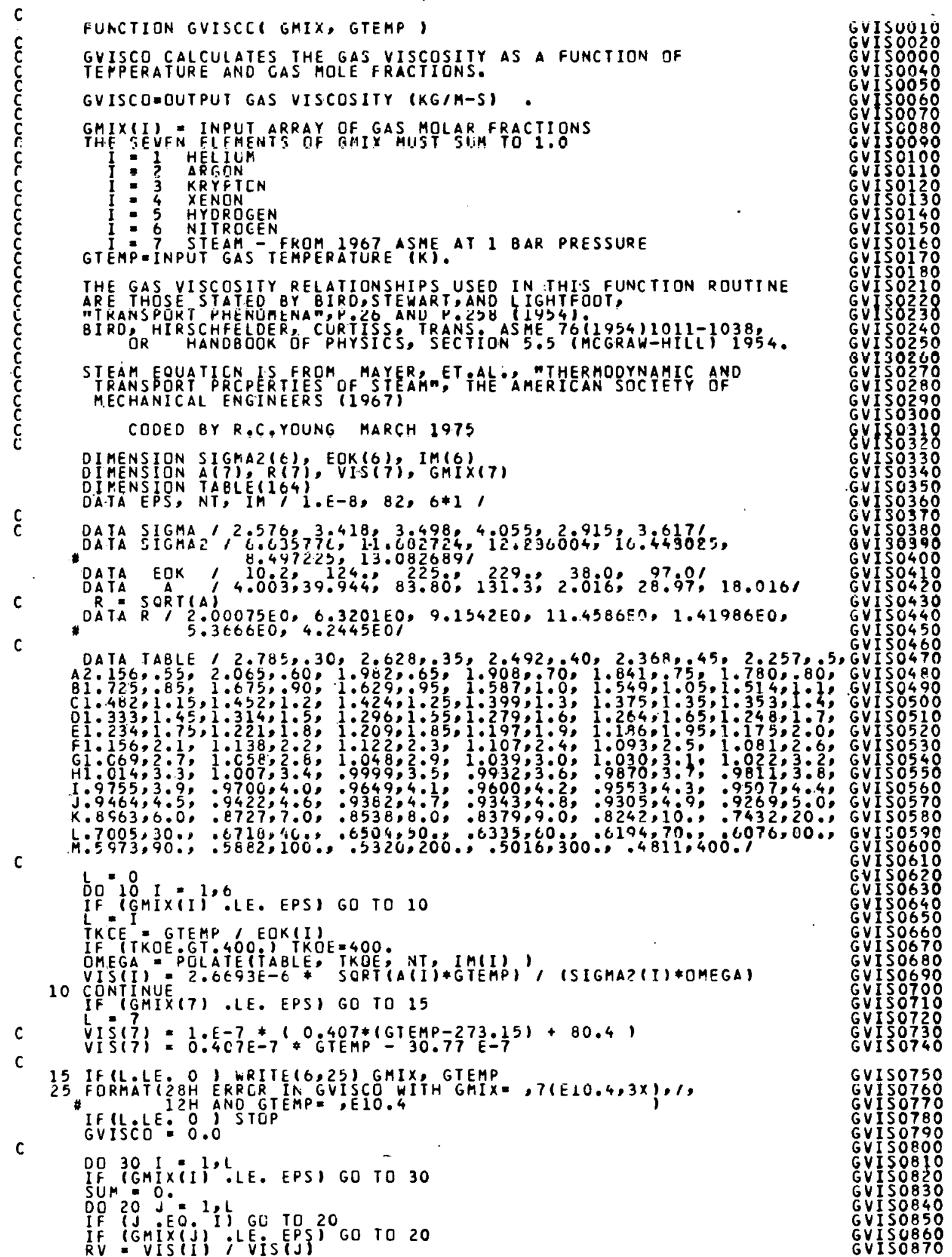




\subsection{References}

C-2.1 S. Bretsznajder, Prediction of Transport and Other Physical Propertics of Fluids, New York: Pergamon Press, 1971.

C-2.2 R. B. Bird, W. E. Stewart, E. N. Lightfoot, Transport Phenomena, New York: John Wiley \& Sons, Inc. 1954.

C-2.3 J. O. Hirschfelder, C. F. Curtiss, R. B. Bird, Molecular Theory of Gases and Liquids, New York: John Wiley \& Sons, Inc., 1954.

C-2.4 C. A. Meyer, R. B. McClintock, G. J. Silvestri, R. C. Spencer, Jr., Thermodynamic and Transport Properties of Steam, New York: The American Society of Mechanical Engineers, 1967.

\section{PHYSICAL PROPERTIES (PHYPRO)}

The routine PHYPRO returns melting temperatures and heats of fusion for $\mathrm{UO}_{2}$, $(\mathrm{U}, \mathrm{Pu}) \mathrm{O}_{2}$, and zircaloy and returns $\alpha$ to $\beta$ transformation temperatures for zirconium and zircaloy. The fuel melting temperatures are modeled as a function of burnup and plutonium content.

\section{$3.1 \mathrm{UO}_{2}$ and $(\mathrm{U}, \mathrm{Pu}) \mathrm{O}_{2}$ Melting Point}

The melting point of unirradiated $\mathrm{UO}_{2}$ has been measured by several investigators with varying results. Brassfield et al[C-3.โ] and Lyons et al[C-3.2] have published compilations and discussions of several recent experimental results and have listed "best" value $\mathrm{UO}_{2}$ melting points of 3113 and $3133 \pm 15 \mathrm{~K}$, respectively, for burnups less than $10000 \mathrm{MWd} / \mathrm{MtU}$. 'l'he routine PHYPRO uses Brassfield's et al recommendation of $3113 \mathrm{~K}$ for the melting temperature of unirradiated $\mathrm{UO}_{2}$.

Lyon and Baily $[\mathrm{C}-3.3]$ determined the phase diagram for stoichiometric $(\mathrm{U}, \mathrm{Pu}) \mathrm{O}_{2}$ mixed oxides. The temperature data for the solidus and for the liquidus boundaries were fit 
by least squares techniques to a parabolic equation and these results are given for the solidus and liquidus boundaries by Equations (C-3.1) and (C-3.2), respectively:

$$
\begin{aligned}
& T(\text { solidus })=3113=5.414 c 17.468 \times 10^{-3} c^{2} \\
& T(1 \text { iquidus })=3113-3.219 c-1.449 \times 10^{-2} c^{2}
\end{aligned}
$$

where

$$
\begin{aligned}
& \mathrm{C}=\text { the mole percent of } \mathrm{PuO}_{2} \\
& \mathrm{~T}=\text { temperature }(\mathrm{K}) .
\end{aligned}
$$

The solidus curve is used for the melting point of mixed oxides and the difference between the liquidus and solidus boundaries defines the temperature range in which solid and liquid coexist. Figure C-3.1 shows the solidus and liquidus boundaries.

Christensen [ $\left[-3.4, C^{-}-3.5\right]$ established that the melting point of his $\mathrm{UO}_{2}$ samples decreased with fuel burnup. The largest decrease measured by Christensen was about $32 \mathrm{~K}$ per $10000 \mathrm{MWd} / \mathrm{MtM}$. Krankota and Craig $[\mathrm{C}-3.6]$ have also reported a 50 to $100 \mathrm{~K}$ decrease in the melting point of irradiated mixed oxide test samples for burnups between 55000 and $85000 \mathrm{MWd} / \mathrm{MtM}$. However, these results are not in accord with those of Reavis and Green $[\mathrm{C}-3.7]$ who reported no significant reduction in the melting point of $\mathrm{UO}_{2}$ due to irradiation. Since a fission event results in the accumulation of cationic fission products together with some liberation of oxygen, a lowering of the melting point of $\mathrm{UO}_{2}$ during irradiation is expected. Therefore following Christensen, the melting point of $\mathrm{UO}_{2}$ and mixed oxides is decreased $32 \mathrm{~K}$ per $10000 \mathrm{MWd} / \mathrm{MtM}$ in PHYPRO.

\section{$\overline{3} . \overline{\mathrm{UO}} \mathrm{U}_{2}$ and $(\mathrm{U}, \overline{\mathrm{Pu}}) \overline{\mathrm{O}}_{2}$ Ileat of Tiusion}

The two calorimetrically determined values for the heat of fusion of unirradiated $\mathrm{UO}_{2}$ are in good agreement. Specifically, Hein and Flagella $[\mathrm{C}-3.8]$ measured a $\mathrm{UO}_{2}$ heat of fusion of $16 \pm 2 \mathrm{~kJ} / \mathrm{mol}$ and Leibowitz et al $[\mathrm{C} 3.9]$ reported a value of $74 \mathrm{~kJ} / \mathrm{mol}$. 'l'hese results suggest that the heat of fusion of unirradiated $\mathrm{UO}_{2}$ is adequately known from present analyses. The routine PHYPRO uses Leibowitz's et al calorimetry value of $2.74 \times 10^{5} \mathrm{~J} / \mathrm{kg}$ for the heat of fusion of $\mathrm{UO}_{2}$.

Leibowitz et al ${ }^{[\mathrm{C}-3.10]}$ determined a heat of fusion for mixed oxides of $67 \mathrm{~kJ} / \mathrm{mol}$ from three tests. This $10 \%$ agreement between $\mathrm{UO}_{2}$ and mixed oxide values for the heat of fusion is quite reasonable because of the similarity in crystal structure and atomic bonding. Therefore, unless conflicting data become available, the $\mathrm{UO}_{2}$ value will be used for the heat of fusion of mixed oxides. 


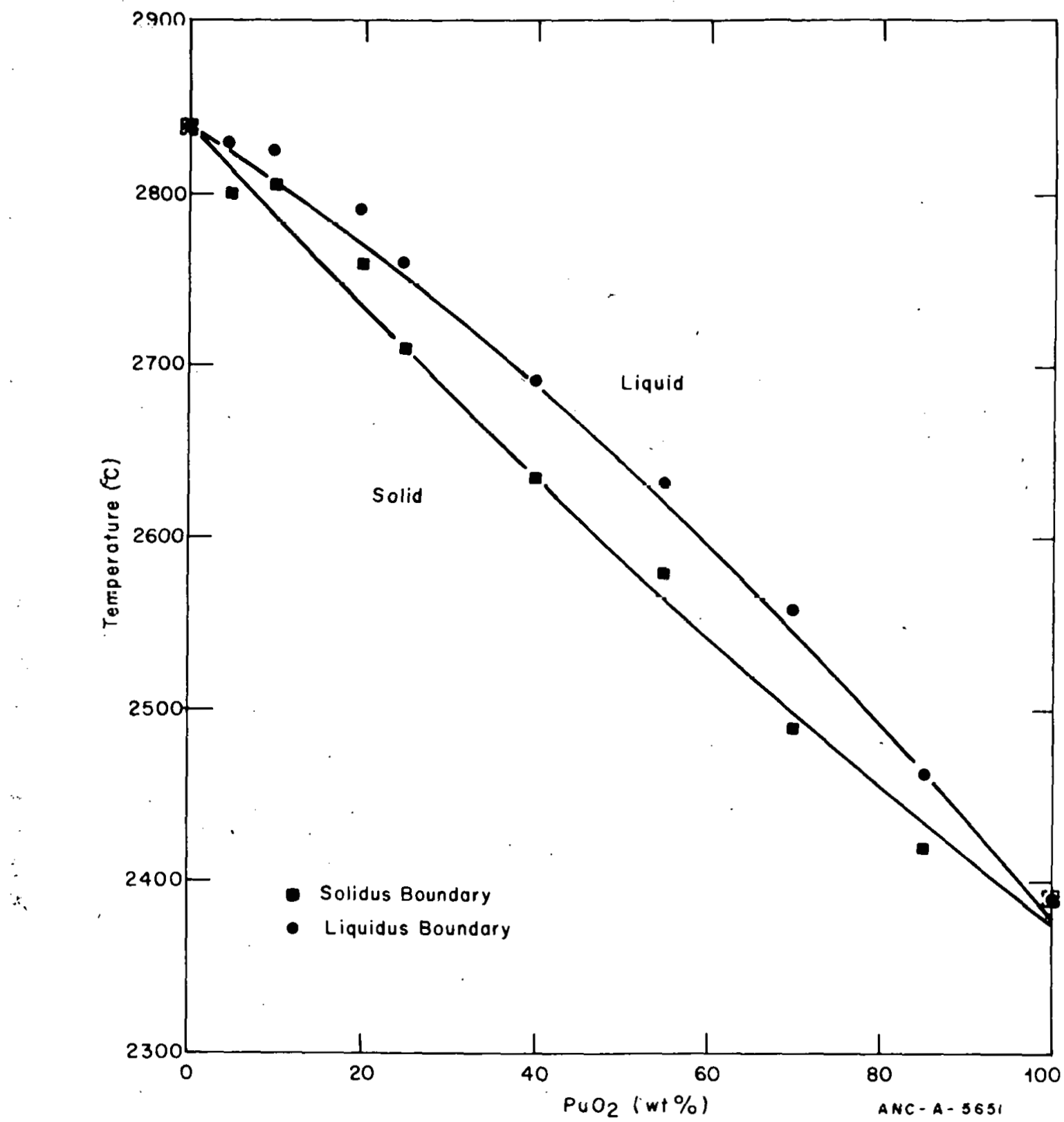

Fig. C-3.1 Phase diagram for stoichiometric mixed uranium-plutonium oxides.

\subsection{Zircaloy Melting Point and Transformation Temperatures}

The reported melting point of zircaloy is below that reported for unalloyed zirconium. The addition of tin lowers the zirconium melting point [C-3.11], and small amounts of iron, nickel, or chromium decrease the solidus temperatures of a binary mixture about $70 \mathrm{~K}$ for each $0.1 \%$ addition of solute ${ }^{[\mathrm{C}-3.12]}$. These results are for the binary mixtures of zirconium and one solute: tin, iron, chromium, or nickel. In the five component zircaloy system, the effect of each solute may not be additive, and therefore a separate determination is required. The zircaloy- 2 melting point has been measured to be about $2098 \mathrm{~K}$, and this value is returned by PHYPRO. 
Pure zirconium isothermally transforms from the $\alpha$ phase to the $\beta$ phase at $1135 \mathrm{~K}^{[\mathrm{C}-3.13]}$. The routine PHYPRO returns $1135.15 \mathrm{~K}$ for the zirconium transformation temperature when the variable CTRANZ is called. Zircaloy, however, undergoes the same transformation over a range of temperatures. PHYRRO returns the variable CTRANB for the beginning of the $\alpha-\beta$ transformation $(1083.15 \mathrm{~K})$ and the variable CTRANE for the end of the $\alpha-\beta$ transformation $(1243.15 \mathrm{~K})^{[\mathrm{C}-3.14]}$.

\subsection{Zircalny Hrat of Fusion}

The heat of fusion of zircaloy will depend to some extent on its composition and the extent of oxidization. Brassfield et al has suggested that the heat of fusion of zircaloy-4 differs little from that of zirconium and lists the heat of fusion of zirconium as $20.5 \mathrm{~kJ} / \mathrm{mol}$. However, Quill[ $\left[\mathrm{C}^{-3.15]}\right.$ lists the heat of fusion of zirconium as $23 \mathrm{~kJ} / \mathrm{mol}$ with uncertainty. The routine PHYPRO returns Brassfield's et al listed heat of fusion for zirconium of $2.2 .5 \times 10^{5} \mathrm{~J} / \mathrm{kg}$ when called.

\subsection{Physical Properties Subcode PHYPRO Listing}

The FORTRAN-subcude PHY'PRO is listed in Table C-3.I.

\section{$3.6 \underline{\text { References }}$}

C-3:1: H: C. Brassfield, J. F. White, L. Sjodahl, J. T. Bittle, Recommended Property and Reactor Kinetics Data for Use in Evaluating a. Light-Water-Cooled Reactor. Loss-of-Coolant Incident Involving Zircaloy-4 of 304-SS-Clad $\mathrm{UO}_{2}$, GEMP-482 (April1968).

C-3.2. M. F. Lyons et al, " $\mathrm{UO}_{2}$ Properties Affecting Performance," Nuclear Engineering. and Design, 21 (1972) p 167.

G-3.3. W. L. Lyon and W. E. Baily, "The Solid-Liquid Phase Diagram for the $\mathrm{UO}_{2}-\mathrm{PuO}_{2}$ System," Joumal of Nuclaar Maturials, 33332 (1967).

C-3.4. J.. A. Chrịstensen, Radiation Effects on $\mathrm{UO}_{2}$ Melting, HW-69234, (March 1962).

C-3.5: J. A: Christensen, R. J. Allio, A. Biancheria, Melting Point of Irradiated Uranium Dioxide, WCAP-6065 (1965).

C-3.6. J. L. Krankota and C. N. Craig, "Melting Point of High Burnup $\mathrm{PuO}_{2}-\mathrm{UO}_{2}$," Transactions of the American Nuclear Society, 11132 (1968).

C-3.7. J. G. Reavis and J. L. Green, "Transformation Temperatures of Irradiated $\mathrm{UO}_{2}-\mathrm{PuO}_{2}$ Fast Reactor Fuels," Transactions of the American Nuclear Society, 14 $593(1971)$. 
TABLE C-3.I

LISTING OF THE PHYPRO SUBCODE

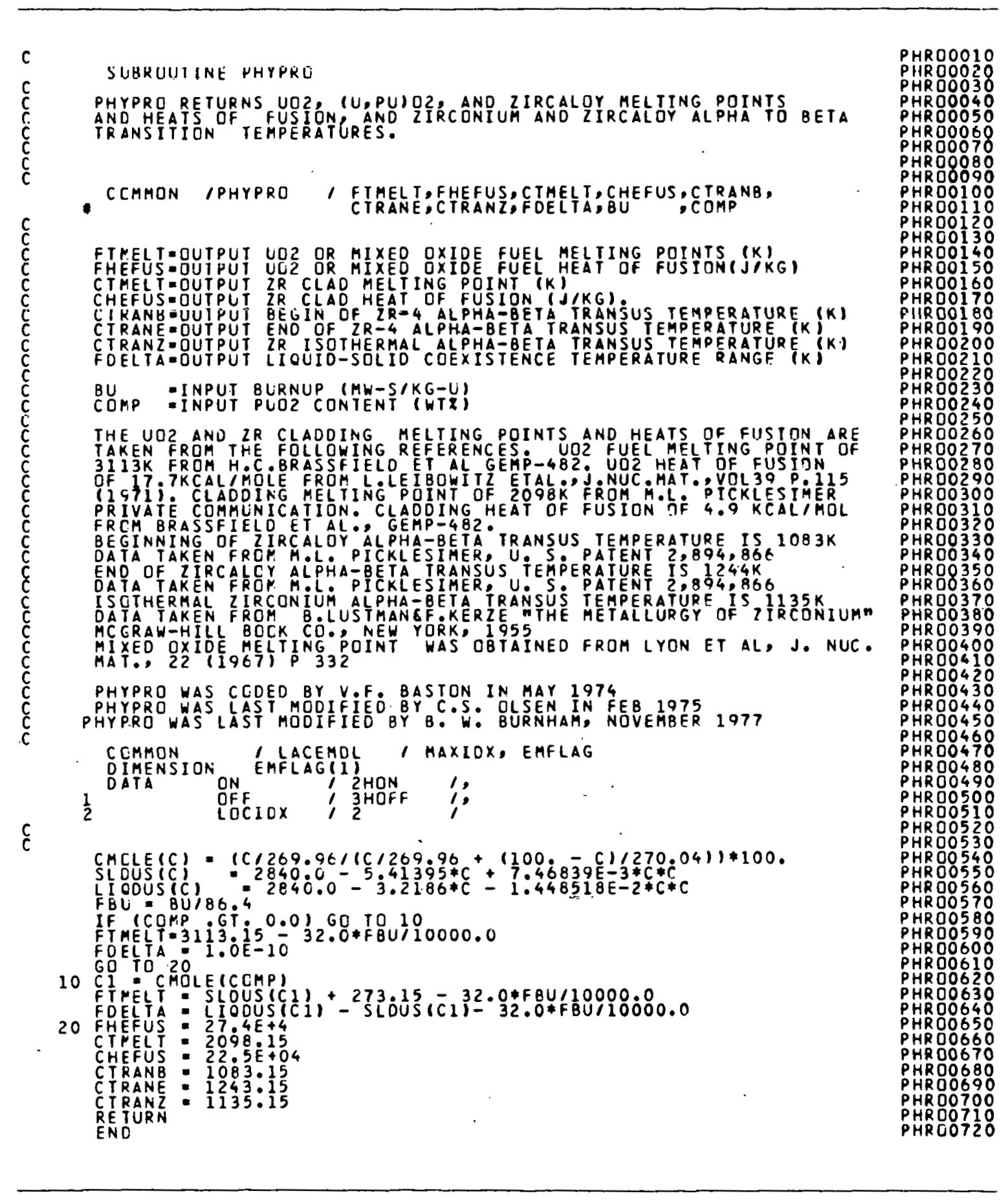


C-3.8. R. A. Hein and P. N. Flagella, Enthalpy Measurements of $\mathrm{UO}_{2}$ and Tungsten to 3,260 $\mathrm{K}$, GE-NMPO-578 (February 1968).

C-3.9. L. Leibowitz, M. G. Chasanov, L. W. Mishler, D. F. Fischer, "Enthalpy of Liquid Uranium Dioxide to 3,500 K," Journal of Nuclear Materials, 39 (1971) p 115.

C-3.10. L. Leibowitz, D. F. Fischer, M. G. Chasanov, Enthalpy of:Molten UraniumPlatonium Oxide. ANI-8082, (February 1975).

C-3.1 1. D. J. McPherson and M. Hansen, "The System Zirconium-Tin," Transactions of the American Society for Metals, 45, 915 (1953).

C-3.12. E. T. Hayes, A. II. Roberson, O. G. Paasche, "Thc Zirconium-Nickel Phase Diagram," I'ransactions of the Amertcan S'ociety for Metals, 45, 893 (1953).

C-3.13. B. Lustman and F. Kerze, The Metallurgy of Zirconium, New York: McGraw-Hill Book Company, Inc., 1955.

C-3.14. M. L. Picklesimer, "Method of Annealing and Rolling Zirconium-Base Alloys," U.S. Patent 2,894;866 (July 14, 1959).

C-3:15: L. L. Quill; Chernistry and Metallurgy of Miscellanious Materials, Thermodynamic, National Nuclear.Energy Series, IV, 19B, New York: McGraw-Hill Book Company, Inc., 1950. 


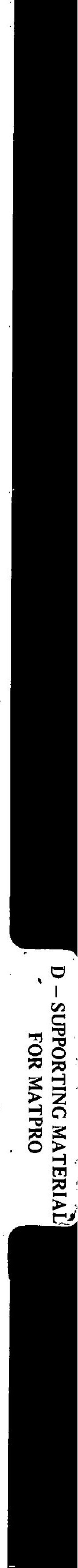


APPENDIX D

SUPPORTING MATERIAL FOR MATPRO 
THIS PAGE WAS INTENTIONALLY LEFT BLANK 


\section{APPENDIX D}

\section{SUPPORTING MATERIAL FOR MATPRO}

This Appendix contains a list of input and output arguments for each of the MATPRO subcodes, the base and derived SI units used in MATPRO, and the linear interpolation routine (POLATE).

\section{INPUT-OUTPUT ARGUMENTS OF MATPRO SUBCODES}

Input and output arguments for each of the MATPRO subcodes are given in Table D-1.I. This description provides a summary of the FORTRAN subcodes that are described in detail in Appendixes A, B, and C. 


\section{TABLE D-1. I}

IMPUT-OUTPUT ARGUPENTS OF MATPRO SUBCODES

Subcode

Fuel Subcodes

Fuel Specific Heat

Capacity (FCP)

w

Fuel Thermal

Conductivity (FTHCON)
Agruments $\quad I / 0^{[a]}$

\begin{tabular}{|c|c|c|}
\hline TENP & I & Fuer temperature $(K)$ \\
\hline FACHOT & I & Fuel fraction that is molten: FACMOT $=1$ for all \\
\hline 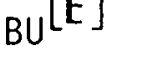 & I & Burnuf of uranium $[(\mathrm{MWs}) / \mathrm{kg}]$ \\
\hline MF & I & Plutorium oxide content (wt\%) \\
\hline$C P$ & 0 & Specific heat capacity $[\mathrm{J} /(\mathrm{kg} \cdot \mathrm{k})]$ \\
\hline ENP & I & Fuel temperature $(\mathrm{K})$ \\
\hline NINP & I & Conductivity integral ( $w / m)$ \\
\hline ALEN & I & $\begin{array}{l}\text { Fractional fuel density -- ratio of actual density } \\
\text { to theoretical density }\end{array}$ \\
\hline & I & $\mathrm{P}^{-}$utor um oxide content in the fuel (wt $\%$ ) \\
\hline & I & Burnuf of urarium $[($ MWs. $) / \mathrm{kg}]$ \\
\hline & 0 & Fuei thermal conductivity $(W / m \cdot K)$. \\
\hline
\end{tabular}

Description 
TABLE D-1.I (continued)

\begin{tabular}{|c|c|c|c|}
\hline Subcode & Arguments & $1 / 0^{[\mathrm{a}]}$ & Description \\
\hline \multirow{3}{*}{$\begin{array}{l}\text { Fuel Subcodes (continued) } \\
\text { Fuel Thermal Conductivity } \\
\text { (FTHCON) (continued) }\end{array}$} & & & \\
\hline & CONINT & 0 & $\begin{array}{l}\text { Integral of thermal conductivity with respect to } \\
\text { temperature }(\mathrm{W} / \mathrm{m})\end{array}$ \\
\hline & CONINV & 0 & $\begin{array}{l}\text { Temperature as a function of the integral of the } \\
\text { thermal conductivity }(K)\end{array}$ \\
\hline \multirow{2}{*}{$\begin{array}{l}\text { Fuel Emissivity } \\
\text { (FEMISS) }\end{array}$} & FTEMP & I & Fuel temperature $(K)$ \\
\hline & FEMISS & 0 & Fuel emissivity (unitless) \\
\hline \multirow{3}{*}{$\begin{array}{l}\text { Fuel Thermal } \\
\text { Expansion (FTHEXP) }\end{array}$} & FTEMP. & I & Fuel temperature $(k)$ \\
\hline & FACMOT & I & Fraction of fuel malten: FACMOT $=1$ for all fuel \\
\hline & $\mathrm{BU}^{[\mathrm{b}]}$ & I & $\begin{array}{l}\text { molten, FACMOT }=0 \text { for all fuel solic } \\
\text { Burnup of uranium }[(\mathrm{MWs} / \mathrm{kg})]\end{array}$ \\
\hline & COMP & I & Plutonium oxide coritent in the fuel (wt\%) \\
\hline . & FTHEXP & 0 & Fuel thermal expansion (unitless! \\
\hline \multirow[t]{2}{*}{$\begin{array}{l}\text { Fuel Elastic } \\
\text { Modulus (FELMOD) }\end{array}$} & FTEMP' & I & Fuel temperature $(k)$ \\
\hline & FRADEN & I & $\begin{array}{l}\text { Fractional fuel density -- ratio of actual density } \\
\text { to theoretical density }\end{array}$ \\
\hline
\end{tabular}

[a] I/0 distinguishes between input and output arguments.

[b] Used to call the fuel melting temperature from PHYPRO. 
TABLE D-1.I (coritinued)

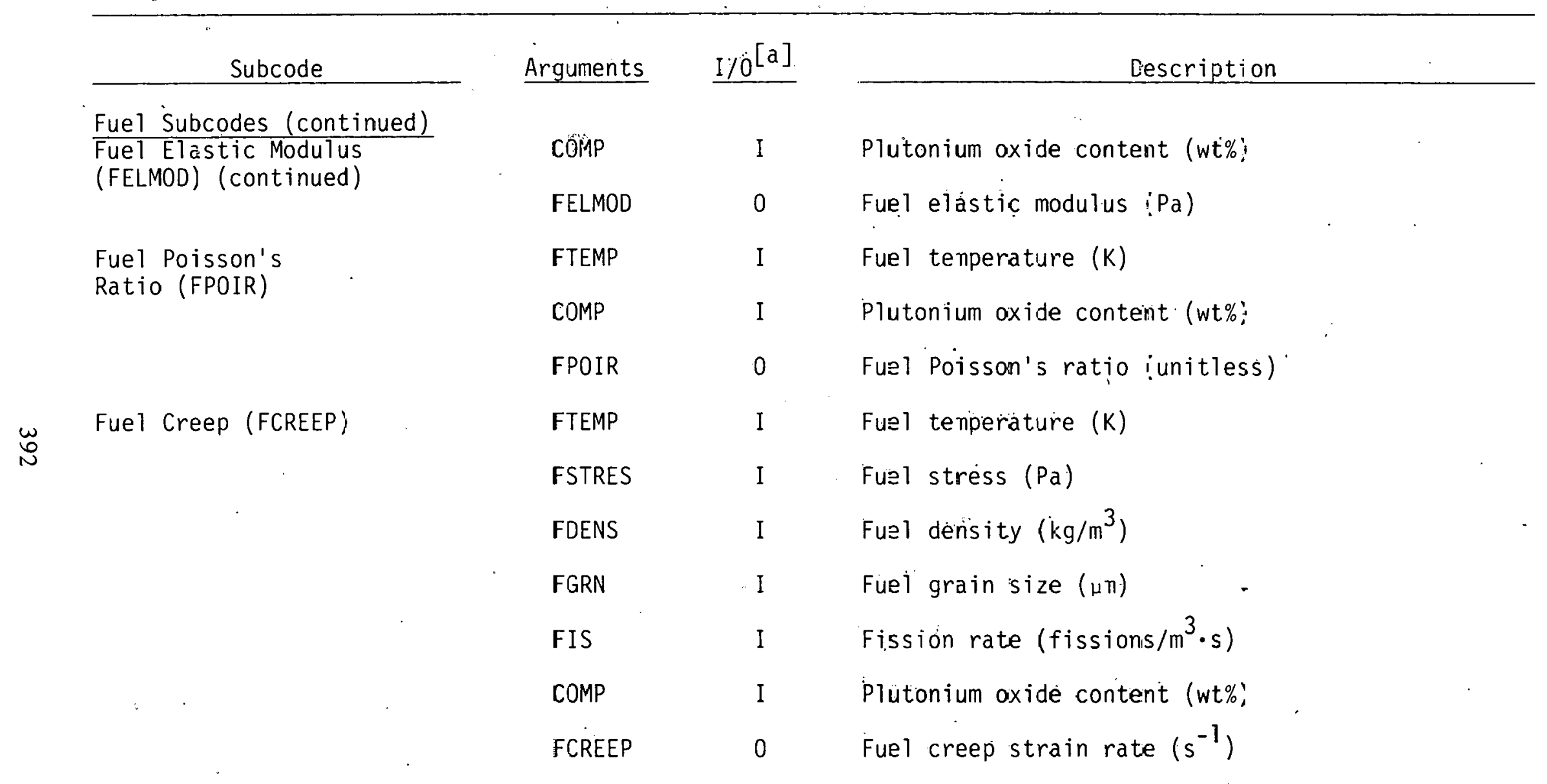

[a] I/0 distinguishès between input and output arguments: 
TABLE D-1.I (continued)

\begin{tabular}{|c|c|c|c|}
\hline Subcode & Arguments & $1 / 0^{[\mathrm{a}]}$ & Description \\
\hline \multirow{3}{*}{$\begin{array}{l}\text { Fuel Subcodes (continued) } \\
\text { Fuel Fracture Strength } \\
\text { (FFRACS) }\end{array}$} & FTEMP & I & Fuel temperature $(K)$ \\
\hline & FRADEN & I & $\begin{array}{l}\text { Fractional fuel density -- ratio of actual density } \\
\text { to theoretical density }\end{array}$ \\
\hline & FFRACS & 0 & $\mathrm{UO}_{2}$ fracture strength $(\mathrm{Pa})$ \\
\hline \multirow{3}{*}{$\begin{array}{l}\text { Fuel Swelling } \\
\text { (FSWELL) }\end{array}$} & FTEMP & I & Fuel centerline temperature $(K)$ \\
\hline & BU & I & Burnup of uranium $\left(10^{26}\right.$ fissions $\left./ \mathrm{m}^{3}\right)$ \\
\hline & F́SWELL & 0 & Volume increase of fuel (\%) \\
\hline \multirow{7}{*}{$\begin{array}{l}\text { Integration of Fuel } \\
\text { Swelling and Densification } \\
\text { (CONECT) }\end{array}$} & FTEMP & I & Fuel temperature $(\mathrm{K})$ \\
\hline & FTEMPC & I & Fuel centerline temperature $(K)$ \\
\hline & BU & I & Burnup of fuel $[(\mathrm{MWs}) / \mathrm{kg}]$ \\
\hline & FDENS & I & Fuel density $\left(\mathrm{kg} / \mathrm{m}^{3}\right)$ \\
\hline & RSNTR & $\mathrm{I}$ & Maximum possible density change $\left(\mathrm{kg} / \mathrm{m}^{3}\right)$ \\
\hline & TSINT & I & Fuel sintering temperature $(K)$ \\
\hline & COMP & $\mathrm{I}$ & Plutonium oxide content (wt\%) \\
\hline
\end{tabular}

[a] I/0 distinguishes between input and output arguments. 
TABLE D-1.I (continued)

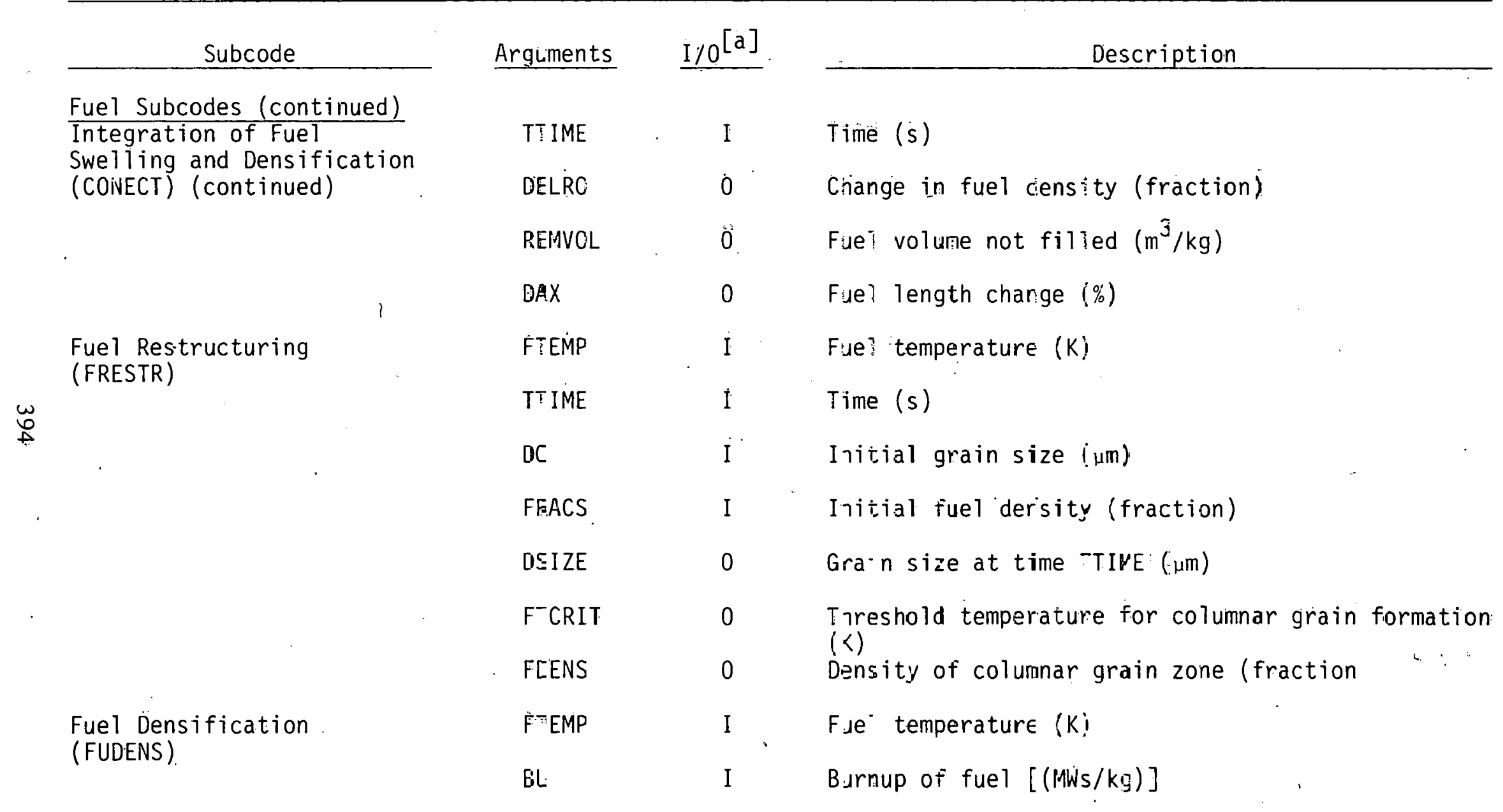

[a] I/0 distinguishes between input anc: output arguments. 
TABLE D-1.I (continued)

\begin{tabular}{|c|c|c|c|}
\hline Subcode & Arguments & $\mathrm{I} / 0^{[\mathrm{a}]}$ & Description \\
\hline \multirow{6}{*}{$\begin{array}{l}\text { Fuel Subcodes (continued) } \\
\text { Fuel Densification } \\
\text { (FUDENS) (continued) }\end{array}$} & FDENS & I & Fuet density $\left(\mathrm{kg} / \mathrm{m}^{3}\right)$ \\
\hline & RSINTR & I & Maximur possible dersity change $\left(\mathrm{kg} / \mathrm{m}^{3}\right)$ \\
\hline & TSINT & I & Fuel sintering temperature $(K)$ \\
\hline & COMP & I & Plutonium oxide content (wtor) \\
\hline & TTIME & I & Time (s) \\
\hline & FUDENS & 0 & Fuel dimensional change $(\%)$ \\
\hline \multirow{4}{*}{$\begin{array}{l}\text { Fission Gas Release } \\
\text { (FGASRL) }\end{array}$} & FTEMP & I & Fuel temperature ( $K$ : \\
\hline & FRADEN & I & $\begin{array}{l}\text { Fractional fuel density -- ratio of actual density } \\
\text { to theoretical density }\end{array}$ \\
\hline & TT.IME & I & Time $(s)$ \\
\hline & FGASRL & 0 & Fraction of fission gas generated which is released \\
\hline \multirow{3}{*}{$\begin{array}{l}\text { Cesium and Iodine } \\
\text { Release (CESIOD) }\end{array}$} & FTEMP & I & Fuel temperature ( $k !$ \\
\hline & FTMAX & I & Maximum previous temperature $(K)$ \\
\hline & BU & I & Burnup at step end $(M W s / \mathrm{kg} \cdot \operatorname{metal})$ \\
\hline
\end{tabular}

[a] I/O distinguishes between input and output arguments. 
TABLE D-1.I (con:inued)

\begin{tabular}{|c|c|c|c|}
\hline Subcode & Arguments & $\underline{I / 0^{[a]}}$ & Description \\
\hline \multirow{3}{*}{$\begin{array}{l}\text { Fuel Subcodes (continued) } \\
\text { Cesium and Iodine } \\
\text { Release (CESIOD) (continued) }\end{array}$} & & & \\
\hline & TELBU & I & Burnup during step (MWs $/ \mathrm{kg} \cdot$ metal) \\
\hline & COMP & I & Plutonium oxide content (wt\%) \\
\hline$\cdot$ & FRADEN & I & $\begin{array}{l}\text { Fractional fuel density -- ratio of actual density } \\
\text { to theoretical density }\end{array}$ \\
\hline e & TIME & I & Time at temperature at step end (s) \\
\hline & DTIME & I & Duration of step (s) \\
\hline . & FTMAX & 0 & Maximum temperature at end of step (s) \\
\hline & $\mathrm{F} 0 \mathrm{ID}(1)$ & 0 & Net specific release $o^{=}$iodine ( $\mathrm{kg}$ iodine/ $\mathrm{kg}$ fuel) \\
\hline & $3010(2)$ & 0 & Net specific release $0^{=}$Iodine $-127\left(\mathrm{~kg}{ }^{127}[/ \mathrm{kg}\right.$ fuel \\
\hline ' & $\therefore 0 \mathrm{ID}(3)$ & 0 & Net specific release o: Iodine-129 $\left(\mathrm{kg}^{129} \mathrm{l} / \mathrm{kg}\right.$ fuel $)$ \\
\hline & $9010(4)$ & $\cdot 0$ & Net specific release $0=$ Iodine $-131\left(\mathrm{~kg}{ }^{131}[/ \mathrm{kg}\right.$ fuel $)$ \\
\hline & $\because 0 I D(5)$ & 0 & Net specific release $0=$ Iodine $-132\left(\mathrm{~kg}^{132}[/ \mathrm{kg}\right.$ fuel $)$ \\
\hline r & $\bar{ت} 0 \operatorname{ID}(6)$ & 0 & Net specific release $\mathrm{o}=$ Iodine $-133\left(\mathrm{~kg}{ }^{133} \mathrm{I} / \mathrm{kg}\right.$ fue $\left.\mathrm{l}\right)$ \\
\hline & $\because 0 I D(7)$ & 0 & Net specific release $0=$ Iodine $-134\left(\mathrm{~kg}{ }^{134} \mathrm{l} / \mathrm{kg}\right.$ fuel $)$ \\
\hline
\end{tabular}

[a] I/0 distinguishes between inp's and output arguments. 
TABLE D-1.I (continued)

\begin{tabular}{|c|c|c|c|}
\hline Subcode & Arguments & $\mathrm{I} / 0^{[\mathrm{a}]}$ & Description \\
\hline \multirow{6}{*}{$\begin{array}{l}\text { Fuel Subcodes (continued) } \\
\text { Cesium and Iodine } \\
\text { Release (CESIOD) (continued) }\end{array}$} & $\operatorname{ROID}(8)$ & 0 . & Net specific release of Iodine-135 $\left(\mathrm{kg}{ }^{135} \mathrm{I} / \mathrm{kg}\right.$ fuel $)$ \\
\hline & $\operatorname{cs}(1)$ & 0 & Net specific release of Cesium ( $\mathrm{kg}$ cesium $/ \mathrm{kg}$ fuel) \\
\hline & $\operatorname{cs}(2)$ & 0 & Net specific release of Cesium-133 $\left(\mathrm{kg}{ }^{133} \mathrm{Cs} / \mathrm{kg}\right.$ \\
\hline & $\operatorname{cs}(3)$ & 0 & $\begin{array}{l}\text { Net specific release of Cesium-135 }\left(\mathrm{kg}{ }^{135} \mathrm{Cs} / \mathrm{kg}\right. \\
\text { fuel) }\end{array}$ \\
\hline & $\operatorname{cs}(4)$ & 0 & $\begin{array}{l}\text { Net specific release of Cesium-137 ( } \mathrm{kg}{ }^{13 /} \mathrm{Cs} / \mathrm{kg} \\
\text { fuel) }\end{array}$ \\
\hline & $\operatorname{CS}(5)$ & 0 & $\begin{array}{l}\text { Net specific release of Cesium-138 }\left(\mathrm{kg}{ }^{100} \mathrm{Cs} / \mathrm{kg}\right. \\
\text { fuel) }\end{array}$ \\
\hline \multicolumn{4}{|l|}{ Cladding Subcodes } \\
\hline \multirow{2}{*}{$\begin{array}{l}\text { Cladding Specific Heat } \\
\text { Capacity (CCP) }\end{array}$} & CTEMP & I & Cladding temperature $(\mathrm{K})$ \\
\hline & CCP & 0 & Cladding specific heat capacity $[\mathrm{J} /(\mathrm{kg} \cdot \mathrm{K})]$ \\
\hline \multirow{3}{*}{$\begin{array}{l}\text { Effect of Hydride } \\
\text { Solution on Cladding } \\
\text { Sepcific Heat (CHSCP) }\end{array}$} & CTEMP & I & Cladding temperature $(K)$ \\
\hline & PPMHYD & I & Concentration of hydrogen in the cladding ( $\mathrm{ppm})$ \\
\hline & CHSCP & 0 & $\begin{array}{l}\text { Addition to specific heat because of hydrides } \\
{[\mathrm{J} /(\mathrm{kg} \cdot \mathrm{K})]}\end{array}$ \\
\hline
\end{tabular}

[a] I/0 distinguishes between input and output arguments. 
TABLE D-1. I (continLEd)

\begin{tabular}{|c|c|c|c|}
\hline Subcode & Arguments & $1 / 0^{[\mathrm{a}]}$ & Description \\
\hline \multirow{4}{*}{$\begin{array}{l}\text { Cladding Subcodes (continued) } \\
\text { Cladding Thermal } \\
\text { Conductivity (CTHCON) }\end{array}$} & CTEMP & I & Cladciing temperature $(\mathrm{K})$ \\
\hline & TIME & & $\begin{array}{l}\text { Time (s) - not presently operational but must be } \\
\text { supplied as a dummy variable in the argument } \\
\text { linkage }\end{array}$ \\
\hline & FLUX & & $\begin{array}{l}\left.\text { Fast neutron flux [neutrons } /\left(m^{2} \cdot s\right)\right] \text { - not presentiy } \\
\text { operational but must be supplied as a dummy } \\
\text { variable in the argument linkage }\end{array}$ \\
\hline & COLDW & & $\begin{array}{l}\text { Cold work (unitless) - not presently operational } \\
\text { tut must be supplied as a dumny variable in the } \\
\text { argument linkage }\end{array}$ \\
\hline & CTHCON & C & Cladding thermal conductivity $(\mathrm{W} / \mathrm{m} \cdot \mathrm{K})$ \\
\hline \multirow{3}{*}{$\begin{array}{l}\text { Zirconium 0xide } \\
\text { Emissivity (ZOEMIS) }\end{array}$} & CTMAX & I & Maximum cladding temperature $(K)$ \\
\hline & ZROXID & $\mathrm{I}$ & (ixide layer thickness $(m)$ \\
\hline & EMISSV & C & (iladding surface emissivity (unitless) \\
\hline \multirow[t]{2}{*}{$\cdots$} & PUEMIS & C: & Fositive standard error in EMISSV \\
\hline & UUEMIS & $\mathrm{C}$ & Negative standard error in EMISS: \\
\hline
\end{tabular}

[a] I/0 distinguishes between input and output arguments. 
TABLE D-1.I (continued)

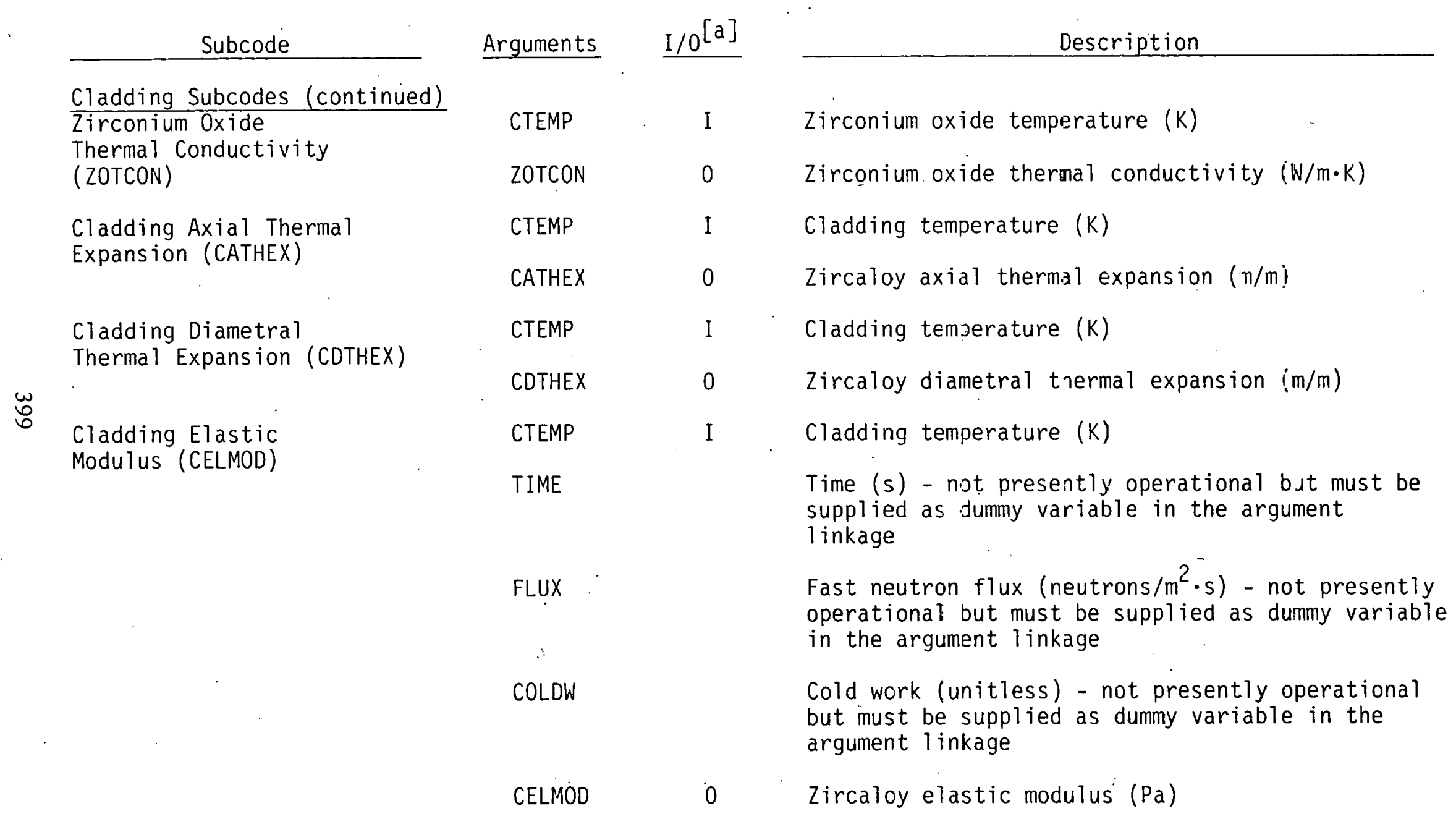

[a] I/0 distinguishes between input and output arguments. 
TABLE D-1.I (continued)

\begin{tabular}{|c|c|c|c|}
\hline Subcode & Arguments & $1 / 0^{[\mathrm{a}]}$ & Descripticn \\
\hline \multirow{10}{*}{$\begin{array}{l}\text { Cladding Subcodes (continued) } \\
\text { Cladding Stress Versus } \\
\text { Strain (CSTRES) }\end{array}$} & CTEMP & I & Clasdding temperature (k) \\
\hline & CTMAX & I & Maximum previous cladding temperiture $(K)$ \\
\hline & TIME & I & Time of irradiation (s) \\
\hline & SIRANT & I & True strain (unitless) \\
\hline & RSTRAN & I & True strain rate $\left(S^{-1}\right)$ \\
\hline & CDLDW & I & Cladding cold work $\left(\mathrm{m}^{2} i \mathrm{~m}^{2}\right)$ \\
\hline & $C=L U X$ & I & Fast neutron flux $\left[\right.$ neutrons $\left./\left(\mathrm{m}^{2} \cdot \mathrm{s}\right)\right]$ \\
\hline & SUTEST & 0 & Cladding true stress (Pa) \\
\hline & STRESE & 0 & Cladding engineering stress (Fa) \\
\hline & CTMAX & 0 & Maximum cladding temperature (K) \\
\hline $\begin{array}{l}\text { Cladding Stress Versus } \\
\text { Strain (CSIGMA) [b] }\end{array}$ & CइIGMA & 0 & Power law true stress (Pa) \\
\hline
\end{tabular}

[a] I/0 distinguishes between input and ostput arguments.

[b] The input arguments for CSIGMA are identical to the CSTRES indst arguments. 
TABLE D-1. I (continued)

\begin{tabular}{|c|c|c|c|}
\hline Subcode & Arguments & $\underline{I / 0^{[a]}}$ & Description \\
\hline \multirow{12}{*}{$\begin{array}{l}\text { Cladding Subcodes (continued) } \\
\text { Cladding Strain Versus } \\
\text { Stress (CSTRAN) }\end{array}$} & CTEMP & I & Cladding temperature $(K)$. \\
\hline & CTMAX & I & Maximum previous cladding temperature $(K)$ \\
\hline & TIME & I & Time of irradiation (s) \\
\hline & STREST & I & True stress $(\mathrm{Pa})$ \\
\hline & RSTRES & I & True stress rate $(\mathrm{Pa} / \mathrm{s})$ \\
\hline & COLDW & I & Cladding cold work $\left(\mathrm{m}^{2} / \mathrm{m}^{2}\right)$ \\
\hline & CFLUX & I & Fast neutron flux $\left[n \geq u t r o n s /\left(m^{2} \cdot s\right)\right]$ \\
\hline & KINDOR & I & $\begin{array}{l}1=\text { constant stress rate } \\
2=\text { constant strain rate from input stress rate } \\
3=\text { average strain rate as input with RSTRAN }\end{array}$ \\
\hline & STRANT & 0 & True strain $(\mathrm{m} / \mathrm{m})$ \\
\hline & STRANE & 0 & Engineering strain $(\mathrm{m} / \mathrm{m})$ \\
\hline & RSTRAN & 0 & True strain rate $\left(\mathrm{s}^{-1}\right)$ \\
\hline & CTMAX & 0 & Maximum cladding temperature $(K)$ \\
\hline
\end{tabular}

[a] I/0 distinguishes between input and output arguments. 
TABLE D-1.I (continued)

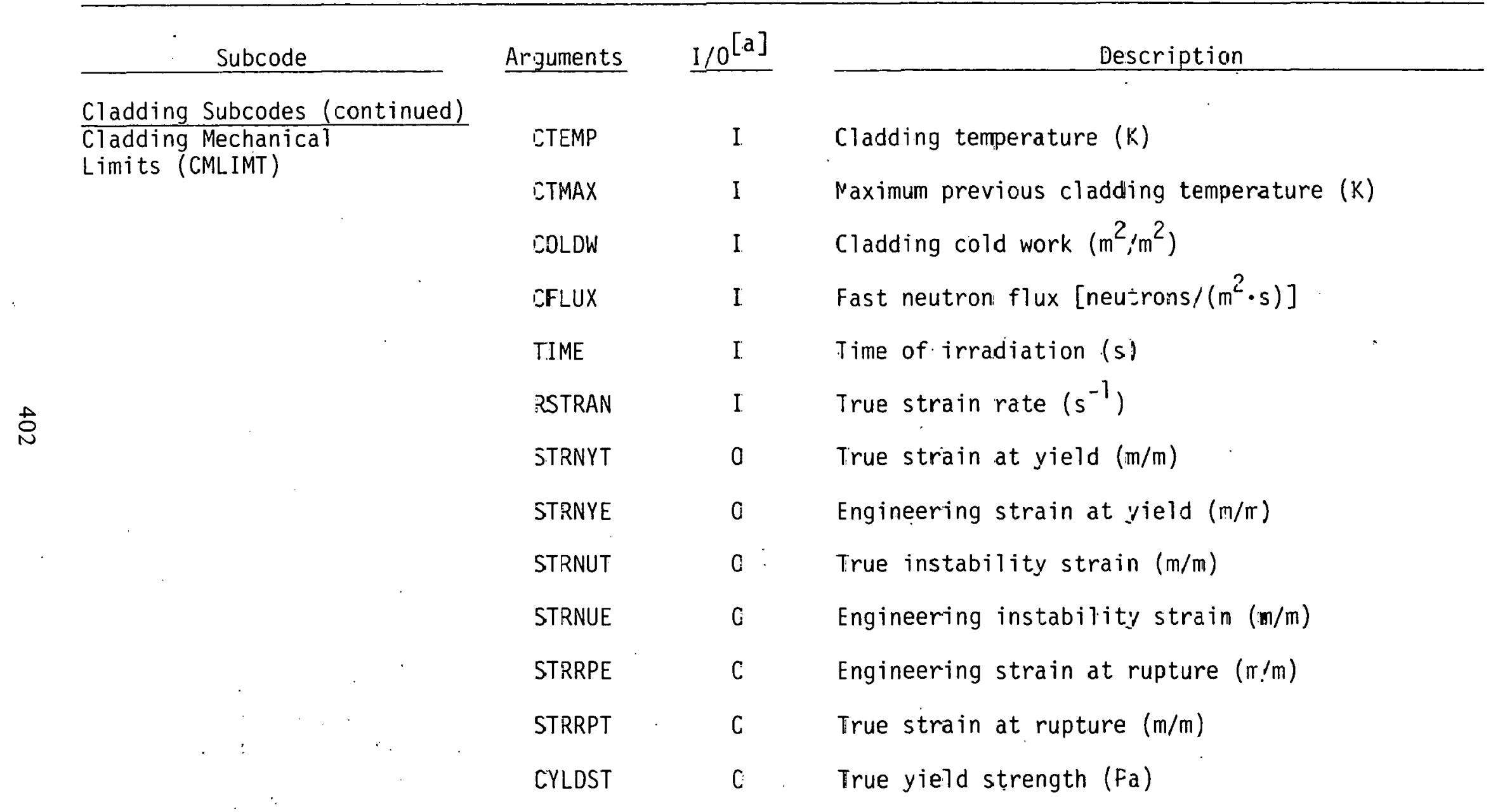

[a] I/0 distinguishes between inpust and output arguments. 
TABLE D-1.I (continued)

\begin{tabular}{|c|c|c|c|}
\hline Subcode & Arguments & $1 / 0^{[\mathrm{a}]}$ & Description \\
\hline \multirow{3}{*}{$\begin{array}{l}\text { Cladding Subcodes (continued) } \\
\text { Cladding Mechanical } \\
\text { Limits (CMLIMIT) (continued) }\end{array}$} & CYLDSE & 0 & Engineering yield strength ( $\mathrm{Pa}$ ) \\
\hline & CULTST & 0 & True ultimate strerigth (Pa) \\
\hline & CULTSE & 0 & Engineering ultimate strength $(\mathrm{Pa})$ \\
\hline \multirow{9}{*}{$\begin{array}{l}\text { Cladding Strain at } \\
\text { Rupture (CSRUPT) }\end{array}$} & CTEMP & I & Cladding temperature $(\mathrm{K})$ \\
\hline & CTMAX & I & Maximum previous cladding temperature ( $K)$ \\
\hline & COLDW & I & Cladding cold work $\left(\mathrm{m}^{2} / \mathrm{m}^{2}\right)$ \\
\hline & FNCE & $\mathrm{I}$ & Fast neutron fluence (neutrons $/ \mathrm{m}^{2}$ ) \\
\hline & STRPPE & 0 & Engineering strain at rupture $(\mathrm{m} / \mathrm{m})$ \\
\hline & USTRPE & 0 & Expected standard error in STRPPE ( $\left.m^{\prime}, m\right)$ \\
\hline & STRRPT & 0 & True strain at rup:ure $(\mathrm{m} / \mathrm{m})$ \\
\hline & USTRPT & 0 & Positive standard error of STRRPT $(m, m)$ \\
\hline & USTRTN & 0 & Negative standard error at STRRPT $\left(m_{\prime}^{\prime} m\right)$ \\
\hline $\begin{array}{l}\text { Cladding Local Strains } \\
\text { at Rupture (CLOCRP) }\end{array}$ & CTEMP & I & Cladding temperature $(K)$ \\
\hline
\end{tabular}

[a] I/0 distinguishes between input and output arguments. 
TABLE D-1.I (cortinued)

\begin{tabular}{|c|c|c|c|}
\hline Subcode & Arguments & $1 / 0^{[\mathrm{a}]}$ & Descript:on \\
\hline \multirow{4}{*}{$\begin{array}{l}\text { Cladding Subcodes (continued) } \\
\text { Cladding Local Strains } \\
\text { at Rupture (CLOCRP) }\end{array}$} & CRTSTN & 0 & True radial strain $(\mathrm{m} / \mathrm{m})$ \\
\hline & CCTSTN & 0 & True circumferential strain $(\mathrm{m} / \mathrm{m})$ \\
\hline & CRESTN & 0 & Engineering radial strain $(\mathrm{m} / \mathrm{m})$ \\
\hline & CCESTN & 0 & Engineering circumferential strain $(\mathrm{m} / \mathrm{m})$ \\
\hline \multirow{5}{*}{$\begin{array}{l}\text { Cladding Creep Rate } \\
\text { (CCRPR) }\end{array}$} & CTEMP & I & Cladding temperature. (K) \\
\hline & CTSRSS & I & Cladding transwerse stress (Pa) \\
\hline & .CFLIJXX & I & Fast neutron flux [neutrons $\left.\left./ \mathrm{im}^{\bar{c}} \cdot \mathrm{s}\right)\right]$ \\
\hline & TIM $三$ & I & Time (s) \\
\hline & CCR?R & 0 & Cladding creep strain rate $\left(s^{-1}\right)$ \\
\hline \multirow{2}{*}{$\begin{array}{l}\text { Cladding Poisson's } \\
\text { Ration (CPOIR) }\end{array}$} & CTEMP & I & Cladding temperature (K) \\
\hline & CPOIR & 0 & Cladding Poisson's ratio (unitless) \\
\hline \multirow{2}{*}{$\begin{array}{l}\text { Cladding Cyclic Fatigue } \\
\text { (CFATIG) }\end{array}$} & CTEMP & I & Cladding temperature $(\mathrm{K})$ \\
\hline & FFN $\sim E$ & I & Fast neutron fluence (neutrons $/ n^{2}$ ) \\
\hline
\end{tabular}

[a] I/O distinguishes between infut and output arguments. 
TABLE D-1.I (continued)

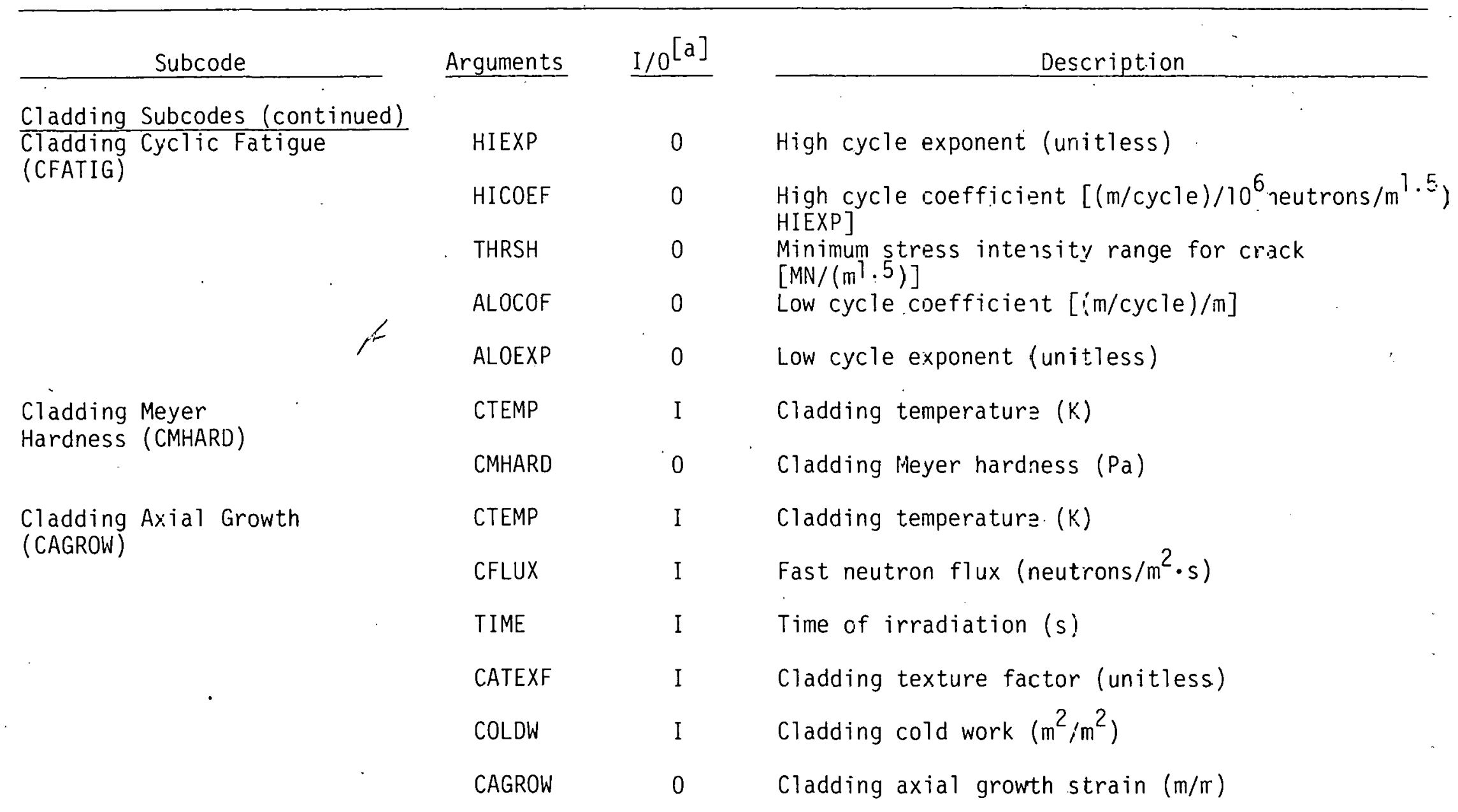

[a] I/0 distinguishes between input and output arguments. 
TABLE D-1.I (continuedi)

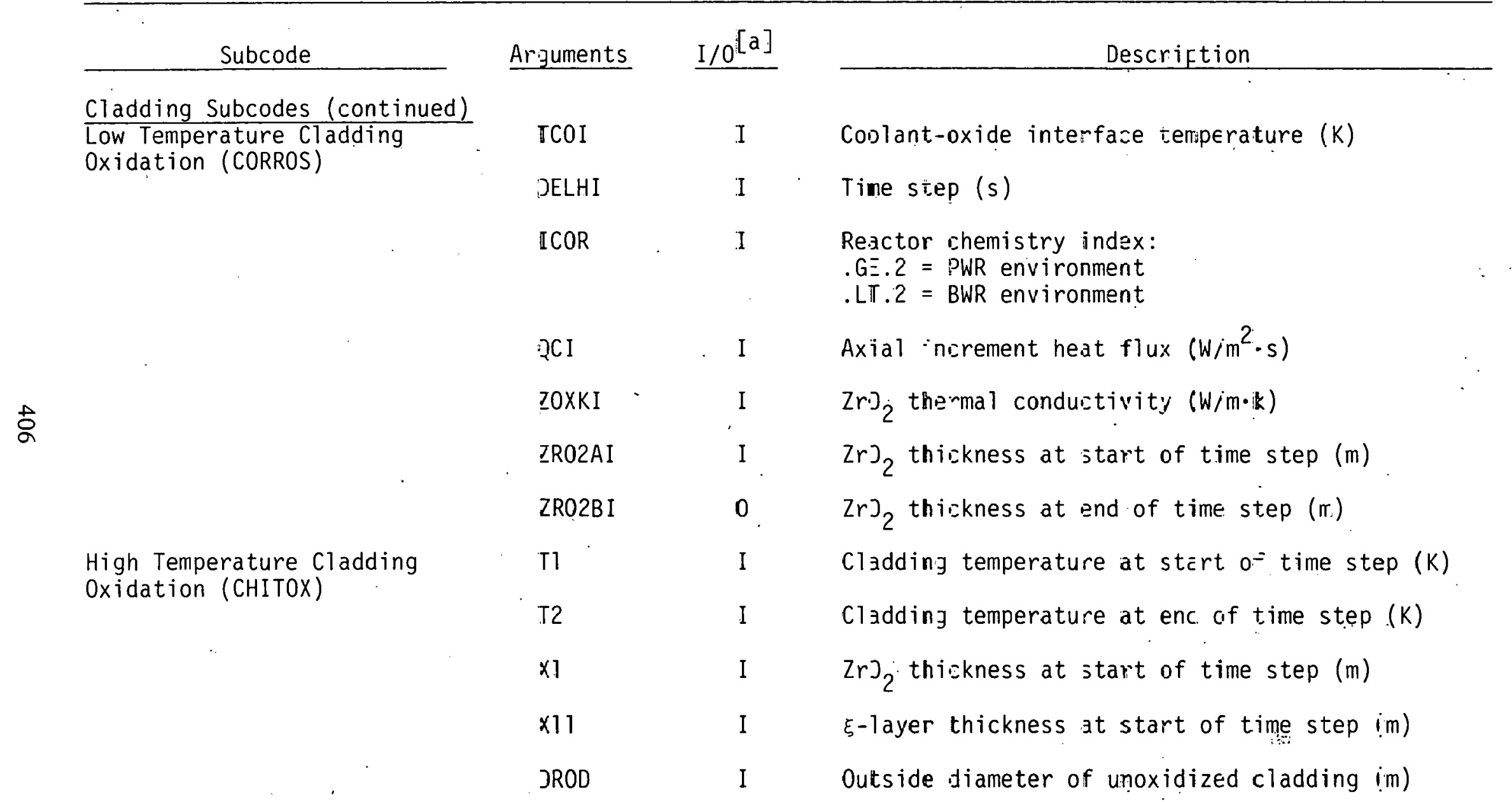

[a] I/0 distinguishes between inpst and output arguments. 
TABLE D-1.I (continued)

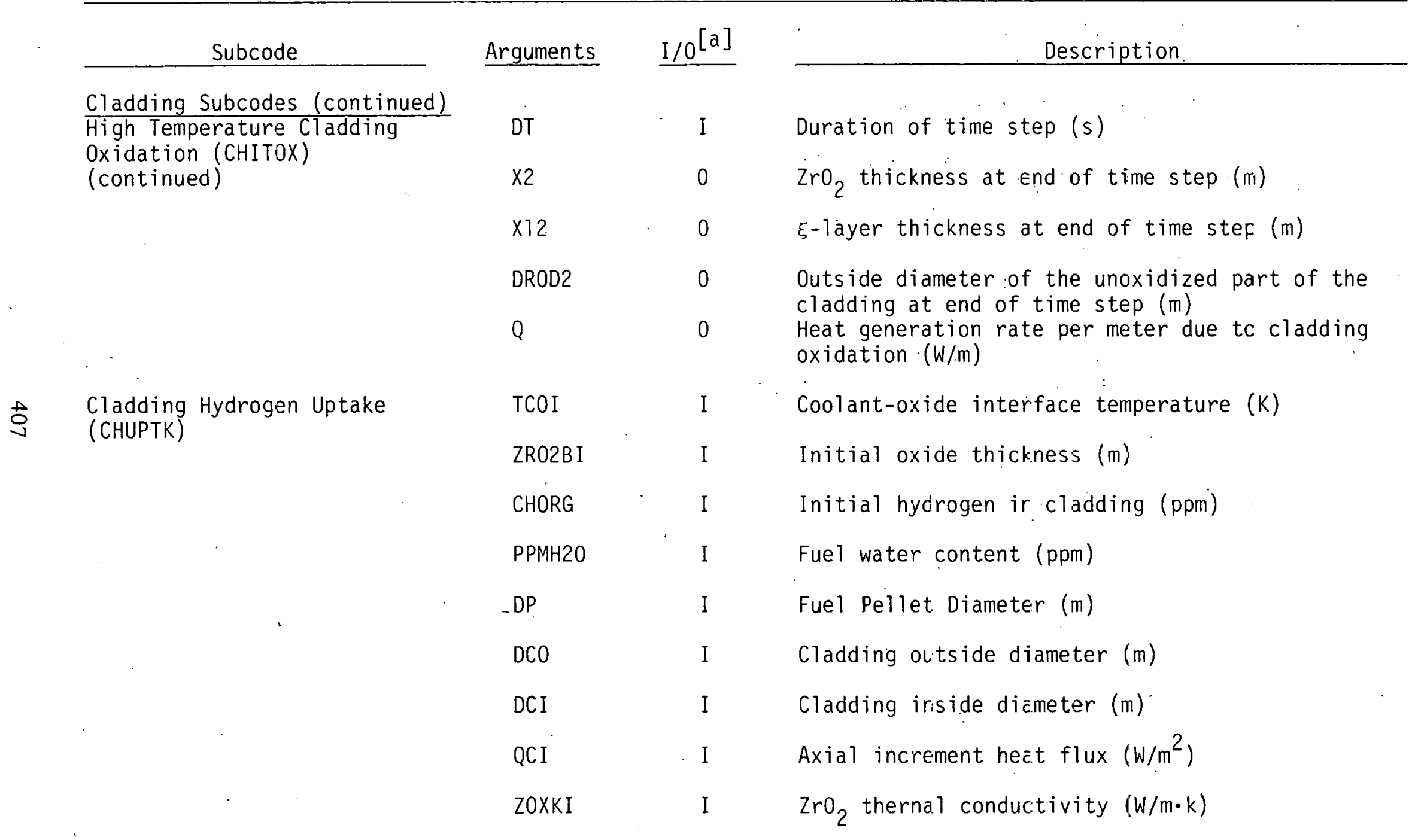

[a] I/0 distinguishes between input and output arguments. 
TABLE D-1.I (continued)

\begin{tabular}{|c|c|c|c|}
\hline Subcode & Arguments & $1 / 0^{[a]}$ & Description \\
\hline \multirow[t]{2}{*}{$\begin{array}{l}\text { Cladding Subcodes (continued) } \\
\text { Cladding Hydrogen Uptake } \\
\text { (CHUPTK) (continued) }\end{array}$} & ICOF: & I & $\begin{array}{l}\text { Reactor chemistry index: } \\
1=\text { PWR environmen }: \\
2=\text { BWR environmen }\end{array}$ \\
\hline & ICM & I & $\begin{array}{l}\text { Cladding llaterial Index } \\
2=\text { Zircaloj-2 cladding } \\
4-\text { Zircaloj-4 cladding }\end{array}$ \\
\hline \multicolumn{4}{|l|}{ Gas and Fuel Rod Property } \\
\hline \multirow[t]{5}{*}{$\begin{array}{l}\text { Gas Thermal Conductivity } \\
\text { (GTHCON) }\end{array}$} & GMIX & I & $\begin{array}{l}\text { Mole fraction of the following Jases: helium, } \\
\text { argon, krypton, xenon, hydrogen, air, and water } \\
\text { vapor }\end{array}$ \\
\hline & GTEMP & I & Gas temperature $(\mathrm{K})$ \\
\hline & GPRES & I & Gas pressure $(\mathrm{Pa})$ \\
\hline & ВРТНК & I & $\begin{array}{l}\text { Effective gas gap thickness for Knudsen domain } \\
\text { comrection factor calculation }(: n)\end{array}$ \\
\hline & GTHCON & 0 & Gas themal conductivity $\left[W /\left(m \cdot k^{\prime}\right)\right]$ \\
\hline Gàs Viscosity (GVISCO) & BMIX: & I & $\begin{array}{l}\text { Mole fraction of the following yases: helium, } \\
\text { argon, krypton, xenon, hydrogen, air, and steam }\end{array}$ \\
\hline
\end{tabular}

[a] I/0 distinguishes between inp!it and output arguments. 
TABLE D-1.I (continued)

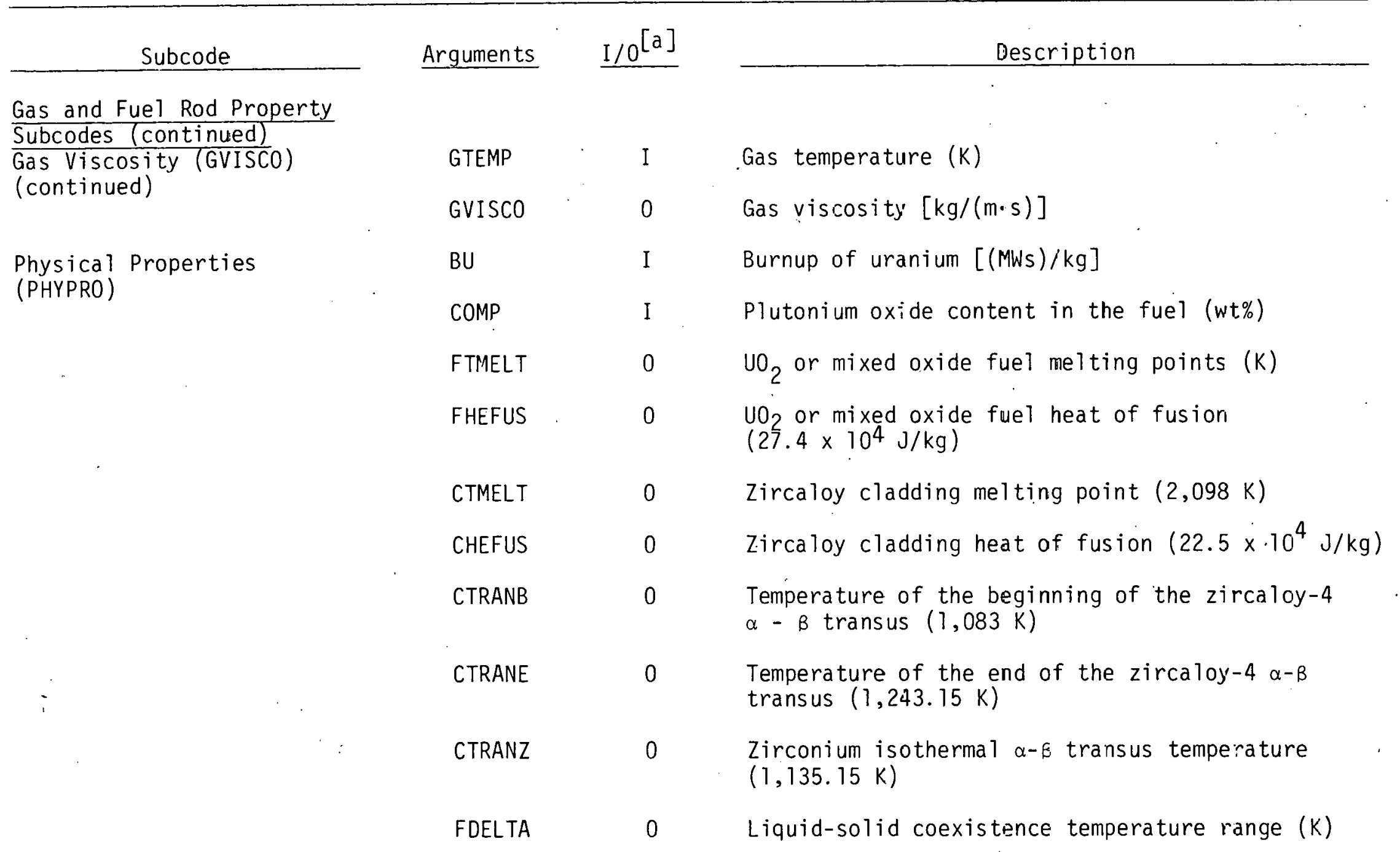

[a] I/0 distinguishes between input and output arguments. 


\section{BASE AND DERIVED SI UNITSIUSED IN MATPRO}

The intent of materials properties work for MATPRO has been to code correlations in the Standard International System (SI) of Units. However, in some cases relationships are other units as taken directly from the literature. Table D-2.I indicates the SI units employed in MATPRO subcodes; Table D-2.II indicates some conversion factors that may be useful in interpreting other units.

TABLE D-2.I

SI UNITS FOR USE IN MATPRO

\begin{tabular}{|c|c|c|c|}
\hline Quant1 ty. & Unit & SI Symbul & Fòrmulà \\
\hline Base Units & $\longrightarrow$ & & \\
\hline length & meter & $\mathrm{m}$ & \\
\hline t1me & second & $s$ & \\
\hline mass & kilogram & $\mathrm{kg}$ & \\
\hline thermodynamic temperature & kelvin & $k^{\prime}$ & \\
\hline amount of substance & mole & mó 7 & \\
\hline Derived Units & - & & \\
\hline area & square meter & . & $m^{2}$ \\
\hline density & kilogram per cubic meter & : & $\mathrm{kg} / \mathrm{m}^{3}$ \\
\hline energy & joule & $\mathrm{J}$ & $N \cdot m$ \\
\hline force & newton & N & $\mathrm{kg} \cdot \mathrm{m} / \mathrm{s}^{2}$ \\
\hline power & watt & . W & $\mathrm{j} / \mathrm{s}$ \\
\hline pressure & pascal & $\mathrm{Pa}$ & $\mathrm{N} / \mathrm{m}^{2}$ \\
\hline specific heat & joule per kilogram kelvin & & $\mathrm{J} / \mathrm{kg} \cdot \mathrm{K}$ \\
\hline stress & newton per meter & $\mathrm{Pa} \because$ & \\
\hline thermal conductivity & watt per meter kelvin & & $W / m \cdot K$ \\
\hline velocity & meter per second & $\mathrm{m} / \mathrm{s}$ & $\cdot$ \\
\hline viscosity (dynamic) & pascal second & $\mathrm{Pa} \cdot \mathrm{s}$ & . \\
\hline volume & cubic meter & $m^{3}$ & \\
\hline
\end{tabular}


TABLE D-2.II

CONVERSION FACTORS

\begin{tabular}{|c|c|c|}
\hline To Convert From & To & Multiply By \\
\hline foot $^{2}$ & meter ${ }^{2}\left(m^{2}\right)$ & $9.29030 E-02$ \\
\hline pound-mass/foot ${ }^{3}$ & kilogram/meter ${ }^{3}\left(\mathrm{~kg} / \mathrm{m}^{3}\right)$ & $1.60185 \mathrm{E}+01$ \\
\hline pound-force-foot & joule (J) & 1. $35582 E+00$ \\
\hline pound-force & newton $(N)$ & $4.44822 E+00$ \\
\hline pound-force-foot/s & watt $(W)$ & $1.35582 E+00$ \\
\hline pound-force/foot ${ }^{2}$ & pascal $(\mathrm{Pa})$ & $4.78803 E+01$ \\
\hline pound-force/inch ${ }^{2}$ (psi) & pascal $(\mathrm{Pa})$ & $6.89476 E+03$ \\
\hline $\begin{array}{l}\text { British thermal unit/ } \\
\text { pound mass- }{ }^{\circ} \text { Fahrenheit }\end{array}$ & $\begin{array}{l}\text { joule/kilogram-kelvin } \\
(\mathrm{J} / \mathrm{kg} \cdot \mathrm{K})\end{array}$ & $4.18400 E+03$ \\
\hline $\begin{array}{l}\text { calorie/gram- }{ }^{\circ} \mathrm{Cel} \text { sius } \\
\text { (thermochemical) }\end{array}$ & $\begin{array}{l}\text { joule/kilogram kelvin } \\
(\mathrm{J} / \mathrm{kg} \cdot \mathrm{K})\end{array}$ & $4.18400 \mathrm{E}+03$ \\
\hline $\begin{array}{l}\text { British thermal unit- } \\
\text { inch/hour-foot }{ }^{2}- \\
{ }^{\circ} \text { Fahrenheit }\end{array}$ & $\begin{array}{l}\text { watt/meter kelvin } \\
(\mathrm{W} / \mathrm{m} \cdot \mathrm{K})\end{array}$ & $1.44131 E-01$ \\
\hline foot/second & meter/second $(\mathrm{m} / \mathrm{s})$ & $3.04800 E-01$ \\
\hline foot $^{3}$ & meter ${ }^{3}\left(m^{3}\right)$ & $2.83168 \mathrm{E}-02$ \\
\hline
\end{tabular}

\section{LINEAR INTERPOLATION ROUTINE (POLATE)}

A number of the MATPRO subcodes contain tables of data for a property rather than analytical expressions. Examples are cladding axial and radial thermal expansion in the region of 800 to $1000^{\circ} \mathrm{C}$ and cladding specific heat capacity. In these cases discontinuities exist in the temperature range of the $\alpha$ and $\beta$ phase transformation. POLATE is used when analytical expressions based on theory are not available and interpolation of reported data is simpler than use of an empirical equation.

A listing of the subcode POLATE is given in Table D-3.I. 
TABLE D-3. I

LISTING OF POLATE SUBCODE

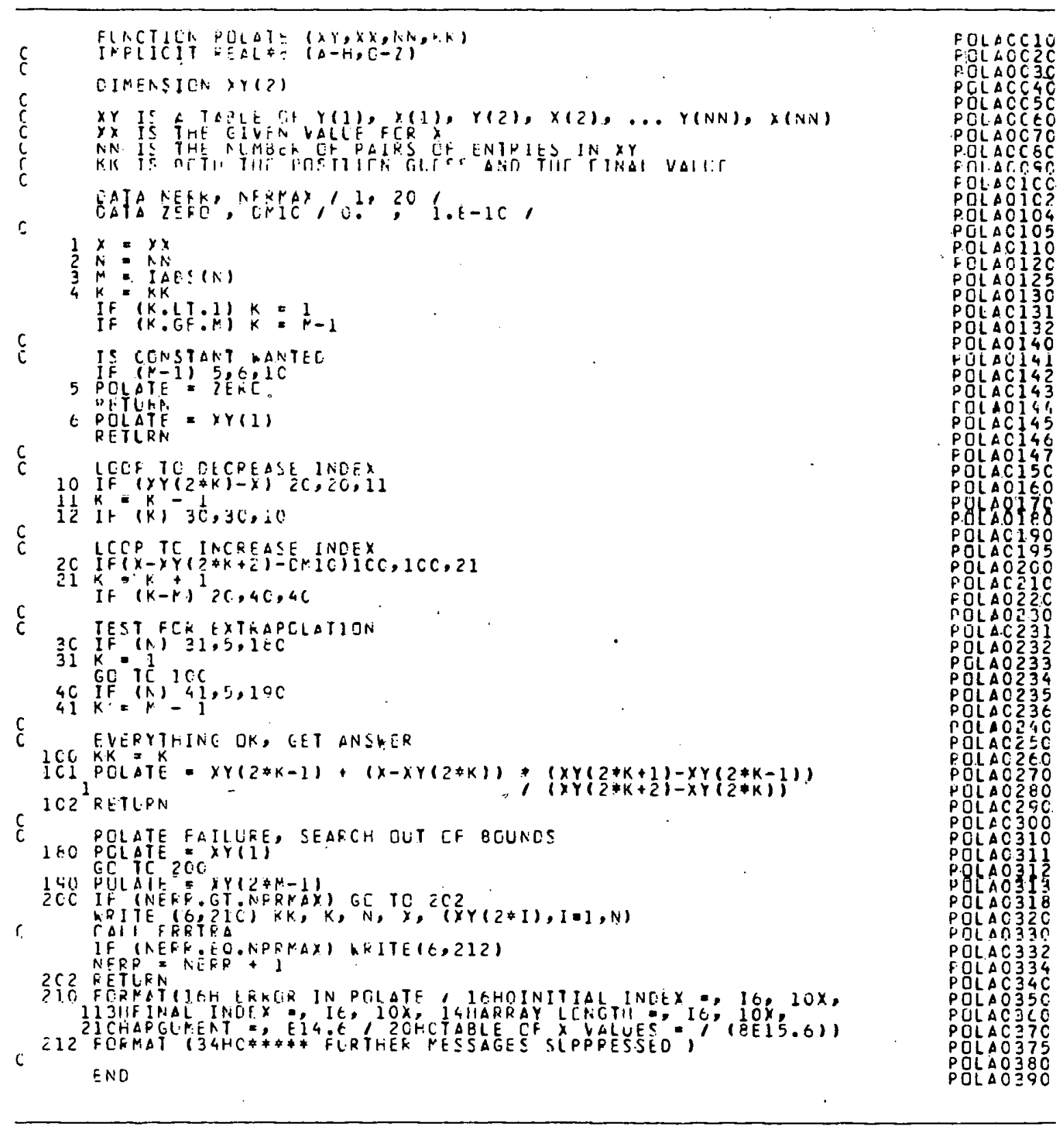


DISTRIBUTION RECORD FOR TREE-NUREG-1180

\section{Internal Distribution}

1 - Chicago Patent Group-DOE 9800 South Cass Avenue Argonne, Illinois 60439

$$
\begin{aligned}
& 2 \text { - C. A. Benson } \\
& \text { Idaho Operations Office-DOE } \\
& \text { Idaho Falls, ID } 83401 \\
& 3 \text { - R. J. Beers, ID } \\
& 4 \text { - P. E. Litteneker, ID } \\
& 5 \text { - R. E. Tiller, ID } \\
& 6 \text { - H. P. Pearson, Supervisor } \\
& \text { Information Management } \\
& 7-16 \text { - INEL Technical Library } \\
& 17-36 \text { - Authors } \\
& 37-165 \text { - Special Internal }
\end{aligned}
$$

\section{External Distribution}

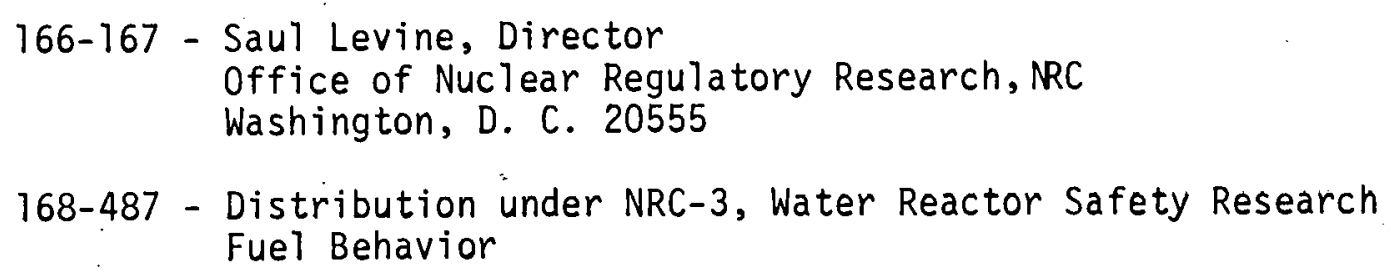

